FELIPE RIBOLLA MASETTI

CARACTERIZAÇÃO DA MANOBRABILIDADE DE EMBARCAÇÕES EM ÁREAS RESTRITAS, BAIXA VELOCIDADE E OPERAÇÃO EM REGIME TRANSITÓRIO 

FELIPE RIBOLLA MASETTI

\section{CARACTERIZAÇÃO DA MANOBRABILIDADE DE EMBARCAÇÕES EM ÁREAS RESTRITAS, BAIXA VELOCIDADE E OPERAÇÃO EM REGIME TRANSITÓRIO}

Dissertação apresentada à Escola

Politécnica da Universidade de São Paulo para obtenção de título de Mestre em Ciências. 

FELIPE RIBOLLA MASETTI

\section{CARACTERIZAÇÃO DA MANOBRABILIDADE DE EMBARCAÇÕES EM ÁREAS RESTRITAS, BAIXA VELOCIDADE E OPERAÇÃO EM REGIME TRANSITÓRIO}

Dissertação apresentada à Escola

Politécnica da Universidade de São Paulo para obtenção de título de Mestre em Ciências.

Área de concentração: Engenharia Naval e Oceânica

Orientador: Prof. Dr. Eduardo Aoun

Tannuri 

Autorizo a reprodução e divulgação total ou parcial deste trabalho, por qualquer meio convencional ou eletrônico, para fins de estudo e pesquisa, desde que citada a fonte.

Este exemplar foi revisado e corrigido em relação à versão original, sob responsabilidade única do autor e com a anuência de seu orientador.

São Paulo de de

Assinatura do autor:

Assinatura do orientador:

\section{Catalogação-na-publicação}

\section{Masetti, Felipe Ribolla}

Caracterização da manobrabilidade de embarcações em áreas restritas, baixa velocidade e operação em regime transitório / F. R. Masetti -- versão corr. - São Paulo, 2018. $195 \mathrm{p}$.

Dissertação (Mestrado) - Escola Politécnica da Universidade de São Paulo. Departamento de Engenharia Naval e Oceânica.

1.simulação em tempo real 2.manobrabilidade de navios 3.ensaios em tanque de provas 4.modelos escala reduzida 5.confrontação numérico experimental I.Universidade de São Paulo. Escola Politécnica. Departamento de Engenharia Naval e Oceânica II.t. 



\section{AGRADECIMENTOS}

À minha família, por ter me apoiado e possibilitado minha trajetória até aqui, me incentivando e provocando para que sempre me mantivesse em evolução. À Paula, por me acompanhar nos últimos anos.

Ao meu orientador, professor Dr. Eduardo Aoun Tannuri, pela orientação durante o mestrado e anteriormente a este, inclusive.

Ao Isaias Masetti, Kazuo Nishimoto, Carlos H. Fucatu e toda a equipe da Petrobrás e da USP que tantas vezes acreditaram no projeto do TPN e do simulador e que acabaram por viabilizar este trabalho e desenvolver tecnologia nacional.

Aos amigos que auxiliaram nesse processo, especialmente ao Pedro Cardozo de Mello, pelo auxílio durante a execução dos ensaios em escala, e ao Felipe Rateiro, por diversos aconselhamentos e apoio.

À Technomar por permitir a dedicação e consequente realização deste trabalho.

À Petrobras, pelo uso do simulador SMH.

À FAPESP, pela construção do modelo em escala reduzida.

Ao Instituto Oceanográfico da USP, pelas informações sobre a embarcação.

Ao laboratório $\mathrm{FCTH}$, pela disponibilidade do tanque de provas para os ensaios experimentais. 



\section{RESUMO}

Esta dissertação de mestrado tem como objetivo a validação do modelo numérico de manobras para navios utilizado pelo simulador chamado SMH - Simulador Marítimo Hidroviário, que foi desenvolvido no laboratório Tanque de Provas Numérico.

Para tanto foram realizados ensaios experimentais de manobras com um modelo em escala reduzida da embarcação Alpha Crucis com o objetivo de criar dados de manobra que serviram como referência para validação do modelo numérico.

Foram selecionados diversos tipos de manobras com o propósito de criar uma caracterização da manobrabilidade da embarcação em baixas velocidades e regime transitório, permitindo a medição de diversas características, que permitem quantificar as capacidades de manobra da embarcação.

Através de experimentos numéricos foram, então, realizadas as mesmas manobras executadas pelo modelo físico em escala reduzida, de forma a reproduzir as mesmas condições iniciais e os mesmos comandos, procurando reproduzir as manobras para validação do modelo implementado no SMH.

Os resultados obtidos apresentam a aderência das características de manobras do modelo implementado no $\mathrm{SMH}$, através da comparação das características de manobra obtidas pelo modelo físico em escala reduzida e das obtidas pelo modelo numérico.

A dissertação apresenta ainda um estudo de sensibilidade que mostra o efeito dos principais fatores utilizados no laboratório Tanque de Provas Numérico para a calibração dos modelos de embarcações, mostrando que para as manobras consideradas neste trabalho alguns dos efeitos possuem pouca influência nos resultados.

Por fim o trabalho conclui que o modelo matemático utilizado pelo SMH representa a capacidade de manobra da embarcação de forma consistente para diversos tipos de manobra, e com um grau de aderência satisfatório.

Palavras-chave: simulação em tempo real, manobrabilidade de navios, ensaios em tanque de provas, modelos escala reduzida, confrontação numérico-experimental, Tanque de Provas Numérico - TPN. 



\begin{abstract}
This research aims to present a validation for the ship maneuvering simulator named $\mathrm{SMH}$, anachronym in Portuguese for Maritime and Waterway Simulator, developed on Tanque de Provas Numérico laboratory.

For this propose small scale tests were performed with a model of Alpha Crucis ship aiming to create maneuver data that was used as reference for the numerical model validation.
\end{abstract}

Several types of maneuver where selected to create a characterization of the maneuverability of the ship at low speeds and transient regime, and the parameters that quantify the maneuverability were measured.

Then were performed numerical experiments recreating the same maneuver executed with the experimental model, with the same initial conditions and propulsion/rudder controls, trying to reproduce the maneuvers to validate the model implemented on the $\mathrm{SMH}$.

The results showed that the maneuvering characteristics predicted by the $\mathrm{SMH}$ simulator are similar to measured values in the experiment.

The dissertation also presents a sensitivity study that shows the effect of the main parameters used in the laboratory Tanque de Provas Numérico for the vessel model calibration, This study showed that for some maneuvers, the tuning parameters have less influence on the results.

Finally, the work concludes that the mathematical model used by the SMH represents the ability of the vessel to maneuver consistently for several types of maneuvers, and with a satisfactory degree of accuracy.

Key-words: real time simulation, ship maneuverability. towing tank model tests, smallscale model tests, numerical-experimental confrontation, Numerical Offshore Tank TPN. 



\section{LISTA DE FIGURAS}

Figura 1 - Diâmetro tático em manobra de giro .............................................21

Figura 2 - Estação de simulação em tempo real ............................................23

Figura 3 - Modelo utilizado com aparato de câmeras ao fundo .............................24

Figura 4 - Sistema de coordenadas no navio ............................................ 33

Figura 5 - Integração seccional utilizada no modelo de Obokata .......................... 35

Figura 6 - Modelo de 4 quadrantes para atuação do propulsor e leme....................37

Figura 7 - Definições do modelo de leme ..................................................... 38

Figura 8 - Plano de linhas da embarcação Alpha Crucis ................................... 40

Figura 9 - Propulsor e leme (leme de boreste retirado) .................................. 41

Figura 10 - Posição do Bowthruster .................................................... 41

Figura 11 - Modelo do casco e superestrutura em escala 1:28 ........................... 42

Figura 12 - Detalhe dos propulsores e leme: (esq) Escala Real; (dir) Escala Reduzida 43

Figura 13 - Ensaio de capacidade de propulsão ........................................ 43

Figura 14 - Empuxo obtido pelos propulsores principais no sentido positivo ...........45

Figura 15 - Empuxo obtido pelos propulsores principais no sentido negativo...........45

Figura 16 - Empuxo obtido pelo túnel de proa...............................................45

Figura 17 - Curva de coeficientes de arrasto obtidos para o leme do modelo em escala 46

Figura 18 - Curva de coeficientes de sustentação obtidos para o leme do modelo em

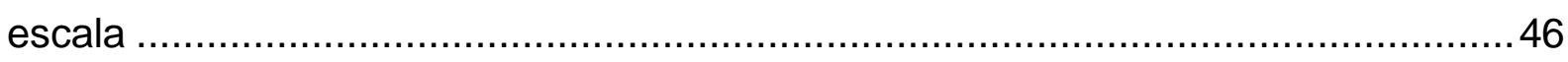

Figura 19 - Tanque utilizado para os ensaios .......................................... 48

Figura 20 - Foto do sistema de câmeras sendo calibrado com o modelo na água ...49

Figura 21 - Posição dos propulsores principais em vermelho..............................52

Figura 22 - Coeficientes de empuxo do propulsor principal ................................53

Figura 23 - Posição do propulsor transversal em amarelo ..................................54

Figura 24 - Coeficientes de empuxo do propulsor transversal .............................55

Figura 25 - Posição dos lemes na embarcação............................................. 55

Figura 26 - Coeficientes de sustentação e arrasto utilizados para os lemes ............55

Figura 27 - Superfície do casco modelado .................................................56

Figura 28 - Malha utilizada para os cálculos por CFD ...................................57 
Figura 29 - Visualização dos coeficientes de pressão para correnteza incidente pela proa 58

Figura 30 - Curvas dos coeficientes de forças e momento na superestrutura em comparação aos resultados experimentais do IPT utilizando a convenção de

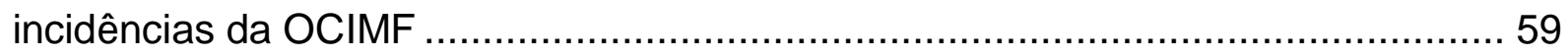

Figura 31 - Coeficientes longitudinais obtidos por CFD …….............................. 60

Figura 32 - Coeficientes transversais obtidos por CFD ....................................... 60

Figura 33 - Coeficientes de momento de yaw obtidos por CFD ............................. 61

Figura 34 - Diagrama da manobra de Turning Circle ........................................... 63

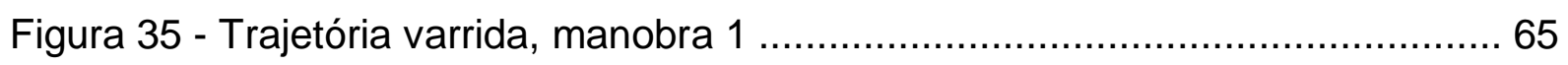

Figura 36 - Gráficos de ângulo de deriva, velocidade angular, velocidade Vx,

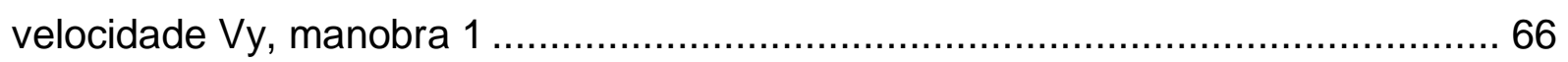

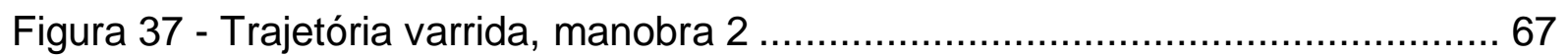

Figura 38 - Gráficos de ângulo de deriva, velocidade angular, velocidade $V x$,

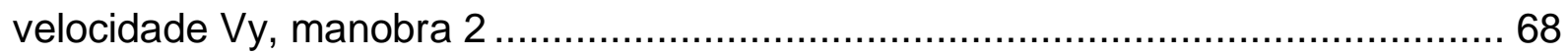

Figura 39 - Trajetória varrida, manobra 1 em águas rasas .................................... 69

Figura 40 - Gráficos de ângulo de deriva, velocidade angular, velocidade Vx,

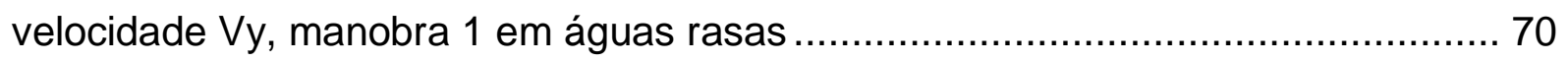

Figura 41 - Trajetória varrida, manobra 2 em águas rasas .................................... 71

Figura 42 - Gráficos de ângulo de deriva, velocidade angular ,velocidade Vx, velocidade $\mathrm{Vy}$, manobra $2 \mathrm{em}$ águas rasas ....................................................... 72

Figura 43 - Resultados obtidos em uma manobra de Initial turning test. Distância fora

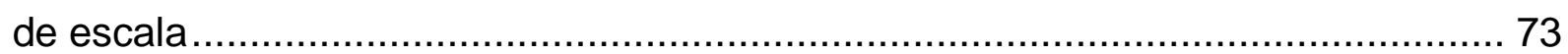

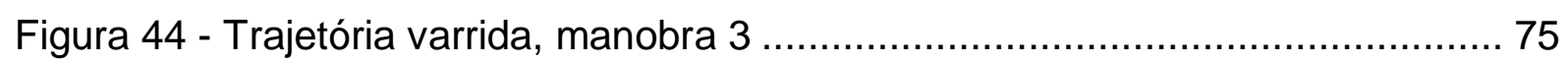

Figura 45 - Aproamento, Ângulo de deriva, manobra 3 ....................................... 75

Figura 46 - Distância percorrida, Rating por ângulo de guinada, manobra 3 ........... 76

Figura 47 - Trajetória varrida, manobra 4 ...................................................... 77

Figura 48 - Aproamento, Ângulo de deriva, Distância percorrida, Rating por ângulo de

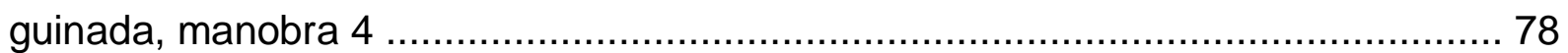

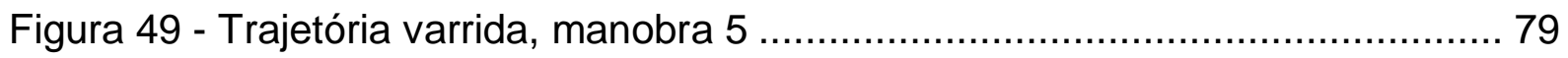

Figura 50 - Aproamento, Ângulo de deriva, Distância percorrida, Rating por ângulo de

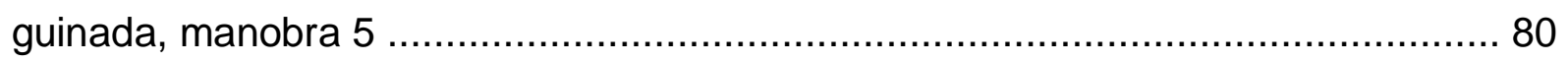

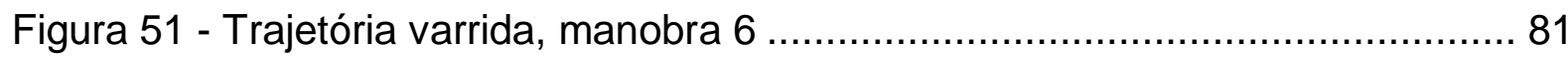


Figura 52 - Aproamento, Ângulo de deriva, Distância percorrida, Rating por ângulo de guinada, manobra 6

Figura 53 - Trajetória varrida, manobra 3

Figura 54 - Aproamento, Ângulo de deriva, Distância percorrida, Rating por ângulo de guinada, manobra 3 84

Figura 55 - Trajetória varrida, manobra 4

Figura 56 - Aproamento, Ângulo de deriva, Distância percorrida, Rating por ângulo de guinada, manobra 4 .86

Figura 57 - Trajetória varrida, manobra 5

Figura 58 - Aproamento, Ângulo de deriva, Distância percorrida, Rating por ângulo de guinada, manobra 5 88

Figura 59 - Trajetória varrida, manobra 6 .89

Figura 60 - Aproamento, Ângulo de deriva, Distância percorrida, Rating por ângulo de guinada, manobra 6 .90

Figura 61 - Resultados para uma manobra de zig-zag........................................91

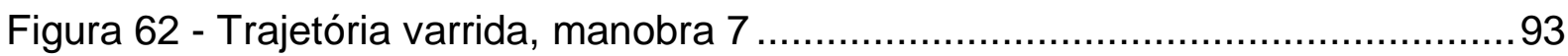

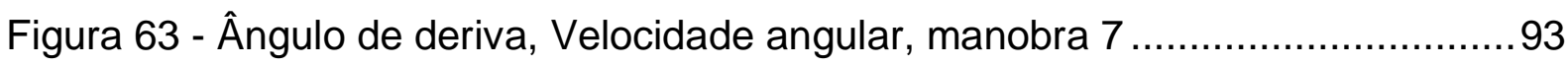

Figura 64 - Velocidade $\mathrm{Vx}$, velocidade $\mathrm{Vy}$, manobra 7 .......................................94

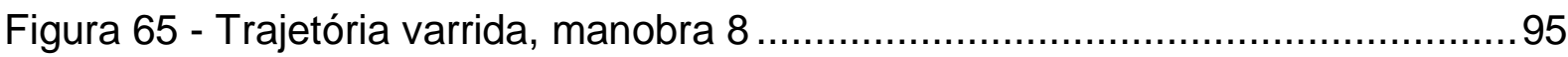

Figura 66 - Ângulo de deriva, Velocidade angular, manobra 8 ….............................95

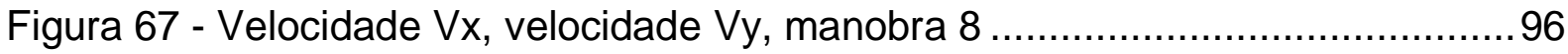

Figura 68 - Trajetória varrida, manobra 7 em águas rasas ...................................97

Figura 69 - Ângulo de deriva, Velocidade angular, Velocidade Vx, velocidade Vy,

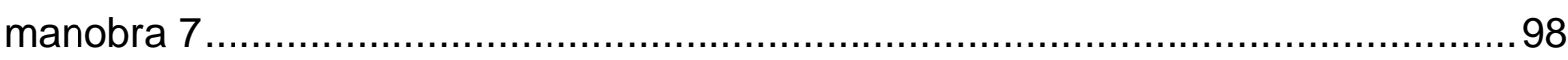

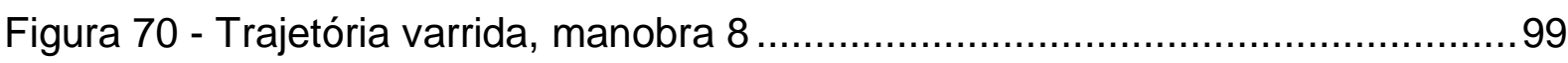

Figura 71 - Ângulo de deriva, Velocidade angular, Velocidade Vx, velocidade Vy,

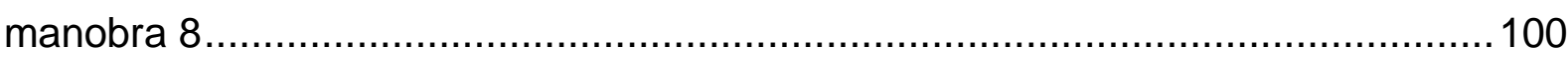

Figura 72 - Grandezas medidas durante a manobra de Crash-Stop. ....................101

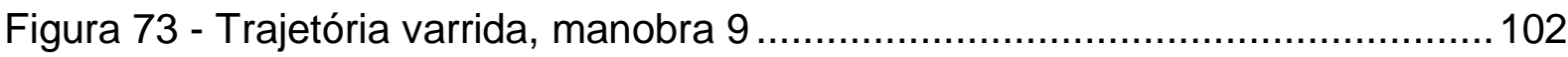

Figura 74 - Ângulo de deriva, Velocidade angular, Velocidade Vx, velocidade Vy,

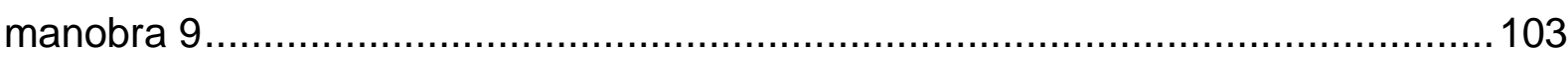

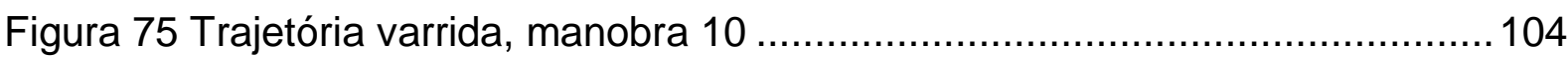

Figura 76 Ângulo de deriva, Velocidade angular, Velocidade $V x$, velocidade $V y$, manobra 10 
Figura 77 - Trajetória varrida, manobra 9

Figura 78 - Ângulo de deriva, Velocidade angular, Velocidade Vx, velocidade Vy,

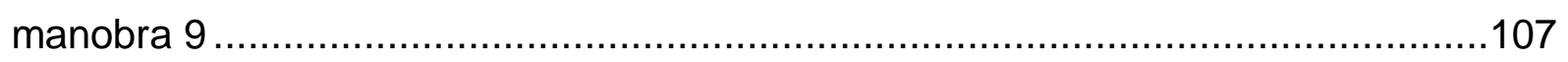

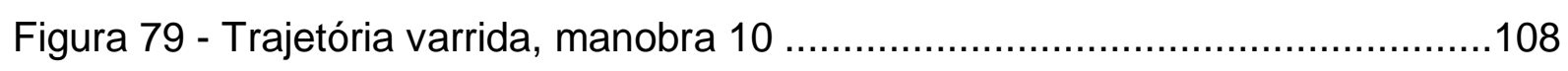

Figura 80 - Ângulo de deriva, Velocidade angular, Velocidade Vx, velocidade $\mathrm{Vy}$,

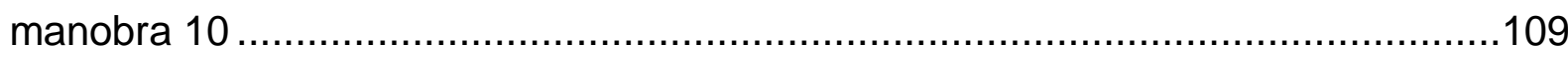

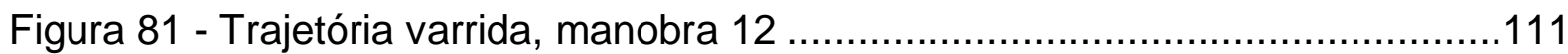

Figura 82 - Ângulo de deriva, Velocidade angular, Velocidade Vx, velocidade Vy,

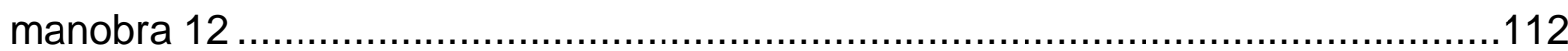

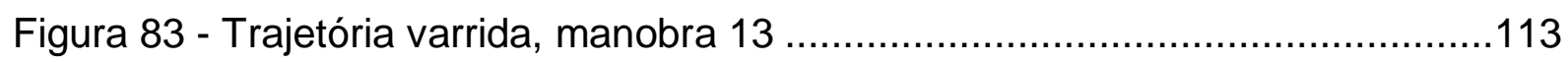

Figura 84 - Ângulo de deriva, Velocidade angular, Velocidade Vx, velocidade Vy,

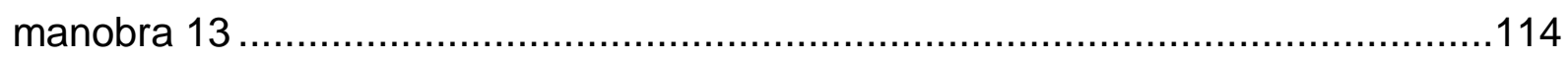

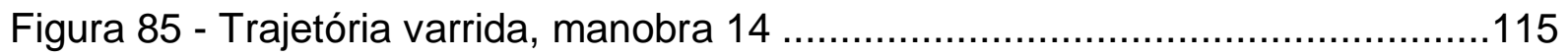

Figura 86 - Ângulo de deriva, Velocidade angular, Velocidade Vx, velocidade Vy,

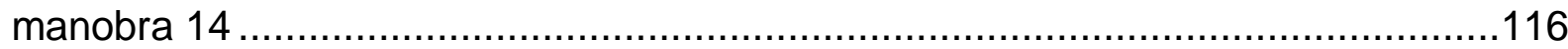

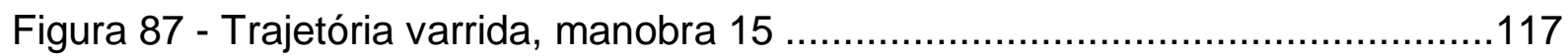

Figura 88 - Ângulo de deriva, Velocidade angular, Velocidade Vx, velocidade Vy,

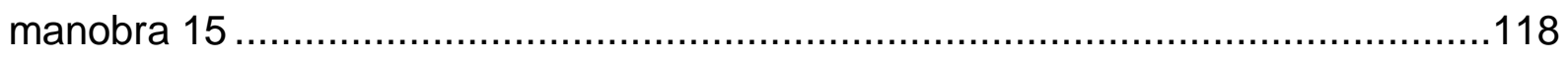

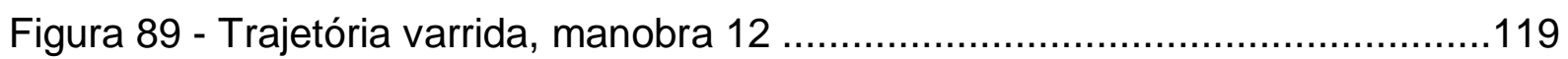

Figura 90 - Ângulo de deriva, Velocidade angular, Velocidade Vx, velocidade Vy,

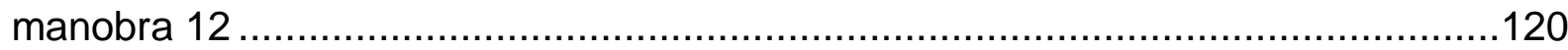

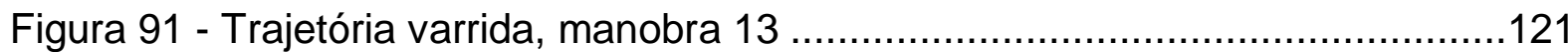

Figura 92 - Ângulo de deriva, Velocidade angular, Velocidade Vx, velocidade Vy,

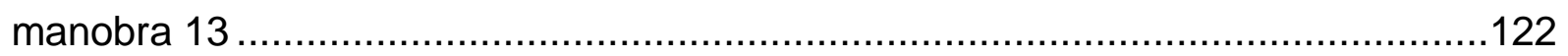

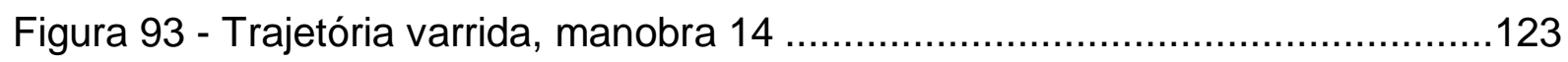

Figura 94 - Ângulo de deriva, Velocidade angular, Velocidade Vx, velocidade Vy,

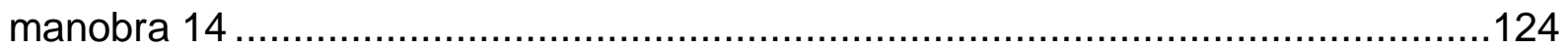

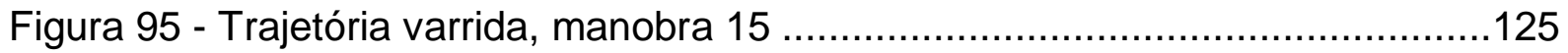

Figura 96 - Ângulo de deriva, Velocidade angular, Velocidade Vx, velocidade Vy,

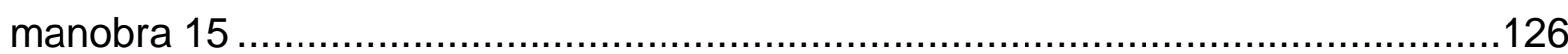

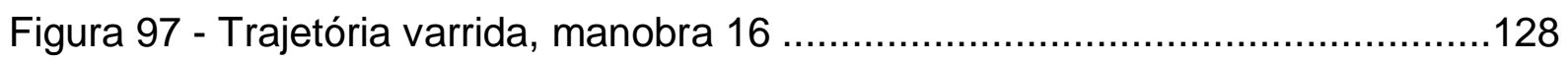

Figura 98 - Ângulo de deriva, Velocidade angular, manobra 16 ..........................128

Figura 99 - Velocidade $\mathrm{Vx}$, velocidade $\mathrm{Vy}$, manobra 16 ...................................129

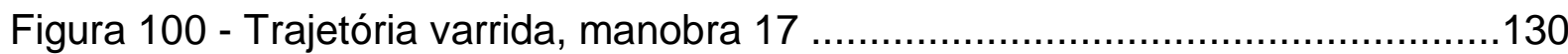


Figura 101 - Ângulo de deriva, Velocidade angular, Velocidade Vx, velocidade Vy, manobra 17

Figura 102 - Trajetória varrida, manobra 18

Figura 103 - Ângulo de deriva, Velocidade angular, Velocidade Vx, velocidade Vy, manobra 18 133

Figura 104 - Trajetória varrida, manobra 17

Figura 105 - Ângulo de deriva, Velocidade angular, Velocidade Vx, velocidade Vy, manobra 17

Figura 106 - Trajetória varrida, manobra 18

Figura 107 - Ângulo de deriva, Velocidade angular, Velocidade Vx, velocidade Vy, manobra 18

Figura 108 - Trajetória varrida, manobra 19 138

Figura 109 - Ângulo de deriva, Velocidade angular, Velocidade Vx, velocidade Vy, manobra 19

Figura 110 - Trajetória varrida, manobra 19

Figura 111 - Ângulo de deriva, Velocidade angular, Velocidade Vx, velocidade Vy, manobra 19

Figura 112 - Velocidade angular no tempo em um teste de Pull out. 142

Figura 113 - Trajetória varrida, manobra 21 143

Figura 114 - Ângulo de deriva, Velocidade angular, manobra 21 144

Figura 115 - Trajetória varrida, Ângulo de deriva, Velocidade angular, manobra 22

Figura 116 - Trajetória varrida, manobra 22 146

Figura 117 - Ângulo de deriva, Velocidade angular, manobra 22 147

Figura 118 - Erros médios para as manobras de Turning circle. 148

Figura 119 - Erros médios para as manobras de Initial turning test 149

Figura 120 - Erros médios para as manobras de Coasting turn 150

Figura 121 - Erros médios para as manobras de Crash stop

Figura 122 - Velocidade de avanço para a manobra 9 (acima) e manobra 10 (abaixo)

Figura 123 - Erros médios para as manobras de Accelerating turn 153

Figura 124 - Velocidade angular e Velocidades para a manobra 12 153

Figura 125 - Erros médios para as manobras de Crash ahead 154

Figura 126 - Erros médios para as manobras de Stopping inertia test 
Figura 127 - Erros médios para as manobras de Lateral thruster capability

Figura 128 - Trajetória varrida, manobra 19, original acima e nova execução abaixo 156

Figura 129 - Ângulo de deriva, Velocidade angular, Velocidade Vx, manobra 19, original acima e nova execução abaixo ........................................................157

Figura 130 - Erros médios para as manobras de Pull out test .............................158

Figura 131 - Média dos valores absolutos dos erros por tipo de manobra ...............161

Figura 132 - Comparação entre a manobra 2 realizada em águas profundas (esquerda) e águas rasas (direita) ...............................................................162

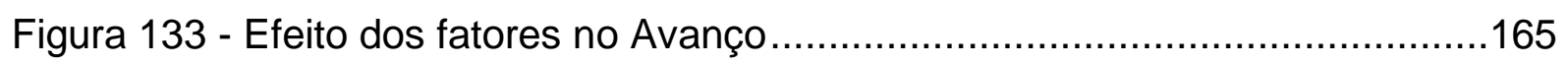

Figura 134 - Efeito dos fatores na Transferência ……………...........................166

Figura 135 - Efeito dos fatores no Diâmetro tático .............................................167

Figura 136 - Efeito dos fatores no Diâmetro final .............................................168

Figura 137 - Efeito dos fatores na Velocidade angular .......................................169

Figura 138 - Efeito dos fatores no Ângulo de deriva ..........................................170

Figura 139 - Efeito dos fatores na Distância a $20^{\circ}$.............................................171

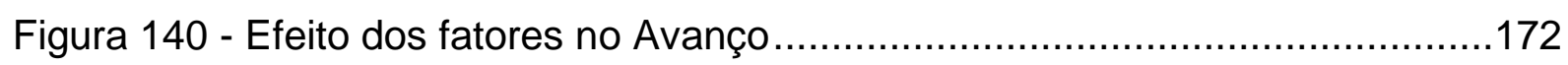

Figura 141 - Efeito dos fatores na Transferência .............................................173

Figura 142 - Efeito dos fatores no Ângulo de deriva .............................................174

Figura 143 - Efeito dos fatores no Avanço.....................................................175

Figura 144 - Efeito dos fatores no Avanço....................................................176

Figura 145 - Efeito dos fatores na Transferência .............................................177

Figura 146 - Efeito dos fatores no Diâmetro tático ………………………........178

Figura 147 - Efeito dos fatores no Diâmetro final ...............................................179

Figura 148 - Efeito dos fatores na Velocidade angular .......................................180

Figura 149 - Efeito dos fatores no Ângulo de deriva .............................................181

Figura 150 - Efeito dos fatores na aceleração longitudinal ..................................182

Figura 151 - Efeito dos fatores na aceleração longitudinal ..................................183

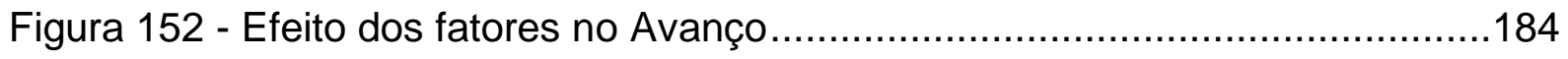

Figura 153 - Efeito dos fatores na Transferência .............................................185

Figura 154 - Efeito dos fatores na Velocidade angular ........................................186

Figura 155 - Efeito dos fatores na Velocidade angular final .................................188 


\section{LISTA DE TABELAS}

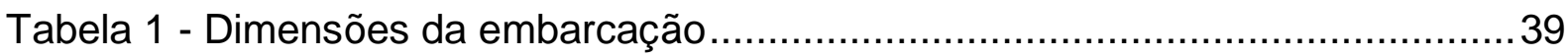

Tabela 2 - Dimensões da embarcação em escala reduzida ................................... 42

Tabela 3 - Resultados de empuxo para os propulsores em escala ........................4 47

Tabela 4 - Manobras realizadas com modelo em escala.......................................51

Tabela 5 - Características dos propulsores principais ..........................................53

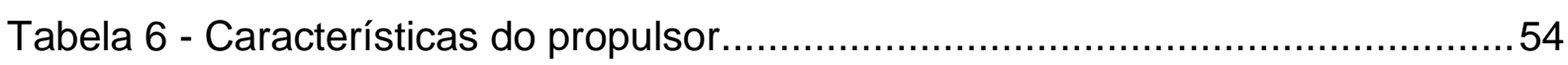

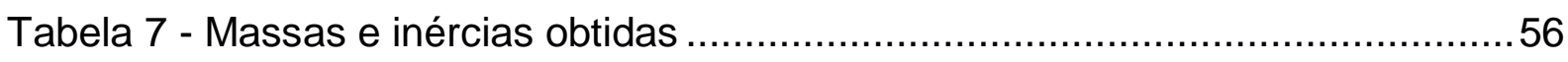

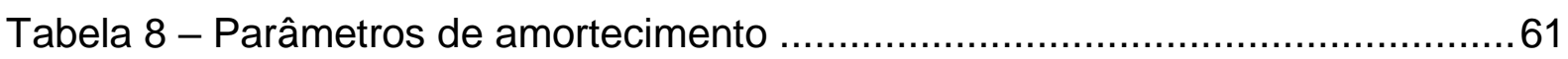

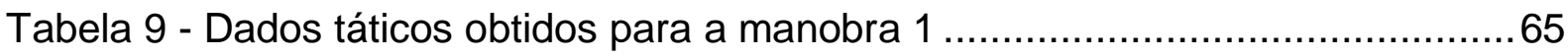

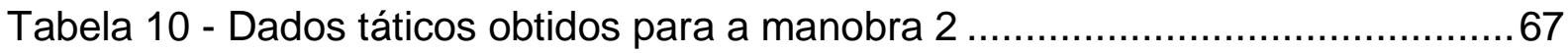

Tabela 11 - Dados táticos obtidos para a manobra 1 em águas rasas ......................69

Tabela 12 - Dados táticos obtidos para a manobra 2 em águas rasas .....................71

Tabela 13 - Dados táticos obtidos para a manobra 3 (convertidos para escala real) 74

Tabela 14 - Dados táticos obtidos para a manobra 4 ..........................................77

Tabela 15 - Dados táticos obtidos para a manobra 5 ......................................... 79

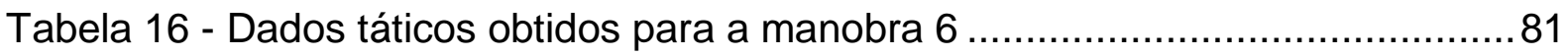

Tabela 17 - Dados táticos obtidos para a manobra 3 em águas rasas ..................... 83

Tabela 18 - Dados táticos obtidos para a manobra 4 em águas rasas ....................... 85

Tabela 19 - Dados táticos obtidos para a manobra 5 em águas rasas ....................87

Tabela 20 - Dados táticos obtidos para a manobra 6 em águas rasas ...................... 89

Tabela 21 - Dados táticos obtidos para a manobra 7 ............................................92

Tabela 22 - Dados táticos obtidos para a manobra 8 .........................................94

Tabela 23 - Dados táticos obtidos para a manobra 7 em águas rasas .....................97

Tabela 24 - Dados táticos obtidos para a manobra 8 em águas rasas .....................99

Tabela 25 - Dados táticos obtidos para a manobra 9 …..................................... 102

Tabela 26 - Dados táticos obtidos para a manobra 10 ....................................... 104

Tabela 27 - Dados táticos obtidos para a manobra 9 em águas rasas ................... 106

Tabela 28 - Dados táticos obtidos para a manobra 10 em águas rasas .................108

Tabela 29 - Dados táticos obtidos para a manobra 12 .....................................111

Tabela 30 - Dados táticos obtidos para a manobra 13 ......................................113

Tabela 31 - Dados táticos obtidos para a manobra 14 .....................................115

Tabela 32 - Dados táticos obtidos para a manobra 15 ......................................117 
Tabela 33 - Dados táticos obtidos para a manobra 12 em águas rasas 119

Tabela 34 - Dados táticos obtidos para a manobra $13 \mathrm{em}$ águas rasas 121

Tabela 35 - Dados táticos obtidos para a manobra 14 em águas rasas .123

Tabela 36 - Dados táticos obtidos para a manobra 15 em águas rasas 125

Tabela 37 - Dados táticos obtidos para a manobra 16 127

Tabela 38 - Dados táticos obtidos para a manobra 17.......................................130

Tabela 39 - Dados táticos obtidos para a manobra 18......................................132

Tabela 40 - Dados táticos obtidos para a manobra 17 em águas rasas .................134

Tabela 41 - Dados táticos obtidos para a manobra 18 em águas rasas .................136

Tabela 42 - Dados táticos obtidos para a manobra 19........................................138

Tabela 43 - Dados táticos obtidos para a manobra 19 em águas rasas .................140

Tabela 44 - Dados táticos obtidos para a manobra 21........................................143

Tabela 45 - Dados táticos obtidos para a manobra 22........................................144

Tabela 46 - Dados táticos obtidos para a manobra 22 em águas rasas .................146

Tabela 47 - Erros obtidos para as manobras de Initial turning test em águas profundas

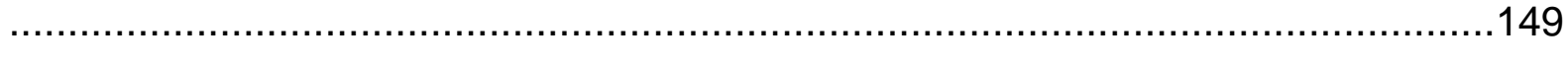

Tabela 48 - Média dos valores absolutos dos erros para cada manobra ................160

Tabela 49 - Conjuntos de manobras...............................................................164

Tabela 50 - Efeitos avaliados .....................................................................164

Tabela 51 - Variação dos efeitos obtida pela alteração dos fatores ........................190

Tabela 52 - Média da variação dos efeitos por tipo de manobra............................191 


\section{SUMÁRIO}

1. INTRODUÇÃO

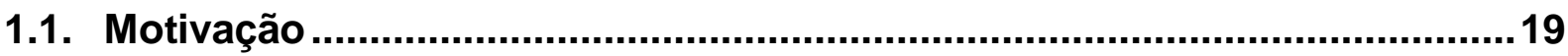

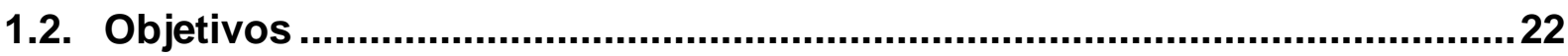

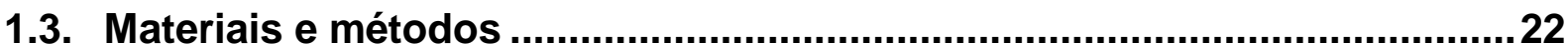

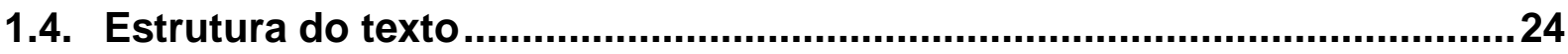

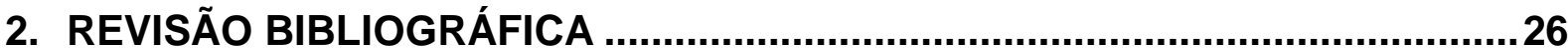

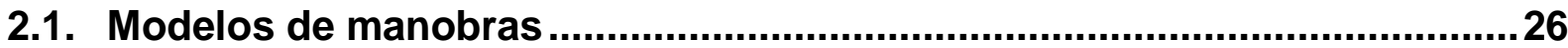

2.2. Caracterização de manobrabilidade .............................................................30

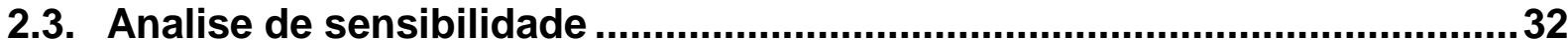

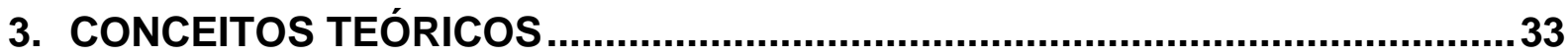

3.1. Modelo dinâmico de manobra ........................................................................3

3.2. Forças hidrodinâmicas e de amortecimento ................................................35

3.3. Modelo dos esforços de propulsor e leme ..................................................36

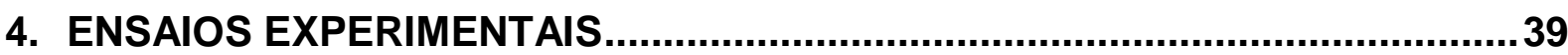

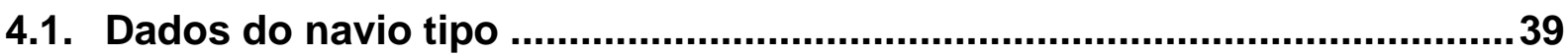

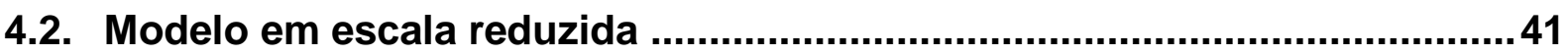

4.3. Descrição do tanque e aparato experimental ..............................................47

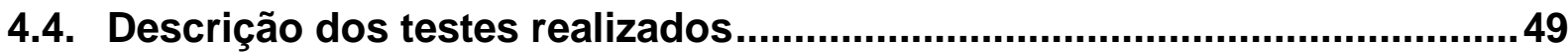

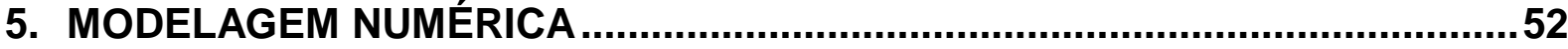

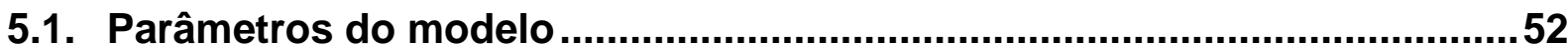

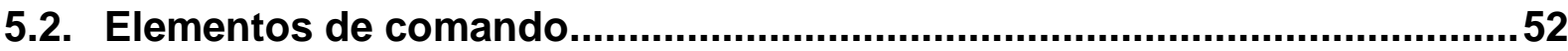

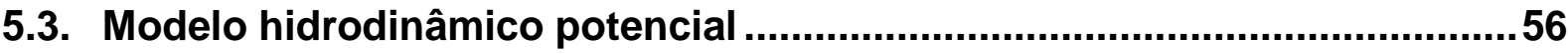

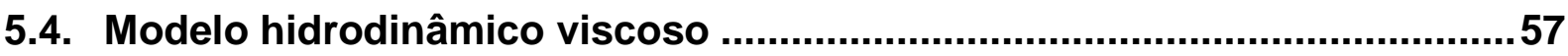

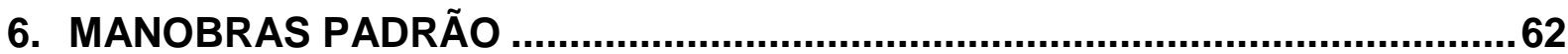

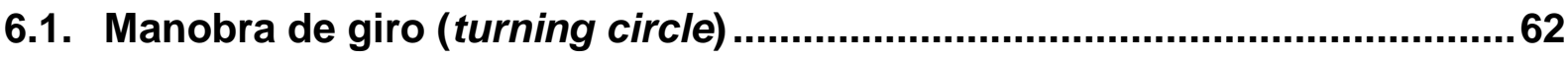

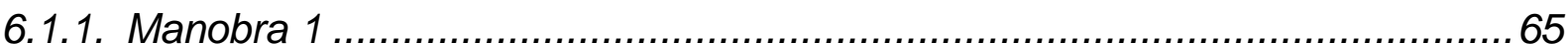




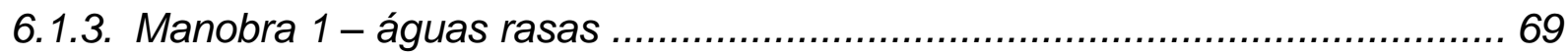

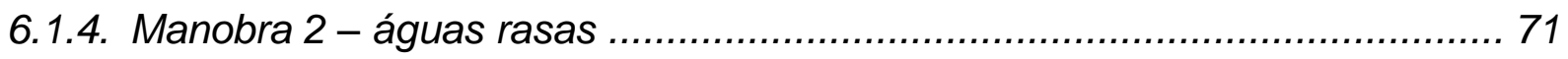

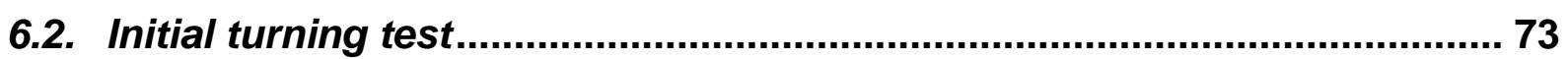

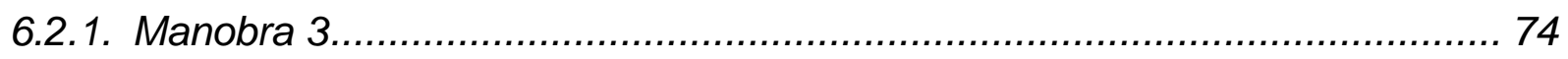

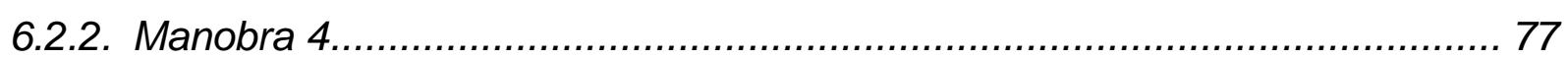

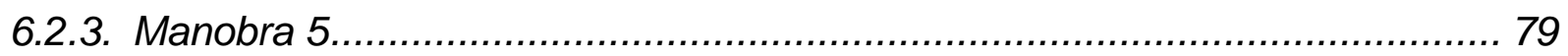

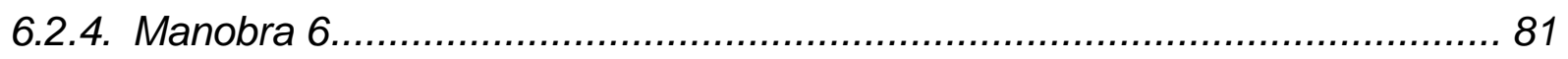

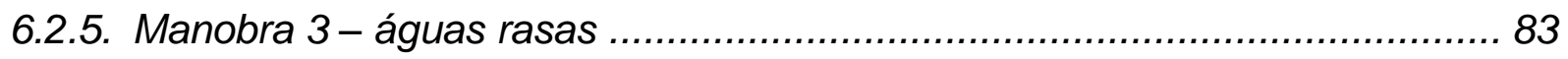

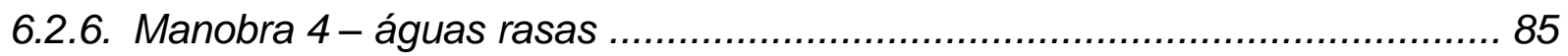

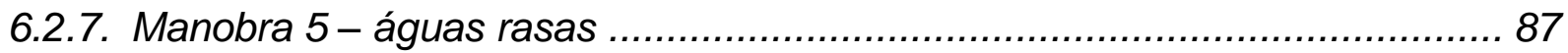

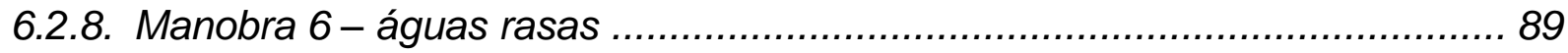

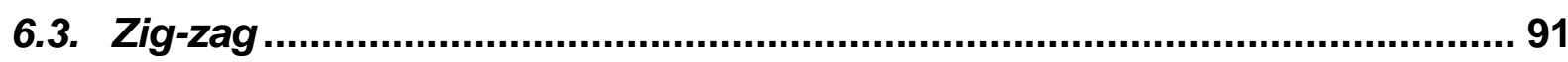

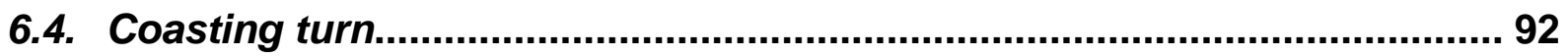

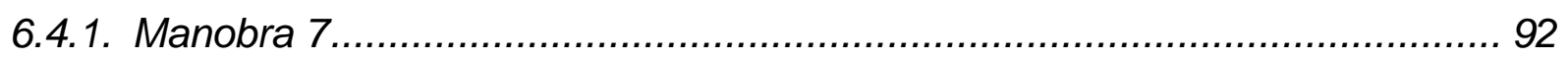

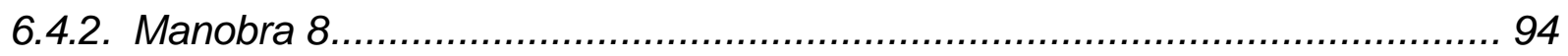

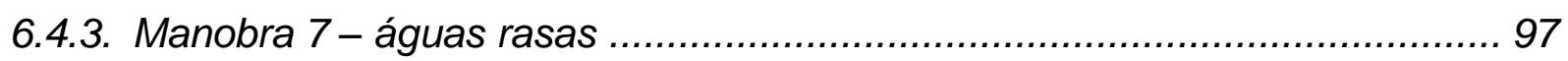

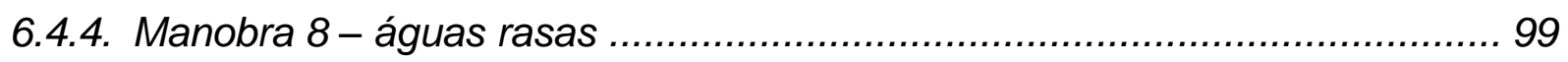

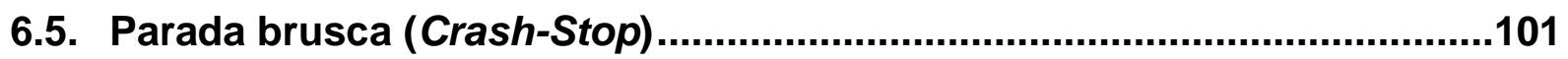

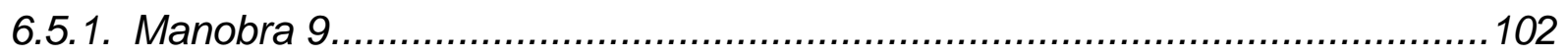

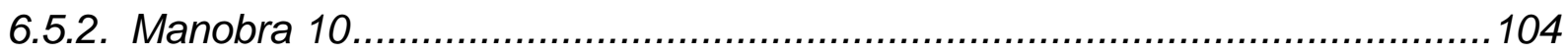

6.5.3. Manobra 9 - águas rasas ......................................................... 106

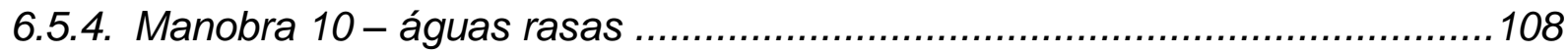

6.6. Accelerating turn (Giro com aceleração) ................................................110

6.6.1. Manobra 12........................................................................ 111

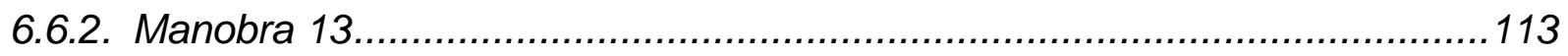

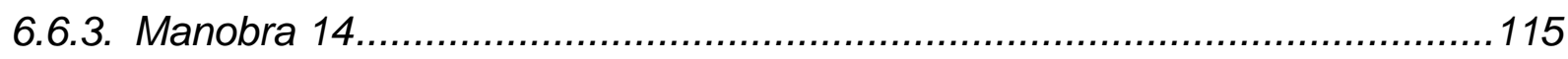


6.6.4. Manobra 15

6.6.5. Manobra 12 -águas rasas ................................................................... 119

6.6.6. Manobra 13 -águas rasas ............................................................ 121

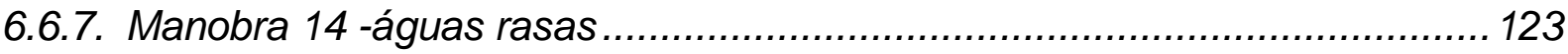

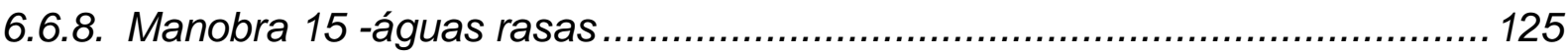

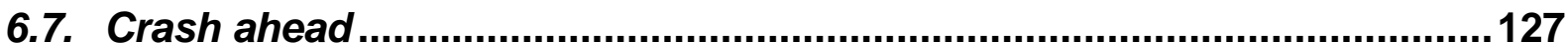

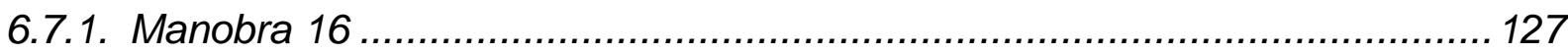

6.8. Stopping inertia test ....................................................................... 129

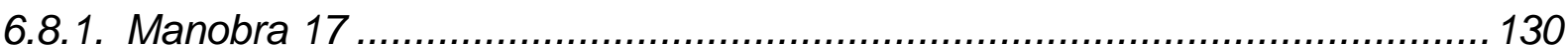

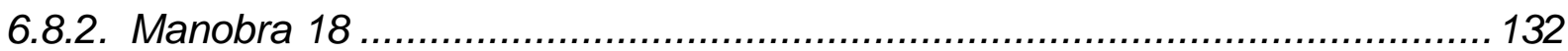

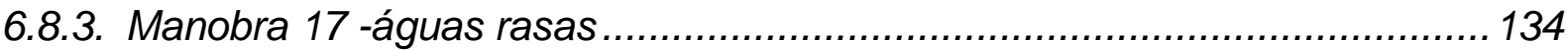

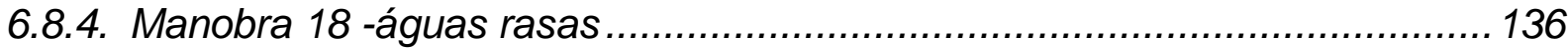

6.9. Lateral thruster capability .....................................................................138

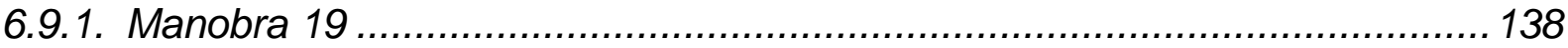

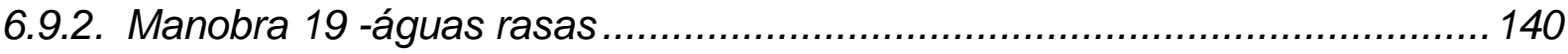

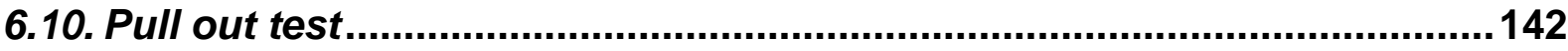

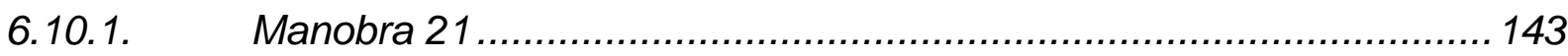

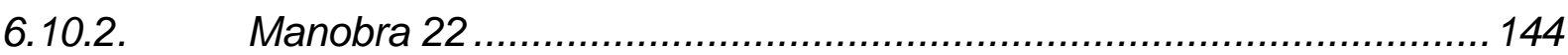

6.10.3. Manobra 22 -águas rasas .................................................... 146

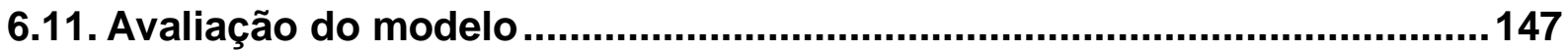

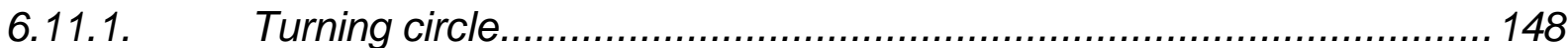

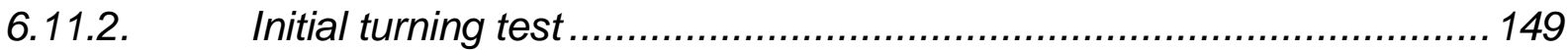

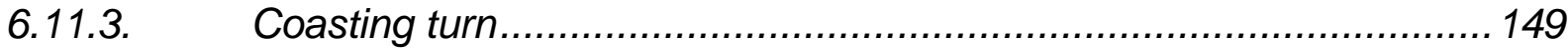

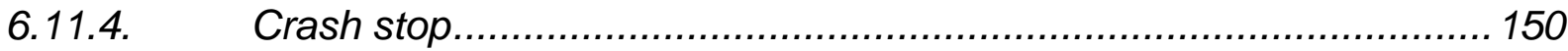

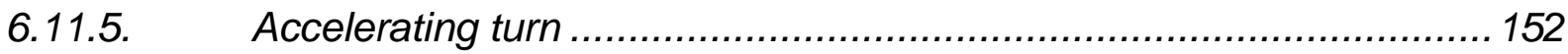

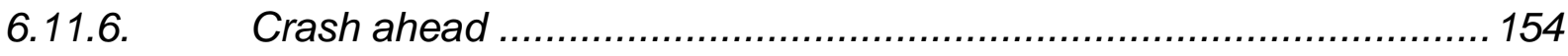

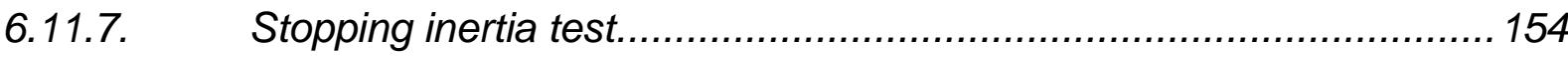




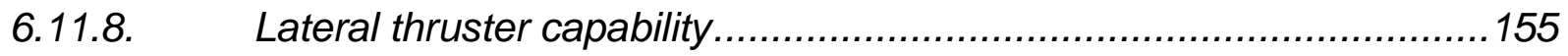

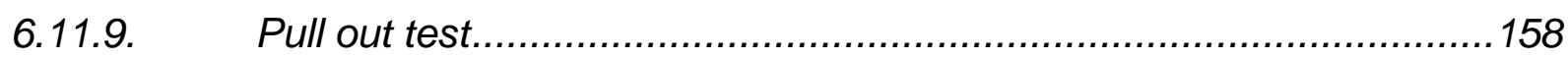

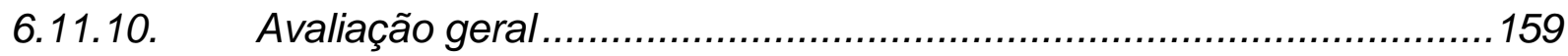

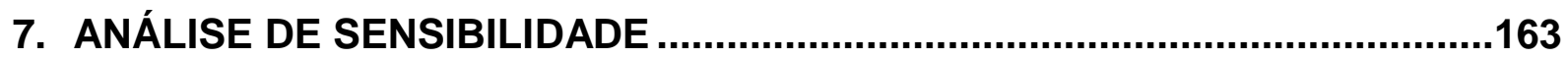

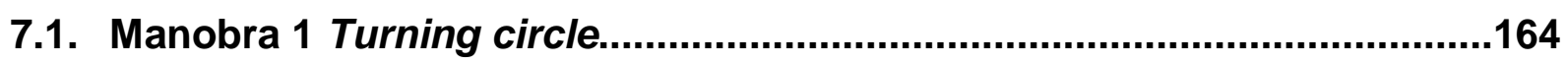

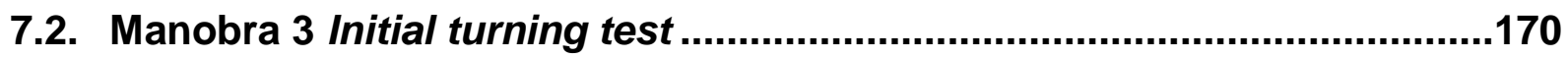

7.3. Manobra 7 Coasting turn .......................................................................171

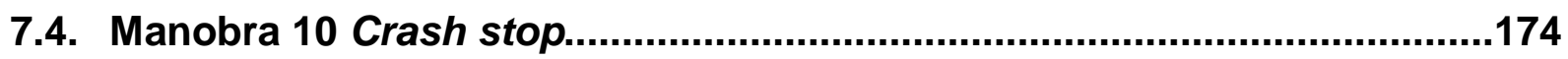

7.5. Manobra 15 Accelerating turn ..................................................................176

7.6. Manobra 17 Stopping inertia test..............................................................181

7.7. Manobra 18 Stopping inertia test - IMO .....................................................182

7.8. Manobra 19 Lateral thruster capability......................................................185

7.9. Manobra 21 Pull out test............................................................................187

7.10. Consolidação da análise de sensibilidade ...............................................188

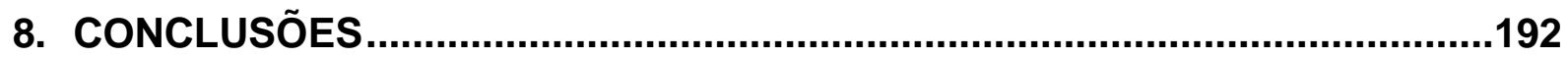

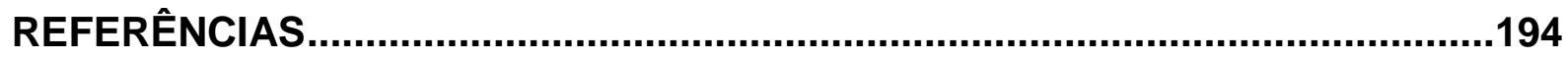




\section{INTRODUÇÃO}

\subsection{Motivação}

A complexidade da operação de embarcações nos sistemas off-shore de produção de petróleo e o aumento do porte das embarcações mercantes gerou ao longo dos anos uma demanda por simulações para navegação, manobras em portos e operações especificas, como ship to ship.

As simulações executadas podem ser divididas em duas classes, sendo realizadas em tempo real (real time - $\mathrm{RT}$ ) ou tempo rápido (fast time - FT). O uso de um simulador em tempo real ou rápido depende do tipo de análise a ser realizada, sendo as simulações FT indicadas para levantamento de informações e formação de bases estatísticas, uma vez que a simulação é controlada por computador com trajetórias predefinidas e com a vantagem de proporcionar rapidez. Os simuladores em tempo real, por outro lado, são indicados para treinamento e verificação de operações. Este tipo de simulação é realizada em projetos na fase de detalhamento, pois são controlados pelos operadores (práticos ou comandantes) e permitem incluir o fator humano na simulação, identificando-se riscos e características da operação relacionados com a interação do operador com o navio e o ambiente.

Os simuladores podem também ser distinguidos com relação a seus objetivos, que podem ser treinamento e capacitação, ou pesquisa e engenharia. Os simuladores dedicados a um ou outro objetivo apresentam diferenças consideráveis em suas características e modelos matemáticos. Os de treinamento reproduzem de forma fiel o ambiente operacional do passadiço e buscam uma representação simplificada do comportamento físico das embarcações. Já os simuladores destinados à pesquisa e engenharia devem reproduzir com fidelidade o comportamento das embarcações provendo um ambiente de passadiço parecido com a realidade, porém sem a necessidade de um mimetismo fidedigno dos equipamentos existentes no navio. $\mathrm{Ou}$ seja, os simuladores que se prestam para fins de treinamento mantêm seu foco no operador, garantindo um ambiente imersivo e que apresente a interface homem máquina fiel à existente nas embarcações, enquanto os simuladores destinados à engenharia e pesquisa mantém seu foco no modelo matemático (embarcação e meio ambiente), garantindo fidelidade ao comportamento das manobras. 
As simulações tratadas neste trabalho dizem respeito ao segundo tipo citado no parágrafo anterior, desta forma, quando forem citadas simulações e modelos, deve-se ter em mente a busca da qualidade do modelo físico que representa a dinâmica do navio e sua interação com o ambiente.

Com a disponibilização de simuladores de manobra capazes de realizar análises de engenharia para operações portuárias e offshore, projetistas de portos e a autoridade marítima têm utilizado simuladores como uma ferramenta para dar suporte aos projetos e subsidiar decisões operacionais e de autorização de tráfego. Devido a este tipo de uso para os simuladores faz-se necessária a boa qualidade dos modelos de simulação, garantindo que o comportamento do navio simulado se assemelhe com a maior exatidão possível ao comportamento do navio real.

Sem que haja uma padronização ou diretrizes para validação dos modelos utilizados por simuladores não é possível garantir que haja uniformidade das simulações realizadas, deixando os resultados de simulações dependentes do método utilizado para calibração dos modelos.

Um exemplo deste problema foi apresentado em Berg et al. (2011). Neste trabalho, diversos institutos que possuem e utilizam simuladores de manobras para fins de engenharia e pesquisa realizaram um teste de manobra de giro em um navio idêntico modelado em seu simulador. O diâmetro tático oriundo da manobra de curva de giro apresentou grande dispersão entre os resultados dos simuladores, variando de 2,15 a 4,38 comprimentos de navio conforme mostrado na Figura 1.

O problema de calibração dos modelos de simulação fica mais evidente com o uso de simuladores para projetos de portos e canais de acesso, pois estas áreas possuem pouca profundidade, o que altera as características hidrodinâmicas das embarcações. $O$ impacto no resultado das simulações desta característica de áreas portuárias é majorado devido à dificuldade na obtenção de dados de manobra de embarcações para águas rasas, onde espera-se que a embarcação apresente maior estabilidade direcional.

No início do desenvolvimento do simulador de manobras do Tanque de Provas Numérico da USP (denominado Simulador Marítimo Hidroviário - SMH), utilizado neste trabalho, os modelos criados correspondiam a barcaças para operação em 
hidrovia, as quais não existiam. Por esse motivo não era possível realizar um processo de calibração devido à falta de alguma referência sobre a capacidade de manobra destas embarcações. Com o continuo uso e desenvolvimento do simulador, este começou a ser utilizado para simulações de engenharia que compreendiam navios e localizações existentes, possibilitando, assim, a comparação com comportamentos de manobra através da opinião dos operadores (comandantes e práticos). Porém há ainda a necessidade da validação do modelo de manobras utilizado por este simulador para a operação em águas rasas e regime transiente de velocidade.

Figura 1 - Diâmetro tático em manobra de giro

\section{Tactical diameter derived from turning circle test}

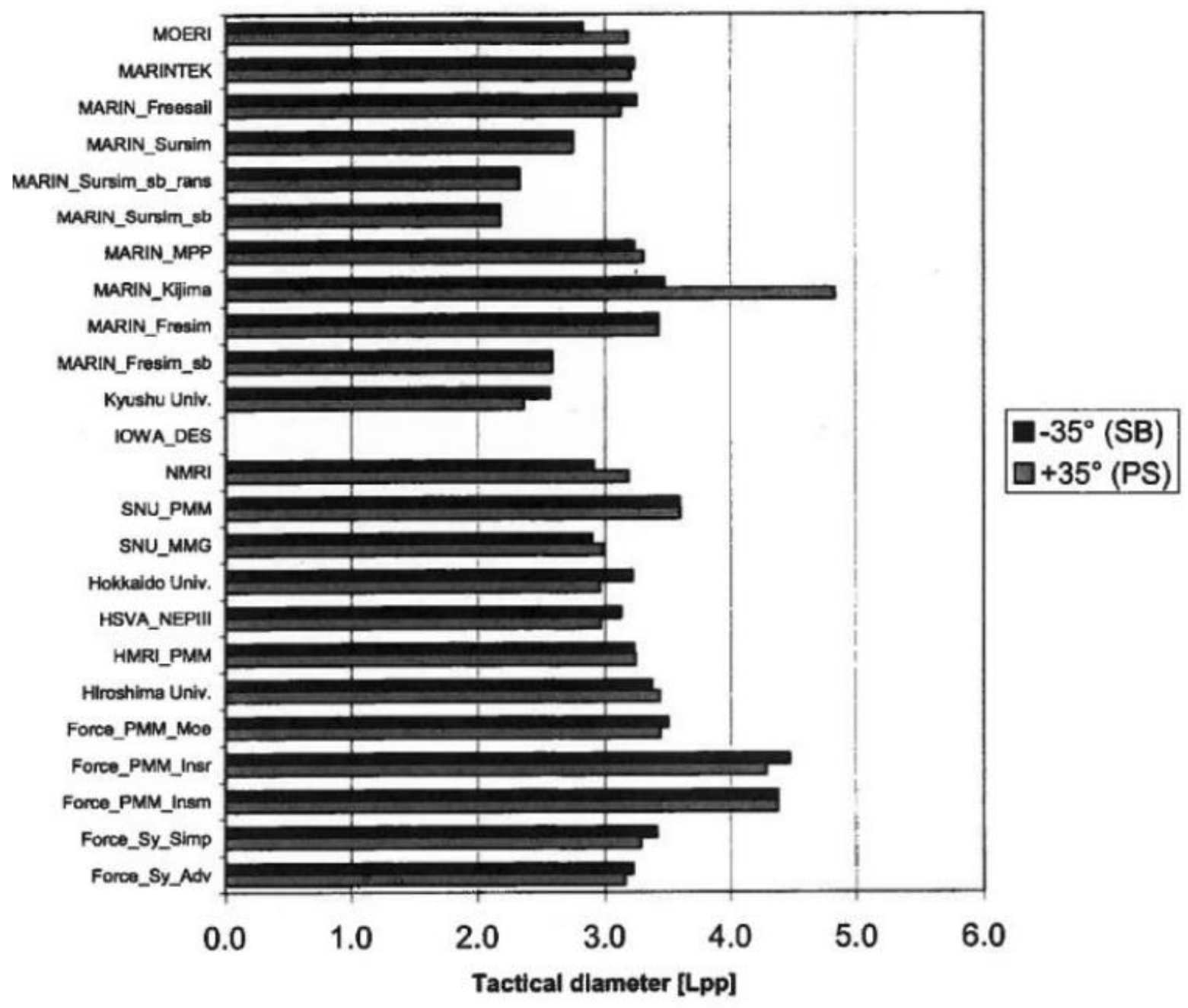

Fonte: (Berg, et al., 2011)

A metodologia aplicada para calibração do modelo de manobras utilizada no Tanque de Provas Numérico realiza comparações de dados táticos obtidos para os navios modelados numericamente e seus correspondentes reais, como diâmetro 
tático e avanço na manobra de curva de giro, e outras manobras que determinam a manobrabilidade das embarcações em éguas profundas e com velocidade constante.

Além da comparação com os dados táticos do navio real, os modelos são calibrados, também, conforme a experiência prática dos profissionais que operam os mesmos, sejam estes comandantes ou práticos. No entanto observa-se que, embora os modelos apresentem boa aderência aos dados táticos, estes modelos matemáticos podem apresentar representatividade ruim para manobras, segundo relatos dos operadores, sobretudo nos casos de manobras em velocidades baixas e em regime transiente. Ademais, por vezes observa-se que diferentes operadores avaliam de forma divergente a qualidade da representação da realidade.

\subsection{Objetivos}

O principal objetivo deste trabalho é, portanto, apresentar a validação do modelo numérico de manobras e da metodologia utilizada para a calibração do simulador SMH, realizando a avaliação dos erros obtidos através da comparação das grandezas que caracterizam as manobras da embarcação num modelo em escala reduzida com os resultados apresentados pelo modelo numérico para es mesmas grandezas medidas.

O trabalho tem por objetivo também apresentar um breve estudo de sensibilidade para possibilitar a identificação da importância dos parâmetros mais utilizados para a calibração do modelo numérico, conforme a metodologia para calibração do SMH utilizada no Tanque de Provas Numérico.

\subsection{Materiais e métodos}

Os recursos para esta dissertação foram fornecidos pelo laboratório Tanque de Provas Numérico da Universidade de São Paulo (TPN-USP).

Este trabalho apresenta uma comparação entre 0 modelo numérico desenvolvido no laboratório TPN e implementado no Simulador Marítimo Hidroviário $(\mathrm{SMH})$ e um modelo em escala da embarcação Alpha Crucis. A Figura 2 apresenta um dos passadiços do simulador. 
Figura 2 - Estação de simulação em tempo real

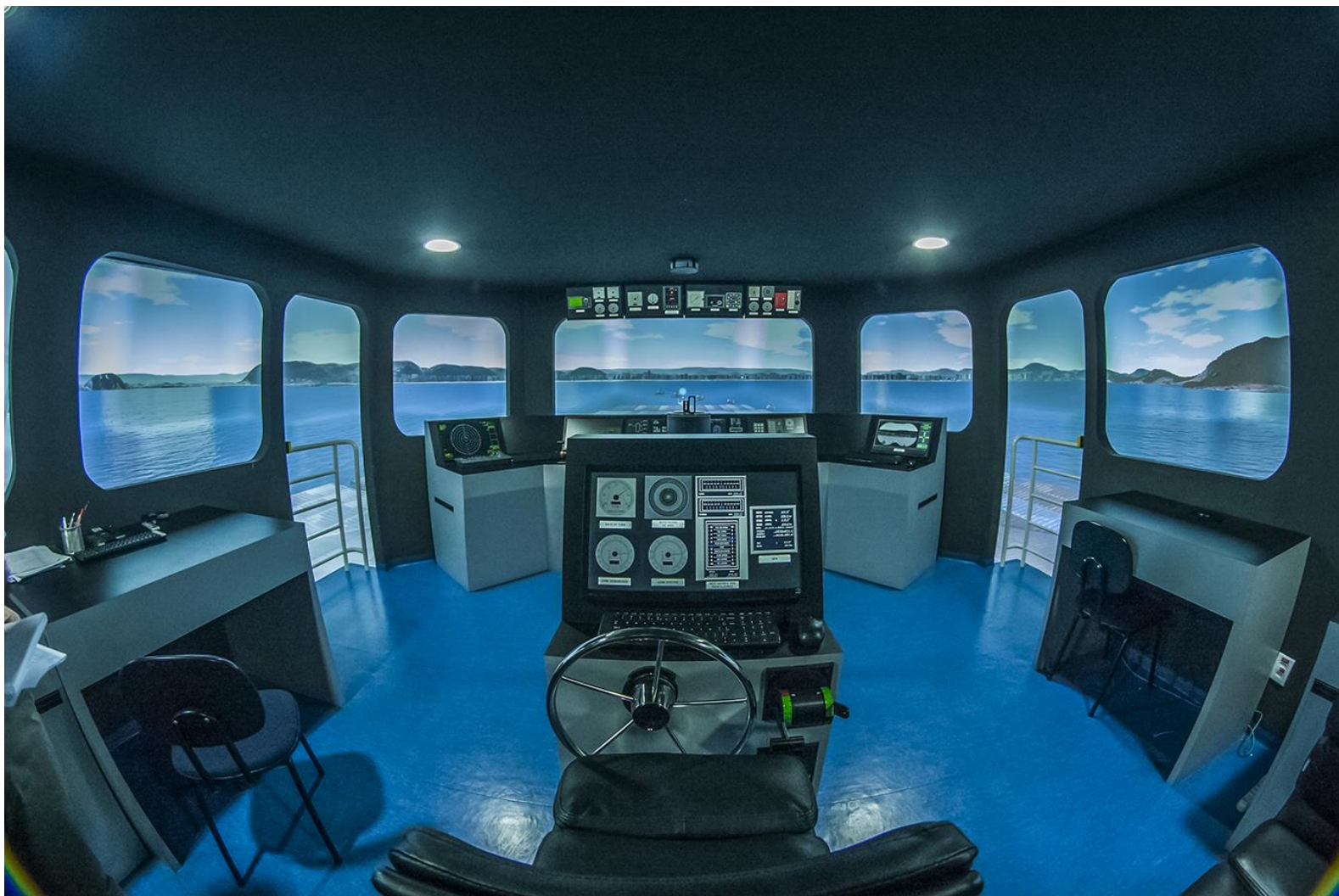

Fonte: Eduardo Aoun Tannuri.

Para realização das simulações numéricas foram utilizados coeficientes obtidos através de programas comerciais, enquanto as simulações em si foram realizadas através do $\mathrm{SMH}$.

O comportamento dinâmico da embarcação, representado no $\mathrm{SMH}$, considera efeitos da teoria potencial hidrodinâmica e efeitos viscosos. Para o levantamento dos coeficientes hidrodinâmicos foi utilizado o software Wamitß, que utiliza o método dos painéis em 3 dimensões para a solução das equações da teoria potencial, e o software StarCCM+ (2014), que utiliza o método dos volumes finitos.

A parte experimental foi realizada no tanque do laboratório Centro de Tecnologia Hidráulica da Universidade de São Paulo (CTH-USP), onde foi utilizado um tanque cujo nível de água pode ser regulado, possibilitando dessa forma, a realização de ensaios com o modelo em escala reduzida em condições de águas rasas e águas profundas. O tanque utilizado não permite a geração de ondas ou correnteza. 
Para medição dos movimentos do modelo foi utilizado um conjunto de câmeras que operam na banda do infravermelho, associadas a alvos reflexivos presos ao mesmo, que permitem sua localização pelo sistema de medição.

O modelo utilizado é uma representação da embarcação Alpha Crucis em escala de 1:28, provido de propulsores e 2 lemes que possibilitam sua navegação (Figura 3).

Figura 3 - Modelo utilizado com aparato de câmeras ao fundo

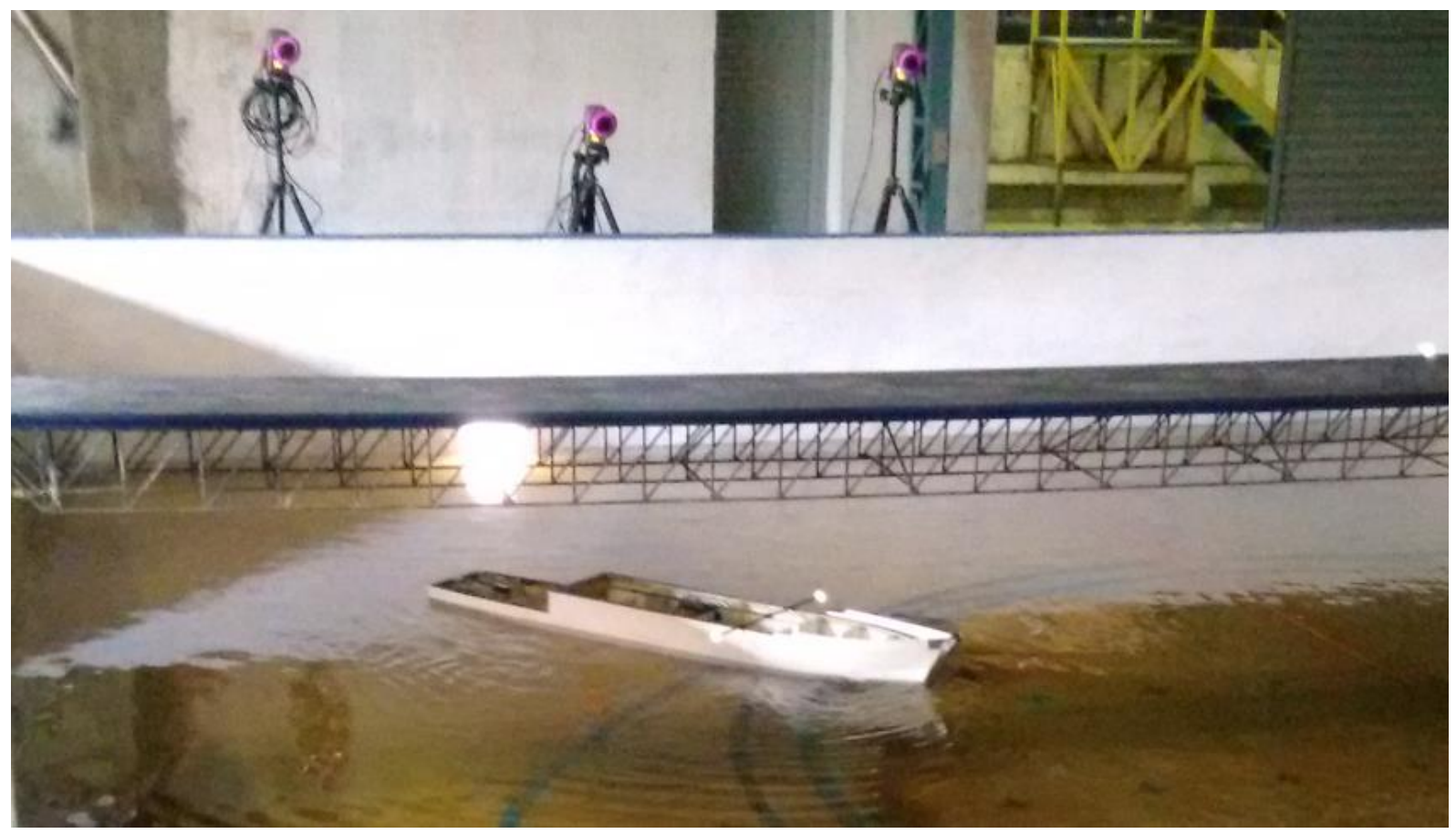

Fonte: Autor.

\subsection{Estrutura do texto}

Após a introdução, no capítulo 2 esta dissertação apresenta uma revisão bibliográfica que contém informações sobre os modelos hidrodinâmicos e modelos de manobra. São apresentados também modelos de propulsão e leme.

A revisão bibliográfica é seguida, no capitulo 3, por uma apresentação dos conceitos teóricos, que possibilitam a representação da embarcação por um modelo numérico. Esta seção apresenta o modelo dinâmico de manobra bem como as forças hidrodinâmicas atuantes no casco e as forças provenientes do sistema de propulsão e leme.

Após a apresentação dos conceitos teóricos, que possibilitam a simulação de uma embarcação em navegação, é apresentado no capitulo 4 o modelo em escala 
reduzida e o tanque utilizado para os ensaios experimentais. Este capítulo apresenta ainda os tipos de manobra utilizadas no trabalho.

O capitulo 5 apresenta os principais elementos do modelo numérico utilizados para a calibração do comportamento da embarcação, nele são mostrados os coeficientes empregados para o modelo calibrado.

No capítulo 6 as manobras utilizadas são descritas em detalhes e faz-se a comparação entre os resultados obtidos para as manobras em escala reduzida e as manobras realizadas pelo modelo numérico.

Após a apresentação dos resultados obtidos, o texto apresenta no capítulo 7 os resultados de uma análise de sensibilidade para os fatores do modelo numérico que são utilizados para a calibração do modelo no laboratório Tanque de Provas Numérico.

Por fim, é apresentada uma conclusão com base nos resultados obtidos, bem como sugestões para estudos futuros. 


\section{REVISÃO BIBLIOGRÁFICA}

\subsection{Modelos de manobras}

A necessidade da predição da manobrabilidade de navios é notada de longa data, sendo tratada por diversos grupos ao longo dos anos. Esta pluralidade propiciou ao problema citado uma gama de soluções com diferentes características. Tão cedo quanto possível iniciou-se o emprego de métodos computacionais no emprego da predição da manobrabilidade de navios, como o modelo de Abkowitz (1964).

Os modelos apresentados para a solução computacional do problema de manobrabilidade de navios se dividem em dois grupos básicos, o primeiro tenta simplificar a modelagem do problema e adota expansões das forças e momentos hidrodinâmicos em séries cujos coeficientes, conhecidos como derivadas hidrodinâmicas, são obtidos normalmente através de ensaios experimentais realizados em torno de um estado de equilíbrio, com combinações definidas de velocidade de avanço, deriva e guinada.

Como exemplo pode ser citado o modelo de Takashina (1986), composto por uma expansão em série de Fourier em que os coeficientes são obtidos a partir de ensaios de giro completo com uma determinada velocidade de guinada. Os modelos de derivadas hidrodinâmicas fazem uso de uma quantidade reduzida de parâmetros constantes, o que facilita seu uso, porém esses modelos só representam bem as condições manobra próximas às condições realizadas nos ensaios experimentais.

O segundo grupo de modelos aborda o problema de forma mais heurística, buscando padrões que relacionem o comportamento das embarcações com a física envolvida no fenômeno. Conforme o trabalho de Ankudinov et al. (1993), estes modelos assumem premissas realistas com base em princípios físicos, enquanto os do primeiro grupo não necessariamente apresentam relação entre as derivadas hidrodinâmicas e os princípios físicos envolvidos. Modelagens heurísticas fazem considerações sobre as dimensões e velocidade do navio para o cálculo das forças hidrodinâmicas. Considerações sobre a forma do casco são também atribuídas através de coeficientes hidrodinâmicos.

Estes modelos podem ainda fazer uso do princípio de local cross flow, incluindo na modelagem a influência da rotação de guinada do navio, no entanto a maior parte 
dos modelos ao fazer a integração seccional considera o coeficiente de arrasto constante ao longo do casco, ignorando efeitos hidrodinâmicos que ocorrem devido à variação da forma do casco nas extremidades do navio.

No entanto há modelos que propõem soluções para a consideração desses efeitos, como tip-vortex, como descrito por Faltinsen et al. (1979). Estes modelos representam tais efeitos através da variação dos coeficientes hidrodinâmicos ao longo do comprimento do navio e da inclusão de amortecimento devido à geração de vórtices nas extremidades da embarcação.

Em suma, os modelos heurísticos tentam representar as forças hidrodinâmicas a partir de coeficientes de arraste obtidos estaticamente, no caso de modelos que representam o princípio de cross flow há ainda o acoplamento das forças em função da velocidade de guinada, de forma a relacionar as forças com os princípios físicos atuantes no casco.

Os modelos de derivadas hidrodinâmicas por sua vez, ao representarem as forças por expansões em séries obtidas através de ensaios que medem diretamente as forças e momentos nas direções de interesse, englobam automaticamente efeitos como a geração de vórtices. Porém não é possível fazer a relação entre os coeficientes e os princípios físicos que representam, dessa forma tornando o modelo válido em condições próximas às que foram realizados os ensaios para levantamento das derivadas.

Conforme apresentado, os modelos utilizados são dependentes de coeficientes que possibilitam seu uso, sejam os modelos heurísticos ou baseados em derivadas hidrodinâmicas. Dessa forma fazem-se necessários certos cuidados para a determinação destes coeficientes, que são dependentes do modelo matemático adotado. Ankudinov et al. (1993) lembra em seu texto que os experimentos realizados para a obtenção de tais coeficientes contêm imperfeições, que podem ser expressas em termos da incerteza de medições, mas que estão relacionadas também a imperfeições das ferramentas e procedimentos utilizados, bem como distúrbios causados pelo próprio ambiente de ensaio.

A realização de experimentos em escala real mostra-se difícil devido à dificuldade de controle do ambiente para realização dos ensaios, e devido à baixa 
disponibilidade de embarcações reais para este propósito. A realização de ensaios em escala torna-se então uma ferramenta útil para o levantamento de informações que alimentam os modelos de manobra, no entanto efeitos de escala são notados, causando alterações entre os resultados obtidos em ensaios com diferentes escalas, devidas principalmente às diferenças ocorridas com relação ao número de Reynolds. Torna-se necessário então o uso de técnicas que permitam a extrapolação dos dados obtidos em escala para seu correto uso em uma simulação em escala real.

Além das forças externas atuantes no casco os modelos devem também representar as forças de controle, tais como leme e propulsor e sua interação com casco. Em seu texto Kose (1982) descreve o modelo hidrodinâmico como um somatório de forças atuantes no casco, no leme, e forças provenientes da interação entre casco, propulsor e leme. Como resultados, são obtidas relações conforme o tipo de casco e o regime de operação do propulsor que levam a alterações na velocidade e ângulo de incidência do fluxo de água sobre o leme.

Assim como Kose, Oltman et al. (1984) evidenciam em seu modelo a importância da interação entre casco, propulsor e leme. Esse modelo considera ainda uma formulação que introduz o ângulo de avanço, que diferentemente da taxa de avanço do propulsor não possui singularidade para propulsores com velocidade de rotação zero e elimina a ambiguidade entre os casos com velocidade de avanço da embarcação positiva e negativa, sendo este um modelo de quatro quadrantes que descreve as forças provenientes do propulsor. O modelo de (Oltmann, et al., 1984) considera ainda a dinâmica do motor que impulsiona o propulsor e introduz assim um importante fator para as simulações de manobra, contribuindo para a alocação de forças pelo propulsor conforme os tempos de resposta condizentes com os do navio.

Ambos os tipos de modelos, baseados em derivadas hidrodinâmicas e modelos heurísticos, seguem as leis básicas da dinâmica de corpo rígido associada à cinemática para transformar as grandezas entre os sistemas de coordenada local ou global. Os modelos se diferenciam na forma de cálculo das forças hidrodinâmicas, que são entradas à equação do movimento.

O modelo de manobras apresentado por Fossen (2011), baseado em derivadas hidrodinâmicas, considera a dinâmica de corpo rígido não linear apresentado na equação (1). 


$$
M_{R B} \dot{v}+C_{R B}(v) v=\tau_{R B}
$$

Em que $M_{R B}$ é a matriz de massa do sistema, $C_{R B}$ é a matriz de efeitos dinâmicos de corpo rígido tais como Coriolis e Centrípeta e $\tau_{R B}$ são as forças e momentos externos. Estes, por sua vez, são dados em função das velocidades e acelerações da embarcação no sentido longitudinal $(u, \dot{u})$ e transversal $(v, \dot{v})$ ao navio, bem como a rotação e aceleração angular de guinada $(r, \dot{r})$.

$$
\tau_{R B}=\left[\begin{array}{lll}
X(x) & Y(x) & N(x)
\end{array}\right]^{\top}
$$

Em que $x$ corresponde ao vetor de velocidades e acelerações, junto com 0 ângulo do leme $\delta$, como apresentado em (3).

$$
x=[u, v, r, \dot{u}, \dot{v}, \dot{r}, \delta]^{T}
$$

Com base nas equações de movimento, Abkowitz (1964) propôs expansões em série de Taylor para as funções $X(x), Y(x), N(x)$ com a forma apresentada em (4). Esta equação exemplifica a formulação utilizada por Abkowitz para as forças no sentido longitudinal da embarcação, na qual as derivadas hidrodinâmicas que compõem a equação necessitam de ensaios experimentais para sua determinação. A maior parte das derivadas hidrodinâmicas oriundas destas expansões não possuem uma correlação clara com fenômenos físicos envolvidos, demandando assim ensaios específicos para cada navio analisado.

$$
\begin{aligned}
X(\mathrm{x})=\mathrm{X}^{*} & +\mathrm{X}_{\dot{\mathrm{u}}} \dot{\mathrm{u}}+\mathrm{X}_{\mathrm{u}} \Delta \mathrm{u}+\mathrm{X}_{\mathrm{uu}} \Delta \mathrm{u}^{2}+\mathrm{X}_{\mathrm{uuu}} \Delta \mathrm{u}^{3}+\mathrm{X}_{\mathrm{vv}} \mathrm{v}^{2}+\mathrm{X}_{\mathrm{rr}} \mathrm{r}^{2}+\mathrm{X}_{\delta \delta} \delta^{2} \\
& +\mathrm{X}_{\mathrm{rv} \delta} \mathrm{rv} \delta+\mathrm{X}_{\mathrm{r} \delta} \mathrm{r} \delta+\mathrm{X}_{\mathrm{v} \delta} \mathrm{v} \delta+\mathrm{X}_{\mathrm{vvu}} \mathrm{v}^{2} \Delta \mathrm{u}+\mathrm{X}_{\mathrm{rru}} \mathrm{r}^{2} \Delta \mathrm{u}+\mathrm{X}_{\delta \delta \mathrm{u}} \delta^{2} \Delta \mathrm{u} \\
& +\mathrm{X}_{\mathrm{rvu}} \mathrm{rvu}+\mathrm{X}_{\mathrm{r} \delta \mathrm{u}} \mathrm{r} \delta \Delta \mathrm{u}+\mathrm{X}_{\mathrm{v} \delta \mathrm{u}} \mathrm{v} \delta \Delta \mathrm{u}
\end{aligned}
$$

As grandezas identificadas com $\Delta$, como $\Delta u$, representam a perturbação da velocidade em torno do estado estacionário $x_{0}$, para o qual foram levantadas as derivadas hidrodinâmicas.

Outros trabalhos apresentam formulações distintas, e fazem uso de diferentes termos de derivadas hidrodinâmicas, como Clarke e Horn (1997) que apresenta um modelo linearizado, e Takashina (1986) e Takashina et al. (1990) que apresenta uma abordagem com um número reduzido de derivadas hidrodinâmicas voltado para manobras em baixas velocidades.

Os modelos heurísticos, por sua vez, não utilizam o conceito de expansão em séries de Taylor e de derivadas hidrodinâmicas. Essa classe de modelos é 
exemplificada pelo modelo de asa curta short-wing model descrito em Simos (2001) e pelo modelo de cross flow estudado por diversos autores como Obokata (1987) e Wichers (1988).

Ao contrário dos modelos de derivadas hidrodinâmicas, esse tipo de modelagem mantém mais evidentes as relações entre os termos e sua origem física, necessitando de menor número de ensaios para levantamento dos coeficientes que alimentam o modelo, permitindo por vezes a extrapolação e ajuste desses coeficientes com base em navios de dimensões distintas devido à relação mais evidente entre os termos utilizados e a física envolvida no modelo.

O efeito de cross flow por exemplo, introduz o conceito de velocidade relativa da correnteza, descrita nas componentes longitudinal e transversal ao navio, respectivamente $u_{c r}$ e $v_{c r}$, havendo também por consequência a consideração de $\Psi$ que representa o ângulo de incidência da correnteza relativa à embarcação.

A equação (5) mostra o modelo apresentado por Obokata (1987) para as forças na direção longitudinal da embarcação que ocorrem devido ao efeito de cross flow.

$$
X=0.5 \cdot \rho \cdot T \int_{-L / 2}^{L / 2}\left[C_{x}\left(\Psi_{L}\right) \cdot V_{L}^{2}\right] d l
$$

Neste modelo a relação entre a força que atua na embarcação e as características físicas da embarcação fica evidente, onde $\rho$ representa a massa específica da água, $T$ representa 0 calado da embarcação, $L$ representa 0 comprimento entre perpendiculares, $C_{X}$ representa o coeficiente de correnteza.

Os termos com índice $L$ representam a velocidade relativa e ângulo de incidência ao longo das seções transversais do navio. O modelo apresentado por Obokata será apresentado na seção 3 .

\subsection{Caracterização de manobrabilidade}

Para a caracterização da manobrabilidade de uma embarcação faz-se necessário definir os critérios que irão distinguir a manobra. Hooft (1994) apontam a incerteza dos indicadores de desempenho da manobrabilidade da embarcação como um dos maiores problemas do projeto de embarcações. Porém diferentes embarcações apresentam diferentes missões ao longo de sua vida útil e devem 
apresentar características de manobra distintas, por este motivo os critérios de manobrabilidade devem ser definidos com base no tipo de manobra que a embarcação deverá executar.

Uma referência comum para definição de critérios de manobrabilidade de embarcações é a resolução da International Maritime Organization (IMO) (2002) que discorre sobre a manobrabilidade de navios. Neste documento são apresentados critérios mínimos relacionados à manobrabilidade a serem alcançados por embarcações de forma a serem consideradas aptas à navegação. Podem também ser definidos critérios classificatórios para a capacidade de manobra das embarcações, como por exemplo os critérios encontrados no guia para manobrabilidade da sociedade classificadora ABS (2006) que nesta publicação define um critério para qualificar as embarcações com relação à sua capacidade de manobra, beneficiando em seu critério embarcações que possuem manobrabilidade melhor do que a requerida pelos critérios básicos da IMO.

Conforme recomendado pela ITTC (2002) os testes realizados para determinação das características de manobra dos navios devem ser capazes de avaliar a capacidade de manobra dos navios com relação a algumas qualidades, como:

- Estabilidade dinâmica (Dynamic Stability)

- Habilidade de manter o curso (Course Keeping Ability)

- Capacidade de mudar o curso (Course Change Ability)

- Habilidade de controlar o aproamento (Heading Control)

- Habilidade de fazer curvas (Turning Ability)

- Habilidade de parar (Stop Ability)

Para que seja possível avaliar estas capacidades é necessário que as manobras sejam realizadas sob determinadas condições, minimizando a influência de fatores alheios à capacidade de manobra do navio e permitindo que os resultados sejam conclusivos. As condições ambientais devem ser limitadas, não havendo a ocorrência de vento, corrente e ondas que afetam as trajetórias da embarcação de forma significativa. A recomendação da IMO é para que estas manobras não sejam 
realizadas com mar em estado superior a escala Beaufort 4, porém o limite pode ser menor conforme as características do navio.

Além das condições ambientais, a ITTC (2002) recomenda que as condições de carregamento durante os testes permitam que o navio esteja próximo de seu calado máximo, pois nessa condição a capacidade de manobra é mais crítica.

Os procedimentos realizados também devem ser consistentes, utilizando conforme a característica de cada manobra toda a potência disponível, e mantendo o navio estável, com velocidade constante e rotação dos motores constante antes do início de cada manobra.

\subsection{Analise de sensibilidade}

Assim como a definição da métrica que caracteriza a capacidade de manobra da embarcação, a sensibilidade do modelo à variação de seus parâmetros é de suma importância. Em seu trabalho Gavrilin et al. (2017) estima a incerteza de dados táticos de manobra através da variação de parâmetros ambientais. Através da técnica de Monte Carlo Gavrilin et al. (2017) mostra a variação dos dados táticos obtidos para a manobra de giro e zig-zag através das curvas de densidade de probabilidade para o avanço, o diâmetro tático e o overshoot obtidos.

Gavrilin et al. (2018) mostra que os coeficientes que descrevem o modelo de manobras possuem diferentes influências sobre os aspectos da manobrabilidade da embarcação, seu trabalho aponta que o grupo de coeficientes que representam as forças atuantes no casco tem grande influência na manobra de giro, enquanto o grupo de coeficientes que representam a interação dos propulsores e leme com o casco são mais importantes que o primeiro grupo para as manobras de zig-zag. 


\section{CONCEITOS TEÓRICOS}

\subsection{Modelo dinâmico de manobra}

O simulador empregado utiliza um integrador numérico de equações diferenciais para obter a resposta do navio no domínio do tempo. O modelo implementado faz uso dos vetores de velocidade e aceleração do navio e sua integração é realizada com base no sistema de coordenadas local (oxyz) do navio, localizado em sua quilha a meia nau e no centro do navio como mostrado na Figura 4. O vetor de posições do navio é representado em relação ao referencial global (OXYZ) que permanece fixo ao longo do tempo e tem seu eixo $Y$ alinhado ao norte e seu eixo $X$ alinhado ao leste. Para a integração do vetor de posição é feita a transformação do sistema de coordenadas local para o sistema de coordenadas global a cada instante, dado que o sistema de coordenadas local se move ao longo do tempo.

Figura 4 - Sistema de coordenadas no navio

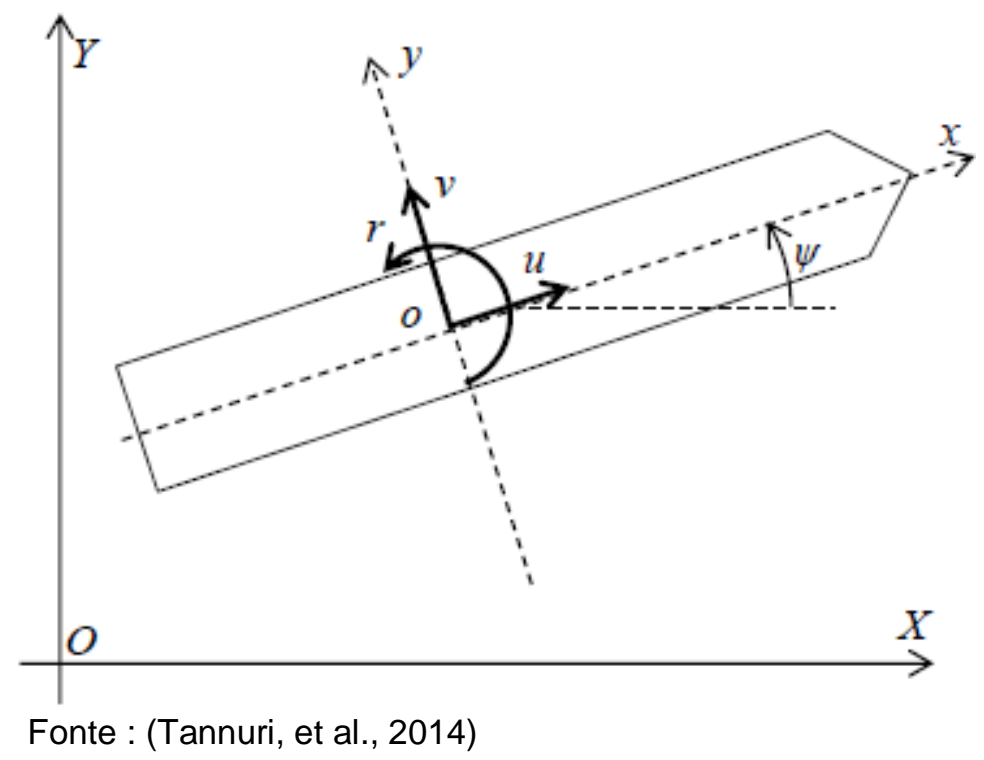

O modelo adotado aplica as leis de Newton ao navio, considerando-o um corpo rígido, e assumindo que a origem do sistema local de coordenadas está localizada no plano de simetria $x z$ da embarcação, e que os eixos do sistema local de coordenadas são paralelos aos eixos principais de inércia do navio, Tannuri et al. (2014) apresenta as equações diferenciais que descrevem o modelo em relação ao referencial oxyz, simplificado para 3 graus de liberdade, com a forma da equação (6). 


$$
\begin{aligned}
M\left(\ddot{x}_{1}-\dot{x}_{2} \dot{x}_{6}-x_{g} \dot{x}_{6}{ }^{2}\right) & =X_{i h}+X_{\text {ext }} \\
M\left(\ddot{x}_{2}-\dot{x}_{1} \dot{x}_{6}-x_{g} \ddot{x}_{6}\right) & =Y_{i h}+Y_{\text {ext }} \\
I_{z} \ddot{x}_{6}-M x_{g}\left(\ddot{x}_{2}+\dot{x}_{1} \dot{x}_{6}\right) & =N_{i h}+N_{\text {ext }}
\end{aligned}
$$

Note que forças inerciais adicionais são incorporadas ao modelo devido à análise em relação a um referencial não inercial. Na equação (6) $M$ e $I_{z}$ representam respectivamente a massa e momento de inércia de guinada (yaw) do navio, $x_{g}$ representa a posição do centro de massa ao longo do eixo de coordenadas local $x$. Os subscritos 1, 2 e 6 se referem respectivamente aos eixos locais $x, y$ e rotação em $z$, enquanto os subscritos ih e ext se referem respectivamente às forças e momentos que representam a reação inercial do fluido ao movimento do navio e forças e momentos causados por agentes ambientais e elementos ambientais externos.

A partir das hipóteses assumidas que permitem escrever as equações de movimento na forma da equação (6), e desconsiderando fatores de menor influência como o amortecimento potencial, Tannuri et al. (2014) mostra ainda a forma das equações diferenciais considerando os termos de inércia hidrodinâmica obtidos pela teoria potencial.

$$
\begin{aligned}
\left(M+M_{11}\right) \ddot{x_{1}}-\left(M+M_{22}\right) \dot{x_{2}} \dot{x_{6}}-\left(M x_{g}+M_{26}\right) \dot{x_{6}}{ }^{2}=X_{\text {ext }} \\
\left(M+M_{22}\right) \ddot{x}_{2}-\left(M x_{g}+M_{26}\right) \ddot{x_{6}}-\left(M+M_{11}\right) \dot{x_{1}} \dot{x}_{6}=Y_{\text {ext }} \\
\left(I_{z}+M_{66}\right) \ddot{x_{6}}-\left(M x_{g}+M_{26}\right)\left(\ddot{x}_{2}+\dot{x_{1}} \dot{x_{6}}\right)-\left(M_{22}-M_{11}\right) \dot{x_{1}} \dot{x_{2}}=N_{\text {ext }}
\end{aligned}
$$

Nas equações (7) as massas com os subscritos 11 e 22 representam as massas adicionais no sentido dos eixos $x$ e $y$ respectivamente, a massa com subscrito 66 representa o momento de inércia adicional no sentido do eixo $z$, e o termo com subscrito 26 representa um termo cruzado de inércia adicional. A demonstração matemática completa para a obtenção destas equações pode ser vista no manual teórico do simulador (Petrobras, 2014). Ressalta-se, porém que a força da reação inercial do fluido ao movimento do navio, que dá origem aos termos de massa adicional, é uma força externa ao corpo rígido que representa a embarcação.

As forças e momentos externos aplicados representam diferentes fatores, conforme mostrado na equação (8). 


$$
\begin{gathered}
X_{\text {ext }}=X_{h}+X_{w}+X_{w v}+X_{p}+X_{\text {tug }}+X_{\text {line }}+X_{\text {fender }} \\
Y_{\text {ext }}=Y_{h}+Y_{w}+Y_{w v}+Y_{p}+Y_{\text {tug }}+Y_{\text {line }}+Y_{\text {fender }} \\
N_{\text {ext }}=N_{h}+N_{w}+N_{w v}+N_{p}+N_{\text {tug }}+N_{\text {line }}+N_{\text {fender }}
\end{gathered}
$$

Onde $X_{h}, Y_{h}, N_{h}$ representa as forças e momentos hidrodinâmicos não potenciais, $X_{p}, Y_{p}, N_{p}$ representa as forças e momentos referentes aos propulsores e leme e são estas as principais parcelas de força estudadas neste trabalho. As demais forças representadas se referem às forças de vento $\left(X_{w}, Y_{w}, N_{w}\right)$, onda $\left(X_{w v}, Y_{w v}, N_{w v}\right)$ e forças externas aplicadas por agentes como rebocadores $\left(X_{t u g}, Y_{t u g}, N_{t u g}\right)$, cabos $\left(X_{\text {line }}, Y_{\text {line }}, N_{\text {line }}\right)$ e defensas $\left(X_{\text {fender }}, Y_{\text {fender }}, N_{\text {fender }}\right)$.

\subsection{Forças hidrodinâmicas e de amortecimento}

Para o cálculo das forças e momentos de manobras o simulador utiliza o modelo desenvolvido por Obokata (1987), baseado no princípio de Local Cross Flow, e da integração seccional ao longo do comprimento do navio. Na Figura 5 é indicada a velocidade relativa à água numa seção próxima à proa da embarcação.

Figura 5 - Integração seccional utilizada no modelo de Obokata

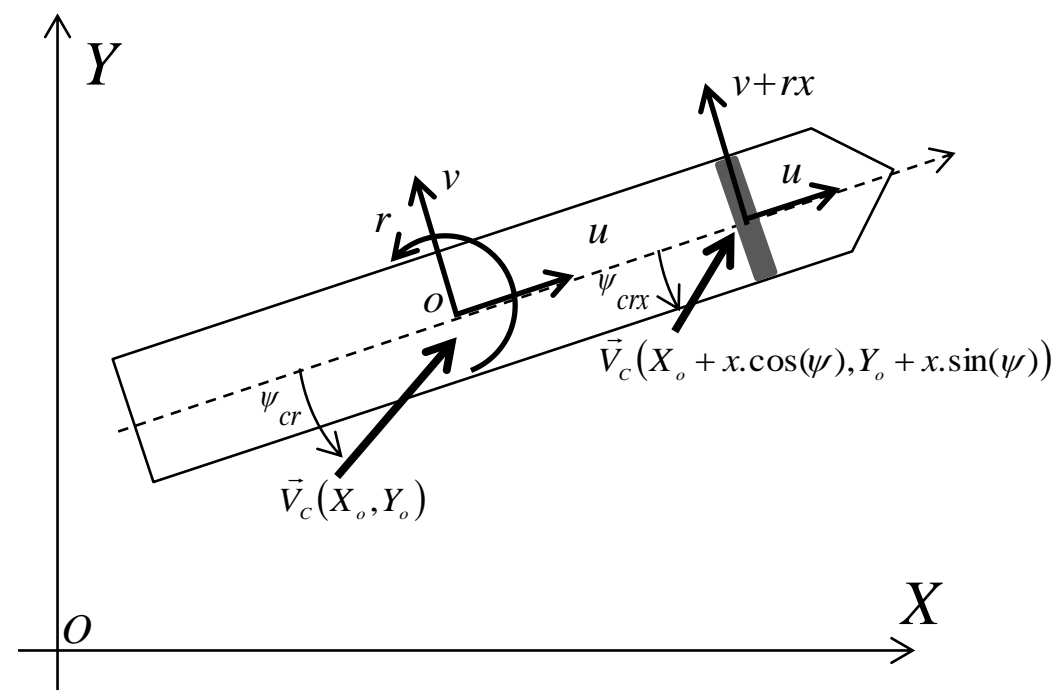

Fonte: (Tannuri, et al., 2014)

A formulação proposta por Obokata (1987) e implementada no simulador é apresentada na equação (9). Ressalta-se que a formulação utilizada considera o mesmo coeficiente de força hidrodinâmica ao longo de todo o comprimento do navio. 


$$
\begin{gathered}
X_{h 1}=\frac{1}{2} \rho T \int_{-L / 2}^{L / 2}\left[C_{x}\left(\Psi_{c r x}\right) V_{c r x}{ }^{2}\right] d l \\
Y_{h 1}=\frac{1}{2} \rho T \int_{-L / 2}^{L / 2}\left[C_{y}\left(\Psi_{c r x}\right) V_{c r x}{ }^{2}\right] d l \\
N_{h 1}=\frac{1}{2} \rho T L^{2} C_{n z}\left(\Psi_{c r}\right) V_{c r}{ }^{2}+\frac{1}{2} \rho T \int_{-L / 2}^{L / 2}\left[C_{y}\left(\Psi_{c r x}\right) V_{c r x}{ }^{2}-C_{y}\left(\Psi_{c r}\right) V_{c r}{ }^{2}\right] l d l
\end{gathered}
$$

Onde:

$V_{c r x}=\sqrt{u_{c r}^{2}+\left(v_{c r}-\dot{x_{6}} l\right)^{2}}$ velocidade seccional relativa da corrente

$\Psi_{c r x}=\arctan \left(\frac{v_{c r}-\dot{x}_{6} l}{u_{c r}}\right)$ ângulo de incidência seccional relativa da corrente

$u_{c r}$ e $v_{c r}$ são as componentes da velocidade da corrente em relação ao navio

Sendo os coeficientes $C_{x, y, n z}(\Psi)$ com respeito ao ângulo de incidência determinados experimentalmente, ou definidos a partir de tabelas de referência como as fornecidos pela OCIMF, ou ainda calculados a partir de programas de dinâmica dos fluidos computacional (CFD).

O modelo contempla também amortecimento linear e quadrático ajustáveis por meio de parâmetros de entrada:

$$
\begin{gathered}
X_{h 2}=c_{11} \cdot u_{c r}+c 2_{11} \cdot u_{c r}^{2} \\
Y_{h 2}=c_{22} \cdot v_{c r}+c 2_{22} \cdot v_{c r}^{2} \\
N_{h 2}=c_{66} \dot{x}_{6}+c 2_{66} \dot{x}_{6}^{2}
\end{gathered}
$$

Assim, a força hidrodinâmica total aplicada no modelo é dada por:

$$
\begin{aligned}
X_{h} & =X_{h 1}+X_{h 2} \\
Y_{h} & =Y_{h 1}+Y_{h 2} \\
N_{h} & =N_{h 1}+N_{h 2}
\end{aligned}
$$

\subsection{Modelo dos esforços de propulsor e leme}

O simulador utilizado tem implementado um modelo de propulsor de 4 quadrantes, ou seja, considera a velocidade de avanço do navio sendo positiva ou negativa, bem como a rotação do propulsor também positiva ou negativa, com suas 
combinações possíveis, como pode ser visto na Figura 6 adaptada de Tannuri et al. (2014).

O modelo adotado possui a dinâmica de um sistema de inércia de segunda ordem, e considera coeficientes de empuxo e torque $\left(\mathrm{k}_{\mathrm{t}} \mathrm{e} \mathrm{k}_{\mathrm{q}}\right)$ bem como a velocidade de incidência da água no propulsor. As situações de sobrecarga de potência são simuladas através da redução da rotação do propulsor quando esta situação é verificada. A descrição completa desse modelo foi feita por Queiroz Filho et al. (2014).

O modelo de leme empregado é um modelo de arrasto e sustentação de asa, e as forças atuantes são obtidas através da equação (12).

$$
\begin{aligned}
& F_{D}\left(\beta_{r}\right)=0.5 \rho A_{r} C_{D}\left(\beta_{r}\right) V_{r}{ }^{2} \\
& F_{L}\left(\beta_{r}\right)=0.5 \rho A_{r} C_{L}\left(\beta_{r}\right) V_{r}{ }^{2}
\end{aligned}
$$

Figura 6 - Modelo de 4 quadrantes para atuação do propulsor e leme

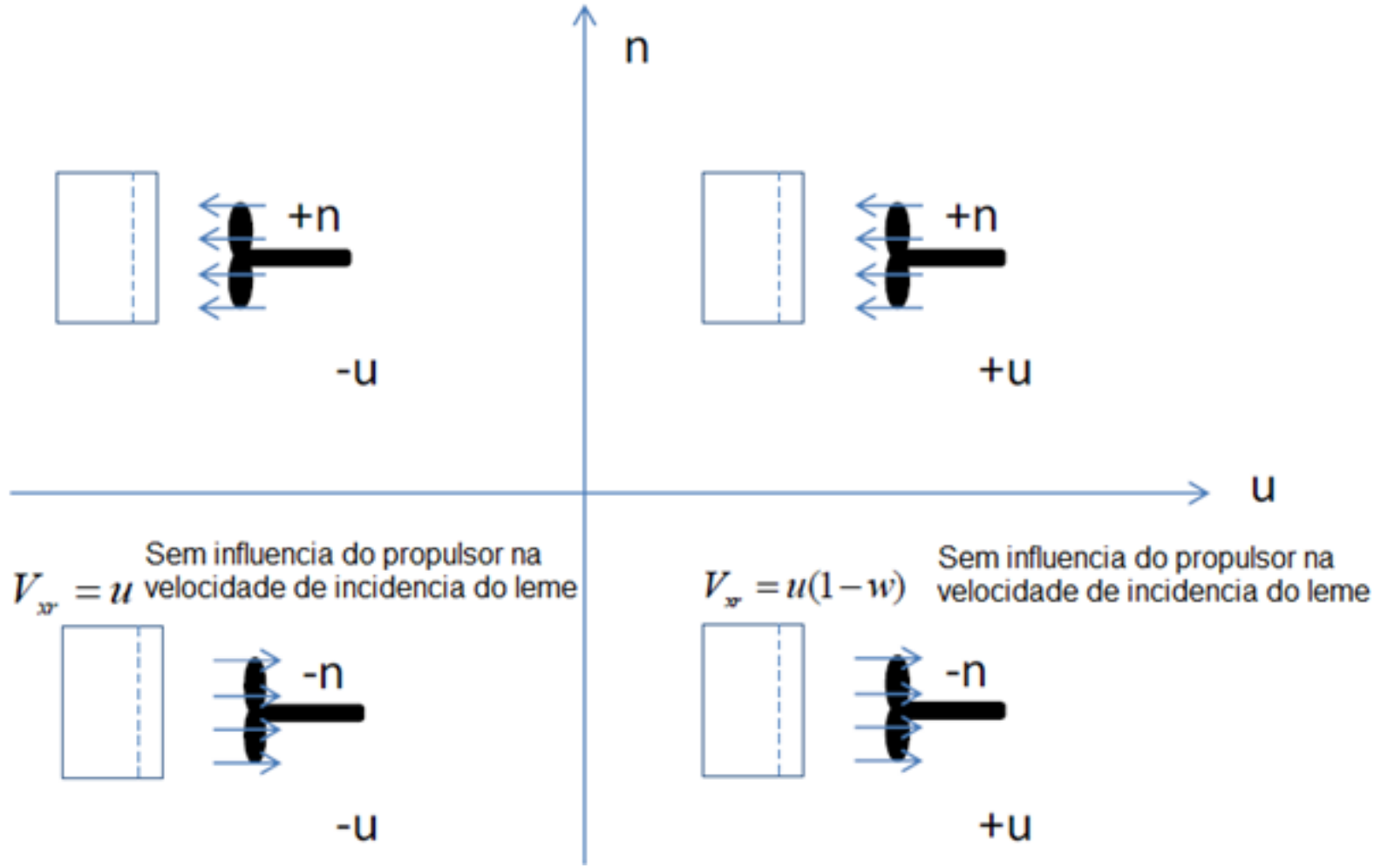

Fonte: adaptado de (Tannuri, et al., 2014)

$\mathrm{Na}$ equação (12) os subscritos $\mathrm{D}$ e $\mathrm{L}$ representam respectivamente arrasto e sustentação, onde $C_{D}$ e $C_{L}$ são os respectivos coeficientes. $A_{r}$ representa a área do leme, e $V_{r}$ representa a velocidade relativa entre o leme e o fluido, como pode ser visto na Figura 7 adaptada de Tannuri et al. (2014). 
Figura 7 - Definições do modelo de leme

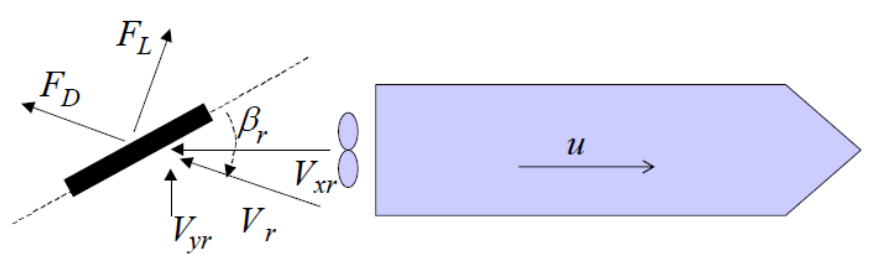

Fonte: (Tannuri, et al., 2014)

O modelo considera ainda a interação entre leme e propulsor, considerando um aumento da velocidade da água incidente no leme de acordo com o uso do propulsor, o que pode tornar o leme mais efetivo. A velocidade da água incidente no propulsor pode ser calculada conforme a equação (13) descrita por Masetti et al. (2015).

$$
V_{x r}=V_{i}+\left(0.5+\frac{0.5}{1+0.15 \frac{X}{D_{p}}}\right)\left(\sqrt{V_{i}^{2}+\frac{8 T_{\text {prop }}}{\rho \pi D_{p}{ }^{2}}}-\operatorname{sign}\left(V_{i}\right) V_{i}\right)
$$

Onde $V_{i}$ é a velocidade da água incidente no leme descrita na equação (14), sem a ação do propulsor, $D_{p}$ é o diâmetro do propulsor, $X$ é a distância entre o leme e o propulsor. Note que a velocidade da água incidente no leme é influenciada pelo casco através de um fator de esteira $w$, e que este fator é atuante somente quando a embarcação se desloca para frente. Ou seja, quando u é negativo $w=0$.

$$
V_{i}=u(1-w)
$$




\section{ENSAIOS EXPERIMENTAIS}

\subsection{Dados do navio tipo}

O navio tipo selecionado é a embarcação Alpha Crucis, pertencente à USP, pois o laboratório Tanque de Provas Numérico da USP possui um modelo em escala reduzida preparado para ensaios em tanque de provas. Essa embarcação possui as características básicas apresentadas na Tabela 1:

Tabela 1 - Dimensões da embarcação

\begin{tabular}{cc}
\hline Dimensão & Escala Real \\
\hline Comprimento Total (LOA) & $63,8 \mathrm{~m}$ \\
Comp. entre Perpendiculares & $61,3 \mathrm{~m}$ \\
(LPP) & $11,0 \mathrm{~m}$ \\
Boca & $4,6 \mathrm{~m}$ \\
Pontal & $4,0 \mathrm{~m}$ \\
Calado Máximo & $2,5 \mathrm{~m}$ \\
Calado Leve & $1891 \mathrm{t}$ \\
Deslocamento máximo & 0.63 \\
Coeficiente de bloco & 0.17 \\
Razão de aspecto do casco & \\
\hline Fonte: Autor
\end{tabular}

A Figura 8 apresenta o plano de linhas da embarcação confeccionado pela University of Hawai (1974), para referência:

O navio é dotado dos seguintes elementos de propulsão e manobra:

- 2 motores principais com 634 kW cada, rotação de 1200rpm modelo Caterpillar D398

- Hélices de passo controlável, diâmetro de $1950 \mathrm{~mm}, 3$ pás, redução de 3.5:1 (rotação efetiva nos hélices de 5,7 rps) - Figura 9

- 2 lemes convencionais com área de 7,3 $\mathrm{m}^{2}$ - Figura 9

- 1 Bowthruster do tipo túnel com 400HP (modelo Thrustmaster, 47TT400$\mathrm{ML}$ ), rotação do hélice de 13,4rps, hélice Kaplan (Diâmetro=1,56m, Passo $=0,85 \mathrm{~m})$ - Figura 10

Nominalmente os propulsores principais do Alpha Crucis apresentam um empuxo de 107 kN cada um, assim como o Bowthruster apresenta um empuxo de 36 $\mathrm{kN}$. 
Figura 8 - Plano de linhas da embarcação Alpha Crucis

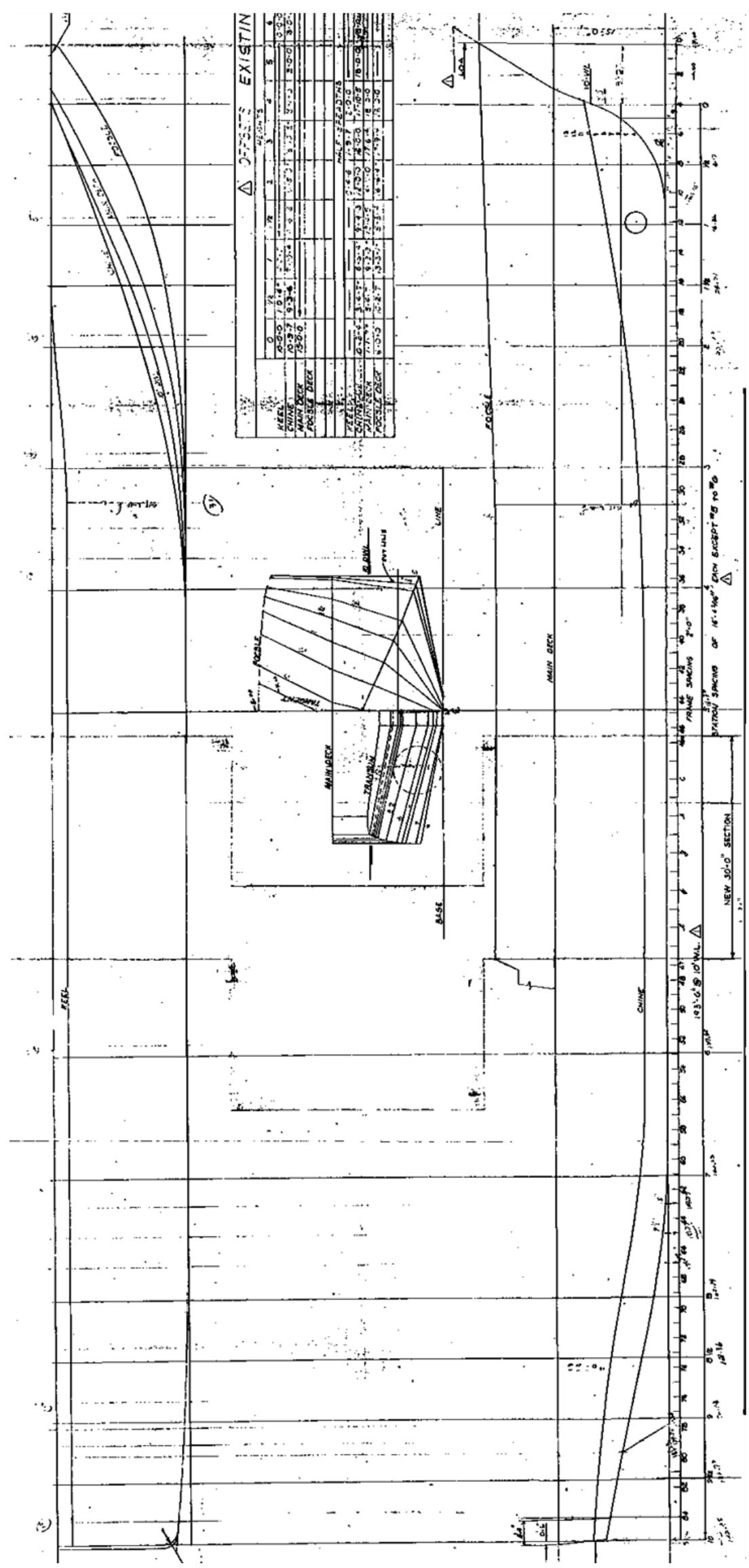

Fonte: (University of Hawaii, 1974) 
Figura 9 - Propulsor e leme (leme de boreste retirado)

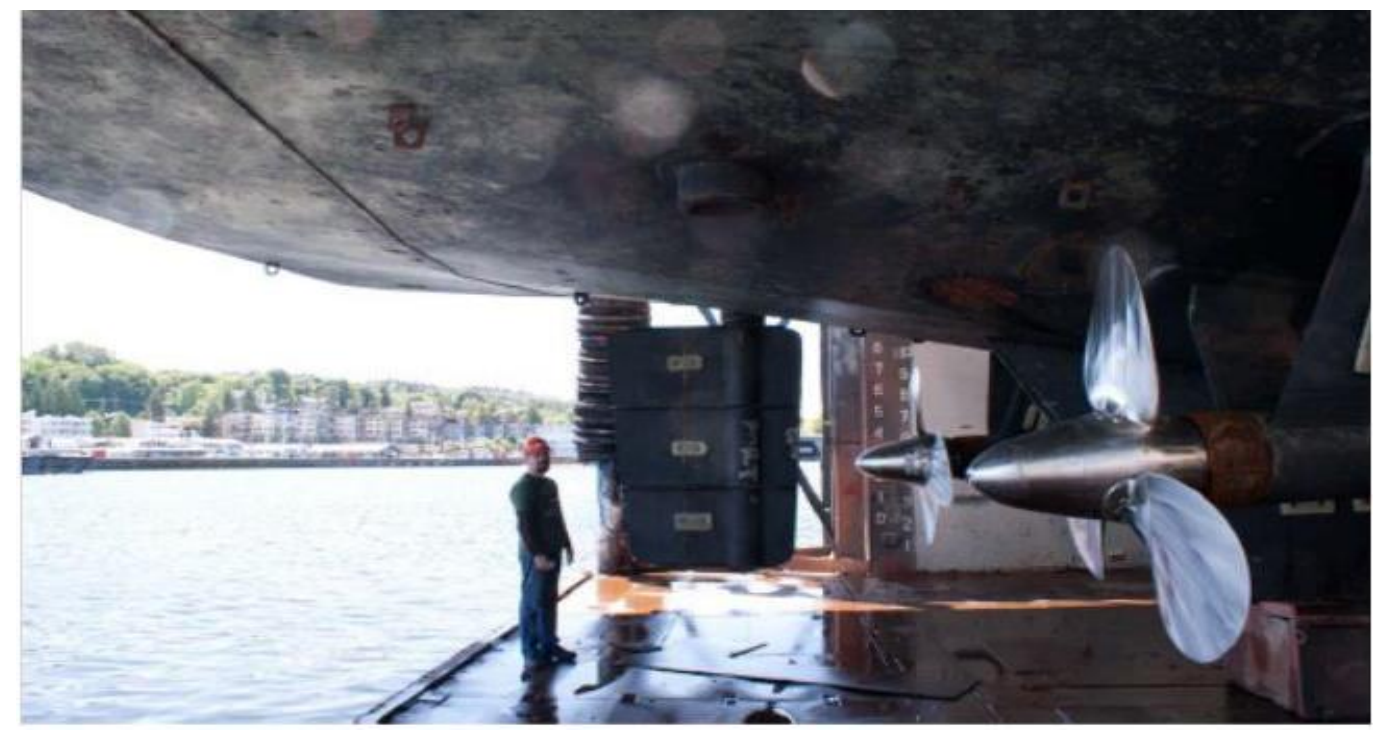

Fonte: Instituto Oceanográfico da USP.

Figura 10 - Posição do Bowthruster

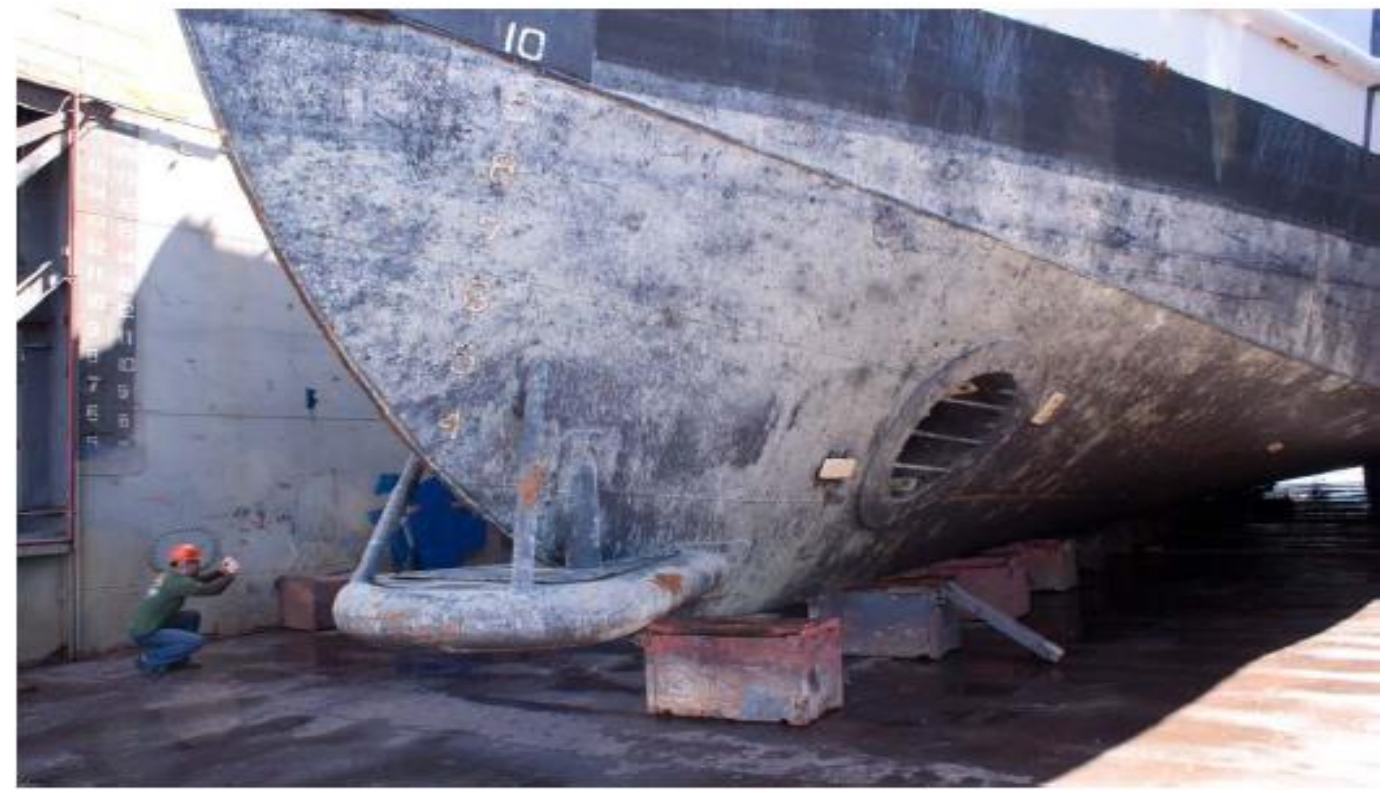

Fonte: Instituto Oceanográfico da USP.

\subsection{Modelo em escala reduzida}

O modelo em escala reduzida foi montado conforme as características da embarcação seguindo com máxima precisão possível suas características.

O casco foi fabricado seguindo-se a escala geométrica de 1:28 (Figura 11), com base no plano de linhas obtido e mostrado na Figura 8, obtendo as características da Tabela 2. 
Figura 11 - Modelo do casco e superestrutura em escala 1:28

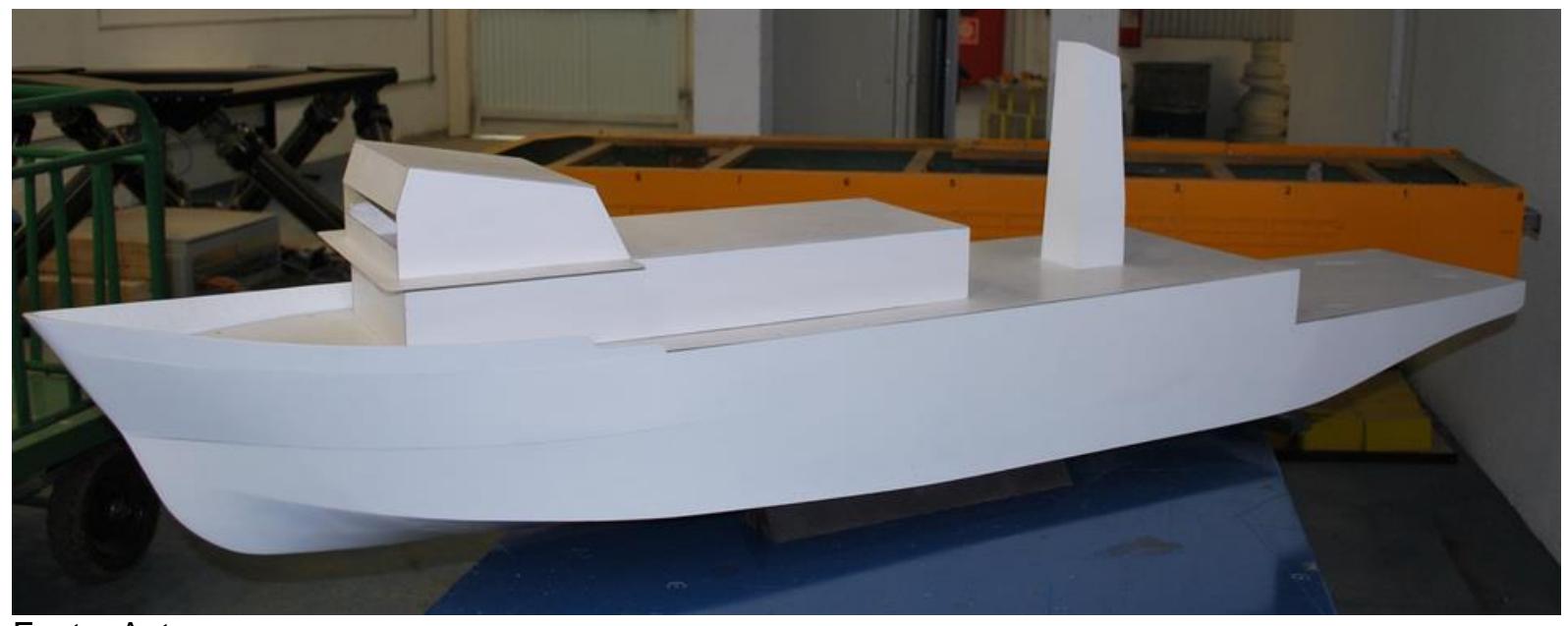

Fonte: Autor.

Para a modelagem dos propulsores foi necessário manter a escala geométrica próxima à utilizada pelo casco. Devido à escala reduzida, existem algumas diferenças entre as dimensões dos propulsores da embarcação real, mostrada nas Figura 9 e Figura 10, e os propulsores fabricados para o modelo em escala reduzida com escala de 1:28. A comparação entre o conjunto de propulsores e lemes para o navio e o modelo em escala pode ser visto na Figura 12.

Contudo a função dos propulsores para a manobra da embarcação é criar uma força controlada numa determinada direção. Então, para a correta simulação e execução dos ensaios em escala reduzida há a necessidade de se manter a equivalência das forças produzidas pelos propulsores e por esse motivo os propulsores foram calibrados através de um teste cativo de capacidade de empuxo.

Tabela 2 - Dimensões da embarcação em escala reduzida

\begin{tabular}{cc} 
Dimensão & $\begin{array}{c}\text { Escala de Modelo } \\
(\mathbf{1 : 2 8 )}\end{array}$ \\
\hline Comprimento Total (LOA) & $2,278 \mathrm{~m}$ \\
Comp. entre Perpendiculares & $2,189 \mathrm{~m}$ \\
(LPP) & $0,393 \mathrm{~m}$ \\
Boca & $0,163 \mathrm{~m}$ \\
Pontal & $0,143 \mathrm{~m}$ \\
Calado Máximo & $0,089 \mathrm{~m}$ \\
Calado Leve & $86,1 \mathrm{~kg}$ \\
Deslocamento máximo & $0,125 \mathrm{~m}$ \\
Calado do ensaio & $69,3 \mathrm{~kg}$ \\
Deslocamento no ensaio &
\end{tabular}

Fonte: Autor. 
Figura 12 - Detalhe dos propulsores e leme: (esq) Escala Real; (dir) Escala Reduzida
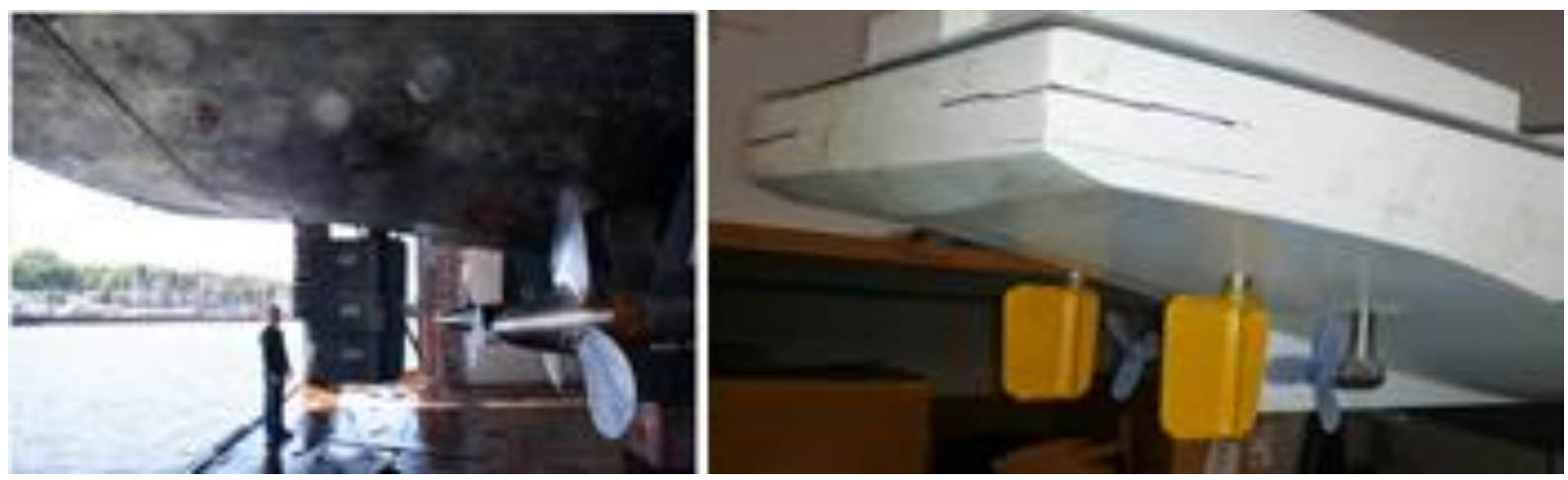

Fonte: Eduardo Aoun Tannuri.

Para realização do ensaio de capacidade de empuxo, o modelo foi preso a um carro estático equipado com uma célula de carga como pode ser visto na Figura 13. Foram realizados ensaios para medição do empuxo dos propulsores principais com rotação avante e reversa com o leme a meio, gerando força respectivamente no sentido positivo e negativo da direção longitudinal do modelo em escala. Para o propulsor em tunel transversal de proa, geram-se forças com direção para ambos os bordos, e para as forças no leme (arrasto e sustentação), geram-se forças para diversas rotações dos propulsores principais.

A partir das forças medidas, foram determinadas as rotações máximas de cada propulsor a fim de manter a equivalência de força entre o modelo matemático e este modelo experimental em escala reduzida. Este ensaio permitiu também o cálculo dos coeficientes de sustentação e arrasto do leme para posterior utilização no modelo numérico.

Figura 13 - Ensaio de capacidade de propulsão

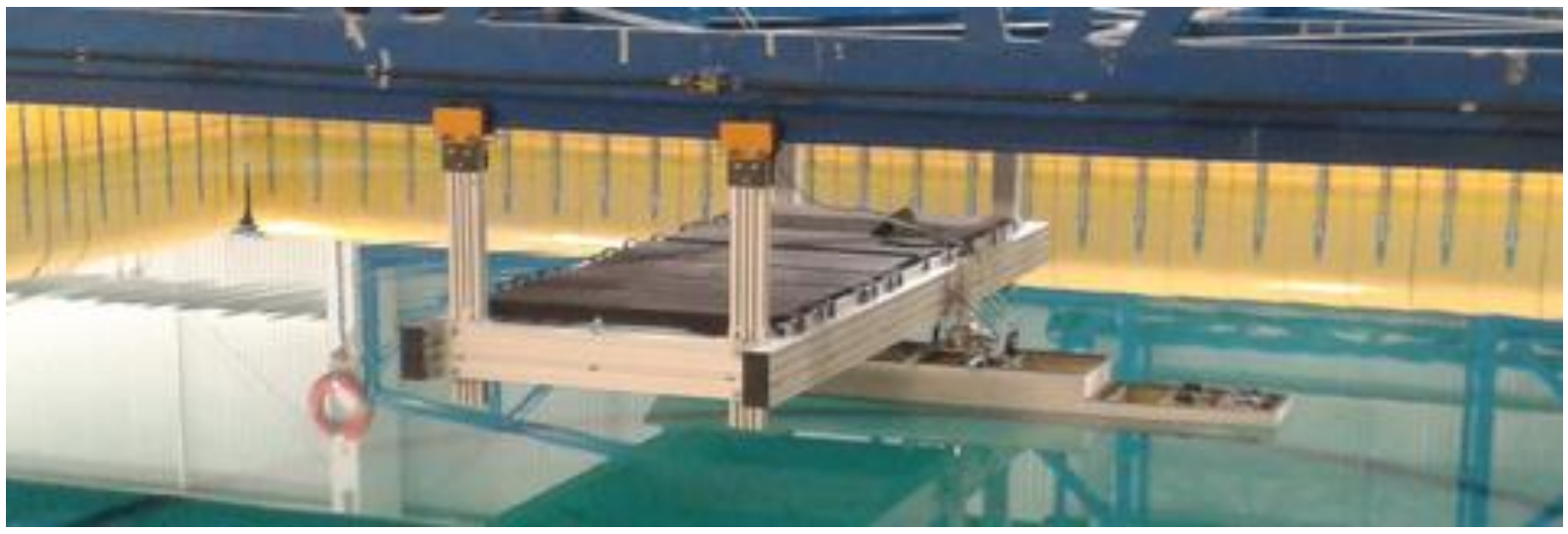

Fonte: Pedro Cardozo de Mello.

Conforme descrito por Zimbres (2015), o empuxo produzido pelo propulsor pode ser obtido pelo coeficiente de empuxo $k_{t}$, conforme a equação (15). 


$$
T=\rho|n| n D^{4} k_{t}(J, p)
$$

$\mathrm{Na}$ qual $n$ representa a rotação do propulsor (medida em rotações por segundo), $\rho$ representa a densidade da água, $D$ representa o diâmetro do propulsor, $p$ o passo do propulsor, e $J$ é o coeficiente de avanço, função da velocidade de incidência da água no propulsor $V$ e da rotação do propulsor $(J=V / n D)$.

As figuras de Figura 14 a Figura 16 mostram a aderência entre os resultados dos experimentos de bollard pull dos propulsores com o modelo de propulsão implementado no simulador. As figuras mostram o empuxo em função da rotação do propulsor, para o experimento com o modelo parado. Neste caso, na condição de velocidade de avanço nula, assume-se $J=0$, e para um propulsor de passo fixo, espera-se uma relação quadrática entre a rotação e empuxo. Pode se ver que 0 modelo teórico dos propulsores baseado na curva de $k_{t}$ apresenta uma boa aderência aos dados experimentais obtidos, quando as rotações são mantidas dentro dos limites necessários para obtenção da escala de força. Ou seja, observou-se uma boa aderência do modelo numérico aos resultados experimentais obtidos quando se manteve a rotação do propulsor principal abaixo de 2150 RPM, e a rotação do túnel de proa abaixo das 2900 RPM. 
Figura 14 - Empuxo obtido pelos propulsores principais no sentido positivo

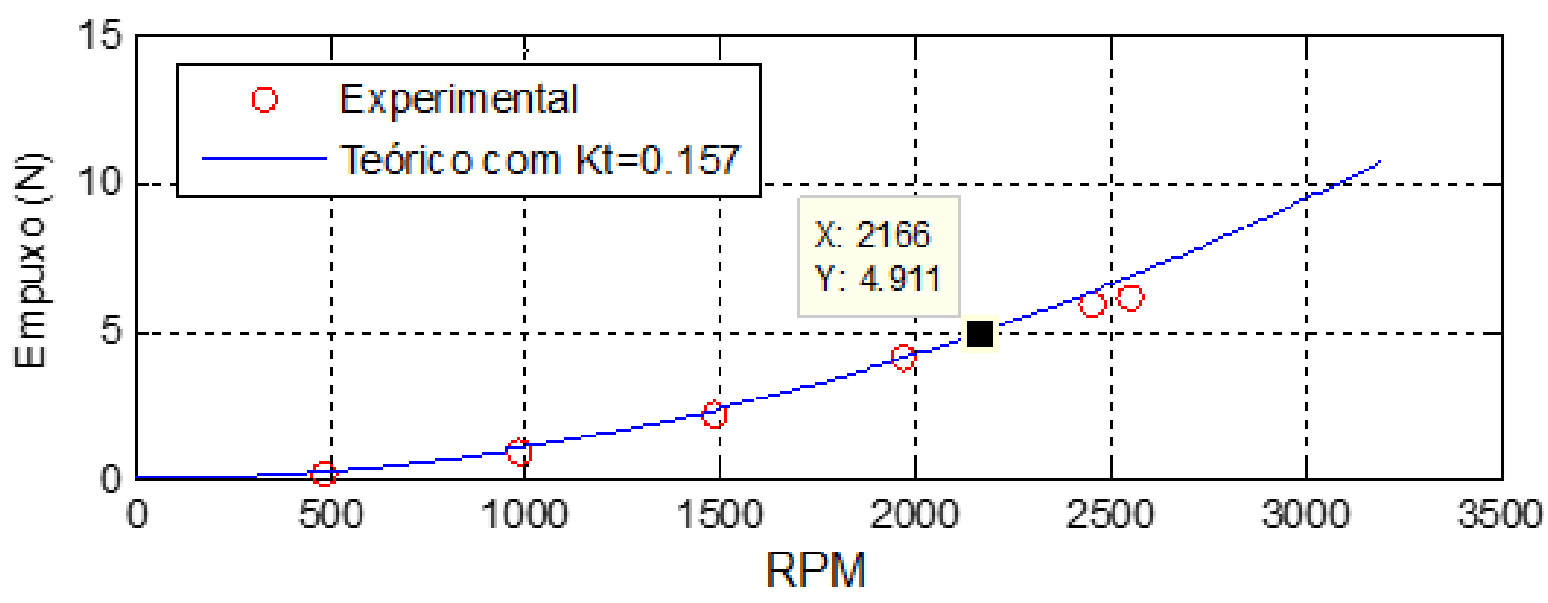

Fonte: Pedro Cardozo de Mello.

Figura 15 - Empuxo obtido pelos propulsores principais no sentido negativo

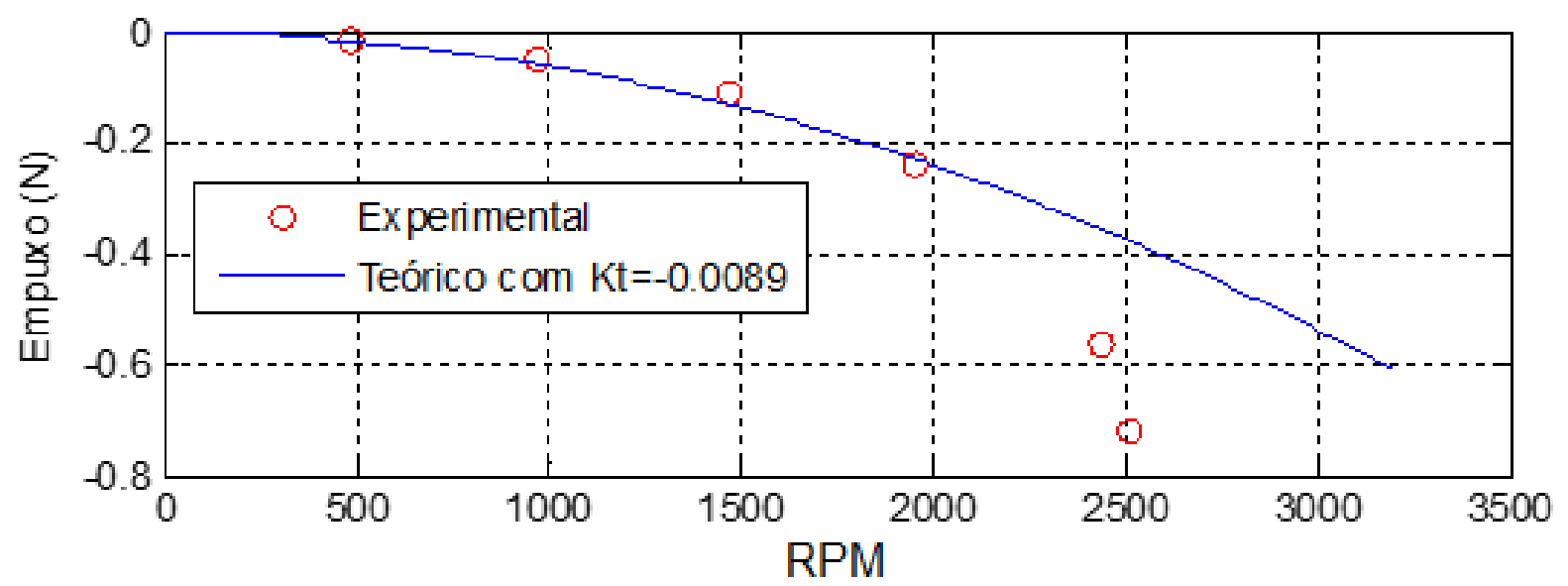

Fonte: Pedro Cardozo de Mello.

Figura 16 - Empuxo obtido pelo túnel de proa

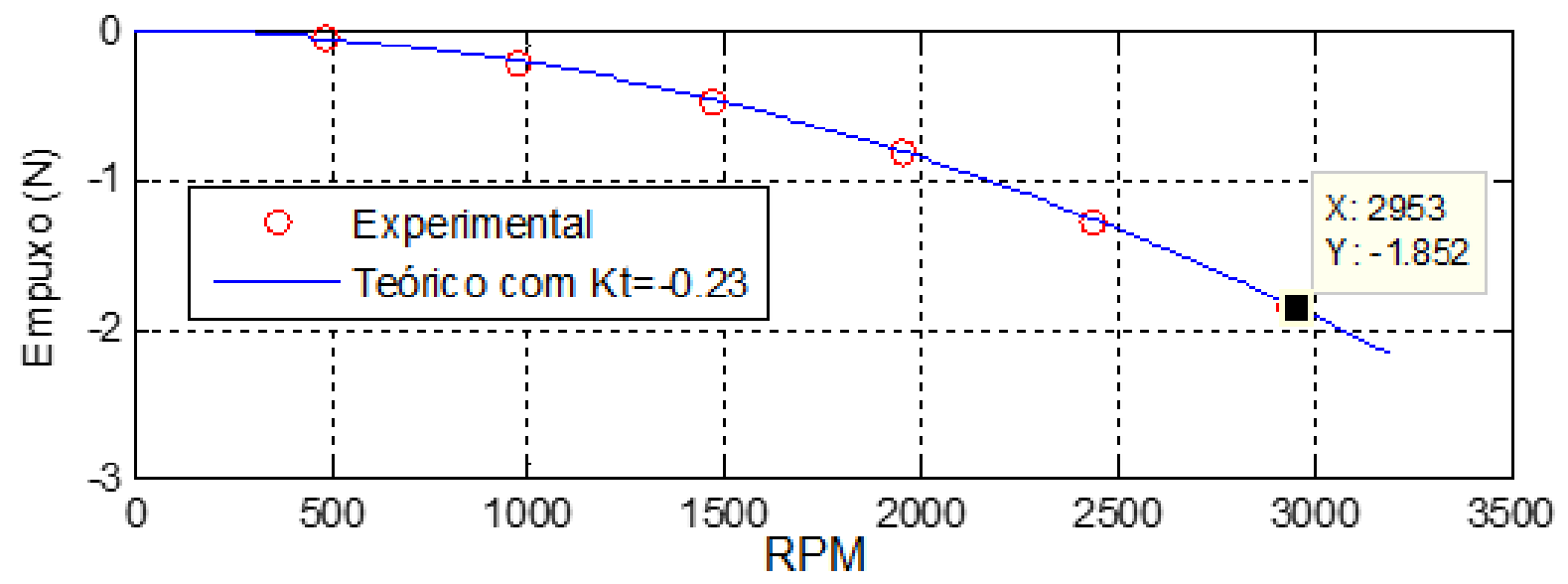

Fonte: Pedro Cardozo de Mello.

Da mesma forma foi feito um ensaio cativo para determinação dos coeficientes de sustentação e arrasto do leme através da medida da força nos sentidos transversal 
e longitudinal respectivamente. A Figura 17 e Figura 18 apresentam os coeficientes levantados para os lemes do modelo conforme a formulação apresentada na seção 3.3.

A Tabela 3 resume o resultado obtido comparando os dados dos propulsores e leme para a embarcação real e o modelo em escala. A coluna "Escala Reduzida Equivalente" apresenta as grandezas de força e as dimensões que o modelo em escala precisa reproduzir para ser capaz de manter a equivalência de forças com o navio em escala real, enquanto a coluna "Escala Reduzida Efetivo" representa as forças obtidas pelo modelo em escala, quando opera com rotações dentro dos limites citados acima.

Figura 17 - Curva de coeficientes de arrasto obtidos para o leme do modelo em escala

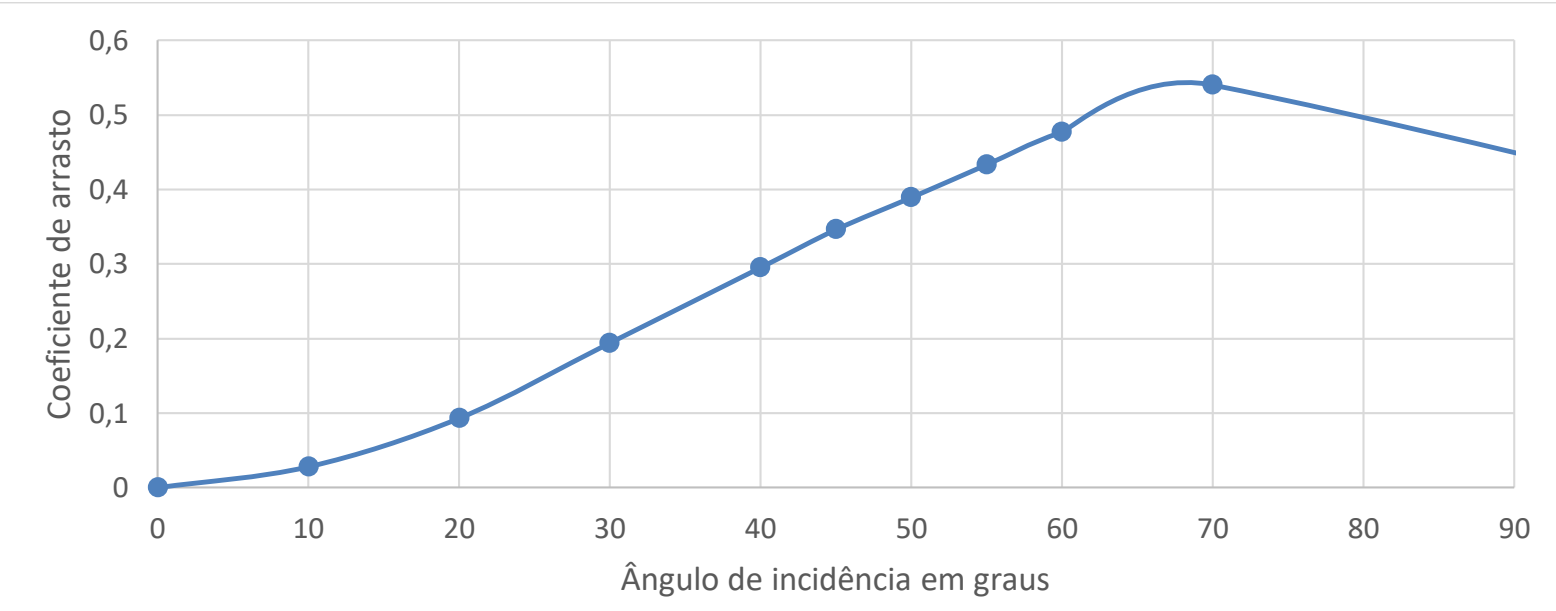

Fonte: Autor.

Figura 18 - Curva de coeficientes de sustentação obtidos para o leme do modelo em escala

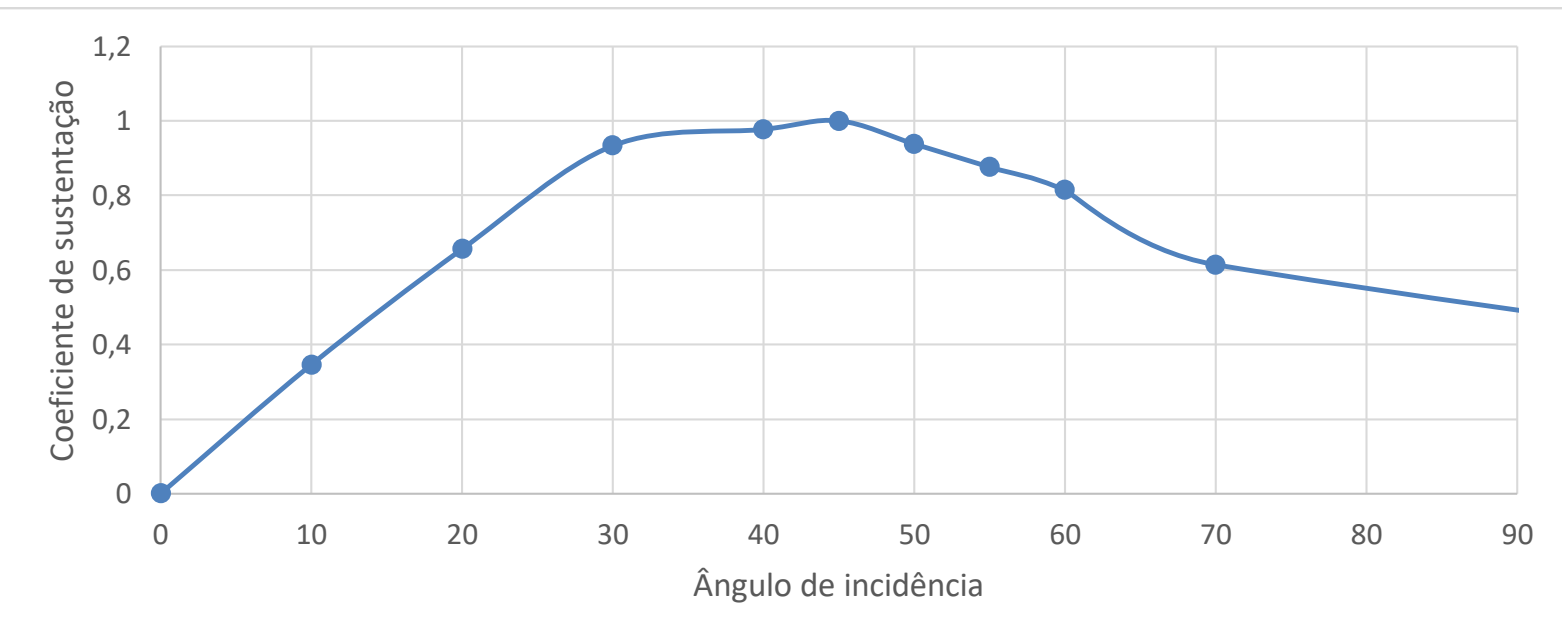

Fonte: Autor. 
Tabela 3 - Resultados de empuxo para os propulsores em escala

\begin{tabular}{|c|c|c|c|c|}
\hline \multicolumn{2}{|c|}{ Elemento de controle } & \multirow{2}{*}{$\begin{array}{c}\text { Escala Real } \\
107 \mathrm{kN} \text { (estimado) }\end{array}$} & \multirow{2}{*}{$\begin{array}{c}\text { Escala Reduzida } \\
\text { Equivalente }\end{array}$} & \multirow{2}{*}{$\begin{array}{c}\begin{array}{c}\text { Escala } \\
\text { Reduzida } \\
\text { Efetivo }\end{array} \\
4,9 \mathrm{~N}\end{array}$} \\
\hline \multirow{6}{*}{$\begin{array}{l}\text { Propulsor } \\
\text { principal }\end{array}$} & Empuxo & & & \\
\hline & Diâmetro & $1,95 \mathrm{~m}$ & $69,0 \mathrm{~mm}$ & $69,0 \mathrm{~mm}$ \\
\hline & Passo & $1.20 \mathrm{~m}$ & $41.4 \mathrm{~mm}$ & $40.0 \mathrm{~mm}$ \\
\hline & Área das pás / & & & \\
\hline & Área do & 0.3 & 0.3 & 0.3 \\
\hline & propulsor & & & \\
\hline \multirow{6}{*}{ Túnel de proa } & Empuxo & 36 kN (estimado) & 1,6 N (estimado) & $1,8 \mathrm{~N}$ \\
\hline & Diâmetro & $1,56 \mathrm{~m}$ & $56,0 \mathrm{~mm}$ & $43,0 \mathrm{~mm}$ \\
\hline & Passo & não informado & não informado & $26.0 \mathrm{~mm}$ \\
\hline & Área das pás / & & & \\
\hline & Área do & 0.3 & 0.3 & 0.3 \\
\hline & propulsor & & & \\
\hline \multirow{2}{*}{ Leme } & Leme Altura & $2,25 \mathrm{~m}$ & $80,0 \mathrm{~mm}$ & $73,0 \mathrm{~mm}$ \\
\hline & Leme Largura & $1,62 \mathrm{~m}$ & $58,5 \mathrm{~mm}$ & $65,0 \mathrm{~mm}$ \\
\hline
\end{tabular}

Fonte: Autor.

Nota-se na Tabela 3 que os propulsores em escala reduzida mantiveram a proporção de forças com os propulsores em escala real.

Devido à disponibilidade de informações não foi possível realizar o mesmo tipo de comparação para o leme. Nota-se que devido a restrições de construção, o leme do modelo reduzido não possui a mesma razão de aspecto do leme do navio real. Ressalta-se porém que o leme utilizado no modelo numérico preservou a mesma razão de aspecto e forças geradas em relação ao modelo experimental, o qual foi utilizado como paradigma neste trabalho.

\subsection{Descrição do tanque e aparato experimental}

As manobras foram realizadas em um tanque com profundidade variável, mostrado na Figura 19, através da variação do nível de água, possibilitando a realização de ensaios em condições de águas rasas e águas profundas.

O tanque utilizado possui dimensão de $10 \mathrm{~m}$ de largura por $26 \mathrm{~m}$ de comprimento. A profundidade máxima do tanque é de $1,1 \mathrm{~m}$, os ensaios realizados foram executados com profundidade de $160 \mathrm{~mm}$ para representação da navegação 
em águas rasas, e 500mm para representação da navegação em águas profundas, correspondendo às respectivas razões entre profundidade e calado do modelo de 1,28 e 4,00.

Figura 19 - Tanque utilizado para os ensaios

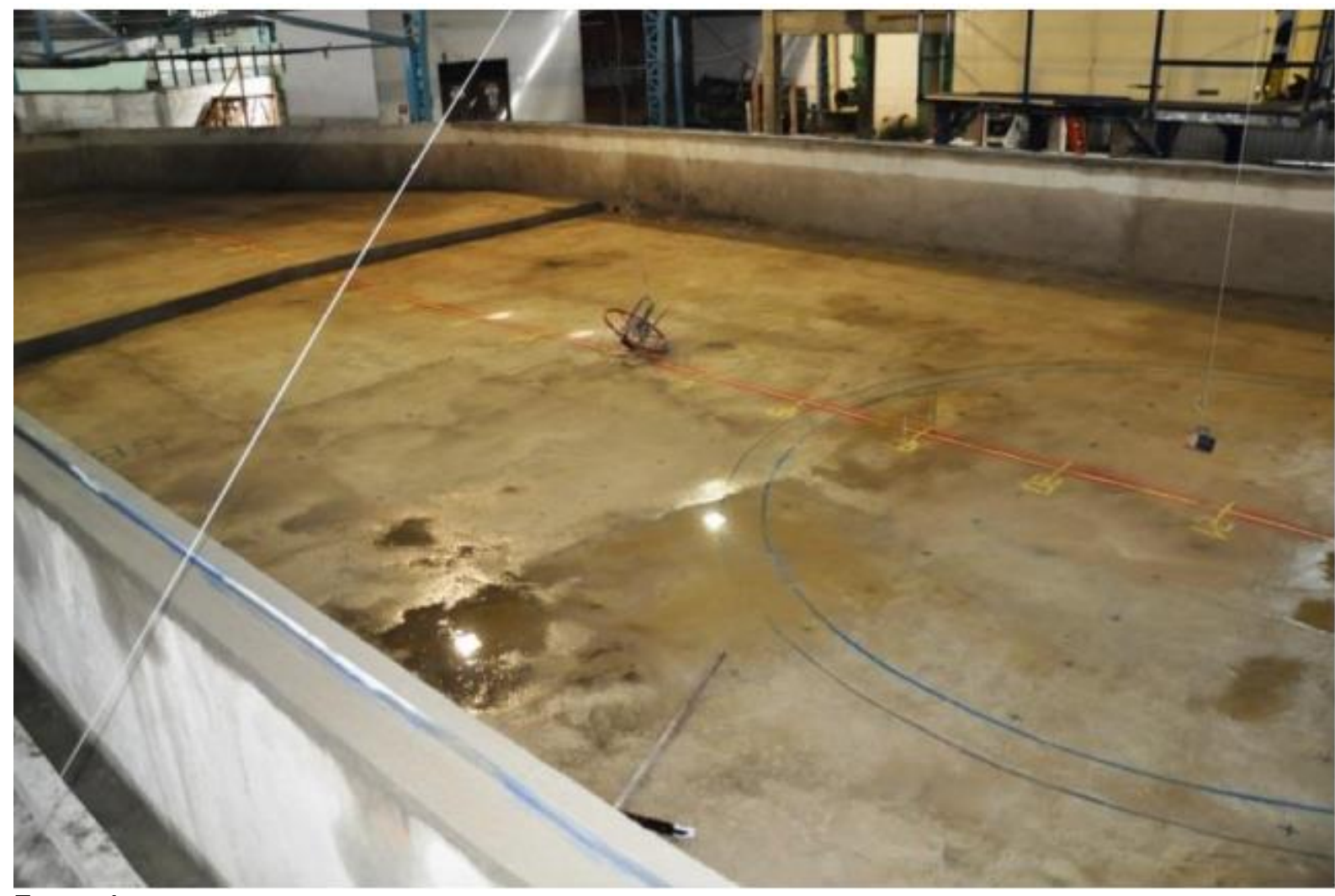

Fonte: Autor.

Para medição da posição e velocidade do modelo foi utilizado um conjunto de 3 câmeras do sistema de captura de movimentos da Qualisys ${ }^{\circledR}$ conforme ilustrado na Figura 20. Foram utilizadas câmeras Oqus, com resolução de 12 megapixels (Qualisys $A B, 2016)$ em uma taxa de aquisição de 30 frames por segundo (fps).

Para melhor medição de posição do modelo em escala reduzida pelo conjunto de câmeras foram posicionados 3 alvos esféricos reflexivos no modelo de forma que o sistema de câmeras identificasse o modelo com um eixo de coordenadas centrado na meia nau do navio.

Conforme o fabricante (Qualisys AB, 2016) estas câmeras possuem um alcance de visão de $25 \mathrm{~m}$, com os alvos utilizados, que possuem $30 \mathrm{~mm}$ de diâmetro. Entretanto, devido à quantidade de câmeras disponíveis e ao ângulo de abertura das 
lentes não foi possível cobrir toda a área do tanque, ficando a área monitorada reduzida a um quadrado de $10 \mathrm{~m}$ por $10 \mathrm{~m}$.

Na Figura 19 pode se ver a presença de um degrau no fundo do tanque, ressalta-se que as manobras foram executadas sempre sobre a região mais baixa, evitando assim a interferência de efeitos transientes devido à variação da profundidade.

Figura 20 - Foto do sistema de câmeras sendo calibrado com o modelo na água

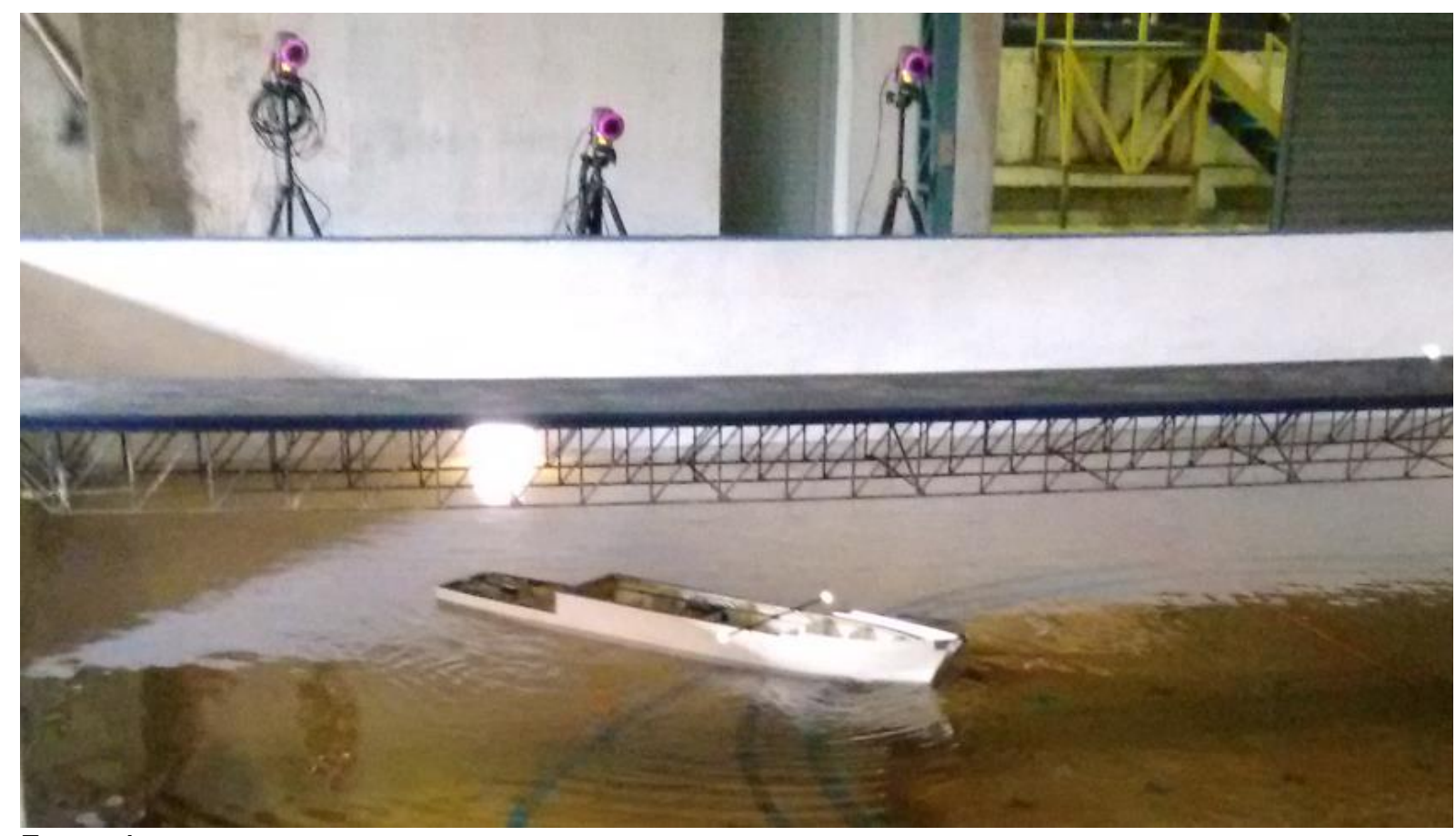

Fonte: Autor.

O sistema de câmeras indica também a precisão das medidas realizadas, tendo apresentado durante os experimentos uma precisão média de 2,33mm na posição do modelo, equivalendo a um desvio de $65,24 \mathrm{~mm}$ na escala real. O maior valor de precisão apresentado pelo sistema foi de $11,11 \mathrm{~mm}$, representando na escala real $311,08 \mathrm{~mm}$. Esta precisão é considerada satisfatória para o tipo de manobra a ser realizada, sendo sua ordem de grandeza cerca de 300 vezes menor do que as dimensões que originam os dados táticos de manobra avaliados nesse trabalho.

\subsection{Descrição dos testes realizados}

Os testes foram realizados no tanque descrito na seção 4.3 com auxílio do sistema de câmeras para registro das manobras. O software utilizado para monitoramento das câmeras e aquisição dos dados da manobra possui uma limitação, 
não permite a retroalimentação em tempo real dos parâmetros obtidos para uso pelo controle do modelo em escala.

Devido a esta limitação não foi possível a realização de manobras em que o controle dependa do comportamento do modelo, como por exemplo a manobra de zigzag na qual o leme é acionado de acordo com o aproamento da embarcação.

Foram selecionadas então as manobras que não demandam atuação variável ao longo de suas execuções, ou seja, que os elementos de controle (propulsores e lemes) sejam acionados no início da manobra e permanecem com o mesmo comando ao longo de todo o teste.

Para obtenção de resultados mais representativos, as manobras foram realizadas com diversas velocidades, rotações de propulsores e ângulos de leme, criando assim maior diversidade de situações de manobra para comparação com os resultados numéricos.

$\mathrm{Na}$ Tabela 4 os comandos de rotação de propulsores se referem aos propulsores principais da embarcação, a menos quando explicitamente informado que o comando se refere ao propulsor transversal de proa. Os comandos realizados para os propulsores principais e para os lemes foram executados de forma simultânea por ambos propulsores e lemes.

A seção 6 apresentará as manobras realizadas, com suas respectivas descrições e grandezas medidas. Os resultados experimentais já são apresentados com valores convertidos para escala real. 
Tabela 4 - Manobras realizadas com modelo em escala

\begin{tabular}{|c|c|c|c|c|}
\hline & Manobra & & Sequência de comandos & \\
\hline 1 & Turning circle & $\begin{array}{c}\text { Devagar avante } \\
\text { (500rpm) }\end{array}$ & Leme $30^{\circ}$ & \\
\hline 2 & Turning circle & $\begin{array}{c}\text { Meia força avante } \\
\text { (1050rpm) }\end{array}$ & Leme $30^{\circ}$ & \\
\hline 3 & Initial turning test & $\begin{array}{c}\text { Meia força avante } \\
\text { (1050rpm) }\end{array}$ & Leme $20^{\circ}$ & \\
\hline 4 & Initial turning test & $\begin{array}{l}\text { Meia força avante } \\
\quad(1050 \mathrm{rpm})\end{array}$ & Leme $10^{\circ}$ & \\
\hline 5 & Initial turning test & $\begin{array}{l}\text { Devagar avante } \\
\text { (500rpm) }\end{array}$ & Leme $20^{\circ}$ & \\
\hline 6 & Initial turning test & $\begin{array}{c}\text { Devagar avante } \\
(500 \mathrm{rpm})\end{array}$ & Leme $10^{\circ}$ & \\
\hline 7 & Coasting turn & $\begin{array}{c}\text { Meia força avante } \\
\quad(1050 \mathrm{rpm})\end{array}$ & Parar motor & Leme $30^{\circ}$ \\
\hline 8 & Coasting turn & $\begin{array}{c}\text { Meia força avante } \\
\text { (1050rpm) }\end{array}$ & Parar motor & Leme $20^{\circ}$ \\
\hline 9 & Crash stop & $\begin{array}{l}\text { Devagar avante } \\
\text { (500rpm) }\end{array}$ & $\begin{array}{c}\text { Meia força a ré (sentido } \\
\text { negativo) }\end{array}$ & \\
\hline 10 & Crash stop & $\begin{array}{c}\text { Meia força avante } \\
\text { (1050rpm) }\end{array}$ & $\begin{array}{c}\text { Devagar força a ré (sentido } \\
\text { negativo) }\end{array}$ & \\
\hline 12 & Acelerating turn & Leme $30^{\circ}$ & $\begin{array}{c}\text { Meia força avante } \\
\text { (1050rpm) }\end{array}$ & \\
\hline 13 & Acelerating turn & Leme $20^{\circ}$ & $\begin{array}{c}\text { Meia força avante } \\
\text { (1050rpm) }\end{array}$ & \\
\hline 14 & Acelerating turn & Leme $30^{\circ}$ & Devagar avante (500rpm) & \\
\hline 15 & Acelerating turn & Leme $20^{\circ}$ & Devagar avante (500rpm) & \\
\hline 16 & Crash ahead & $\begin{array}{c}\text { Máquina a ré } \\
\text { (sentido negativo) } \\
\text { 2000rpm }\end{array}$ & $\begin{array}{c}\text { Quando o navio andar } 1 \\
\text { comprimento meia força } \\
\text { avante (1050rpm) }\end{array}$ & \\
\hline 17 & $\begin{array}{l}\text { Stopping inertia } \\
\text { test (free stop) }\end{array}$ & $\begin{array}{c}\text { Devagar avante } \\
\text { (500rpm) }\end{array}$ & Parar motor & \\
\hline 18 & $\begin{array}{l}\text { Stopping inertia } \\
\text { test (IMO stop) }\end{array}$ & $\begin{array}{c}\text { Devagar avante } \\
\text { (500rpm) }\end{array}$ & Parar motor & Leme $30^{\circ}$ \\
\hline 19 & $\begin{array}{l}\text { Lateral thruster } \\
\text { capability }\end{array}$ & Máquina parada & $\begin{array}{c}\text { Propulsor transversal de } \\
\text { proa 2000rpm }\end{array}$ & \\
\hline 21 e 22 & Pull out & Devagar avante & Leme $30^{\circ}$ & $\begin{array}{l}\text { Leme a } \\
\text { meio }\end{array}$ \\
\hline
\end{tabular}

Fonte: Autor. 


\section{MODELAGEM NUMÉRICA}

\subsection{Parâmetros do modelo}

O modelo numérico foi calibrado considerando os coeficientes do modelo em escala reduzida, porém os resultados são apresentados na escala real, dessa forma podem ser comparados diretamente aos resultados experimentais. Foram desenvolvidos dois modelos, sendo um para águas rasas e outro para águas profundas, nas mesmas profundidades adotadas nos ensaios em escala reduzida.

O modelo de simulação foi resolvido com um passo de integração de $0,5 \mathrm{~s}$. $\mathrm{O}$ calado adotado no modelo é de 3,5m.

\subsection{Elementos de comando}

Os propulsores e lemes foram representados da mesma maneira para ambos os modelos, de águas rasas e profundas, assumindo-se que a alteração da profundidade não causa influência no desempenho desses elementos, conforme 0 modelo adotado, apresentado na seção 3.3 .

O modelo possui 2 propulsores principais, dispostos de maneira simétrica em relação ao plano longitudinal da embarcação. Esses propulsores estão localizados a 24,33 m atrás da meia nau da embarcação, e 2,43 m distantes do plano longitudinal central do navio, tal como mostrado na Figura 21. A Tabela 5 apresenta as características dos propulsores modelados.

Figura 21 - Posição dos propulsores principais em vermelho

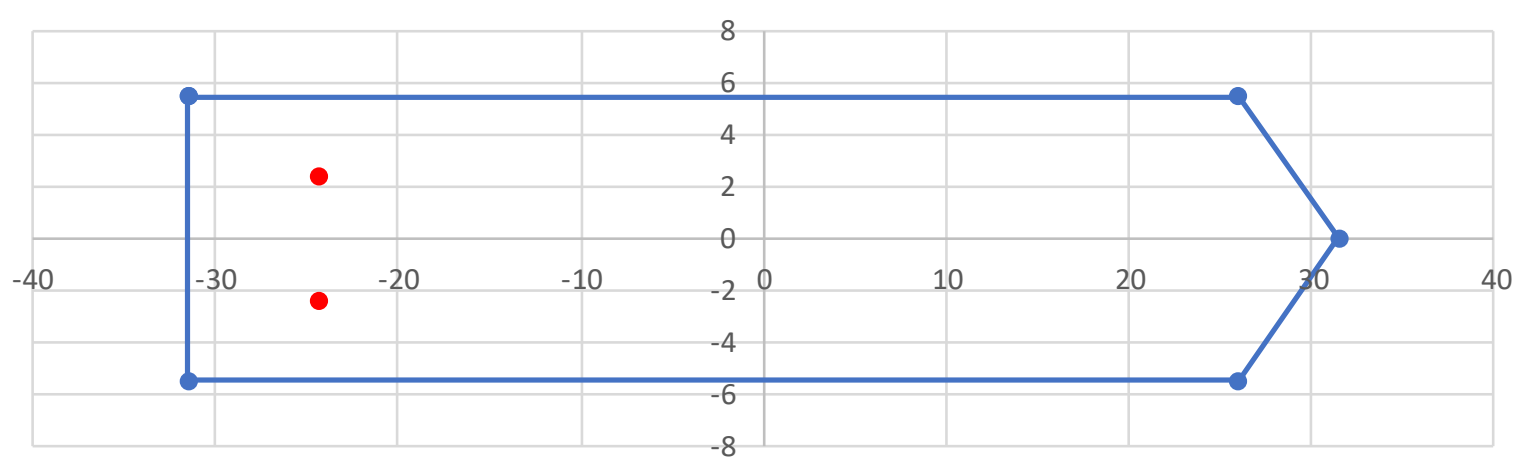

Fonte: Autor. 
Tabela 5 - Características dos propulsores principais

\begin{tabular}{cc}
\hline Propriedade & Valor \\
\hline Diâmetro & $1,960 \mathrm{~m}$ \\
Passo & $1,176 \mathrm{~m}$ \\
Rotação & $343 \mathrm{RPM}$ \\
Potência & $634 \mathrm{~kW}$ \\
Área do propulsor / \\
Área das pás \\
Potência no sentido \\
negativo
\end{tabular}

Fonte: Autor.

Os propulsores principais utilizaram curva de coeficientes de empuxo kt em função da taxa de avanço $\mathrm{J}$ apresentada na Figura 22. Esta curva foi gerada a partir de dois pontos interpolados. O primeiro é o valor de $k_{t}(J=0)$, obtido a partir do valor experimental apresentado na seção 4.2. O segundo é o valor de $J$ para o qual o coeficiente de empuxo é nulo a taxa de avanço nula, e a partir da taxa de avanço que apresenta coeficiente de empuxo nulo $\left(k_{t}=0\right)$, obtido a partir da série do propulsor utilizada para seu projeto.

Figura 22 - Coeficientes de empuxo do propulsor principal

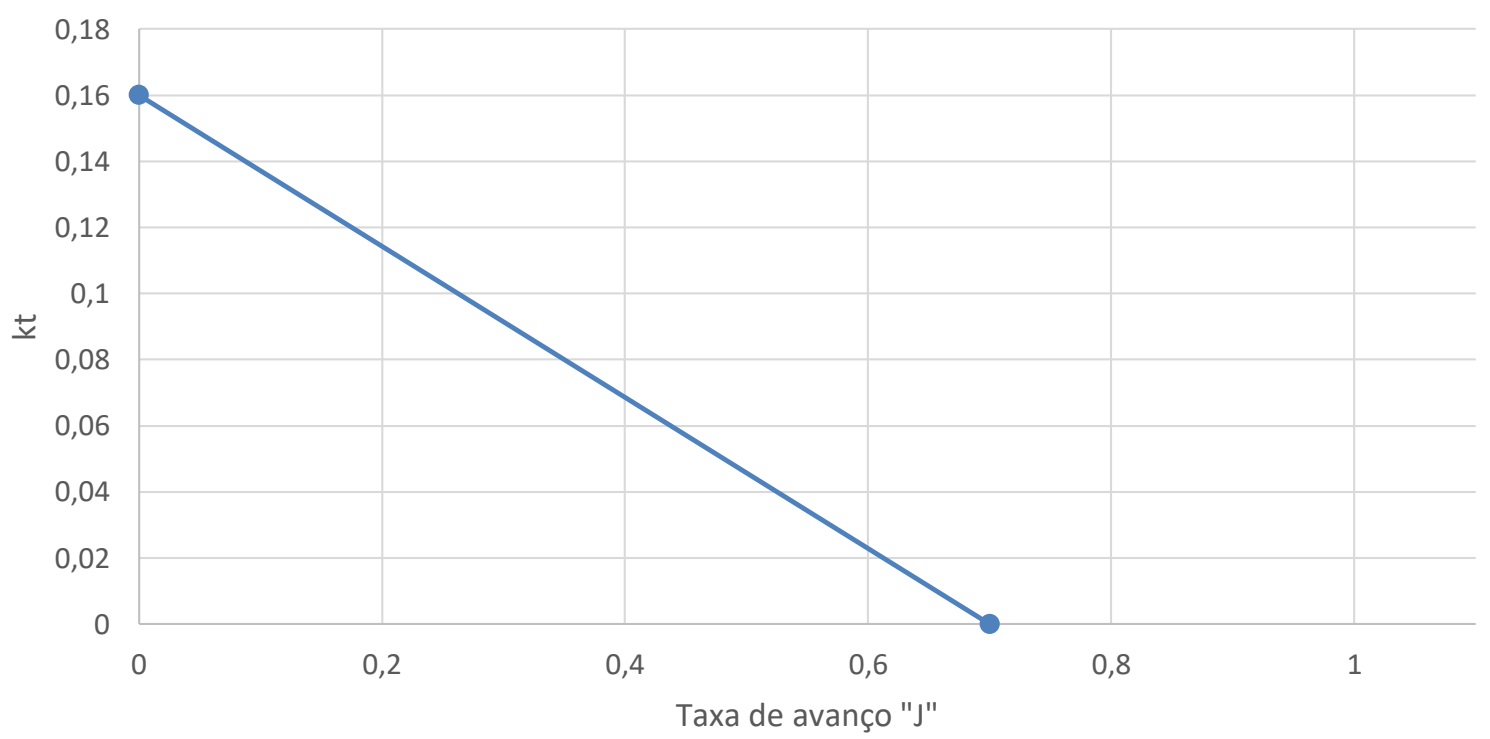

Fonte: Autor.

O modelo possui um propulsor transversal posicionado a $24,0 \mathrm{~m}$ a frente da meia nau, como mostrado na Figura 23. A Tabela 6 apresenta as características desse propulsor. 
Figura 23 - Posição do propulsor transversal em amarelo

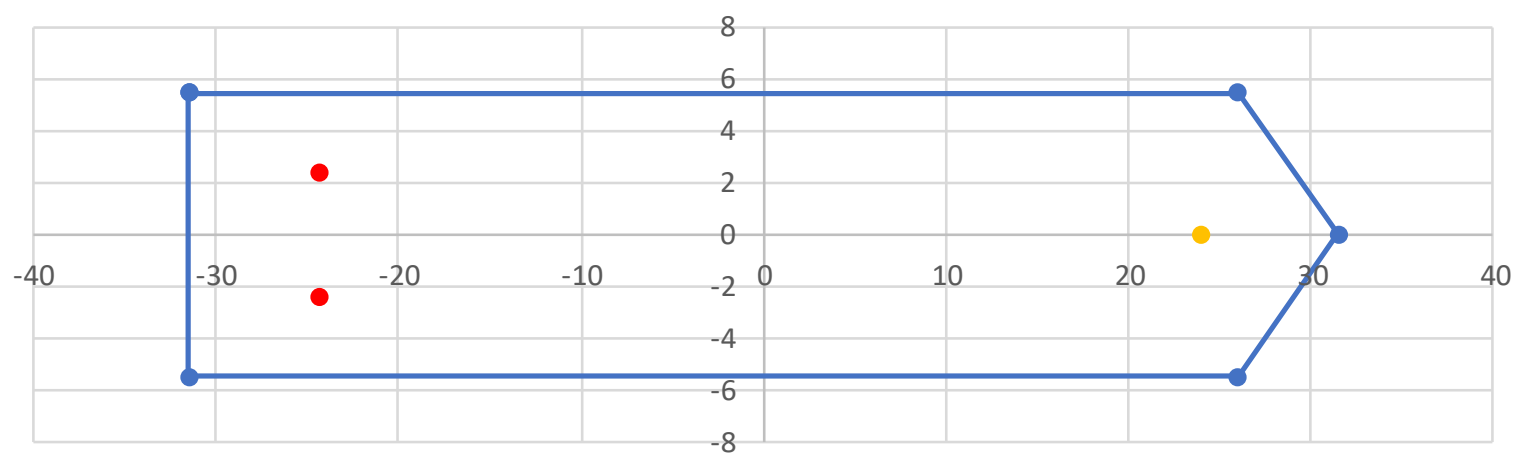

Fonte: Autor.

Tabela 6 - Características do propulsor

\begin{tabular}{cc}
\hline Propriedade & Valor \\
\hline Diâmetro & $1,560 \mathrm{~m}$ \\
Passo & $0,848 \mathrm{~m}$ \\
Rotação & $97 \mathrm{RPM}$ \\
Potência & $299 \mathrm{~kW}$ \\
Área do propulsor / & 0.3 \\
Área das pás & $100 \%$ \\
Potência a bombordo & $100 \%$ \\
\hline Potência a boreste &
\end{tabular}

Fonte: Autor.

O propulsor transversal apresenta a seguinte curva de coeficiente de empuxo $k_{t}$ em função da taxa de avanço $\mathrm{J}$, da Figura 24.

O modelo possui ainda dois lemes convencionais posicionados atrás de cada propulsor principal, 26,0 $\mathrm{m}$ atrás da meia nau. Cada leme possui uma área de 3,7 $\mathrm{m}^{2}$ e gira até 35\% para cada bordo. A posição dos lemes pode ser vista na Figura 25, e os coeficientes utilizados para sustentação e arrasto podem ser vistos na Figura 26.

Os modelos utilizados para representação das forças produzidas pelos propulsores e lemes representam a ação de cada um destes elementos de forma individual, sendo a resultante de forças aplicada ao modelo numérico calculada através da soma vetorial das forças produzidas por cada propulsor e leme incluído no modelo. 
Figura 24 - Coeficientes de empuxo do propulsor transversal

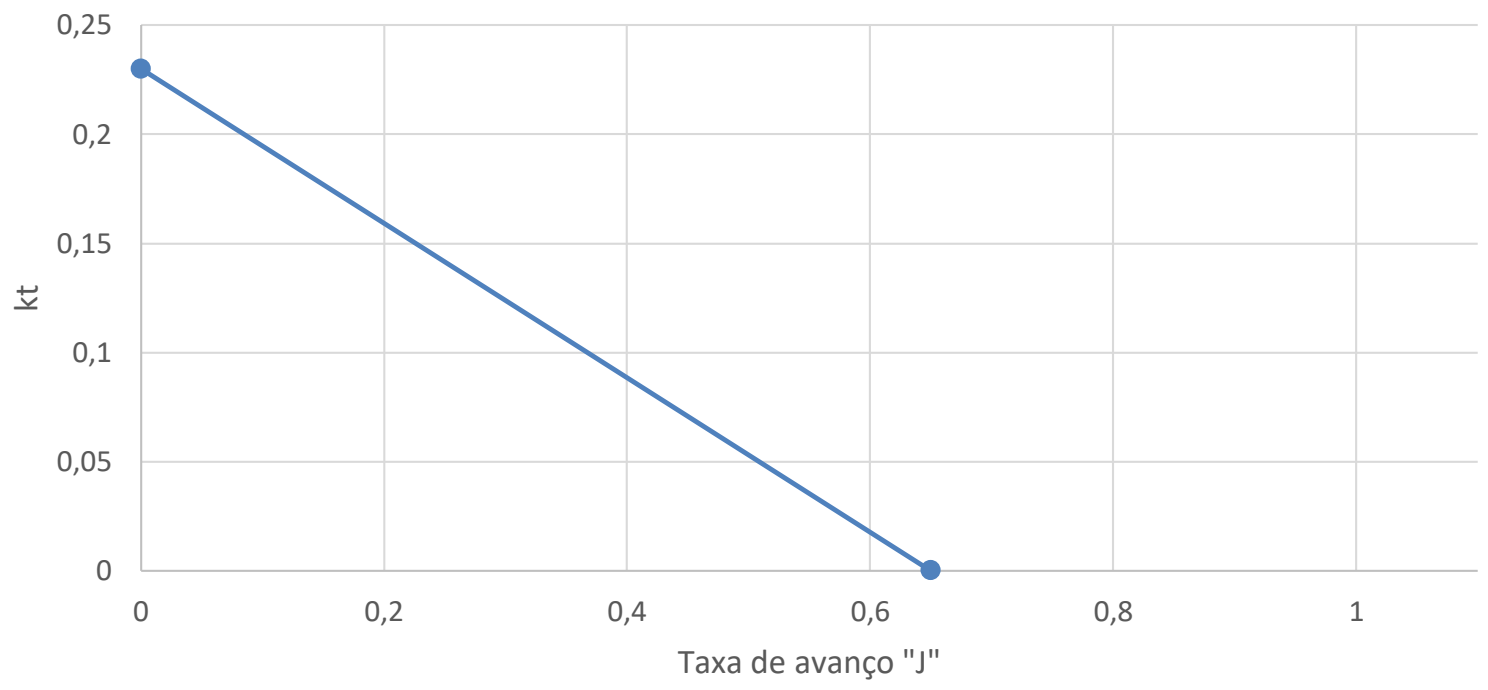

Fonte: Autor.

Figura 25 - Posição dos lemes na embarcação

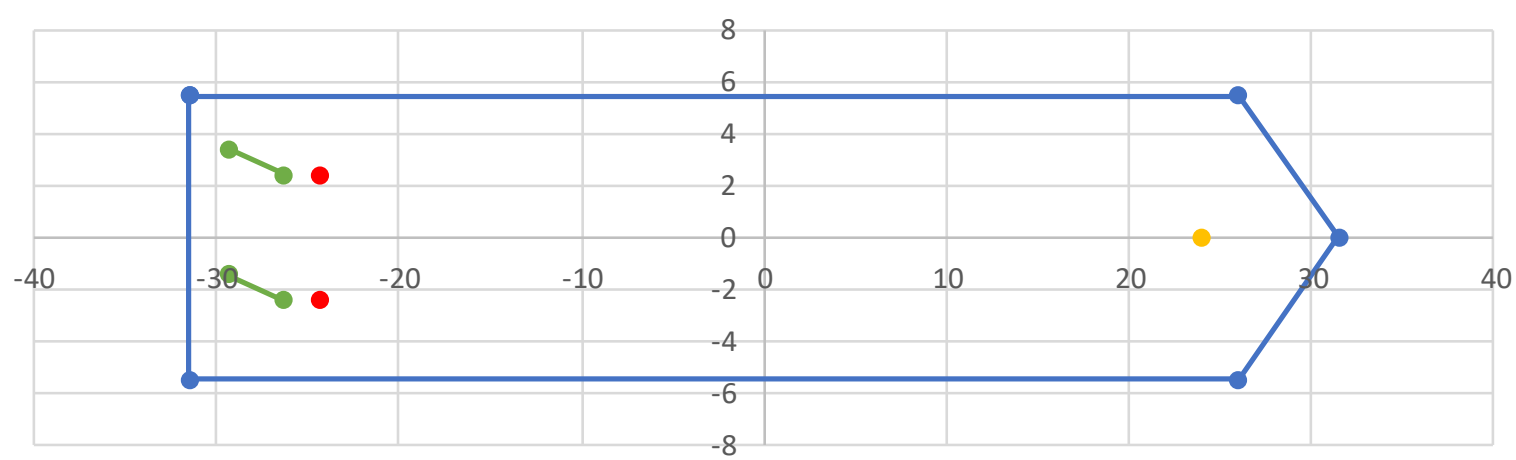

Fonte: Autor.

Figura 26 - Coeficientes de sustentação e arrasto utilizados para os lemes

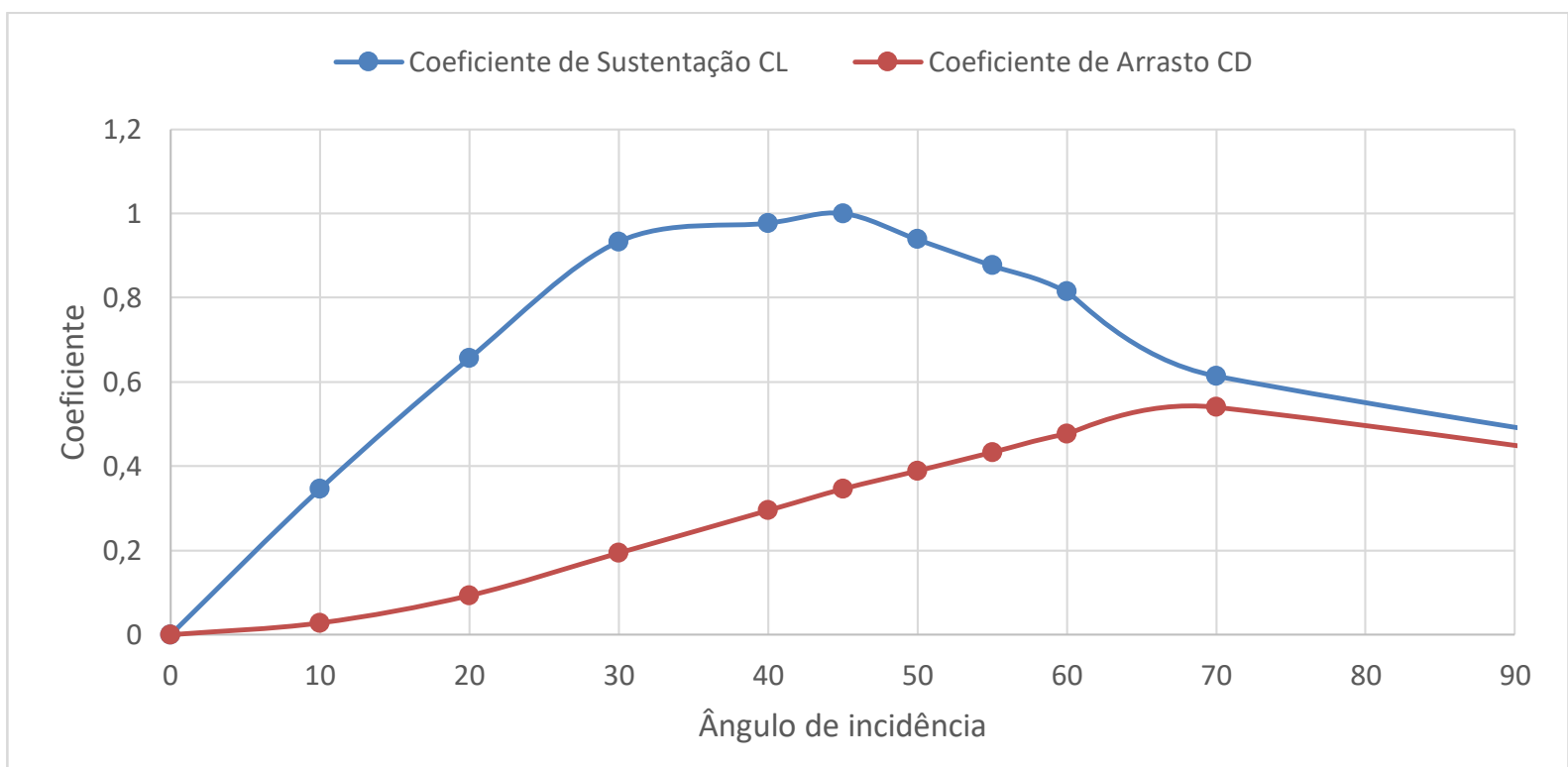

Fonte: Autor. 


\subsection{Modelo hidrodinâmico potencial}

Para a solução da parte potencial do problema hidrodinâmico foi utilizado o modelo de função de memória, com seus coeficientes calculados através do programa Wamitß. O cálculo tem como dado de entrada a geometria do casco modelada de acordo com o plano de linhas apresentado na Figura 8. A malha gerada pode ser vista na Figura 27.

Figura 27 - Superfície do casco modelado

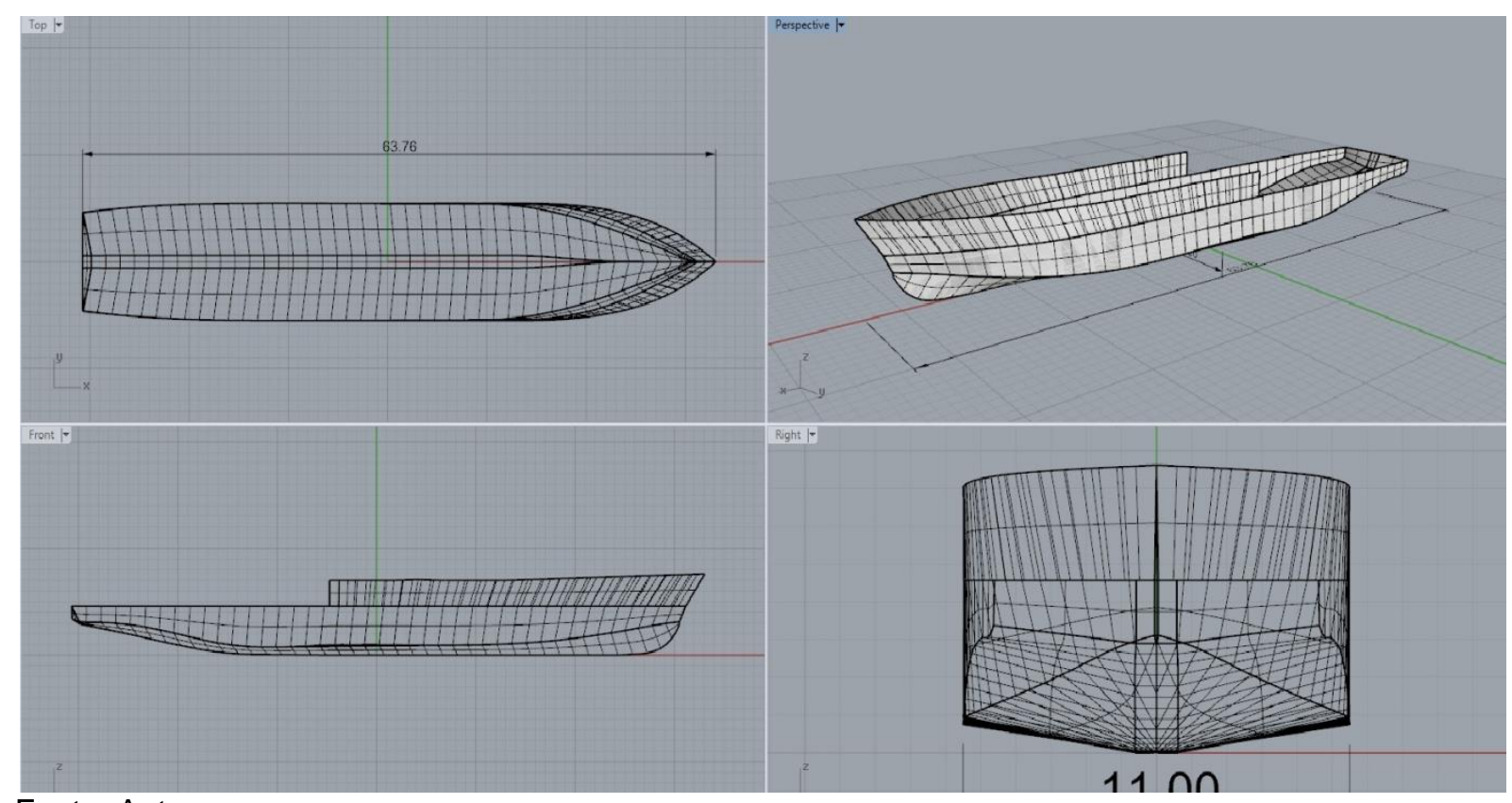

Fonte: Autor.

Os resultados obtidos pela teoria potencial, através do Wamitß são apresentados na Tabela 7 .

Tabela 7 - Massas e inércias obtidas

\begin{tabular}{cc}
\hline Propriedade & Valor \\
\hline Volume deslocado & $1520,7 \mathrm{~m}^{3}$ \\
Massa total & $1561,1 \mathrm{ton}$ \\
Momento de inércia em z (yaw) & 1547910,0 ton $\cdot \mathrm{m}$ \\
Massa adicional em x & 208,8 ton \\
Massa adicional em y & 2351,0 ton \\
Inércia adicional em z (yaw) & 270357,0 ton $\mathrm{m}$ \\
\hline
\end{tabular}

Fonte: Autor. 


\subsection{Modelo hidrodinâmico viscoso}

Os coeficientes de forças de corrente utilizados como entrada do modelo de Obokata (1987) foram estimados a partir de ensaios em túnel de vento em conjunto com cálculos realizados por CFD (computer fluid dynamics) conforme descrito em Masetti et.al. (2016).

Para os cálculos por CFD foi utilizado o pacote StarCCM, baseado em volumes finitos, através da solução de um problema de escoamento multifásico com interface entre a superfície da água e do ar. A malha utilizada para os cálculos do modelo em CFD é mostrada na Figura 28.

Figura 28 - Malha utilizada para os cálculos por CFD

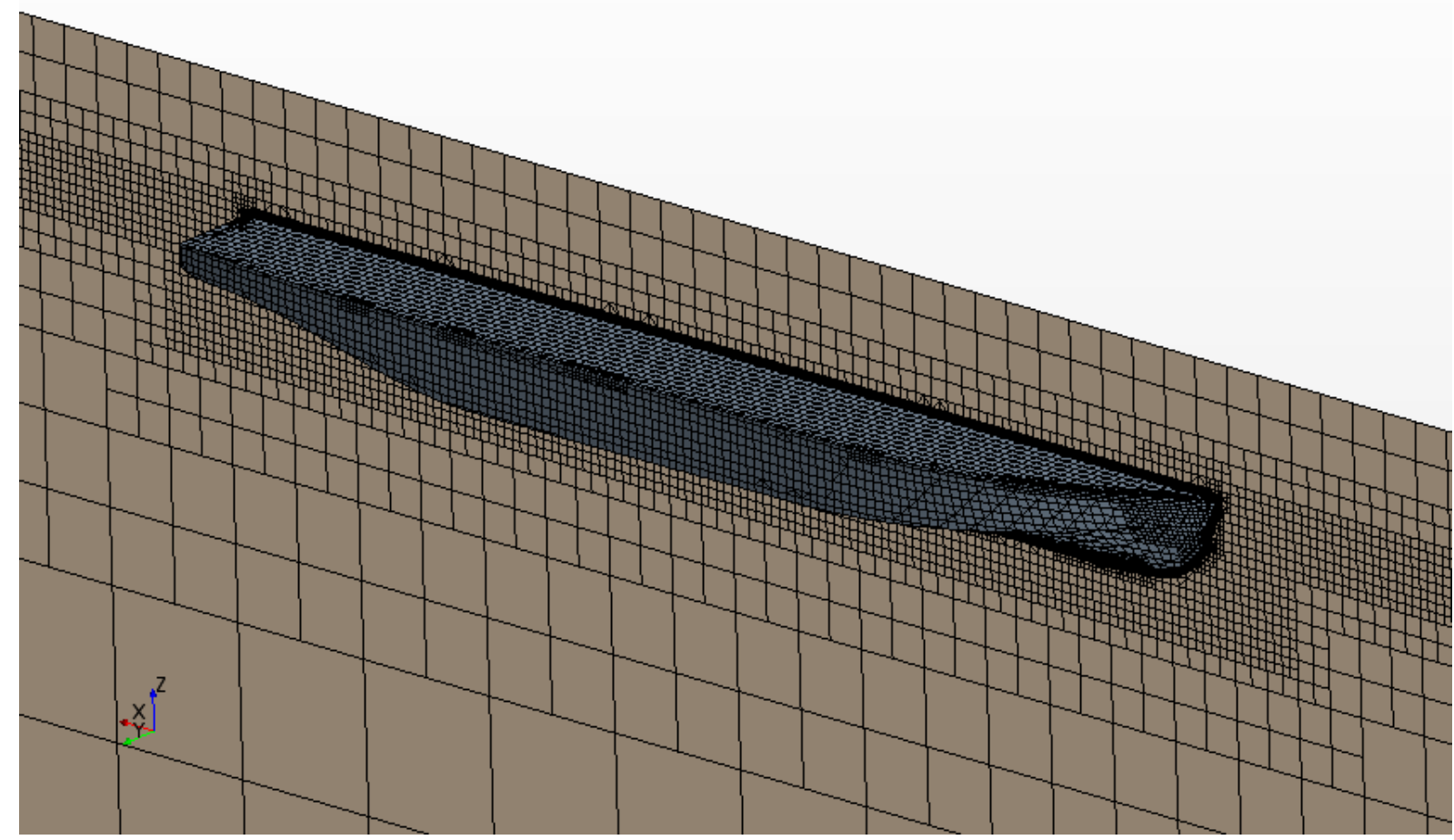

Fonte: (Rosetti, et al., 2014)

As forças utilizadas para o cálculo dos coeficientes hidrodinâmicos foram então obtidas a partir da integração do campo de pressões na superfície do casco modelado. Um exemplo do campo de pressões gerado pode ser visto na Figura 29. 
Figura 29 - Visualização dos coeficientes de pressão para correnteza incidente pela proa

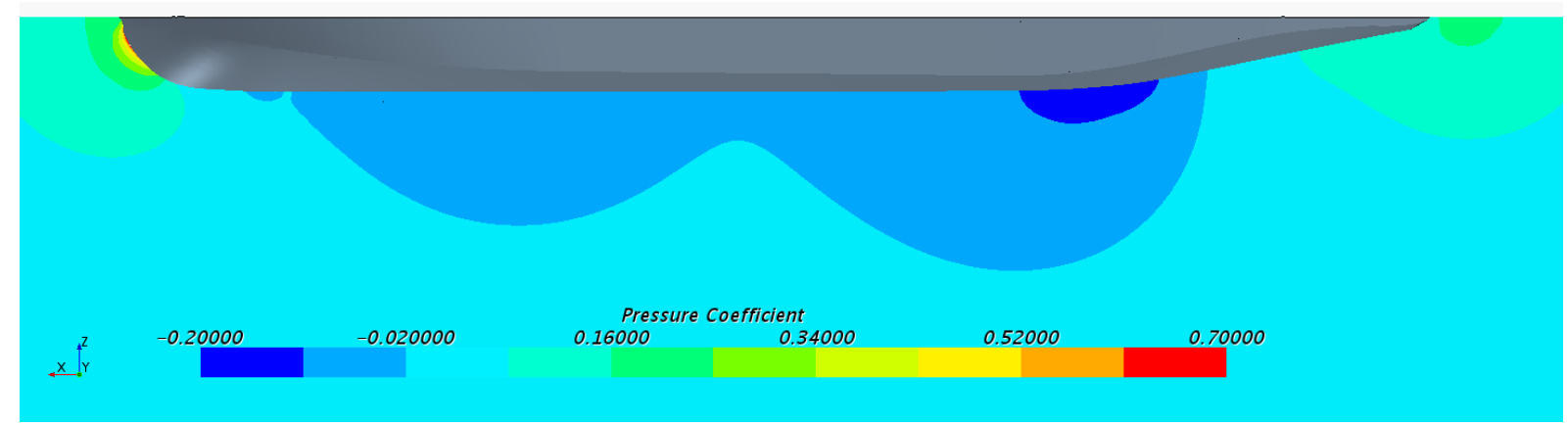

Fonte: (Rosetti, et al., 2014)

Observa-se no estudo realizado por Rosetti et.al. (2014) que os resultados obtidos através dos ensaios em túnel de vento possuem aderência qualitativa em relação aos dados obtidos por CFD, apresentando maior discrepância para as correntezas com incidência transversal à embarcação. Ressalta-se que o modelo calculado por CFD possui superfície livre e os limites do domínio de controle estão afastados do casco do navio, condições que não se aplicam da mesma forma para os ensaios em túnel de vento, que possui o chão rígido do tanque no lugar da superfície livre, e possui paredes laterais mais próximas do que os limites do modelo computacional.

Rosetti et.al. (2014) realizou então simulações por CFD sem a hipótese de superfície livre, portanto com condições de contorno mais próximas às observadas no túnel de vento. Obteve então resultados quantitativamente coerentes com os resultados obtidos por túnel de vento, validando o modelo numérico. Porém, em seu relatório recomenda que sejam utilizados os coeficientes levantados com o modelo que considera a superfície livre, pois esse modelo representa de forma mais fiel às condições reais de navegação da embarcação.

$\mathrm{Na}$ Figura 30 podem ser comparados os coeficientes obtidos através do túnel de vento, e pelas simulações por CFD, com os resultados das simulações com e sem superfície livre. Pode ser visto que os resultados obtidos por CFD sem superfície livre, ou seja, com superfície simétrica, apresentam resultados próximos aos obtidos por túnel de vento. 
Figura 30 - Curvas dos coeficientes de forças e momento na superestrutura em comparação aos resultados experimentais do IPT utilizando a convenção de incidências da OCIMF

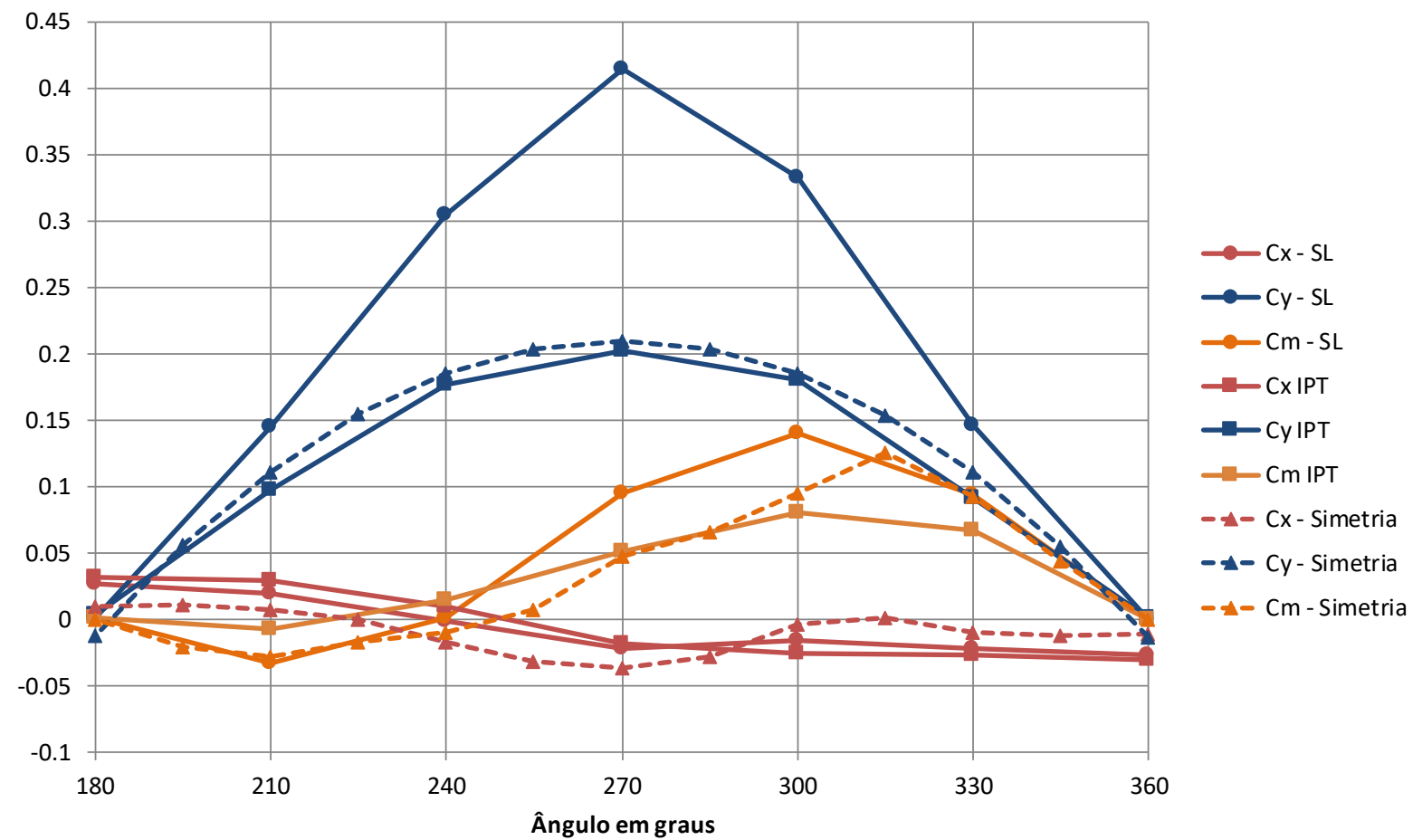

Fonte: adaptado de (Rosetti, et al., 2014).

Observou-se que os coeficientes apresentados por Rosetti et.al. (2014) estão adimensionalizados para uma área de $0,25 \mathrm{~m}^{2}$, considerando a escala do modelo utilizado no túnel de vento (1:40). Porém a formulação de Obokata (1987) já apresentada na equação (9), utiliza uma área proporcional ao comprimento e ao calado da embarcação, que no caso do Alpha Crucis em escala de 1:40 representa uma área de $0,135 \mathrm{~m}^{2}$.

Por esse motivo é necessário corrigir os coeficientes oriundos da análise de CFD para serem adotados no modelo do simulador. Se considerarmos a força produzida em função de um coeficiente e área genéricos obtemos a relação mostrada na equação (16).

$$
\begin{gathered}
F \cong \frac{1}{2} \rho C_{C F D} A_{\text {ref }} U^{2}=\frac{1}{2} \rho C_{\text {Simulador }} L T U^{2} \\
C_{\text {Simulador }}=\frac{A_{\text {ref }} C_{C F D}}{L T}=\frac{0.25 C_{C F D}}{1.5 \cdot 0.09}=1.85185 C_{C F D}
\end{gathered}
$$

Na qual $U$ corresponde à velocidade de referência, $A_{\text {ref }}$ corresponde à área considerada por Rosetti et.al. (2014), $L$ e $T$ representam o comprimento e calado do navio na escala de 1:40. Obtém-se então um fator que deve ser multiplicado pelos coeficientes obtidos por CFD para a correta simulação. 
A Figura 31 a Figura 33 mostram os coeficientes obtidos por Rosetti et.al. (2014) com superfície livre, com a correção relacionada à área aplicada.

Figura 31 - Coeficientes longitudinais obtidos por CFD

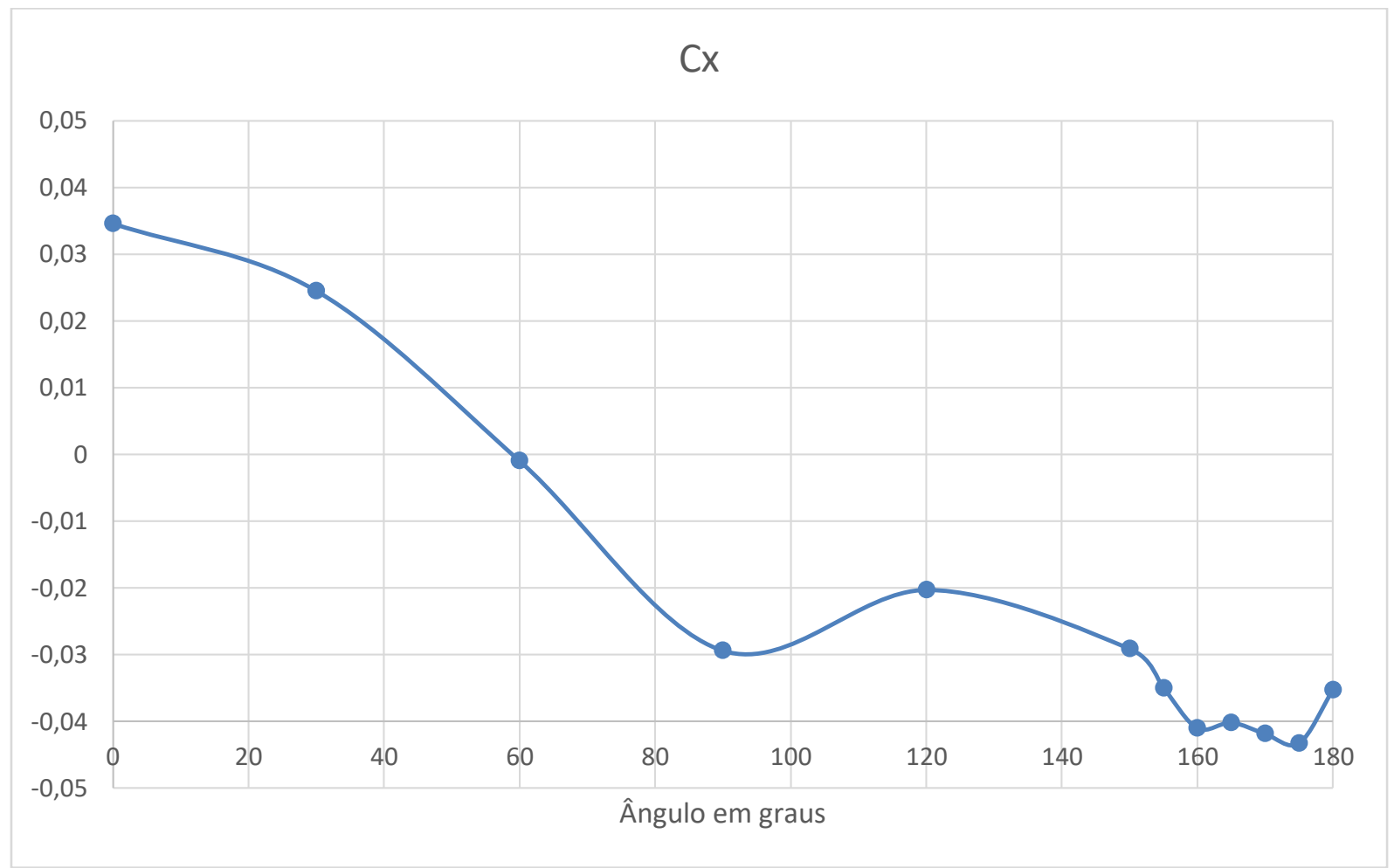

Fonte: Autor.

Figura 32 - Coeficientes transversais obtidos por CFD

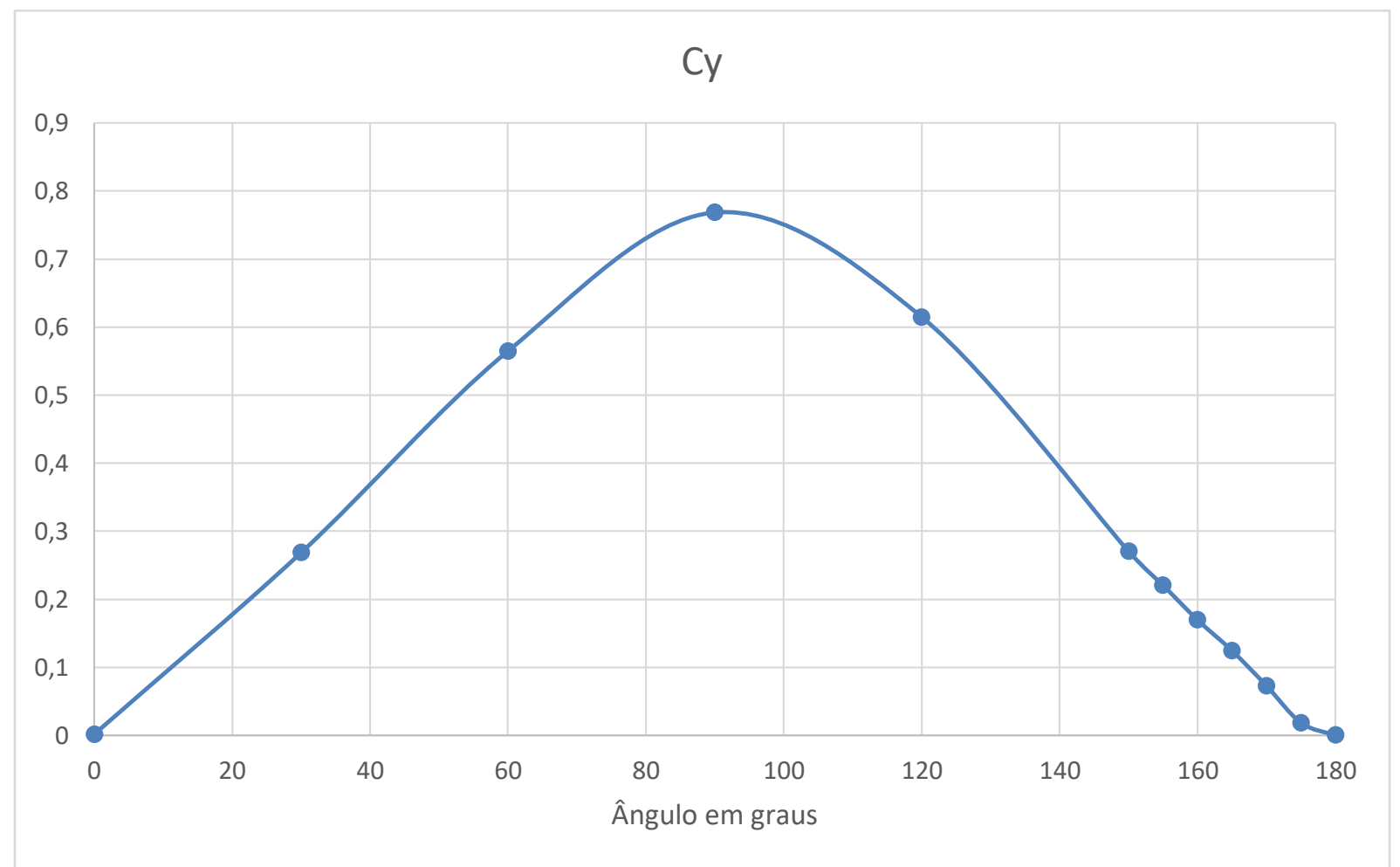

Fonte: Autor. 
Figura 33 - Coeficientes de momento de yaw obtidos por CFD

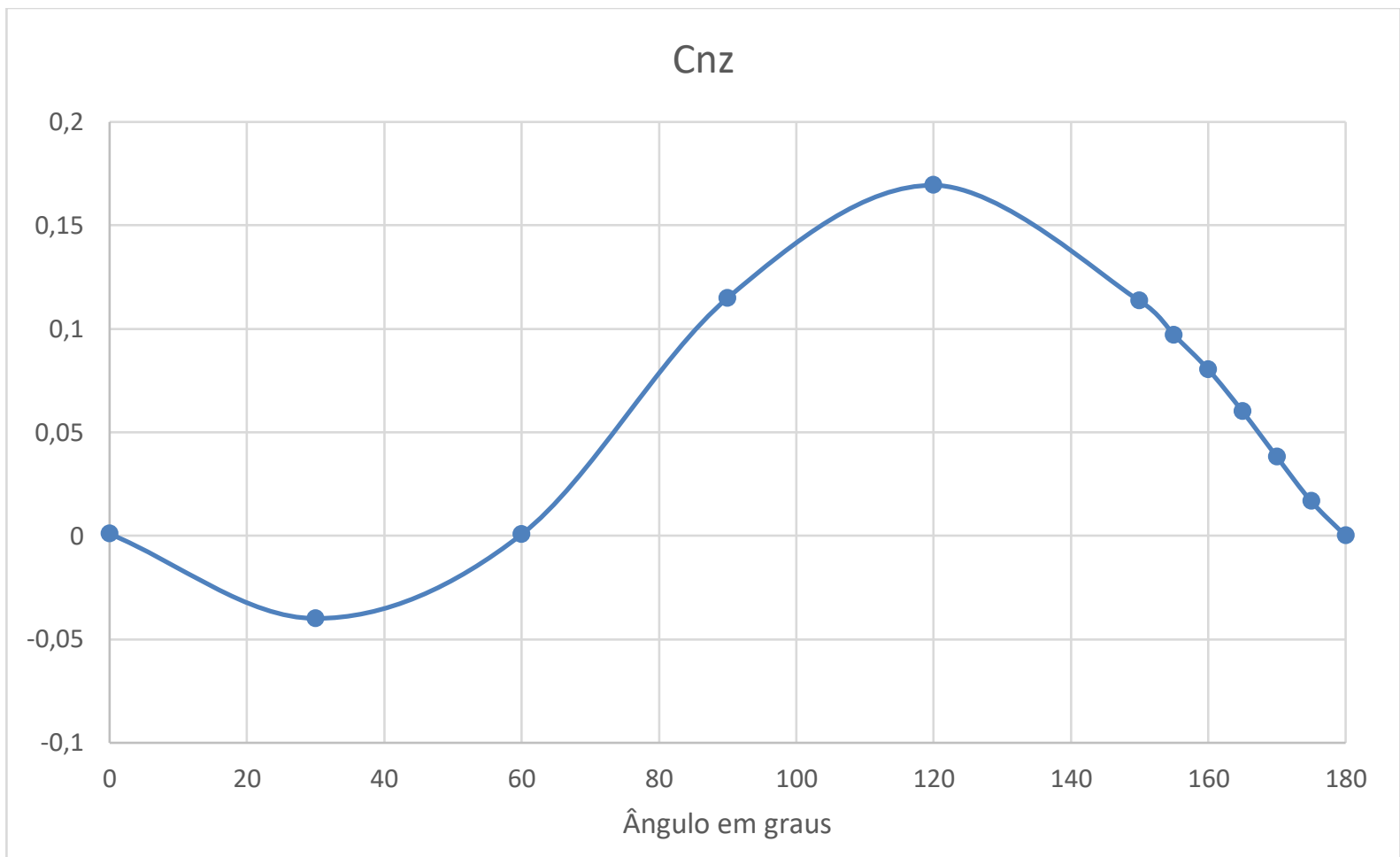

Fonte: Autor.

Os parâmetros de amortecimento utilizados no modelo matemático são:

Tabela 8 - Parâmetros de amortecimento

\begin{tabular}{cc}
\hline Propriedade & Valor \\
\hline$c_{11}$ & $5,0 \mathrm{kN} /(\mathrm{m} / \mathrm{s})$ \\
$c 2_{11}$ & $0 \mathrm{kN} /(\mathrm{m} / \mathrm{s})^{2}$ \\
$c_{22}$ & $0 \mathrm{kN} /(\mathrm{m} / \mathrm{s})$ \\
$c 2_{22}$ & $0 \mathrm{kN} /(\mathrm{m} / \mathrm{s})^{2}$ \\
$c_{66}$ & $0(\mathrm{kN} \cdot \mathrm{m}) /(\mathrm{rad} / \mathrm{s})$ \\
$c 2_{66}$ & $1.273 .070,8(\mathrm{kN} \cdot \mathrm{m}) /(\mathrm{rad} / \mathrm{s})^{2}$ \\
\hline
\end{tabular}

Fonte: Autor. 


\section{MANOBRAS PADRÃO}

Para a comparação e validação do modelo numérico é necessária a definição de critérios de comparação, e por esse motivo não podem ser realizadas manobras de forma indiscriminada pois dessa forma não ficam determinadas as capacidades de manobra da embarcação. Foi definida então uma série de manobras padronizadas que permitem a caracterização da manobrabilidade da embarcação. Essas manobras são descritas ao longo deste capítulo.

Na seção sobre cada tipo de manobra é apresentada a comparação entre os resultados experimentais e numéricos através de gráficos que ilustram a trajetória e velocidades da embarcação.

\subsection{Manobra de giro (turning circle)}

Esta manobra mede a capacidade do navio guinar com o leme em sua posição máxima. Para sua execução conforme as recomendações da IMO (2002) a manobra deve ser realizada com a velocidade de serviço do navio, e no início da manobra o navio deve manter sua velocidade angular nula. A velocidade do navio também deve estar estável e o motor deve manter a rotação do propulsor constante.

Com as condições de velocidade e aproamento satisfeitas a manobra é iniciada, aplicando o leme máximo para um dos bordos e mantendo a rotação do propulsor constante até que a manobra esteja completa, conforme mostrado na Figura 34.

Nessa manobra devem ser medidas algumas grandezas básicas para a caracterização da capacidade de guinada do navio, a saber:

- Diâmetro tático, compreende a distância entre a reta que descrevia o movimento da embarcação antes do início da manobra e a posição do centro de massa da embarcação quando houve uma mudança de $180^{\circ}$ em seu aproamento.

- Avanço, distância entre a reta transversal ao navio que passa por seu centro de massa no instante em que a manobra é iniciada e a posição do centro de massa quando há uma alteração de $90^{\circ}$ no aproamento. 
- Transferência, distância medida entre a reta que descrevia o movimento da embarcação antes da manobra iniciar e o centro de massa da embarcação quando há uma alteração de $90^{\circ} \mathrm{em}$ seu aproamento.

- Perda de velocidade, diferença entre a velocidade de avanço da embarcação no início e no término da manobra.

- Tempo para mudar o aproamento da embarcação em 90․

- Tempo para mudar o aproamento da embarcação em 180․

- Ângulo de deriva (drift), diferença entre a direção de aproamento da embarcação e sua direção de movimento.

Figura 34 - Diagrama da manobra de Turning Circle

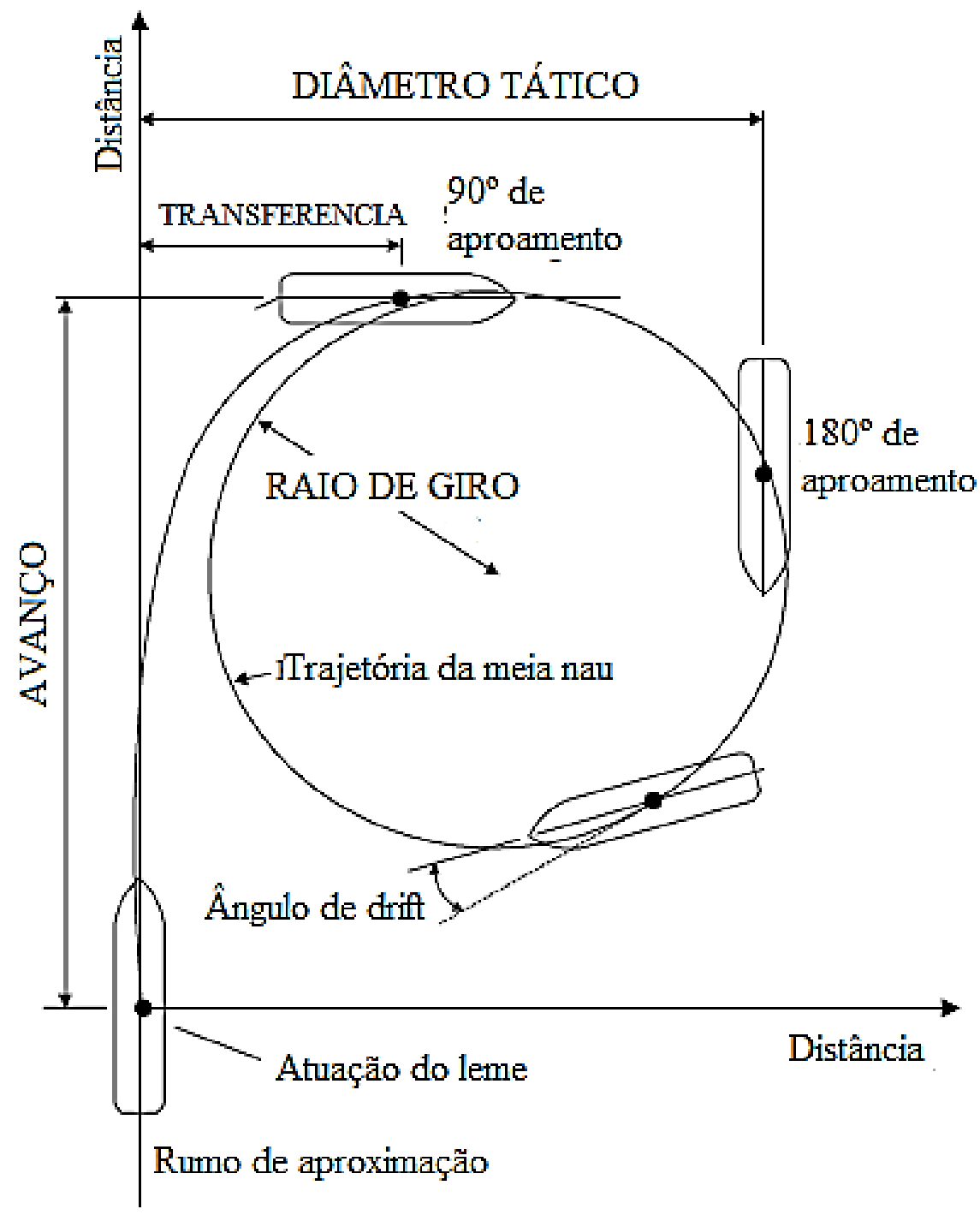

Fonte: Adaptado de (American Bureau of Shipping, 2006) 
Conforme as recomendações da ITTC (2002), quando possível esta manobra deve ser realizada também com velocidades mais baixas do que a velocidade de serviço da embarcação.

No experimento realizado foram testadas duas rotações dos propulsores principais, 500 RPM e 1050 RPM, equivalendo respectivamente às ordens de meia força e devagar avante, conforme os resultados obtidos na calibração dos propulsores. Em ambas as manobras o leme foi colocado na posição de $30^{\circ}$. Não foi realizada manobra com a rotação máxima dos propulsores devido à limitação do tamanho do tanque disponível. 


\subsubsection{Manobra 1}

Nessa manobra foi realizada uma curva de giro com máquina devagar avante (500 RPM), com leme de 30ํe em águas profundas. A Tabela 9 apresenta os dados táticos obtidos:

Tabela 9 - Dados táticos obtidos para a manobra 1

\begin{tabular}{|l|l|l|l|l|}
\hline Experimental & Avanço & Transferência & Diâmetro tático & Diâmetro final \\
\hline Simulado & $161.5 \mathrm{~m}(2,6 \mathrm{~L})$ & $37,8 \mathrm{~m}(0,6 \mathrm{~L})$ & $133,6 \mathrm{~m}(2,1 \mathrm{~L})$ & $132,9 \mathrm{~m}(2,1 \mathrm{~L})$ \\
\hline Erro & $2.4 \%$ & $60,2 \mathrm{~m}(1,0 \mathrm{~L})$ & $153,4 \mathrm{~m}(2,5 \mathrm{~L})$ & $120,0 \mathrm{~m}(1,9 \mathrm{~L})$ \\
\hline & Vx final & $59,3 \%$ & $14,8 \%$ & $-9,7 \%$ \\
\hline Experimental & 1,2 nós & 0,8 nós & $\begin{array}{l}\text { Velocidade } \\
\text { angular }\end{array}$ & $\begin{array}{l}\text { Ângulo de } \\
\text { deriva }\end{array}$ \\
\hline Simulado & 0,9 nós & 0,5 nós & $30,6^{\circ} / \mathrm{min}$ & $31,9^{\circ}$ \\
\hline Erro & $-29,2 \%$ & $-30,3 \%$ & $-19,0 \%$ & $30,6^{\circ}$ \\
\hline
\end{tabular}

Fonte: Autor.

Observa-se através da Figura 35 que nessa manobra o modelo numérico apresentou uma trajetória similar à do modelo em escala reduzida, obtendo dados táticos próximos aos experimentais. A simulação, no entanto, apresentou menor sobressinal para a velocidade angular e transversal $(\mathrm{Vy})$ do que observado no modelo experimental como pode ser visto na Figura 36.

Figura 35 - Trajetória varrida, manobra 1

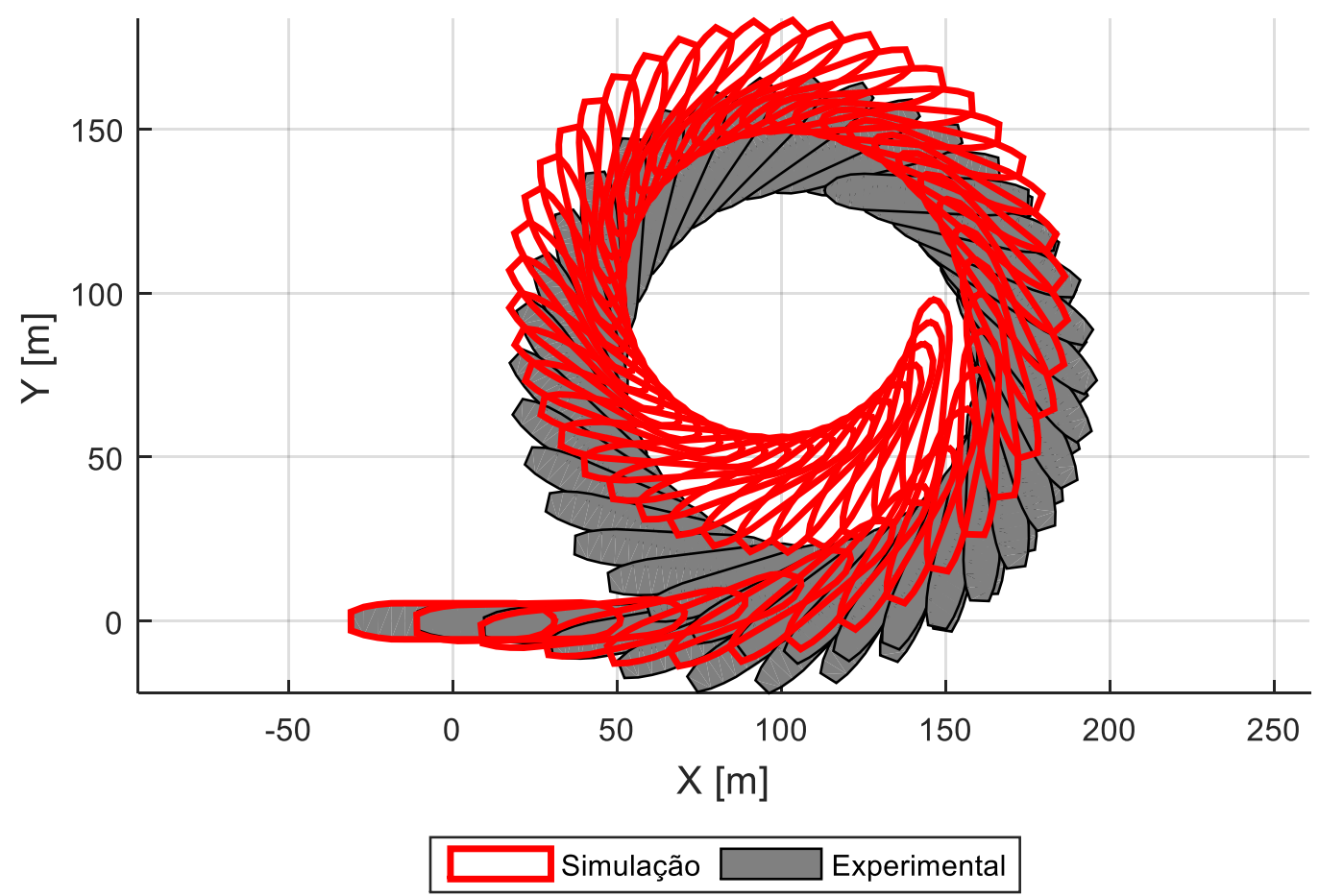

Fonte: Autor. 
Figura 36 - Gráficos de ângulo de deriva, velocidade angular, velocidade $\mathrm{Vx}$, velocidade $\mathrm{Vy}$, manobra 1
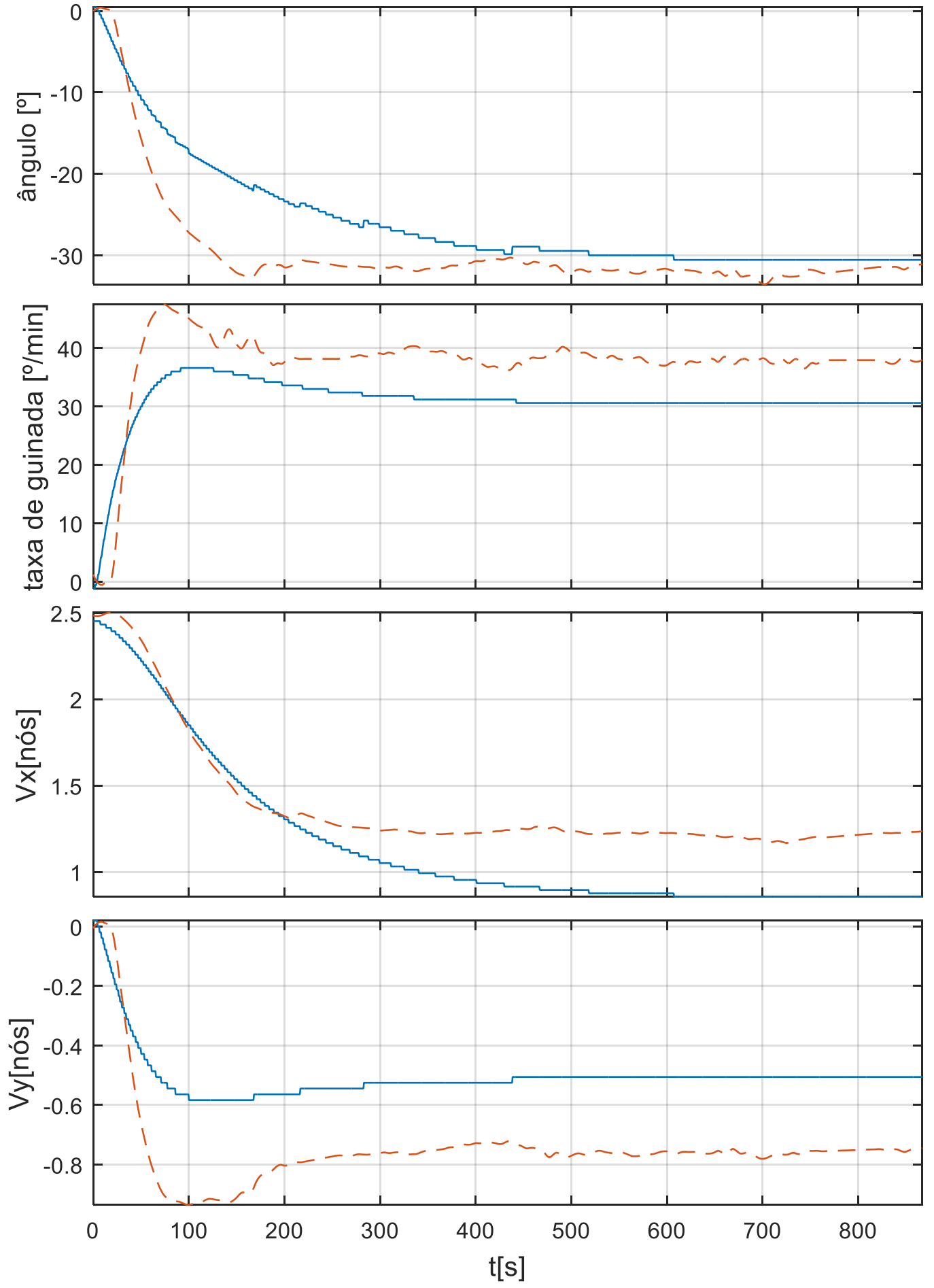

Fonte: Autor.

Simulação - - Experimental 


\subsubsection{Manobra 2}

Nessa manobra foi realizada uma curva de giro com máquina meia força avante (1050 RPM), com leme de 30‥ A Tabela 10 apresenta os dados táticos obtidos:

Tabela 10 - Dados táticos obtidos para a manobra 2

\begin{tabular}{|l|l|l|l|l|}
\hline Experimental & Avanço & Transferência & Diâmetro tático & Diâmetro final \\
\hline Simulado & $171,8 \mathrm{~m}(2,7 \mathrm{~L})$ & $41,0 \mathrm{~m}(0,7 \mathrm{~L})$ & $144,4 \mathrm{~m}(2,3 \mathrm{~L})$ & $138,8 \mathrm{~m}(2,2 \mathrm{~L})$ \\
\hline Erro & $1,4 \%$ & $62,9 \mathrm{~m}(1,0 \mathrm{~L})$ & $162,0 \mathrm{~m}(2,6 \mathrm{~L})$ & $137,8 \mathrm{~m}(2,2 \mathrm{~L})$ \\
\hline & Vx final & $53,4 \%$ & $12,2 \%$ & $-0,8 \%$ \\
\hline Experimental & 2,4 nós & Vy final & $\begin{array}{l}\text { Velocidade } \\
\text { angular }\end{array}$ & $\begin{array}{l}\text { Ângulo de } \\
\text { deriva }\end{array}$ \\
\hline Simulado & 2,2 nós & 1,5 nós & $72,0 \% \mathrm{~min}$ & $32,1^{\circ}$ \\
\hline Erro & $-5,4 \%$ & $-26,9 \%$ & $65,4 \%$ min & $25,9{ }^{\circ}$ \\
\hline
\end{tabular}

Fonte: Autor.

A Figura 37 mostra que as trajetórias obtidas diferem principalmente para as dimensões medidas no eixo Y. A Figura 38 mostra que a velocidade de avanço apresentou boa aderência entre os modelos durante toda a manobra, e que o ângulo de deriva obtido pela simulação foi inferior ao da manobra experimental.

Figura 37 - Trajetória varrida, manobra 2

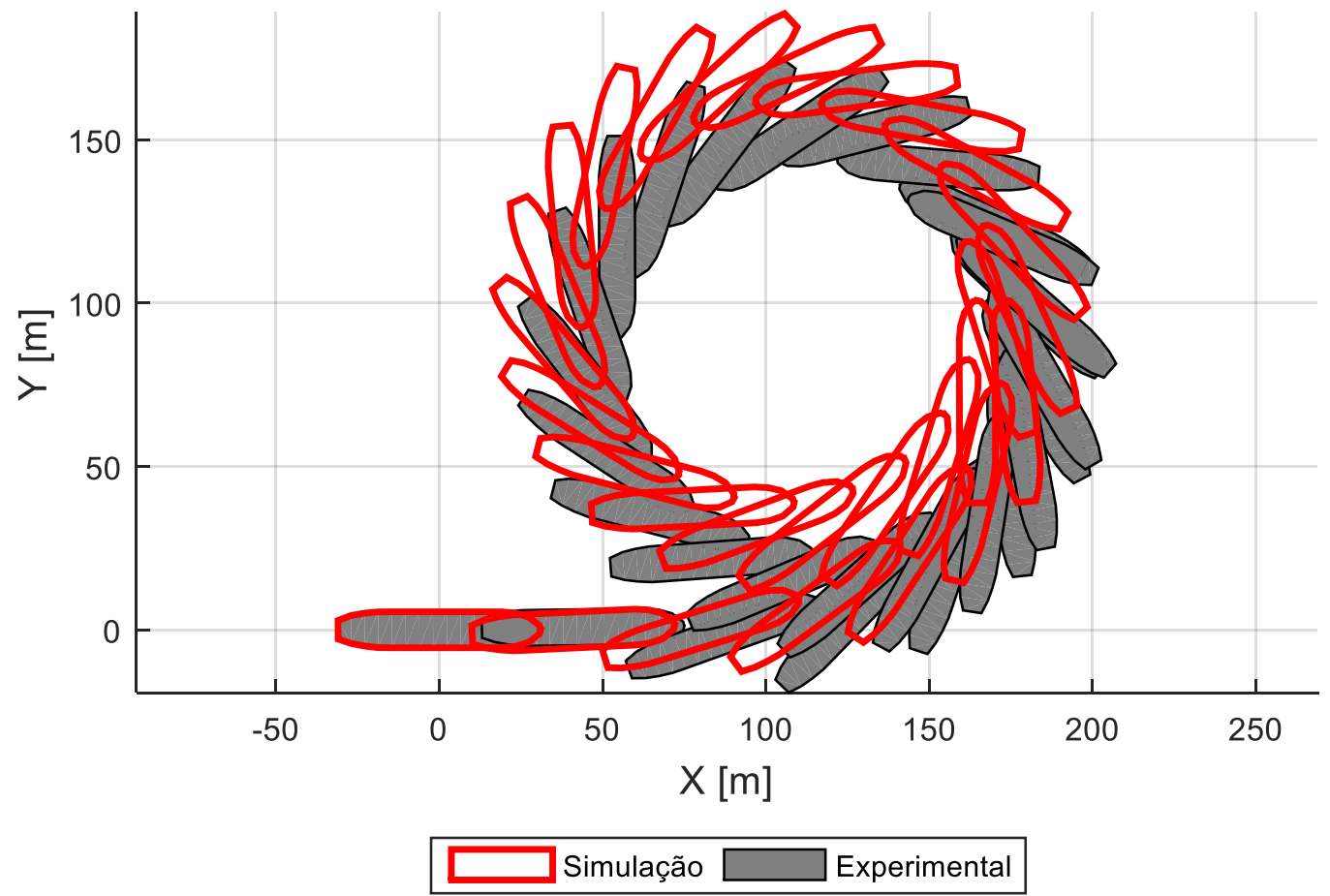

Fonte: Autor. 
Figura 38 - Gráficos de ângulo de deriva, velocidade angular, velocidade $V x$, velocidade $V y$, manobra 2
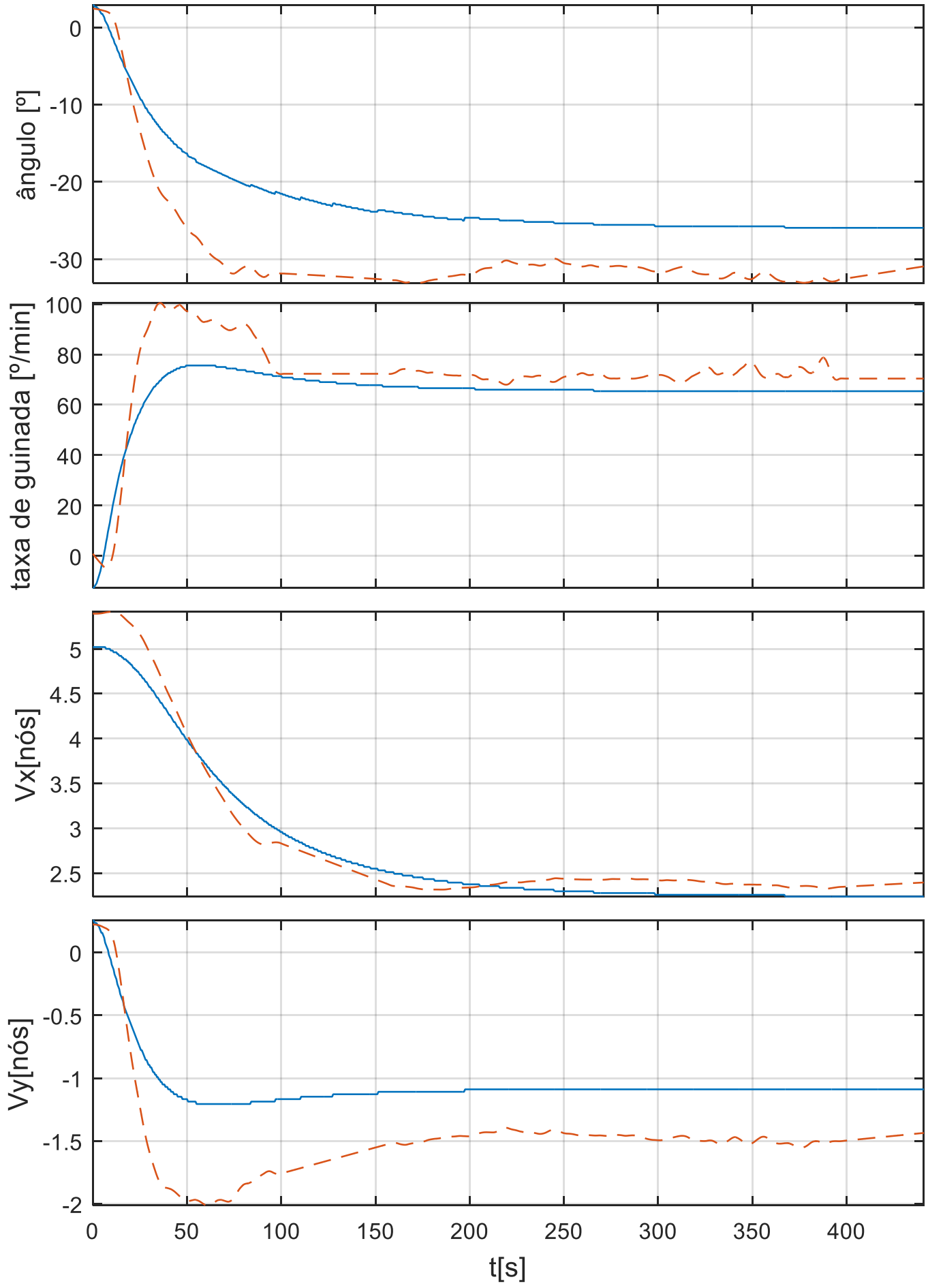

Fonte: Autor.

Simulação - - - Experimental 
6.1.3. Manobra 1 - águas rasas

Nessa manobra foi realizada uma curva de giro com máquina devagar avante (500 RPM), com leme de 30 em águas rasas. A Tabela 11 apresenta os dados táticos obtidos:

Tabela 11 - Dados táticos obtidos para a manobra 1 em águas rasas

\begin{tabular}{|c|c|c|c|c|}
\hline & Avanço & Transferência & Diâmetro tático & Diâmetro final \\
\hline Experimental & $128,8 \mathrm{~m}(2,1 \mathrm{~L})$ & $51,3 \mathrm{~m}(0,8 \mathrm{~L})$ & & \\
\hline Simulado & $133,3 \mathrm{~m}(2,1 \mathrm{~L})$ & $64,9 \mathrm{~m}(1,0 \mathrm{~L})$ & & \\
\hline Erro & $3,4 \%$ & $26,5 \%$ & & \\
\hline & Vx final & Vy final & $\begin{array}{l}\text { Velocidade } \\
\text { angular }\end{array}$ & $\begin{array}{l}\text { Ângulo } \\
\text { deriva }\end{array}$ \\
\hline Experimental & 1,5 nós & 0,5 nó & $35,4 \% \min$ & $15,8^{\circ}$ \\
\hline Simulado & 1,6 nós & 0,3 nó & $33,6^{\circ} / \mathrm{min}$ & $12,3^{\circ}$ \\
\hline Erro & $4,8 \%$ & $-29,5 \%$ & $-5,2 \%$ & $-22,2 \%$ \\
\hline
\end{tabular}

Fonte: Autor.

Não foi possível realizar esta manobra integralmente devido à restrição de tamanho do tanque. Porém a Figura 39 mostra que embora a trajetória obtida por ambas manobras seja similar, a taxa de guinada obtida aparenta ser menor para a manobra simulada. Este comportamento pode ser confirmado na Figura 40 onde pode-se verificar que o modelo numérico apresenta comportamento mais amortecido do que o modelo em escala reduzida.

Figura 39 - Trajetória varrida, manobra 1 em águas rasas

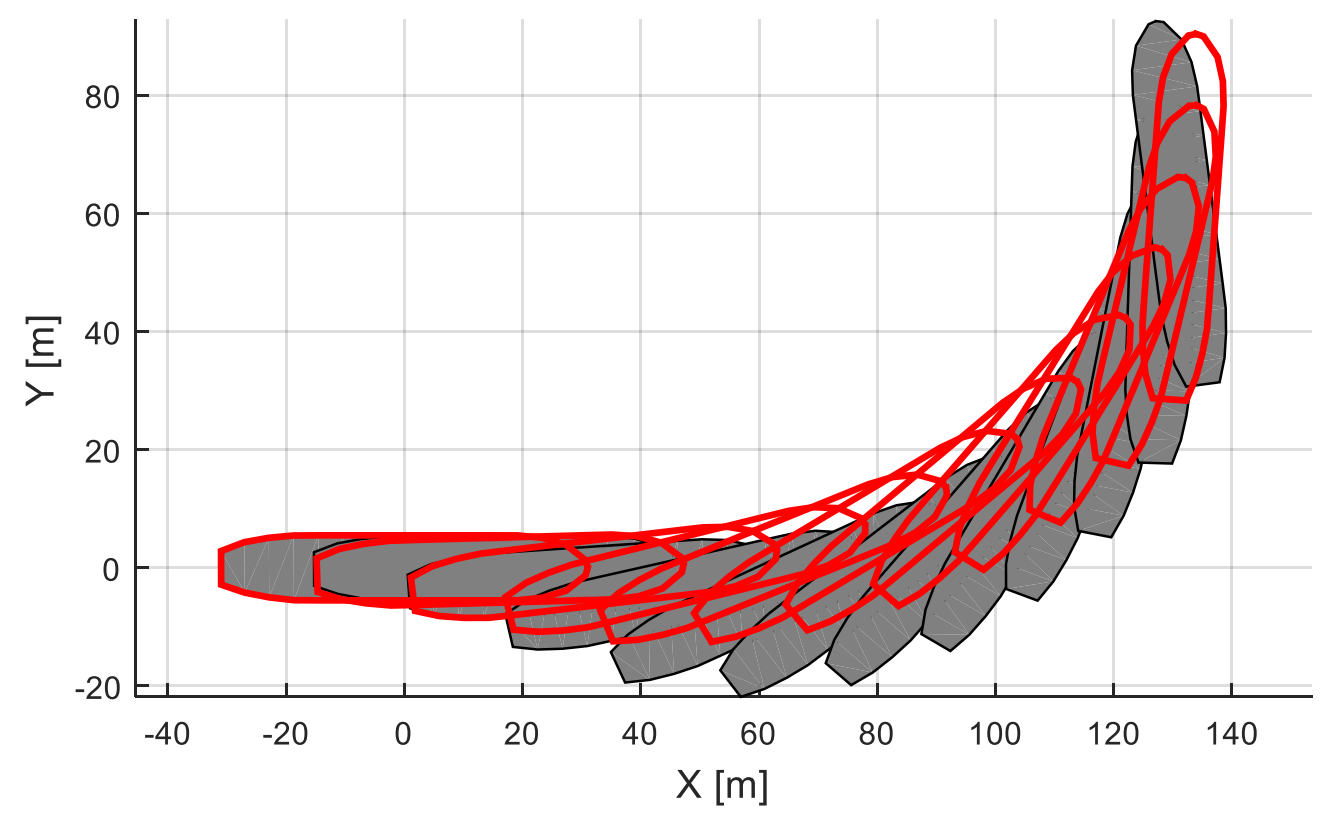

Fonte: Autor.

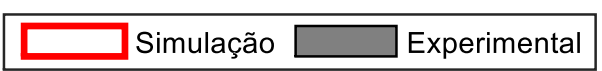


Figura 40 - Gráficos de ângulo de deriva, velocidade angular, velocidade $V x$, velocidade $V y$, manobra 1 em águas rasas
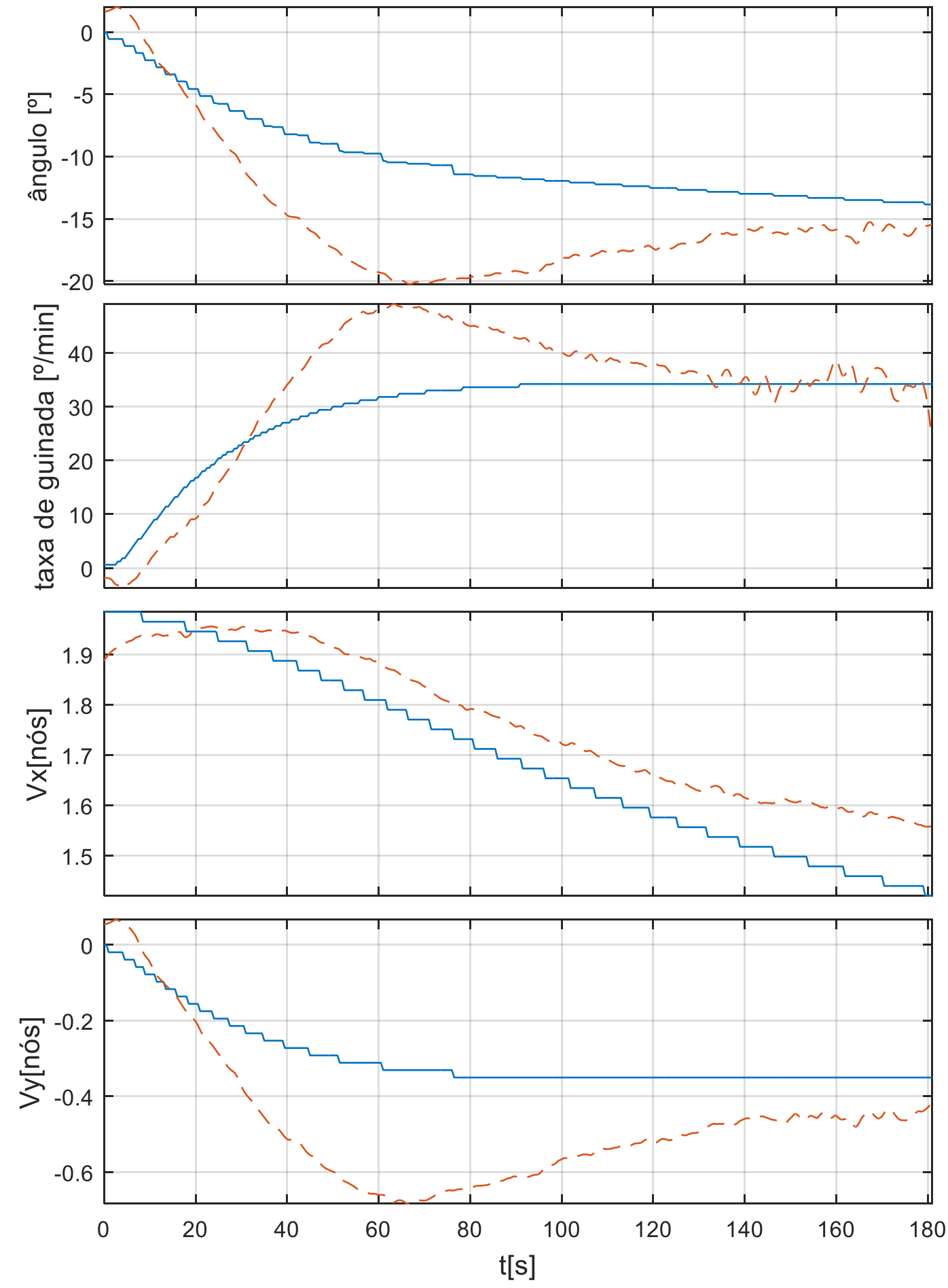

Fonte: Autor.

Simulação - - Experimental 
6.1.4. Manobra 2 - águas rasas

Nessa manobra foi realizada uma curva de giro com máquina meia força avante (1050 RPM), com leme de 30ํem águas rasas. A Tabela 12 apresenta os dados táticos obtidos:

Tabela 12 - Dados táticos obtidos para a manobra 2 em águas rasas

\begin{tabular}{|l|l|l|l|l|}
\hline Experimental & Avanço & Transferência & Diâmetro tático & Diâmetro final \\
\hline Simulado & $125,9 \mathrm{~m}(2,0 \mathrm{~L})$ & $38,4 \mathrm{~m}(0,6 \mathrm{~L})$ & $126,3 \mathrm{~m}(2,0 \mathrm{~L})$ & $141,2 \mathrm{~m}(2,3 \mathrm{~L})$ \\
\hline Erro & $3,6 \%$ & $65,4 \mathrm{~m}(1,0 \mathrm{~L})$ & $155,6 \mathrm{~m}(2,5 \mathrm{~L})$ & $-137,3 \mathrm{~m}(2,2 \mathrm{~L})$ \\
\hline Experimental & 3,0 nós & $76.3 \%$ & $23,2 \%$ & $2,8 \%$ \\
\hline Simulado & 2,6 nós & Vy final & $\begin{array}{l}\text { Velocidade } \\
\text { angular }\end{array}$ & $\begin{array}{l}\text { Ângulo de } \\
\text { deriva }\end{array}$ \\
\hline Erro & $-13,0 \%$ & $-1,1$ nós & $80,2 \% \mathrm{~min}$ & $20,4^{\circ}$ \\
\hline
\end{tabular}

Fonte: Autor.

A Figura 41 mostra uma maior discrepância para a transferência e diâmetro tático, observa-se também que o erro para estas duas medidas apresenta mesma ordem de grandeza, embora proporcionalmente o erro da transferência seja maior. A Figura 42 mostra que houve para a simulação um comportamento mais amortecido para a velocidade de avanço, e maior resistência à deriva, resultando em uma menor velocidade transversal.

Figura 41 - Trajetória varrida, manobra 2 em águas rasas

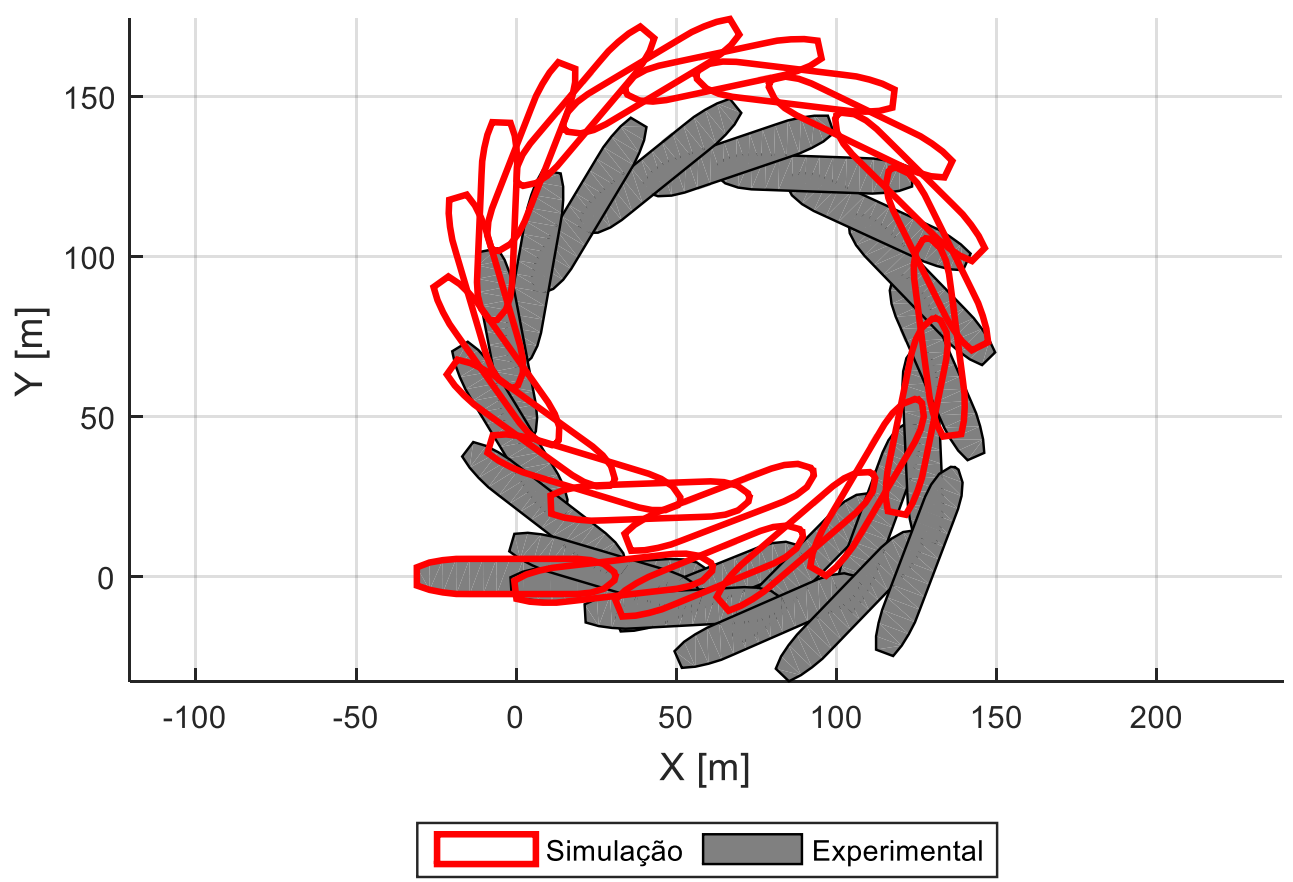

Fonte: Autor. 
Figura 42 - Gráficos de ângulo de deriva, velocidade angular ,velocidade Vx, velocidade Vy, manobra 2 em águas rasas
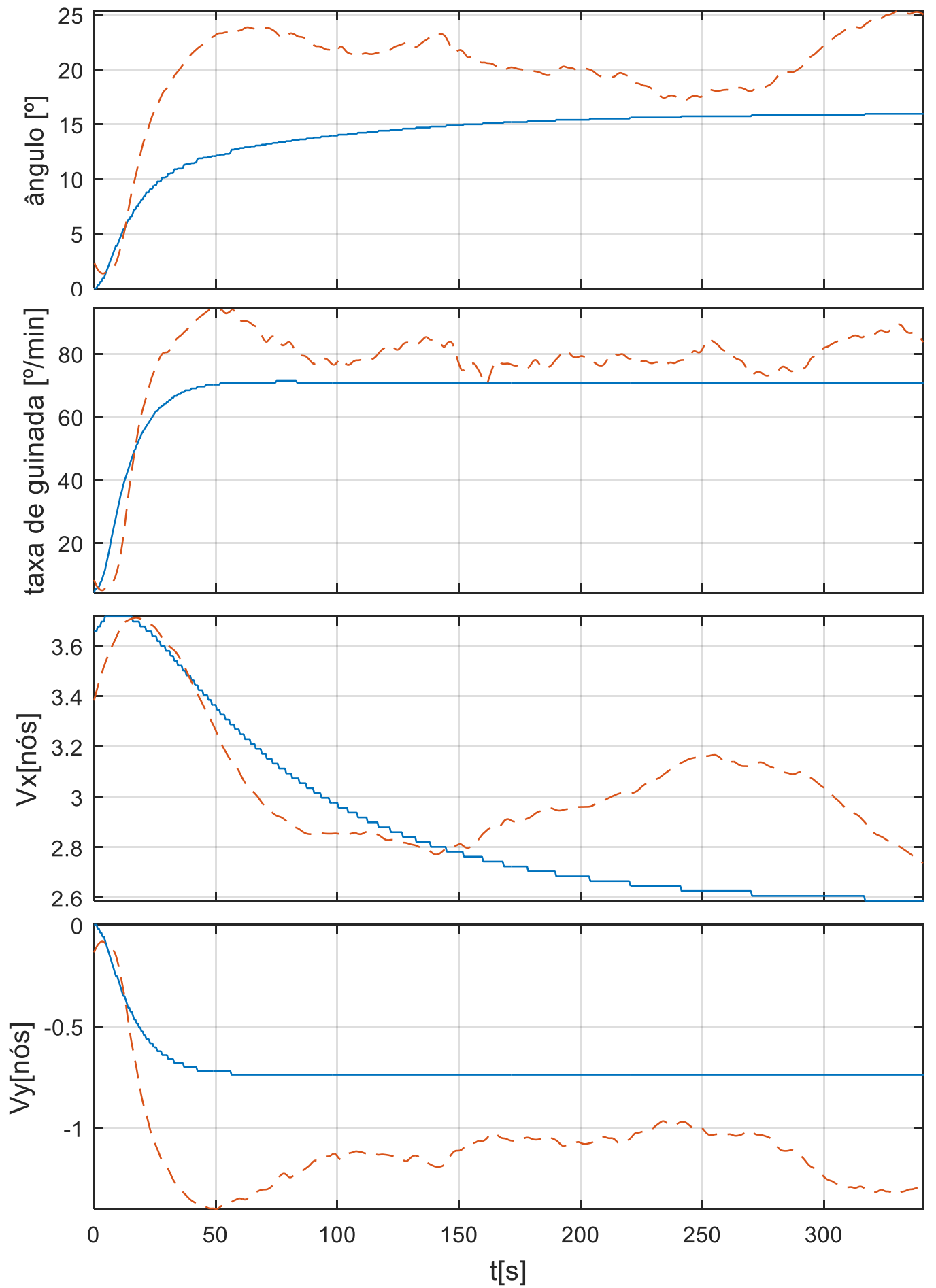

Fonte: Autor.

Simulação - - - Experimental 


\subsection{Initial turning test}

Esta manobra mede a capacidade do navio mudar seu aproamento a partir do uso do leme, não necessariamente em sua posição máxima. Para a execução dessa manobra o navio deve estar navegando com velocidade longitudinal estável, e velocidade angular nula, o leme é então posicionado a 10 ou 20 graus, conforme a especificação da manobra, é então medida a distância percorrida pelo navio até que seu aproamento mude respectivamente a mesma quantidade em graus que o leme foi posicionado, como exemplificado na Figura 43.

Os dados para essa manobra são coletados no início da manobra de zig-zag, por esse motivo usualmente são utilizados os ângulos de 10 e 20 graus.

Figura 43 - Resultados obtidos em uma manobra de Initial turning test. Distância fora de escala

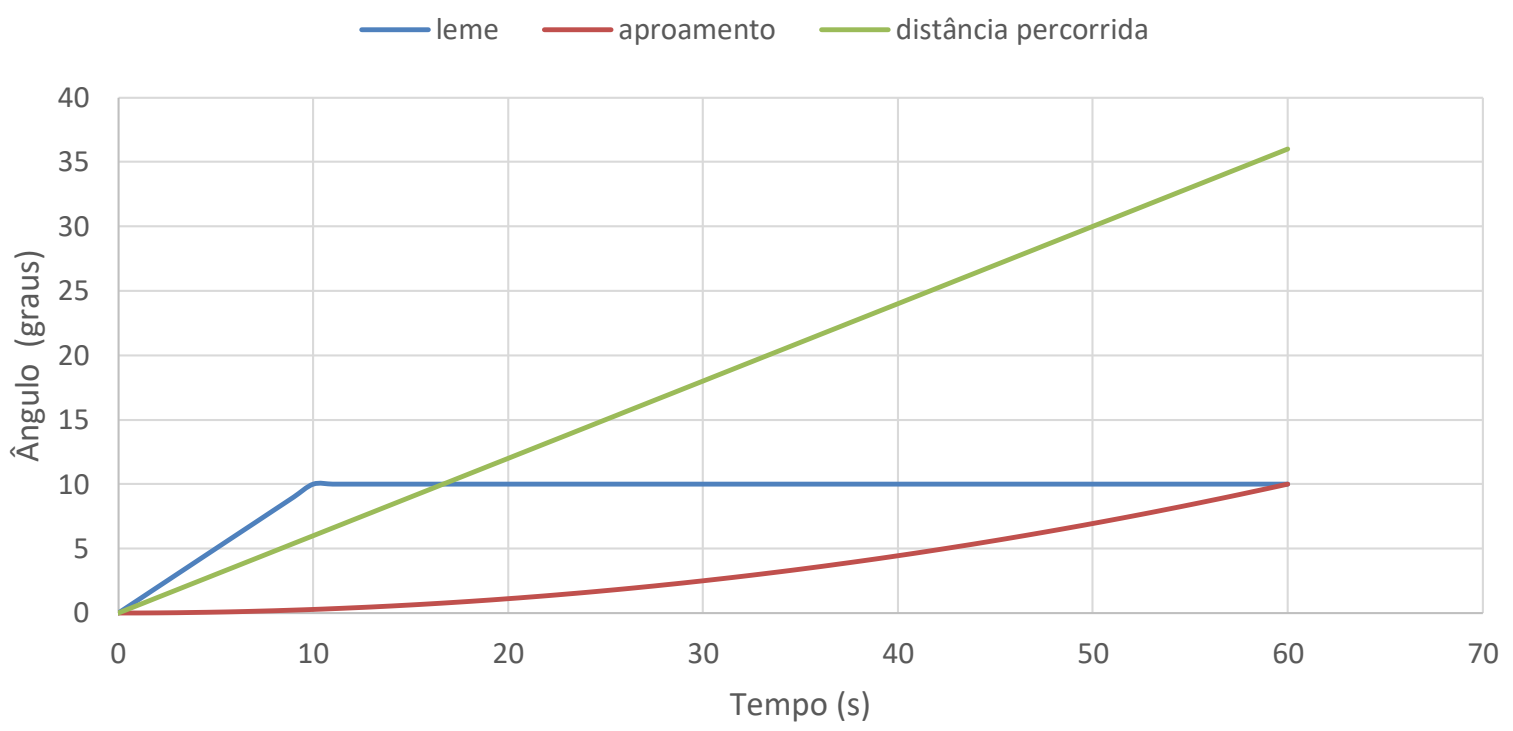

Fonte: Autor.

Esta manobra aponta a relação entre distância percorrida com o ângulo da guinada (Rating $=l_{10 / 20} / \alpha$ ) sendo melhor a capacidade de guinada do navio quanto menores as distâncias percorridas. O termo $l_{10 / 20}$ representa a distância percorrida e $\alpha$ representa o ângulo de guinada utilizado (10 ou 20 graus).

Para esse trabalho foram realizadas manobras de initial turning test com as ordens de máquina de devagar e meia força (1050 RPM e 500 RPM respectivamente), e os ângulos de leme de $10^{\circ}$ e $20^{\circ}$. 
Nos resultados, é apresentado para cada manobra o Rating $=l_{10 / 20} / \alpha$ obtido, conforme indicado pela ABS (2006). O rating máximo permitido é de 16.

Por esta manobra não ser realizada no início de um teste de zig-zag e por limitação do aparato experimental, que não era capaz de informar a mudança de aproamento em tempo real, usou-se como ângulo para término do teste o ângulo de $45^{\circ}$ e não $10^{\circ}$ ou $20^{\circ}$ como sugerido para a manobra padrão, o ângulo final foi observado através de marcações no tanque que permitiram a navegação visual.

\subsubsection{Manobra 3}

Nessa manobra foi realizado o initial turning test com máquina meia força avante (1050 RPM), com leme de 20‥ A Tabela 13 apresenta os dados táticos obtidos:

Tabela 13 - Dados táticos obtidos para a manobra 3 (convertidos para escala real)

Fonte: Autor.

\begin{tabular}{|l|c|c|l|}
\hline & Distância 20 & $\begin{array}{l}\text { Distância } \\
\text { máxima (IMO) }\end{array}$ & Rating 20 $^{\mathbf{0}}$ \\
\hline Experimental & $58,3 \mathrm{~m}(0,9 \mathrm{~L})$ & $126,00 \mathrm{~m}(2,0 \mathrm{~L})$ & $2,9 \mathrm{~m} /{ }^{\circ}$ \\
\hline Simulado & $77,1 \mathrm{~m}(1,2 \mathrm{~L})$ & $126,00 \mathrm{~m}(2,0 \mathrm{~L})$ & $3,9 \mathrm{~m} /{ }^{\circ}$ \\
\hline Erro & & $32,3 \%$ & \\
\hline
\end{tabular}

A Figura 44 mostra trajetórias similares para ambos modelos, enquanto a Figura 46 mostra uma capacidade de guinada compatível durante toda a execução da manobra. Porém o modelo numérico apresenta menor ângulo de deriva do que o modelo experimental, como pode ser visto na Figura 45. 
Figura 44 - Trajetória varrida, manobra 3

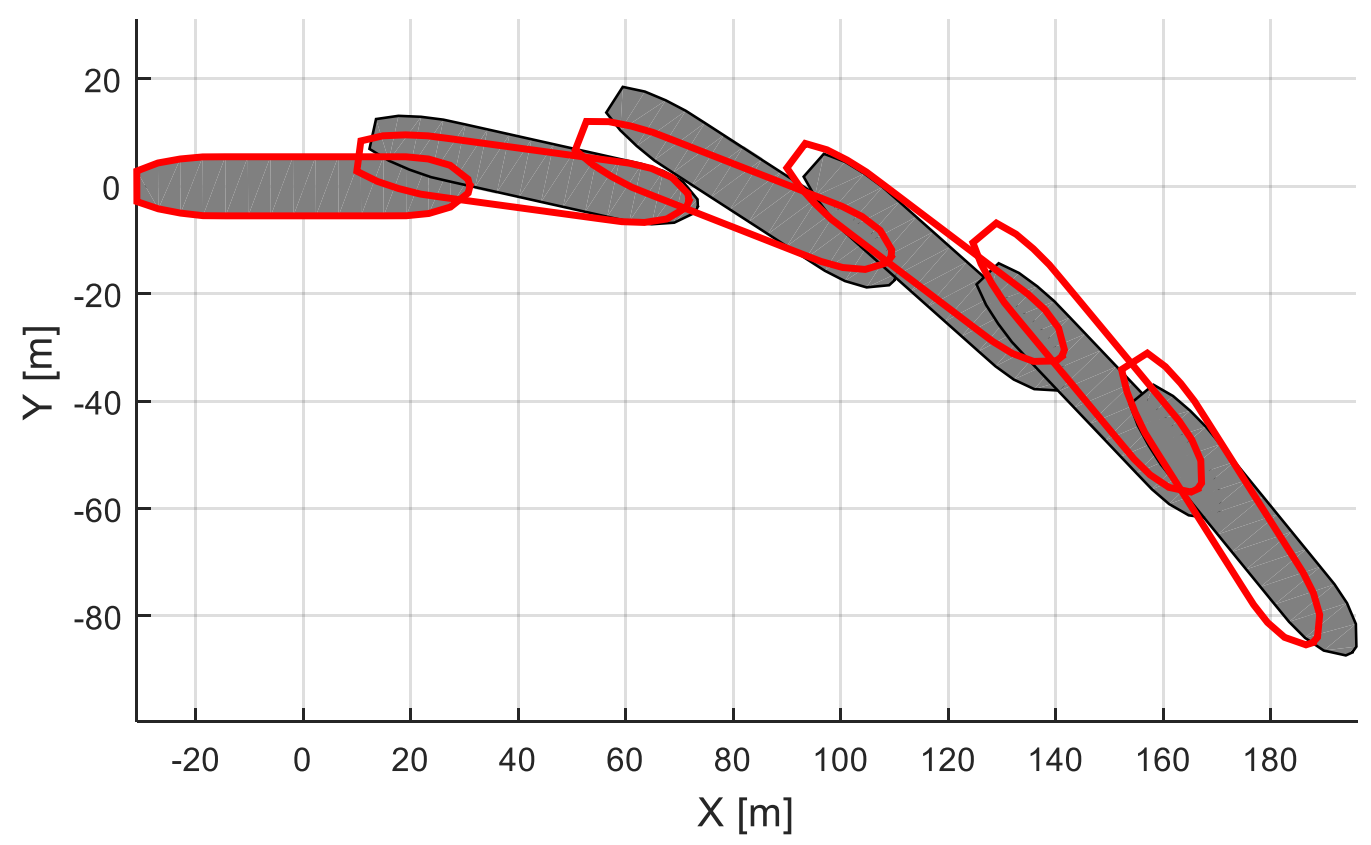

Fonte: Autor.

Figura 45 - Aproamento, Ângulo de deriva, manobra 3

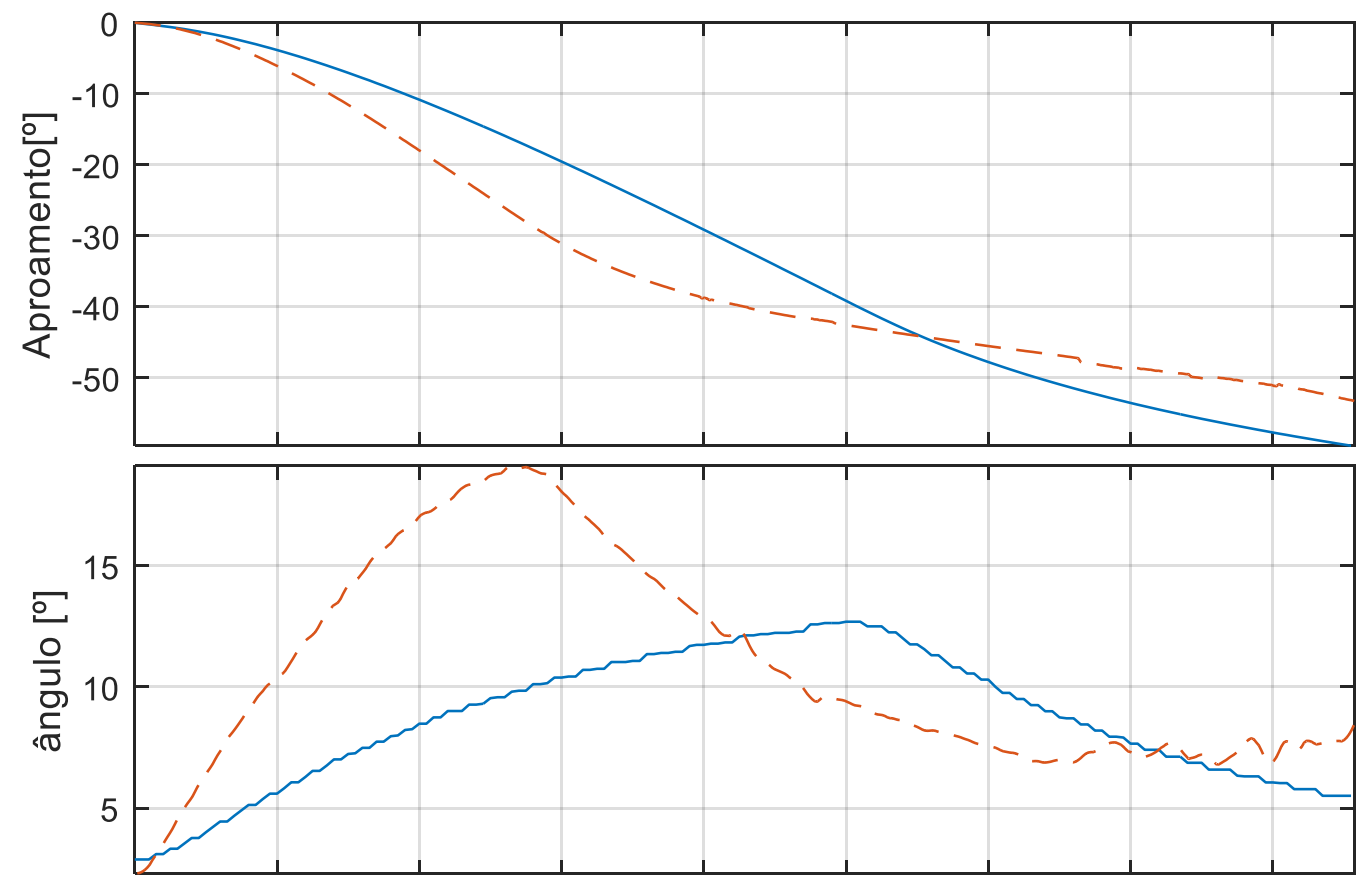

Fonte: Autor. 
Figura 46 - Distância percorrida, Rating por ângulo de guinada, manobra 3

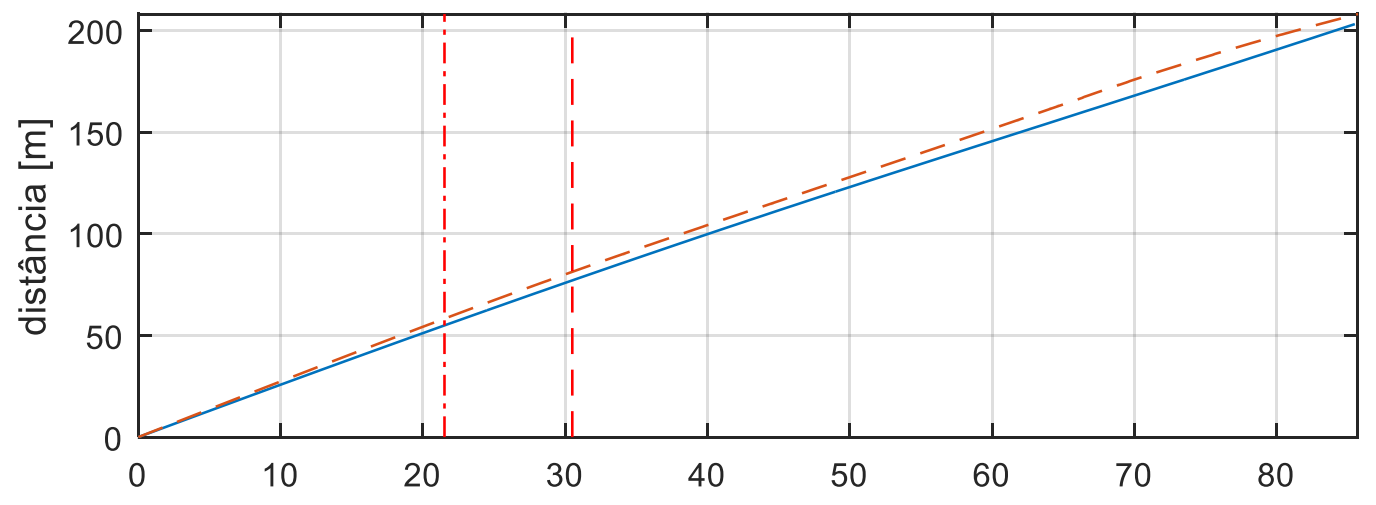

$\mathrm{t}[\mathrm{s}]$

Simulação - - - Experimental -- - Tempo simulação $-\cdot-\cdot-$ Tempo experimental

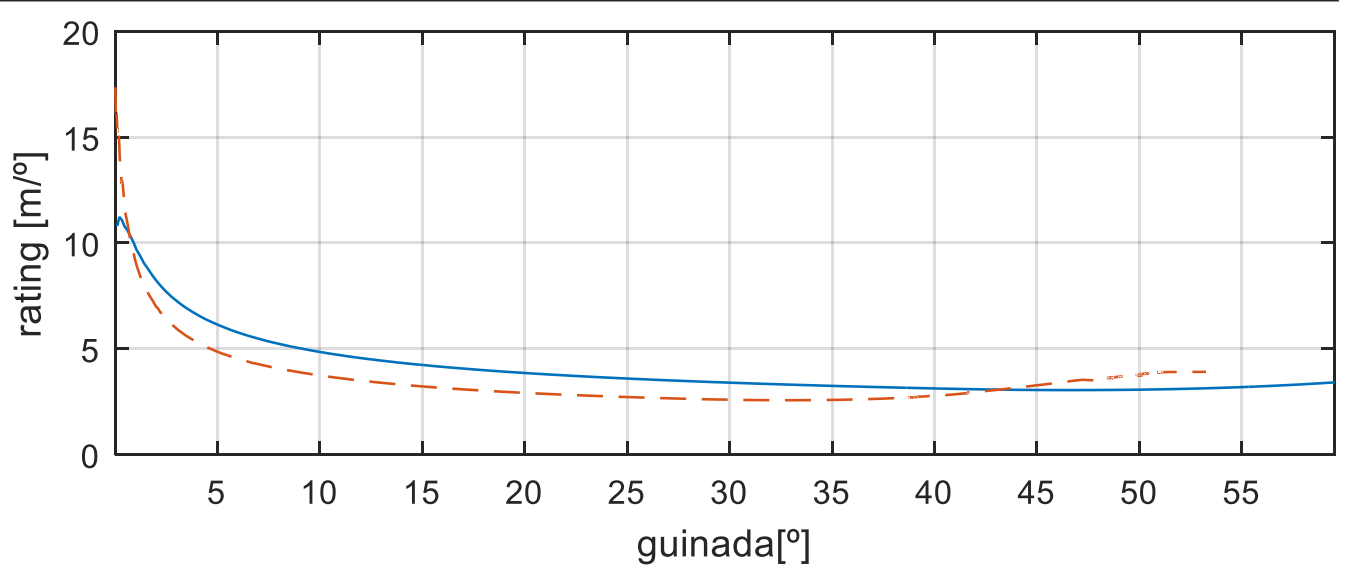

Fonte: Autor. 


\subsubsection{Manobra 4}

Nessa manobra foi realizado o initial turning test com máquina meia força avante (1050 RPM), com leme de 10‥ A Tabela 14 apresenta os dados táticos obtidos:

Tabela 14 - Dados táticos obtidos para a manobra 4

\begin{tabular}{|l|c|l|l|}
\hline & Distância $\mathbf{1 0}^{\mathbf{o}}$ & $\begin{array}{l}\text { Distância } \\
\text { máxima (IMO) }\end{array}$ & ${\text { Rating } \mathbf{1 0}^{\mathbf{o}}}$ \\
\hline Experimental & $89,9 \mathrm{~m}(1,4 \mathrm{~L})$ & $157,50 \mathrm{~m}(2,5 \mathrm{~L})$ & $9,0 \mathrm{~m} /{ }^{\circ}$ \\
\hline Simulado & $60,5 \mathrm{~m}(1,0 \mathrm{~L})$ & $157,50 \mathrm{~m}(2,5 \mathrm{~L})$ & $6,0 \mathrm{~m} /{ }^{\circ}$ \\
\hline Erro & & $-32,8 \%$ & \\
\hline
\end{tabular}

Fonte: Autor.

A Figura 47 mostra que no início da manobra ambos modelos apresentam comportamento similar, havendo maior diferença nas posições ao término da manobra. A Figura 48 mostra que o modelo numérico apresenta resposta mais rápida no início da manobra, demonstrando maior capacidade de mudar seu aproamento, porém ao término da manobra ambos os modelos apresentam a mesma classificação de $5 \mathrm{~m} /{ }^{\circ}$.

Figura 47 - Trajetória varrida, manobra 4

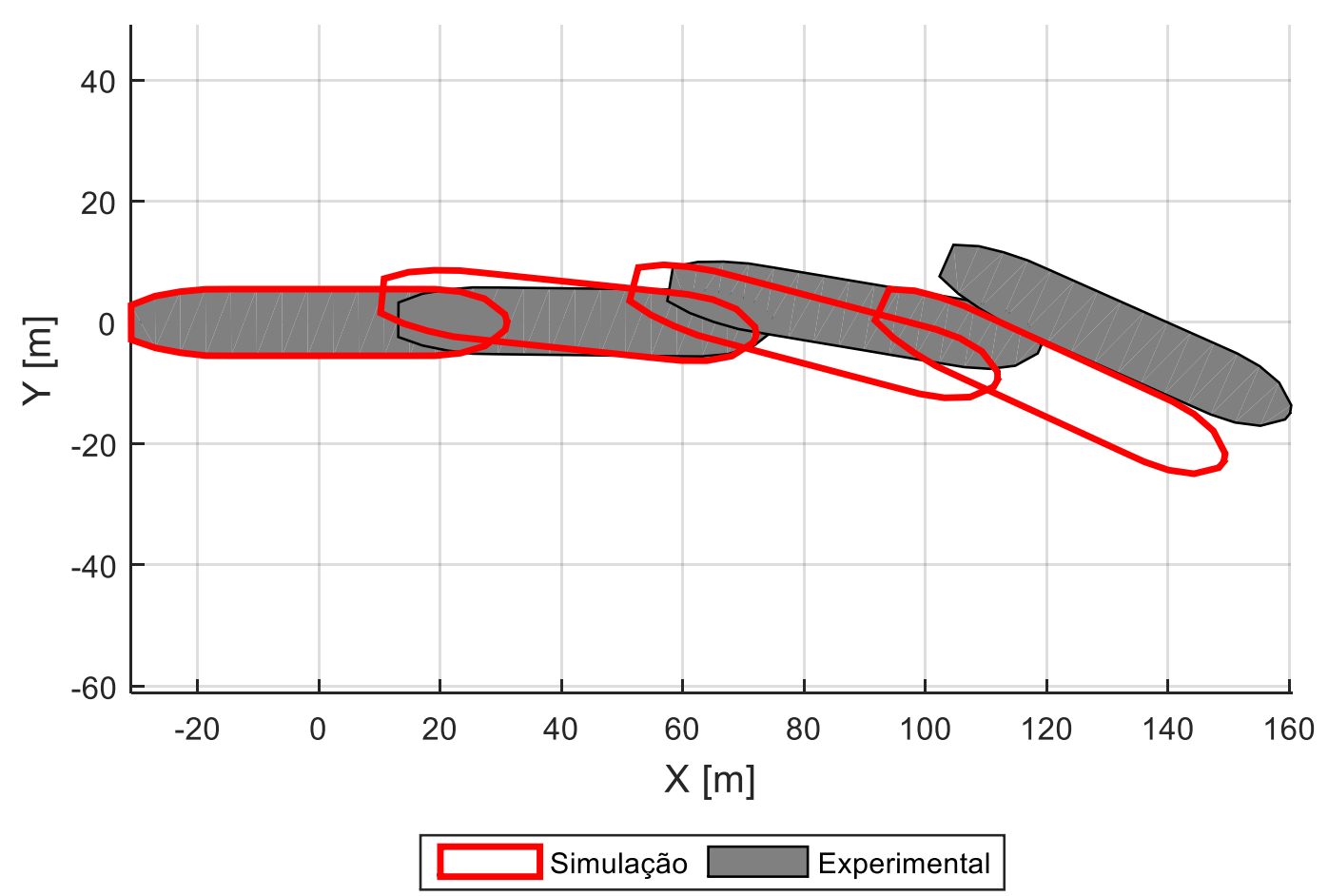

Fonte: Autor. 
Figura 48 - Aproamento, Ângulo de deriva, Distância percorrida, Rating por ângulo de guinada, manobra 4
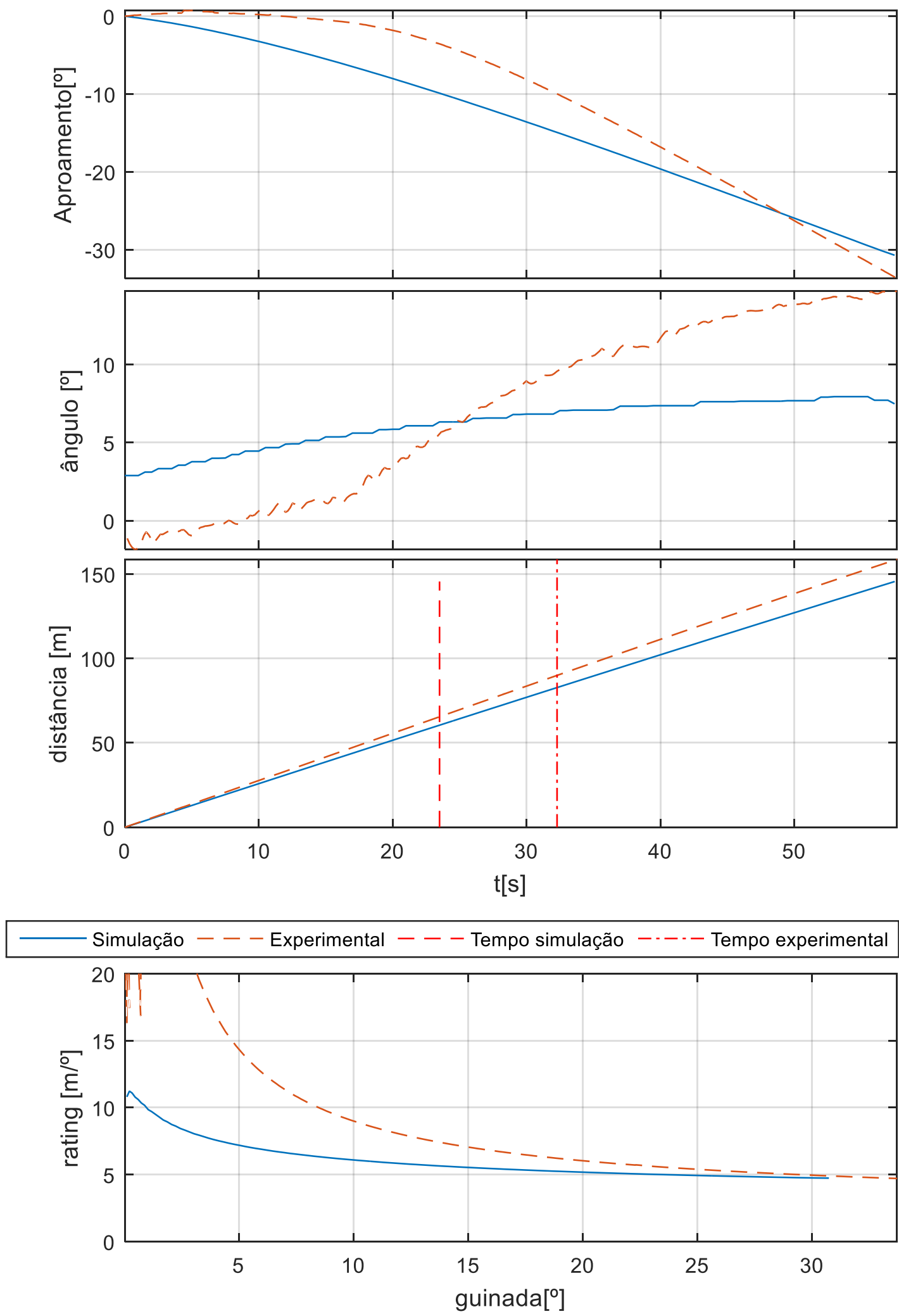

Fonte: Autor. 


\subsubsection{Manobra 5}

Nessa manobra foi realizado o initial turning test com máquina meia força avante (500 RPM), com leme de 20․ A Tabela 15 apresenta os dados táticos obtidos:

Tabela 15 - Dados táticos obtidos para a manobra 5

\begin{tabular}{|l|l|l|l|}
\hline & Distância 20 & $\begin{array}{l}\text { Distância } \\
\text { máxima (IMO) }\end{array}$ & Rating 20 $^{\mathbf{o}}$ \\
\hline Experimental & $70,2 \mathrm{~m}(1,1 \mathrm{~L})$ & $126,00 \mathrm{~m}(2,0 \mathrm{~L})$ & $3,5 \mathrm{~m} /{ }^{\circ}$ \\
\hline Simulado & $84,2 \mathrm{~m}(1,3 \mathrm{~L})$ & $126,00 \mathrm{~m}(2,0 \mathrm{~L})$ & $4,2 \mathrm{~m} /{ }^{\circ}$ \\
\hline Erro & & $20,0 \%$ \\
\hline
\end{tabular}

Fonte: Autor.

A Figura 49 demonstra uma trajetória compatível para os dois modelos, sendo o deslocamento da popa da embarcação mais proeminente na manobra experimental. A Figura 50 mostra um comportamento mais amortecido para o ângulo de deriva do modelo numérico, porém os dois modelos apresentaram um rating similar durante toda a manobra.

Figura 49 - Trajetória varrida, manobra 5

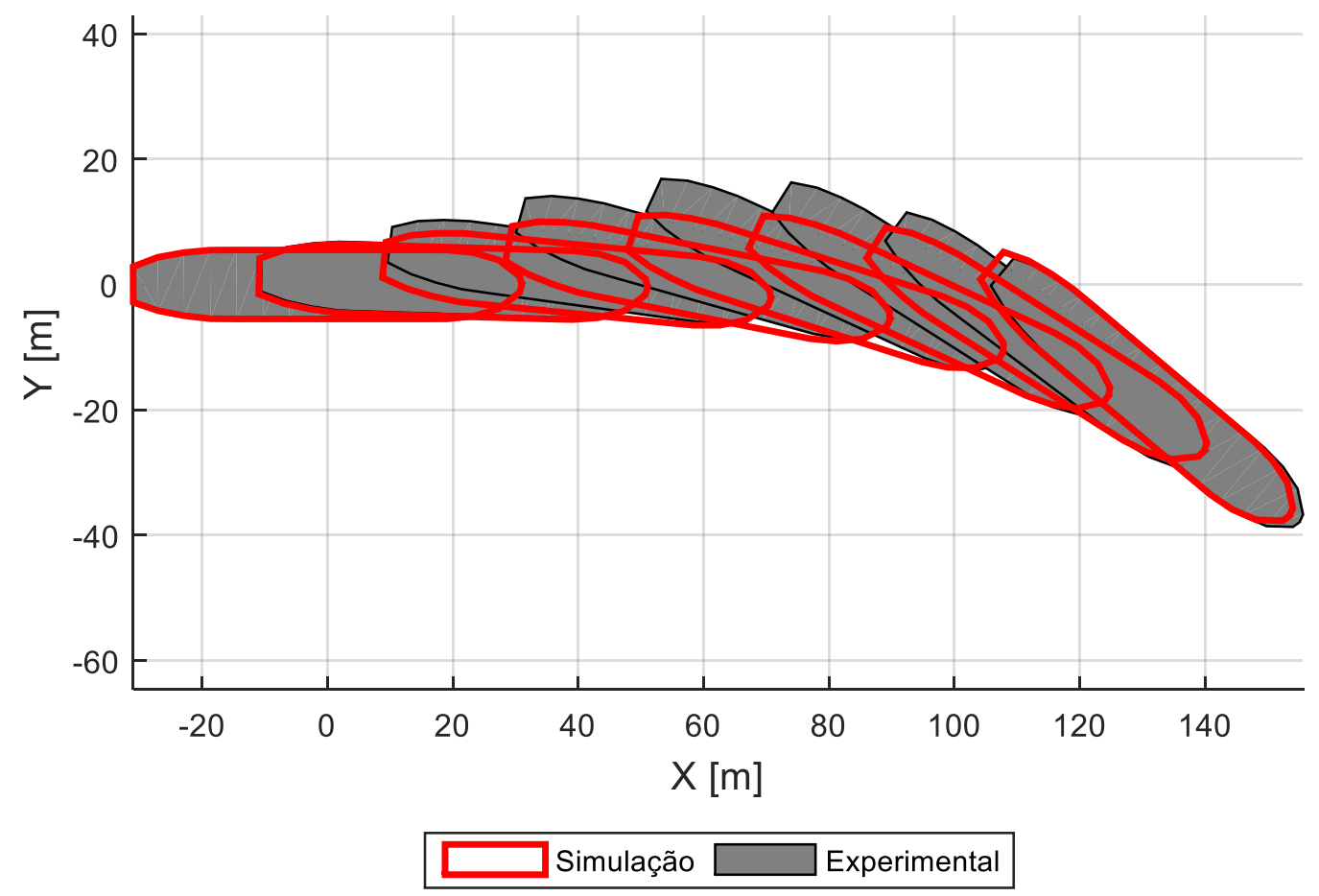

Fonte: Autor. 
Figura 50 - Aproamento, Ângulo de deriva, Distância percorrida, Rating por ângulo de guinada, manobra 5
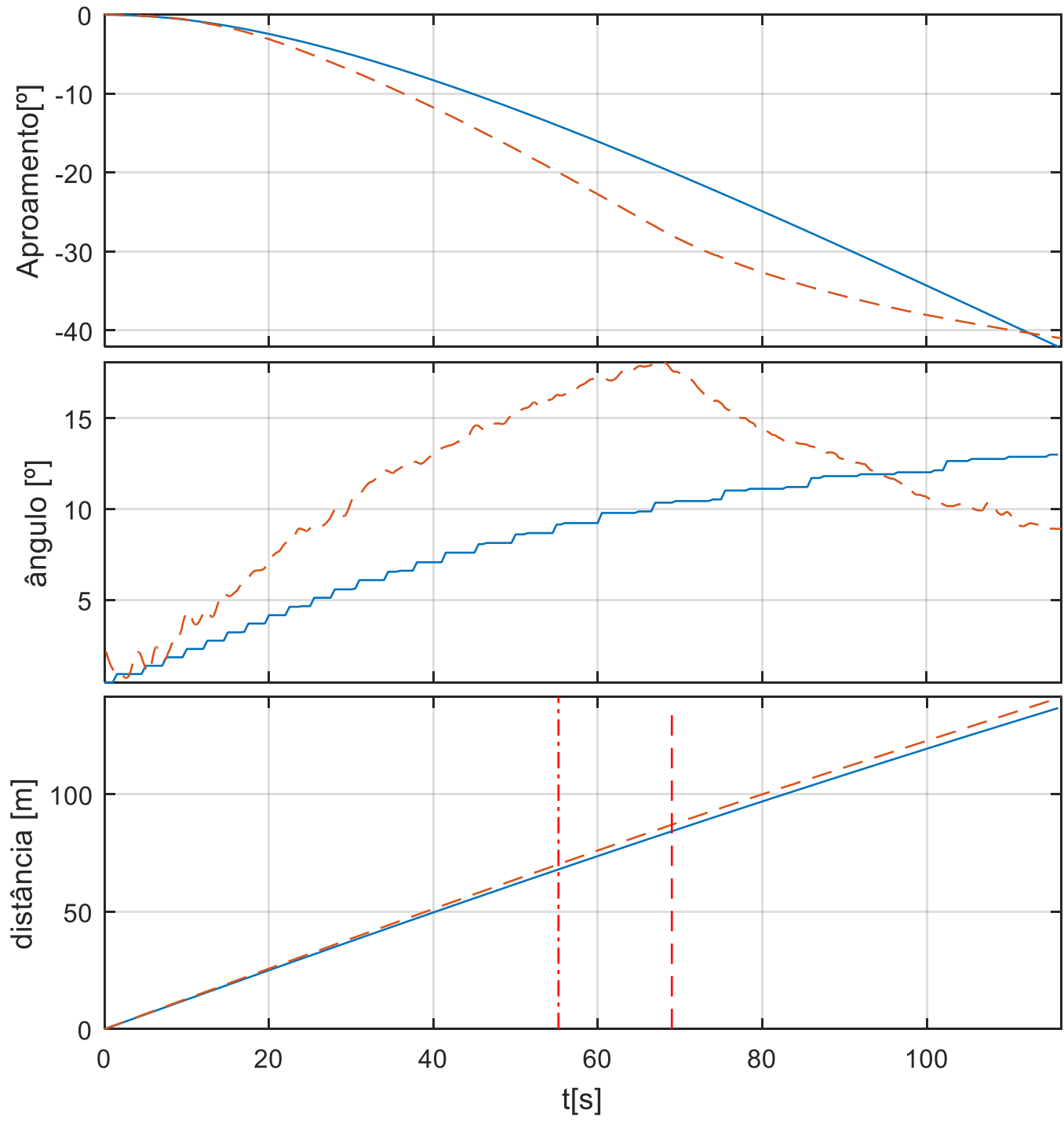

- Simulação --- Experimental --- Tempo simulação $-\cdot-\cdot-$ Tempo experimental

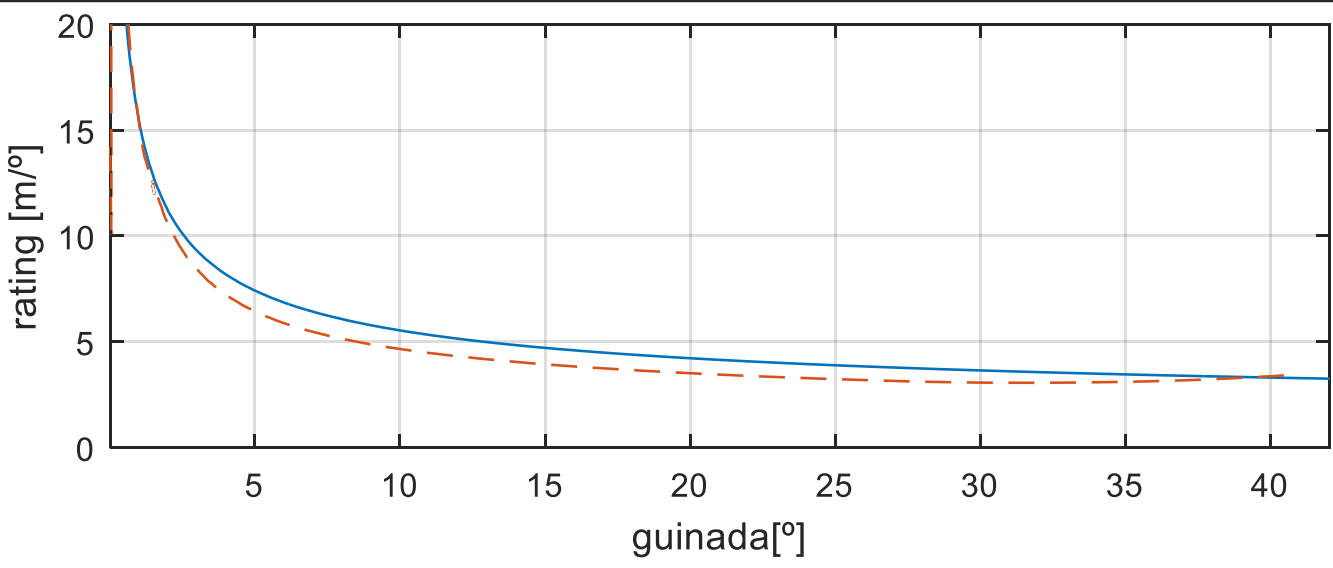

Fonte: Autor.

Simulação - - Experimental 


\subsubsection{Manobra 6}

Nessa manobra foi realizado o initial turning test com máquina meia força avante (500 RPM), com leme de 10․ A Tabela 16 apresenta os dados táticos obtidos:

Tabela 16 - Dados táticos obtidos para a manobra 6

\begin{tabular}{|l|c|l|l|}
\hline & Distância 10 & $\begin{array}{l}\text { Distância } \\
\text { máxima (IMO) }\end{array}$ & Rating $\mathbf{1 0}^{\mathbf{o}}$ \\
\hline Experimental & $59,8 \mathrm{~m}(1,0 \mathrm{~L})$ & $157,50 \mathrm{~m}(2,5 \mathrm{~L})$ & $6,0 \mathrm{~m} /{ }^{\circ}$ \\
\hline Simulado & $74,8 \mathrm{~m}(1,1 \mathrm{~L})$ & $157,50 \mathrm{~m}(2,5 \mathrm{~L})$ & $7,5 \mathrm{~m} /{ }^{\circ}$ \\
\hline Erro & & $25,1 \%$ \\
\hline
\end{tabular}

Fonte: Autor.

Embora a Figura 51 mostre que ambos os modelos descreveram trajetórias quase idênticas nesta manobra, a Figura 52 mostra que o modelo numérico se mostrou menos manobrável, experimentando menor variação do aproamento e um rating maior do que o modelo experimental.

Figura 51 - Trajetória varrida, manobra 6
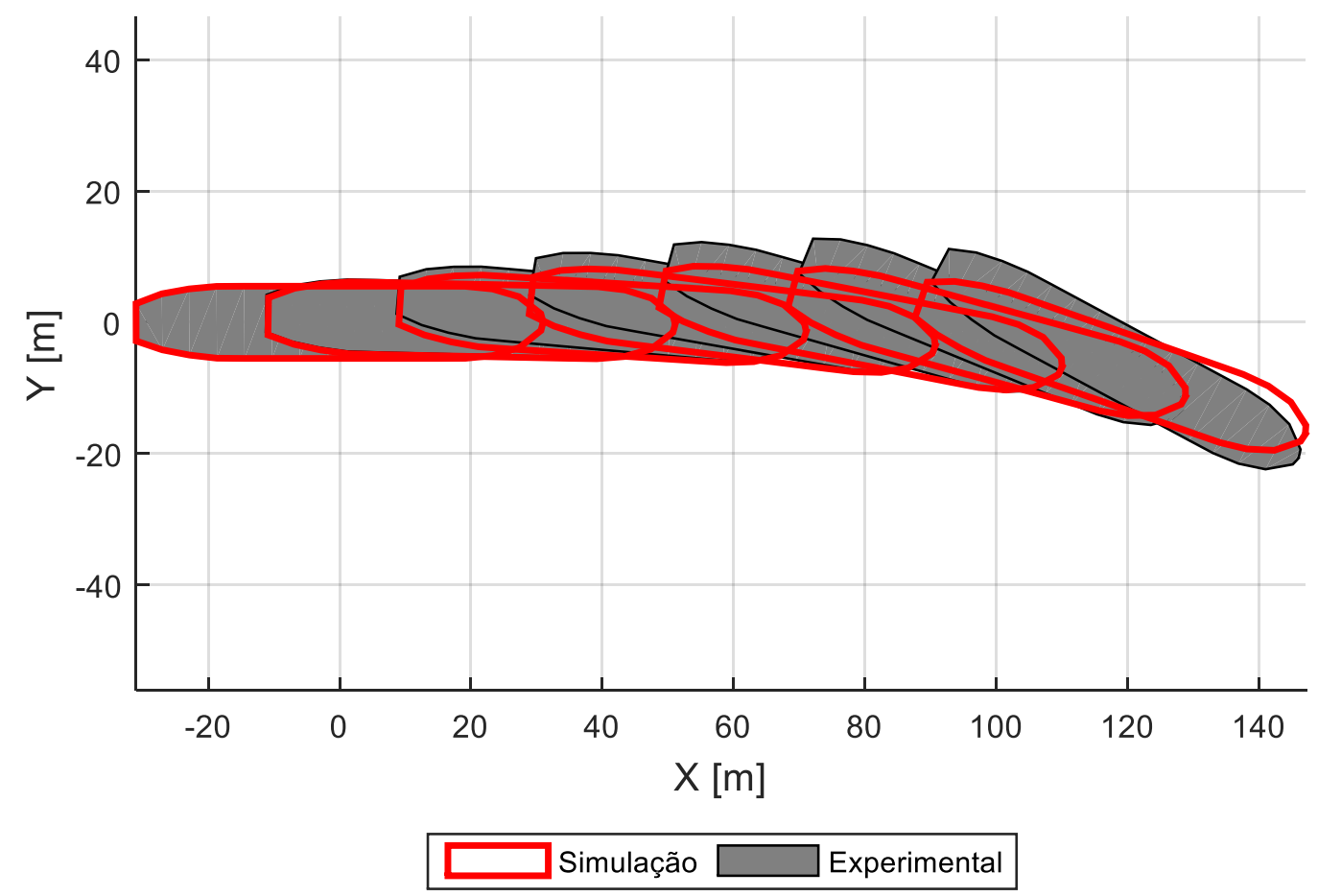

Fonte: Autor. 
Figura 52 - Aproamento, Ângulo de deriva, Distância percorrida, Rating por ângulo de guinada, manobra 6
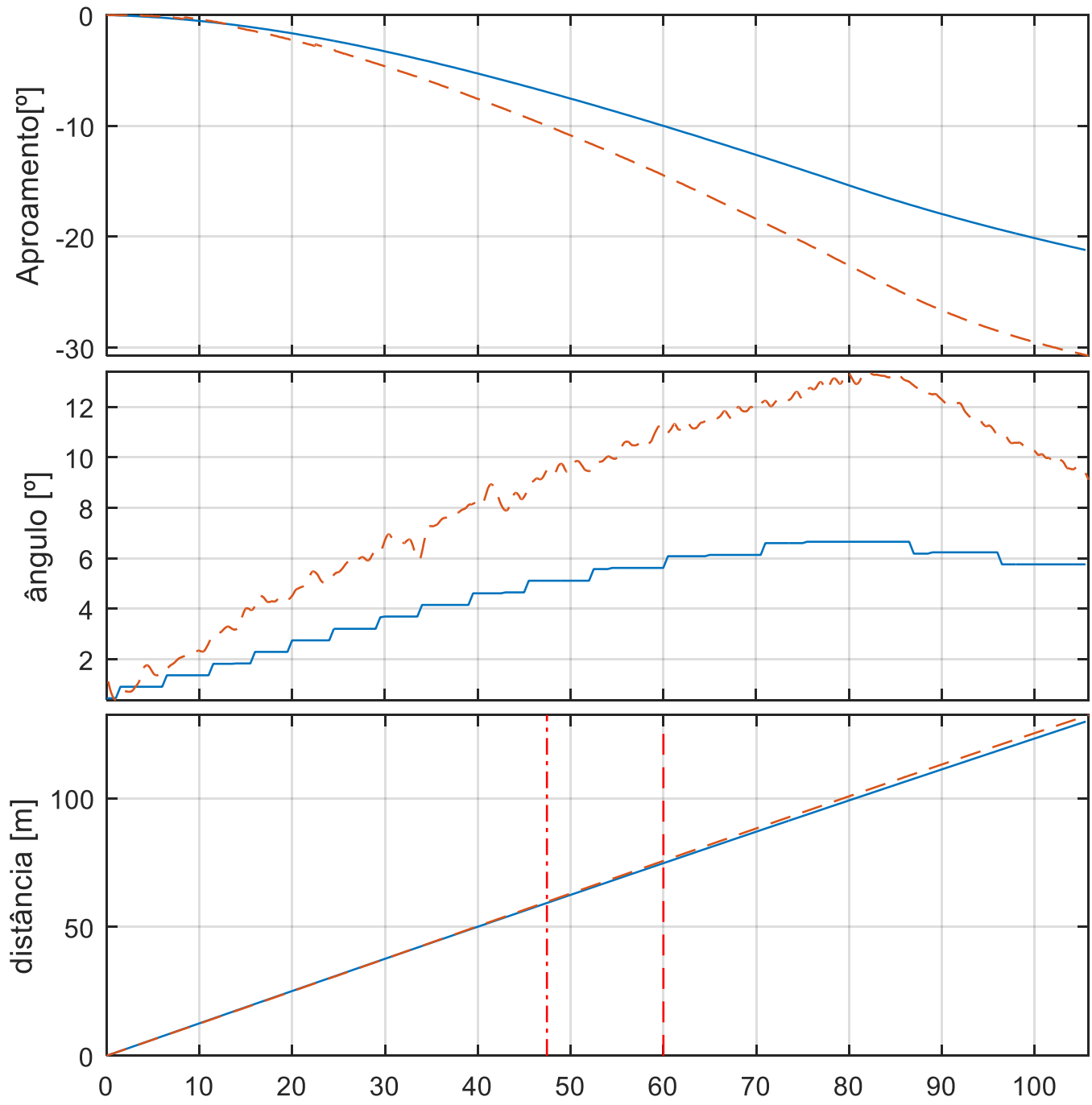

$\mathrm{t}[\mathrm{s}]$

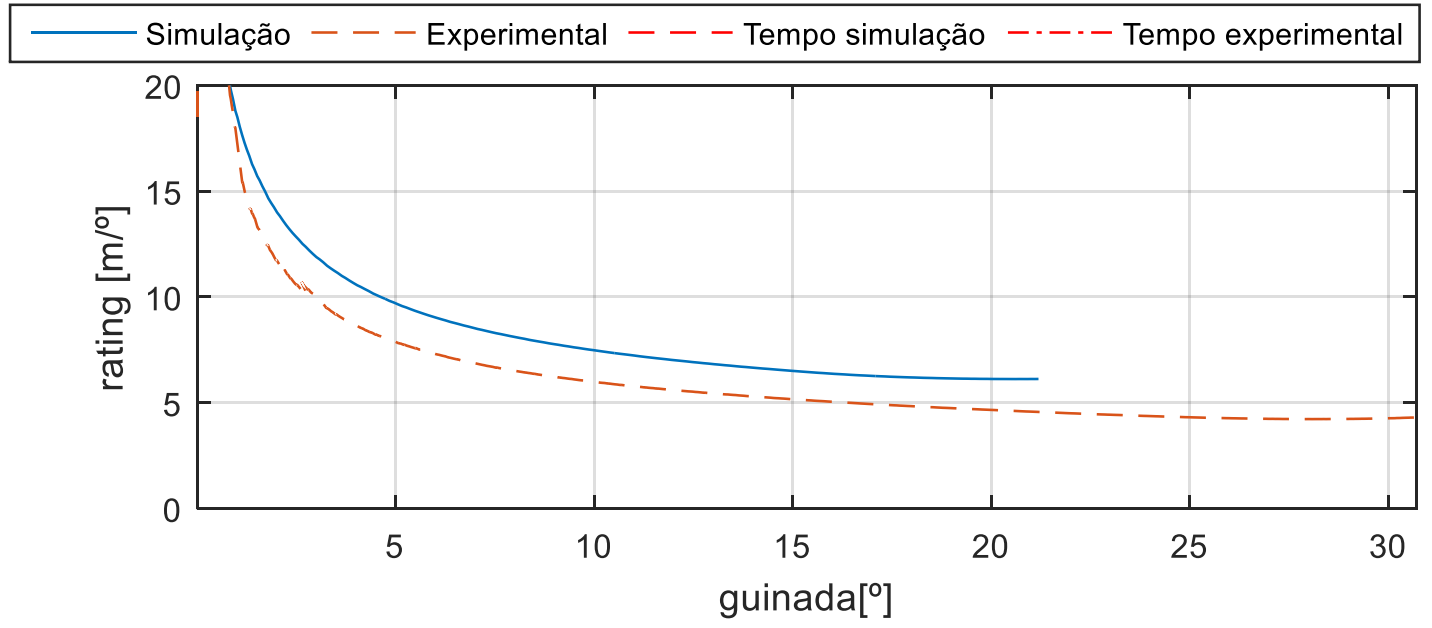

Fonte: Autor.

Simulação - - Experimental 
6.2.5. Manobra 3 - águas rasas

Nessa manobra foi realizado o initial turning test com máquina meia força avante (1050 RPM), com leme de 20․ A Tabela 17 apresenta os dados táticos obtidos:

Tabela 17 - Dados táticos obtidos para a manobra 3 em águas rasas

\begin{tabular}{|l|l|l|l|}
\hline & Distância 20 & $\begin{array}{l}\text { Distância } \\
\text { máxima (IMO) }\end{array}$ & Rating 20 $^{\mathbf{o}}$ \\
\hline Experimental & $56,1 \mathrm{~m}(0,9 \mathrm{~L})$ & $126,00 \mathrm{~m}(2,0 \mathrm{~L})$ & $2,8 \mathrm{~m} /{ }^{\circ}$ \\
\hline Simulado & $71,8 \mathrm{~m}(1,1 \mathrm{~L})$ & $126,00 \mathrm{~m}(2,0 \mathrm{~L})$ & $3,6 \mathrm{~m} /{ }^{\circ}$ \\
\hline Erro & & $28,0 \%$ \\
\hline
\end{tabular}

Fonte: Autor.

A Figura 54 mostra que o modelo em escala reduzida apresentou uma capacidade de guinada maior do que o modelo numérico, embora haja pouca diferença entre os resultados obtidos para o rating desta manobra. A Figura 53 indica que o centro do modelo em escala reduzida mantém sua trajetória por mais tempo, indicando que há maior resistência ao movimento de deriva no modelo numérico, em relação ao modelo experimental.

Figura 53 - Trajetória varrida, manobra 3

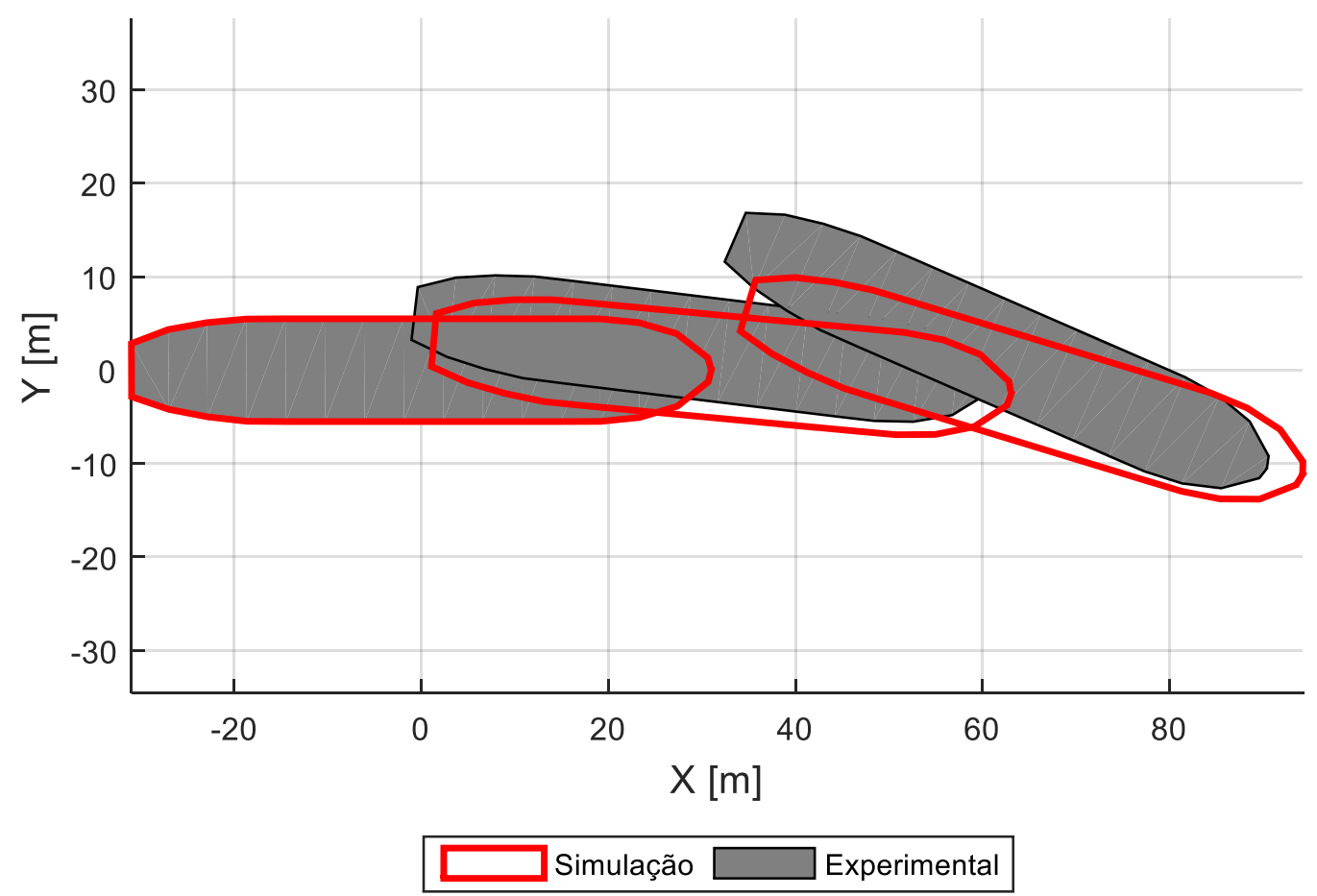

Fonte: Autor. 
Figura 54 - Aproamento, Ângulo de deriva, Distância percorrida, Rating por ângulo de guinada, manobra 3
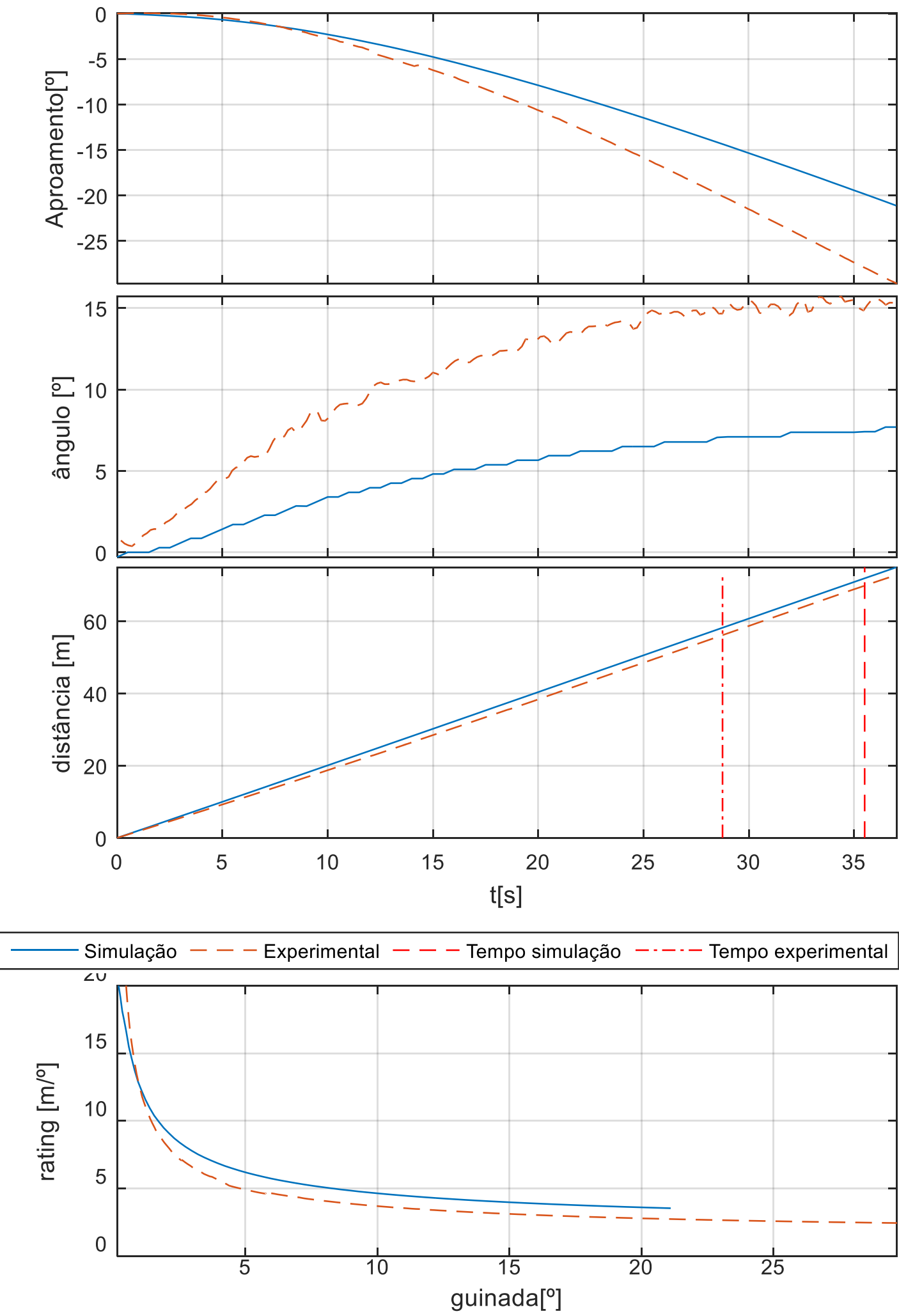

Fonte: Autor. 
6.2.6. Manobra 4 - águas rasas

Nessa manobra foi realizado o initial turning test com máquina meia força avante (1050 RPM), com leme de 10․ A Tabela 18 apresenta os dados táticos obtidos:

Tabela 18 - Dados táticos obtidos para a manobra 4 em águas rasas

\begin{tabular}{|l|l|l|l|}
\hline & Distância 10 & $\begin{array}{l}\text { Distância } \\
\text { máxima (IMO) }\end{array}$ & ${\text { Rating } \mathbf{1 0}^{\mathbf{o}}}$ \\
\hline Experimental & $77,6 \mathrm{~m}(1,2 \mathrm{~L})$ & $157,50 \mathrm{~m}(2,5 \mathrm{~L})$ & $7,8 \mathrm{~m} /{ }^{\circ}$ \\
\hline Simulado & $64,9 \mathrm{~m}(1,0 \mathrm{~L})$ & $157,50 \mathrm{~m}(2,5 \mathrm{~L})$ & $6,5 \mathrm{~m} /{ }^{\circ}$ \\
\hline Erro & & $16,3 \%$ \\
\hline
\end{tabular}

Fonte: Autor.

A Figura 55 mostra uma trajetória não esperada para o modelo experimental, apresentando uma deriva para a esquerda da embarcação. Porém, a Figura 56 mostra um comportamento do modelo matemático compatível com as demais manobras deste tipo, indicando uma capacidade de guinada ligeiramente menor do que a mesma manobra realizada em águas profundas.

Figura 55 - Trajetória varrida, manobra 4

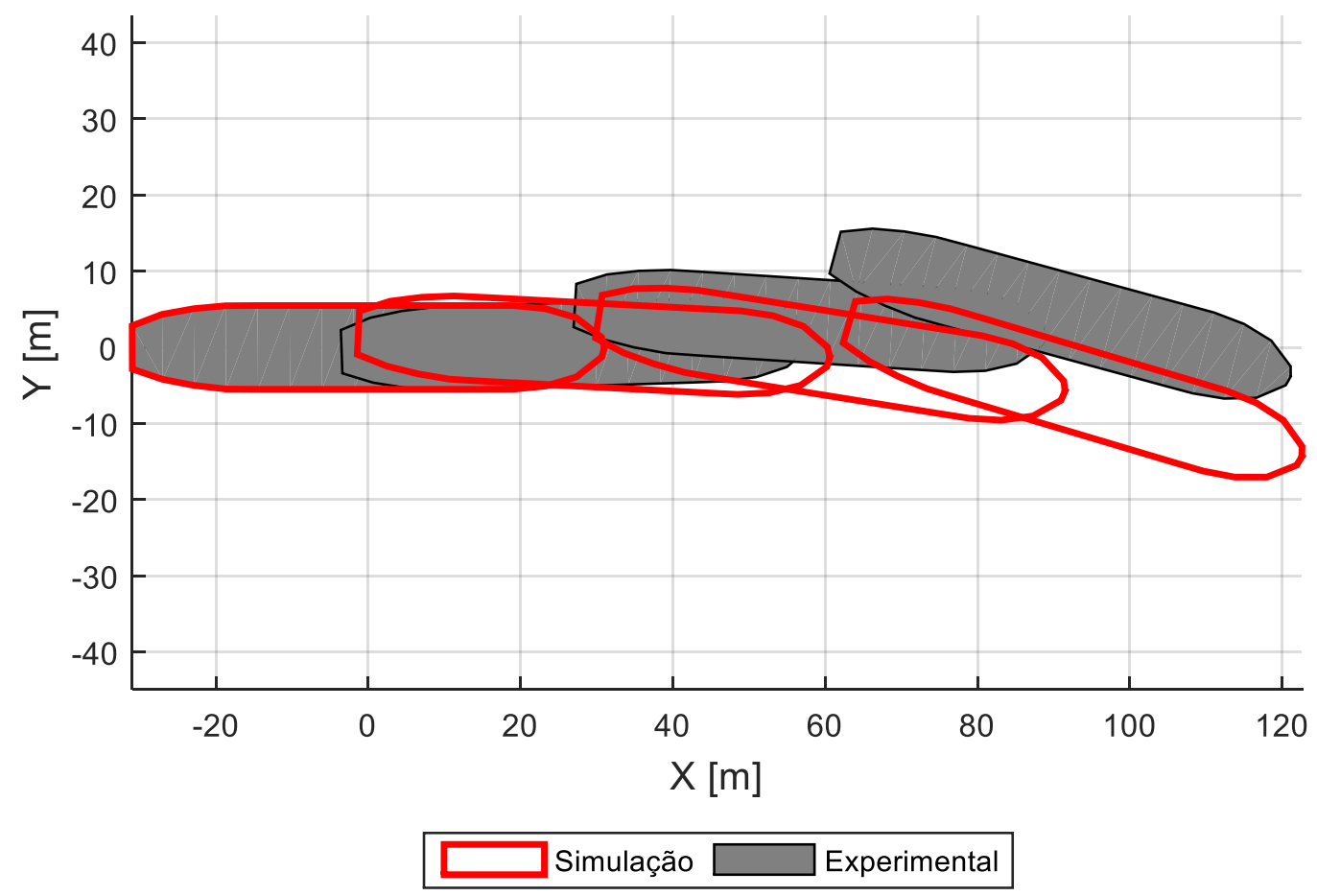

Fonte: Autor. 
Figura 56 - Aproamento, Ângulo de deriva, Distância percorrida, Rating por ângulo de guinada, manobra 4
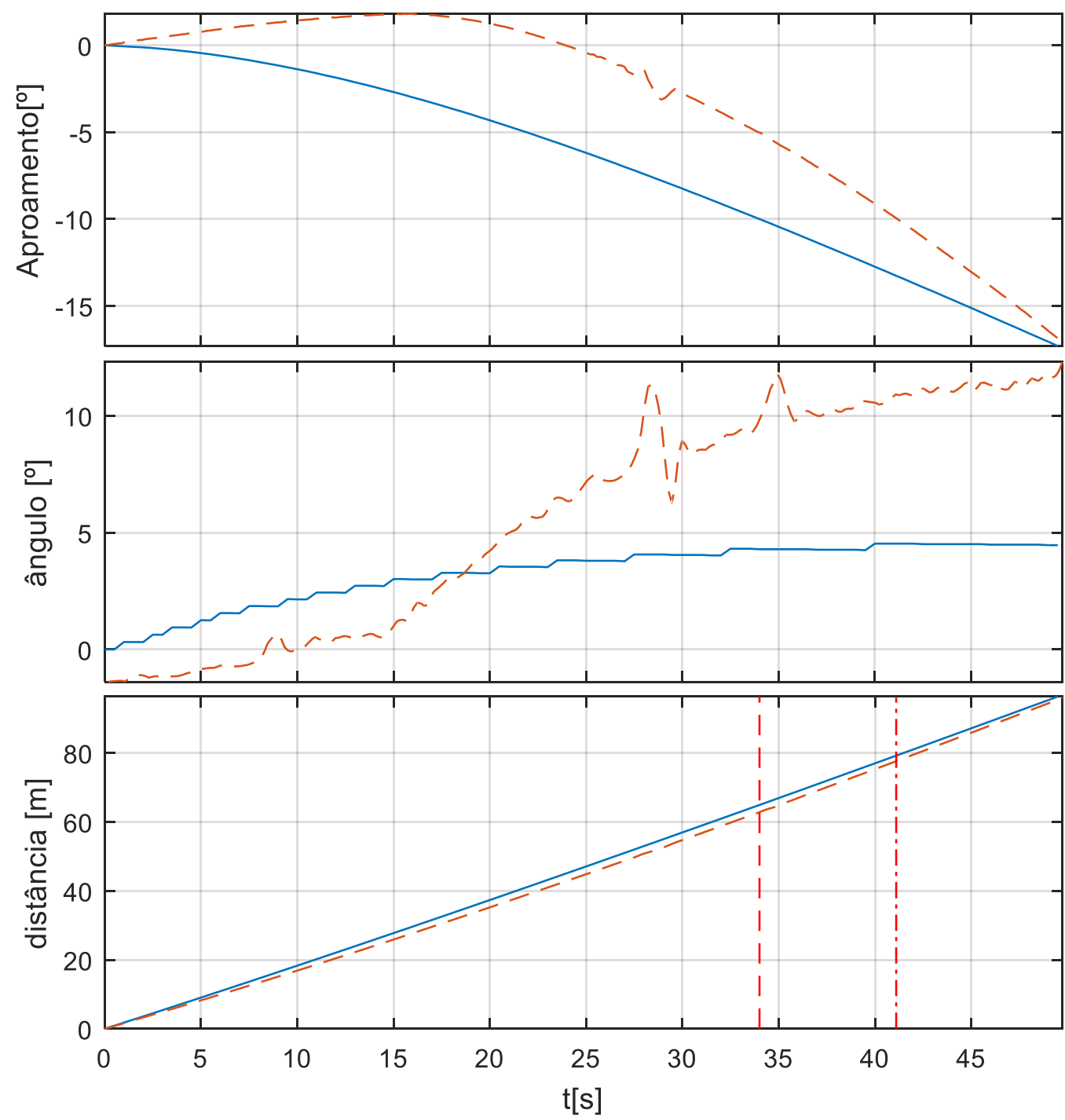

- Simulação --- Experimental --- Tempo simulação $-\cdot-\cdot-$ Tempo experimental

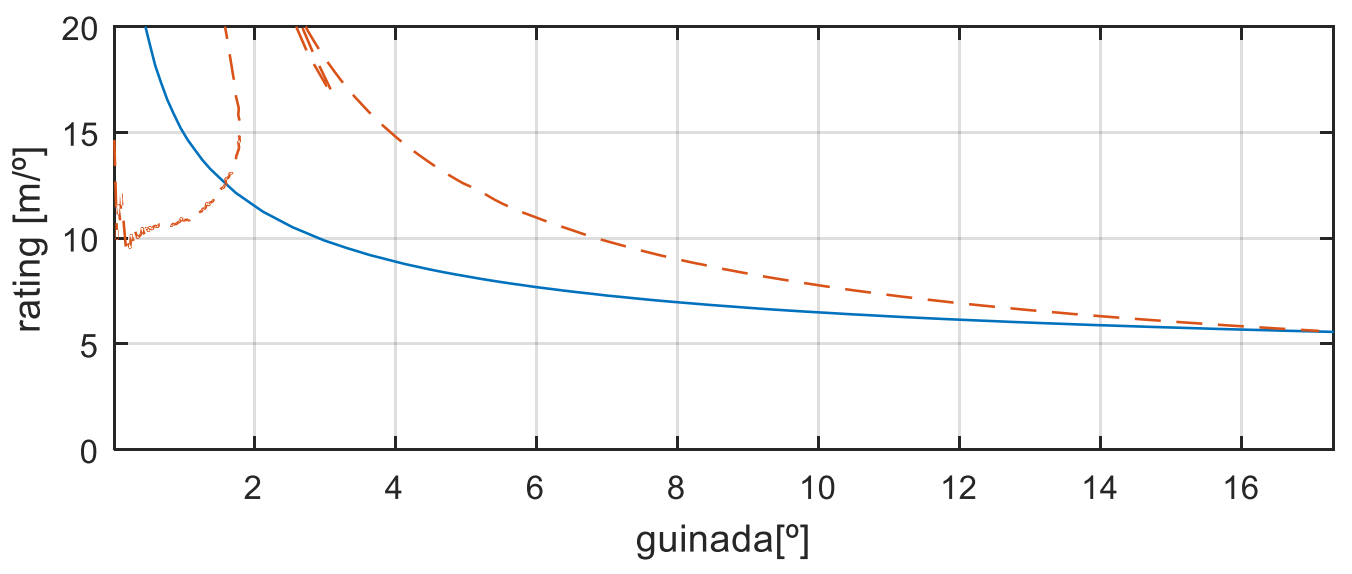

Fonte: Autor. 
6.2.7. Manobra 5 - águas rasas

Nessa manobra foi realizado o initial turning test com máquina meia força avante (500 RPM), com leme de 20․․ A Tabela 19 apresenta os dados táticos obtidos:

Tabela 19 - Dados táticos obtidos para a manobra 5 em águas rasas

\begin{tabular}{|l|l|l|l|}
\hline & Distância 20 & $\begin{array}{l}\text { Distância } \\
\text { máxima (IMO) }\end{array}$ & Rating 20 $^{\mathbf{o}}$ \\
\hline Experimental & $61,9 \mathrm{~m}(1,0 \mathrm{~L})$ & $126,00 \mathrm{~m}(2,0 \mathrm{~L})$ & $3,1 \mathrm{~m} /{ }^{\circ}$ \\
\hline Simulado & $67,9 \mathrm{~m}(1,1 \mathrm{~L})$ & $126,00 \mathrm{~m}(2,0 \mathrm{~L})$ & $3,4 \mathrm{~m} /{ }^{\circ}$ \\
\hline Erro & & $9,6 \%$ & \\
\hline
\end{tabular}

Fonte: Autor.

As Figura 57 e Figura 58 mostram uma boa aderência entre os modelos numérico e experimental para esta manobra, havendo um deslocamento da popa da embarcação experimental ligeiramente maior do que o do modelo numérico, comportamento visto também na manobra em águas profundas.

Figura 57 - Trajetória varrida, manobra 5

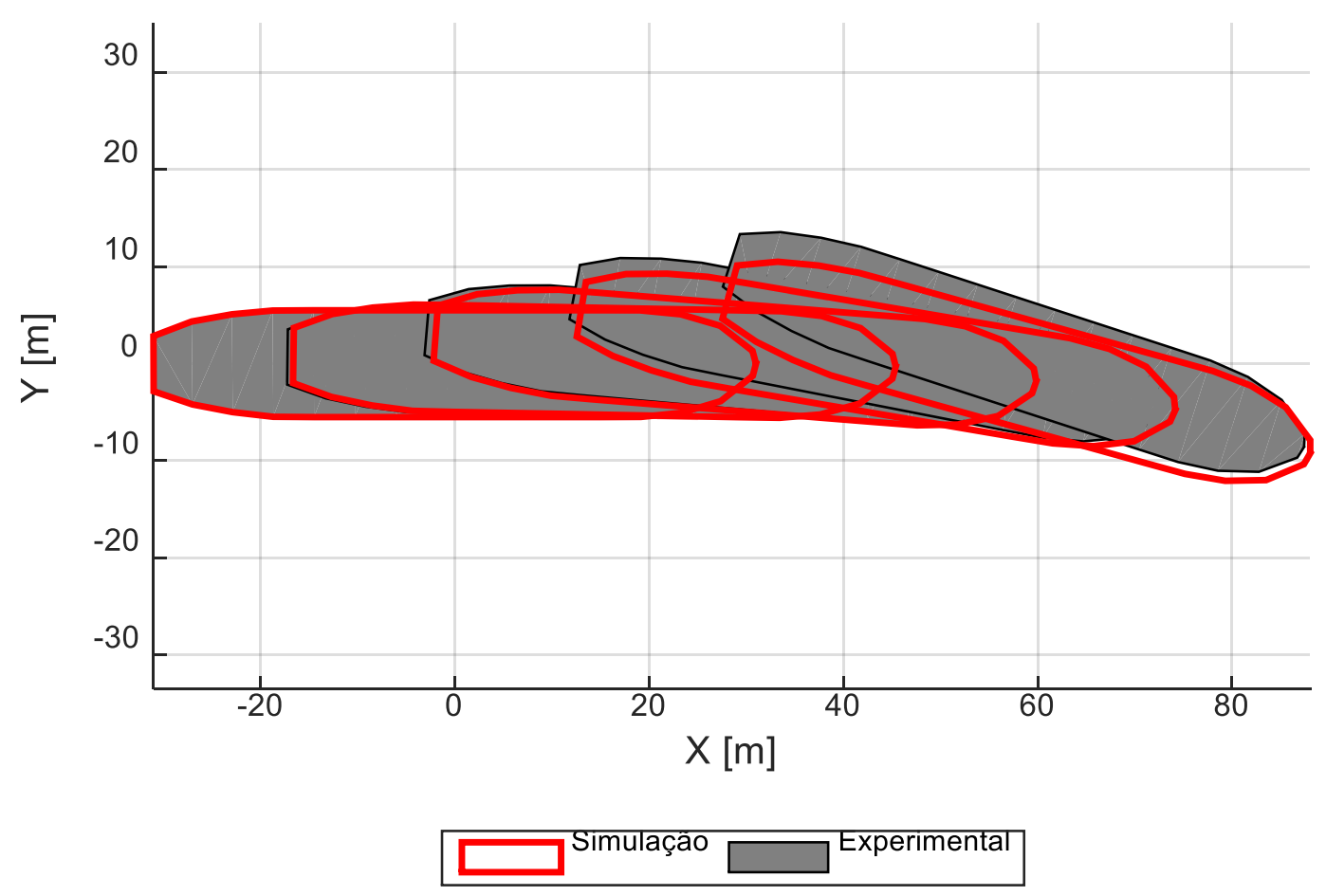

Fonte: Autor. 
Figura 58 - Aproamento, Ângulo de deriva, Distância percorrida, Rating por ângulo de guinada, manobra 5
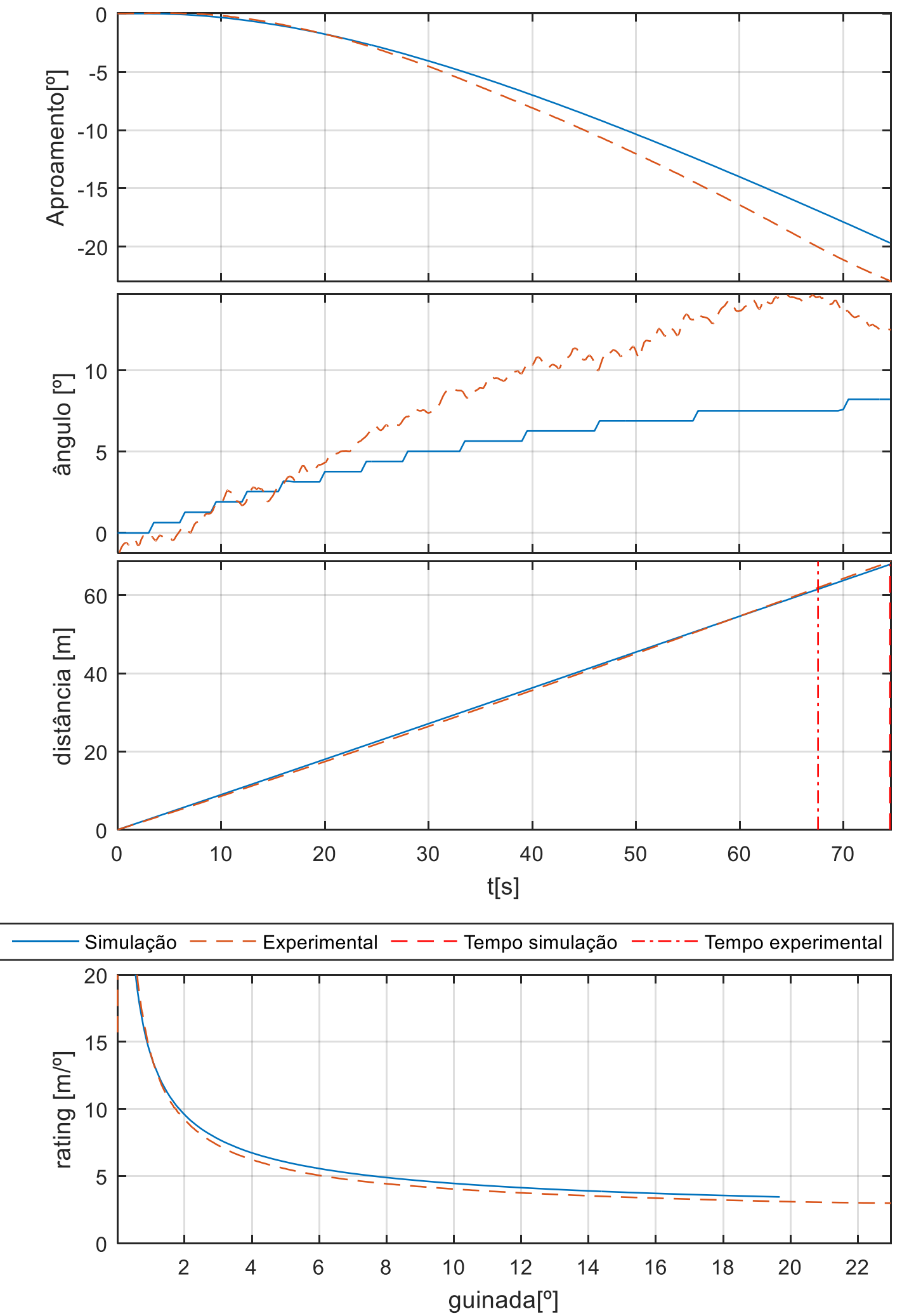

Fonte: Autor.

Simulação - - Experimental 
6.2.8. Manobra 6 - águas rasas

Nessa manobra foi realizado o initial turning test com máquina meia força avante (500 RPM), com leme de 10․ A Tabela 20 apresenta os dados táticos obtidos:

Tabela 20 - Dados táticos obtidos para a manobra 6 em águas rasas

\begin{tabular}{|l|l|l|l|}
\hline & Distância 10 & $\begin{array}{l}\text { Distância } \\
\text { máxima (IMO) }\end{array}$ & Rating 10 $^{\mathbf{o}}$ \\
\hline Experimental & $66,2 \mathrm{~m}(1,1 \mathrm{~L})$ & $157,50 \mathrm{~m}(2,5 \mathrm{~L})$ & $6,6 \mathrm{~m} /{ }^{\circ}$ \\
\hline Simulado & $83,3 \mathrm{~m}(1,3 \mathrm{~L})$ & $157,50 \mathrm{~m}(2,5 \mathrm{~L})$ & $8,3 \mathrm{~m} /{ }^{\circ}$ \\
\hline Erro & & $25,9 \%$ \\
\hline
\end{tabular}

Fonte: Autor.

Pode-se observar na Figura 59 a diferença da trajetória da popa da embarcação entre os dois modelos, na Figura 60 pode ser visto que a maior discrepância encontrada entre os modelos, para esta manobra, foi do ângulo de deriva.

Figura 59 - Trajetória varrida, manobra 6

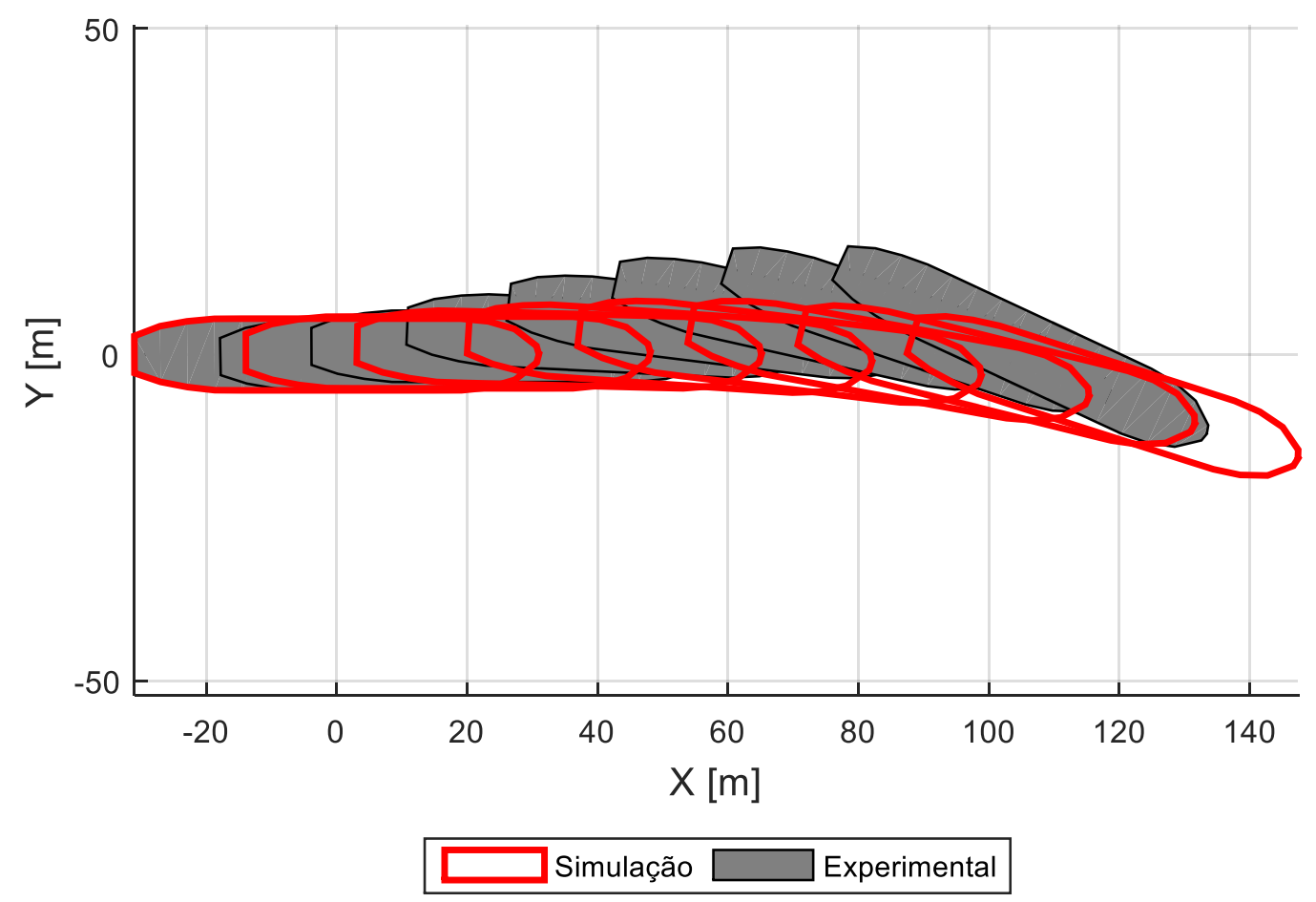

Fonte: Autor. 
Figura 60 - Aproamento, Ângulo de deriva, Distância percorrida, Rating por ângulo de guinada, manobra 6
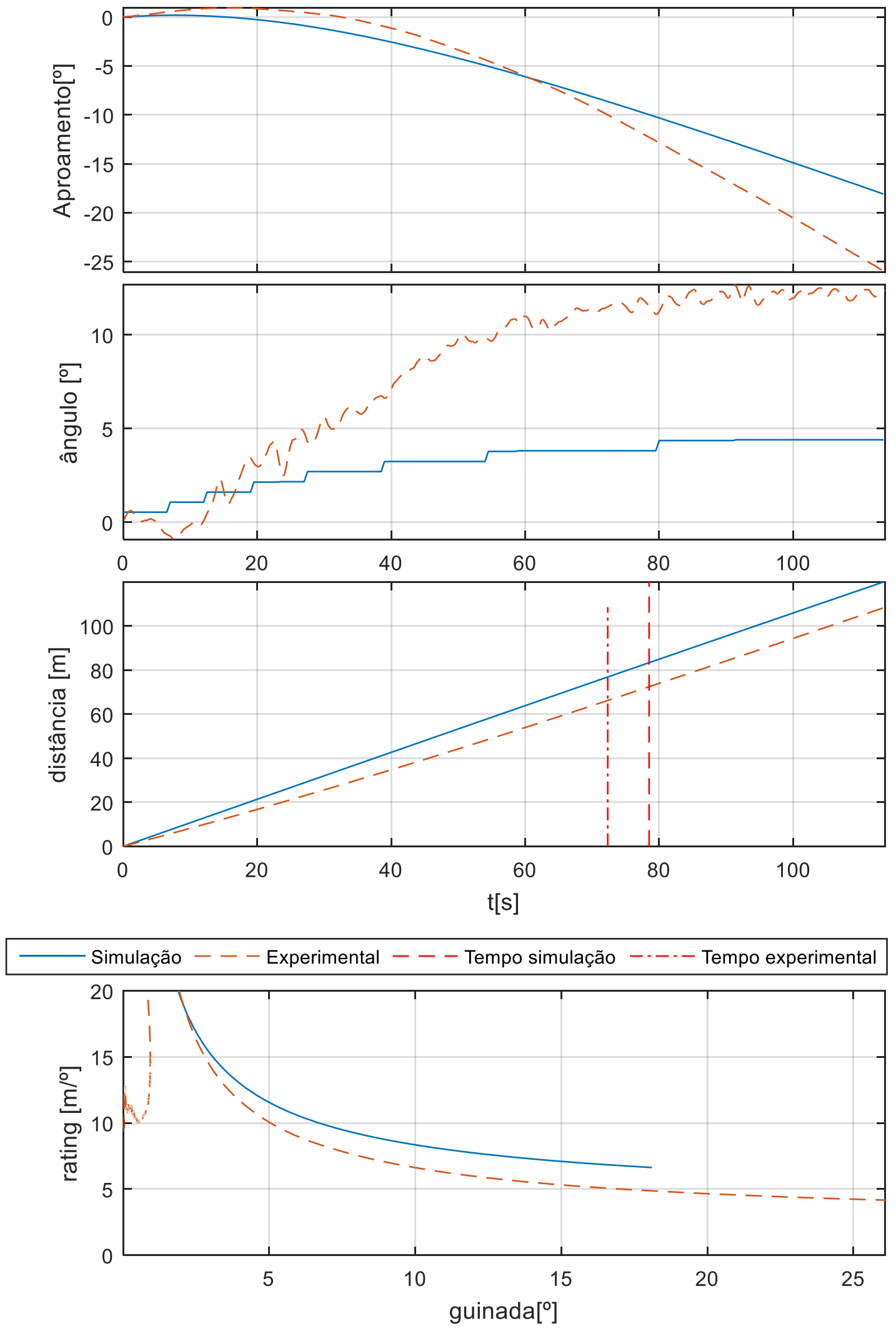

Fonte: Autor. 


\subsection{Zig-zag}

Essa manobra mede a capacidade de o navio responder a um comando de leme durante a execução de uma guinada. Para sua realização o navio deve inicialmente navegar com velocidade e aproamento estáveis, no início da manobra o(s) leme(s) é acionado e posto na posição de $10^{\circ}$ ou $20^{\circ}$ conforme a especificação da manobra.

Após uma mudança no aproamento do navio de $10^{\circ}$ ou $20^{\circ}$, correspondente ao leme acionado, o leme é posicionado com a mesma angulação para o bordo oposto, repetindo essa operação duas vezes.

Figura 61 - Resultados para uma manobra de zig-zag.

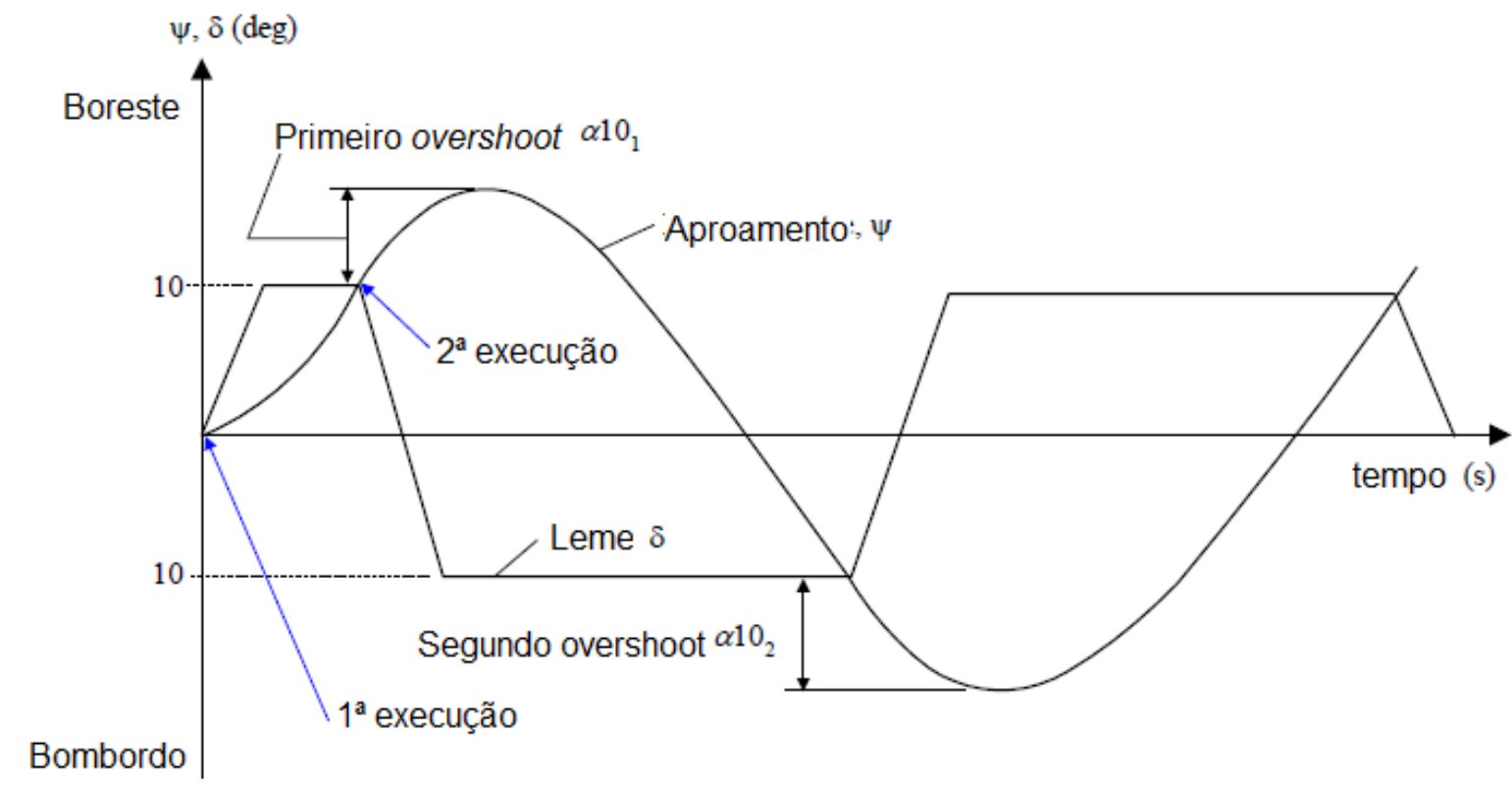

Fonte: Adaptado de (American Bureau of Shipping, 2006)

Essa manobra apresenta como principais resultados os ângulos de sobressinal de aproamento das primeira e segunda execuções. Esta manobra indica a capacidade de o navio manter seu aproamento, de forma que o navio apresenta maior capacidade quando os sobressinais são pequenos.

O tempo entre as inversões de leme também indicam a capacidade de o navio manter seu aproamento, porém esta capacidade tem maior relação com a manobra de initial turning test, descrita anteriormente.

Por motivos descritos na seção 4.4, este tipo de manobra não foi incluído neste trabalho. 


\subsection{Coasting turn}

Esta manobra ocorre de forma similar à manobra de Turning Circle, porém quando a manobra é iniciada a máquina do navio é parada. O objetivo dessa manobra é avaliar a capacidade do navio guinar com máquina parada, quando o propulsor não aumenta a velocidade da água incidente no leme. Esta ocasião ocorre durante manobras em portos, onde o espaço é restrito e o navio se movimenta por sua inércia.

A sequência da manobra consiste em manter a navegação com velocidade e rumo estável e quando a manobra é iniciada, é dada a ordem para parar máquinas e simultaneamente a ordem de leme que será utilizada. Conforme recomendações da $\mathrm{IMO}$, para esta manobra podem ser utilizados ângulos de leme diferentes de 35 graus.

As manobras foram realizadas conforme a descrição acima, porém a comparação com a manobra de turning circle não foi completa pois devido ao comportamento do navio e ao espaço disponível o giro não foi completo.

\subsubsection{Manobra 7}

Nessa manobra foi realizado o coasting turn com máquina inicialmente com meia força avante (1050 RPM), com leme de 30․ A Tabela 21 apresenta os dados táticos obtidos:

Tabela 21 - Dados táticos obtidos para a manobra 7

\begin{tabular}{|l|l|l|l|l|}
\hline & Avanço & Transferência & Diâmetro tático & Diâmetro final \\
\hline Experimental & $196,1 \mathrm{~m}(3,1 \mathrm{~L})$ & $47,4 \mathrm{~m}(0,8 \mathrm{~L})$ & $---\mathrm{m}$ & $---\mathrm{m}$ \\
\hline Simulado & $184,9 \mathrm{~m}(3,0 \mathrm{~L})$ & $83,5 \mathrm{~m}(1,3 \mathrm{~L})$ & $---\mathrm{m}$ & $---\mathrm{m}$ \\
\hline Erro & $-5,7 \%$ & $77,2 \%$ & --- & --- \\
\hline & Vx final & Vy final & $\begin{array}{l}\text { Velocidade } \\
\text { angular }\end{array}$ & $\begin{array}{l}\text { Ângulo de } \\
\text { deriva }\end{array}$ \\
\hline Experimental & 1,0 nós & 0,9 nós & $35,8 \% \mathrm{~min}$ & $40,2^{\circ}$ \\
\hline Simulado & 1,7 nós & 0,5 nós & $31,5 \% \mathrm{~min}$ & $17,5^{\circ}$ \\
\hline Erro & $67,0 \%$ & $-36,5 \%$ & $-11,9 \%$ & $-56,5 \%$ \\
\hline
\end{tabular}

Fonte: Autor.

Na Figura 62 pode ser visto que o modelo numérico apresentou menor ângulo de deriva do que o modelo experimental. A Figura 63 e a Figura 64 mostram que o modelo numérico apresentou menor eficiência do leme, resultando numa menor taxa de guinada, e que há uma maior resistência ao movimento lateral. O navio parou seu 
avanço antes de completar $180^{\circ}$ de mudança em seu aproamento, e por isso não foi possível estimar o diâmetro tático da manobra.

Figura 62 - Trajetória varrida, manobra 7

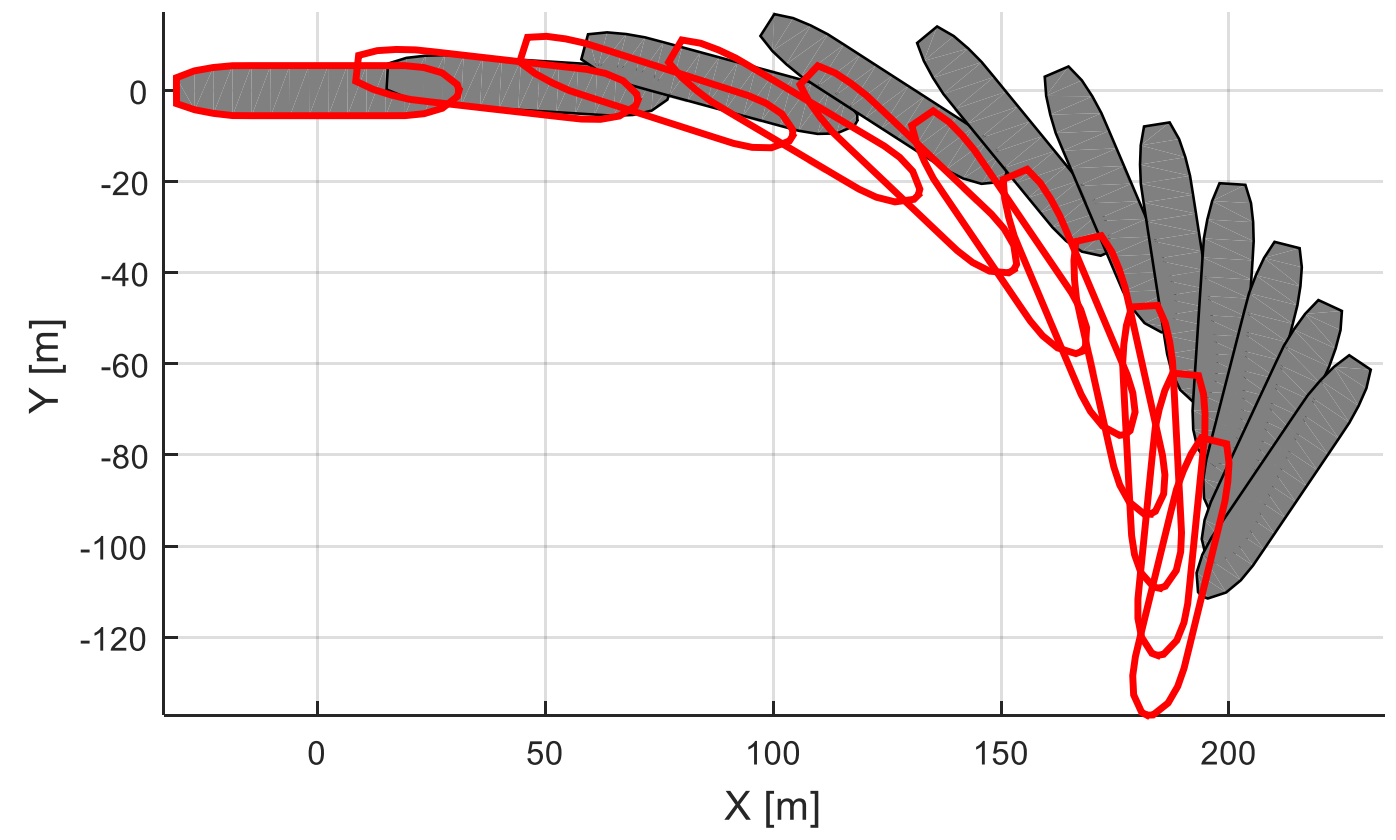

Fonte: Autor.

Figura 63 - Ângulo de deriva, Velocidade angular, manobra 7

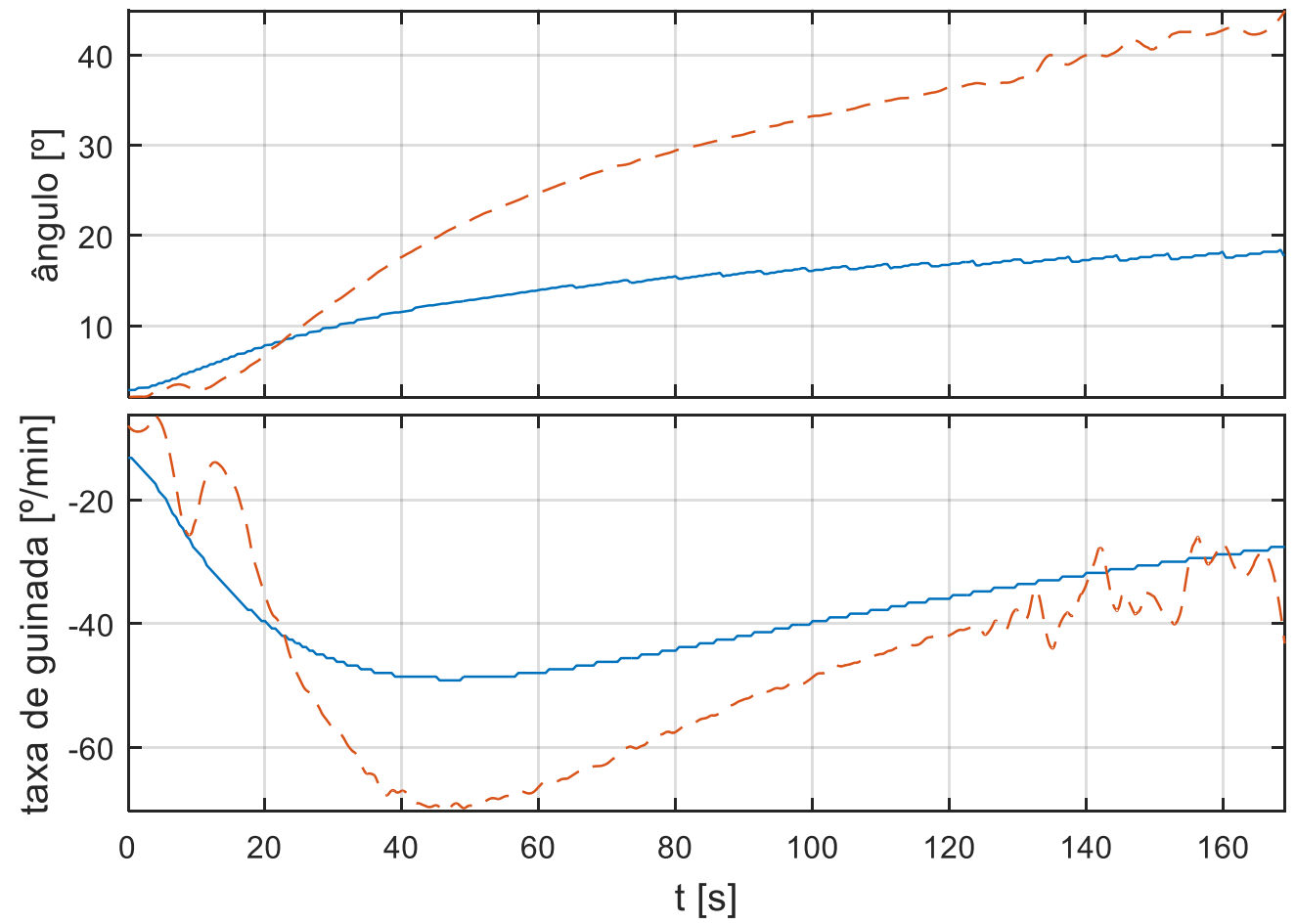

Fonte: Autor. 
Figura 64 - Velocidade Vx, velocidade Vy, manobra 7
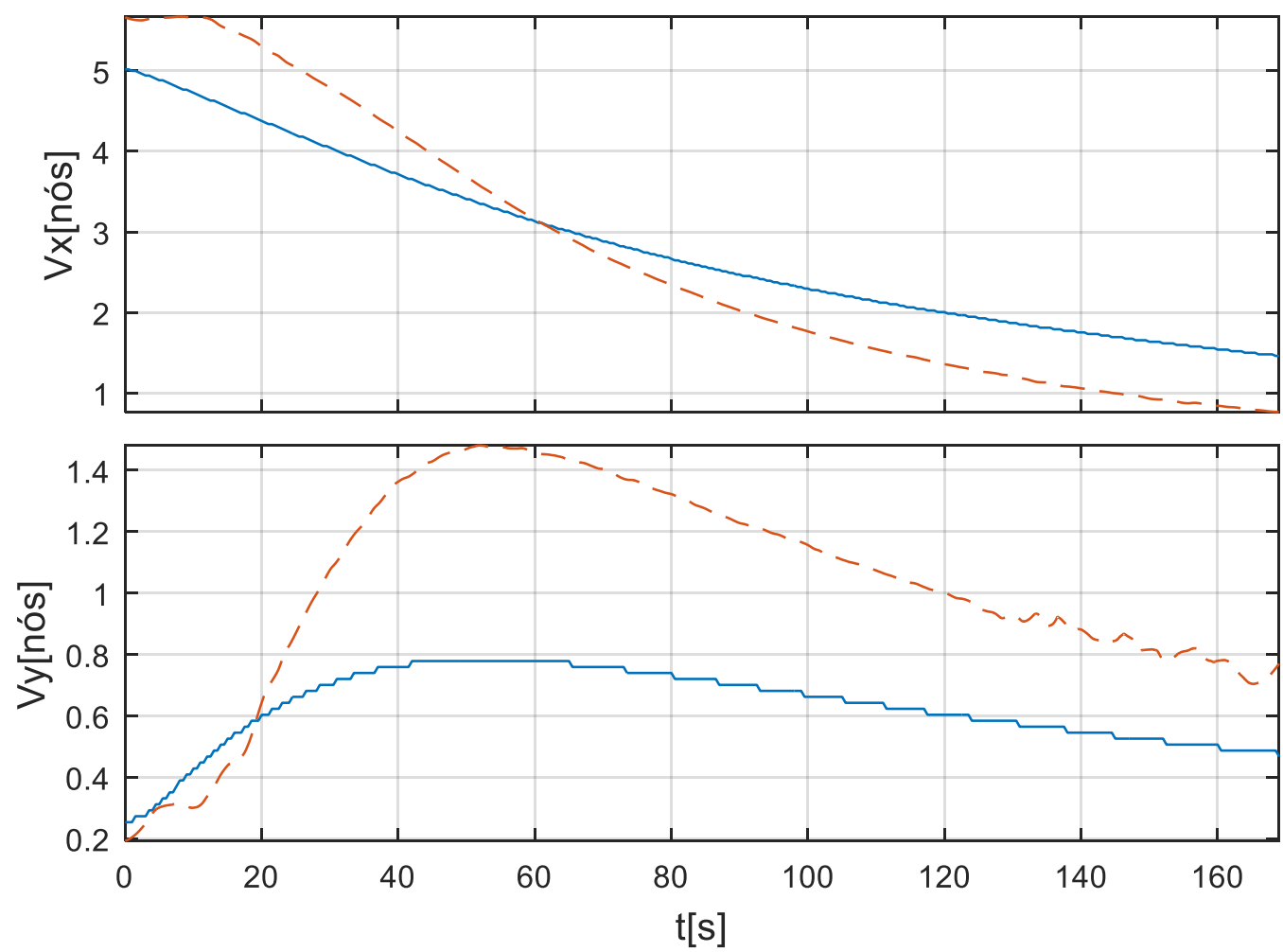

Fonte: Autor.

Simulação - - Experimental

\subsubsection{Manobra 8}

Nessa manobra foi realizado o coasting turn com máquina inicialmente com meia força avante (1050 RPM), com leme de 20․ A Tabela 22 apresenta os dados táticos obtidos:

Tabela 22 - Dados táticos obtidos para a manobra 8

\begin{tabular}{|l|l|l|l|l|}
\hline & Avanço & Transferência & Diâmetro tático & Diâmetro final \\
\hline Experimental & $---\mathrm{m}$ & $---\mathrm{m}$ & $---\mathrm{m}$ & $---\mathrm{m}$ \\
\hline Simulado & $---\mathrm{m}$ & $---\mathrm{m}$ & $---\mathrm{m}$ & $---\mathrm{m}$ \\
\hline Erro & --- & --- & --- & --- \\
\hline Experimental & Vx final & Vy final & $\begin{array}{l}\text { Velocidade } \\
\text { angular }\end{array}$ & $\begin{array}{l}\text { Ângulo } \\
\text { deriva }\end{array}$ \\
\hline Simulado & 3,6 nós & 1,1 nós & $51,2 \% \mathrm{~min}$ & $17,3^{\circ}$ \\
\hline Erro & $2,1 \%$ & 0,6 nós & $38,6 \% \mathrm{~min}$ & $9,7^{\circ}$ \\
\hline Fon & $-43,2 \%$ & $-24,7 \%$ & $-44,2 \%$ \\
\hline
\end{tabular}

Fonte: Autor.

A Figura 65 mostra uma melhor aproximação entre os modelos numérico e experimental, quando comparados estes resultados com os da manobra 7. Porém a 
Figura 66 e Figura 67 indicam diferença para a velocidade de deriva, que influencia também no ângulo de deriva obtido.

Figura 65 - Trajetória varrida, manobra 8

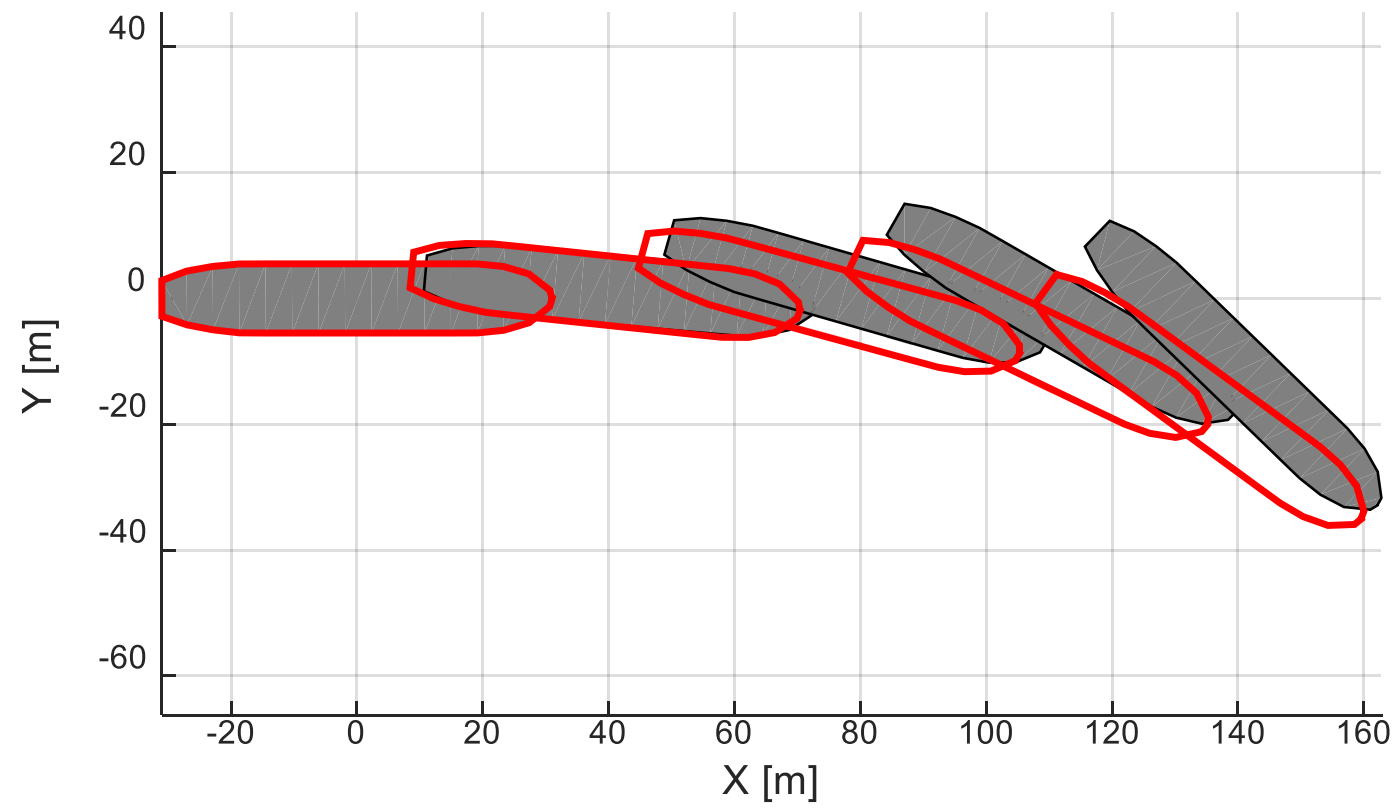

Fonte: Autor.

Figura 66 - Ângulo de deriva, Velocidade angular, manobra 8
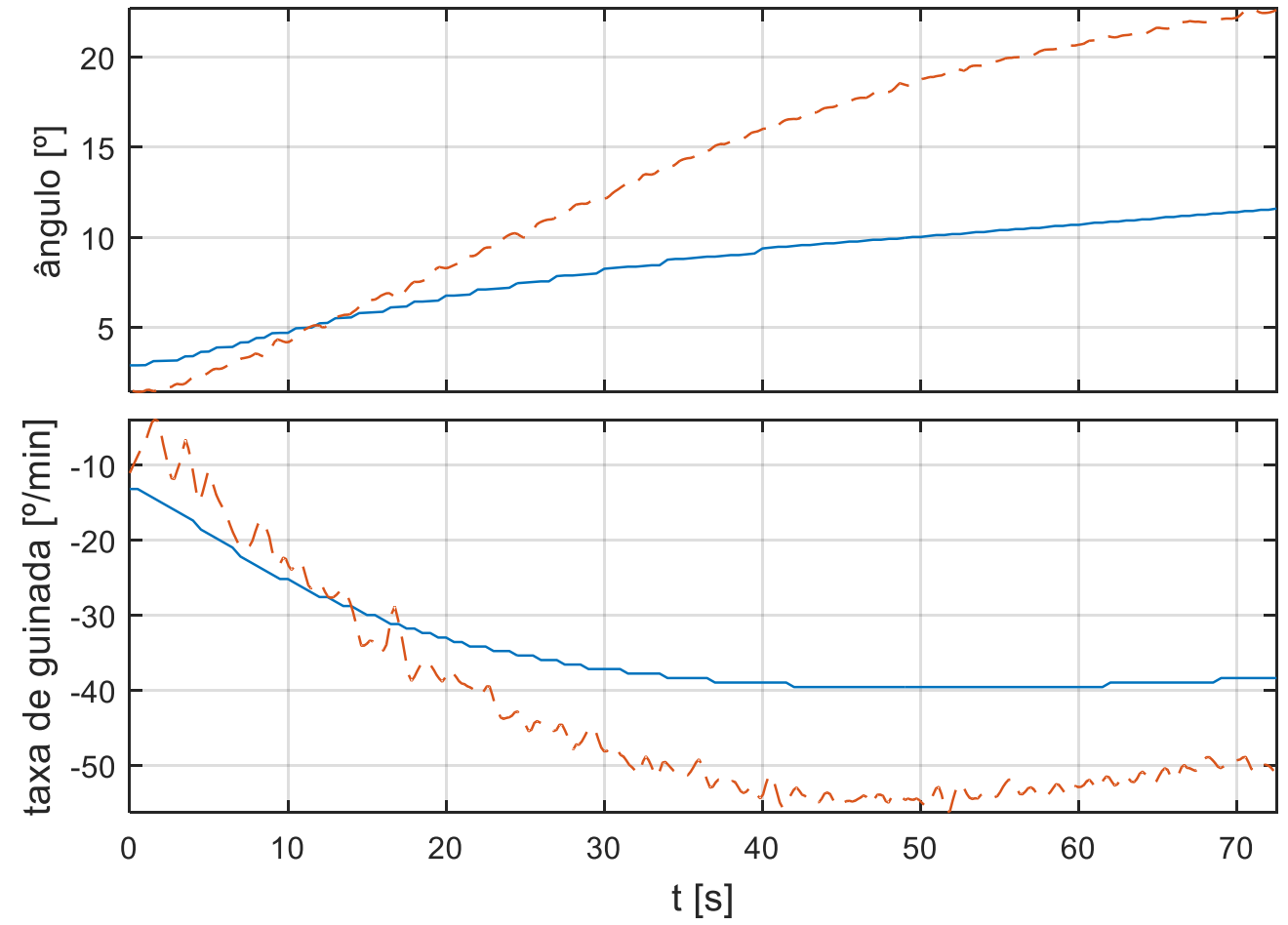

Fonte: Autor. 
Figura 67 - Velocidade Vx, velocidade Vy, manobra 8
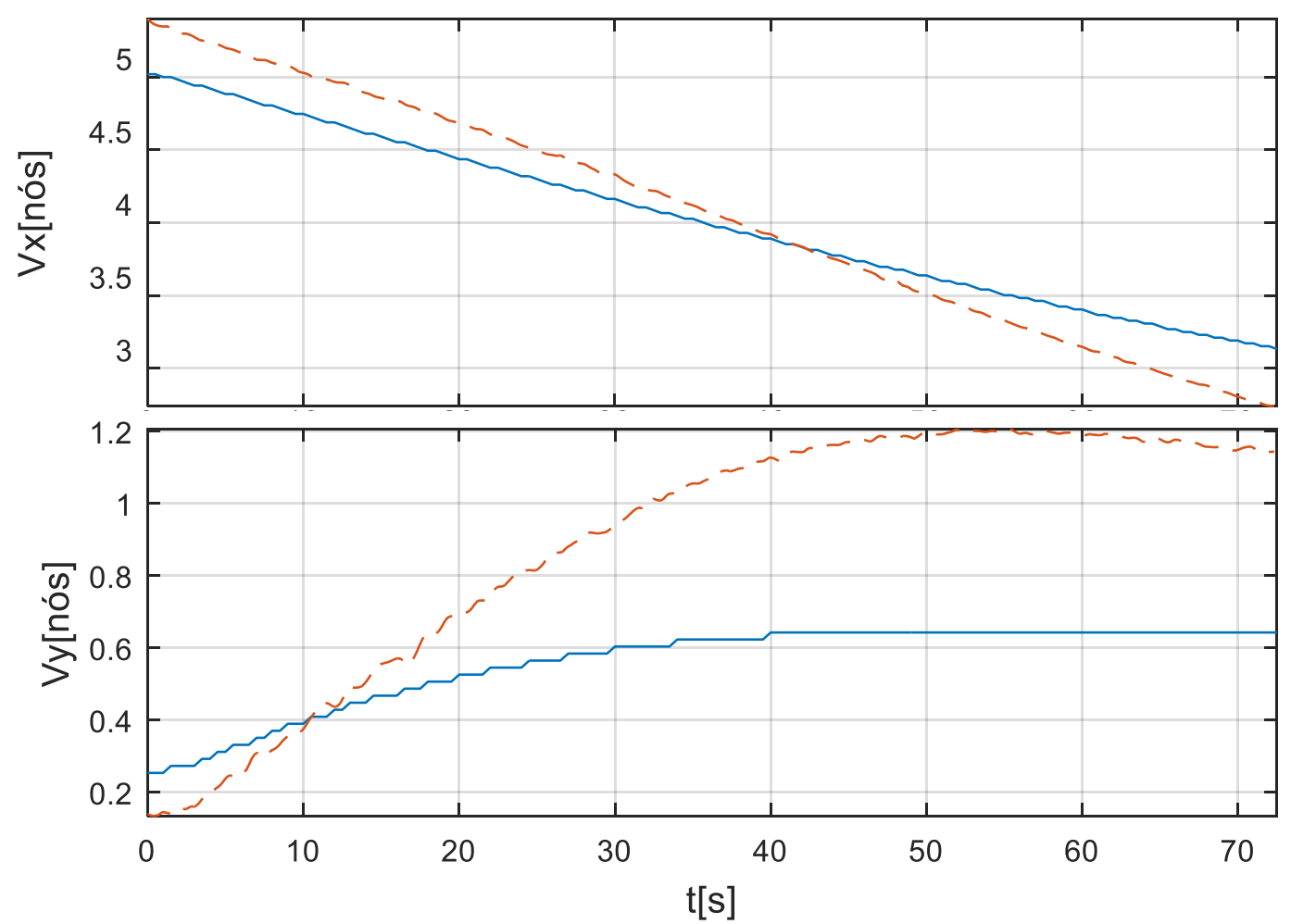

Simulação - - Experimental

Fonte: Autor. 
6.4.3. Manobra 7-águas rasas

Nessa manobra foi realizado o coasting turn com máquina inicialmente com meia força avante (1050 RPM), com leme de 30․

A Tabela 23 apresenta os dados táticos obtidos:

Tabela 23 - Dados táticos obtidos para a manobra 7 em águas rasas

\begin{tabular}{|l|l|l|l|l|}
\hline Experimental & Avanço & Transferência & Diâmetro tático & Diâmetro final \\
\hline Simulado & $---\mathrm{m}$ & $---\mathrm{m}$ & $---\mathrm{m}$ & $---\mathrm{m}$ \\
\hline Erro & --- & $---\mathrm{m}$ & $---\mathrm{m}$ & $---\mathrm{m}$ \\
\hline Experimental & Vx final & --- & --- & --- \\
\hline Simulado & 2,6 nós & Vy final & $\begin{array}{l}\text { Velocidade } \\
\text { angular }\end{array}$ & $\begin{array}{l}\text { Ângulo de } \\
\text { deriva }\end{array}$ \\
\hline Erro & 3,0 nós & 0,5 nós & $35,8 \% \mathrm{~min}$ & $12,0^{\circ}$ \\
\hline
\end{tabular}

Fonte: Autor.

A Figura 68 indica que, embora a manobra não tenha sido completa, o modelo numérico apresentou maior avanço do que o modelo experimental. A Figura 69 mostra que o modelo numérico apresentou um bom comportamento da velocidade angular, porém com velocidade longitudinal superior ao modelo experimental.

Figura 68 - Trajetória varrida, manobra 7 em águas rasas

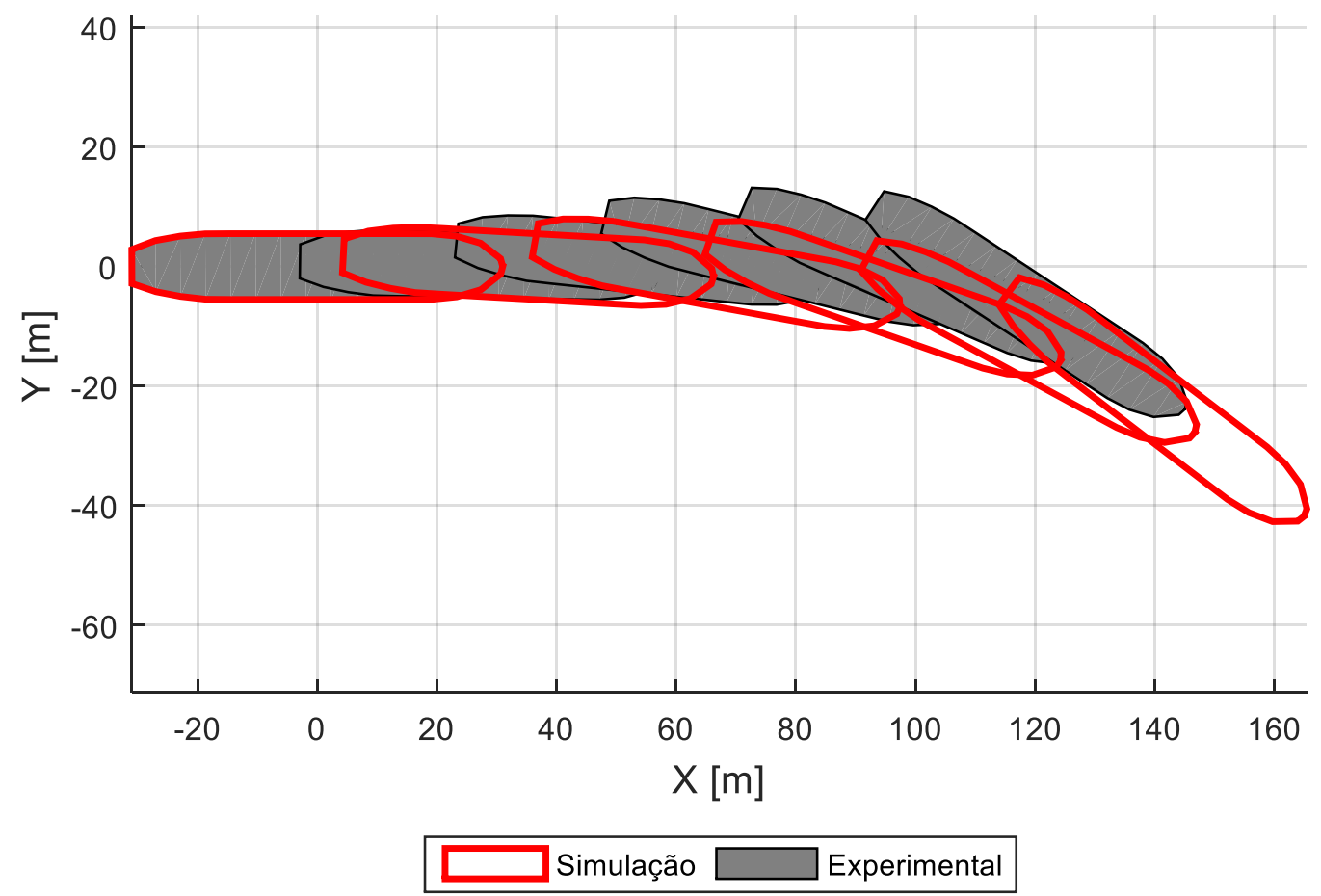

Fonte: Autor. 
Figura 69 - Ângulo de deriva, Velocidade angular, Velocidade Vx, velocidade Vy, manobra 7
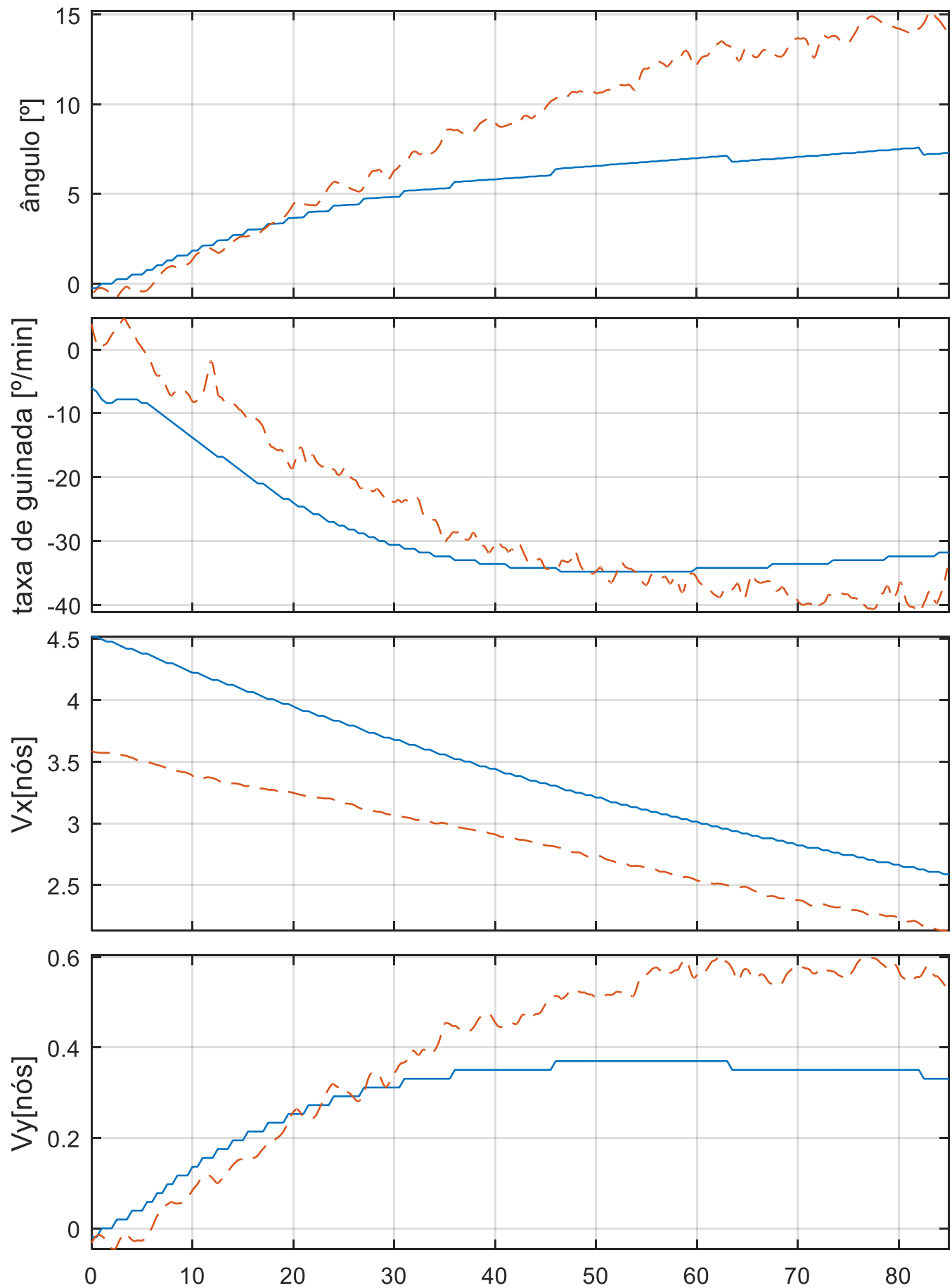

$\mathrm{t}[\mathrm{s}]$

Fonte: Autor. 
6.4.4. Manobra 8 - águas rasas

Nessa manobra foi realizado o coasting turn com máquina inicialmente com meia força avante (1050 RPM), com leme de $20^{\circ}$.

A Tabela 24 apresenta os dados táticos obtidos:

Tabela 24 - Dados táticos obtidos para a manobra 8 em águas rasas

\begin{tabular}{|l|l|l|l|l|}
\hline & Avanço & Transferência & Diâmetro tático & Diâmetro final \\
\hline Experimental & $---\mathrm{m}$ & $---\mathrm{m}$ & $---\mathrm{m}$ & $---\mathrm{m}$ \\
\hline Simulado & $---\mathrm{m}$ & $---\mathrm{m}$ & $---\mathrm{m}$ & $---\mathrm{m}$ \\
\hline Erro & --- & --- & --- & --- \\
\hline Experimental & Vx final & Vy final & $\begin{array}{l}\text { Velocidade } \\
\text { angular }\end{array}$ & $\begin{array}{l}\text { Ângulo de } \\
\text { deriva }\end{array}$ \\
\hline Simulado & 2,3 nós & 0,4 nós & $29,2 \% \mathrm{~min}$ & $10,9^{\circ}$ \\
\hline Erro & $17,5 \%$ & 0,2 nós & $21,6 \% \mathrm{~min}$ & $5,8^{\circ}$ \\
\hline
\end{tabular}

Fonte: Autor.

A Figura 70 mostra que o modelo numérico realiza a curva com menor deriva, este comportamento pode ser explicado pelo maior sobressinal apresentado pelo modelo experimental para a taxa de guinada e para a velocidade no eixo transversal do navio, comportamentos apresentados na Figura 71.

Figura 70 - Trajetória varrida, manobra 8

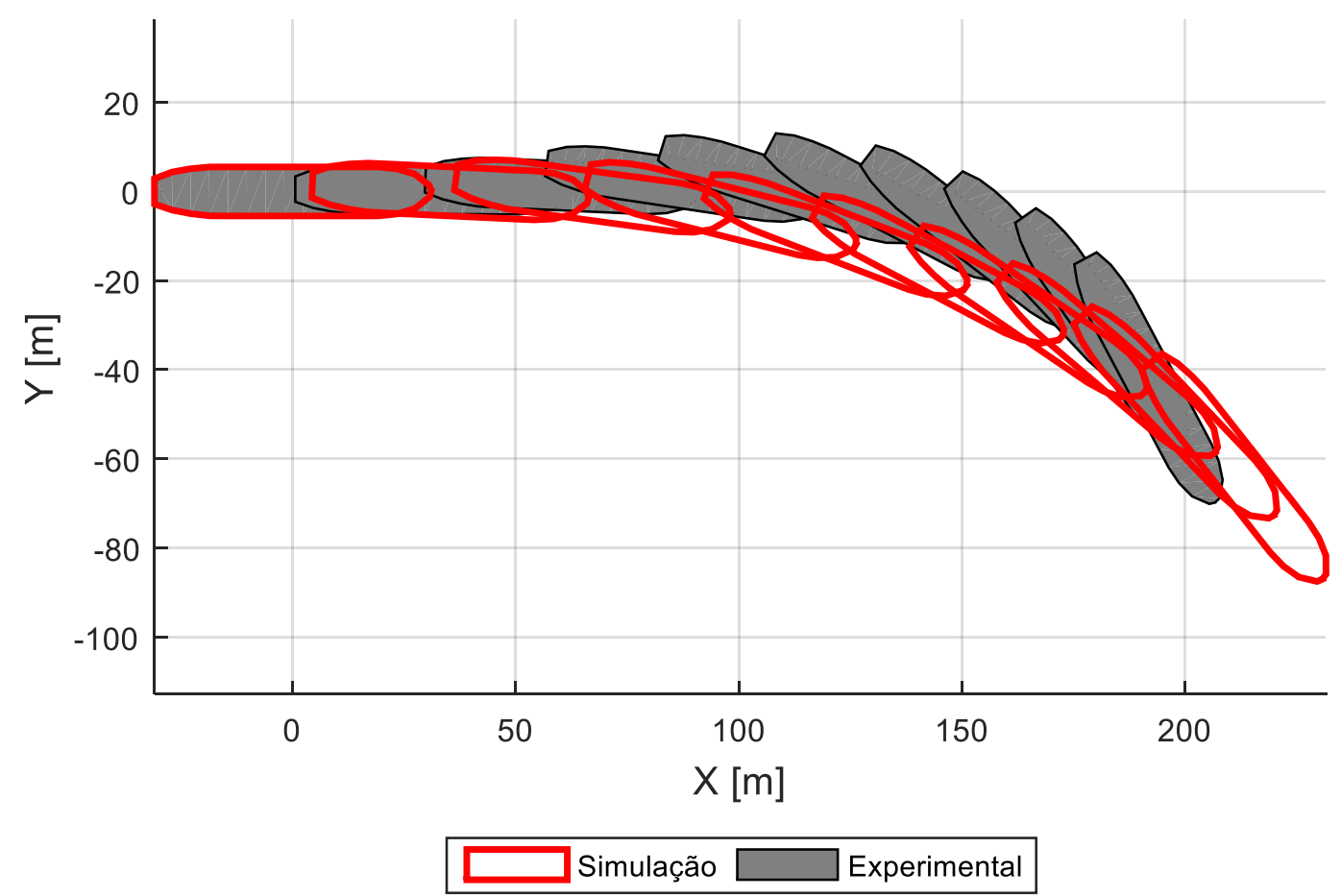

Fonte: Autor. 
Figura 71 - Ângulo de deriva, Velocidade angular, Velocidade Vx, velocidade $\mathrm{Vy}$, manobra 8
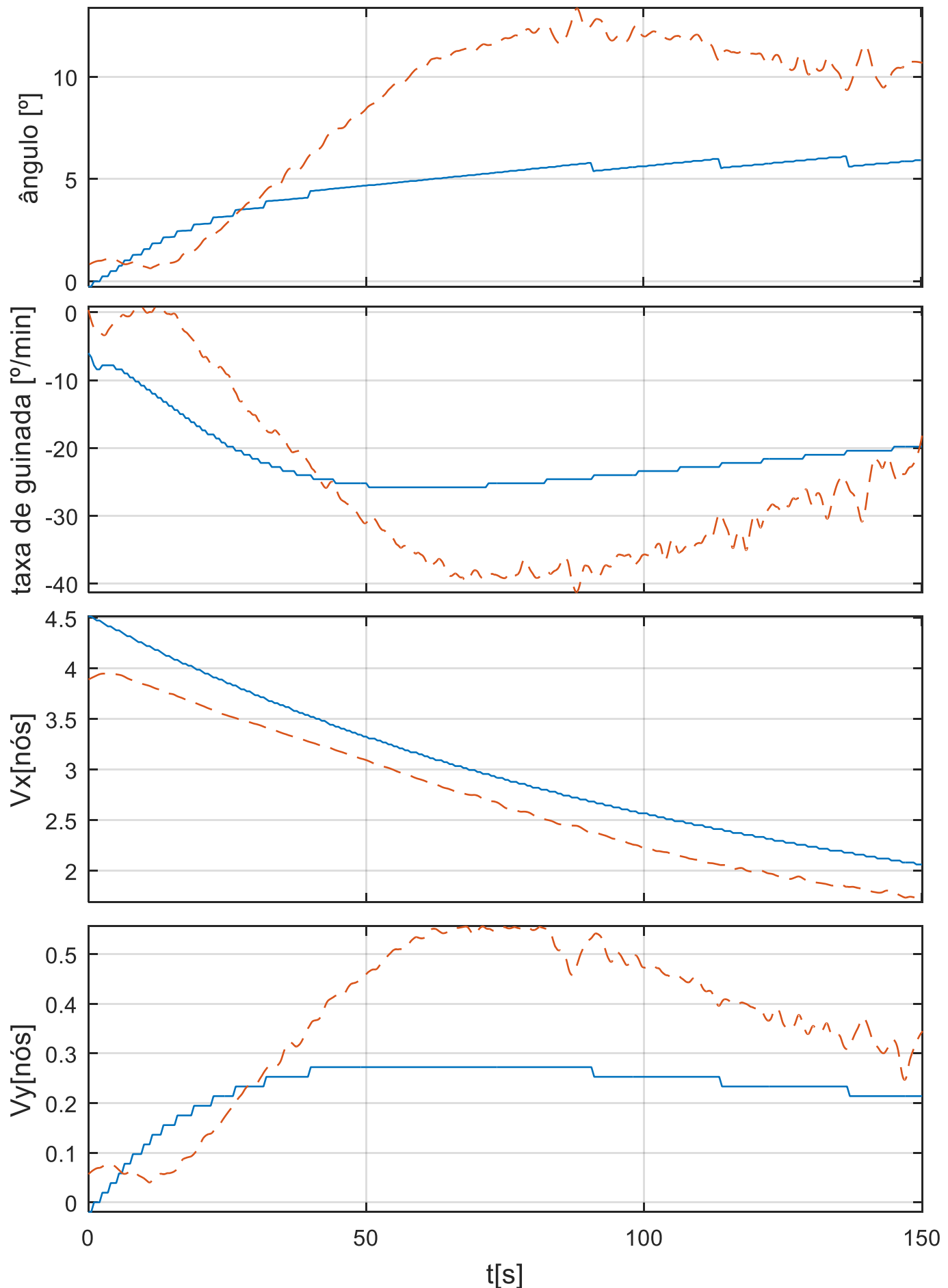

Fonte: Autor.

Simulação - - Experimental 


\subsection{Parada brusca (Crash-Stop)}

Esta manobra mede a capacidade de parada do navio. Para a realização da manobra o navio é mantido a uma velocidade constante, normalmente a velocidade de serviço, e com um rumo constante. Uma vez iniciada a manobra é dada a ordem de máquinas a ré, o que faz o motor parar e reverter seu sentido de rotação produzindo força no sentido negativo da direção longitudinal da embarcação, este regime é mantido até a parada da embarcação.

Durante a execução da manobra o leme é mantido ao centro, não influenciando de forma ativa na direção da proa do navio, dessa forma a trajetória é dependente do efeito de pá gerado devido à assimetria do fluxo de água causado no casco pelo propulsor gerando força no sentido negativo.

Para esta manobra são medidos o alcance longitudinal (head reach), alcance lateral (side reach), e a distância percorrida (track reach) mostrados na Figura 72.

Figura 72 - Grandezas medidas durante a manobra de Crash-Stop.

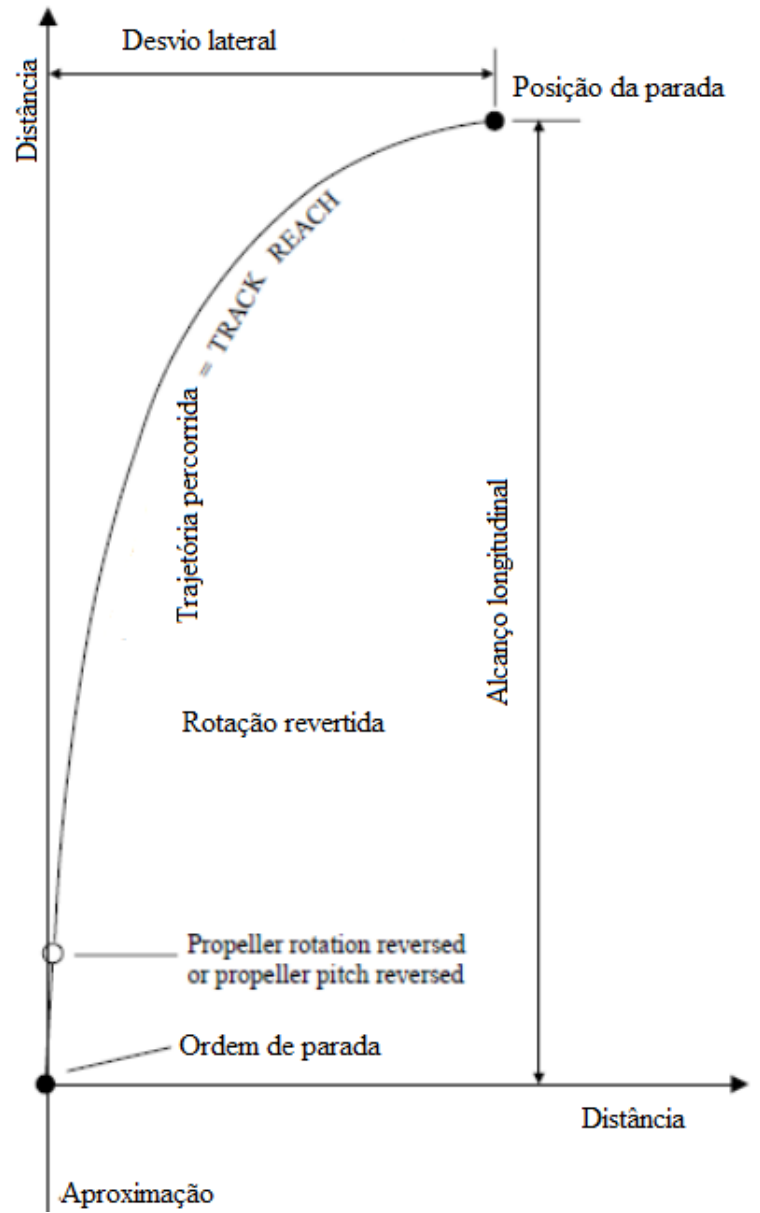

Fonte: Adaptado de (American Bureau of Shipping, 2006) 


\subsubsection{Manobra 9}

Nessa manobra foi realizada a parada brusca com avanço devagar avante (500 rpm).

A Tabela 25 apresenta os dados táticos obtidos:

Tabela 25 - Dados táticos obtidos para a manobra 9

Fonte: Autor.

\begin{tabular}{|l|l|l|l|}
\hline & $\begin{array}{l}\text { Alcance } \\
\text { longitudinal }\end{array}$ & $\begin{array}{l}\text { Alcance } \\
\text { transversal }\end{array}$ & $\begin{array}{l}\text { Distância } \\
\text { percorrida }\end{array}$ \\
\hline Experimental & $51,2 \mathrm{~m}(0,8 \mathrm{~L})$ & $4,7 \mathrm{~m}(0,1 \mathrm{~L})$ & $51,5 \mathrm{~m}(0,8 \mathrm{~L})$ \\
\hline Simulado & $41,8 \mathrm{~m}(0,7 \mathrm{~L})$ & $1,9 \mathrm{~m}(0,0 \mathrm{~L})$ & $41,8 \mathrm{~m}(0,7 \mathrm{~L})$ \\
\hline Erro & $-18,4 \%$ & $-58,4 \%$ & $-18,7 \%$ \\
\hline
\end{tabular}

Observou-se uma rápida parada nessa manobra com alcance longitudinal de cerca de 1 comprimento de navio mostrado na Figura 73, por se tratar de uma embarcação com dois propulsores principais posicionados lado a lado não foi observado o efeito de pá que normalmente induz uma velocidade angular, como pode ser verificado na Figura 74.

Figura 73 - Trajetória varrida, manobra 9

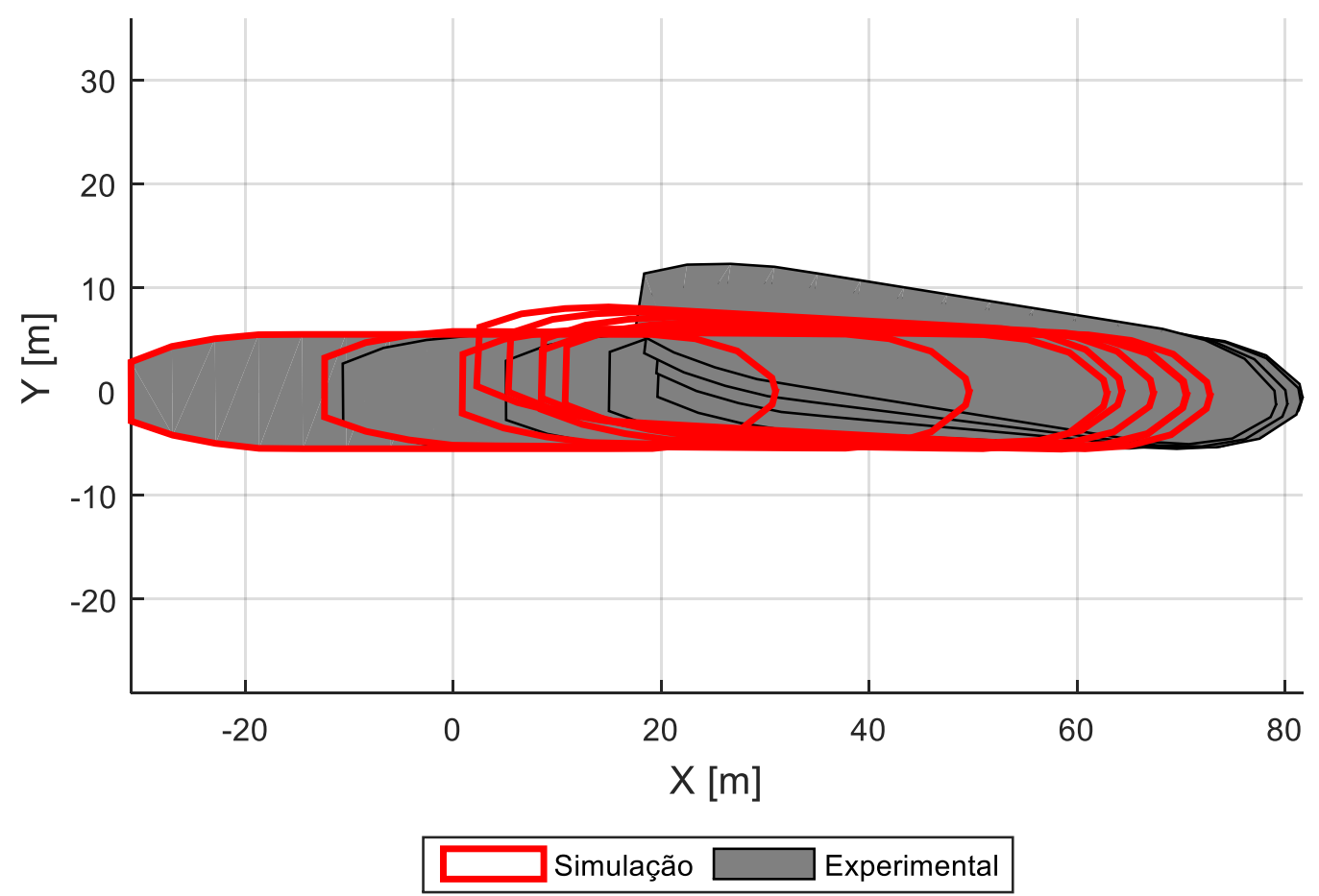

Fonte: Autor. 
Figura 74 - Ângulo de deriva, Velocidade angular, Velocidade Vx, velocidade Vy, manobra 9
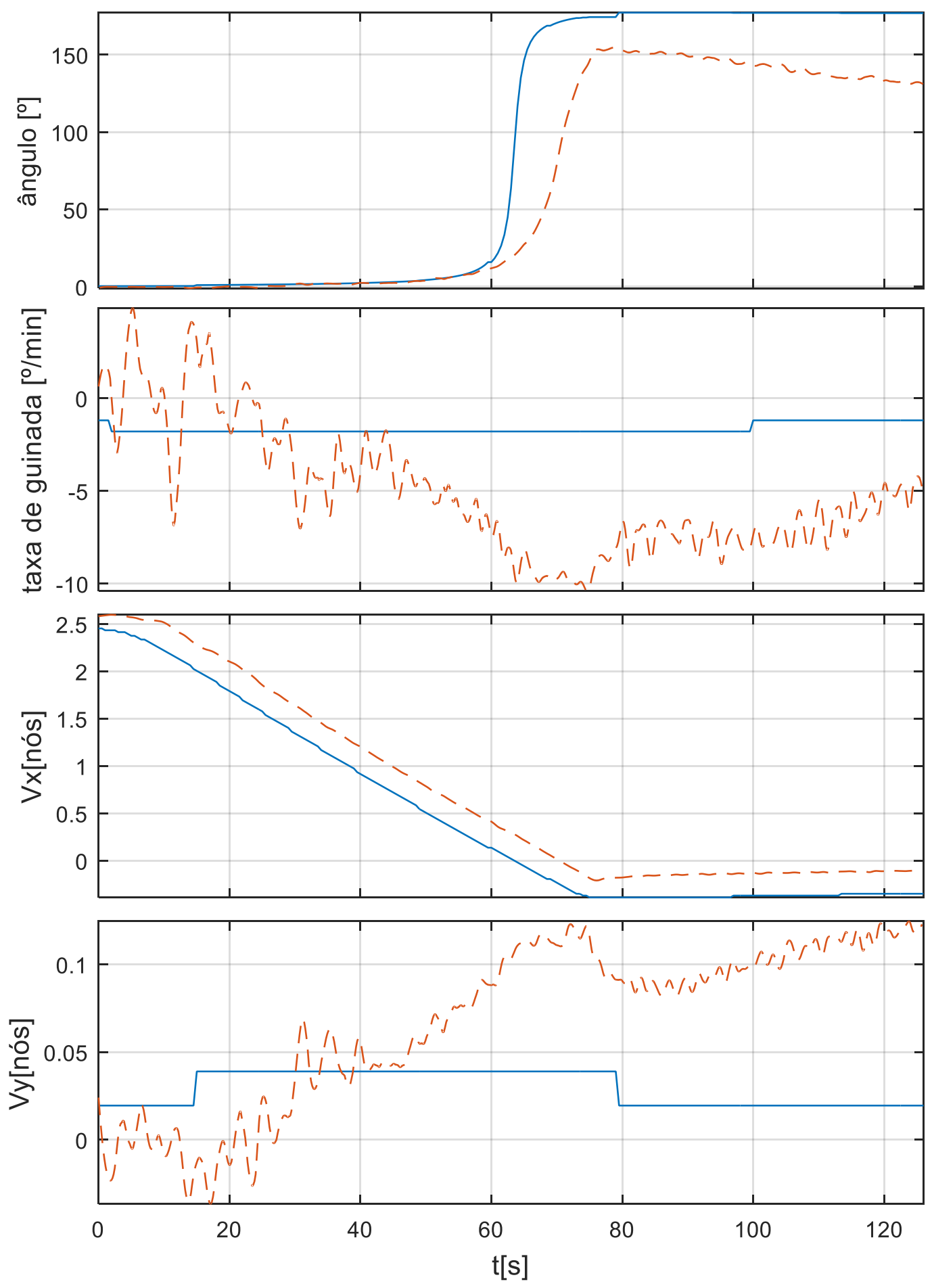

Fonte: Autor. 


\subsubsection{Manobra 10}

Nessa manobra foi realizada a parada brusca com avanço meia força avante (1050 rpm).

A Tabela 26 apresenta os dados táticos obtidos:

Tabela 26 - Dados táticos obtidos para a manobra 10

Fonte: Autor.

\begin{tabular}{|l|l|l|l|}
\hline & $\begin{array}{l}\text { Alcance } \\
\text { longitudinal }\end{array}$ & $\begin{array}{l}\text { Alcance } \\
\text { transversal }\end{array}$ & $\begin{array}{l}\text { Distância } \\
\text { percorrida }\end{array}$ \\
\hline Experimental & $150,2 \mathrm{~m}(2,4 \mathrm{~L})$ & $2,2 \mathrm{~m}(0,0 \mathrm{~L})$ & $150,4 \mathrm{~m}(2,4 \mathrm{~L})$ \\
\hline Simulado & $125,6 \mathrm{~m}(2,0 \mathrm{~L})$ & $4,6 \mathrm{~m}(0,1 \mathrm{~L})$ & $125,4 \mathrm{~m}(2,0 \mathrm{~L})$ \\
\hline Erro & $-16,4 \%$ & $103,0 \%$ & $-16,4 \%$ \\
\hline
\end{tabular}

A Figura 75 apresenta um erro observado para o alcance longitudinal com cerca de meio comprimento de navio, porém na Figura 76 pode-se observar que a desaceleração experimentada foi compatível para ambos os modelos.

Figura 75 Trajetória varrida, manobra 10

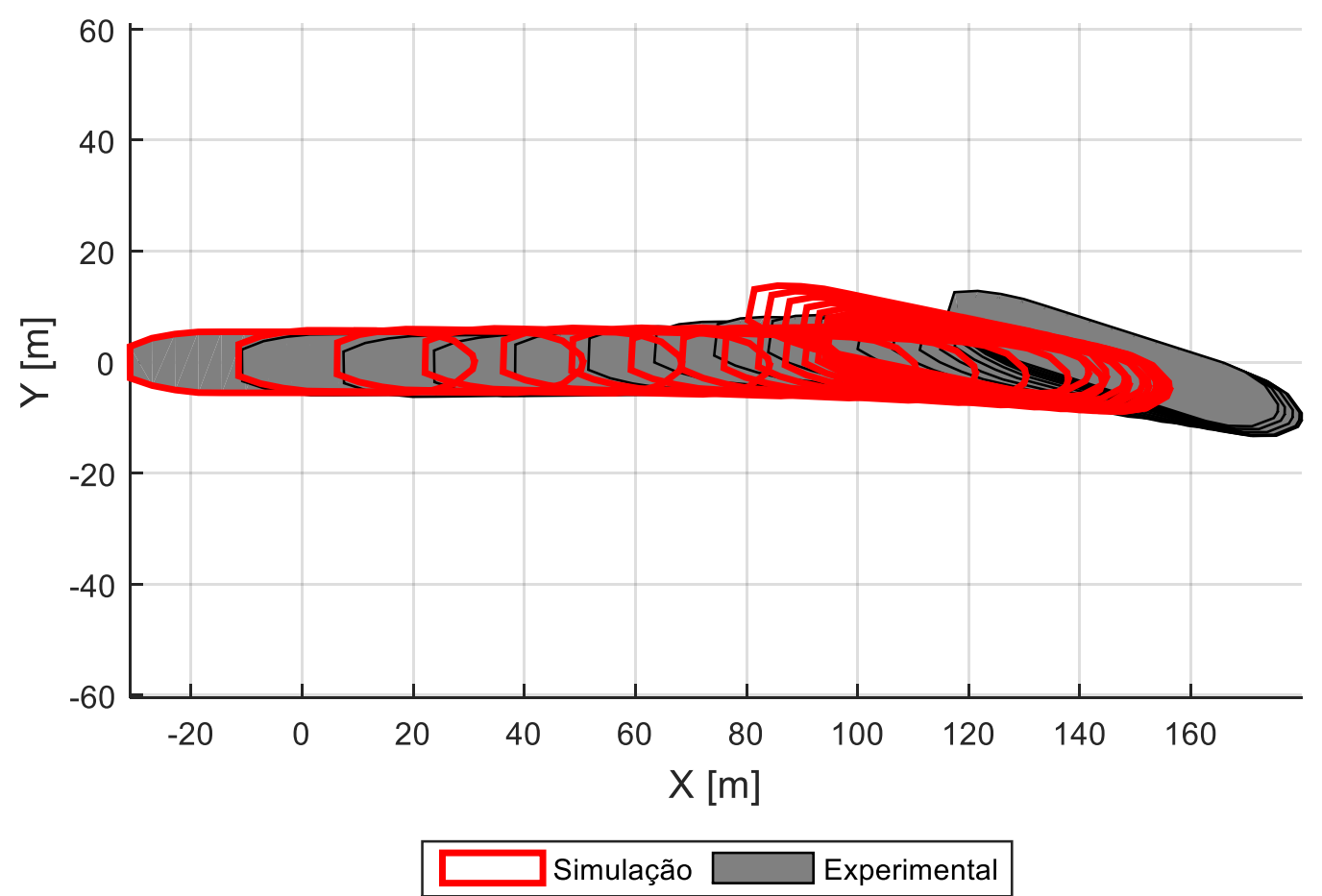

Fonte: Autor. 
Figura 76 Ângulo de deriva, Velocidade angular, Velocidade Vx, velocidade Vy, manobra 10
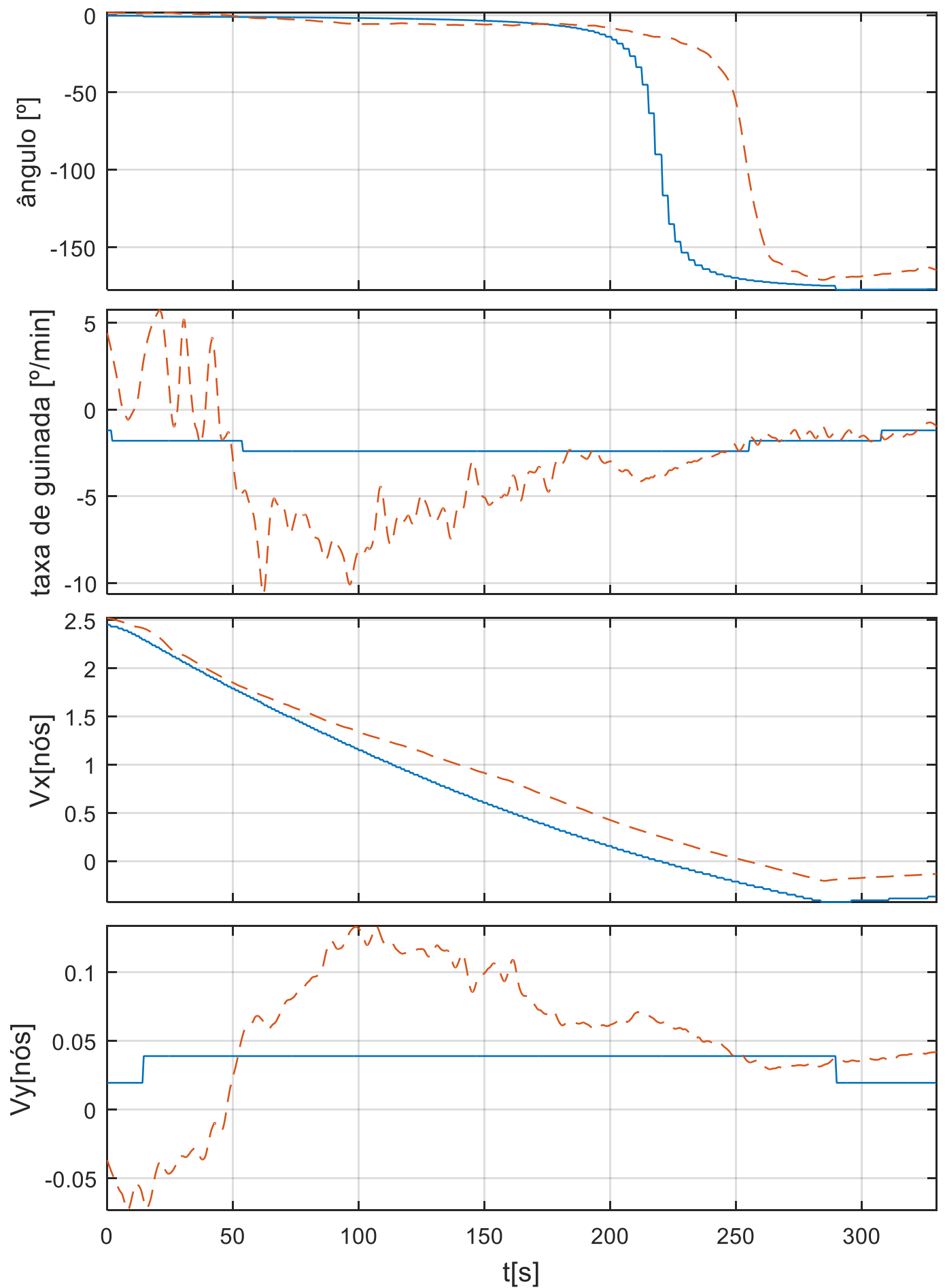

Fonte: Autor. 


\subsubsection{Manobra 9-águas rasas}

Nessa manobra foi realizada a parada brusca com avanço devagar avante (500 rpm).

A Tabela 27 apresenta os dados táticos obtidos:

Tabela 27 - Dados táticos obtidos para a manobra 9 em águas rasas

\begin{tabular}{|l|l|l|l|}
\hline & $\begin{array}{l}\text { Alcance } \\
\text { longitudinal }\end{array}$ & $\begin{array}{l}\text { Alcance } \\
\text { transversal }\end{array}$ & $\begin{array}{l}\text { Distância } \\
\text { percorrida }\end{array}$ \\
\hline Experimental & $23,9 \mathrm{~m}(0,4 \mathrm{~L})$ & $0,3 \mathrm{~m}(0,0 \mathrm{~L})$ & $23,9 \mathrm{~m}(0,4 \mathrm{~L})$ \\
\hline Simulado & $33,4 \mathrm{~m}(0,5 \mathrm{~L})$ & $0,2 \mathrm{~m}(0,0 \mathrm{~L})$ & $33,4 \mathrm{~m}(0,5 \mathrm{~L})$ \\
\hline Erro & $39,6 \%$ & $-28,7 \%$ & $39,5 \%$ \\
\hline
\end{tabular}

Fonte: Autor.

Nesta manobra o modelo numérico apresentou uma maior distância de parada do que o modelo experimental sendo este comportamento inverso ao observado para as manobras em águas profundas., como pode ser visto na Figura 77. Porém pode ser visto na Figura 78 que houve algum fator durante a execução da manobra experimental que aumentou a aceleração do modelo a partir da metade da manobra.

Figura 77 - Trajetória varrida, manobra 9

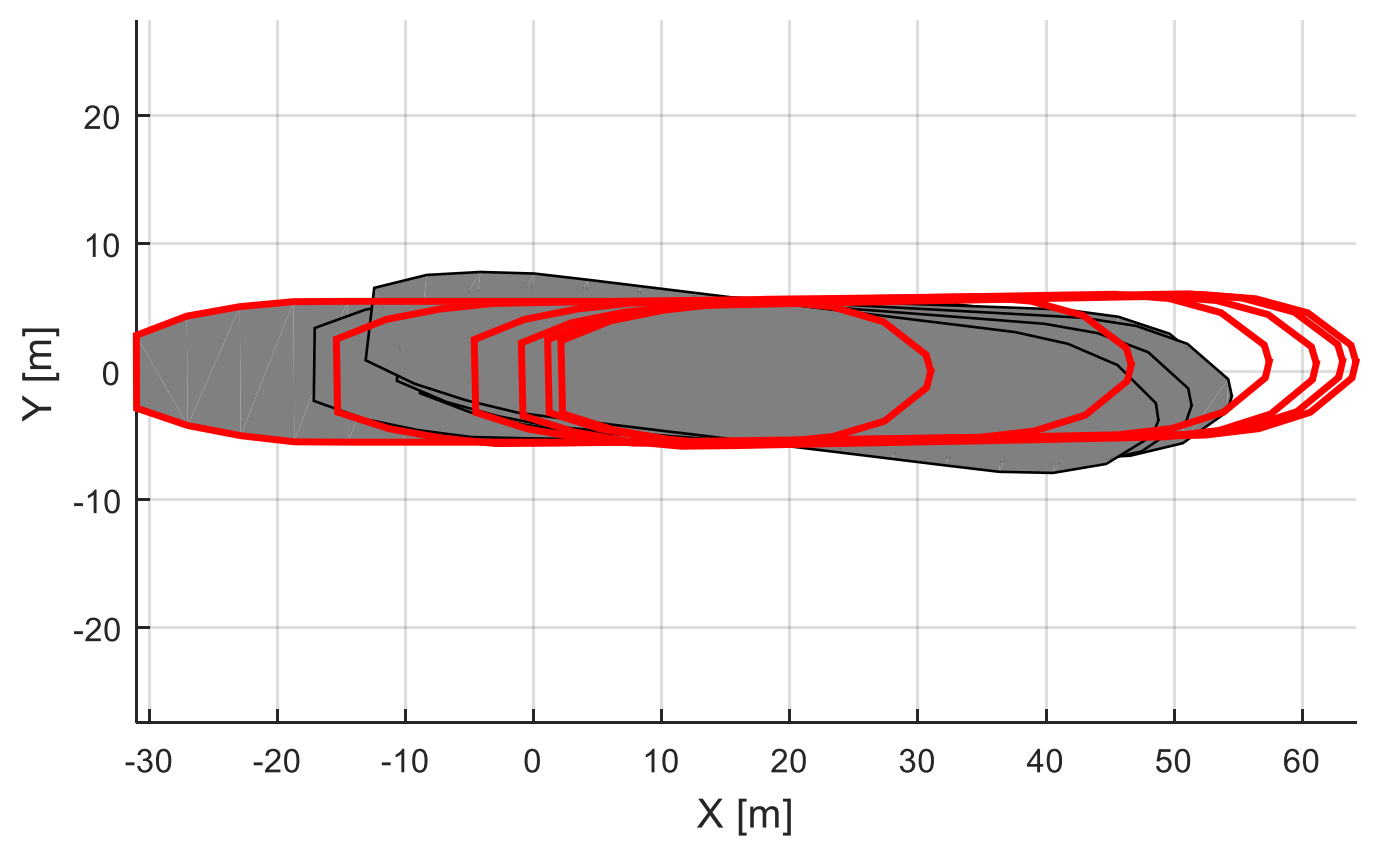

Fonte: Autor. 
Figura 78 - Ângulo de deriva, Velocidade angular, Velocidade Vx, velocidade Vy, manobra 9
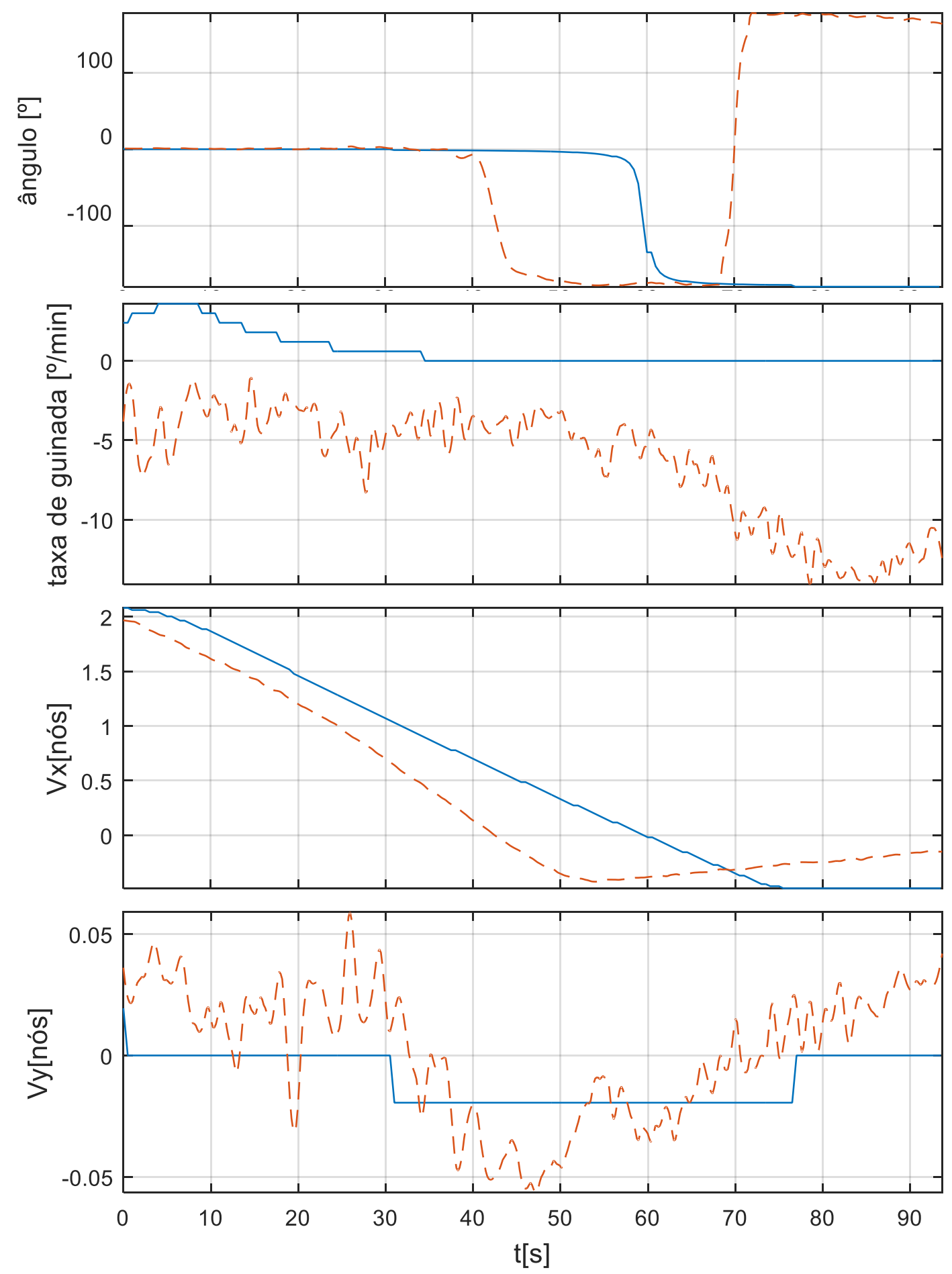

Fonte: Autor. 


\subsubsection{Manobra 10 - águas rasas}

Nessa manobra foi realizada a parada brusca com avanço meia força avante (1050 rpm).

A Tabela 28 apresenta os dados táticos obtidos:

Tabela 28 - Dados táticos obtidos para a manobra 10 em águas rasas

Fonte: Autor.

\begin{tabular}{|l|l|l|l|}
\hline & $\begin{array}{l}\text { Alcance } \\
\text { longitudinal }\end{array}$ & $\begin{array}{l}\text { Alcance } \\
\text { transversal }\end{array}$ & $\begin{array}{l}\text { Distância } \\
\text { percorrida }\end{array}$ \\
\hline Experimental & $86,9 \mathrm{~m}(1,4 \mathrm{~L})$ & $9,1 \mathrm{~m}(0,1 \mathrm{~L})$ & $88,1 \mathrm{~m}(1,4 \mathrm{~L})$ \\
\hline Simulado & $101,3 \mathrm{~m}(1,6 \mathrm{~L})$ & $0,5 \mathrm{~m}(0,0 \mathrm{~L})$ & $101,3 \mathrm{~m}(1,6 \mathrm{~L})$ \\
\hline Erro & $16,6 \%$ & $-94,6 \%$ & $15,0 \%$ \\
\hline
\end{tabular}

A Figura 79 indica que o modelo experimental apresentou abatimento durante a manobra e velocidade angular ao seu término, No entanto na Figura 80 pode ser visto que a aceleração longitudinal de ambos modelos foi compatível.

Figura 79 - Trajetória varrida, manobra 10

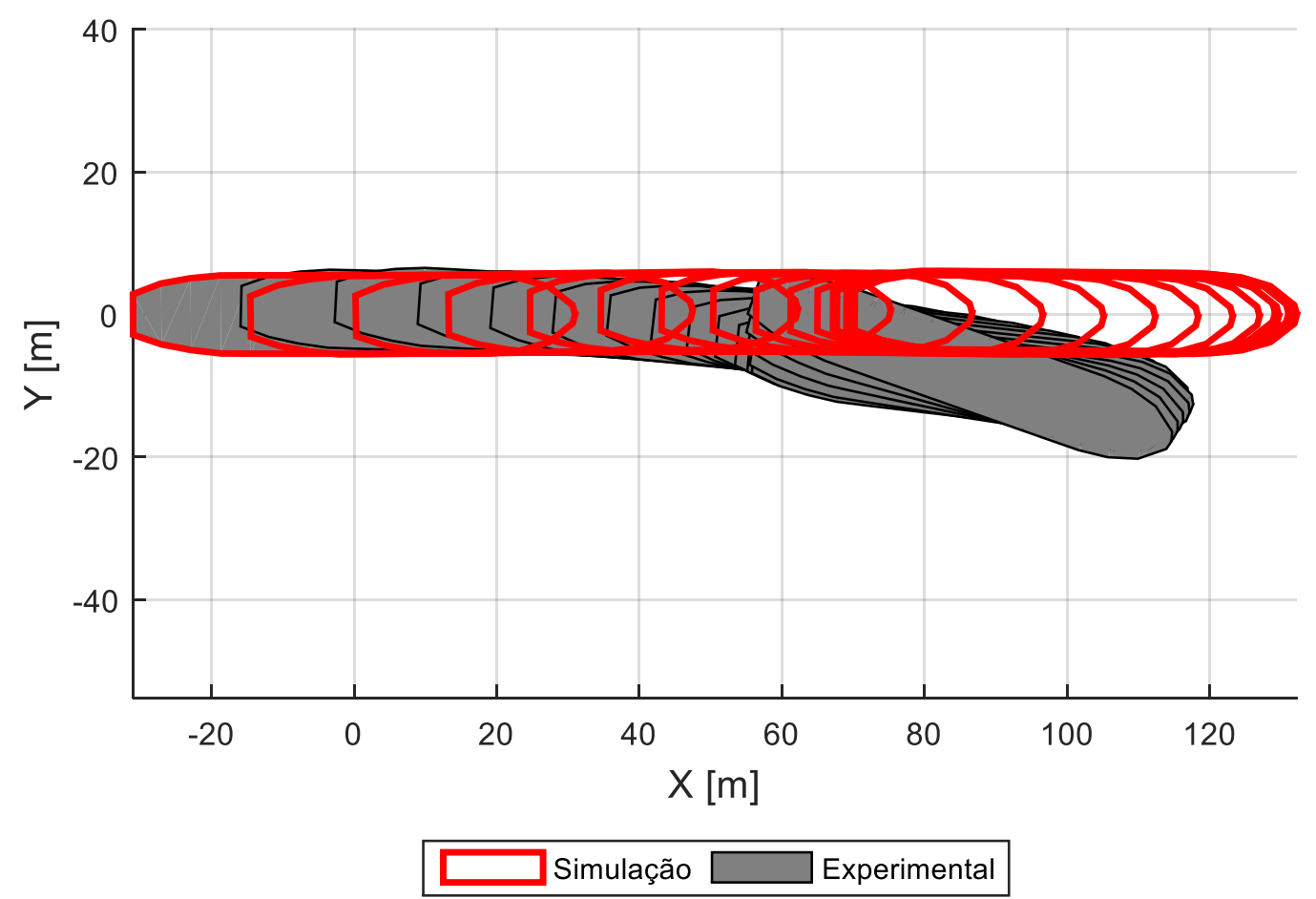

Fonte: Autor. 
Figura 80 - Ângulo de deriva, Velocidade angular, Velocidade Vx, velocidade Vy, manobra 10
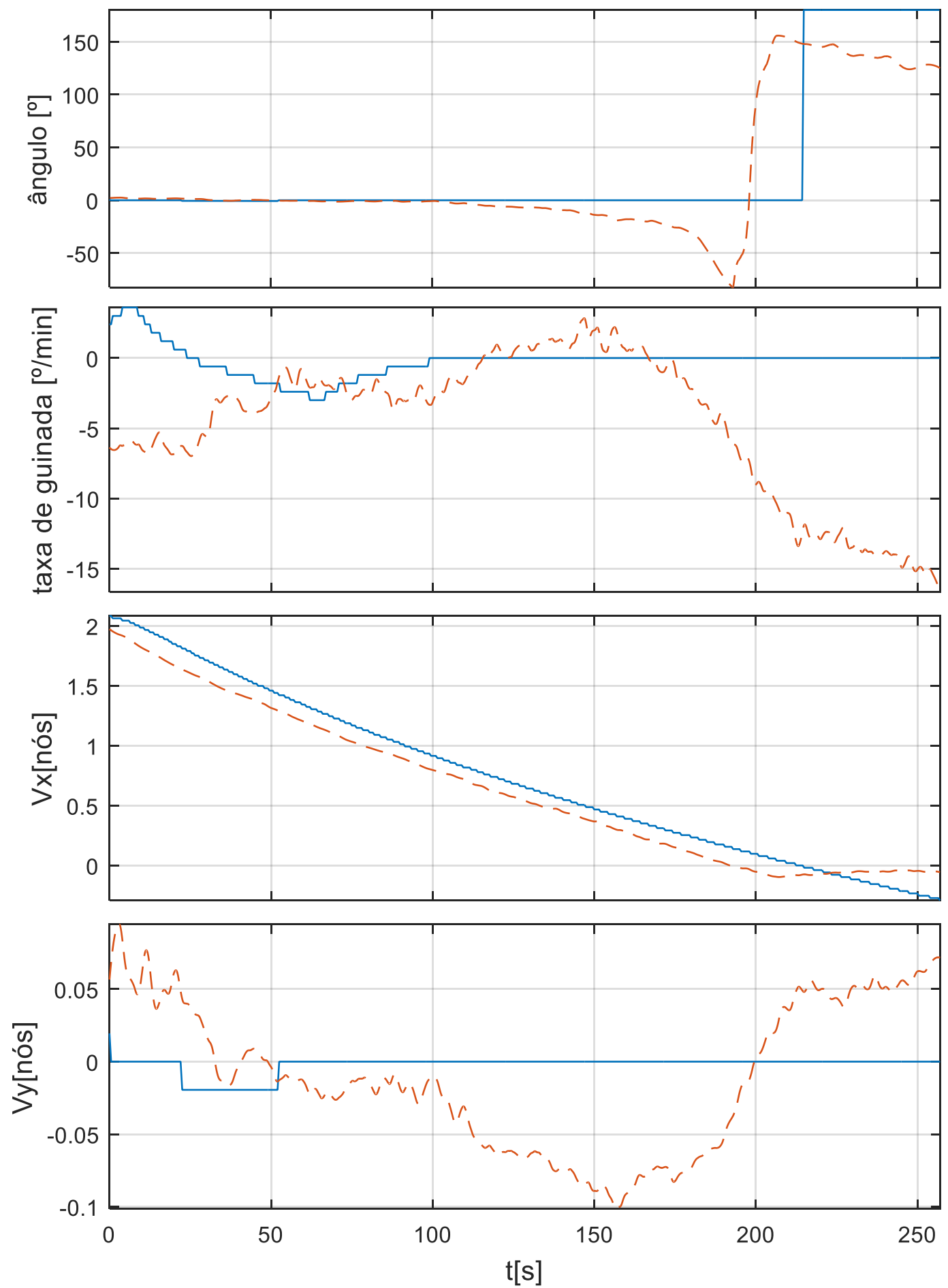

Fonte: Autor.

Simulação - - Experimental 


\subsection{Accelerating turn (Giro com aceleração)}

Conforme descrito pelo grupo ITTC (2002) esta manobra descreve a capacidade do navio guinar com a influência de pequenos impulsos do motor, que ocorrem num curto período de tempo e depois cessam. Este tipo de ocasião ocorre em manobras de portos, onde não há espaço suficiente para permitir o ganho de velocidade.

Para o início dessa manobra o navio deve estar em repouso com máquinas paradas e sem velocidade angular. A manobra inicia com o leme todo para um dos bordos e em seguida é dada a ordem de máquina avante, esta condição é mantida até o fim da manobra.

As principais grandezas medidas a partir dessa manobra são:

- Diâmetro tático, compreende a distância entre a reta que descrevia o movimento da embarcação antes do início da manobra e a posição do centro de massa da embarcação quando houve uma mudança de $180^{\circ}$ em seu aproamento.

- Avanço, distância entre a reta transversal ao navio que passa por seu centro de massa no instante em que a manobra é iniciada e a posição do centro de massa quando há uma alteração de $90^{\circ}$ no aproamento da embarcação.

- Transferência, distância medida entre a reta que descrevia o movimento da embarcação antes da manobra iniciar e o centro de massa da embarcação quando há uma alteração de $90^{\circ} \mathrm{em}$ seu aproamento.

- Velocidade final.

- Tempo para mudar o aproamento da embarcação em 90‥

- Tempo para mudar o aproamento da embarcação em $180^{\circ}$.

- Ângulo de deriva (drift), diferença entre a direção de aproamento da embarcação e sua direção de movimento. 


\subsubsection{Manobra 12}

Nessa manobra foi realizada uma curva de giro com máquina meia força avante (1050 RPM), com leme de 30‥ A Tabela 29 apresenta os dados táticos obtidos:

Tabela 29 - Dados táticos obtidos para a manobra 12

\begin{tabular}{|l|l|l|l|l|}
\hline Experimental & Avanço & Transferência & Diâmetro tático & Diâmetro final \\
\hline Simulado & $61,0 \mathrm{~m}(1,2 \mathrm{~L})$ & $19,6 \mathrm{~m}(0,3 \mathrm{~L})$ & $102,1 \mathrm{~m}(1,6 \mathrm{~L})$ & $120,1 \mathrm{~m}(1,9 \mathrm{~L})$ \\
\hline Erro & $-17,5 \%$ & $19,4 \mathrm{~m}(0,3 \mathrm{~L})$ & $101,9 \mathrm{~m}(1,6 \mathrm{~L})$ & $131,2 \mathrm{~m}(2,1 \mathrm{~L})$ \\
\hline & Vx final & $-1,1 \%$ & $-0,2 \%$ & $9,3 \%$ \\
\hline Experimental & 2,3 nós & 1,7 nós & $\begin{array}{l}\text { Velocidade } \\
\text { angular }\end{array}$ & $\begin{array}{l}\text { Ângulo de } \\
\text { deriva }\end{array}$ \\
\hline Simulado & 2,2 nós & 1,1 nós & $65,3 \% \mathrm{~min}$ & $36,5^{\circ}$ \\
\hline Erro & $-5,6 \%$ & $-36,7 \%$ & $-23,4 \%$ & $26,2 \%$ \\
\hline
\end{tabular}

Fonte: Autor.

A Figura 81 mostra que a trajetória no início da manobra foi boa e piorou ao longo do tempo. Como pode ser visto na Figura 82, nesta manobra as velocidades mostraram-se estáveis, com pouca oscilação, também não foram identificados sobressinais na velocidade angular nem no ângulo de deriva.

Figura 81 - Trajetória varrida, manobra 12

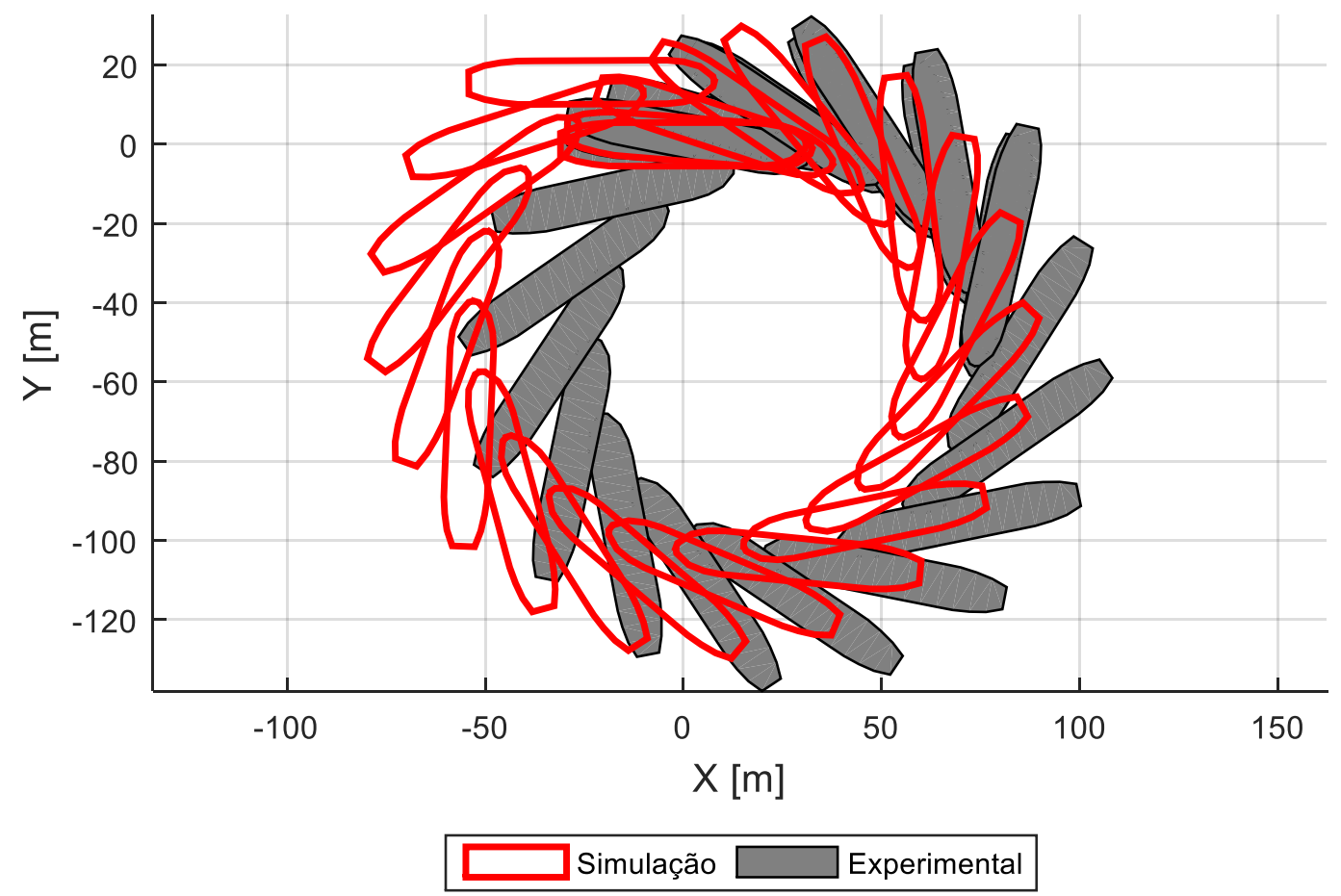

Fonte: Autor. 
Figura 82 - Ângulo de deriva, Velocidade angular, Velocidade Vx, velocidade Vy, manobra 12
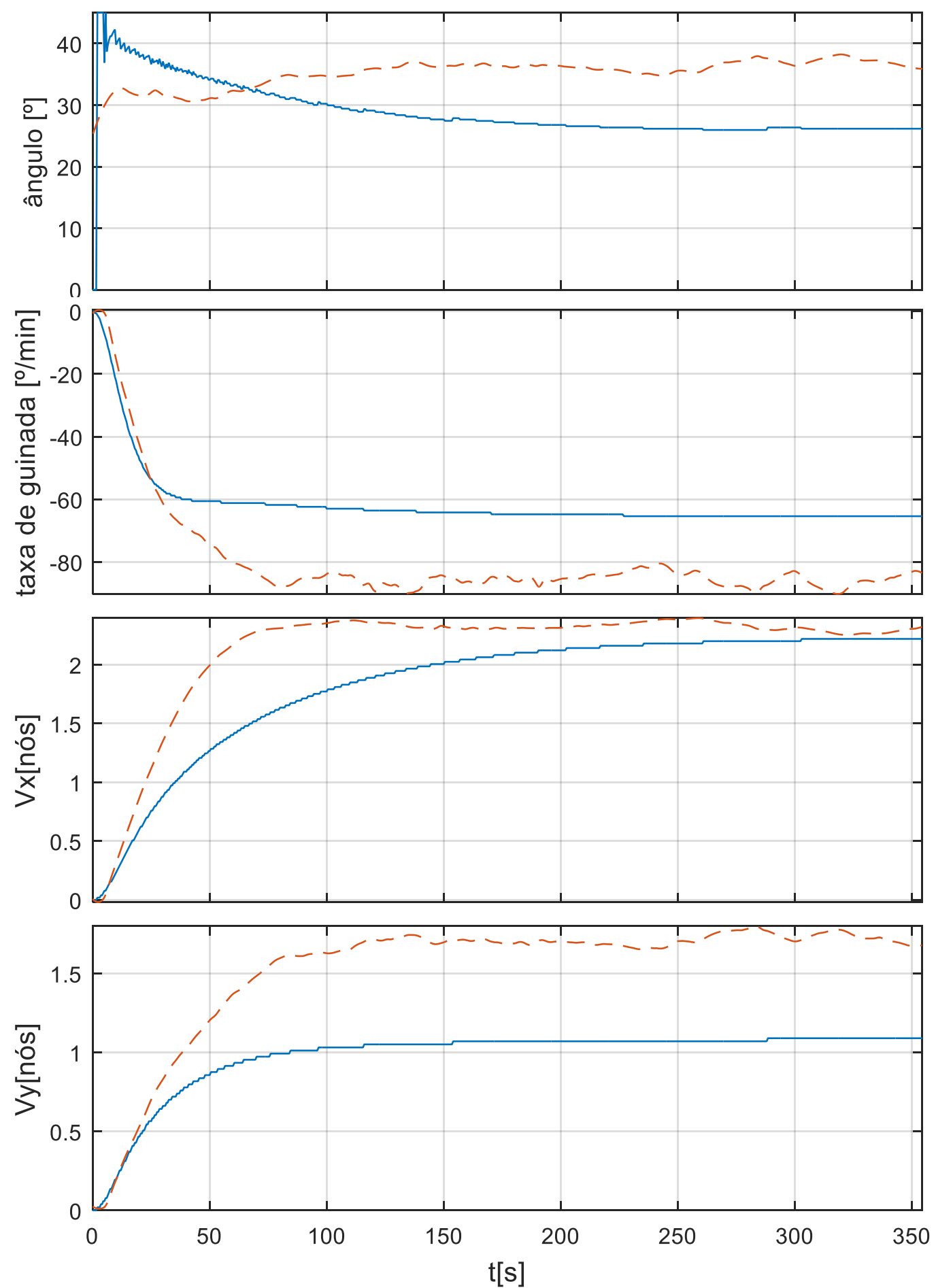

Fonte: Autor.

Simulação - - Experimental 


\subsubsection{Manobra 13}

Nessa manobra foi realizada uma curva de giro com máquina meia força avante (1050 RPM), com leme de 20․․ A Tabela 30 apresenta os dados táticos obtidos:

Tabela 30 - Dados táticos obtidos para a manobra 13

\begin{tabular}{|l|l|l|l|l|}
\hline Experimental & Avanço & Transferência & Diâmetro tático & Diâmetro final \\
\hline Simulado & $92,8 \mathrm{~m}(1,5 \mathrm{~L})$ & $50,6 \mathrm{~m}(0,8 \mathrm{~L})$ & $170,5 \mathrm{~m}(2,7 \mathrm{~L})$ & $177,2 \mathrm{~m}(2,8 \mathrm{~L})$ \\
\hline Erro & $-11,9 \%$ & $17,2 \%$ & $188,0 \mathrm{~m}(3,0 \mathrm{~L})$ & $217,5 \mathrm{~m}(3,5 \mathrm{~L})$ \\
\hline & Vx final & Vy final & $\begin{array}{l}10,3 \% \\
\text { Velocidade } \\
\text { angular }\end{array}$ & $\begin{array}{l}22,8 \% \\
\text { Ângulo de } \\
\text { deriva }\end{array}$ \\
\hline Experimental & 3,2 nós & 1,6 nós & $71,6 \% \mathrm{~min}$ & $26,1^{\circ}$ \\
\hline Simulado & 3,4 nós & 0,9 nós & $57,6 \% \mathrm{~min}$ & $15,2^{\circ}$ \\
\hline Erro & $8,5 \%$ & $-40,0 \%$ & $-19,6 \%$ & $-41,8 \%$ \\
\hline
\end{tabular}

Fonte: Autor.

A Figura 83 mostra um diâmetro de giro maior quando comparado à manobra 12, com o modelo numérico apresentando menor ângulo de deriva. Este comportamento foi causado pela baixa velocidade de deriva, que pode ser visto através da Figura 84.

Figura 83 - Trajetória varrida, manobra 13

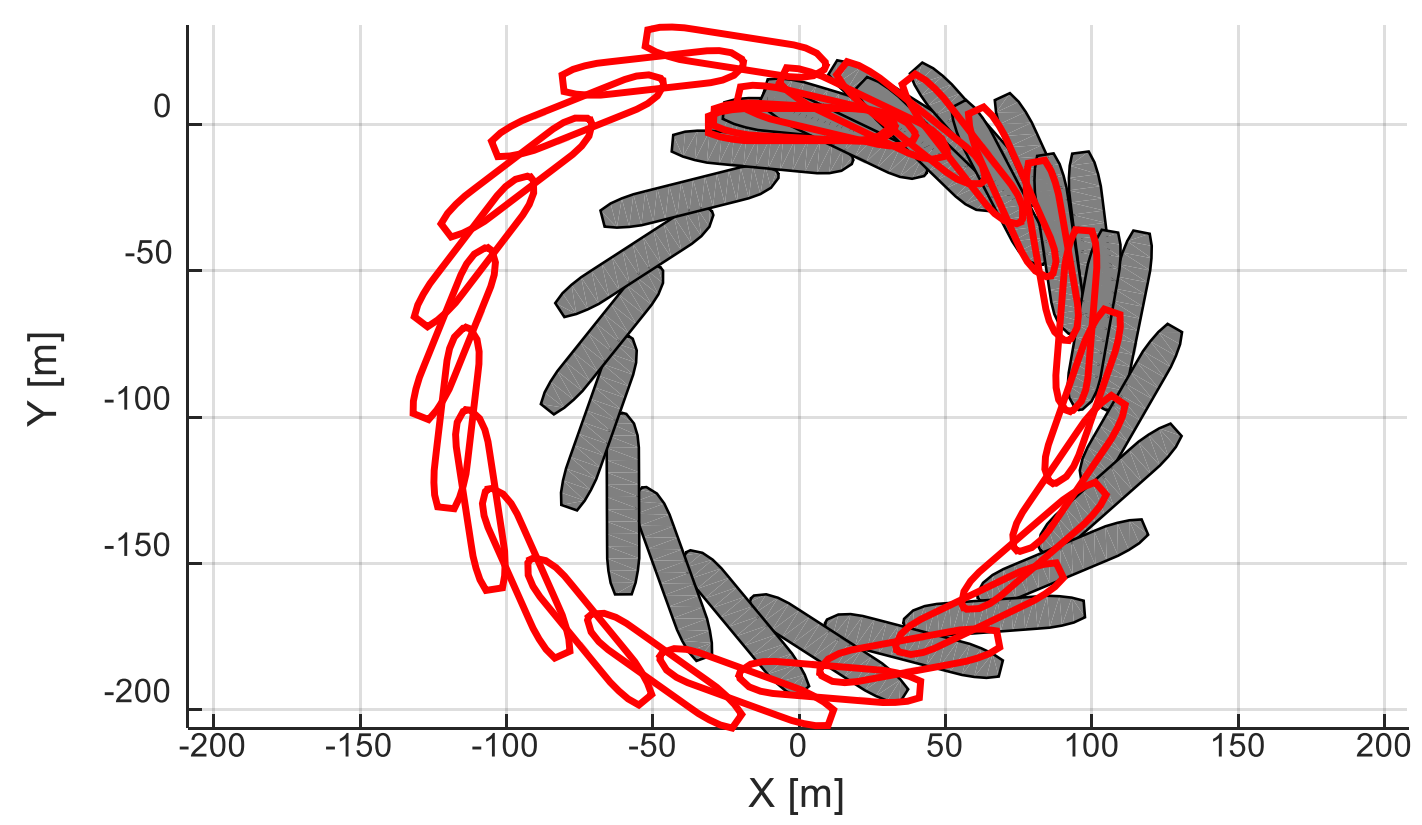

Fonte: Autor.

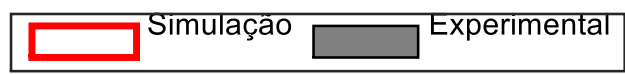


Figura 84 - Ângulo de deriva, Velocidade angular, Velocidade Vx, velocidade Vy, manobra 13
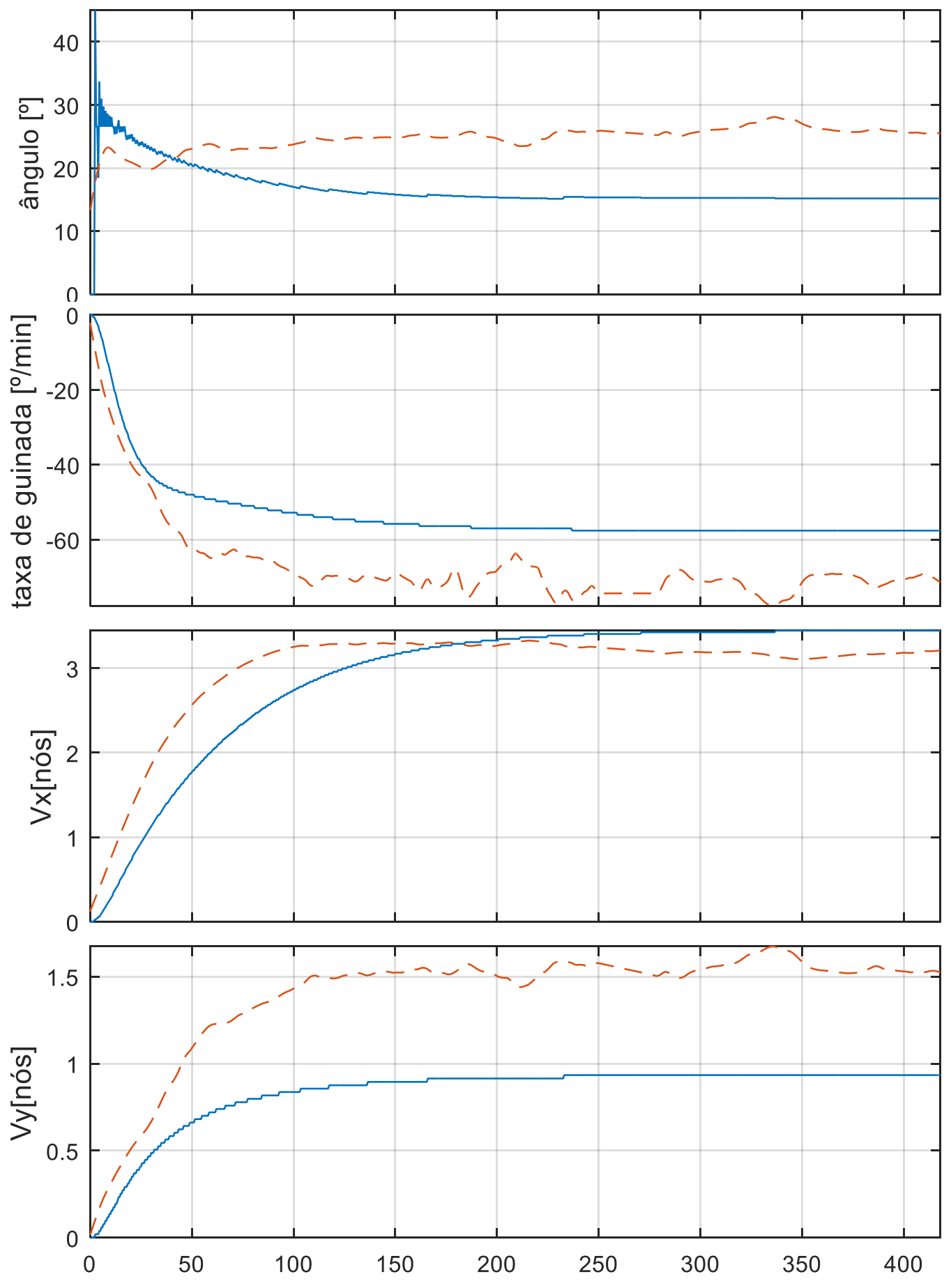

$\mathrm{t}[\mathrm{s}]$

Fonte: Autor. 


\subsubsection{Manobra 14}

Nessa manobra foi realizada uma curva de giro com máquina devagar avante (500 RPM), com leme de 30‥ A Tabela 31 apresenta os dados táticos obtidos:

Tabela 31 - Dados táticos obtidos para a manobra 14

\begin{tabular}{|l|l|l|l|l|}
\hline Experimental & Avanço & Transferência & Diâmetro tático & Diâmetro final \\
\hline Simulado & $58,1 \mathrm{~m}(1,3 \mathrm{~L})$ & $26,6 \mathrm{~m}(0,4 \mathrm{~L})$ & $112,7 \mathrm{~m}(1,8 \mathrm{~L})$ & $127,0 \mathrm{~m}(2,0 \mathrm{~L})$ \\
\hline Erro & $-26,8 \%$ & $15,3 \mathrm{~m}(0,2 \mathrm{~L})$ & $90,5 \mathrm{~m}(1,4 \mathrm{~L})$ & $113,4 \mathrm{~m}(1,8 \mathrm{~L})$ \\
\hline & Vx final & $-42,4 \%$ & $-19,7 \%$ & $-10,7 \%$ \\
\hline Experimental & 1,1 nós & 0,8 nós & $\begin{array}{l}\text { Velocidade } \\
\text { angular }\end{array}$ & $\begin{array}{l}\text { Ângulo de } \\
\text { deriva }\end{array}$ \\
\hline Simulado & 0,8 nós & 0,5 nós & $39,3 \%$ min & $36,2^{\circ}$ \\
\hline Erro & $-20,5 \%$ & $-31,5 \%$ & $-22,2 \%$ & $31,2^{\circ}$ \\
\hline
\end{tabular}

Fonte: Autor.

Nesta manobra a velocidade de deriva ainda foi menor para o modelo numérico, como pode ser visto na Figura 86, porém a velocidade de avanço também foi inferior à do modelo experimental, resultando em um giro com menor diâmetro como ilustrado pela Figura 85.

Figura 85 - Trajetória varrida, manobra 14

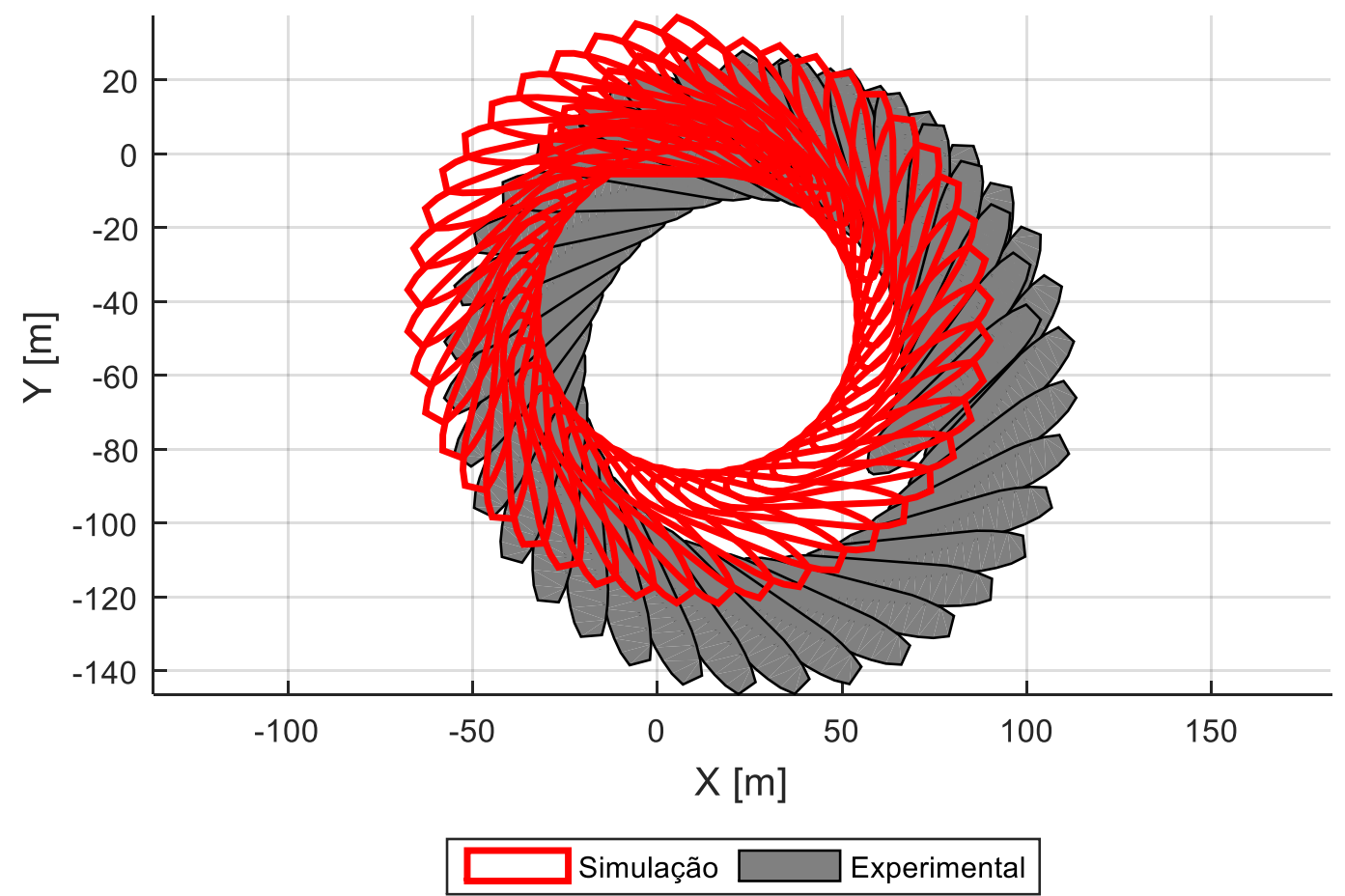

Fonte: Autor. 
Figura 86 - Ângulo de deriva, Velocidade angular, Velocidade Vx, velocidade Vy, manobra 14
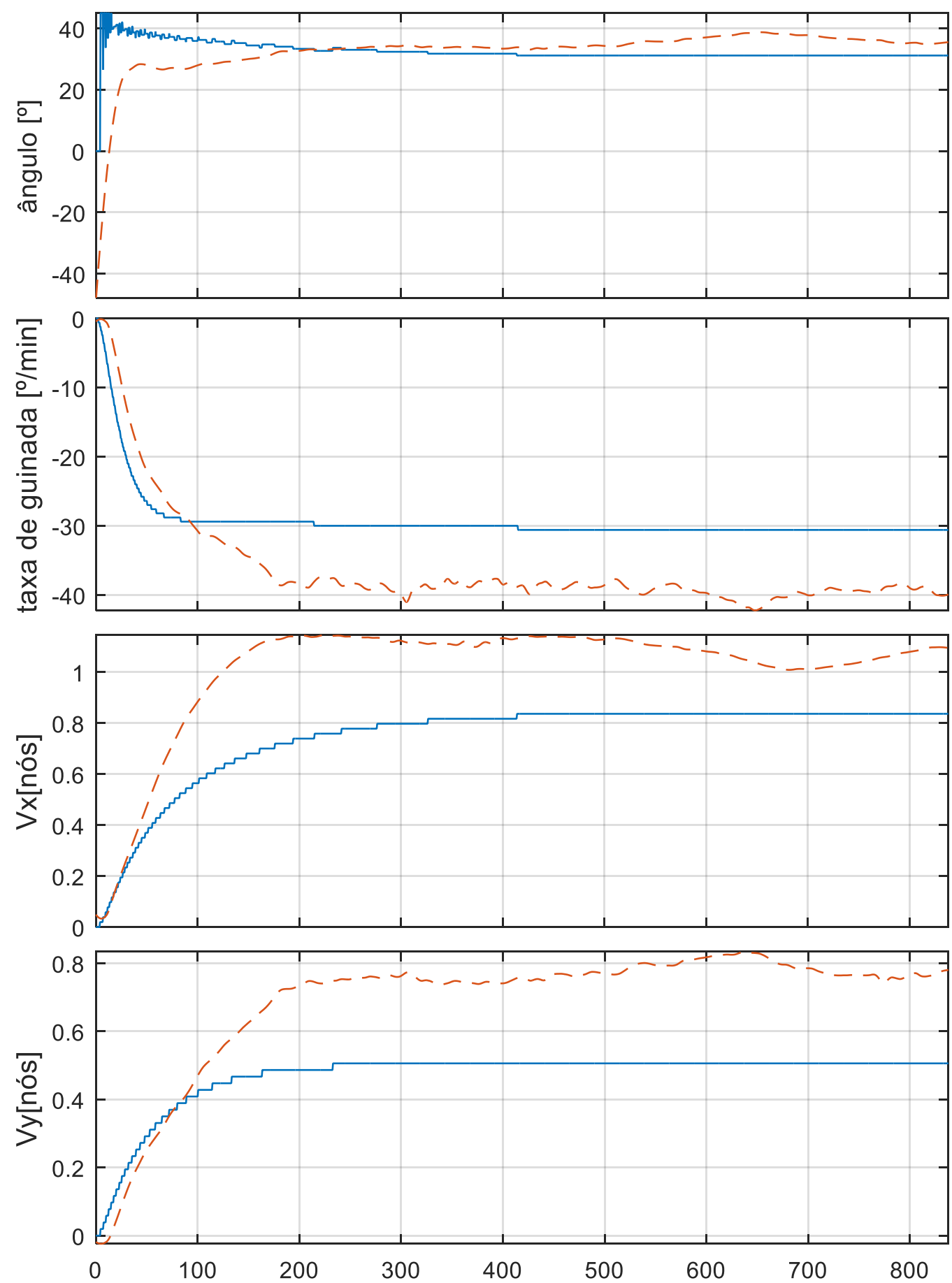

$\mathrm{t}[\mathrm{s}]$

Fonte: Autor. 


\subsubsection{Manobra 15}

Nessa manobra foi realizada uma curva de giro com máquina devagar avante (500 RPM), com leme de 20‥ A Tabela 32 apresenta os dados táticos obtidos:

Tabela 32 - Dados táticos obtidos para a manobra 15

\begin{tabular}{|l|l|l|l|l|}
\hline Experimental & Avanço & Transferência & Diâmetro tático & \multicolumn{1}{|c|}{ Diâmetro final } \\
\hline Simulado & $88,7 \mathrm{~m}(1,6 \mathrm{~L})$ & $53,4 \mathrm{~m}(0,9 \mathrm{~L})$ & $176,2 \mathrm{~m}(2,8 \mathrm{~L})$ & $190,6 \mathrm{~m}(3,1 \mathrm{~L})$ \\
\hline Erro & $-12,8 \%$ & $52,1 \mathrm{~m}(0,8 \mathrm{~L})$ & $171,1 \mathrm{~m}(2,7 \mathrm{~L})$ & $200,5 \mathrm{~m}(3,2 \mathrm{~L})$ \\
\hline & Vx final & $-2,4 \%$ & $-2,9 \%$ & $5,2 \%$ \\
\hline Experimental & 1,6 nós & 0,7 nós & $\begin{array}{l}\text { Velocidade } \\
\text { angular }\end{array}$ & $\begin{array}{l}\text { Ângulo de } \\
\text { deriva }\end{array}$ \\
\hline Simulado & 1,5 nós & 0,4 nós & $27,0 \%$ min & $22,4^{\circ}$ \\
\hline Erro & $-8,7 \%$ & $-32,7 \%$ & $-13,5 \%$ & $16,1^{\circ}$ \\
\hline
\end{tabular}

Fonte: Autor.

A Figura 88 mostra que o maior erro nesta manobra foi gerado devido à baixa velocidade de deriva do modelo numérico. Contudo a Figura 87 mostra que a trajetória dos modelos foi próxima.

Figura 87 - Trajetória varrida, manobra 15

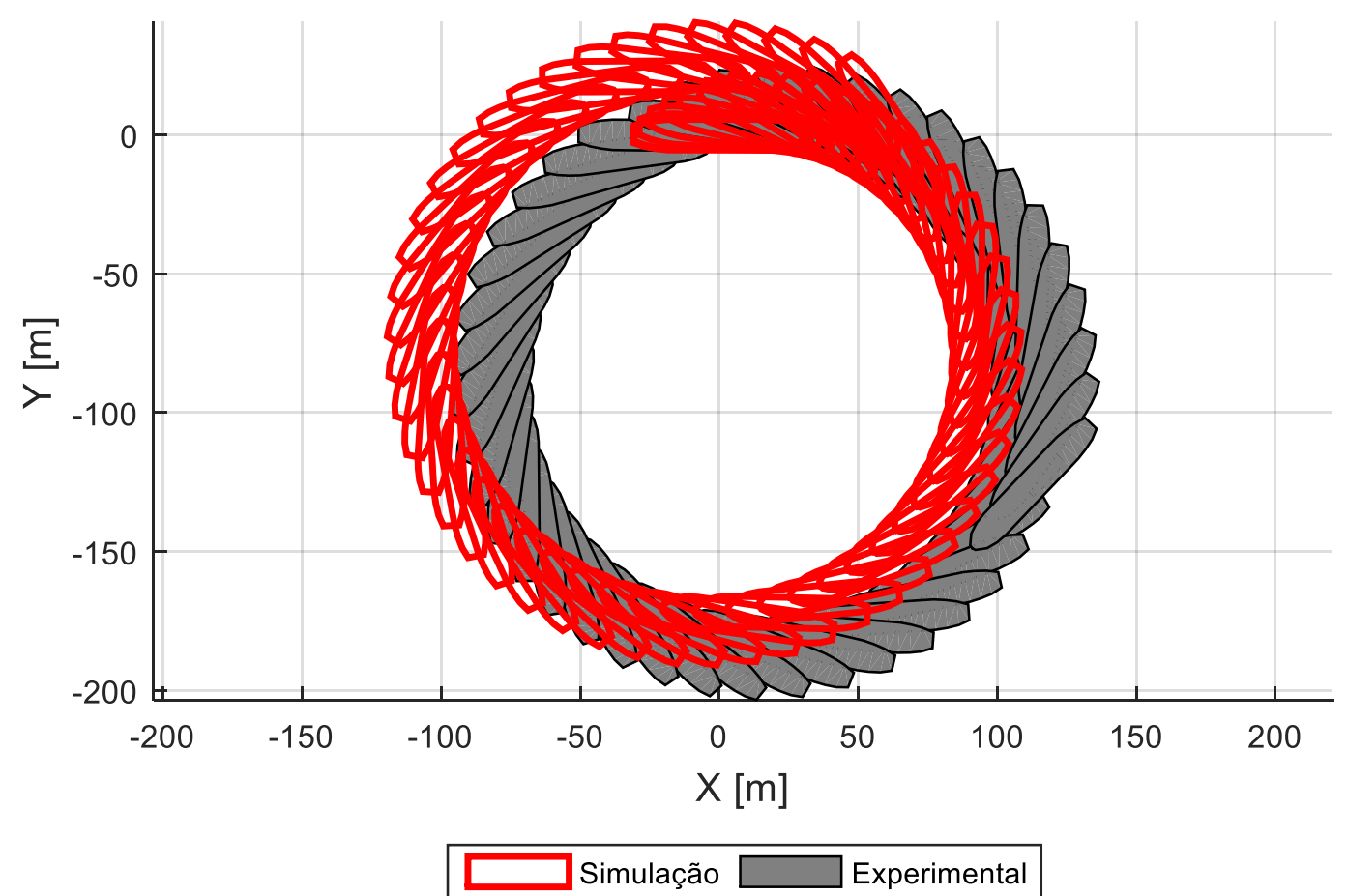

Fonte: Autor. 
Figura 88 - Ângulo de deriva, Velocidade angular, Velocidade Vx, velocidade Vy, manobra 15
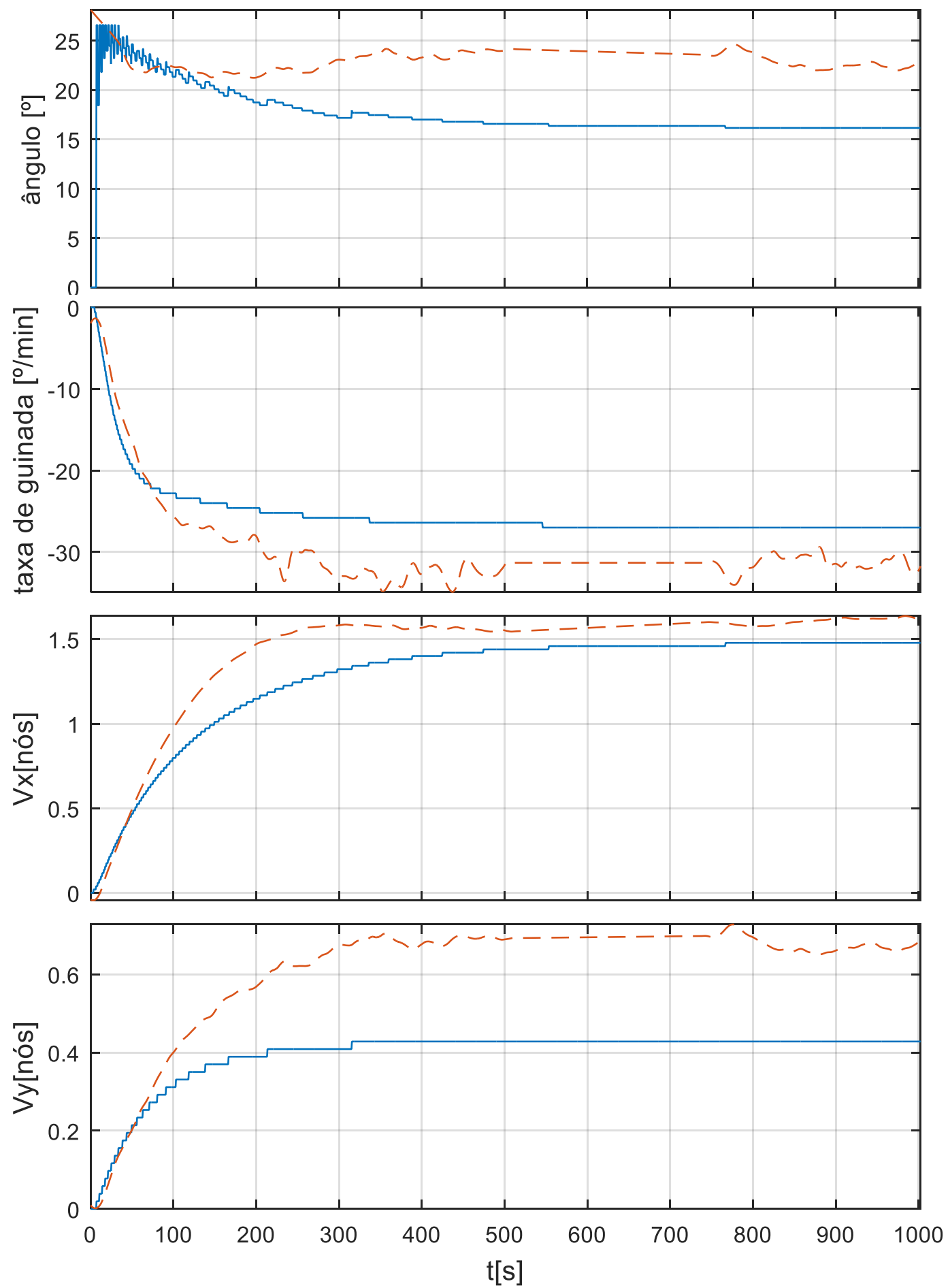

Fonte: Autor. 


\subsubsection{Manobra 12 -águas rasas}

Nessa manobra foi realizada uma curva de giro com máquina meia força avante (1050 RPM), com leme de 30‥ A Tabela 33 apresenta os dados táticos obtidos:

Tabela 33 - Dados táticos obtidos para a manobra 12 em águas rasas

\begin{tabular}{|l|l|l|l|l|}
\hline Experimental & Avanço & Transferência & Diâmetro tático & Diâmetro final \\
\hline Simulado & $47,3 \mathrm{~m}(1,3 \mathrm{~L})$ & $41,9 \mathrm{~m}(0,7 \mathrm{~L})$ & $130,6 \mathrm{~m}(2,1 \mathrm{~L})$ & $140,0 \mathrm{~m}(2,2 \mathrm{~L})$ \\
\hline Erro & $-41,2 \%$ & $19,8 \mathrm{~m}(0,3 \mathrm{~L})$ & $87,9 \mathrm{~m}(1,4 \mathrm{~L})$ & $125,5 \mathrm{~m}(2,0 \mathrm{~L})$ \\
\hline & Vx final & $-52,8 \%$ & $-32,7 \%$ & $-10,3 \%$ \\
\hline Experimental & 3,1 nós & 1,0 nós & $\begin{array}{l}\text { Velocidade } \\
\text { angular }\end{array}$ & $\begin{array}{l}\text { Ângulo de } \\
\text { deriva }\end{array}$ \\
\hline Simulado & 2,4 nós & 0,7 nós & $70,7 \%$ min & $18,6^{\circ}$ \\
\hline Erro & $-21,0 \%$ & $-29,0 \%$ & $-11,1 \%$ & $16,8^{\circ}$ \\
\hline
\end{tabular}

Fonte: Autor.

A Figura 90 mostra que a velocidade de avanço do modelo numérico apresenta um comportamento com maior amortecimento do que o modelo experimental, e menor velocidade de deriva após a fase transiente de velocidades Estas características resultam no comportamento observado através da Figura 89, que mostra um maior erro da trajetória no fim da manobra.

Figura 89 - Trajetória varrida, manobra 12

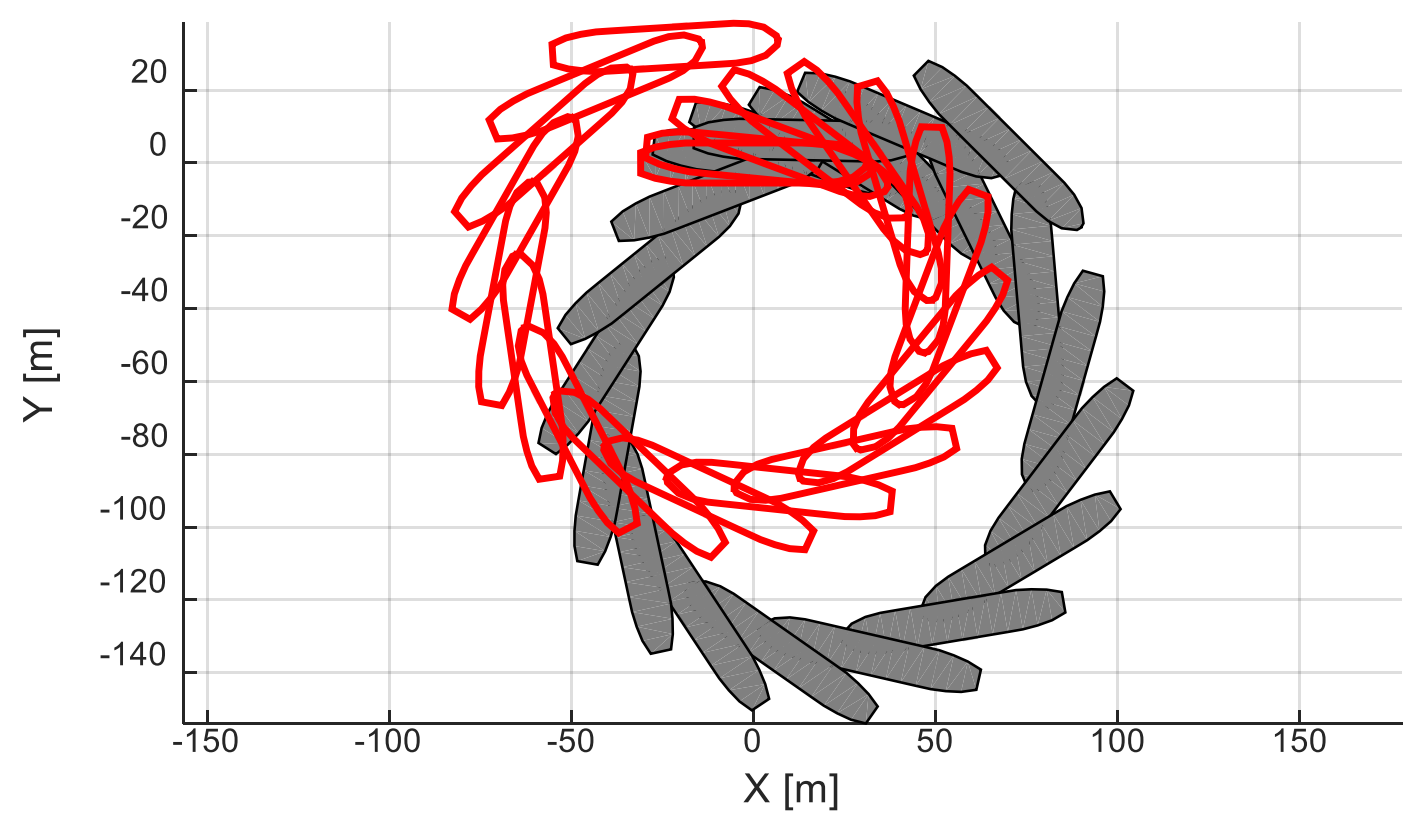

Fonte: Autor. 
Figura 90 - Ângulo de deriva, Velocidade angular, Velocidade Vx, velocidade Vy, manobra 12
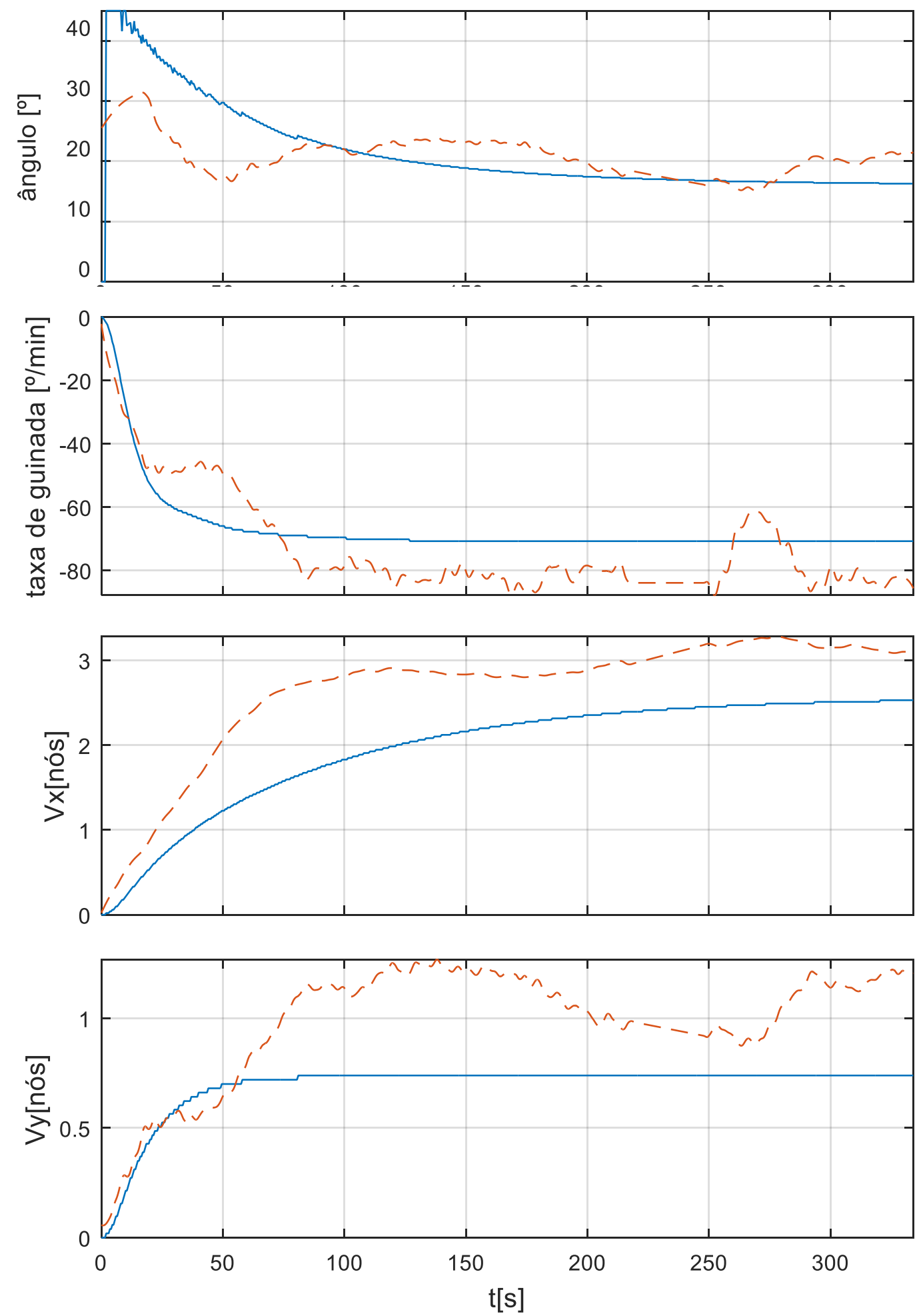

- Simulação - - Experimental

Fonte: Autor. 
6.6.6. Manobra 13 -águas rasas

Nessa manobra foi realizada uma curva de giro com máquina meia força avante (1050 RPM), com leme de 20‥ A Tabela 34 apresenta os dados táticos obtidos:

Tabela 34 - Dados táticos obtidos para a manobra 13 em águas rasas

\begin{tabular}{|c|c|c|c|c|}
\hline & Avanço & Transferência & Diâmetro tático & Diâmetro final \\
\hline Experimental & $100,7 \mathrm{~m}(1,6 \mathrm{~L})$ & 82,6 m (1,3 L) & $181,5 \mathrm{~m}(2,9 \mathrm{~L})$ & \\
\hline Simulado & $67,3 \mathrm{~m}(1,1 \mathrm{~L})$ & $61,0 \mathrm{~m}(1,0 \mathrm{~L})$ & $179,3 \mathrm{~m}(2,9 \mathrm{~L})$ & \\
\hline Erro & $-33,2 \%$ & $-26,2 \%$ & $-1,2 \%$ & \\
\hline & Vx final & Vy final & $\begin{array}{l}\text { Velocidade } \\
\text { angular }\end{array}$ & $\begin{array}{l}\text { Ângulo } \\
\text { deriva }\end{array}$ \\
\hline Experimental & 3,6 nós & 1,0 nós & $71,6^{\circ} / \mathrm{min}$ & $14,1^{\circ}$ \\
\hline Simulado & 3,5 nós & 0,5 nós & $53,6 \% \mathrm{~min}$ & $9,2^{\circ}$ \\
\hline Erro & $-2,8 \%$ & $-50,0 \%$ & $-25,1 \%$ & $-34,8 \%$ \\
\hline
\end{tabular}

Fonte: Autor.

A Figura 91 mostra uma grande diferença entre as trajetórias dos dois modelos. A principal diferença observada na trajetória desta manobra foi para o avanço. A Figura 92 mostra que o modelo numérico apresentou bom comportamento, porém com comportamento mais amortecido que o modelo experimental.

Figura 91 - Trajetória varrida, manobra 13

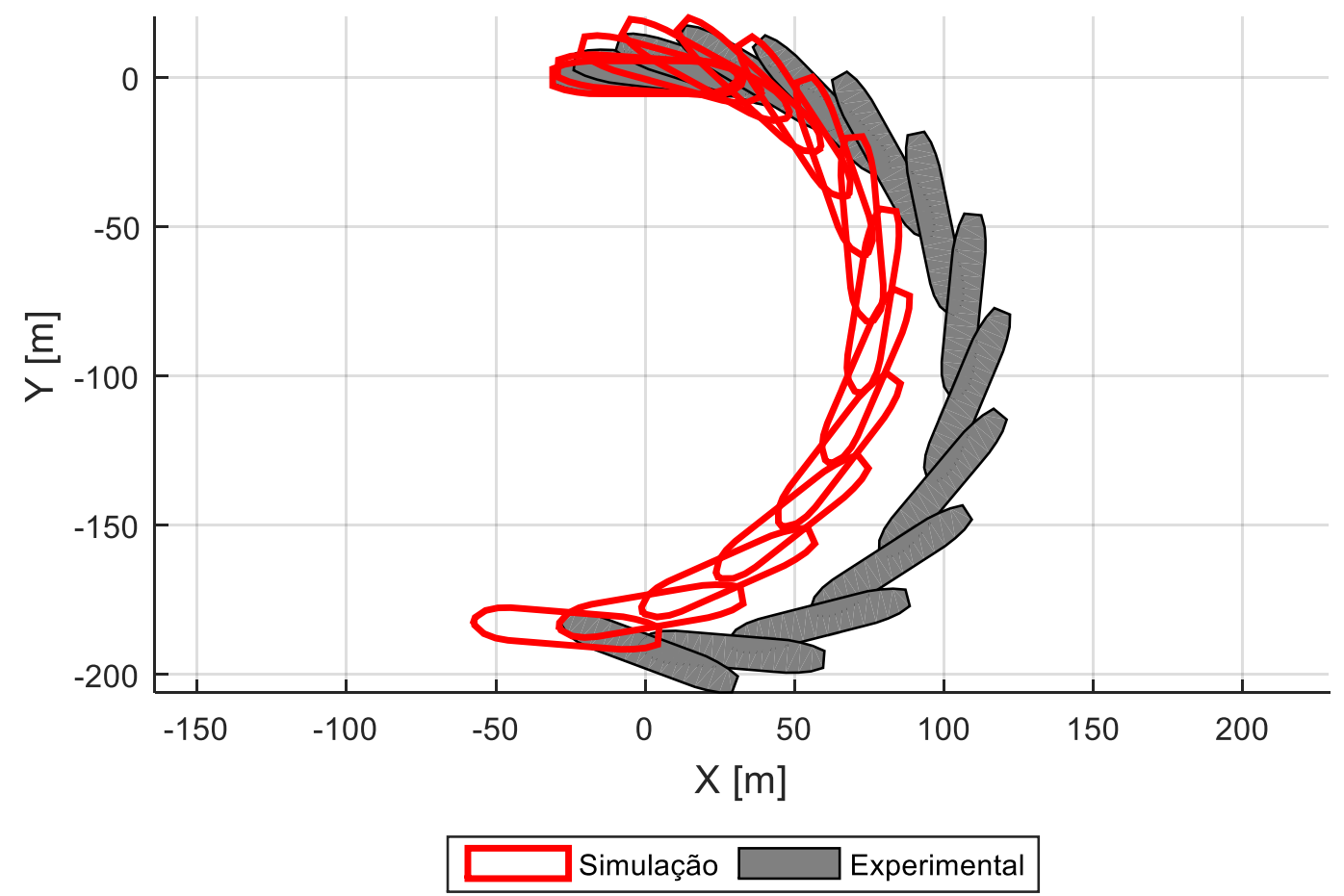

Fonte: Autor. 
Figura 92 - Ângulo de deriva, Velocidade angular, Velocidade Vx, velocidade Vy, manobra 13
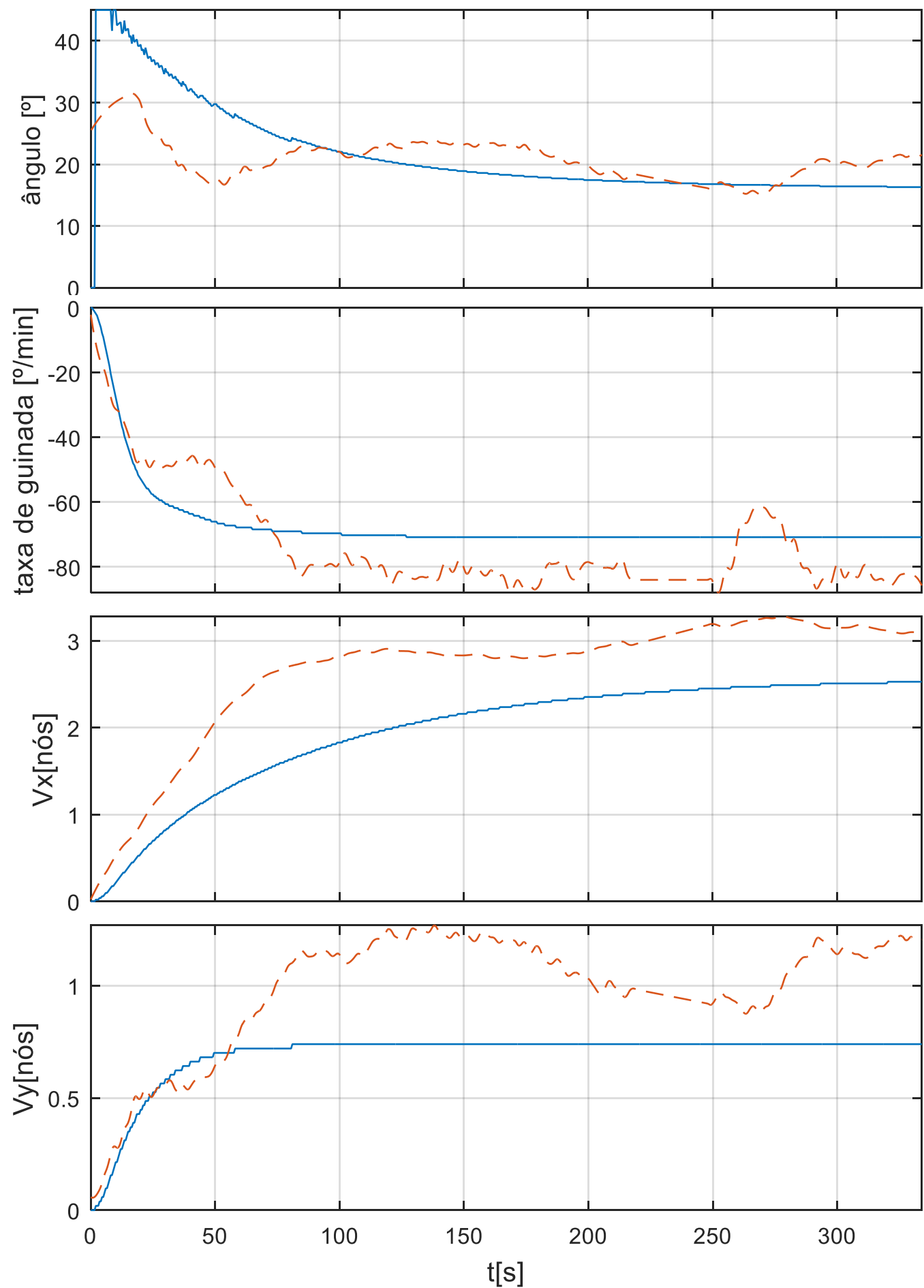

Fonte: Autor.

Simulação - - Experimental 


\subsubsection{Manobra 14 -águas rasas}

Nessa manobra foi realizada uma curva de giro com máquina devagar avante (500 RPM), com leme de 30‥ A Tabela 35 apresenta os dados táticos obtidos:

Tabela 35 - Dados táticos obtidos para a manobra 14 em águas rasas

\begin{tabular}{|l|l|l|l|l|}
\hline & Avanço & Transferência & Diâmetro tático & Diâmetro final \\
\hline Experimental & $95,7 \mathrm{~m}(1,5 \mathrm{~L})$ & $53,1 \mathrm{~m}(0,8 \mathrm{~L})$ & $151,2 \mathrm{~m}(2,4 \mathrm{~L})$ & $127,7 \mathrm{~m}(2,0 \mathrm{~L})$ \\
\hline Simulado & $46,7 \mathrm{~m}(0,7 \mathrm{~L})$ & $18,4 \mathrm{~m}(0,3 \mathrm{~L})$ & $83,6 \mathrm{~m}(1,3 \mathrm{~L})$ & $115,1 \mathrm{~m}(1,8 \mathrm{~L})$ \\
\hline Erro & $-51,2 \%$ & $-65,3 \%$ & $-44,7 \%$ & $-9,9 \%$ \\
\hline & Vx final & Vy final & $\begin{array}{l}\text { Velocidade } \\
\text { angular }\end{array}$ & $\begin{array}{l}\text { Ângulo de } \\
\text { deriva }\end{array}$ \\
\hline Experimental & 1,4 nós & 0,5 nós & $36,0 \% \mathrm{~min}$ & $17,9^{\circ}$ \\
\hline Simulado & 1,1 nós & 0,4 nós & $34,2 \% \mathrm{~min}$ & $17,7^{\circ}$ \\
\hline Erro & $-22,7 \%$ & $-23,5 \%$ & $-5,0 \%$ & $-0,7 \%$ \\
\hline
\end{tabular}

Fonte: Autor.

Assim como a manobra 13 em águas rasas, esta apresentou trajetória elíptica, como pode ser visto na Figura 93, com oscilação das velocidades mostrada na Figura 94.

Figura 93 - Trajetória varrida, manobra 14

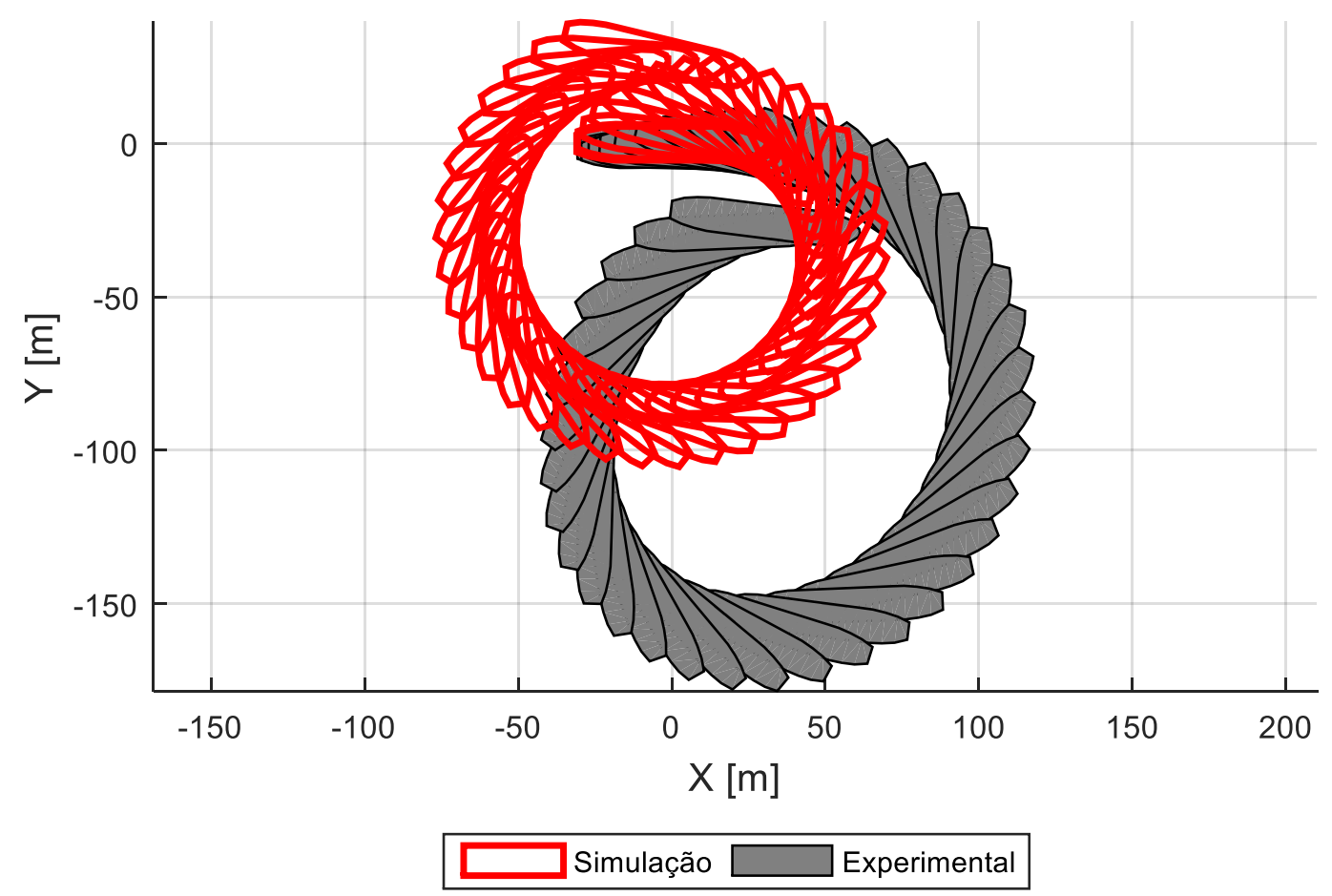

Fonte: Autor. 
Figura 94 - Ângulo de deriva, Velocidade angular, Velocidade Vx, velocidade Vy, manobra 14
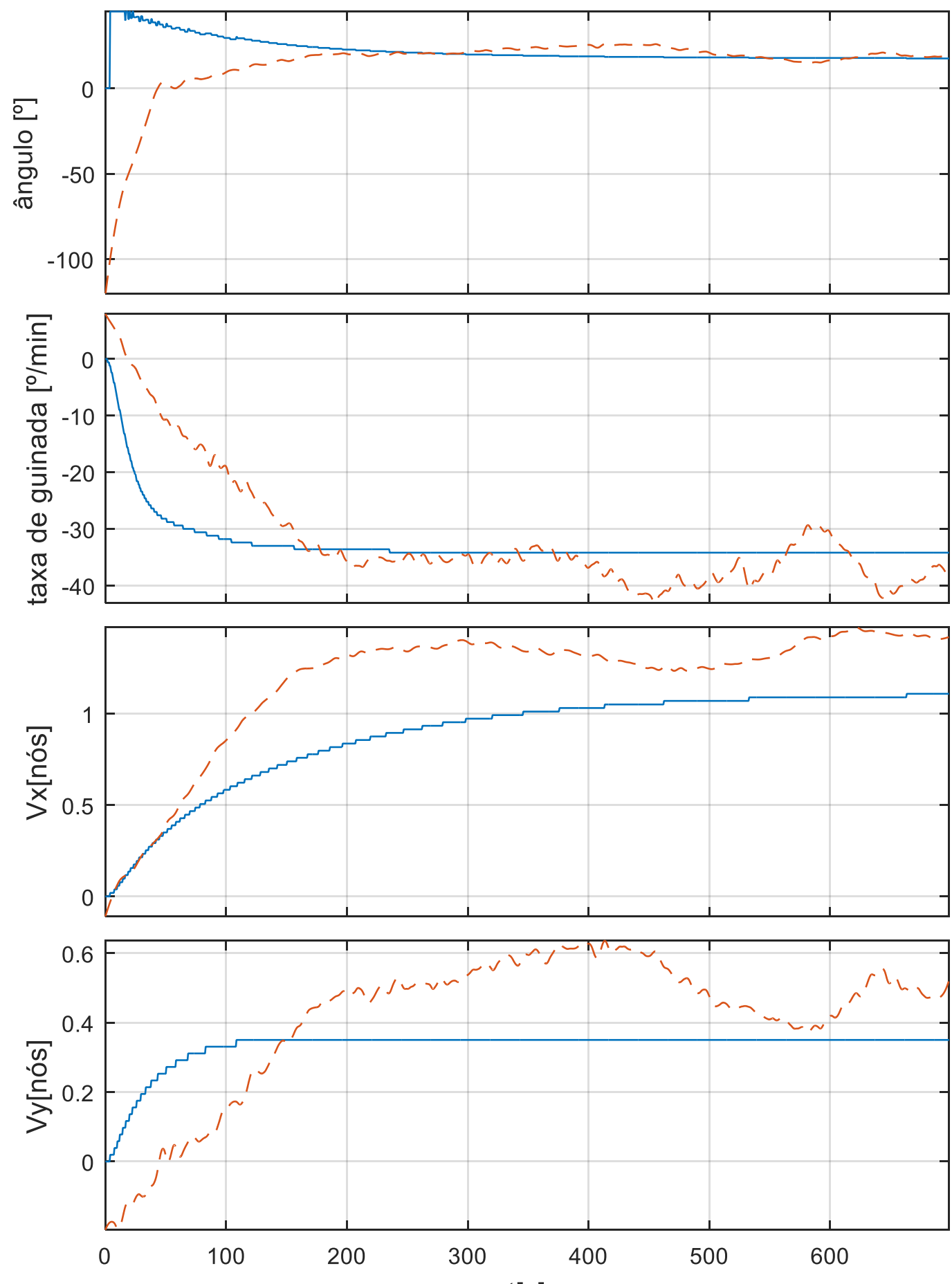

$\mathrm{t}[\mathrm{s}]$

Fonte: Autor. 
6.6.8. Manobra 15 -águas rasas

Nessa manobra foi realizada uma curva de giro com máquina devagar avante (500 RPM), com leme de $20^{\circ}$. A Tabela 36 apresenta os dados táticos obtidos:

Tabela 36 - Dados táticos obtidos para a manobra 15 em águas rasas

\begin{tabular}{|c|c|c|c|c|}
\hline & Avanço & Transferência & Diâmetro tático & Diâmetro final \\
\hline Experimental & $119,1 \mathrm{~m}(1,9 \mathrm{~L})$ & 76,7 m (1,2 L) & & \\
\hline Simulado & 73,7 m (1,2 L) & $56,6 \mathrm{~m}(0,9 \mathrm{~L})$ & & \\
\hline \multirow[t]{2}{*}{ Erro } & $-38,1 \%$ & $-26,2 \%$ & & \\
\hline & Vx final & Vy final & $\begin{array}{l}\text { Velocidade } \\
\text { angular }\end{array}$ & $\begin{array}{l}\text { Ângulo } \\
\text { deriva }\end{array}$ \\
\hline Experimental & 1,7 nós & 0,5 nós & $29,7^{\circ} / \mathrm{min}$ & $16,8^{\circ}$ \\
\hline Simulado & 1,4 nós & 0,3 nós & $25,8 \% \mathrm{~min}$ & $11,0^{\circ}$ \\
\hline Erro & $-15,4 \%$ & $-46,0 \%$ & $-13,2 \%$ & $-34,7 \%$ \\
\hline
\end{tabular}

Fonte: Autor.

Como mostrado pela Figura 95, esta manobra não foi completa devido ao tamanho do tanque utilizado. Porém observa-se que as trajetórias se afastaram rapidamente com o modelo numérico apresentando menor estabilidade direcional. Este comportamento resulta da velocidade de avanço do modelo numérico mais amortecida do que o modelo experimental, como pode ser visto na Figura 96, e da maior resistência a velocidade de deriva deste modelo.

Figura 95 - Trajetória varrida, manobra 15

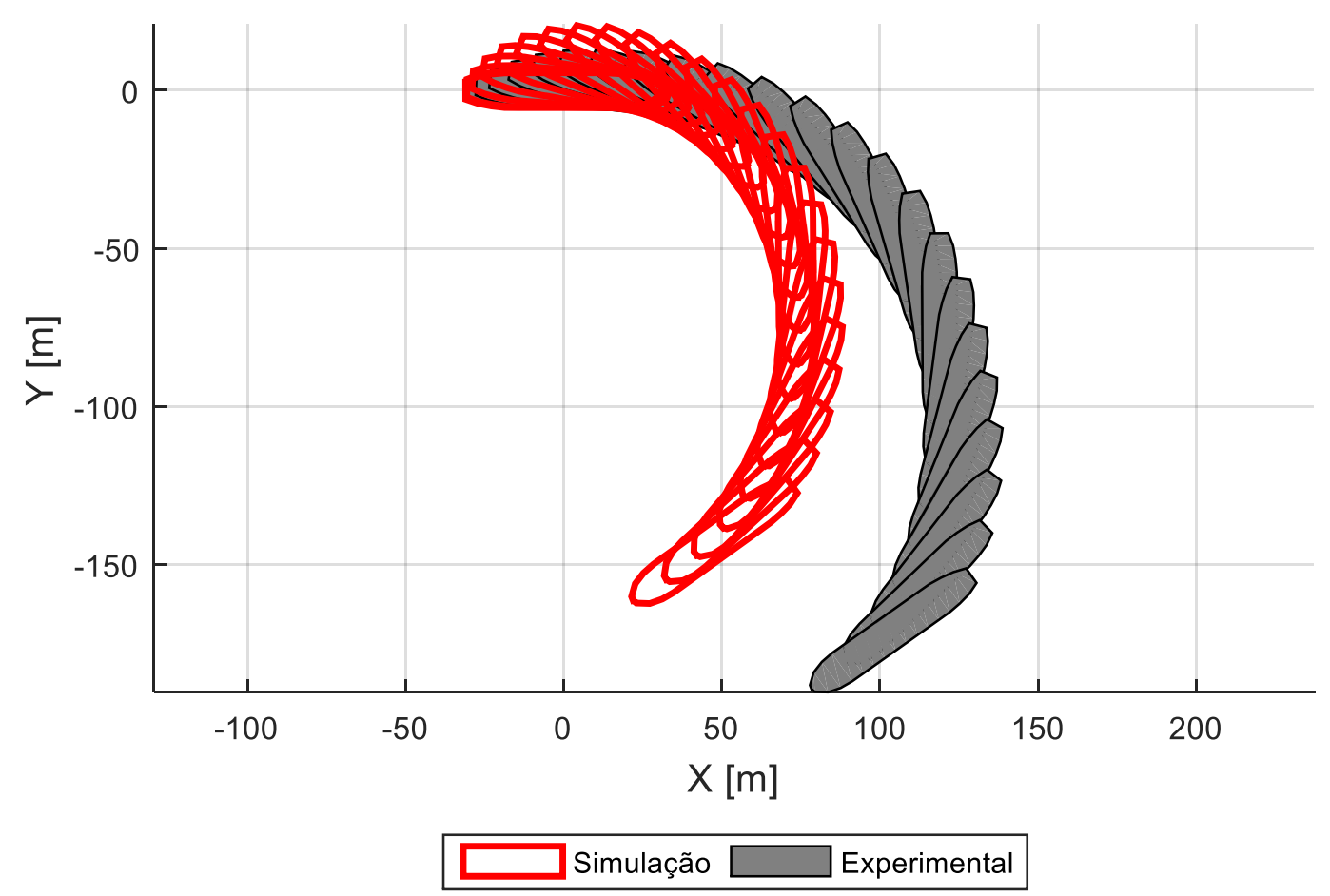

Fonte: Autor. 
Figura 96 - Ângulo de deriva, Velocidade angular, Velocidade Vx, velocidade Vy, manobra 15
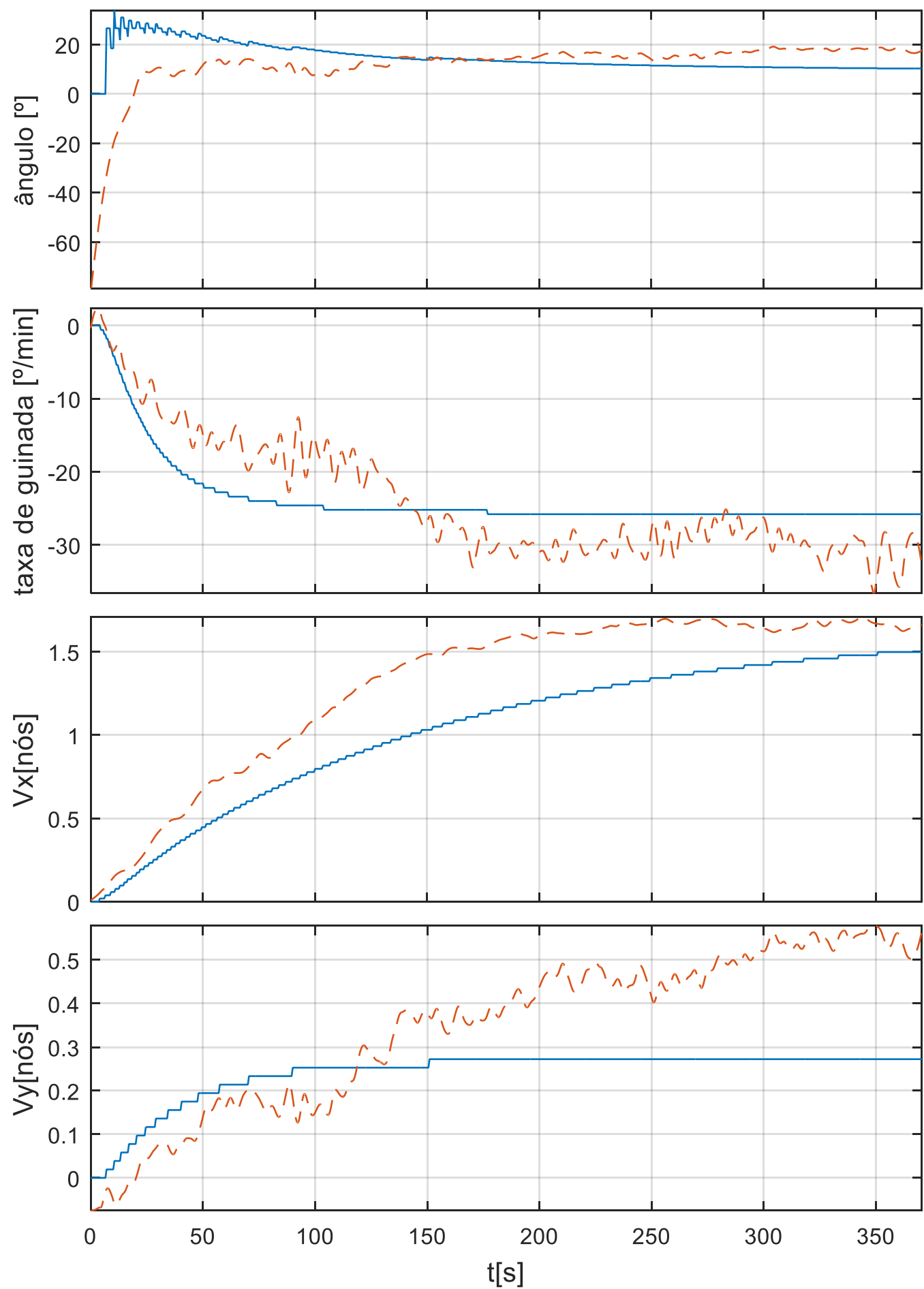

Fonte: Autor.

Simulação - - Experimental 


\subsection{Crash ahead}

Esta manobra mede a capacidade dos propulsores principais pararem um navio com velocidade de avanço negativa. Este tipo de manobra ocorre em regiões portuárias onde o navio apresenta velocidade de avanço negativa para manobrar e desviar de obstáculos.

Para sua execução o navio deve estar inicialmente em repouso, e com máquinas paradas, em seu início, com leme a meio. Em seguida é dada a ordem de máquina a ré, aumentando a velocidade de avanço no sentido negativo, e após o navio se deslocar a distância de um comprimento no sentido negativo é dada a ordem de toda a força avante.

As grandezas medidas nesta manobra são a distância percorrida e desvios laterais, bem como eventuais mudanças de aproamento.

\subsubsection{Manobra 16}

Nessa manobra foi realizado o crash ahead, iniciando o movimento com toda a força para trás, e após o deslocamento de um comprimento de navio foi acionada a máquina com toda força para frente. A Tabela 37 apresenta os dados táticos obtidos:

Tabela 37 - Dados táticos obtidos para a manobra 16

Fonte: Autor.

\begin{tabular}{|l|l|l|l|}
\hline & $\begin{array}{l}\text { Alcance } \\
\text { longitudinal }\end{array}$ & $\begin{array}{l}\text { Alcance } \\
\text { transversal }\end{array}$ & $\begin{array}{l}\text { Distância } \\
\text { percorrida }\end{array}$ \\
\hline Experimental & $89,0 \mathrm{~m}(-1,4 \mathrm{~L})$ & $0,0 \mathrm{~m}(0,0 \mathrm{~L})$ & $89,0 \mathrm{~m}(1,4 \mathrm{~L})$ \\
\hline Simulado & $81,8 \mathrm{~m}(-1,3 \mathrm{~L})$ & $0,0 \mathrm{~m}(0,0 \mathrm{~L})$ & $81,8 \mathrm{~m}(1,3 \mathrm{~L})$ \\
\hline Erro & $8,1 \%$ & & $8,1 \%$ \\
\hline
\end{tabular}

A Figura 97 mostra que ambos os modelos apresentaram o mesmo alcance longitudinal, porém o modelo experimental apresentou velocidade angular durante a fase de aceleração positiva da manobra, indicando uma possível assimetria do modelo, que não ocorre no modelo numérico. A Figura 98 mostra que a aceleração longitudinal dos dois modelos é compatível durante todas as fases da manobra. 
Figura 97 - Trajetória varrida, manobra 16

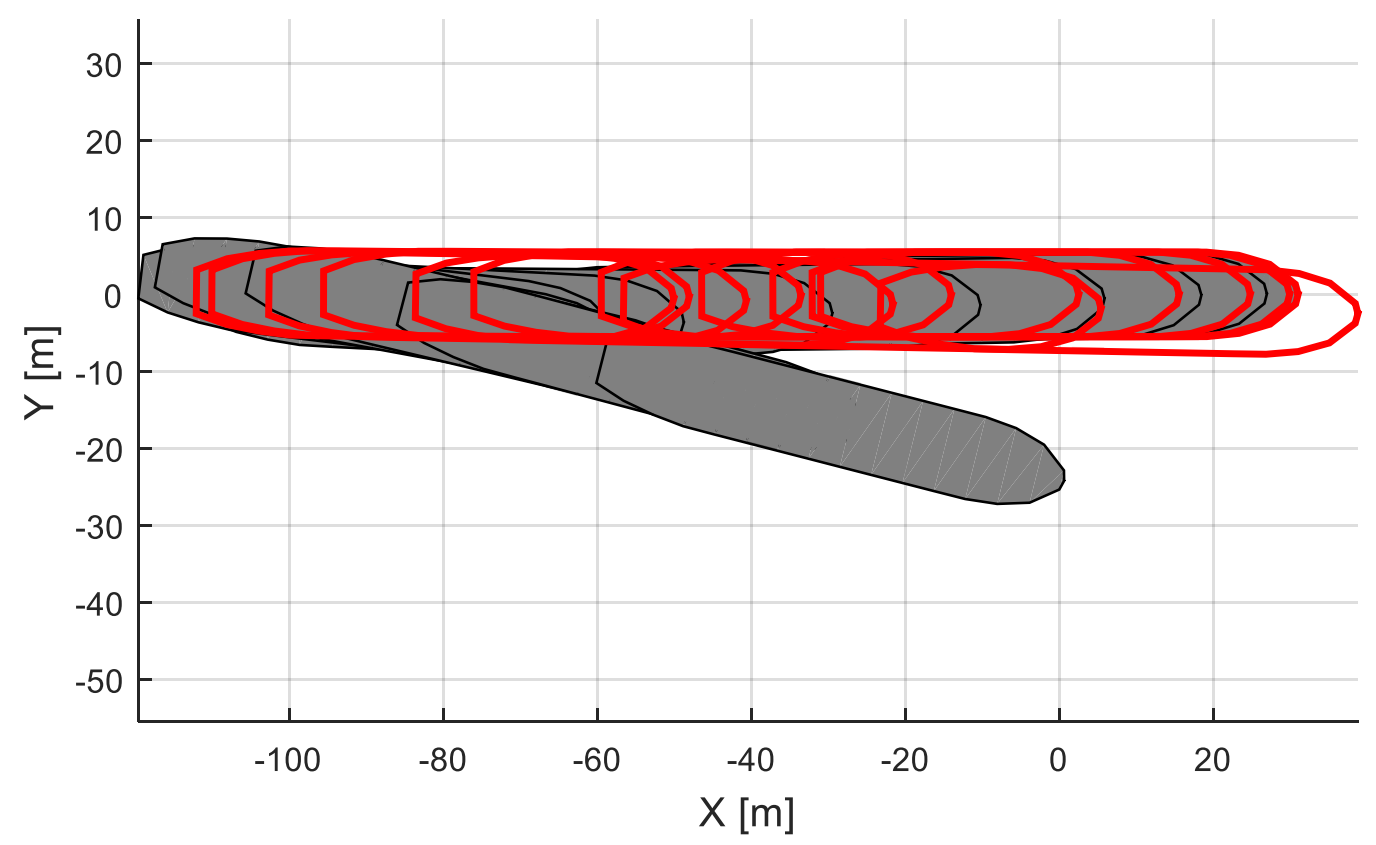

Fonte: Autor.

Figura 98 - Ângulo de deriva, Velocidade angular, manobra 16
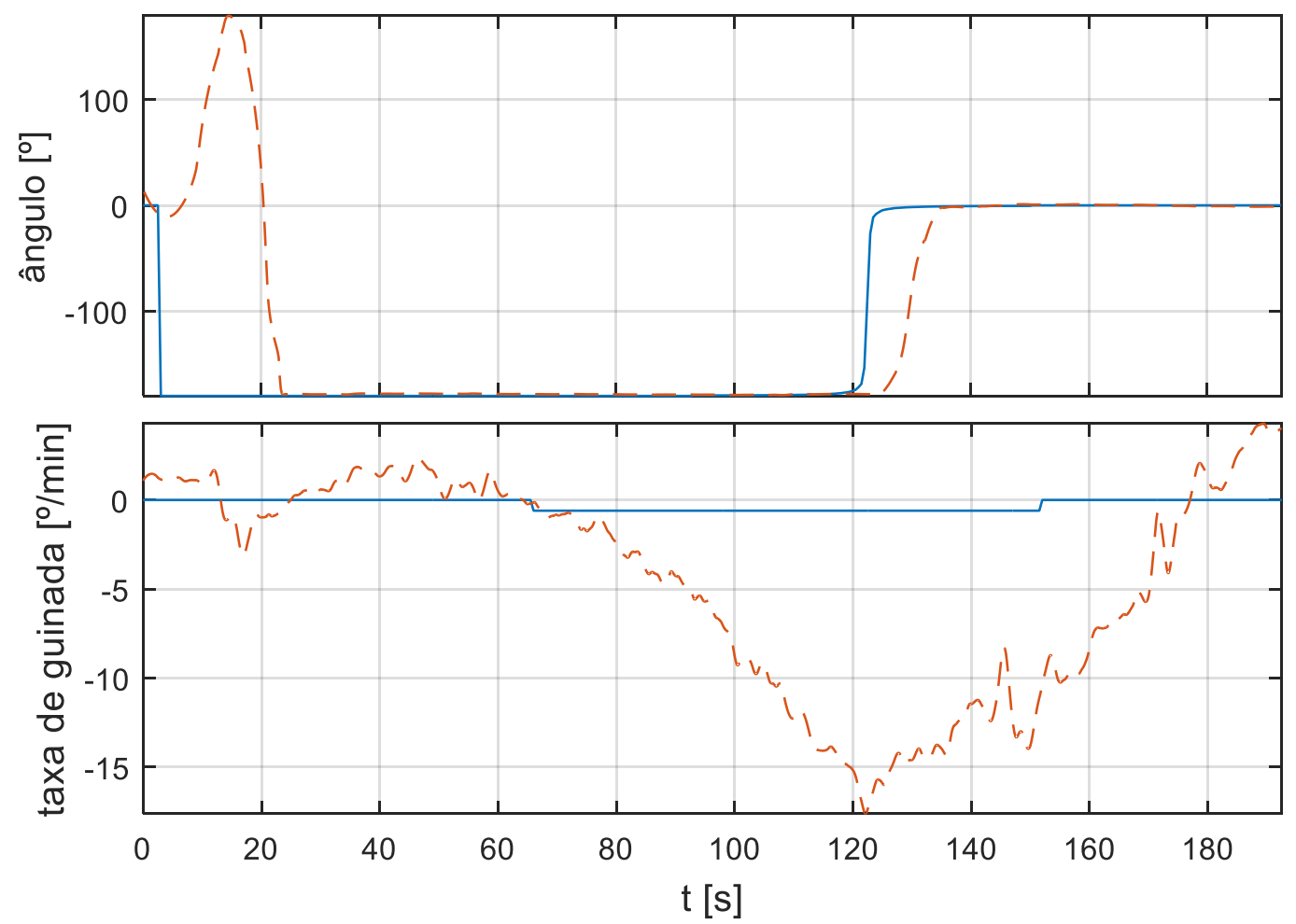

Fonte: Autor. 
Figura 99 - Velocidade $\mathrm{Vx}$, velocidade $\mathrm{Vy}$, manobra 16

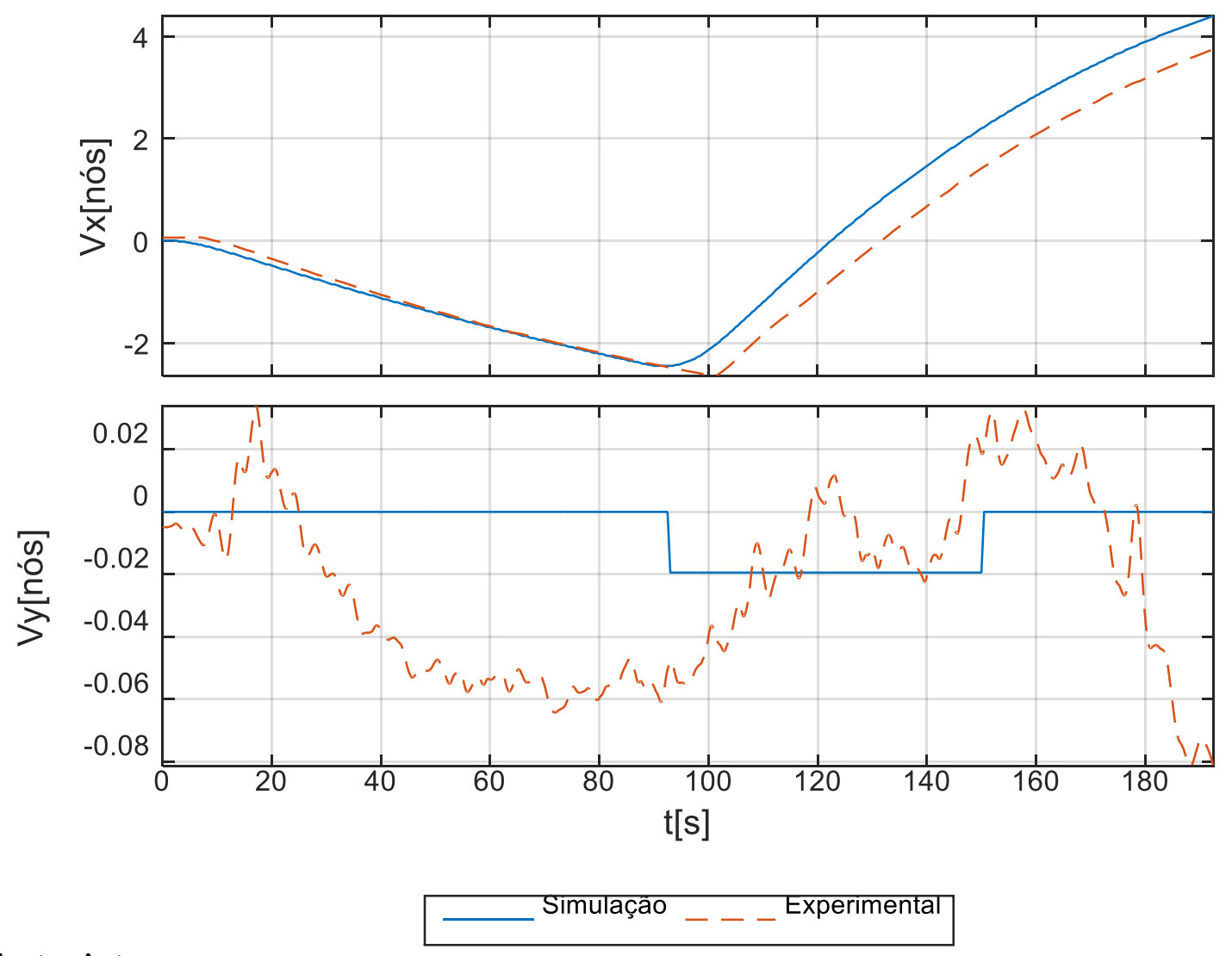

Fonte: Autor.

\subsection{Stopping inertia test}

Esta manobra é realizada para verificar a desaceleração do navio sem que haja ação do propulsor principal. A partir da velocidade inicial determinada a máquina é parada rapidamente e a manobra termina quando a velocidade é menor do que uma velocidade determinada, normalmente 5 nós.

As grandezas medidas durante essa manobra são as mesmas da manobra de Crash-Stop, sendo o alcance longitudinal (head reach), alcance lateral (side reach), e a distância percorrida (track reach).

Há ainda duas versões desta manobra, a primeira denominada free stop (parada livre) que se caracteriza por manter o leme a meio durante toda a manobra, e a segunda (recomendada pela IMO) caracterizada por acionar o leme completamente para um dos bordos durante toda a manobra. Estas versões da manobra medem basicamente as características de resistência ao avanço do navio respectivamente sem e com a influência de uma velocidade de guinada. 
Devido à dimensão reduzida do tanque, não foi possível realizar a manobra até a parada total da embarcação, por esse motivo essas manobras foram realizadas dentro do espaço possível analisando a fase inicial de desaceleração.

\subsubsection{Manobra 17}

Nessa manobra foi realizado o stopping inertia test com avanço devagar avante (500 rpm) em sua versão free stop, onde a máquina é parada e o leme é mantido a meio. A Tabela 38 apresenta os dados táticos obtidos:

Tabela 38 - Dados táticos obtidos para a manobra 17

Fonte: Autor.

\begin{tabular}{|l|l|l|}
\hline & Velocidade inicial & Velocidade final \\
\hline Experimental & 2,5 nós & 1,4 nós \\
\hline Simulado & 2,4 nós & 1,4 nós \\
\hline Erro & $-1,6 \%$ & $0,4 \%$ \\
\hline
\end{tabular}

A Figura 100 mostra que ambos os modelos descreveram a mesma trajetória, na Figura 101 pode ser visto que a aceleração longitudinal dos modelos é compatível durante toda a manobra.

Figura 100 - Trajetória varrida, manobra 17

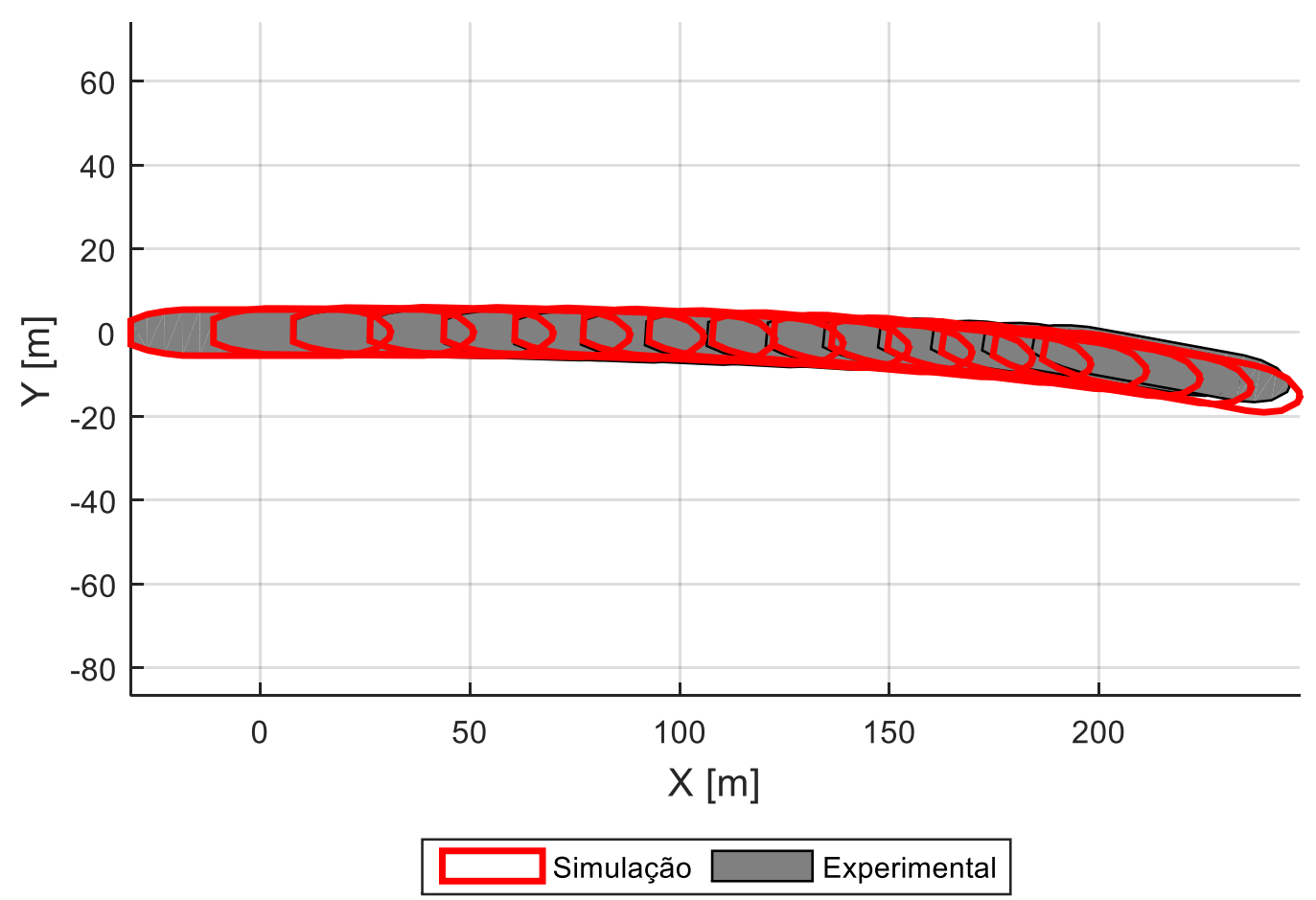

Fonte: Autor. 
Figura 101 - Ângulo de deriva, Velocidade angular, Velocidade Vx, velocidade Vy, manobra 17
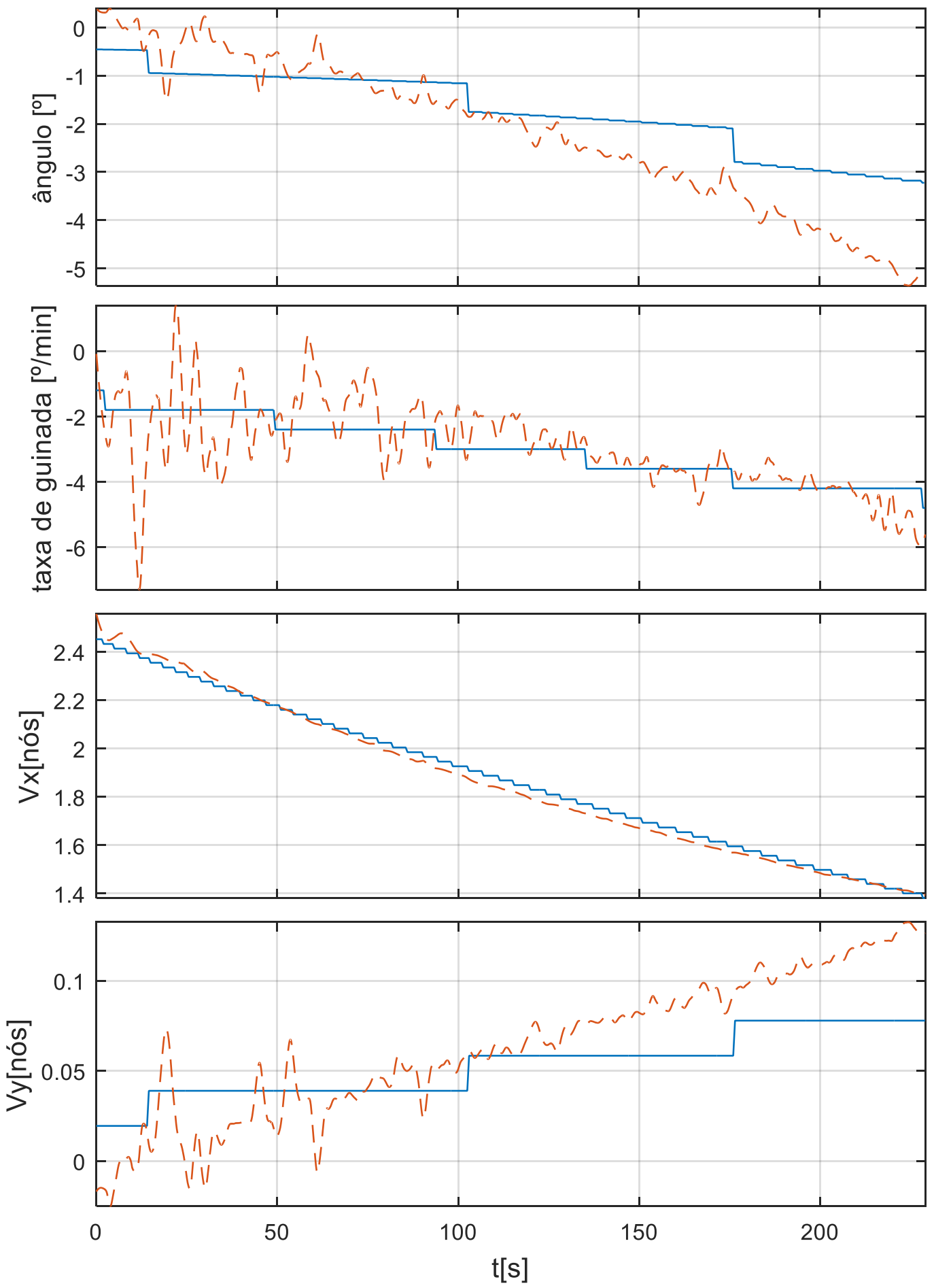

Fonte: Autor.

Simulação - - Experimental 


\subsubsection{Manobra 18}

Nessa manobra foi realizado o stopping inertia test com avanço devagar avante (500 rpm) em sua versão IMO stop, onde a máquina é parada e o leme é mantido a 30 . A Tabela 39 apresenta os dados táticos obtidos:

Tabela 39 - Dados táticos obtidos para a manobra 18

Fonte: Autor.

\begin{tabular}{|l|l|l|}
\hline & Velocidade inicial & Velocidade final \\
\hline Experimental & 2,5 nós & 0,1 nós \\
\hline Simulado & 2,4 nós & 0,0 nós \\
\hline Erro & $-2,4 \%$ & $-55,6 \%$ \\
\hline Experimental & Avanço & Transferencia \\
\hline Simulado & $191,2 \mathrm{~m}(3,3 \mathrm{~L})$ & $50,4 \mathrm{~m}(0,8 \mathrm{~L})$ \\
\hline Erro & $-7,9 \%$ & $76,6 \mathrm{~m}(1,2 \mathrm{~L})$ \\
\hline
\end{tabular}

Nota-se pela Figura 102 que o modelo numérico apresenta menor ângulo de deriva, causando influência na trajetória da embarcação. Porém a Figura 103 mostra que os modelos apresentaram comportamento compatível para as velocidades longitudinal e velocidade angular, indicando a mesma capacidade de parada para ambos os modelos.

Figura 102 - Trajetória varrida, manobra 18

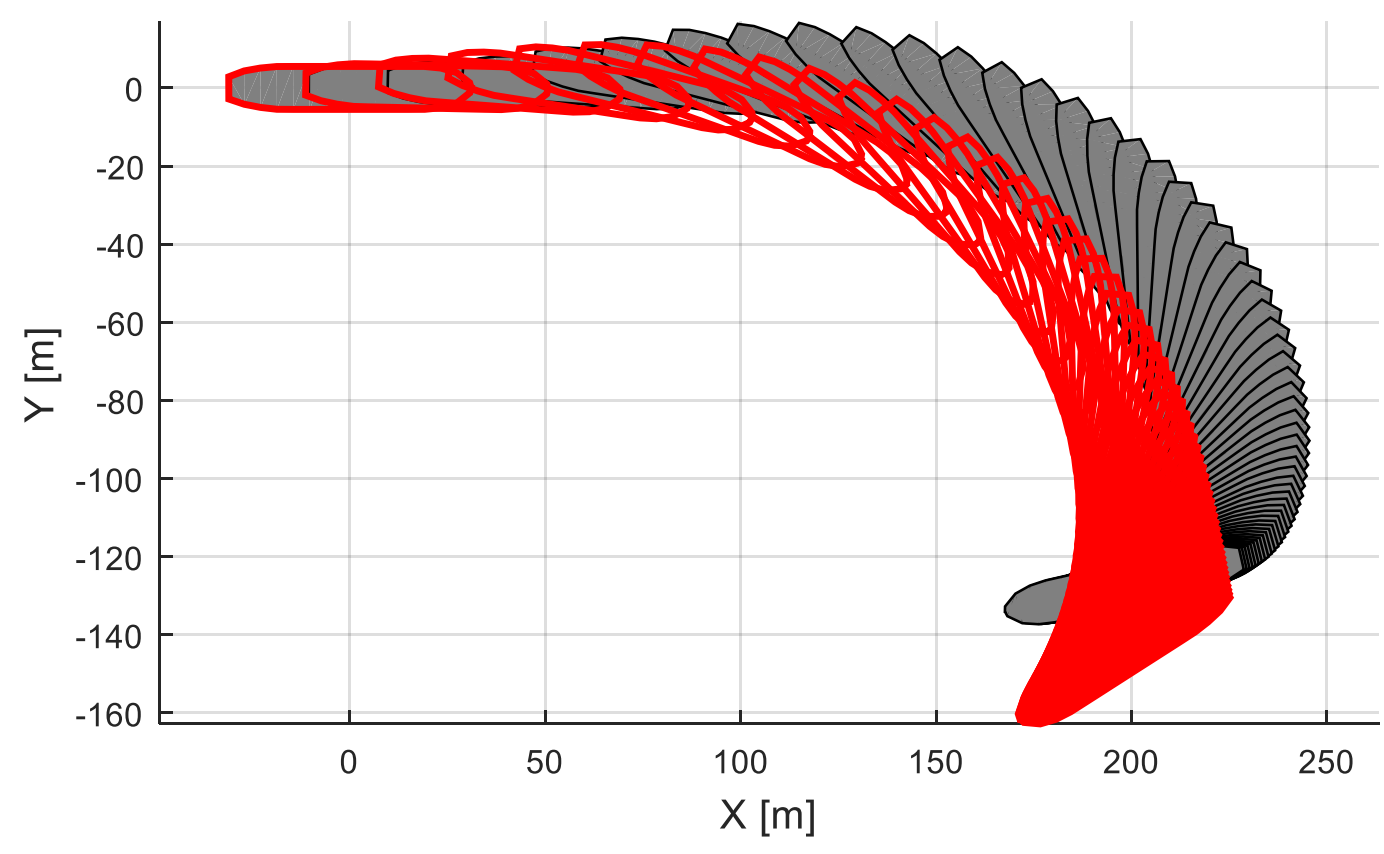

Fonte: Autor. 
Figura 103 - Ângulo de deriva, Velocidade angular, Velocidade Vx, velocidade Vy, manobra 18
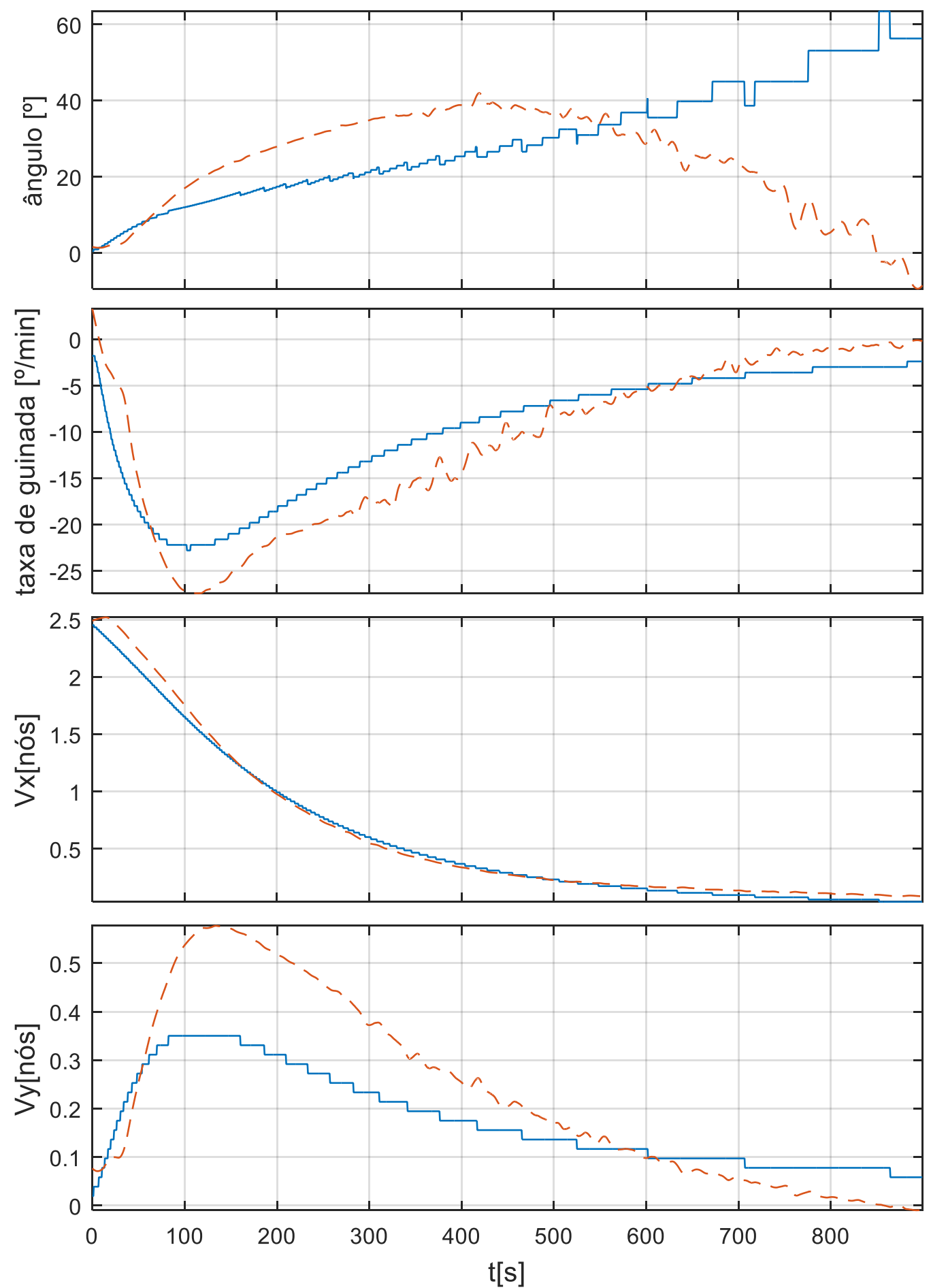

Fonte: Autor.

Simulação - - Experimental 


\subsubsection{Manobra 17 -águas rasas}

Nessa manobra foi realizado o stopping inertia test com avanço devagar avante (500 rpm) em sua versão free stop, onde a máquina é parada e o leme é mantido a meio. A Tabela 40 apresenta os dados táticos obtidos:

Tabela 40 - Dados táticos obtidos para a manobra 17 em águas rasas

Fonte: Autor.

\begin{tabular}{|l|l|l|}
\hline & Velocidade inicial & Velocidade final \\
\hline Experimental & 2,2 nós & 1,6 nós \\
\hline Simulado & 2,1 nós & 1,5 nós \\
\hline Erro & $-4,2 \%$ & $-6,1 \%$ \\
\hline
\end{tabular}

Assim como na manobra 17 em águas profundas o modelo experimental apresentou assimetria, como pode ser visto através da Figura 104, porém a aceleração longitudinal dos modelos se mostrou compatível, conforme ilustrado na Figura 105.

Figura 104 - Trajetória varrida, manobra 17

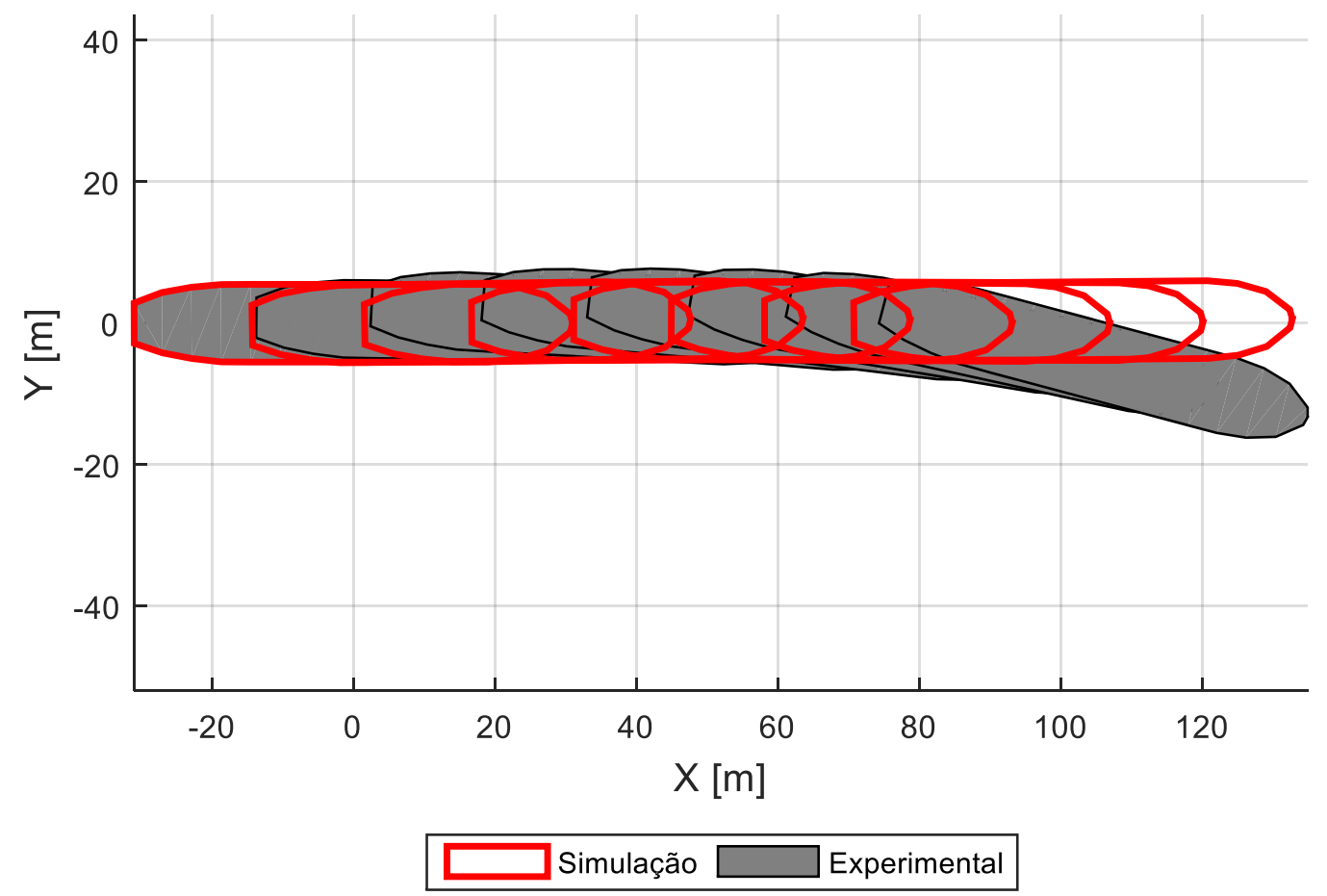

Fonte: Autor. 
Figura 105 - Ângulo de deriva, Velocidade angular, Velocidade Vx, velocidade Vy, manobra 17
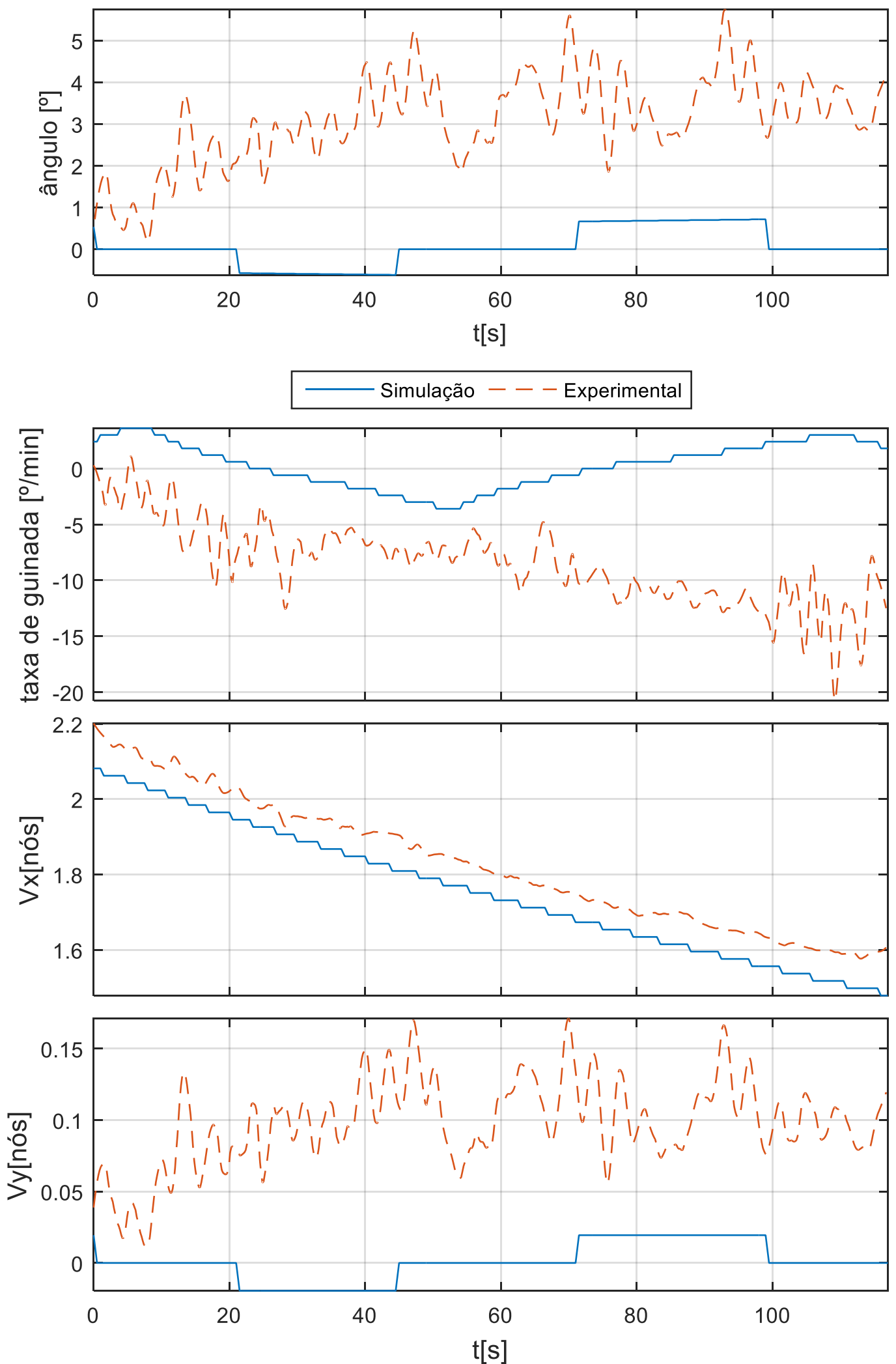

Fonte: Autor. 


\subsubsection{Manobra 18 -águas rasas}

Nessa manobra foi realizado o stopping inertia test com avanço devagar avante (500 rpm) em sua versão IMO stop, onde a máquina é parada e o leme é mantido a 30 . A Tabela 41 apresenta os dados táticos obtidos:

Tabela 41 - Dados táticos obtidos para a manobra 18 em águas rasas

Fonte: Autor.

\begin{tabular}{|l|l|l|}
\hline & Velocidade inicial & Velocidade final \\
\hline Experimental & 2,1 nós & 1,0 nós \\
\hline Simulado & 2,1 nós & 1,1 nós \\
\hline Erro & $2,5 \%$ & $9,7 \%$ \\
\hline
\end{tabular}

A Figura 106 apresenta um comportamento similar entre os dois modelos para o movimento longitudinal, havendo maior diferença para os movimentos que ocorrem no sentido transversal da embarcação e para a velocidade angular. A Figura 107 mostra que a aceleração longitudinal dos modelos é compatível, havendo maior diferença para o comportamento das velocidades na direção transversal.

Figura 106 - Trajetória varrida, manobra 18

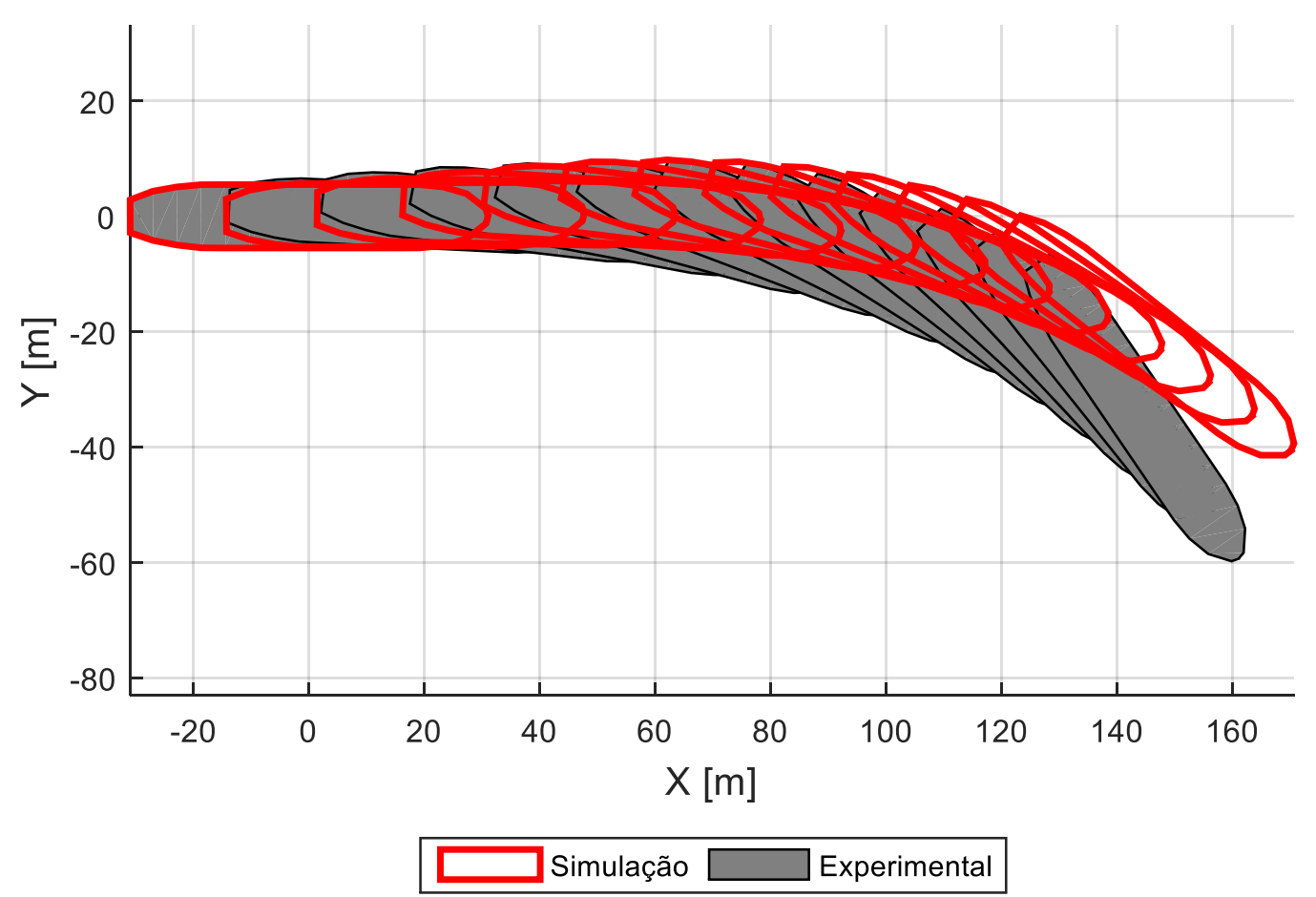

Fonte: Autor. 
Figura 107 - Ângulo de deriva, Velocidade angular, Velocidade Vx, velocidade Vy, manobra 18
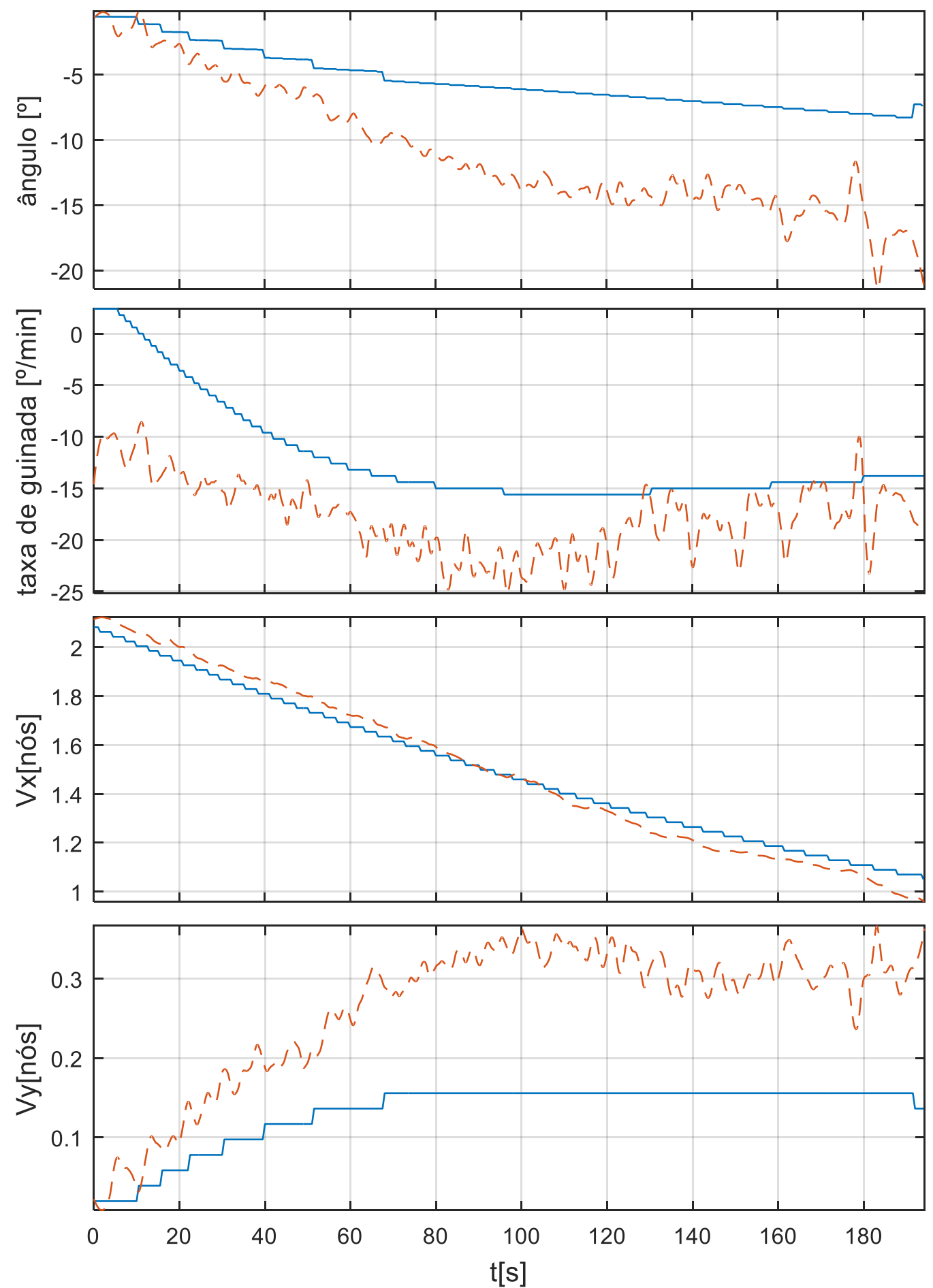

Fonte: Autor. 


\subsection{Lateral thruster capability}

Esta manobra tem como objetivo medir a eficiência e capacidade do tunnel thruster (propulsor transversal próximo à proa) e a resposta do navio ao seu acionamento. Com o navio seguindo com velocidade entre 0 nós e 8 nós o tunnel thruster é acionado com toda a força com o objetivo de guinar o navio. O leme é mantido a meio para garantir que o resultado obtido seja atribuído exclusivamente à ação do tunnel thruster.

\subsubsection{Manobra 19}

Nessa manobra foi realizado o lateral thruster capability test com a embarcação inicialmente em repouso e máquina principal parada.

A Tabela 42 apresenta os dados táticos obtidos:

Tabela 42 - Dados táticos obtidos para a manobra 19

Fonte: Autor.

\begin{tabular}{|l|l|l|l|}
\hline & Avanço & Transferência & Diâmetro tático \\
\hline Experimental & $10,5 \mathrm{~m}(0,2 \mathrm{~L})$ & $6,2 \mathrm{~m}(0,1 \mathrm{~L})$ & $30,4 \mathrm{~m}(0,5 \mathrm{~L})$ \\
\hline Simulado & $-5,3 \mathrm{~m}(0,1 \mathrm{~L})$ & $38,6 \mathrm{~m}(0,5 \mathrm{~L})$ & Não atingido \\
\hline Erro & $-150,4 \%$ & $522,6 \%$ & \\
\hline
\end{tabular}

Figura 108 - Trajetória varrida, manobra 19

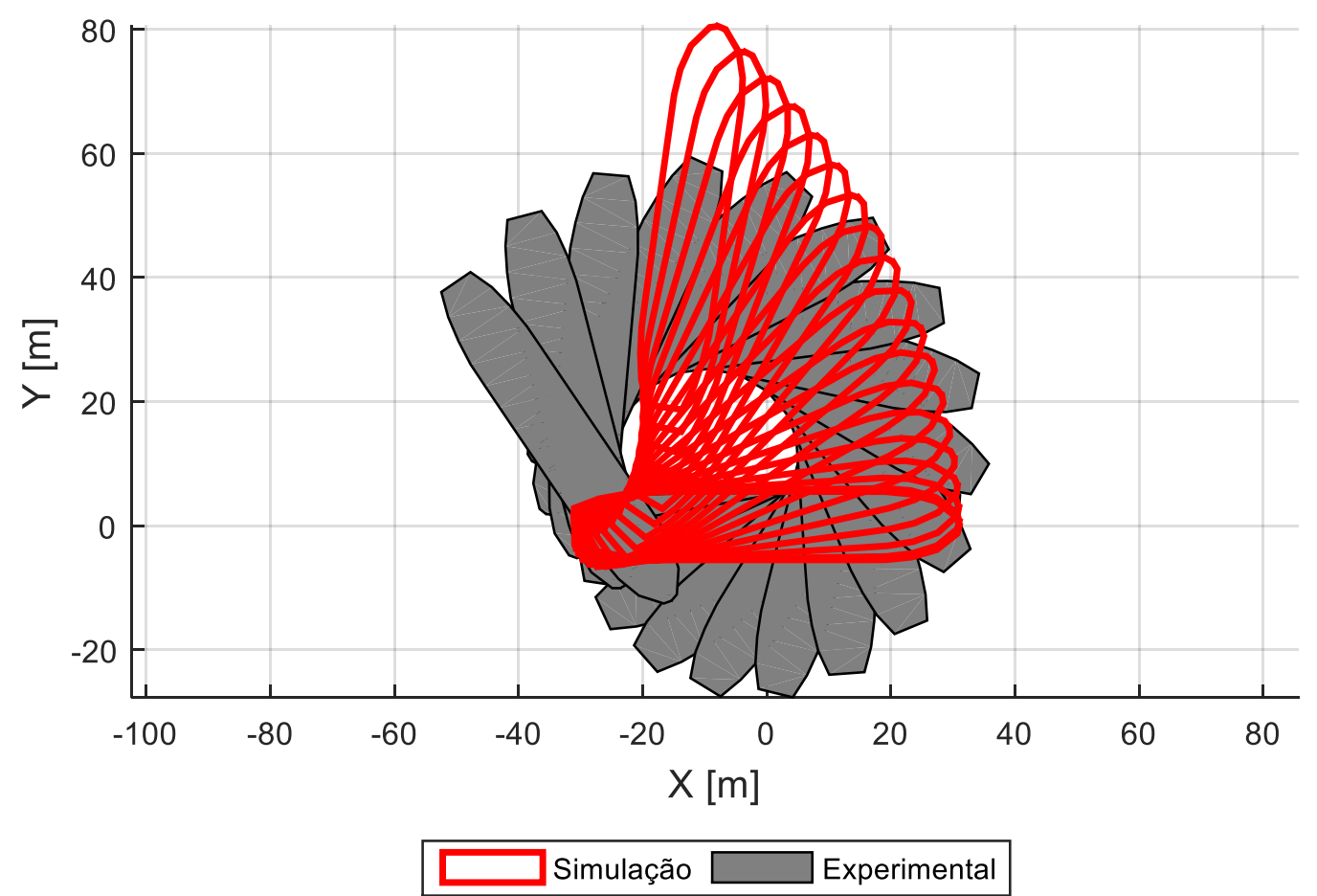

Fonte: Autor. 
A Figura 108 apresenta trajetórias diferentes para ambos modelos, com um comportamento distinto apresentado na Figura 109, indicando que o modelo numérico não representou de forma satisfatória esta manobra.

Figura 109 - Ângulo de deriva, Velocidade angular, Velocidade Vx, velocidade Vy, manobra 19
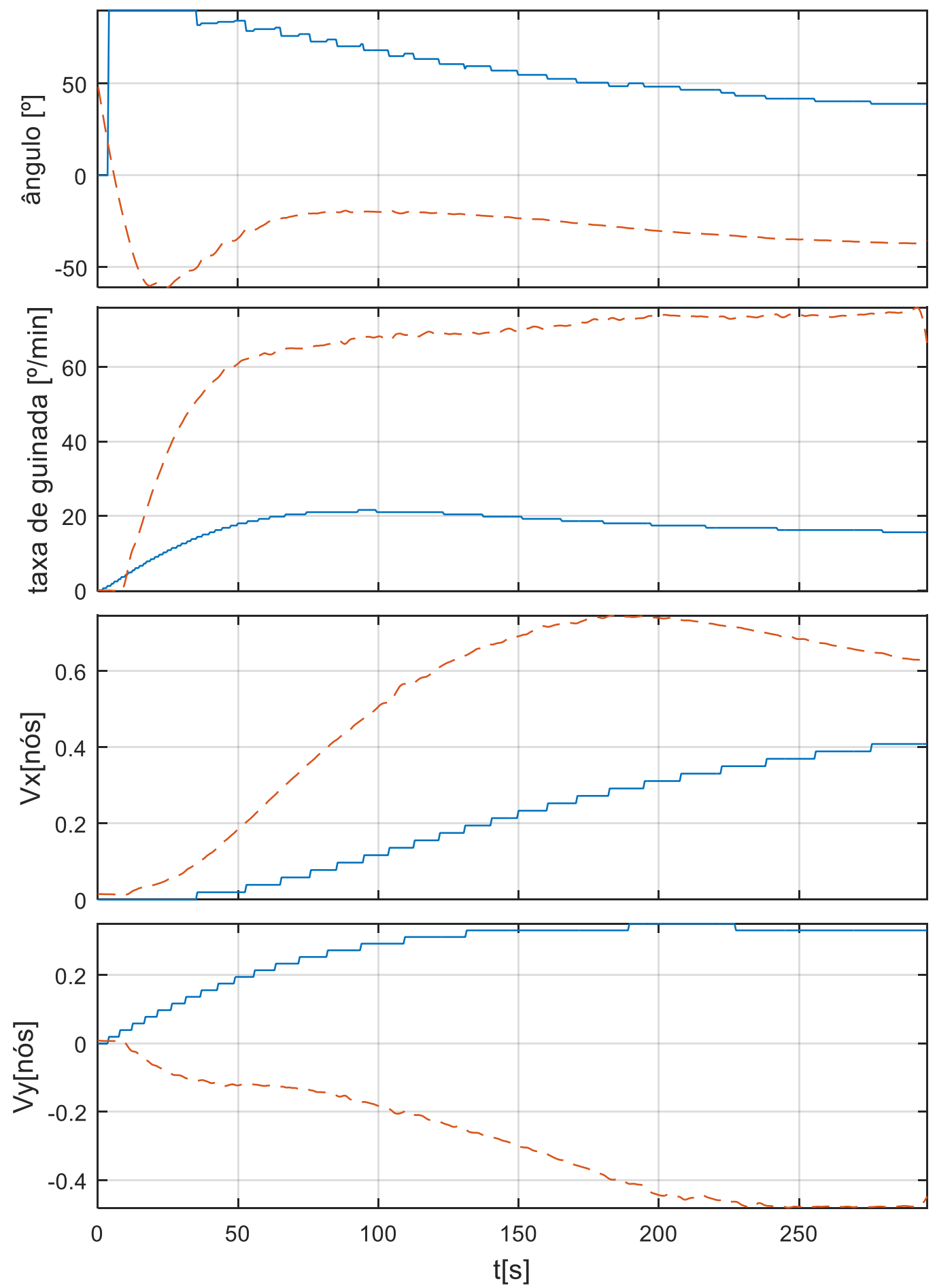

Fonte: Autor. 


\subsubsection{Manobra 19 -águas rasas}

Nessa manobra foi realizado o lateral thruster capability test com a embarcação inicialmente em repouso e máquina principal parada. A Tabela 43 apresenta os dados táticos obtidos:

Tabela 43 - Dados táticos obtidos para a manobra 19 em águas rasas

\begin{tabular}{|l|l|l|l|}
\hline & Avanço & Transferência & Diâmetro tático \\
\hline Experimental & $16,3 \mathrm{~m}(0,3 \mathrm{~L})$ & $2,9 \mathrm{~m}(0, \mathrm{~L})$ & $28,1 \mathrm{~m}(0,4 \mathrm{~L})$ \\
\hline Simulado & Não atingido & Não atingido & Não atingido \\
\hline
\end{tabular}

Fonte: Autor.

A Figura 110 apresenta trajetórias diferentes para ambos modelos, com um comportamento distinto apresentado na Figura 111, indicando que o modelo numérico não representou de forma satisfatória esta manobra.

Figura 110 - Trajetória varrida, manobra 19

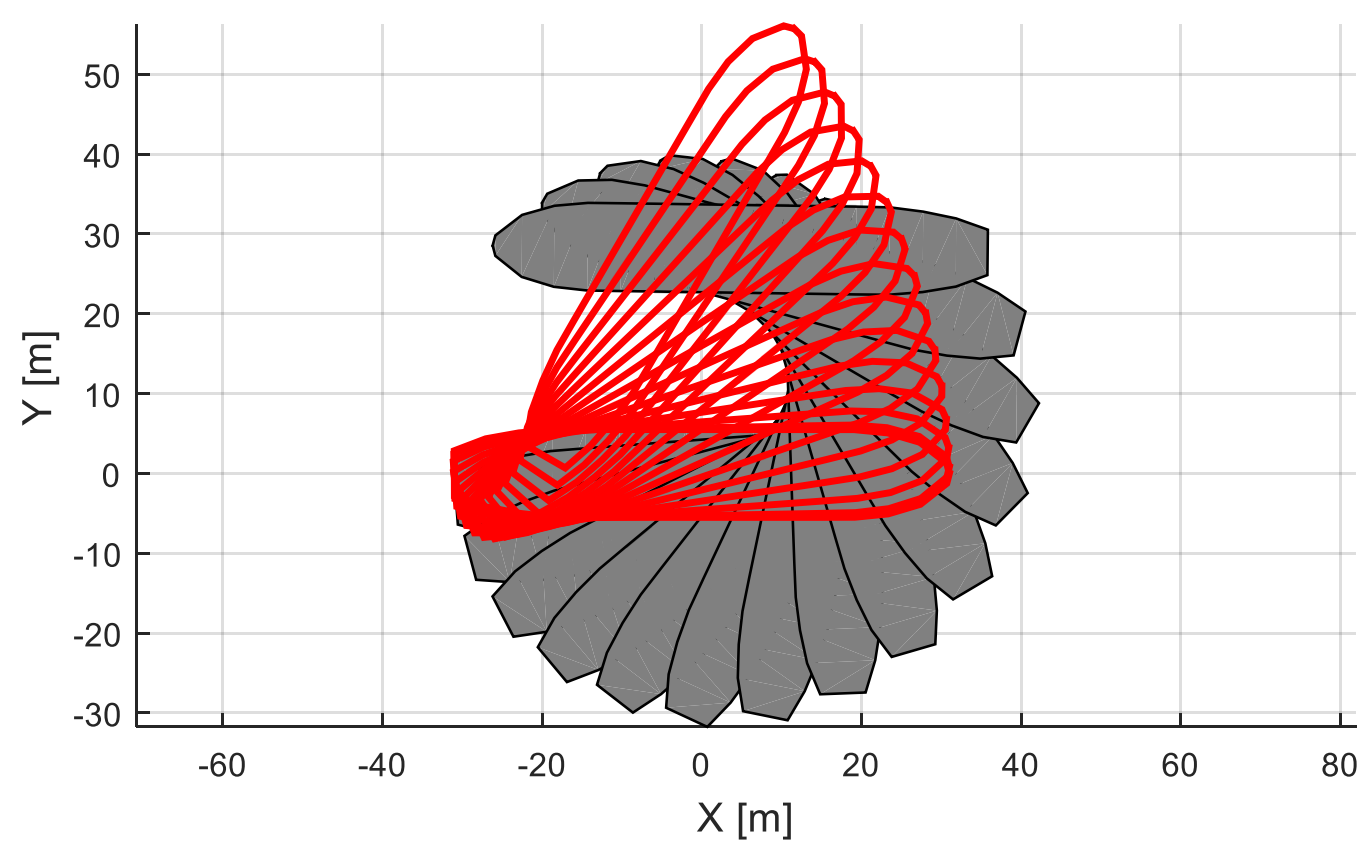

Fonte: Autor. 
Figura 111 - Ângulo de deriva, Velocidade angular, Velocidade Vx, velocidade Vy, manobra 19
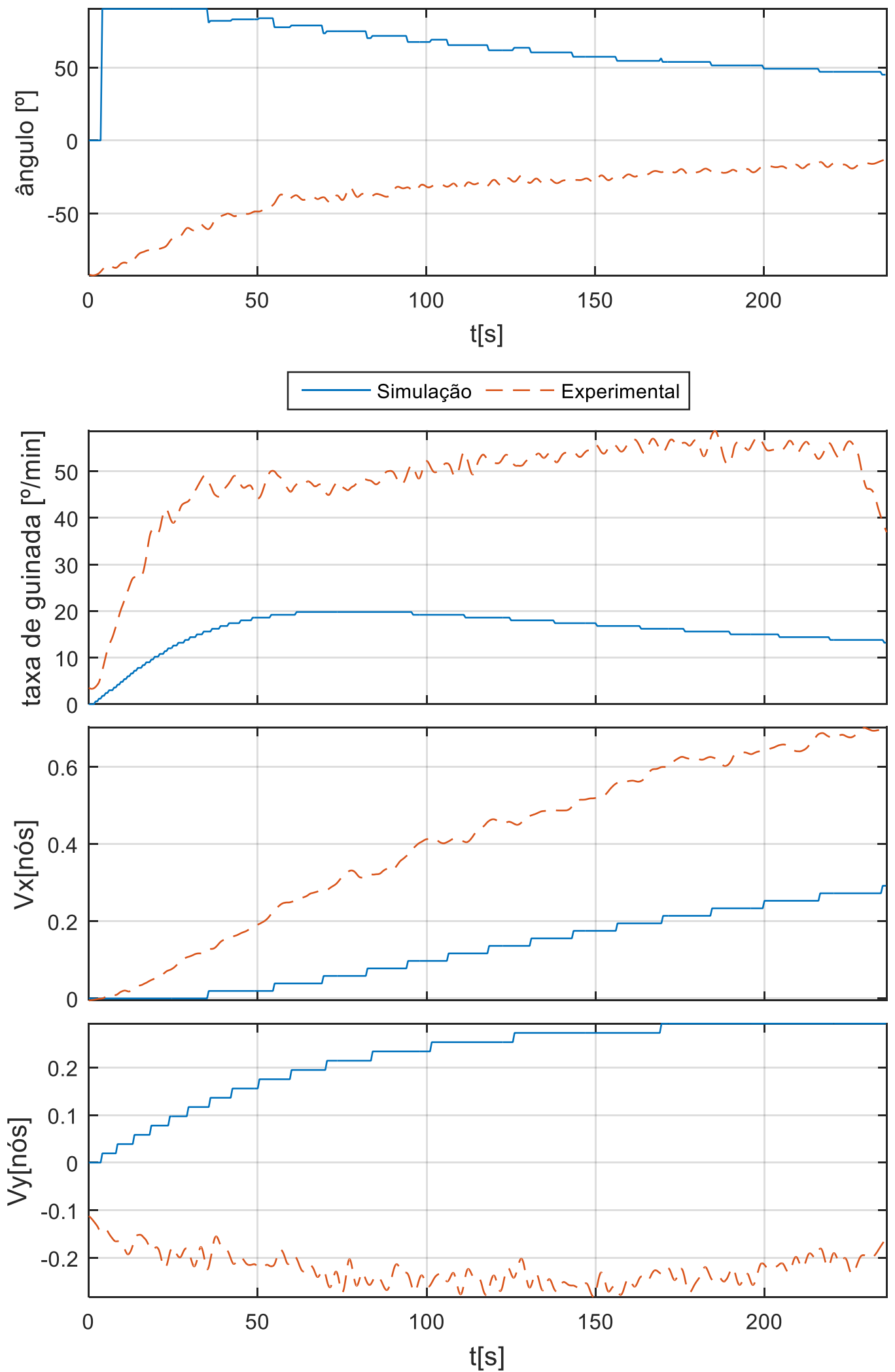

Fonte: Autor. 


\subsection{Pull out test}

Esta manobra fornece uma indicação sobre a estabilidade direcional do navio. Para execução dessa manobra, o navio é mantido em navegação com uma velocidade angular estável com o leme em uma posição constante, por exemplo a 30 graus. Em seguida o leme é posto a meio e o comportamento da embarcação é observado.

A indicação da estabilidade direcional do navio ocorre através do comportamento da embarcação quando o leme é colocado a meio. É esperado que a velocidade angular do navio reduza com o tempo, e no caso de um navio perfeitamente estável a velocidade angular tende a zero após algum tempo. No caso de navios instáveis, a velocidade angular é reduzida, porém não se anulando, restando uma velocidade angular residual.

Esta manobra normalmente é realizada ao término da manobra de zig-zag ou da manobra de turning circle.

Figura 112 - Velocidade angular no tempo em um teste de Pull out.
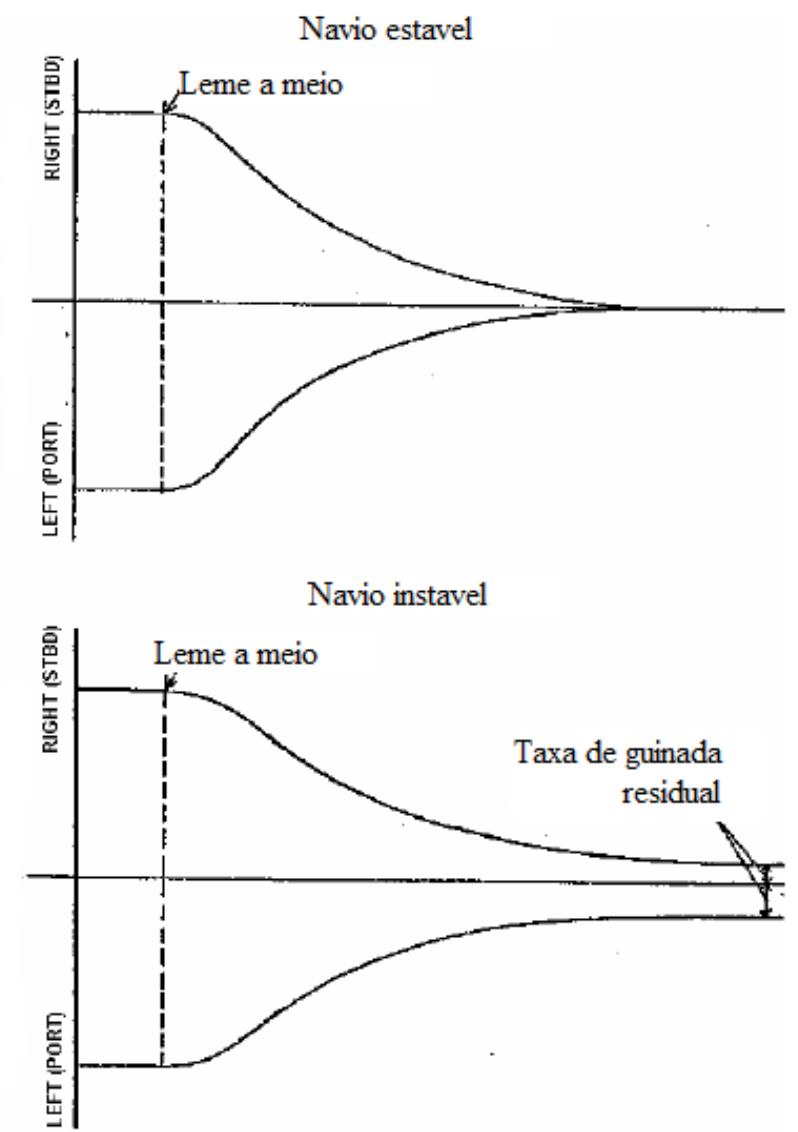

Fonte: Adaptado de (American Bureau of Shipping, 2006). 
6.10.1. Manobra 21

Para a realização dessa manobra a embarcação foi colocada em um giro com máquina devagar avante e leme de $30^{\circ}$, e quando o giro se estabilizou o leme foi posto a meio.

A Tabela 44 apresenta os dados táticos obtidos:

Tabela 44 - Dados táticos obtidos para a manobra 21

Fonte: Autor.

\begin{tabular}{|l|l|l|}
\hline & $\begin{array}{l}\text { Velocidade } \\
\text { angular inicial }\end{array}$ & $\begin{array}{l}\text { Velocidade } \\
\text { angular final }\end{array}$ \\
\hline Experimental & $40,5 \%$ min & $4,2 \%$ min \\
\hline Simulado & $32,4 \% \mathrm{~min}$ & $3,6 \% \mathrm{~min}$ \\
\hline Erro & $-20,0 \%$ & $-13,8 \%$ \\
\hline
\end{tabular}

A Figura 113 mostra a trajetória para os dois modelos, pode se ver pela Figura 114 que a velocidade angular dos modelos permanece com o mesmo comportamento durante toda a manobra.

Figura 113 - Trajetória varrida, manobra 21

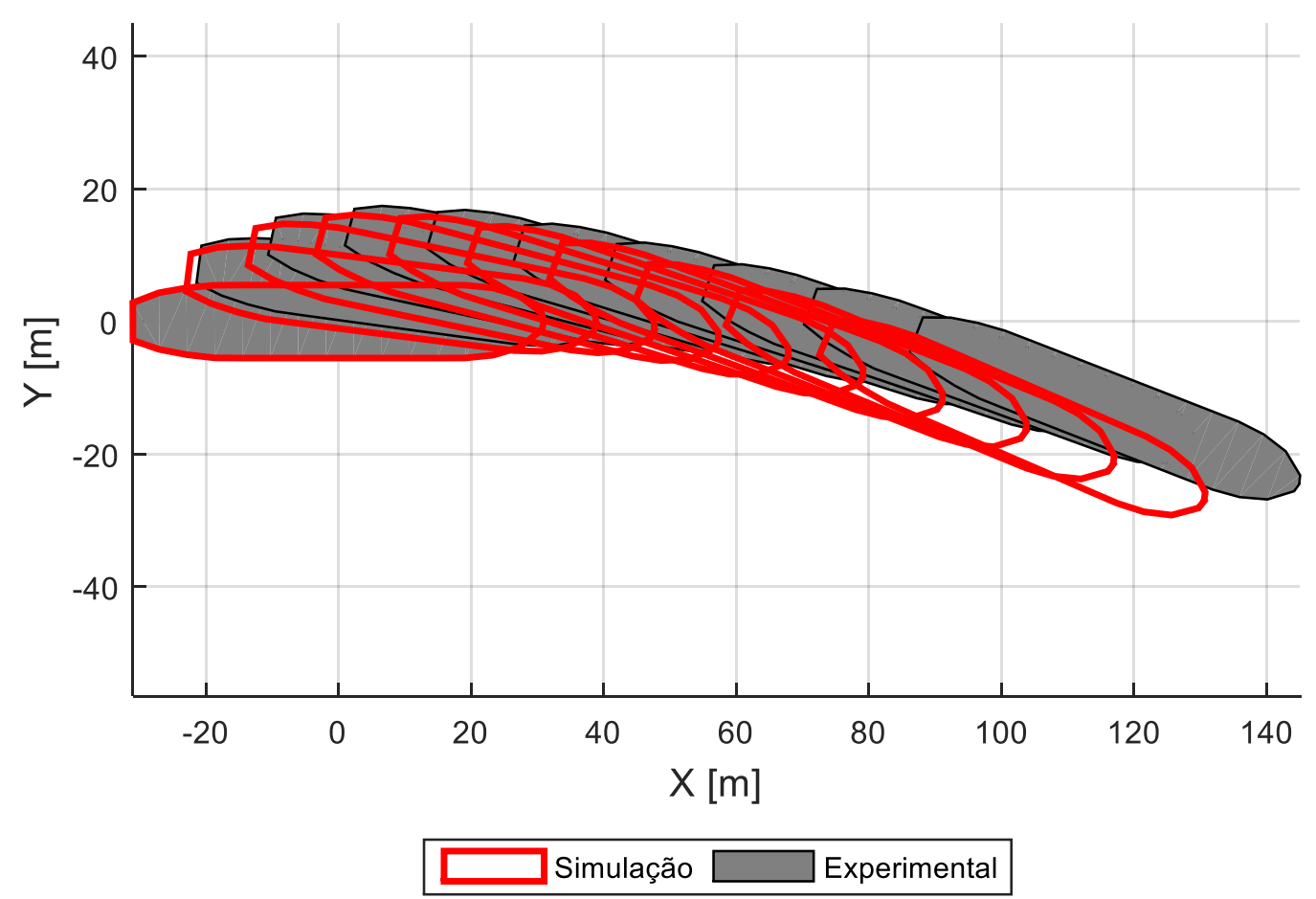

Fonte: Autor. 
Figura 114 - Ângulo de deriva, Velocidade angular, manobra 21
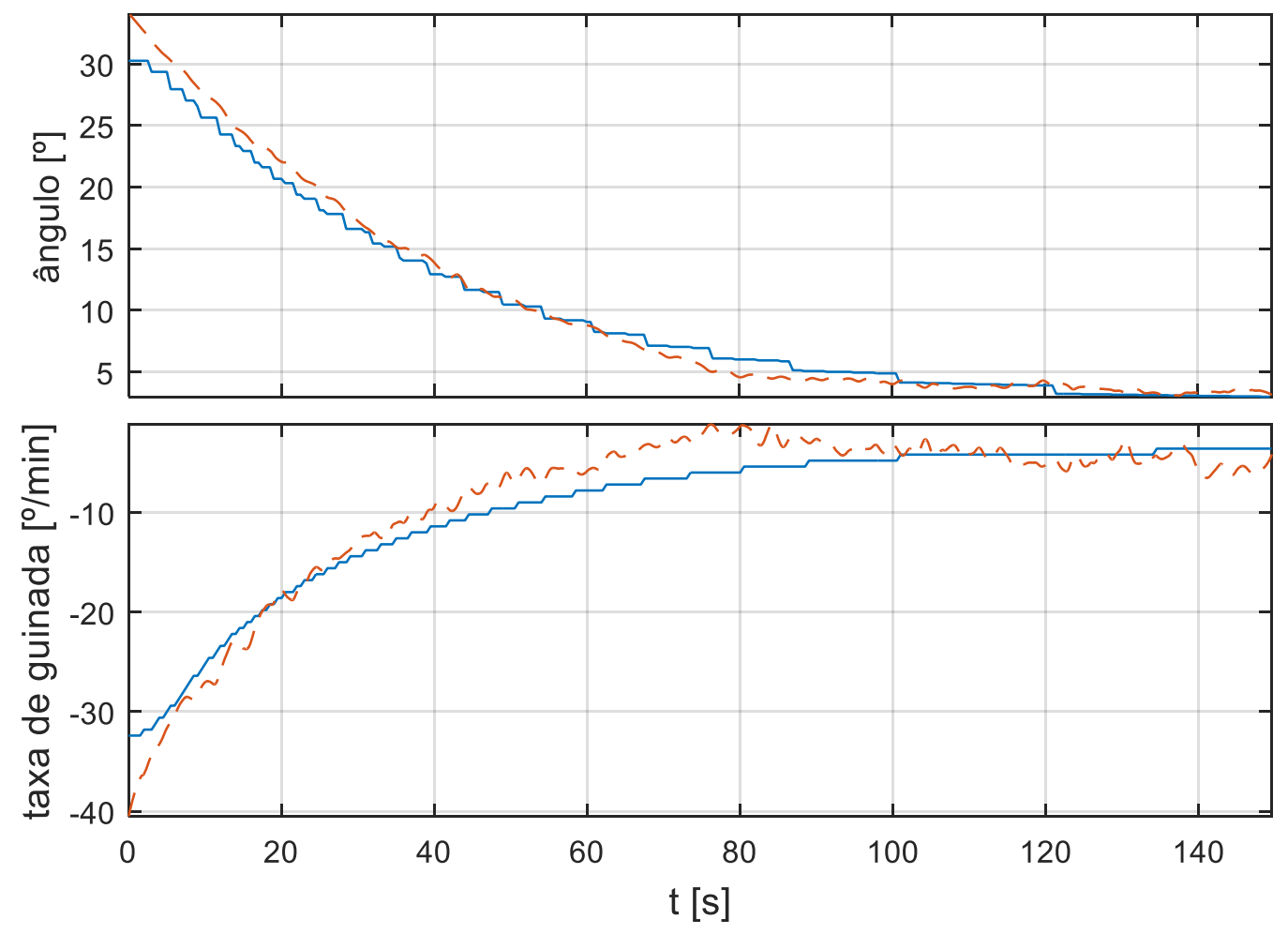

Fonte: Autor.

\subsubsection{Manobra 22}

Para a realização dessa manobra a embarcação foi colocada em um giro com máquina devagar avante e leme de $30^{\circ}$, e quando o giro se estabilizou o leme foi posto a meio. A Tabela 45 apresenta os dados táticos obtidos:

Tabela 45 - Dados táticos obtidos para a manobra 22

Fonte: Autor.

\begin{tabular}{|l|l|l|}
\hline & $\begin{array}{l}\text { Velocidade } \\
\text { angular inicial }\end{array}$ & $\begin{array}{l}\text { Velocidade } \\
\text { angular final }\end{array}$ \\
\hline Experimental & $37,7 \%$ min & $0.6 \%$ min \\
\hline Simulado & $30,6 \% \mathrm{~min}$ & $3.6 \% \mathrm{~min}$ \\
\hline Erro & $-18,9 \%$ & $461.2 \%$ \\
\hline
\end{tabular}

A Figura 115 mostra que o ensaio experimental foi realizado com velocidade superior ao ensaio com modelo numérico. Pode ser visto na Figura 115 que o modelo experimental iniciou a manobra com velocidade angular maior do que o modelo numérico, mas ao longo da manobra o comportamento dos modelos foi compatível. 
Figura 115 - Trajetória varrida, Ângulo de deriva, Velocidade angular, manobra 22
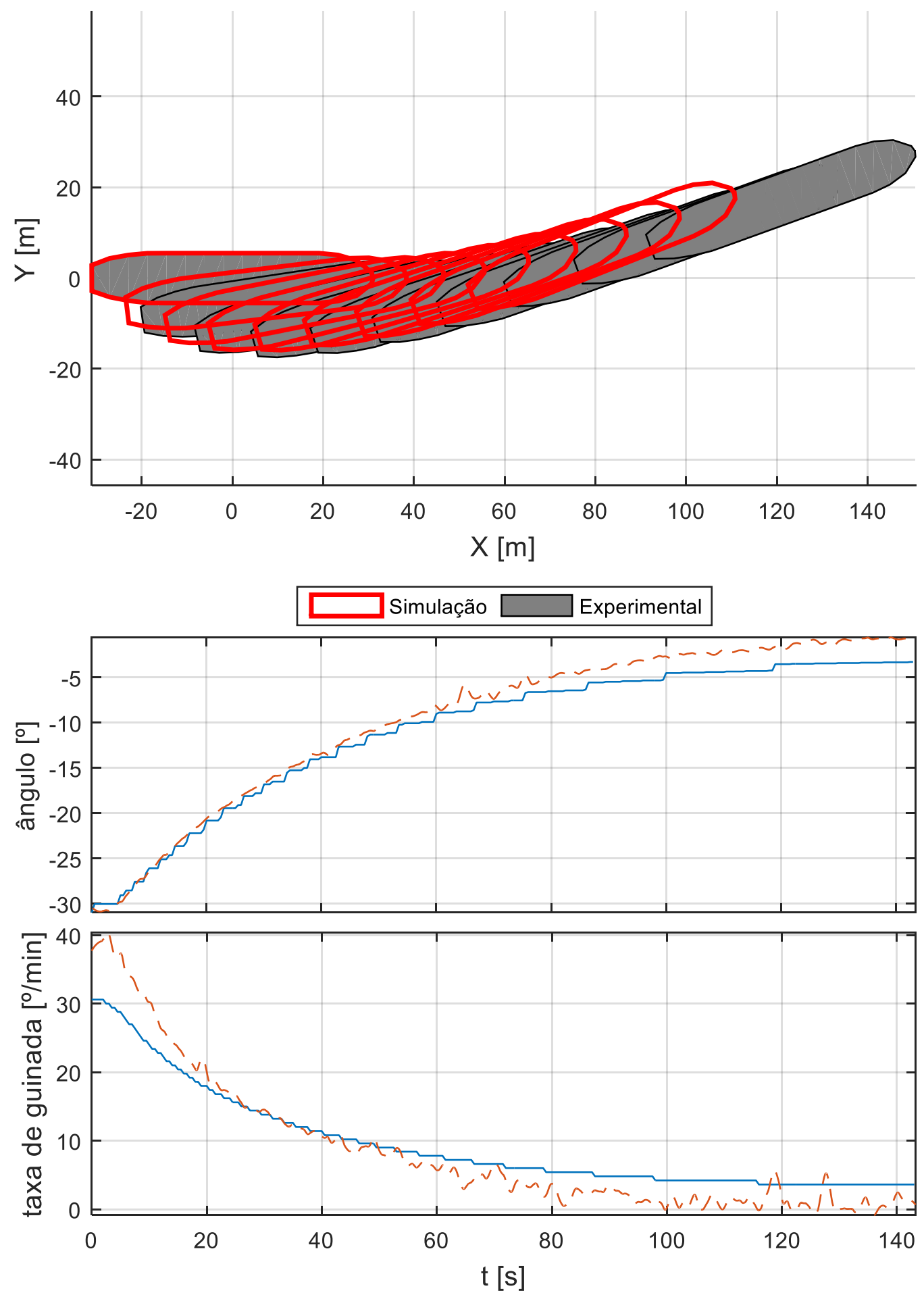

Fonte: Autor. 


\subsubsection{Manobra 22 -águas rasas}

Para a realização dessa manobra a embarcação foi colocada em um giro com máquina devagar avante e leme de $30^{\circ}$, e quando o giro se estabilizou o leme foi posto a meio. A Tabela 46 apresenta os dados táticos obtidos:

Tabela 46 - Dados táticos obtidos para a manobra 22 em águas rasas

Fonte: Autor.

\begin{tabular}{|l|l|l|}
\hline & $\begin{array}{l}\text { Velocidade } \\
\text { angular inicial }\end{array}$ & $\begin{array}{l}\text { Velocidade } \\
\text { angular final }\end{array}$ \\
\hline Experimental & $41,6 \% \mathrm{~min}$ & $4,5 \% \mathrm{~min}$ \\
\hline Simulado & $34,8 \% \mathrm{~min}$ & $1,2 \% \mathrm{~min}$ \\
\hline Erro & $-16,4 \%$ & $-73,3 \%$ \\
\hline
\end{tabular}

A Figura 116 mostra que diferente do que é esperado para esta manobra em águas rasas, o modelo experimental ficou mais instável do que para a navegação em águas profundas. Este efeito pode ter sido causado por algum fator ambiental não controlado durante o experimento. No entanto pode se ver através da Figura 117 que a aceleração angular dos dois modelos é compatível.

Figura 116 - Trajetória varrida, manobra 22

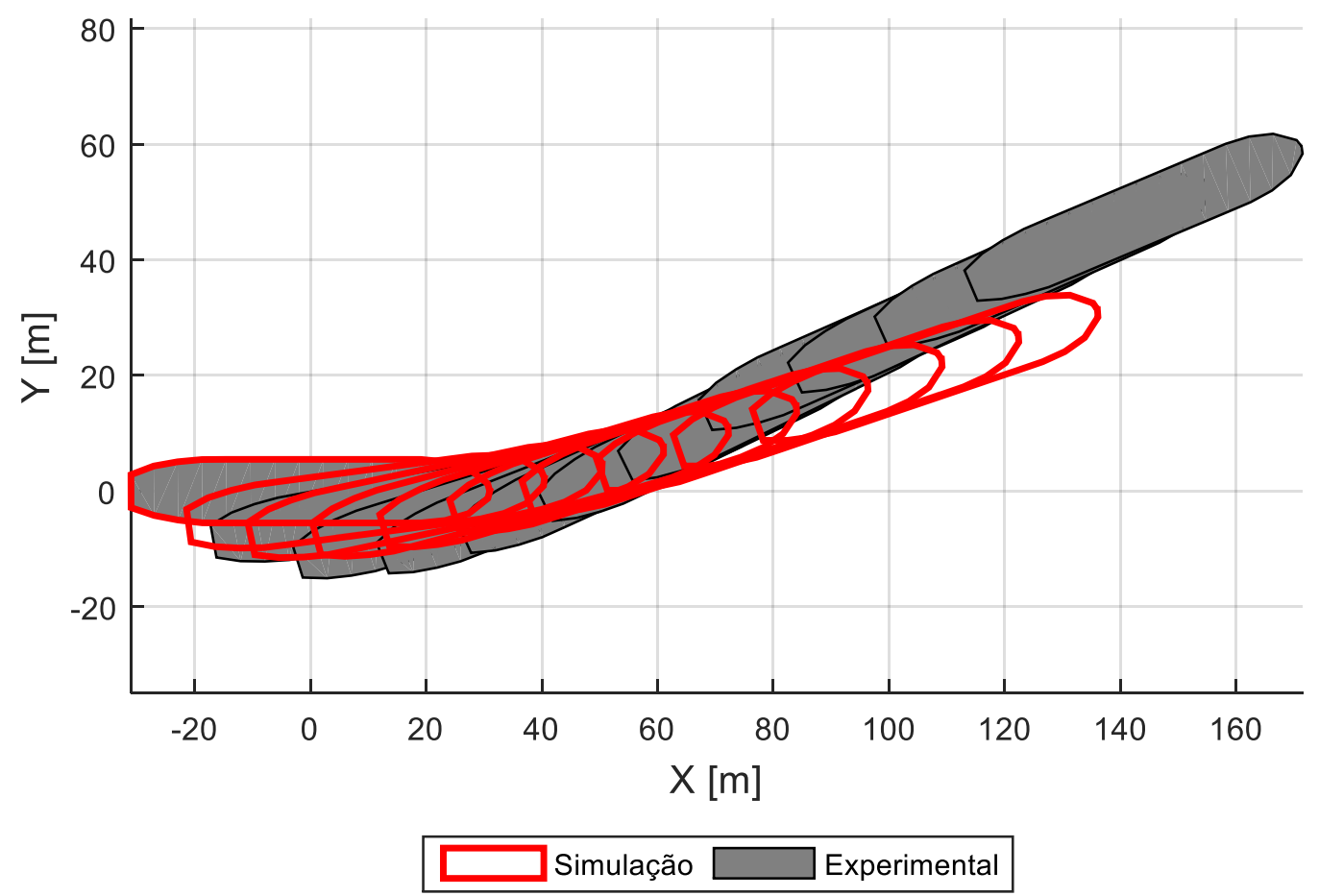

Fonte: Autor. 
Figura 117 - Ângulo de deriva, Velocidade angular, manobra 22

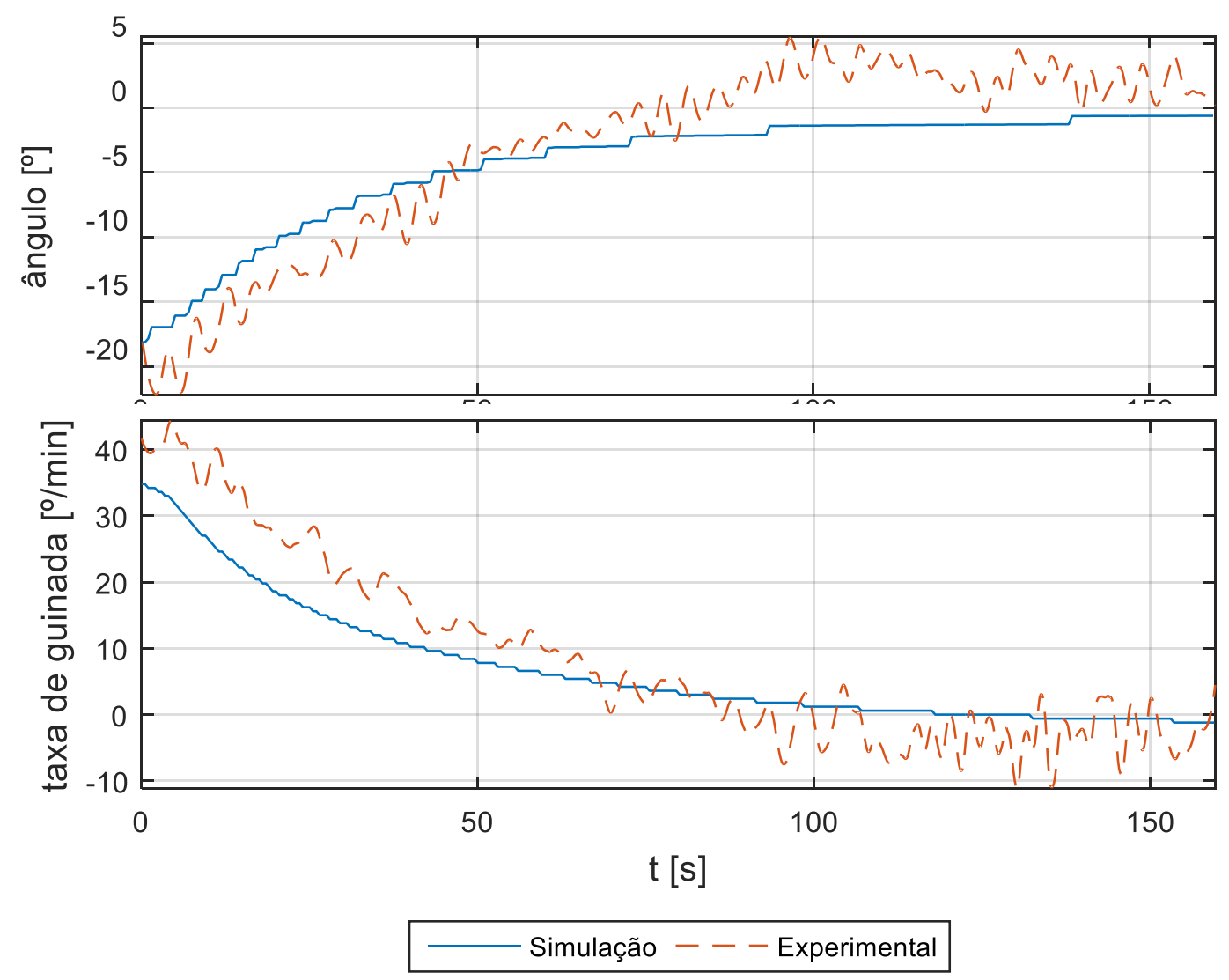

Fonte: Autor.

\subsection{Avaliação do modelo}

As seções anteriores mostram que o modelo numérico representa a capacidade de manobra do modelo em escala de forma consistente. Os erros encontrados através da comparação dos resultados experimentais com os resultados numéricos se mostraram adequados, permitindo a representação da manobrabilidade da embarcação através das simulações numéricas.

A seguir serão apresentados os erros médios obtidos para cada tipo de manobra, sendo o valor do erro calculado em relação ao valor obtido experimentalmente para a respectiva medida, como descrito na equação (17) que exemplifica o erro para o avanço. Note que o cálculo do erro para cada medida foi feito tomando a média dos valores absolutos dos erros. 


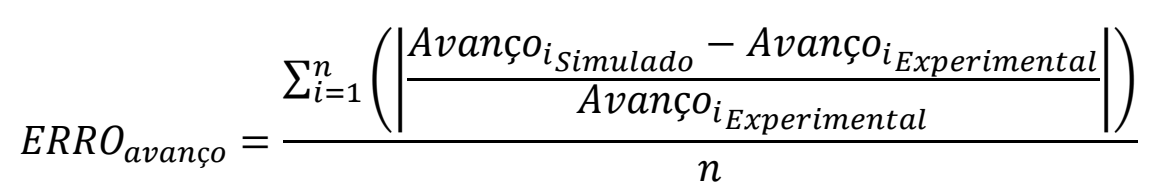

\subsubsection{Turning circle}

A Figura 118 mostra que para as manobras em águas rasas e em águas profundas os erros apresentados pelo modelo numérico em relação ao modelo experimental foram da ordem de $10 \%$ a $20 \%$ com exceção da transferência e da velocidade transversal final.

Figura 118 - Erros médios para as manobras de Turning circle

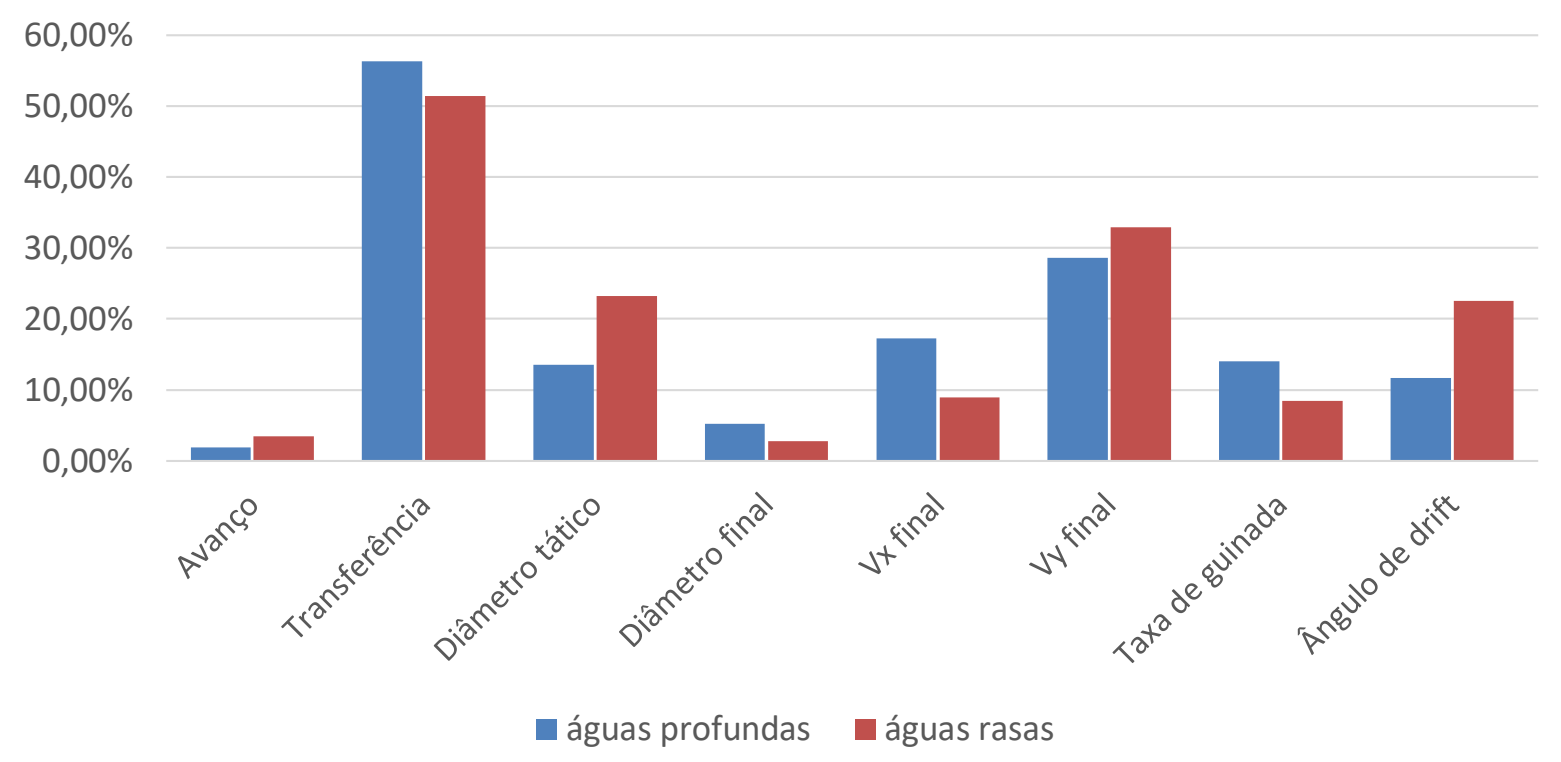

Fonte: Autor.

Para este tipo de manobra os deslocamentos que ocorrem no sentido transversal da manobra, com transferência e diâmetro tático, apresentaram um erro consistente da ordem de $20 \mathrm{~m}$, esse erro manteve esta ordem de grandeza tanto para transferência quanto para o diâmetro tático indicando que o erro experimentado para o diâmetro tático se originou no início da manobra.

Os valores de erro percentual apresentados foram mais altos para a transferência medida devido a sua dimensão menor do que o diâmetro tático, visto que o erro para ambas medidas se originou durante a fase transiente inicial da manobra.

Quando observados os gráficos de velocidade obtidos nestas manobras notase que as acelerações apresentadas pelo modelo numérico, para velocidade 
transversal e velocidade de guinada, são inferiores às apresentadas pelo modelo em escala reduzida.

\subsubsection{Initial turning test}

As manobras deste tipo, conforme apresentado na Figura 119, apresentaram erros menores nas manobras em águas rasas de forma consistente.

Figura 119 - Erros médios para as manobras de Initial turning test

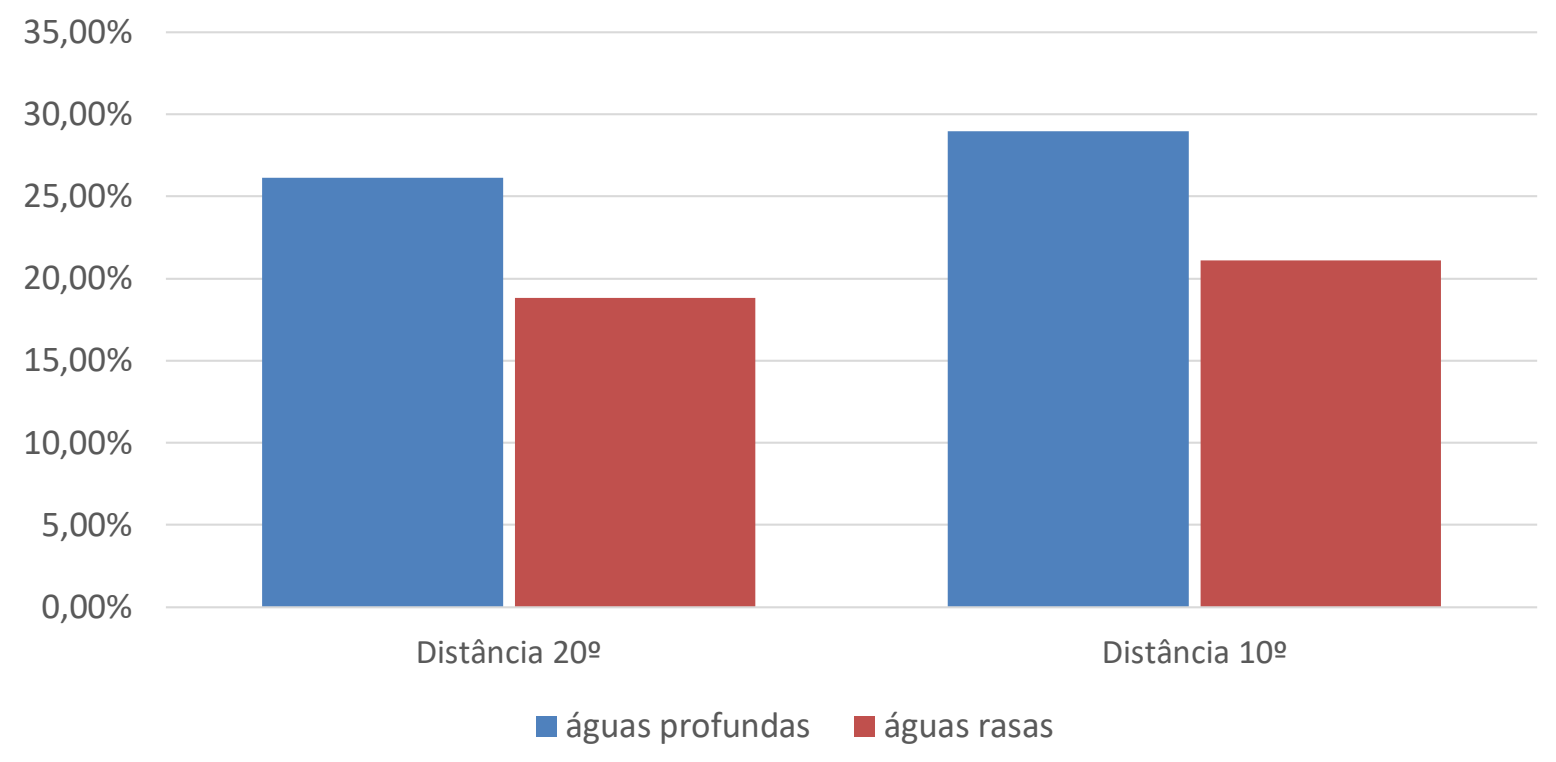

Fonte; Autor.

As manobras em águas profundas apresentaram ainda erro maior nas situações com os propulsores girando mais rápido, o que indica que o modelo de interação entre propulsor e leme está mais adequado a rotações mais baixas, como pode ser visto através da Tabela 47.

Tabela 47 - Erros obtidos para as manobras de Initial turning test em águas profundas

Fonte: Autor.

\begin{tabular}{|c|c|c|c|}
\hline $\begin{array}{c}\text { Rotação } \\
{[\mathrm{RPM}]}\end{array}$ & $20^{\circ}$ & $10^{\circ}$ & média \\
\hline 500 & $20.0 \%$ & $25.1 \%$ & $22.6 \%$ \\
\hline 1050 & $32.3 \%$ & $32.8 \%$ & $32.6 \%$ \\
\hline
\end{tabular}

\subsubsection{Coasting turn}

Para as manobras de coasting turn em que a guinada é realizada sem a ação dos propulsores, os resultados foram consistentes e apresentaram velocidade transversal inferior à medida experimentalmente. 
Ressalta-se que o erro para a velocidade angular apresentado é compatível com o erro apresentado nos demais tipos de manobra, dessa forma conclui-se que a atuação dos lemes foi satisfatória.

Contudo as velocidades transversais observadas são baixas e dessa forma pequenas diferenças de velocidade implicam em um grande erro de transferência dentro da escala adotada.

Conforme pode ser observado na Figura 120, o comportamento observado para este tipo de manobra está de acordo com o comportamento observado nas manobras de turning circle. Verifica-se maior erro para o ângulo de deriva, pois esta manobra ocorre integralmente durante a fase transiente onde há a aceleração no sentido transversal da embarcação, fase da manobre em que há maior acumulo de erro conforme descrito na seção 6.11.1.

Figura 120 - Erros médios para as manobras de Coasting turn

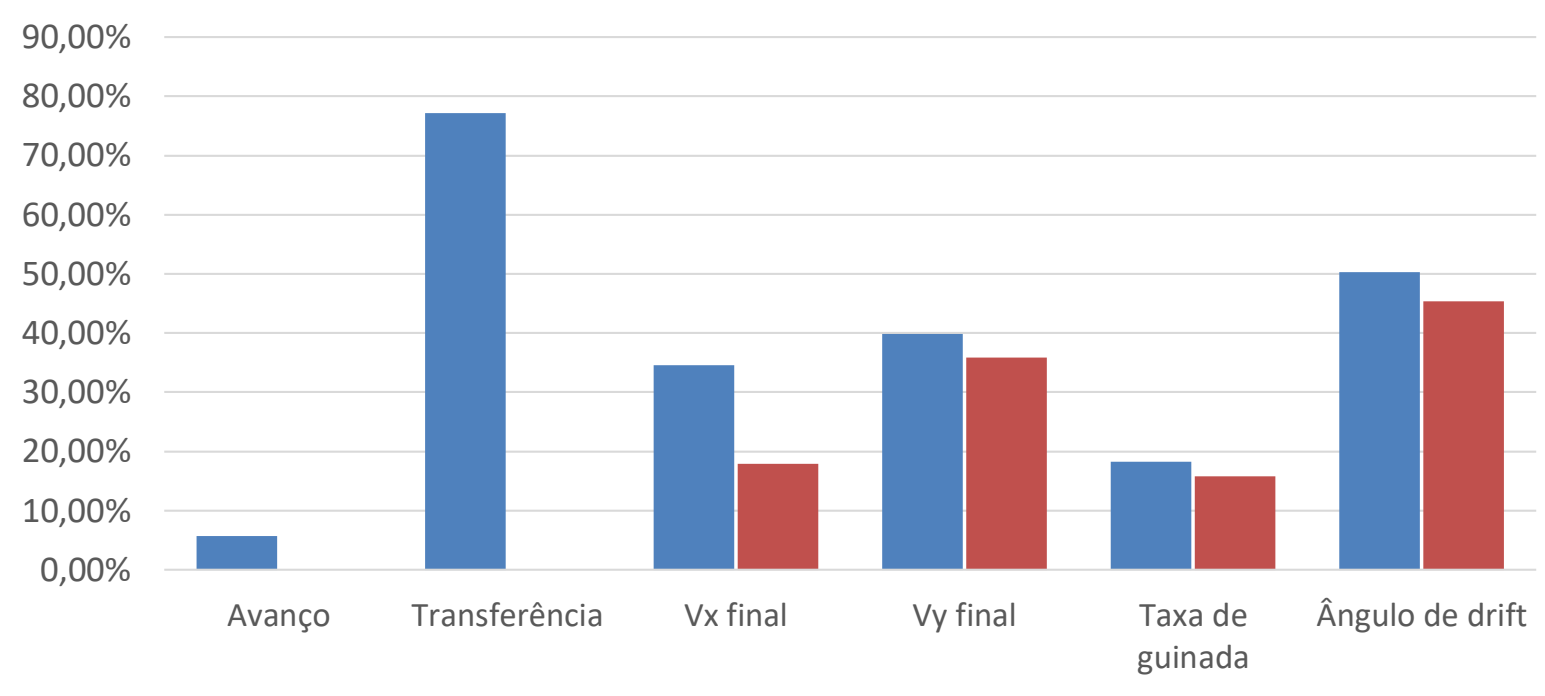

—águas profundas a águas rasas

Fonte: Autor.

\subsubsection{Crash stop}

Para as manobras de crash stop foram medidos os alcances longitudinal, transversal e a distância percorrida pela embarcação. Devido à embarcação utilizada possuir 2 propulsores principais simétricos não foi observado o efeito de pá que faz 0 navio guinar de forma acentuada durante a parada, por esse motivo o alcance transversal medido nessas manobras foi quase nulo e deve ser descartado das 
avaliações. A Figura 121 no entanto mostra os erros obtidos para as 3 grandezas medidas.

Foi observado um erro consistente menor que $20 \%$ no alcance longitudinal, com exceção da manobra número 9 em águas rasas que apresentou um erro de $39.6 \%$. Este erro é atribuído a algum fator externo desconhecido durante a realização da manobra com o modelo em escala que provocou uma desaceleração maior a partir do meio da manobra, como pode ser notado na descrição da manobra 9 de águas rasas, e na comparação dos gráficos de velocidade de avanço das manobras 9 e 10 apresentada na Figura 122.

Figura 121 - Erros médios para as manobras de Crash stop

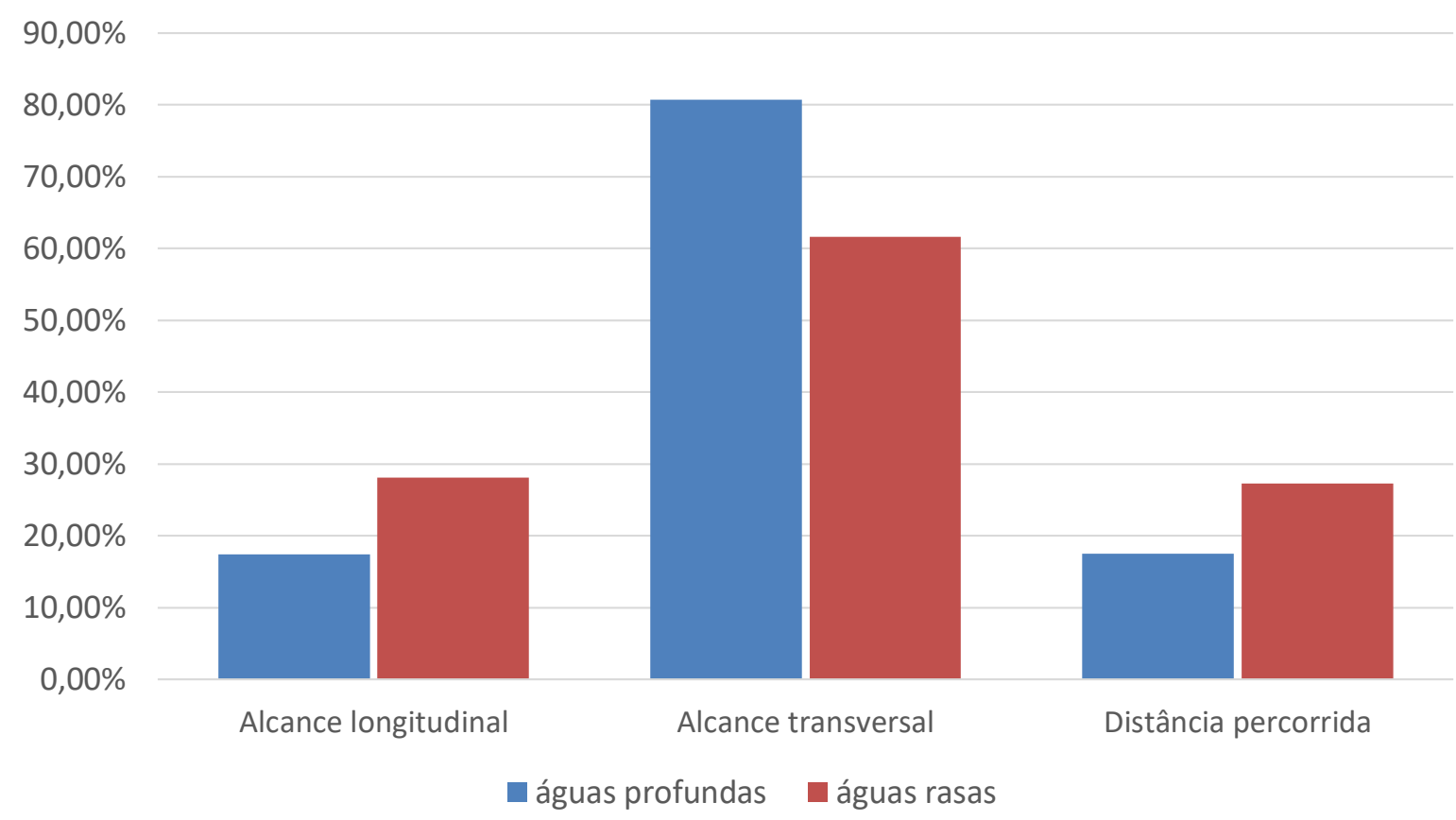

Fonte: Autor. 
Figura 122 - Velocidade de avanço para a manobra 9 (acima) e manobra 10 (abaixo)
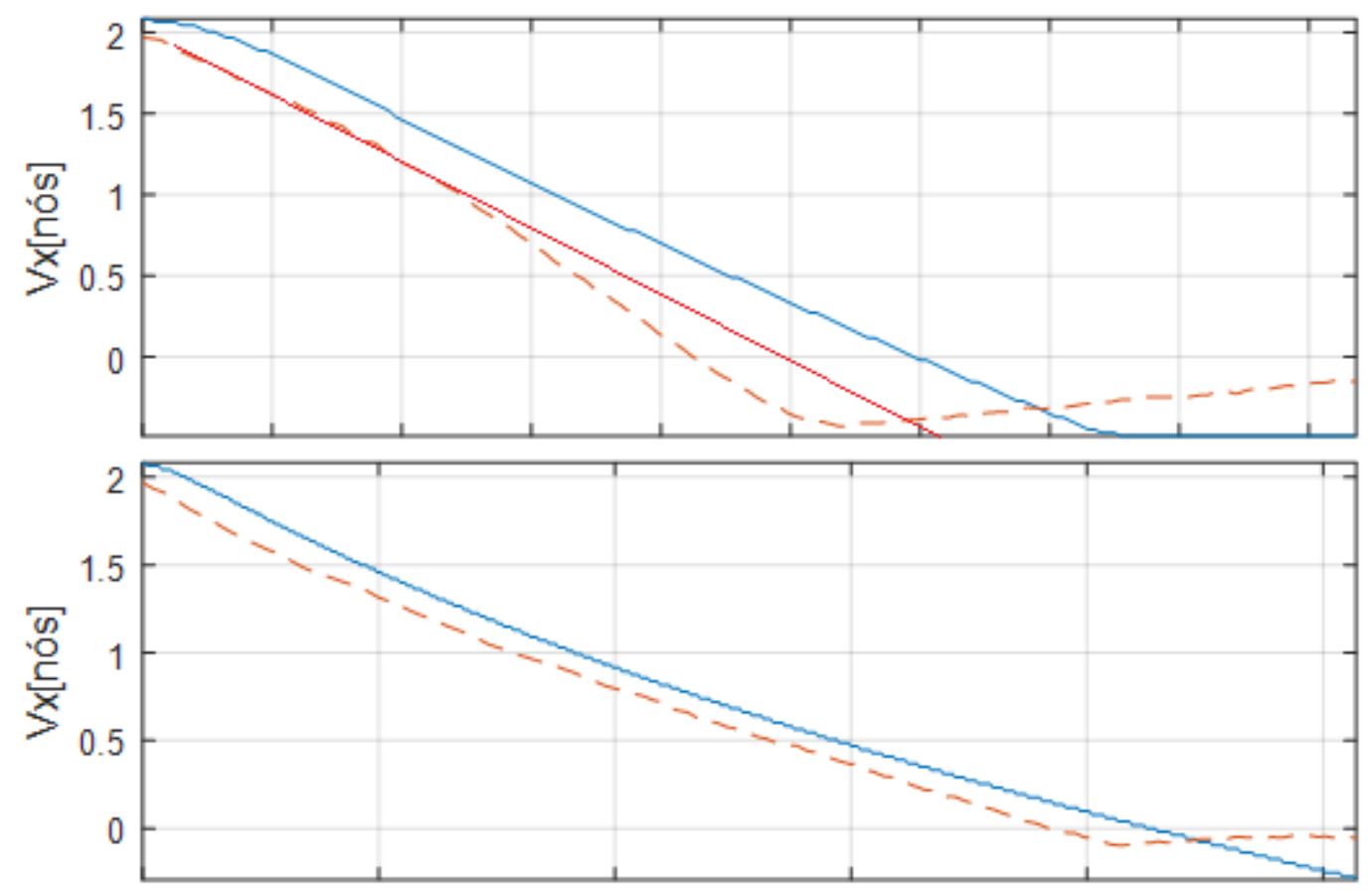

Fonte: Autor.

\subsubsection{Accelerating turn}

As manobras de accelerating turn apresentaram resultados similares aos experimentais, porém quando comparadas com as manobras de turning circle o avanço observado apresentou maior erro.

Observa-se também que o aumento do erro do diâmetro final, na comparação com as manobras de turning circle, foi menor do que o aumento observado para o avanço. Este fato indica que o erro obtido para este tipo de manobra está relacionado com o início da manobra onde ocorrem os regimes transientes de velocidade.

De fato, os gráficos de velocidade apresentados nas seções destas manobras, incluídos na Figura 124, indicam que o modelo numérico tem um comportamento com maior amortecimento para as velocidades de avanço e deriva do que o modelo experimental, o que ocorre com menor intensidade para a velocidade angular, justificando o menor raio descrito pela embarcação no início da manobra.

Os altos erros indicados para as manobras em águas rasas, indicados na Figura 123, foram induzidos por algum problema ocorrido durante os ensaios experimentais que apresentaram trajetórias elípticas, compatíveis com manobras de 
giro realizadas na presença de fortes ventos, situação não reproduzida no modelo numérico.

Figura 123 - Erros médios para as manobras de Accelerating turn

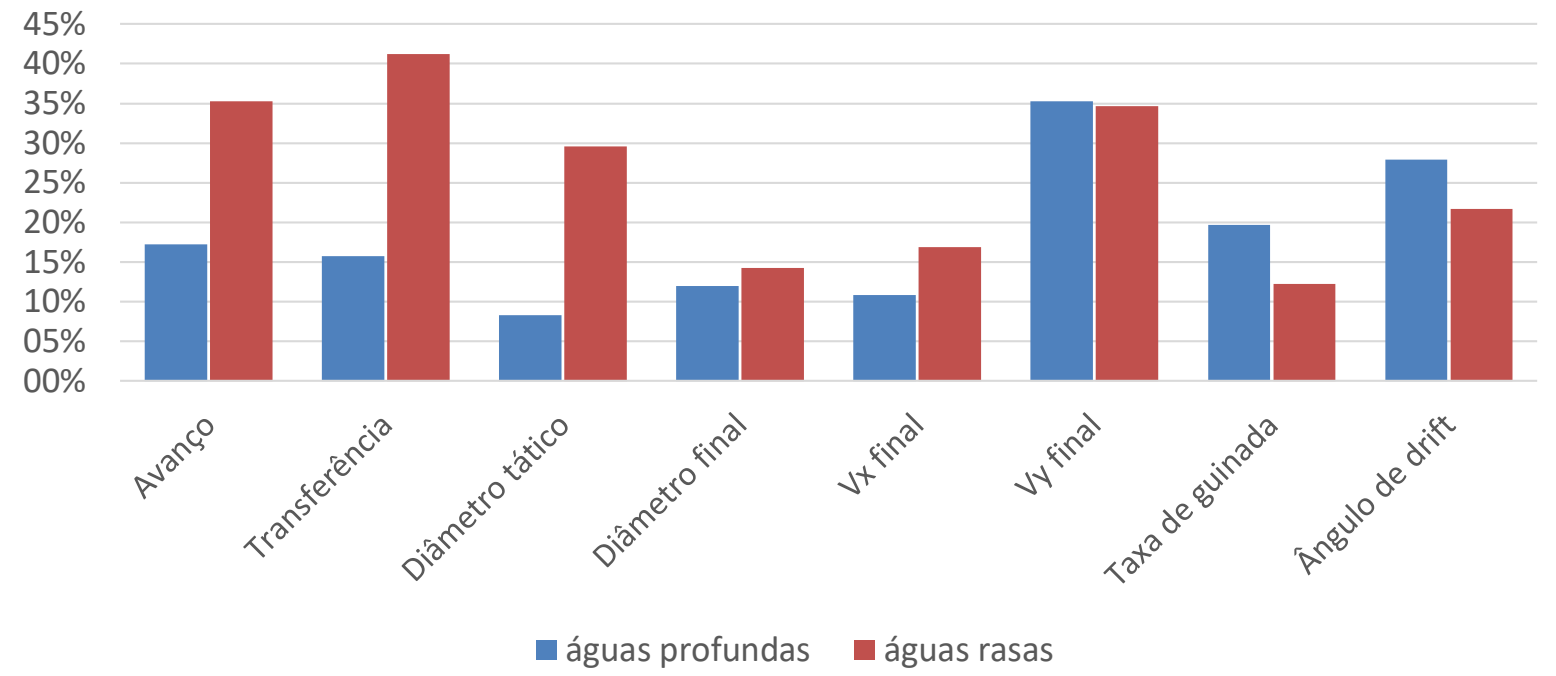

Fonte: Autor.

Figura 124 - Velocidade angular e Velocidades para a manobra 12
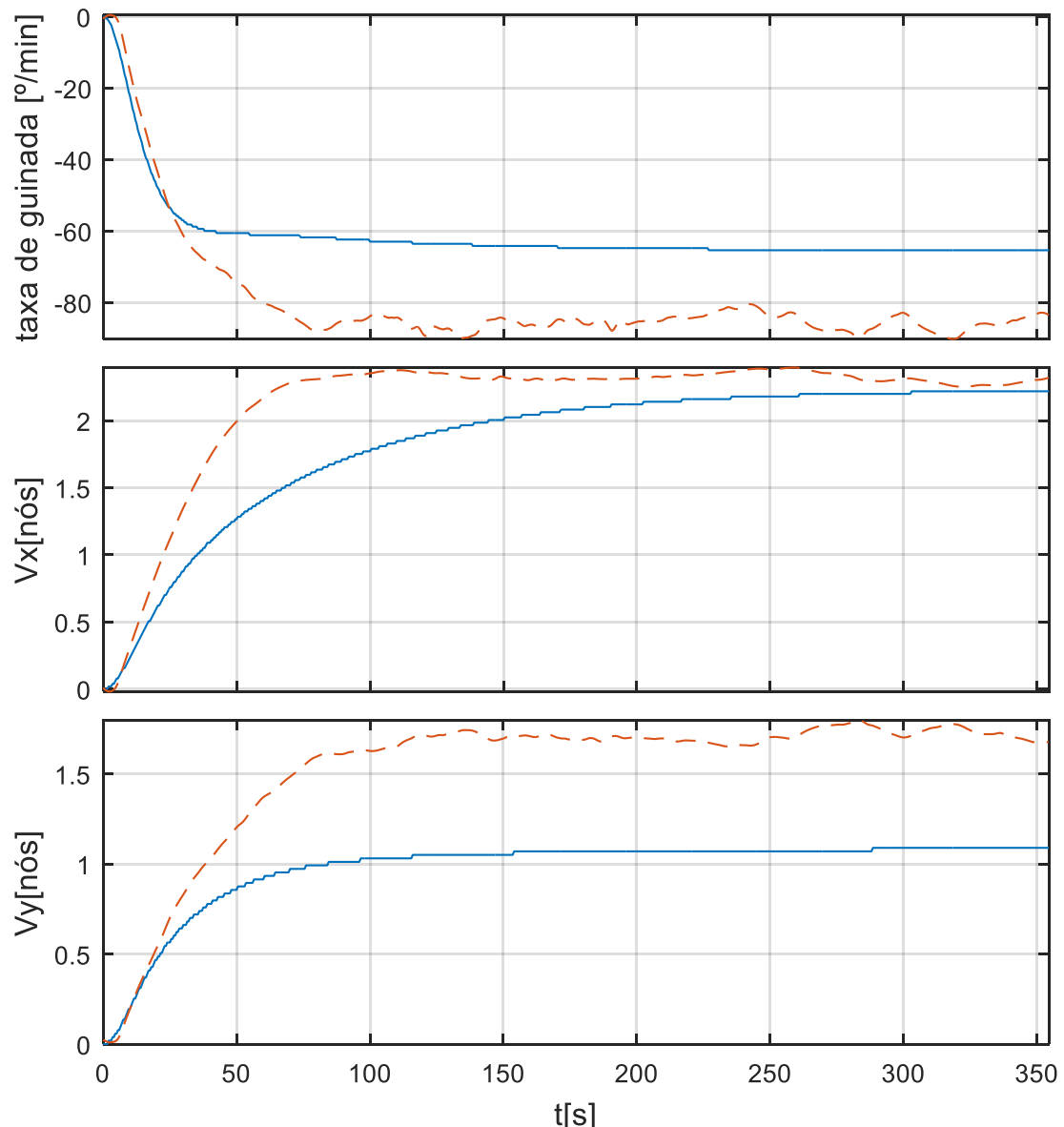

Fonte: Autor. 


\subsubsection{Crash ahead}

Esta manobra apresentou bom resultado como pode ser visto na Figura 125, indicando uma boa aderência do modelo de máquinas em baixa velocidade.

Não foram obtidas execuções satisfatórias desta manobra para águas rasas, por este motivo são apresentados somente os resultados para águas profundas.

Figura 125 - Erros médios para as manobras de Crash ahead

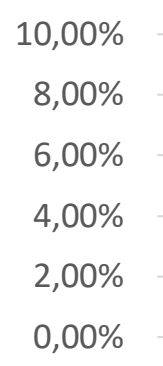

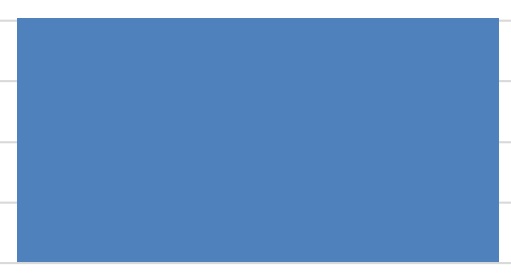

Alcance longitudinal

- águas profundas

— águas rasas

Fonte: Autor.

\subsubsection{Stopping inertia test}

As manobras de parada por inércia apresentaram bons resultados para a aceleração de avanço. $O$ erro apontado para a velocidade final da manobra 18 para águas profundas foi descartado pois devido a forma de cálculo do erro acarreta um valor alto de erro para uma diferença de velocidade inferior a 0,1 nó.

A diferença de velocidade transversal, mais baixa para o modelo numérico, reflete o erro apresentado para a transferência, indicado na Figura 126. 
Figura 126 - Erros médios para as manobras de Stopping inertia test

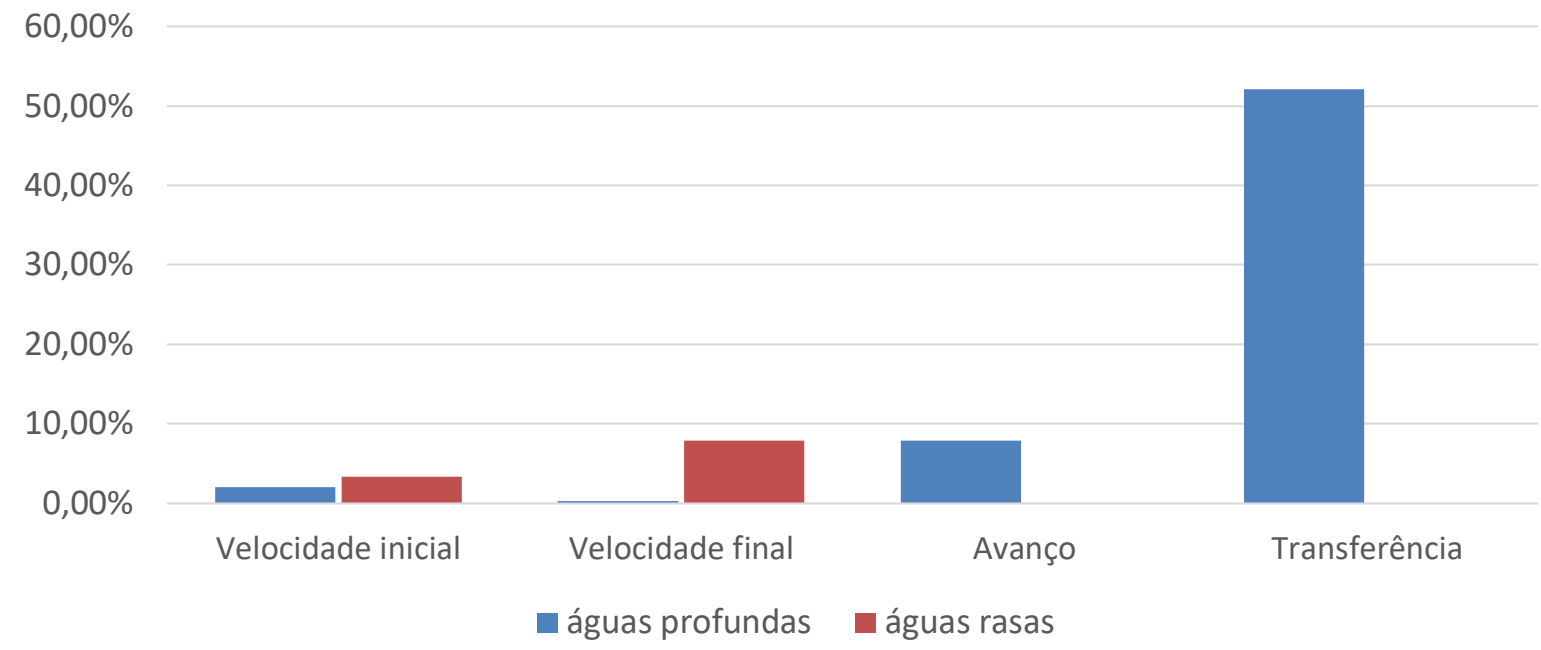

Fonte: Autor.

\subsubsection{Lateral thruster capability}

Não foi possível completar esta manobra com o modelo numérico. Este modelo apresentou a velocidade angular muito menor do que a do modelo experimental, apresentando erros superiores a $60 \%$ como indicado na Figura 127, não sendo possível medir o avanço, transferência e diâmetro tático, portanto o erro para este tipo de manobra foi medido com base na velocidade angular obtida. Observou-se tanto para águas rasas quanto para profundas a velocidade angular apresentada pelo modelo numérico foi inferior à do modelo experimental. Conclui-se que o modelo não representou de forma adequada esta manobra.

Figura 127 - Erros médios para as manobras de Lateral thruster capability

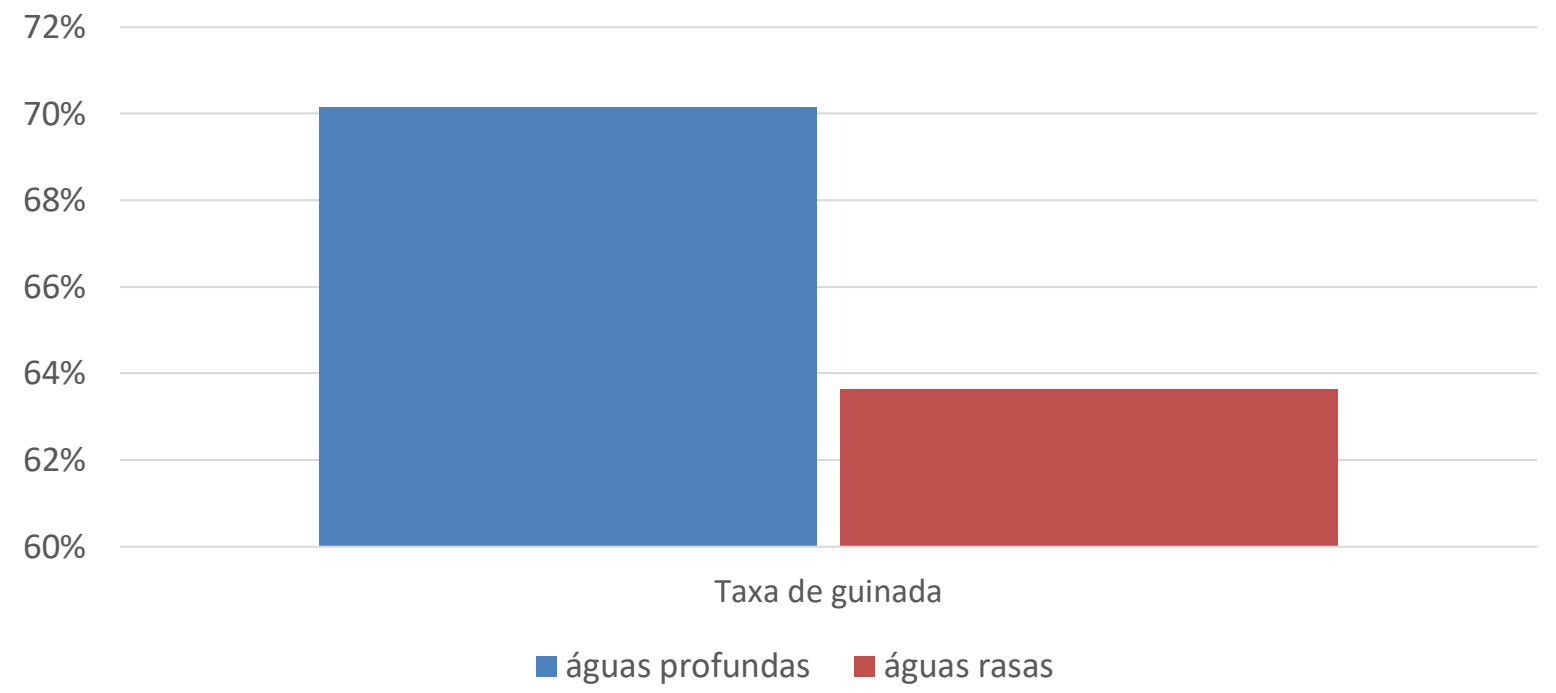

Fonte: Autor. 
Foi levantada a hipótese de que o propulsor transversal de proa não foi representado de forma adequada pelo modelo numérico, devido à baixa força de empuxo em comparação ao modelo experimental. Por este motivo foi realizada uma nova simulação desta manobra com maior capacidade do propulsor transversal de proa, utilizando uma velocidade de 204 RPM com um empuxo 4 vezes maior do que o original.

Figura 128 - Trajetória varrida, manobra 19, original acima e nova execução abaixo

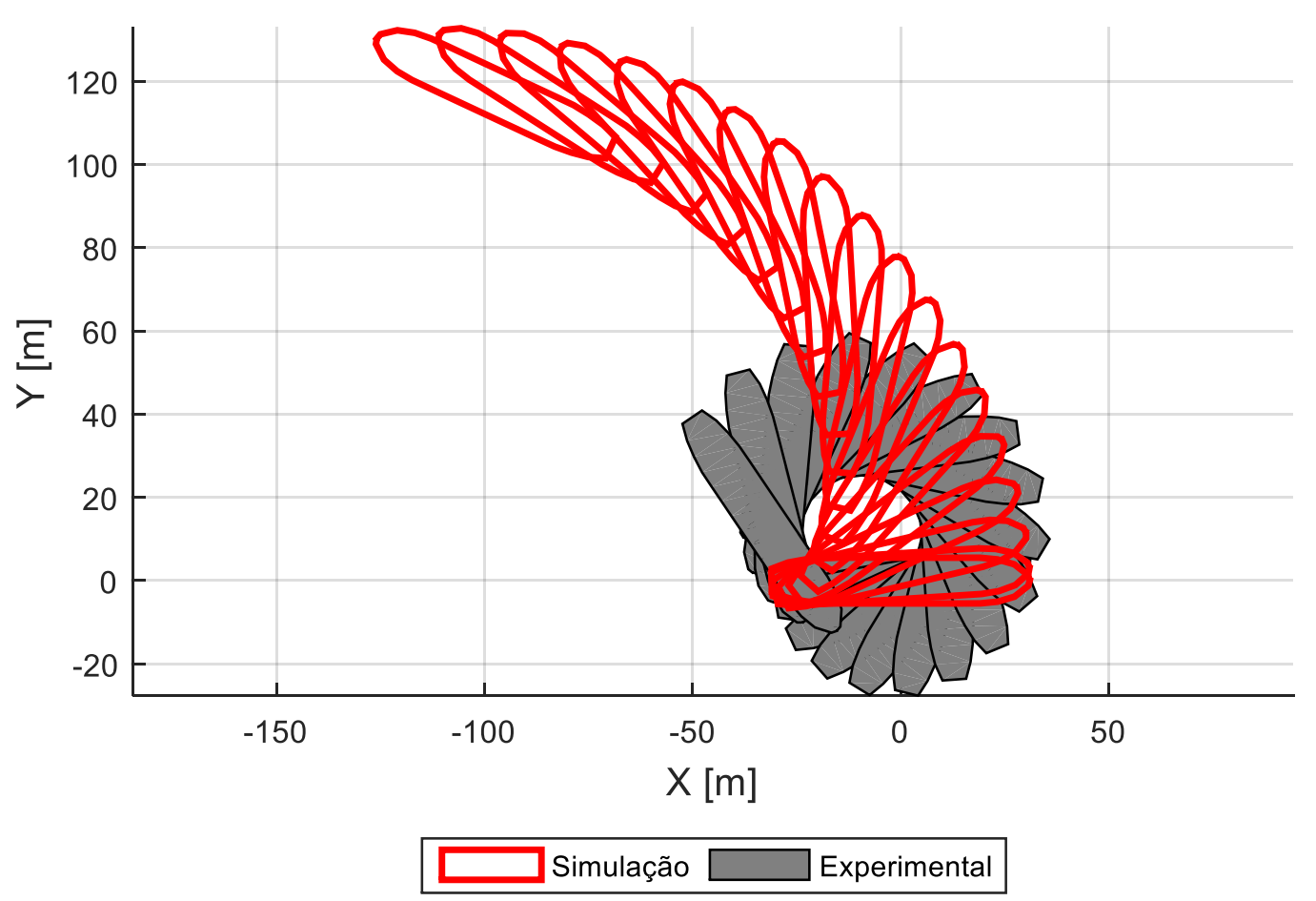

Fonte: Autor. 
Figura 129 - Ângulo de deriva, Velocidade angular, Velocidade Vx, manobra 19, original acima e nova execução abaixo
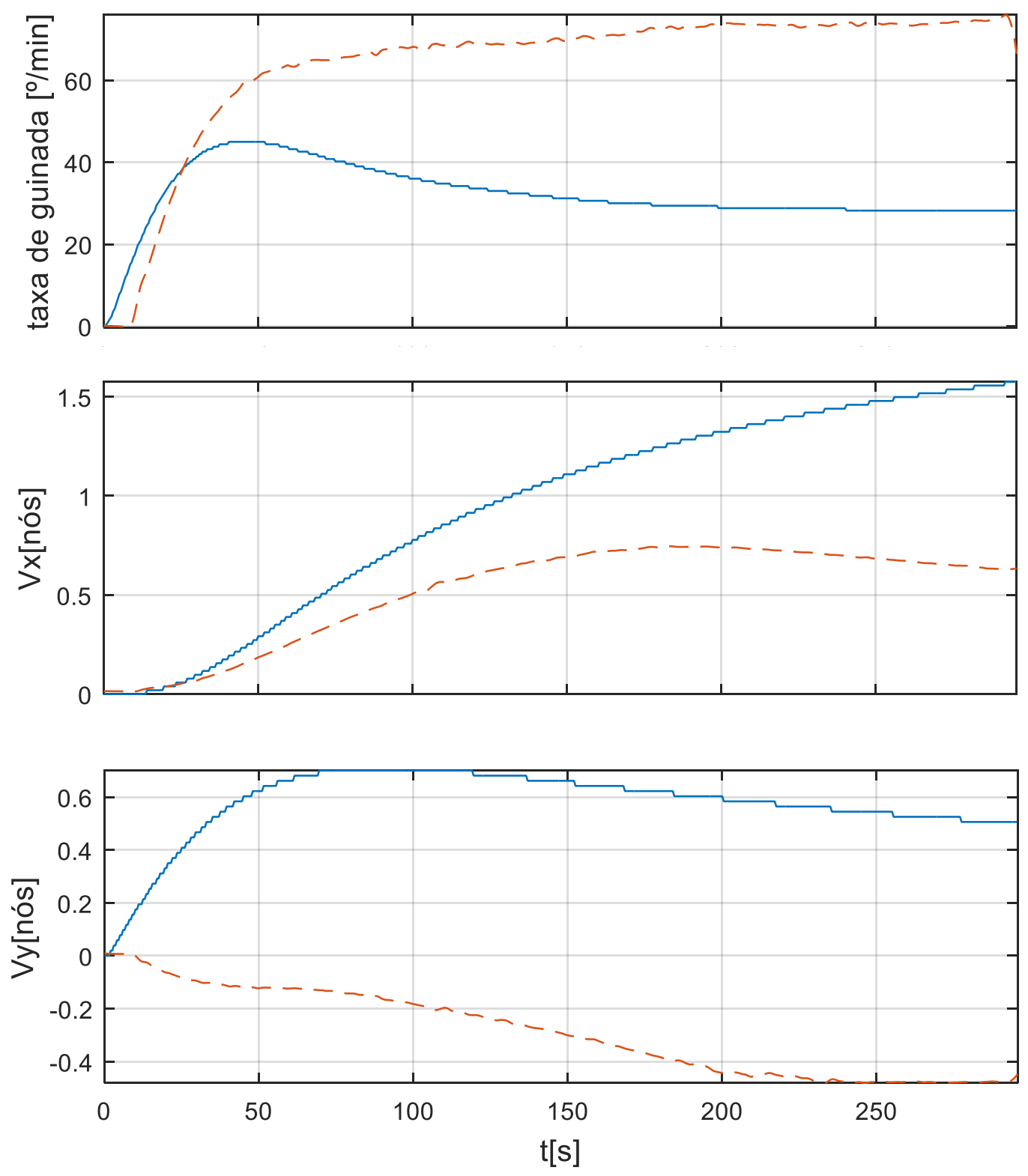

Simulação - - Experimental

Fonte: Autor.

As figuras 128 e 129 mostram que com o aumento da rotação o modelo numérico se aproximou do modelo experimental, para a taxa de guinada e velocidade de avanço, porém a velocidade de deriva aumentou e se manteve na direção oposta à obtida experimentalmente. O comportamento obtido indica que há outro fator além do empuxo do propulsor que impede a boa representação desta manobra pelo modelo numérico. 


\subsubsection{Pull out test}

Esta manobra apresentou um bom comportamento do modelo numérico. $\mathrm{O}$ alto erro apresentado para a velocidade angular final na Figura 130, que mede a estabilidade direcional da embarcação, se deve à forma de mensurar o erro que divide o erro de 3 \% min obtido na manobra 22 em águas rasas pela baixa velocidade angular atingida pelo modelo experimental.

Esta manobra mostra que o modelo experimental, assim como as embarcações reais, apresenta comportamento assimétrico, que resultou em uma velocidade angular residual de 4,2 \%/min quando a manobra foi realizada para boreste e 0,6 $\%$ min quando realizada para bombordo, enquanto o modelo numérico apresentou $3,6 \% / \mathrm{min}$ para ambos os bordos, como esperado.

A comparação entre a manobra em águas rasas e águas profundas também confirmou que o modelo numérico apresenta maior estabilidade direcional em águas rasas conforme esperado. Este comportamento não foi observado para o modelo experimental, esta divergência da expectativa para a velocidade angular final pode ter ocorrido pela ação de algum fator ambiental não controlado durante a realização dos experimentos.

Figura 130 - Erros médios para as manobras de Pull out test

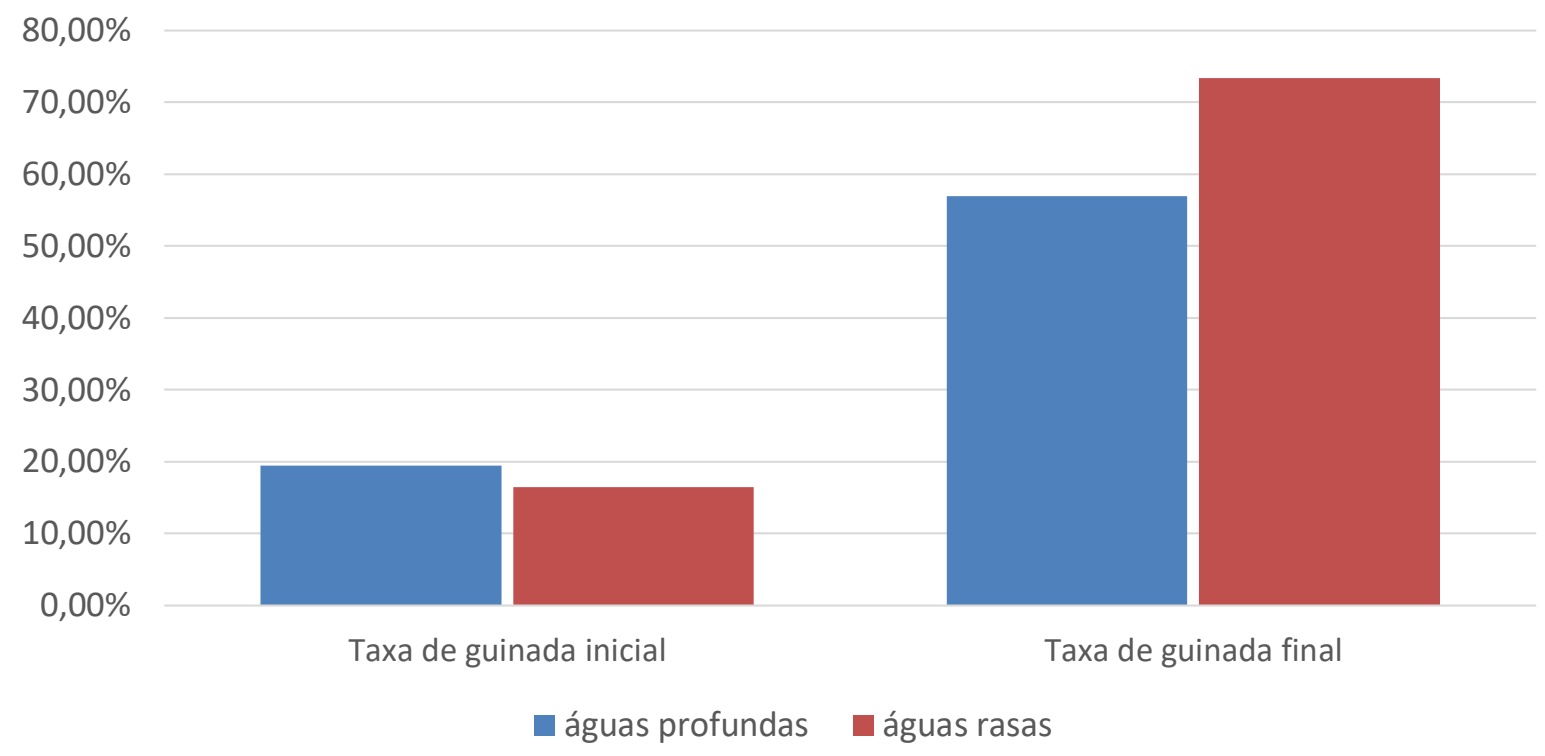

Fonte: Autor. 


\subsubsection{Avaliação geral}

Como pode ser visto através da Tabela 48 os resultados apresentados pelo modelo numérico foram consistentes, mantendo a ordem de grandeza do erro obtido nas medições das manobras tanto para manobras em águas rasas quanto manobras em águas profundas. A tabela apresenta ainda a separação entre os erros das grandezas que medem distâncias e das que medem velocidade. Por exemplo, para a manobra de giro compõem os erros que medem distâncias as grandezas avanço, transferência, diâmetro tático, diâmetro final, e ângulo de deriva, e as grandezas que medem os erros de velocidade são a velocidade de avanço final, velocidade de deriva final, e velocidade angular.

Algumas variações no valor do erro obtido podem ser vistas entre manobras do mesmo tipo, como por exemplo, no caso das manobras de initial turning test que apresentou erros médios próximos a $32 \%$ nas manobras com os propulsores girando a 1050 RPM e erros médios próximos a 22\% com os propulsores girando a 500 RPM. Esta observação indica que o modelo matemático utilizado possui pontos ótimos de operação onde as características de manobrabilidade são melhor representadas e os erros obtidos nas medições das manobras são minimizados.

A observação consolidada dos erros por tipo de manobra pode ser feita através da Figura 131, esta figura mostra que o modelo se mostrou consistente para as manobras testadas com erros médios variando na faixa de $20 \%$ a $30 \%$, com exceção das manobras de crash ahead, stopping inertia test e lateral thruster capability.

Esta diferença entre os tipos de manobra indica que o modelo não representou de forma satisfatória a manobra de lateral thruster capability. 
Tabela 48 - Média dos valores absolutos dos erros para cada manobra

\begin{tabular}{|c|c|c|c|c|c|c|c|}
\hline \multirow{2}{*}{\multicolumn{2}{|c|}{ Manobra }} & \multicolumn{2}{|c|}{ Erro médio [\%] } & \multicolumn{2}{|c|}{ Erros de distância } & \multicolumn{2}{|c|}{ Erros de velocidade } \\
\hline & & \multirow{2}{*}{$\begin{array}{c}\begin{array}{c}\text { águas } \\
\text { profundas }\end{array} \\
20.8 \%\end{array}$} & \multirow{2}{*}{$\begin{array}{l}\begin{array}{c}\text { águas } \\
\text { rasas }\end{array} \\
15.3 \%\end{array}$} & \multirow{2}{*}{\begin{tabular}{|c|}
$\begin{array}{c}\text { águas } \\
\text { profundas }\end{array}$ \\
$17.6 \%$
\end{tabular}} & \multirow{2}{*}{$\begin{array}{c}\begin{array}{c}\text { águas } \\
\text { rasas }\end{array} \\
17.4 \%\end{array}$} & \multirow{2}{*}{\begin{tabular}{|c|}
$\begin{array}{c}\text { águas } \\
\text { profundas }\end{array}$ \\
$26.2 \%$
\end{tabular}} & \multirow{2}{*}{$\begin{array}{c}\begin{array}{c}\text { águas } \\
\text { rasas }\end{array} \\
13.2 \%\end{array}$} \\
\hline 1 & Turning circle & & & & & & \\
\hline 2 & Turning circle & $16.1 \%$ & $23.7 \%$ & $17.4 \%$ & $25.8 \%$ & $13.8 \%$ & $20.4 \%$ \\
\hline 3 & Initial turning test & $32.3 \%$ & $28.0 \%$ & $32.3 \%$ & $28.0 \%$ & - & - \\
\hline 4 & Initial turning test & $32.8 \%$ & $16.3 \%$ & $32.8 \%$ & $16.3 \%$ & - & - \\
\hline 5 & Initial turning test & $20.0 \%$ & $9.6 \%$ & $20.0 \%$ & $9.6 \%$ & - & - \\
\hline 6 & Initial turning test & $25.1 \%$ & $25.9 \%$ & $25.1 \%$ & $25.9 \%$ & - & - \\
\hline 7 & Coasting turn & $37.6 \%$ & $25.4 \%$ & $46.5 \%$ & $43.8 \%$ & $24.2 \%$ & $19.3 \%$ \\
\hline 8 & Coasting turn & $28.6 \%$ & $32.1 \%$ & $44.2 \%$ & $46.9 \%$ & $23.3 \%$ & $27.2 \%$ \\
\hline 9 & Stopping Ability & $18.6 \%$ & $39.6 \%$ & $18.6 \%$ & $39.6 \%$ & - & - \\
\hline 10 & Stopping Ability & $16.4 \%$ & $15.8 \%$ & $16.4 \%$ & $15.8 \%$ & - & - \\
\hline 12 & Acelerating turn & $15.3 \%$ & $26.0 \%$ & $11.3 \%$ & $29.3 \%$ & $21.9 \%$ & $20.4 \%$ \\
\hline 13 & Acelerating turn & $21.5 \%$ & $21.9 \%$ & $20.8 \%$ & $21.4 \%$ & $22.7 \%$ & $22.7 \%$ \\
\hline 14 & Acelerating turn & $23.5 \%$ & $12.4 \%$ & $22.7 \%$ & $5.3 \%$ & $24.7 \%$ & $17.1 \%$ \\
\hline 15 & Acelerating turn & $13.3 \%$ & $28.9 \%$ & $10.2 \%$ & $33.0 \%$ & $18.3 \%$ & $24.9 \%$ \\
\hline 16 & Crash ahead & $8.1 \%$ & - & $8.1 \%$ & - & - & - \\
\hline 17 & $\begin{array}{l}\text { Stopping inertia } \\
\text { test (free stop) }\end{array}$ & $1.0 \%$ & $5.2 \%$ & - & - & $1.0 \%$ & $5.2 \%$ \\
\hline 18 & $\begin{array}{l}\text { Stopping inertia } \\
\text { test (IMO stop) }\end{array}$ & $15.6 \%$ & $6.1 \%$ & $4.0 \%$ & - & $27.3 \%$ & $6.1 \%$ \\
\hline 19 & $\begin{array}{c}\text { Lateral thruster } \\
\text { capability }\end{array}$ & $70.1 \%$ & $63.6 \%$ & - & - & $70.1 \%$ & $63.6 \%$ \\
\hline 21 & Pull out & $16.9 \%$ & & - & - & $16.9 \%$ & - \\
\hline 22 & Pull out & $24.5 \%$ & $23.2 \%$ & - & - & $24.5 \%$ & $23.2 \%$ \\
\hline & média & $22.9 \%$ & $23.3 \%$ & $21.7 \%$ & $25.6 \%$ & $24.2 \%$ & $21.9 \%$ \\
\hline
\end{tabular}

Fonte: Autor.

Os baixos erros observados para as manobras de crash ahead e stopping inertia test indicam que o modelo apresenta um comportamento melhor do que a média obtida para manobras que não apresentam movimentos transversais na embarcação. 
Figura 131 - Média dos valores absolutos dos erros por tipo de manobra

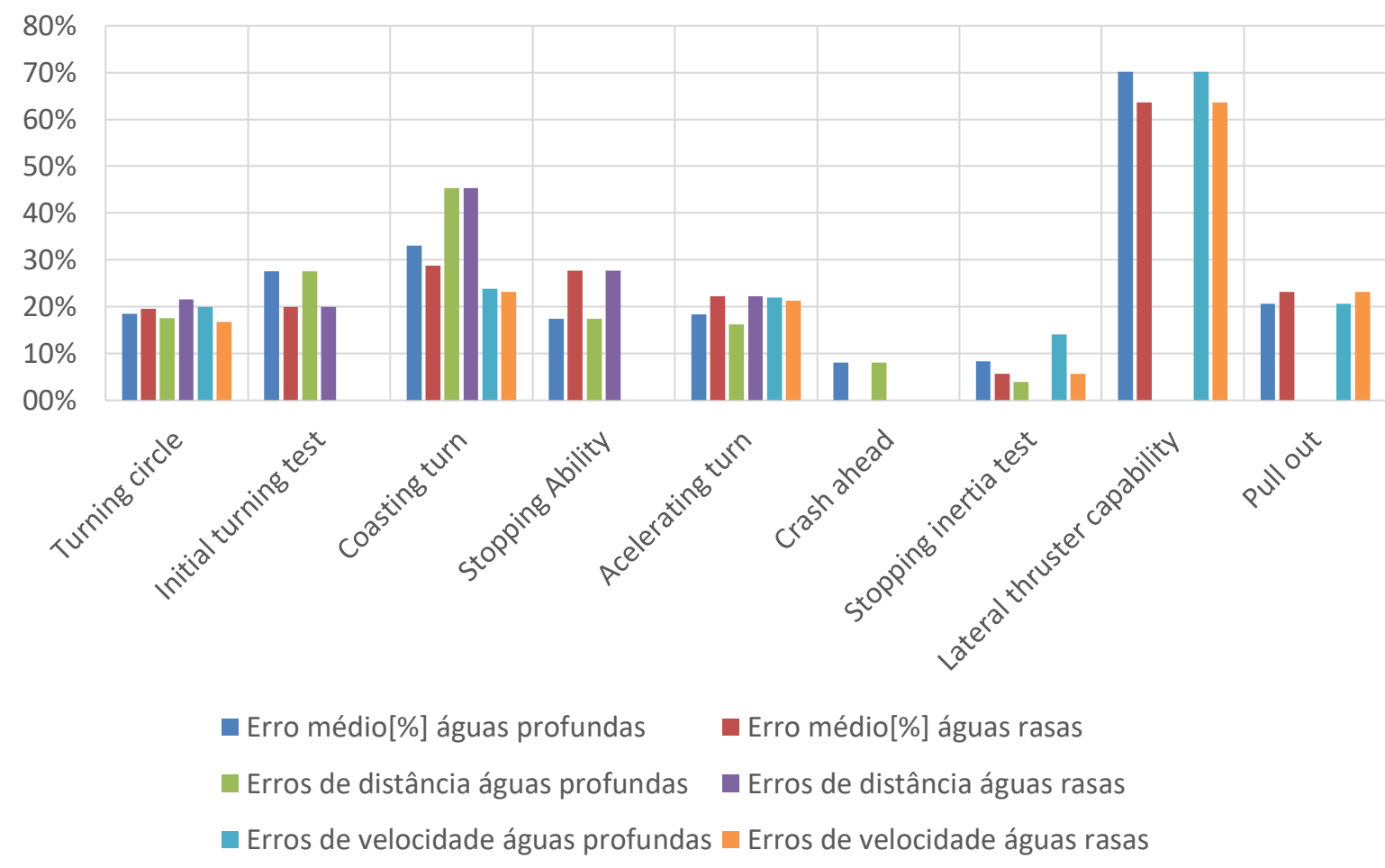

Fonte: Autor.

A Figura 131 e a Tabela 48 mostram também que as características geométricas medidas nas manobras apresentam erros compatíveis com as características de velocidade medidas, e esta propriedade do modelo numérico o torna adequado para a avaliação de problemas diversos de engenharia pois torna possível a avaliação de problemas de natureza distintas com o mesmo grau de acurácia. Por exemplo, o dimensionamento de áreas de manobra onde as dimensões da área ocupada pela embarcação são importantes, ou a avaliação da interação entre embarcações na passagem próxima entre um canal de navegação e um berço de atracação onde as velocidades são importantes.

A Figura 132 exemplifica ainda a diferença apresentada entre a manobra em águas rasas e águas profundas. Observou-se através dos dados apresentados que em águas rasas o modelo experimental apresentou maior estabilidade direcional do que em águas profundas, sendo este comportamento também representado pelo modelo numérico. Este comportamento era esperado e pode ser conferido com mais facilidade através da comparação do ângulo de deriva observado para as manobras de turning circle, que apresentam uma queda de cerca de $15^{\circ}$ no ângulo de deriva em águas rasas. 
Figura 132 - Comparação entre a manobra 2 realizada em águas profundas (esquerda) e águas rasas (direita)

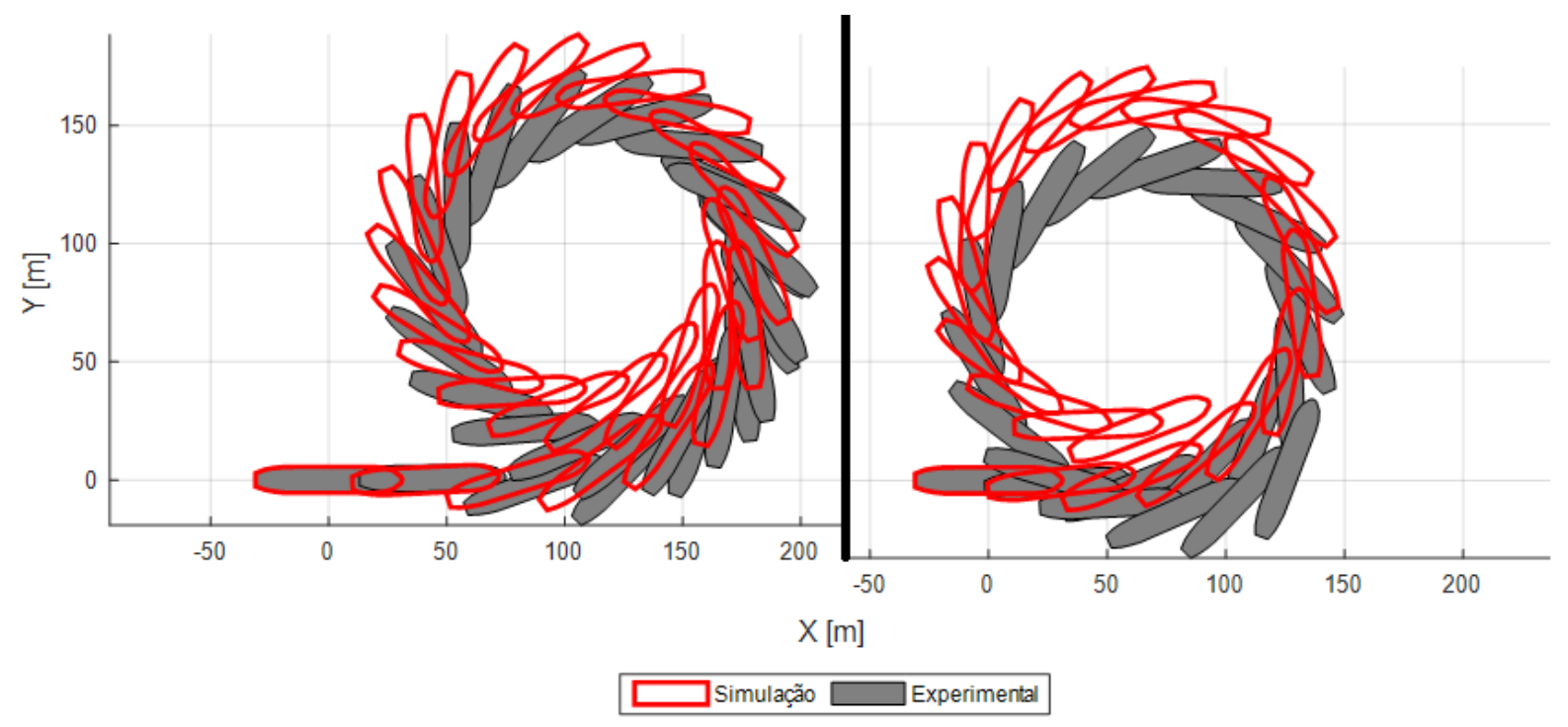

Fonte: Autor.

O mesmo tipo de comportamento pode ser verificado na manobra de pull out, onde a velocidade angular residual obtida no fim da manobra do modelo numérico é de 3,6 /min enquanto a mesma manobra em águas rasas apresenta uma velocidade angular residual de 1,2/min. Ressalta-se que esta redução é esperada também para o modelo em escala reduzida, o que porém não foi observado. Esse comportamento do modelo em escala reduzida pode ter sido causado por alguma assimetria do modelo físico ou algum agente ambiental, como correntes de vento, que tenha atuado durante a manobra. 


\section{ANÁLISE DE SENSIBILIDADE}

Foi realizada uma análise de sensibilidade do modelo numérico com o objetivo de relacionar os principais fatores que podem ser alterados durante o processo de calibração com seu respectivo efeito na manobra realizada pelo simulador. Dessa forma torna-se mais fácil a decisão sobre quais alterações podem ser feitas no modelo numérico de acordo com o efeito desejado para a manobra.

A análise de sensibilidade foi realizada após o processo de calibração com o intuito de utilizar o modelo calibrado como paradigma. Para sua realização foram alterados os parâmetros do modelo de forma individual em cada simulação e os resultados obtidos foram então comparados.

Os parâmetros analisados foram:
A. Massa adicional de deriva (Ma22)
B. Amortecimento linear de avanço $\left(\mathrm{C}_{11}\right)$
C. Amortecimento quadrático de guinada $\left(\mathrm{C}_{66}\right)$
D. Coeficientes de correnteza de deriva $\left(\mathrm{C}_{\mathrm{y}}\right)$
E. Coeficientes de correnteza de guinada $\left(\mathrm{C}_{\mathrm{nz}}\right)$
F. Área do leme

Estes parâmetros foram escolhidos por serem os parâmetros mais utilizados para a calibração dos modelos de manobras no laboratório Tanque de Provas Numérico.

Estes parâmetros foram variados em $\pm 20 \%$ do valor original obtido durante a calibração, totalizando 12 conjuntos de manobras, conforme a Tabela 49.

Para cada um dos 12 conjuntos de manobras foram avaliados os efeitos nos resultados em comparação à manobra de calibração. Os efeitos analisados foram estes, apresentados na Tabela 50

Como resultado da análise de sensibilidade os dados táticos obtidos nas manobras são mostrados através de um gráfico de barras com a amplitude do efeito analisado para cada fator com sua variação entre $80 \%$ e $120 \%$ do valor calibrado. Este gráfico mostra a importância de cada fator para o respectivo efeito. É utilizado também um gráfico que mostra para um determinado efeito quais foram os valores 
obtidos pelo modelo numérico em cada manobra de variação dos fatores, mostrando assim de que forma a variação de cada fator influencia os efeitos, este gráfico apresenta para efeito de comparação uma linha tracejada com o valor obtido experimentalmente.

Tabela 49 - Conjuntos de manobras

\begin{tabular}{ccccccc}
\hline no Teste & A [ton] & B [kN/m/s] & $\begin{array}{c}\text { Fatores } \\
\left.\text { [kN.m/(rad/s) }{ }^{2}\right]\end{array}$ & $\mathbf{D}$ & $\mathbf{E}$ & $\mathbf{F}\left[\mathbf{m}^{2}\right]$ \\
\hline 1 & 624.8 & 5.0 & $1.27 \mathrm{E}+06$ & 1.0 & 1.0 & 3.7 \\
2 & 937.2 & 5.0 & $1.27 \mathrm{E}+06$ & 1.0 & 1.0 & 3.7 \\
3 & 781.0 & 4.0 & $1.27 \mathrm{E}+06$ & 1.0 & 1.0 & 3.7 \\
4 & 781.0 & 6.0 & $1.27 \mathrm{E}+06$ & 1.0 & 1.0 & 3.7 \\
5 & 781.0 & 5.0 & $1.02 \mathrm{E}+06$ & 1.0 & 1.0 & 3.7 \\
6 & 781.0 & 5.0 & $1.53 \mathrm{E}+06$ & 1.0 & 1.0 & 3.7 \\
7 & 781.0 & 5.0 & $1.27 \mathrm{E}+06$ & 0.8 & 1.0 & 3.7 \\
8 & 781.0 & 5.0 & $1.27 \mathrm{E}+06$ & 1.2 & 1.0 & 3.7 \\
9 & 781.0 & 5.0 & $1.27 \mathrm{E}+06$ & 1.0 & 0.8 & 3.7 \\
10 & 781.0 & 5.0 & $1.27 \mathrm{E}+06$ & 1.0 & 1.2 & 3.7 \\
11 & 781.0 & 5.0 & $1.27 \mathrm{E}+06$ & 1.0 & 1.0 & 3.0 \\
12 & 781.0 & 5.0 & $1.27 \mathrm{E}+06$ & 1.0 & 1.0 & 4.5 \\
Calibração & 781.0 & 5.0 & $1.27 \mathrm{E}+06$ & 1.0 & 1.0 & 3.7 \\
\hline Fonte: Autor & & & & & &
\end{tabular}

Fonte: Autor.

Tabela 50 - Efeitos avaliados

\begin{tabular}{ll|ll}
\hline Manobra & Efeito & Manobra & Efeito \\
\hline & Avanço & & Avanço \\
& Transferência & & Transferência \\
Manobra 1 & Diâmetro tático & Manobra 15 & Diâmetro tático \\
& Diâmetro final & & Diâmetro final \\
& ROT & & ROT \\
& Drift & Drift \\
Manobra 3 & Distância 20 & Manobra 17 & Acel x \\
& Avanço & & Acel x \\
Manobra 7 & Transferência & Manobra 18 & Avanço \\
& Drift & & Transferência \\
Manobra 10 & Alcance & Manobra 19 & ROT \\
& & Manobra 21 & ROT final \\
\hline
\end{tabular}

Fonte: Autor.

\subsection{Manobra 1 Turning circle}

Pode-se observar através das figuras a seguir que os fatores com maior influência para esta manobra são os coeficientes de correnteza. Com exceção da velocidade angular, os coeficientes $C_{y}$ possuem o maior efeito para a calibração da 
manobra de giro. A velocidade angular se apresentou mais influenciável pelos coeficientes $\mathrm{C}_{\mathrm{nz}}$ e em seguida pelo amortecimento quadrático de guinada.

Quando os coeficientes $\mathrm{C}_{\mathrm{y}}$ tiveram seu valor aumentado, a embarcação se mostrou mais estável, aumentando as dimensões do giro realizado, enquanto os coeficientes $\mathrm{C}_{\mathrm{nz}}$ apresentaram comportamento oposto.

Figura 133 - Efeito dos fatores no Avanço

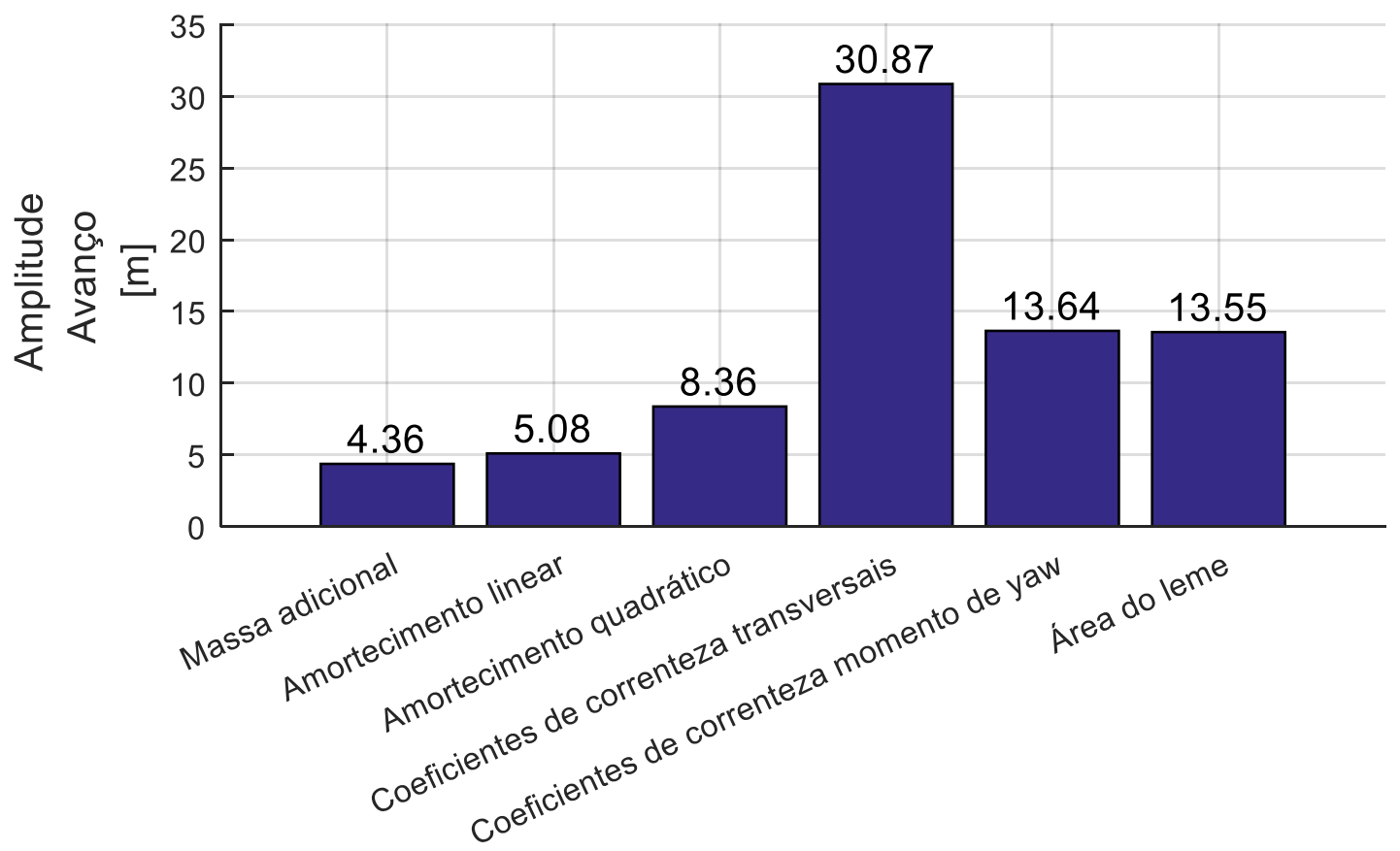

Fatores

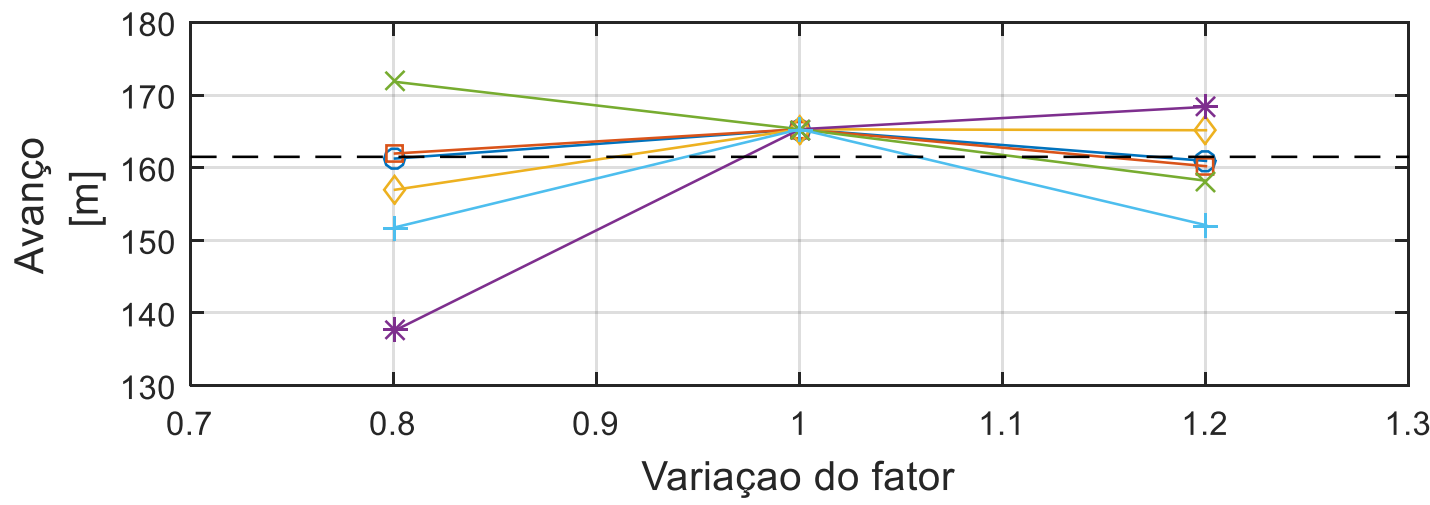

$$
\begin{aligned}
& - \text { Massa adicional } \\
& \square-\text { Amortecimento linear } \\
& - \text { Amortecimento quadrático } \\
& +\quad \text { Coeficientes de correnteza transversais } \\
& \times \quad \text { Coeficientes de correnteza momento de yaw } \\
& +\quad \text { Área do leme } \\
& -- \text { Experimental }
\end{aligned}
$$

Fonte: Autor. 
Figura 134 - Efeito dos fatores na Transferência

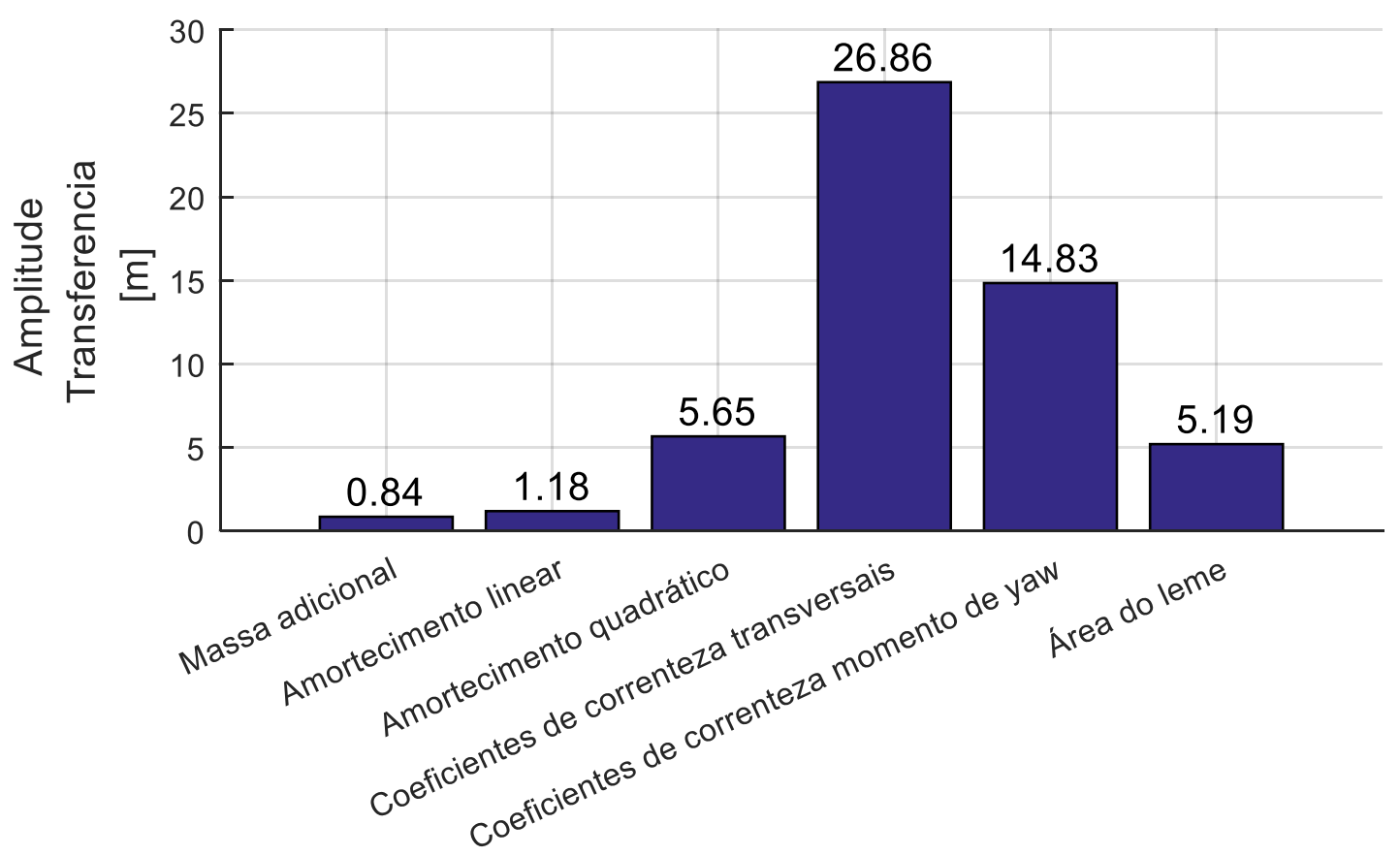

Fatores

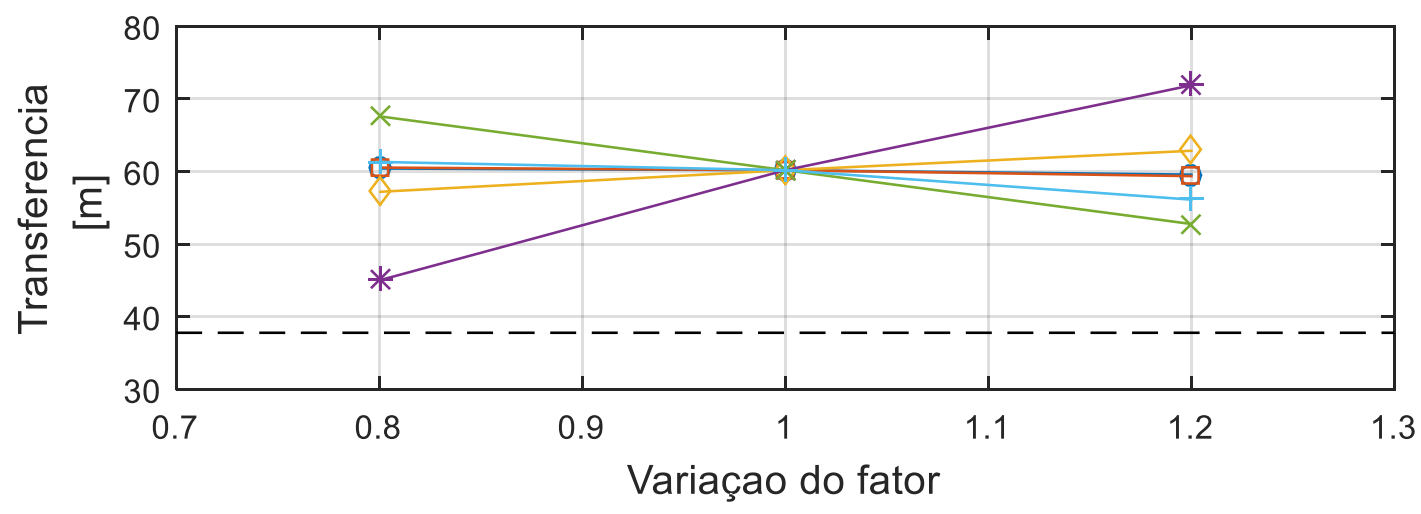

\begin{tabular}{l}
\hline - Massa adicional \\
$\square-$ Amortecimento linear \\
- Amortecimento quadrático \\
$+\quad$ Coeficientes de correnteza transversais \\
$+\quad$ Coeficientes de correnteza momento de yaw \\
+- Área do leme \\
\hline- Experimental
\end{tabular}

Fonte: Autor. 
Figura 135 - Efeito dos fatores no Diâmetro tático

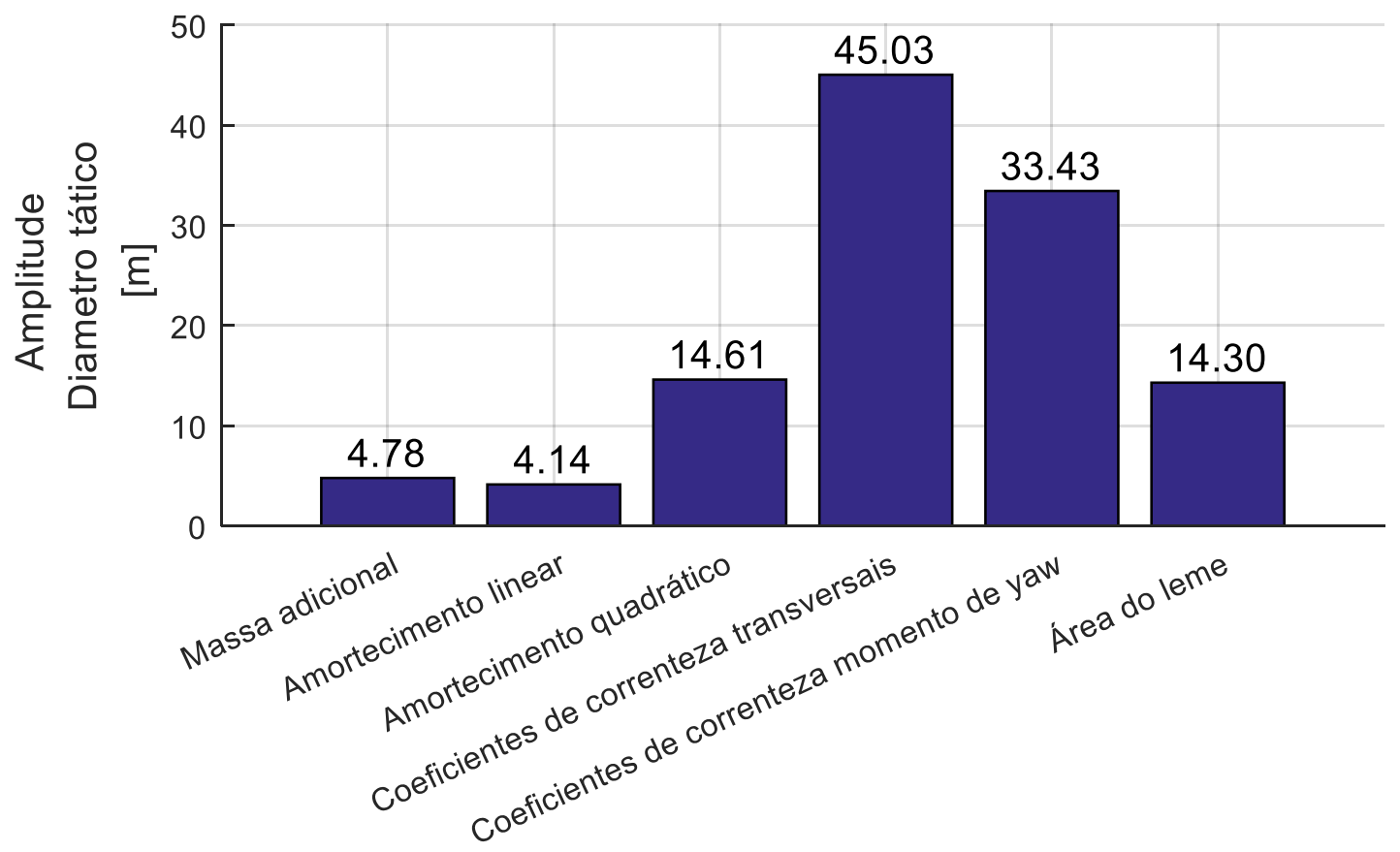

Fatores

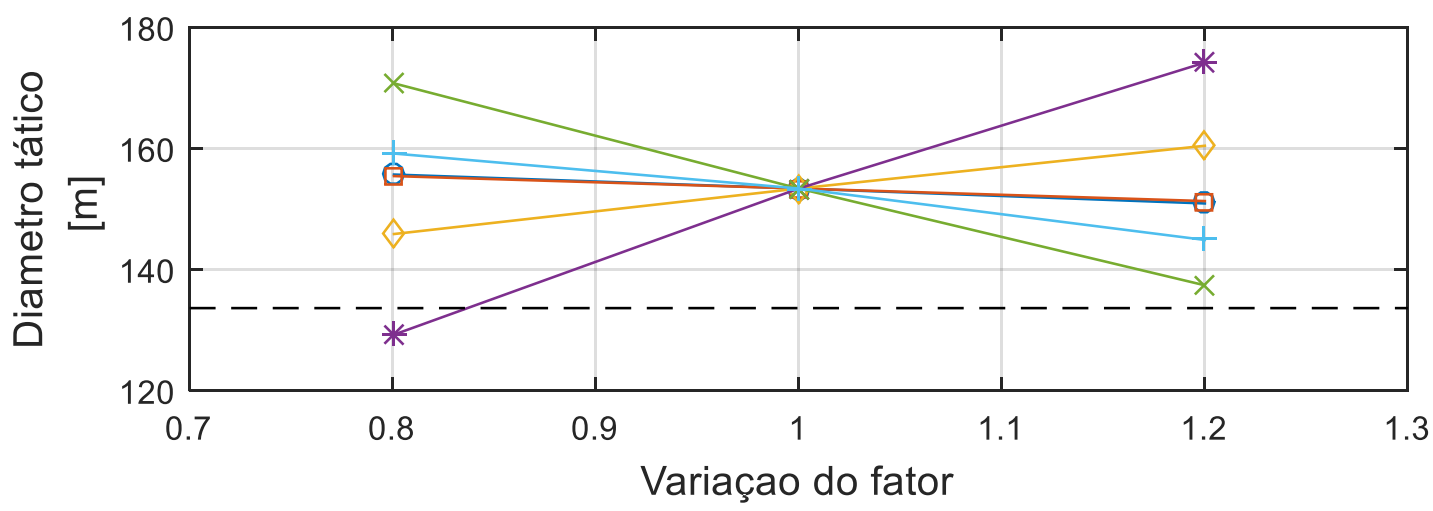

$-\bigcirc$ Massa adicional
$\square-$ Amortecimento linear
- Amortecimento quadrático
$+\quad$ Coeficientes de correnteza transversais
$\times \quad$ Coeficientes de correnteza momento de yaw
$+\quad$ Área do leme
-- Experimental

Fonte: Autor. 
Figura 136 - Efeito dos fatores no Diâmetro final

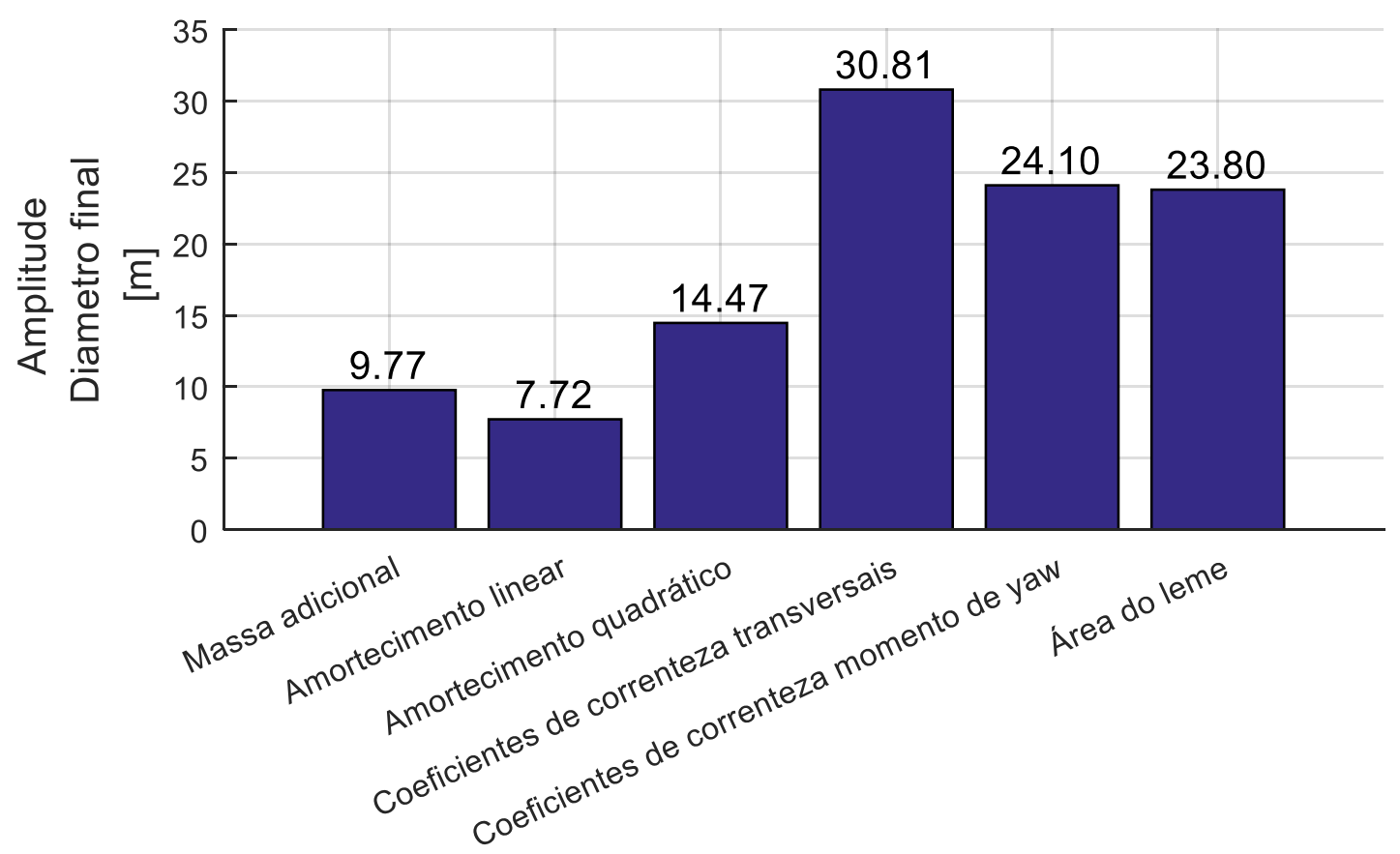

Fatores

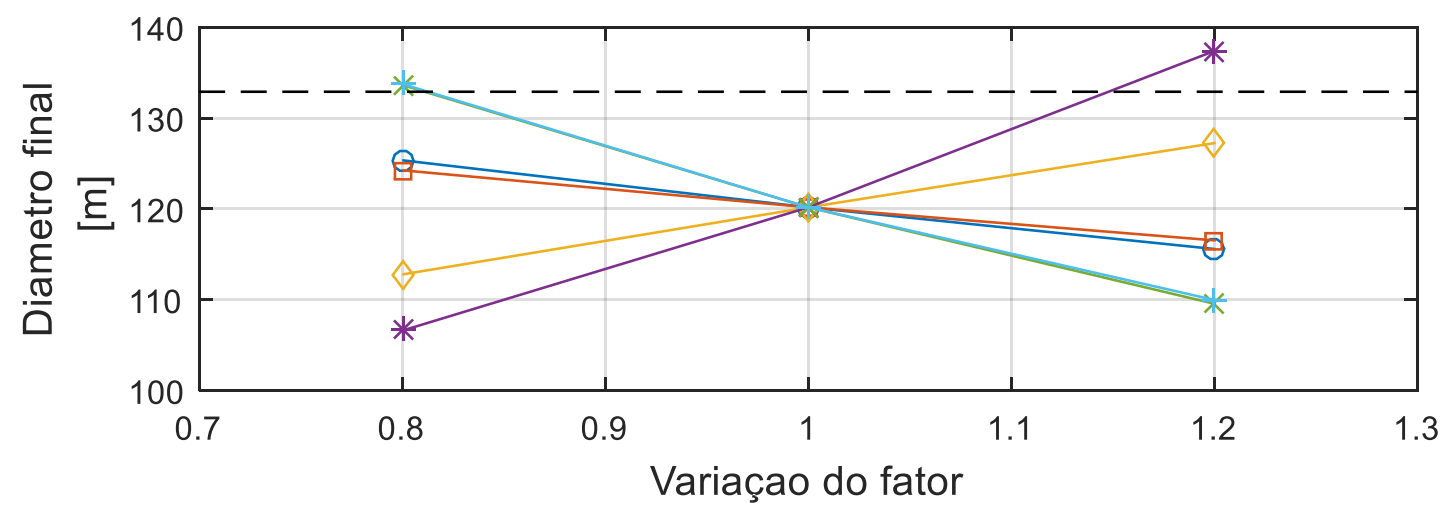

- Massa adicional
$\square-$ Amortecimento linear
- Amortecimento quadrático
$+\quad$ Coeficientes de correnteza transversais
$+\quad$ Coeficientes de correnteza momento de yaw
$+\quad$ Área do leme
-- Experimental

Fonte: Autor. 
Figura 137 - Efeito dos fatores na Velocidade angular

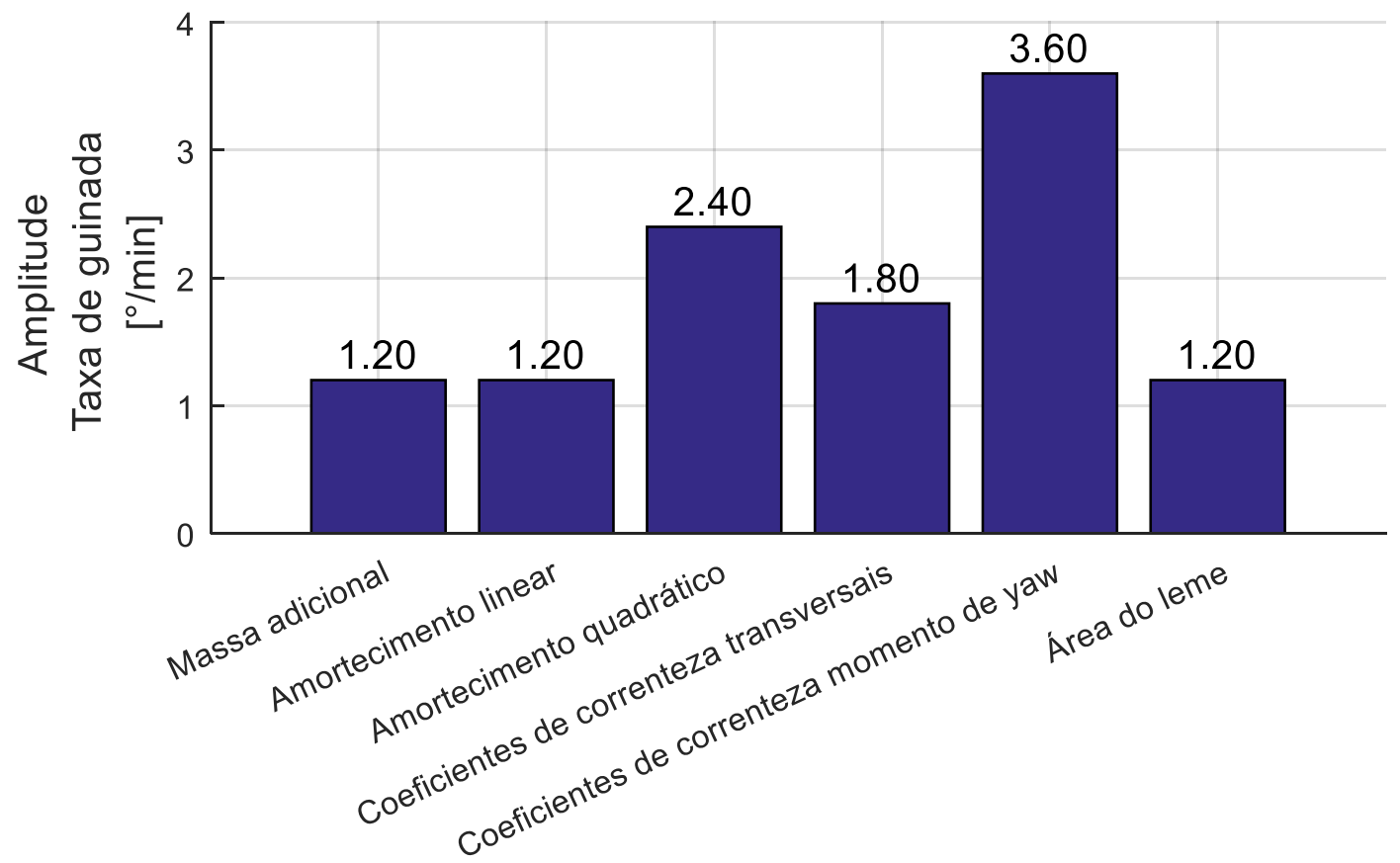

Fatores

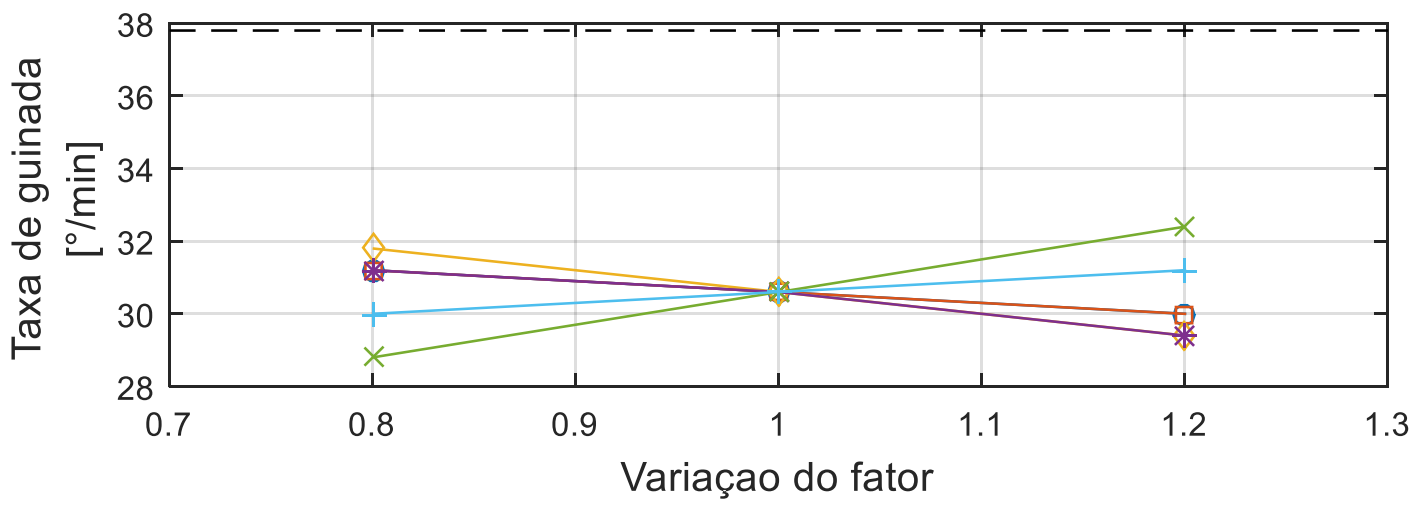

$-\quad$ Massa adicional
$\square-$ Amortecimento linear
- Amortecimento quadrático
$+\quad$ Coeficientes de correnteza transversais
$\times-$ Coeficientes de correnteza momento de yaw
$+\quad$ Área do leme
-- Experimental

Fonte: Autor. 
Figura 138 - Efeito dos fatores no Ângulo de deriva

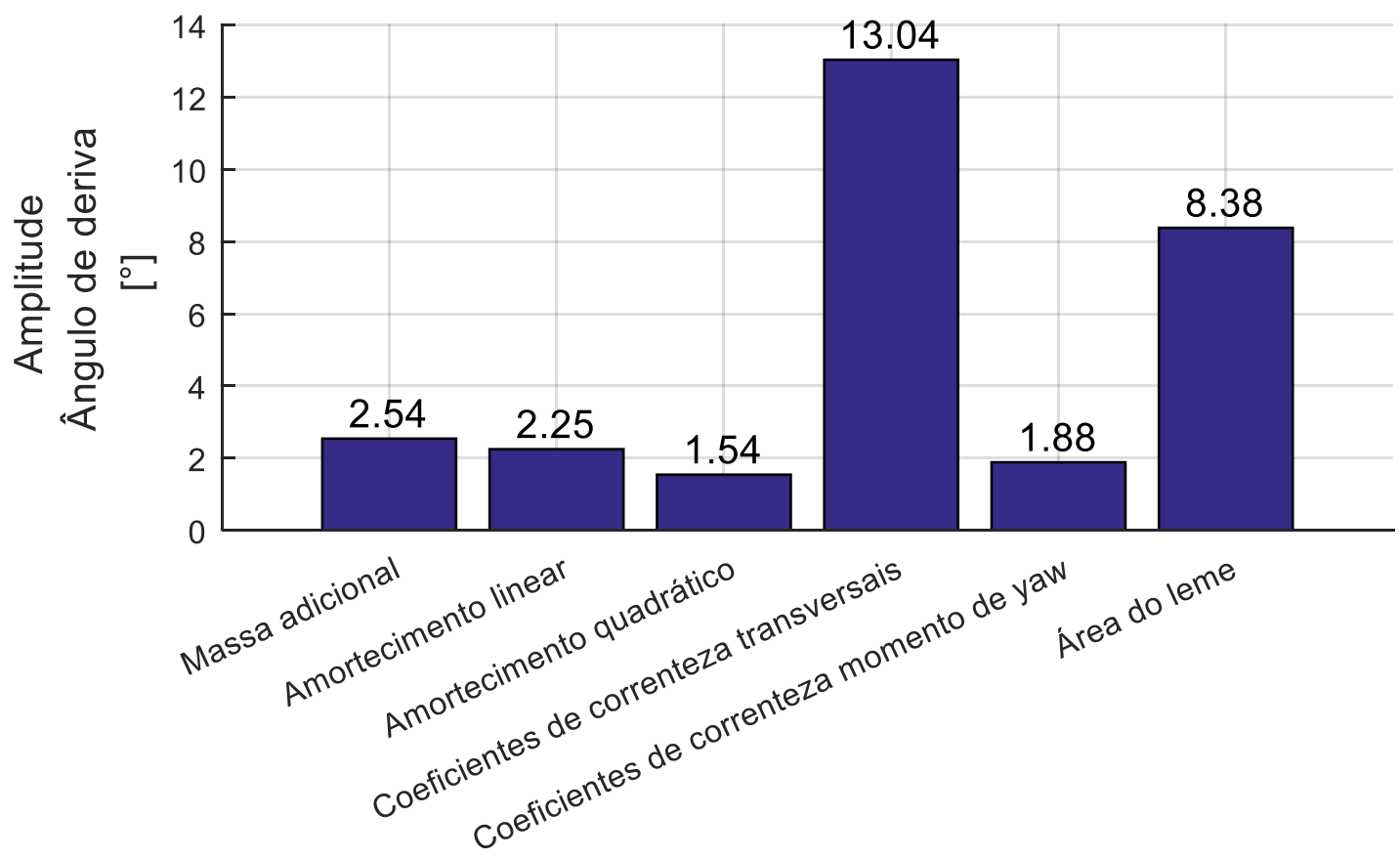

Fatores

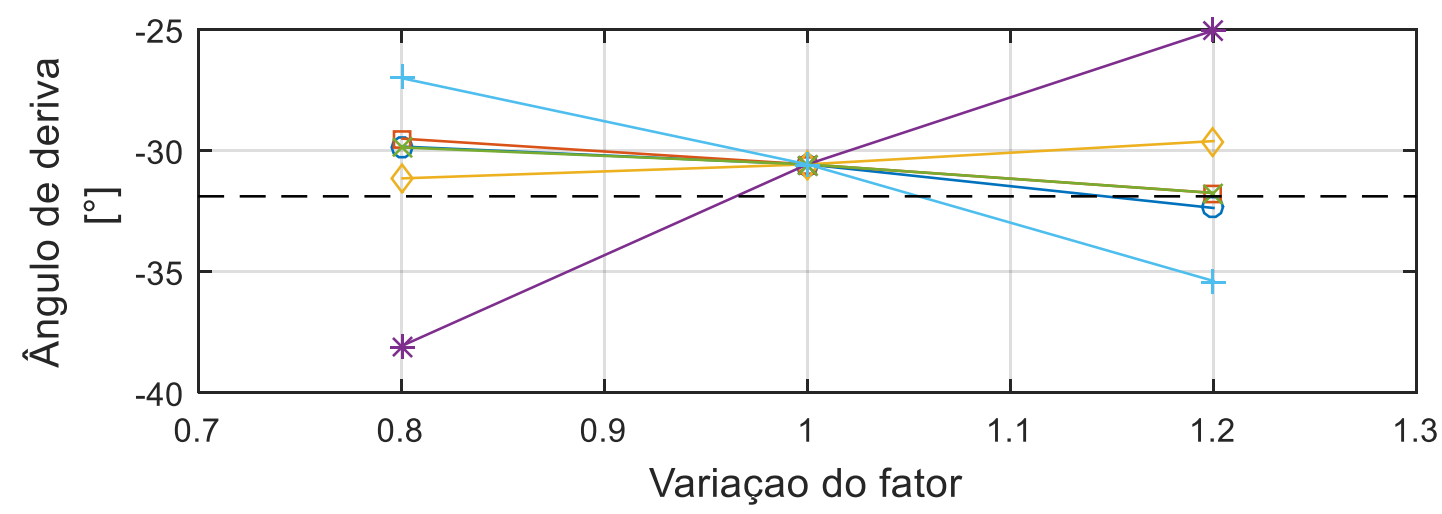

\begin{tabular}{l}
\hline$\bigcirc$ Massa adicional \\
$\square-$ Amortecimento linear \\
- Amortecimento quadrático \\
$+\quad$ Coeficientes de correnteza transversais \\
$+\quad$ Coeficientes de correnteza momento de yaw \\
+- Área do leme \\
\hline- Experimental
\end{tabular}

Fonte: Autor.

\subsection{Manobra 3 Initial turning test}

Para esta manobra o fator com maior importância foi a área do leme como pode ser visto na Figura 139, apresentando um efeito de variação de 43,66m na distância percorrida para uma variação de $\pm 20 \%$ da área, contra $27,16 \mathrm{~m}$ em comparação com o segundo fator mais importante (coeficientes $\mathrm{C}_{\mathrm{nz}}$ ). 
Porém, quando observado o efeito da variação da área do leme nota-se que há um ponto que minimiza a distância percorrida, e no caso de a área continuar a aumentar, a distância percorrida também aumenta.

Figura 139 - Efeito dos fatores na Distância a 20

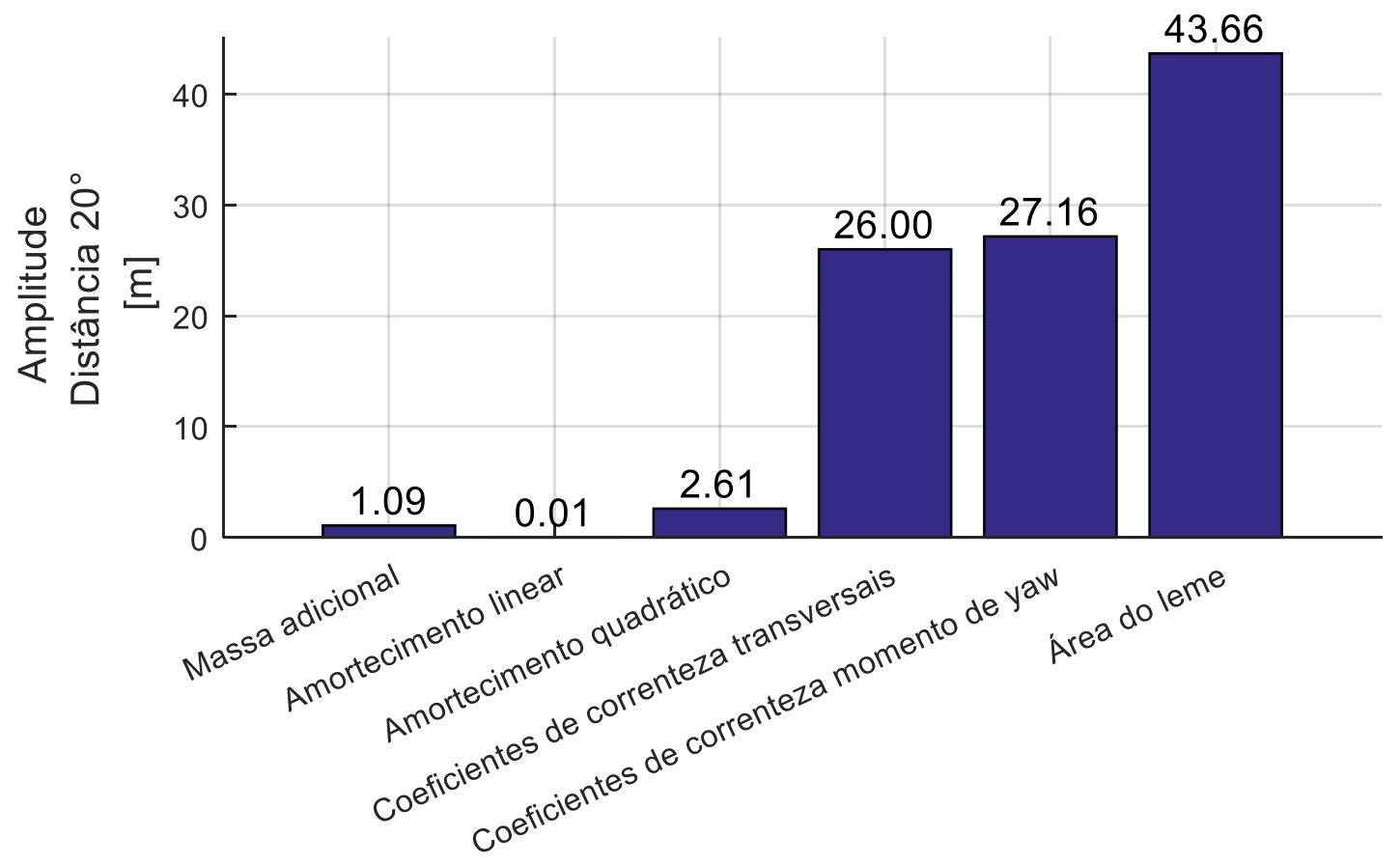

Fatores

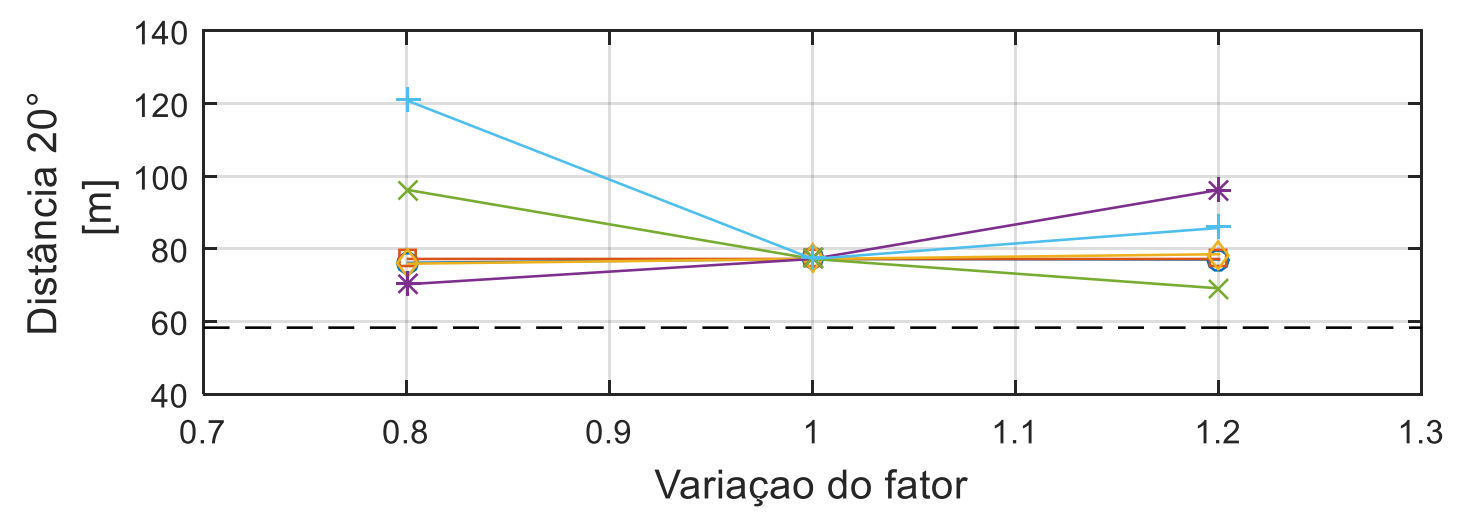

\begin{tabular}{l}
\hline$\bigcirc$ Massa adicional \\
$\square$ Amortecimento linear \\
$\checkmark$ Amortecimento quadrático \\
- Coeficientes de correnteza transversais \\
$-\quad$ Coeficientes de correnteza momento de yaw \\
$-\quad$ Area do leme \\
-- Experimental
\end{tabular}

Fonte: Autor.

\subsection{Manobra 7 Coasting turn}

Como pode ser visto da Figura 140 a Figura 142, nesta manobra a área do leme apresentou um maior efeito do que os demais fatores para o avanço. Para as 
demais características de manobra, os coeficientes $\mathrm{C}_{\mathrm{y}}$ novamente apresentaram maior importância.

Figura 140 - Efeito dos fatores no Avanço

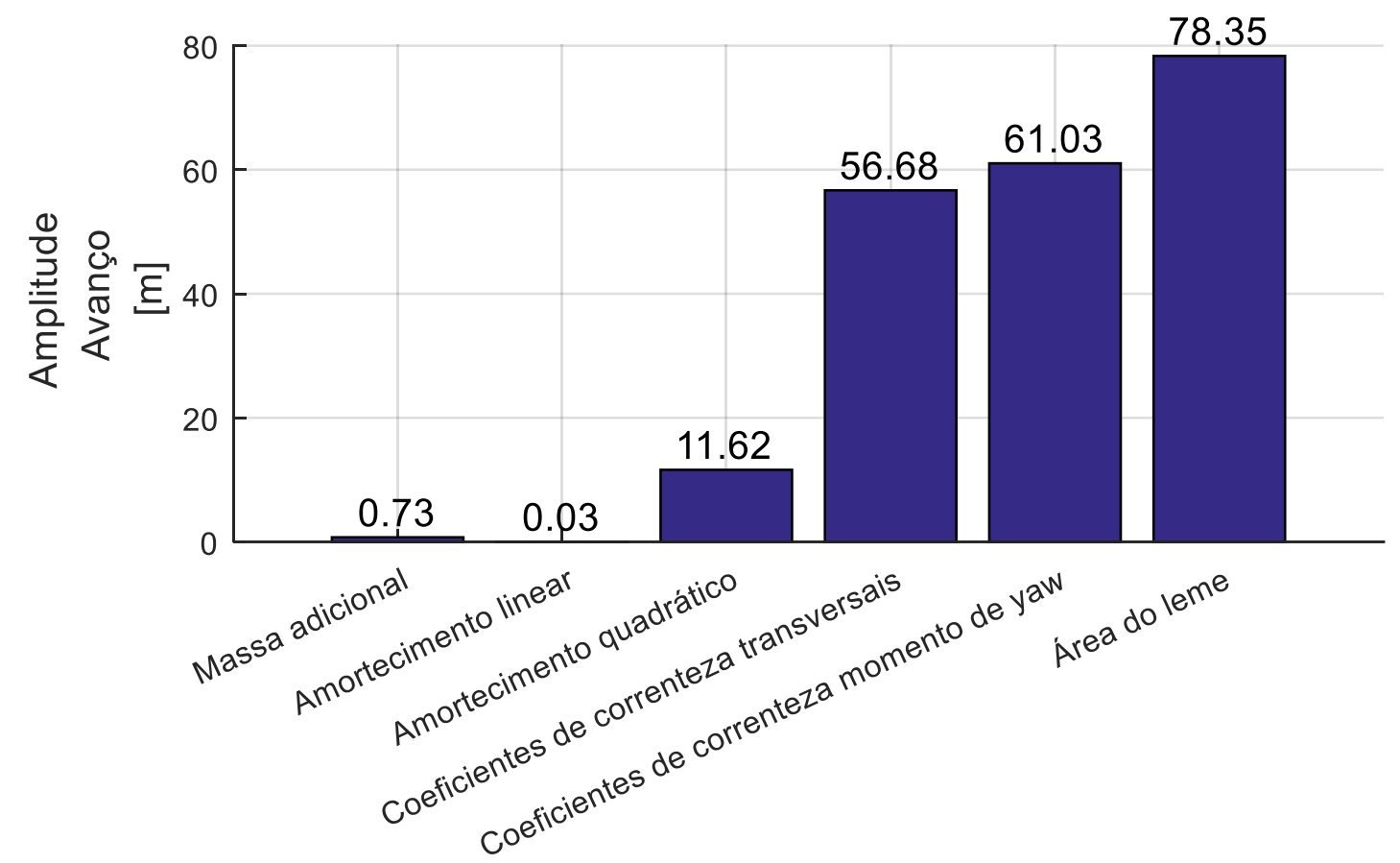

Fatores

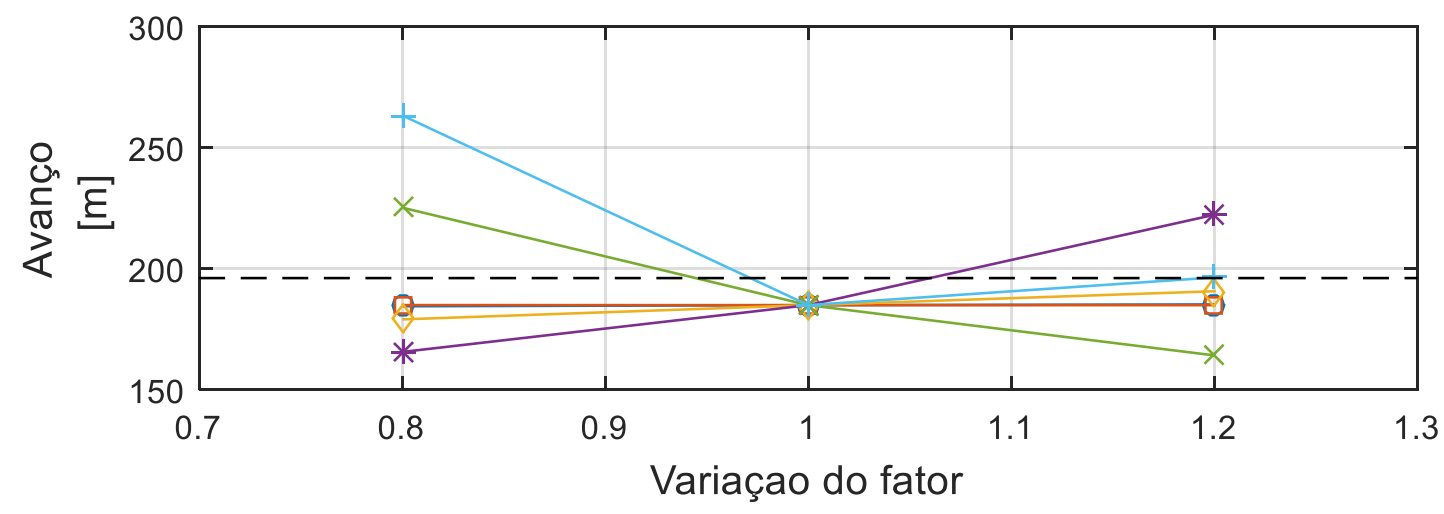

\begin{tabular}{l}
\hline$\bigcirc$ Massa adicional \\
$\square$ Amortecimento linear \\
- Amortecimento quadrático \\
$+\quad$ Coeficientes de correnteza transversais \\
$\times \quad$ Coeficientes de correnteza momento de yaw \\
$+\quad$ Área do leme \\
-- Experimental
\end{tabular}

Fonte: Autor. 
Figura 141 - Efeito dos fatores na Transferência

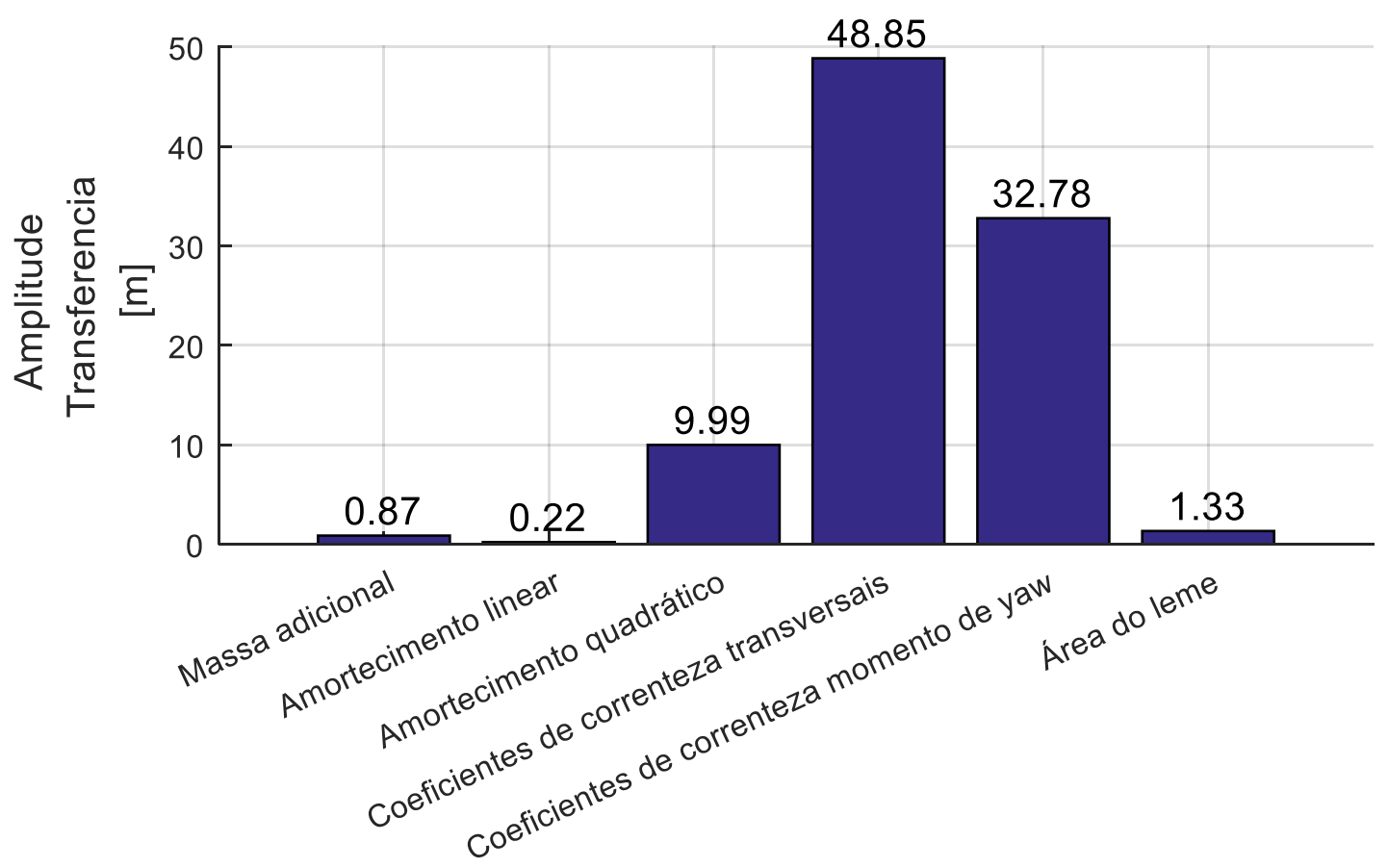

Fatores

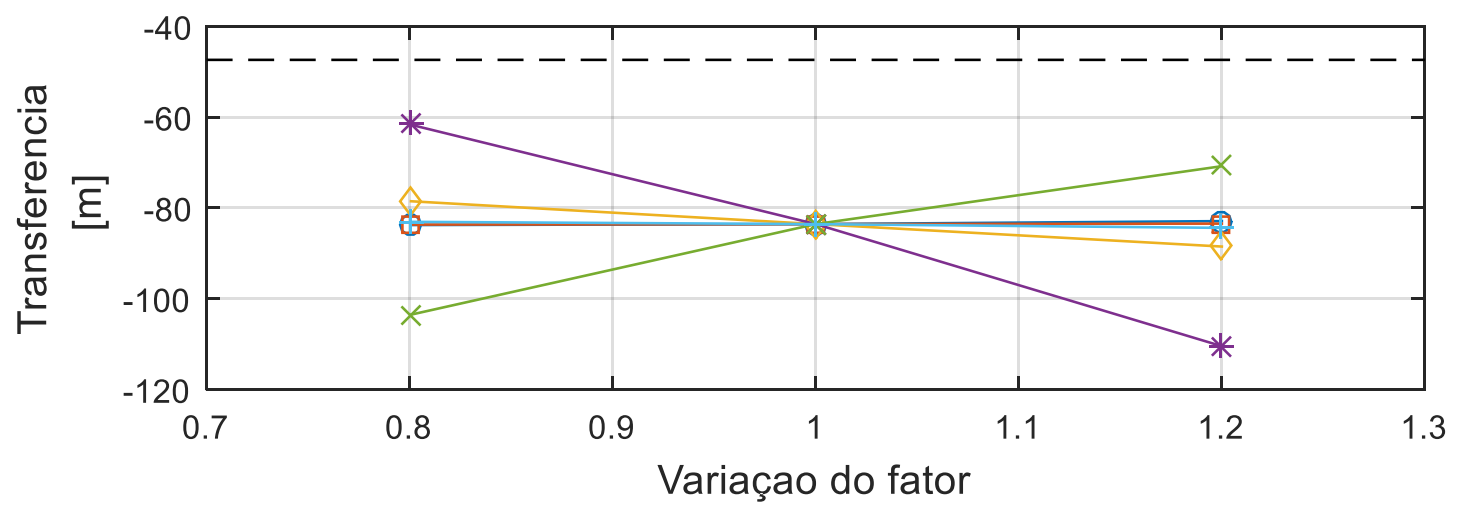

Fonte: Autor.

$-\bigcirc$ Massa adicional
$\square$ Amortecimento linear
- Amortecimento quadrático
$-\quad$ Coeficientes de correnteza transversais
$\times \quad$ Coeficientes de correnteza momento de yaw
$+\quad$ Área do leme
$-\quad-$ Experimental


Figura 142 - Efeito dos fatores no Ângulo de deriva

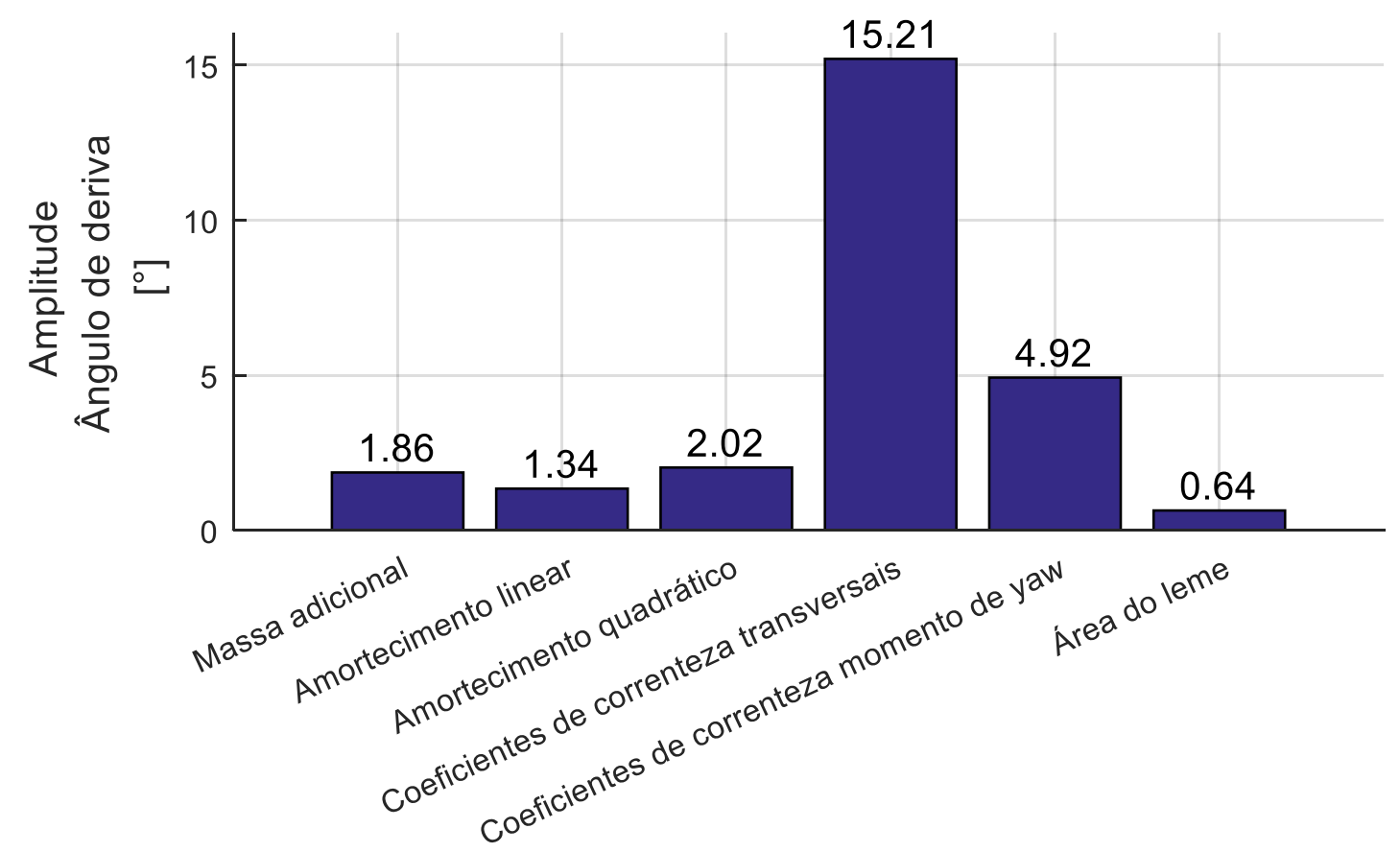

Fatores

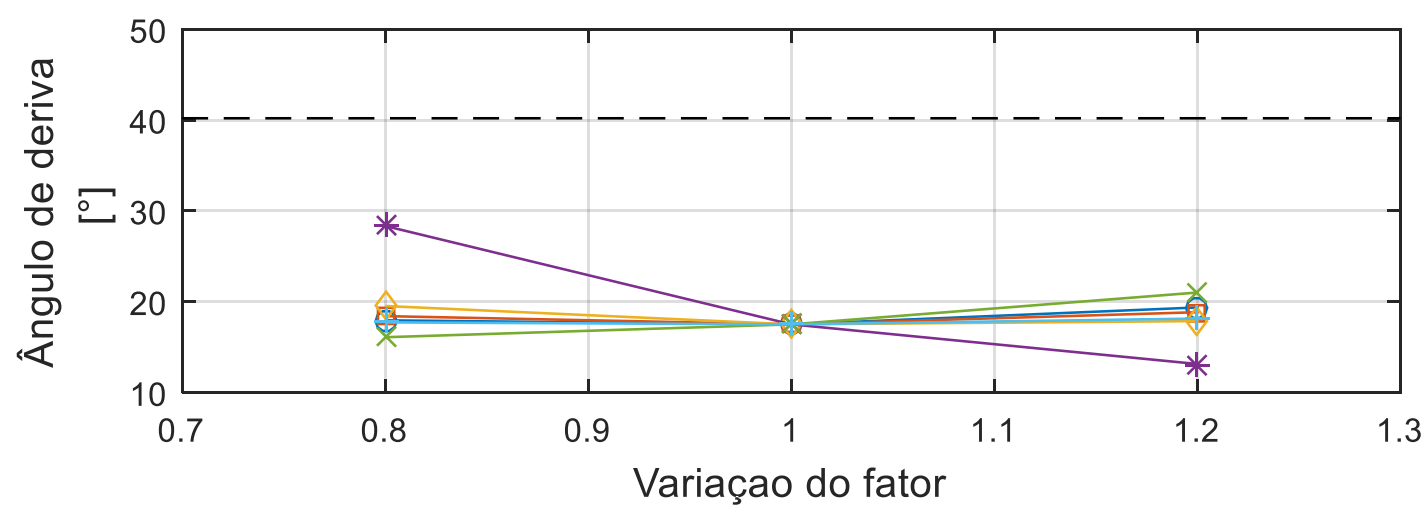

\begin{tabular}{|c|}
\hline $\begin{array}{l}\text { - Massa adicional } \\
\square-\text { Amortecimento linear } \\
* \quad \text { Amortecimento quadrático } \\
\times \quad \text { Coeficientes de correnteza transversais } \\
+\quad \text { Área do leme } \\
-- \text { Experimental }\end{array}$ \\
\hline
\end{tabular}

Fonte: Autor.

\subsection{Manobra 10 Crash stop}

Nesta manobra, como mostrado na Figura 143, verificou-se pouca influência do amortecimento linear longitudinal, ao menos dentro da faixa de variação adotada para o parâmetro. Foi observado um comportamento diferente do esperado para esta manobra, com maior influência sobre a distância de parada dos coeficientes de 
correnteza e da área do leme. Contudo ao observar a trajetória da embarcação na manobra 10, observa-se uma leve guinada da embarcação no fim da manobra. Como foi observado que os fatores de área do leme e coeficientes de correnteza estão relacionados com a estabilidade direcional da embarcação, o efeito da parada mais rápida da embarcação é atribuído nesta manobra à guinada que ocorre no fim da manobra.

Figura 143 - Efeito dos fatores no Avanço

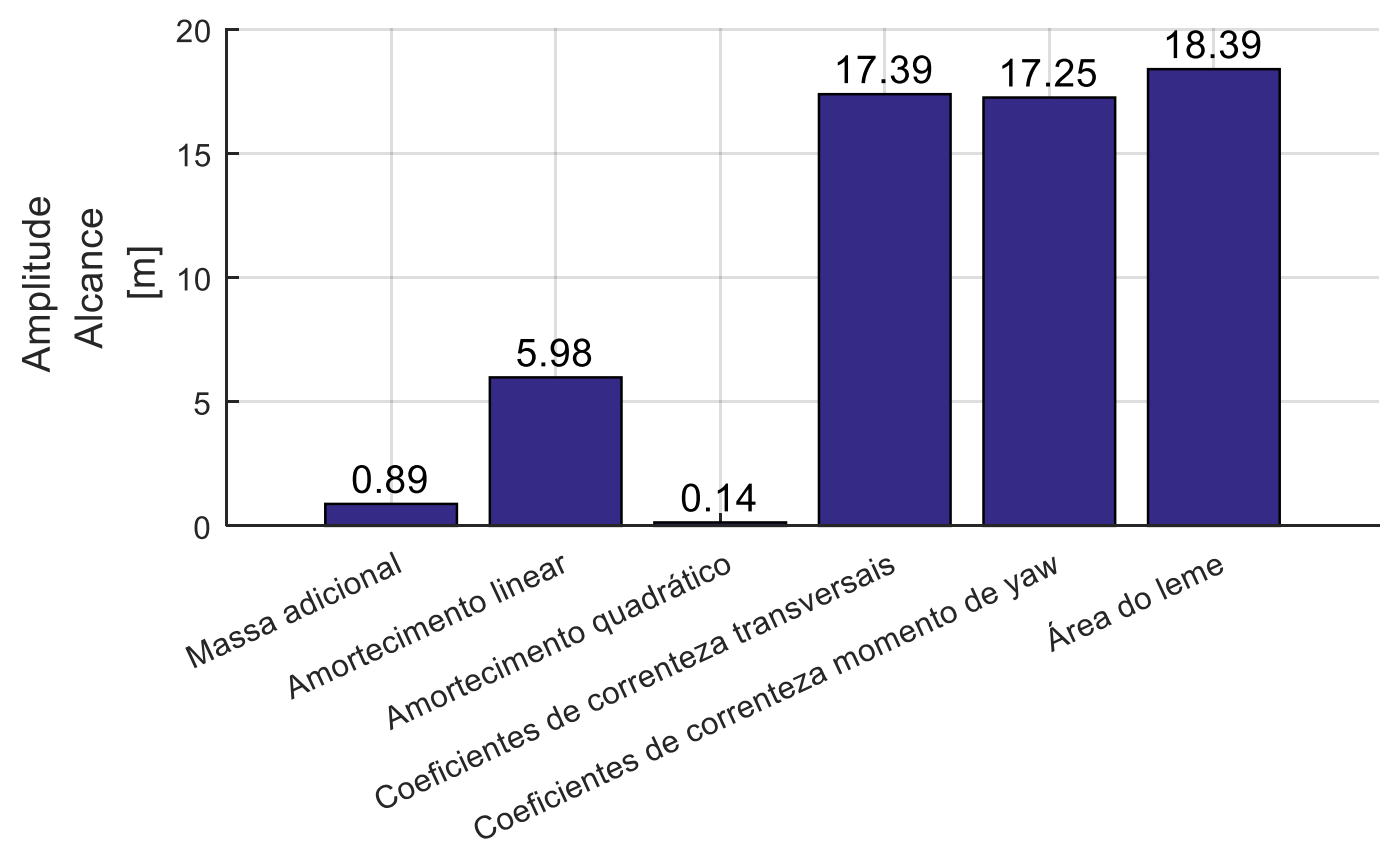

Fatores

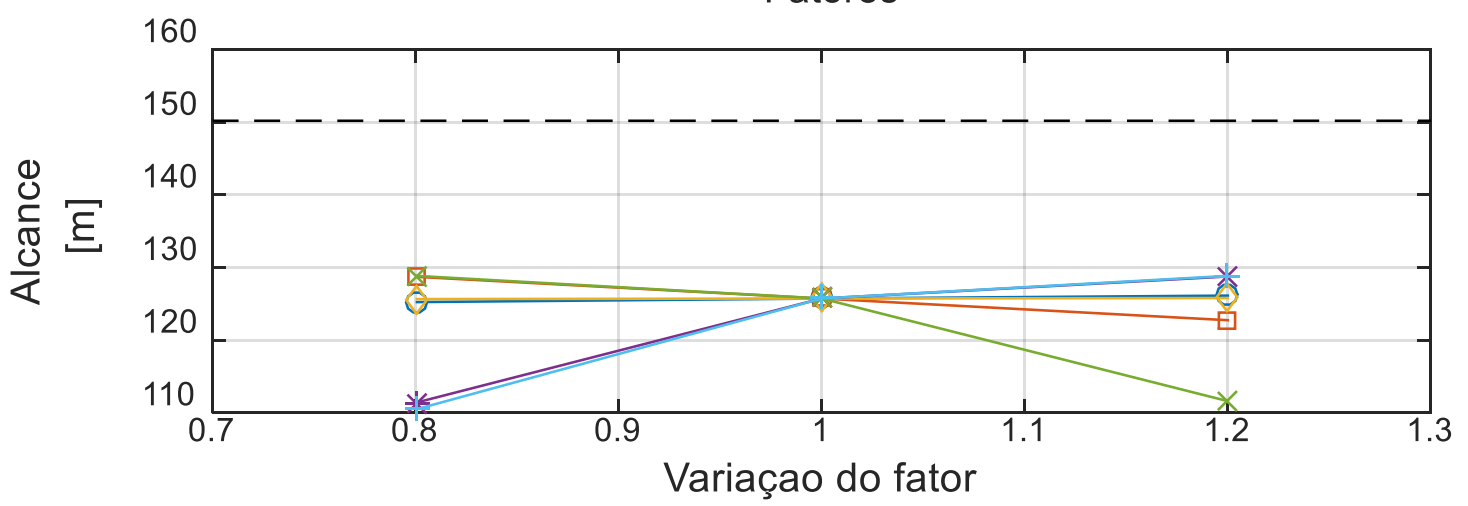

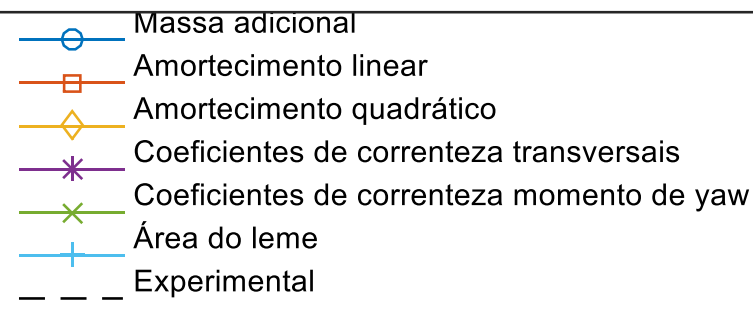

Fonte: Autor. 


\subsection{Manobra 15 Accelerating turn}

Os efeitos para os fatores analisados nesta manobra se mostraram similares aos observados na manobra de turning circle, como pode ser verificado nas figuras de 142 a 147, com exceção da área do leme que se mostrou mais efetiva para a maior parte dos efeitos, indicando uma maior influência do leme para manobras de baixa velocidade.

Figura 144 - Efeito dos fatores no Avanço

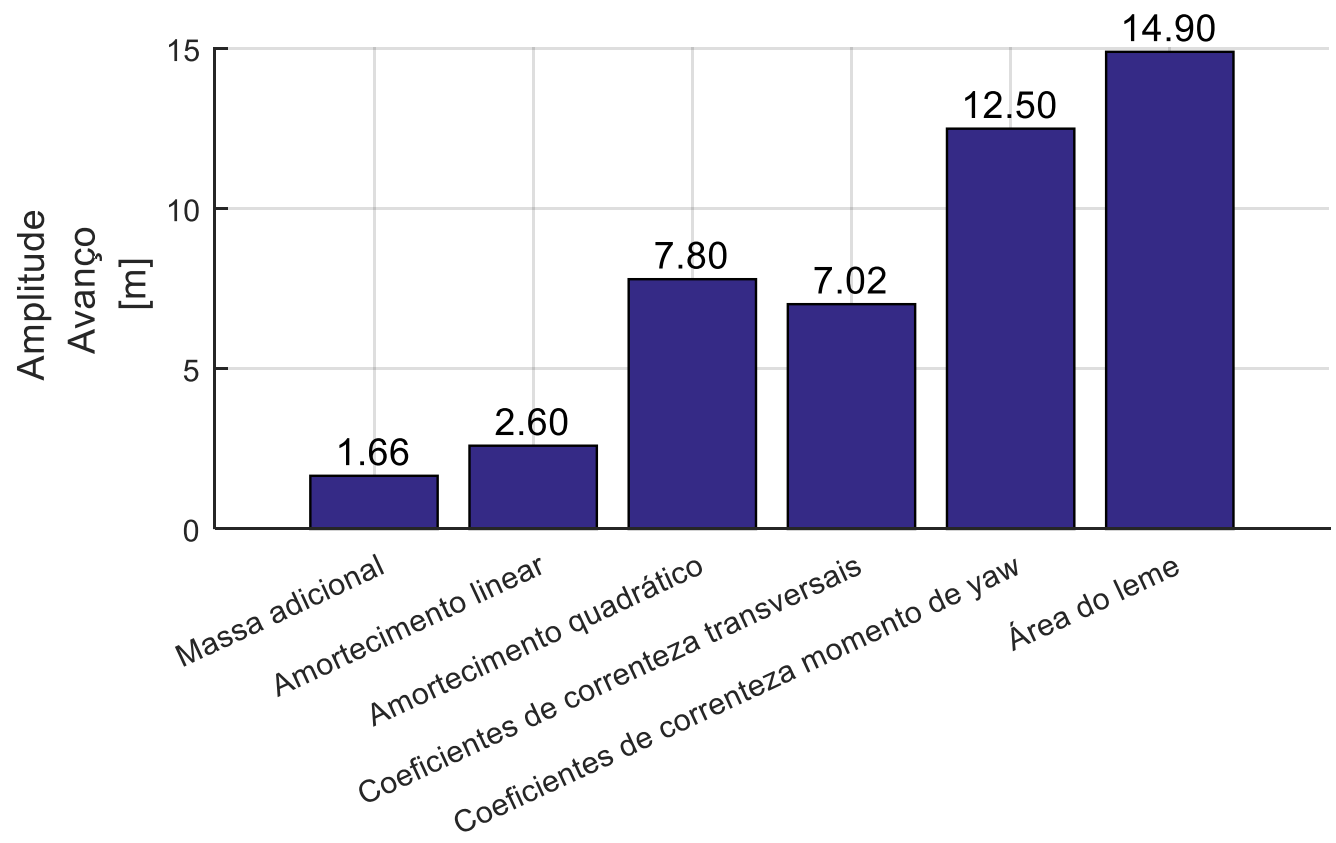

Fatores

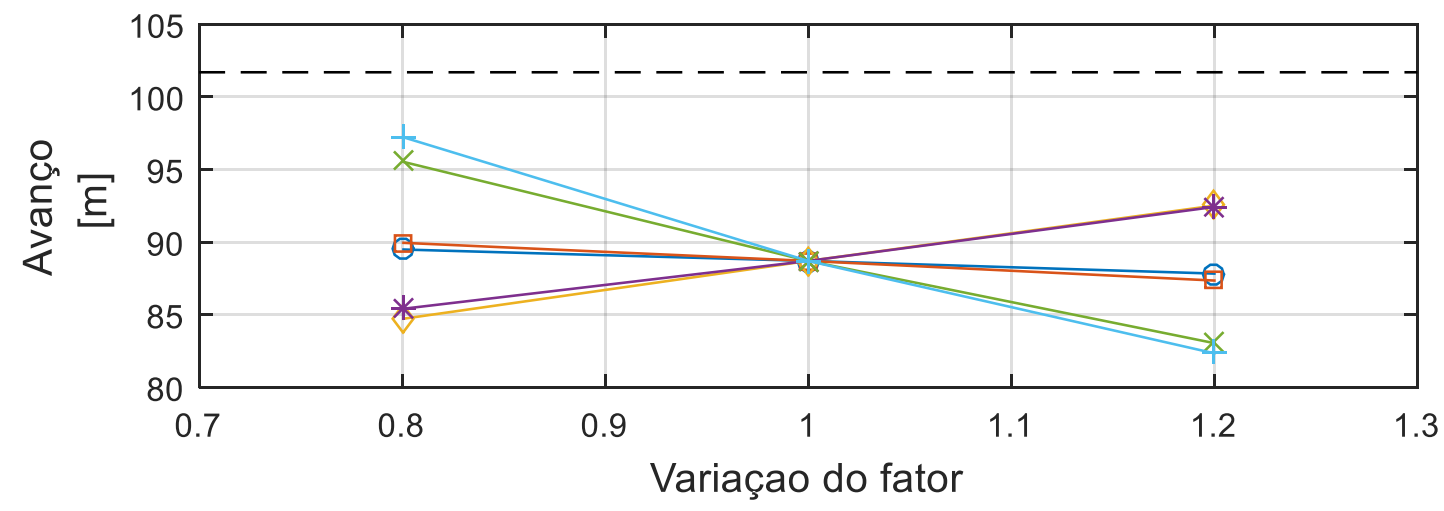

$-\vartheta$ Massa adicional
$\square-$ Amortecimento linear
- Amortecimento quadrático
- Coeficientes de correnteza transversais
$+\quad$ Coeficientes de correnteza momento de yaw
$-\quad$ Área do leme

Fonte: Autor. 
Figura 145 - Efeito dos fatores na Transferência

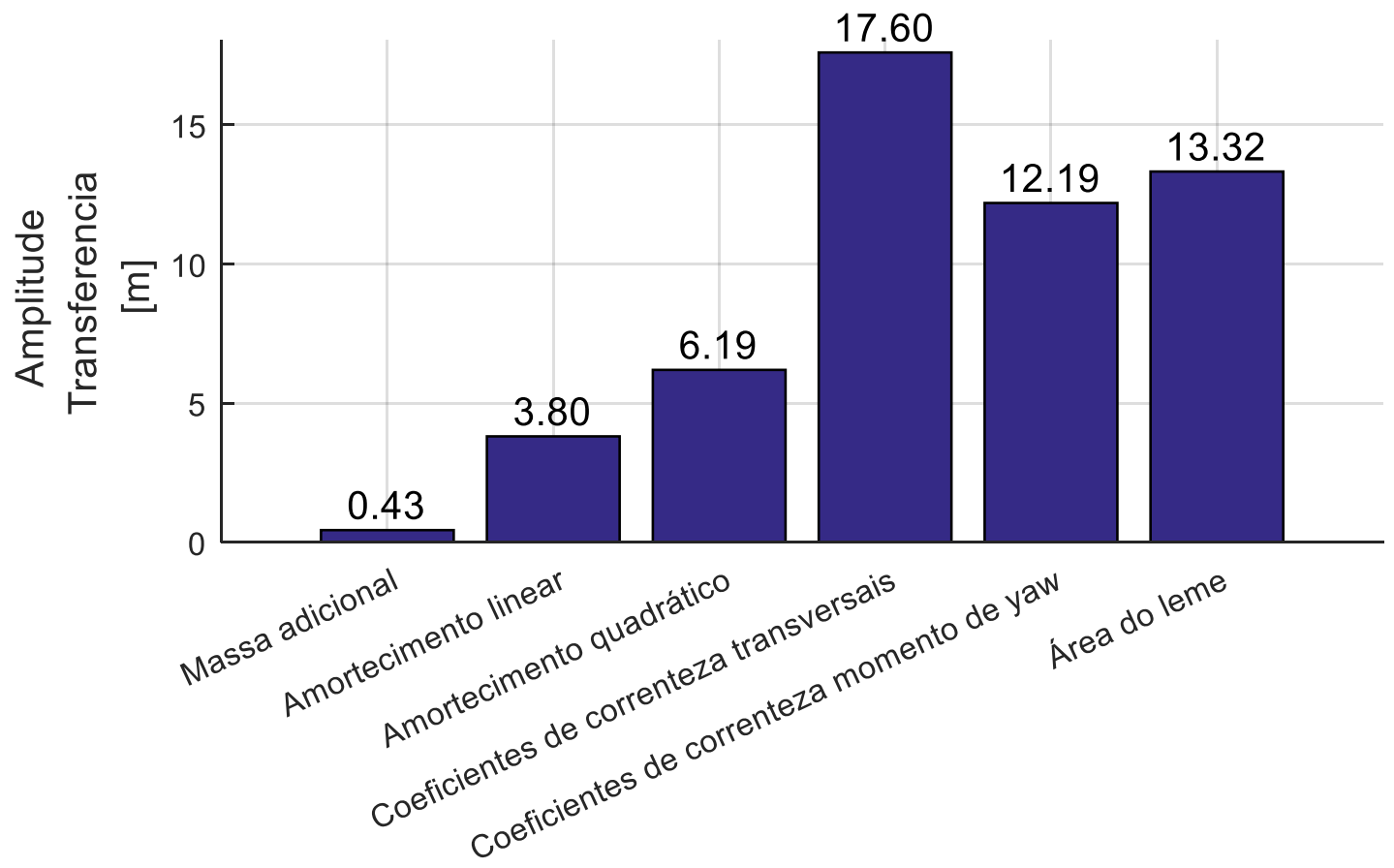

Fatores

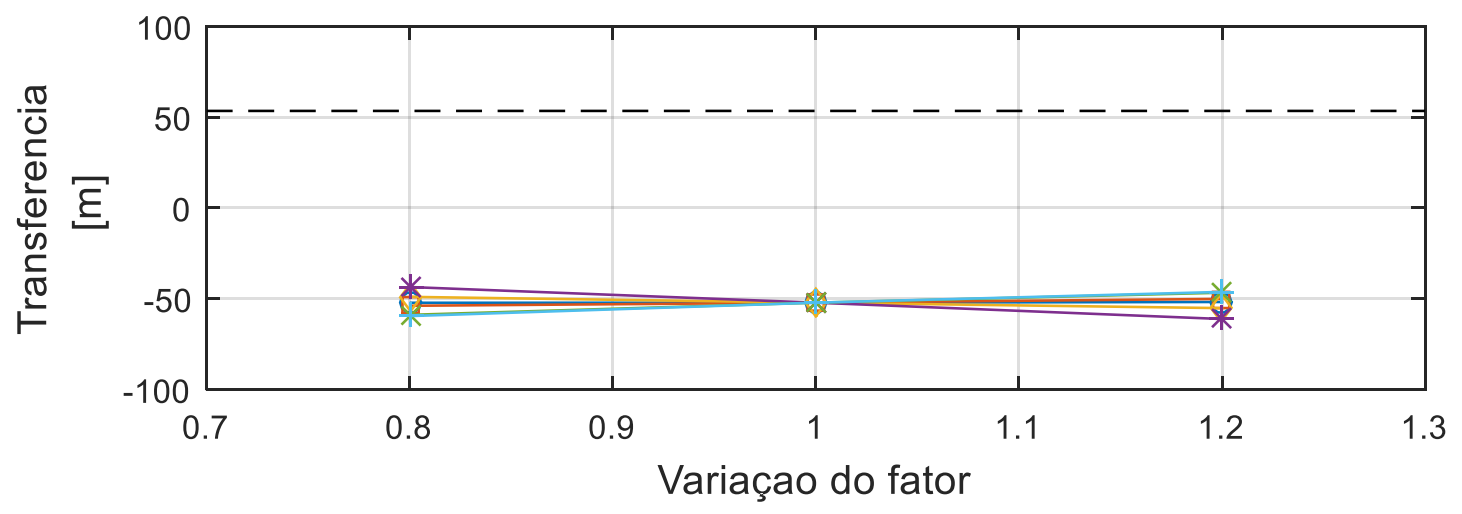

- Massa adicional
$\square-$ Amortecimento linear
- Amortecimento quadrático
$+\quad$ Coeficientes de correnteza transversais
$+\quad$ Coeficientes de correnteza momento de yaw
+- Área do leme

Fonte: Autor. 
Figura 146 - Efeito dos fatores no Diâmetro tático

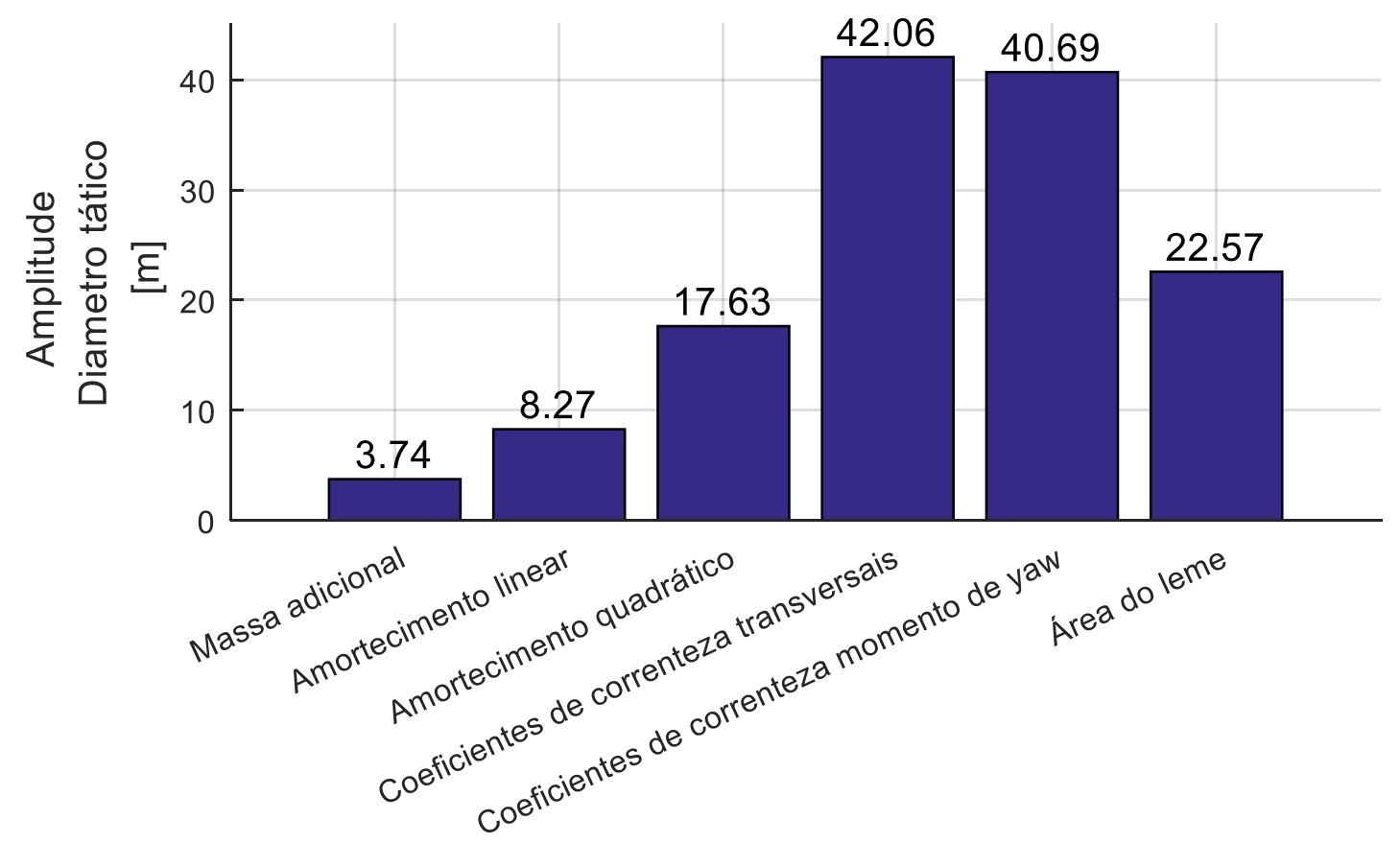

Fatores

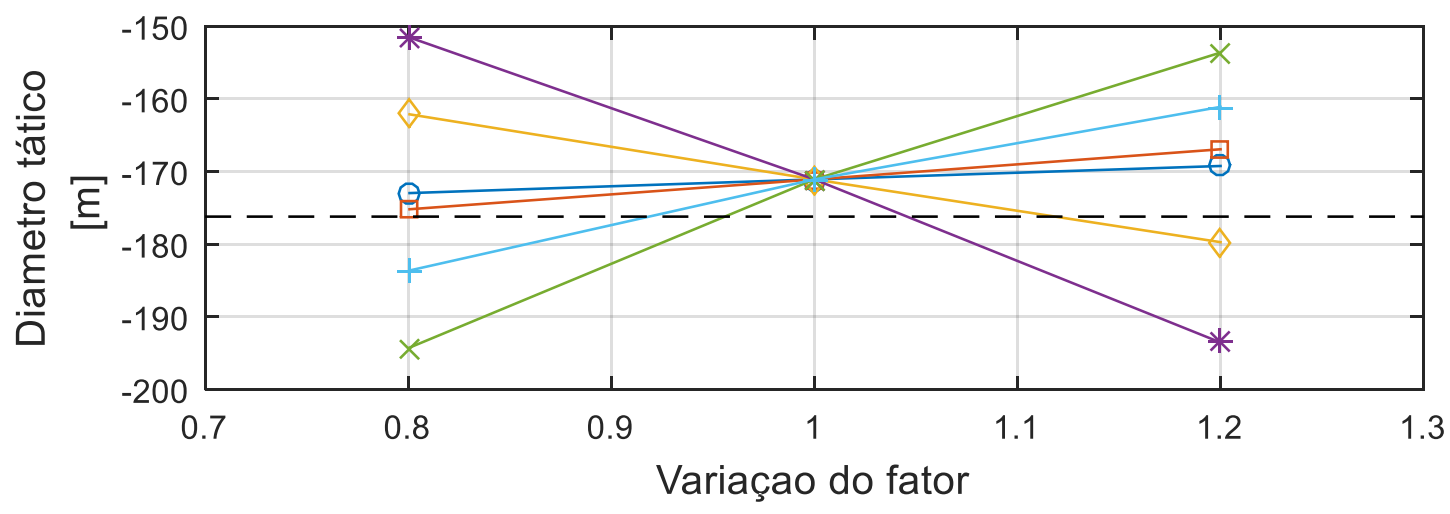

\begin{tabular}{l}
\hline$\bigcirc$ Massa adicional \\
$\square-$ Amortecimento linear \\
- Amortecimento quadrático \\
$+\quad$ Coeficientes de correnteza transversais \\
$\times \quad$ Coeficientes de correnteza momento de yaw \\
$+\quad$ Área do leme \\
-- Experimental
\end{tabular}

Fonte: Autor. 
Figura 147 - Efeito dos fatores no Diâmetro final

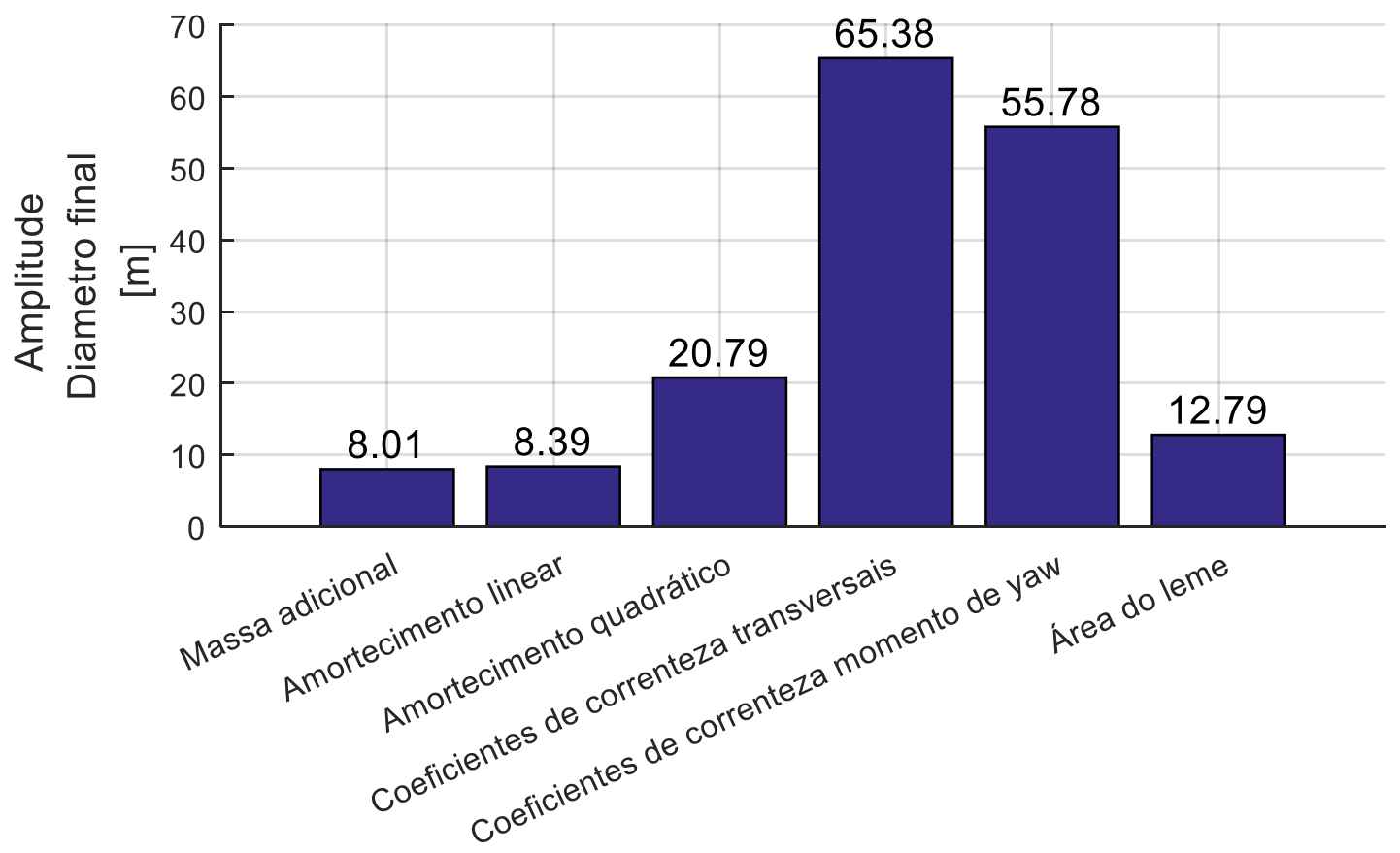

Fatores

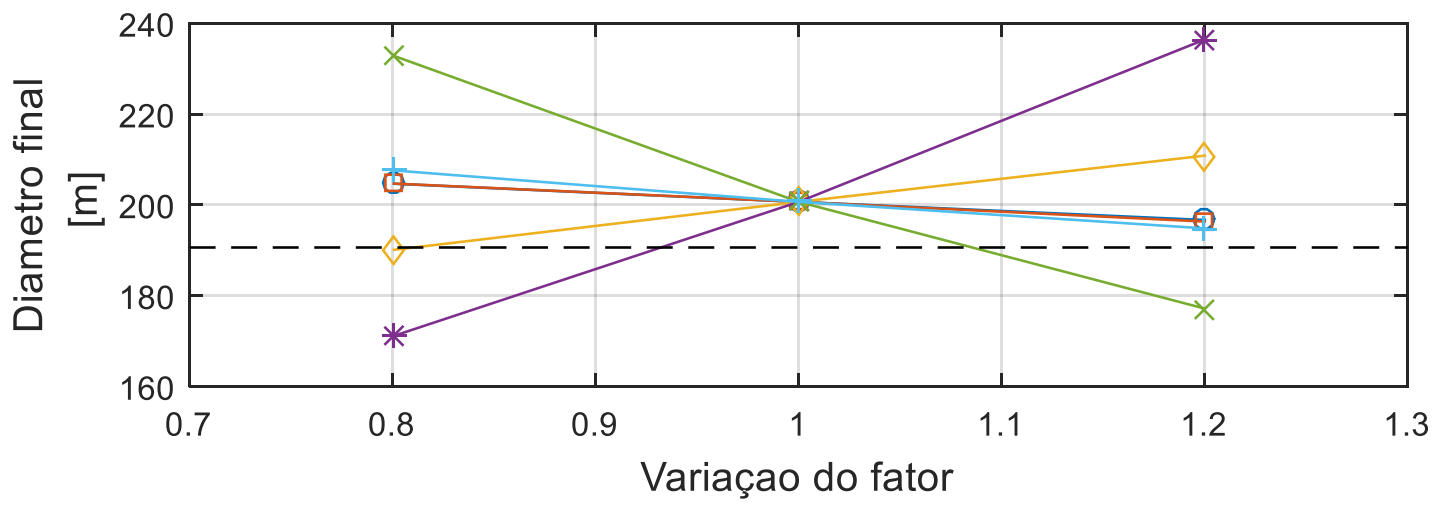

Fonte: Autor.

- Massa adicional
$\square$ Amortecimento linear
- Amortecimento quadrático
$-\quad$ Coeficientes de correnteza transversais
$\times \quad$ Coeficientes de correnteza momento de yaw
$+\quad$ Área do leme
$-\quad-$ Experimental


Figura 148 - Efeito dos fatores na Velocidade angular

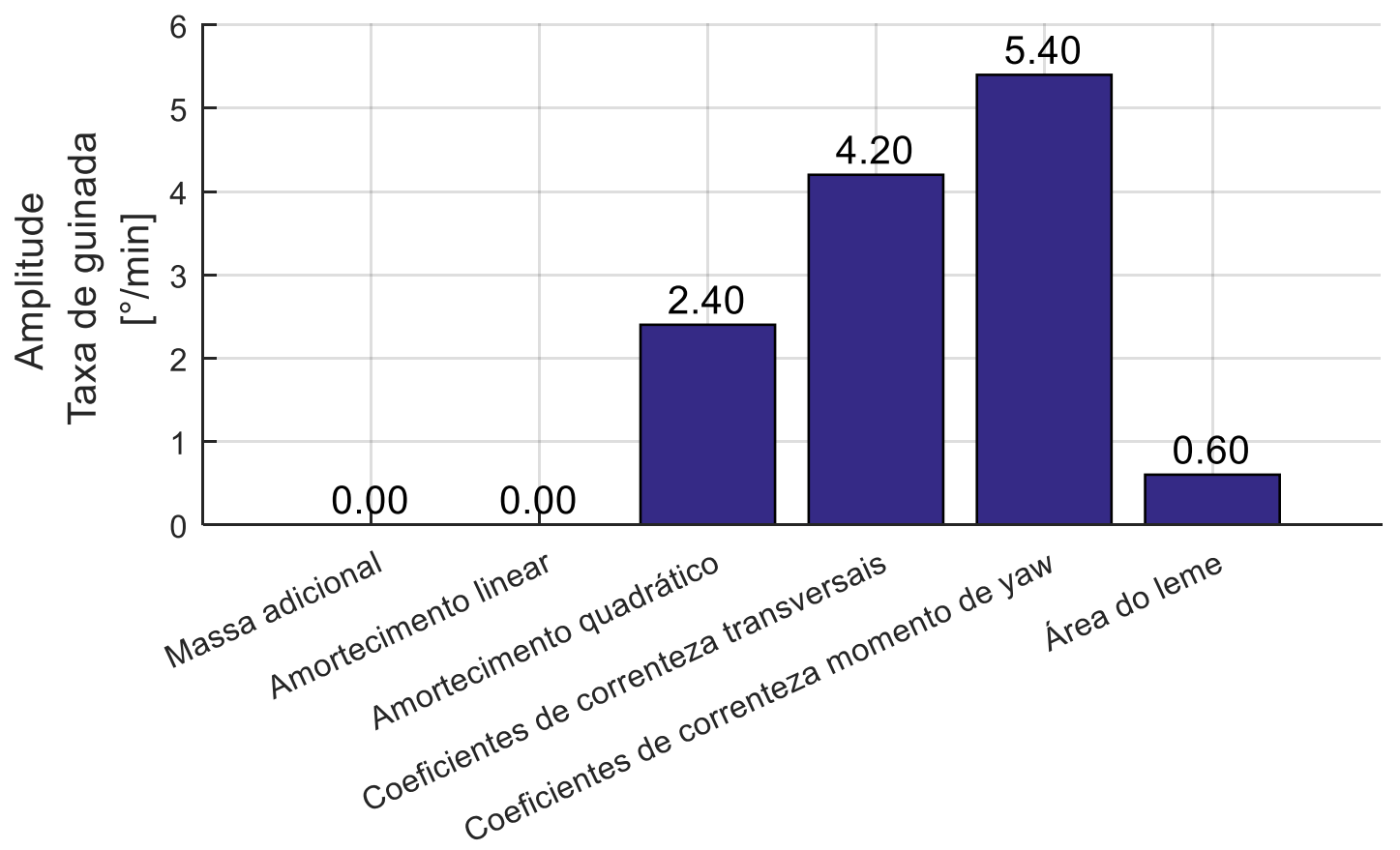

Fatores

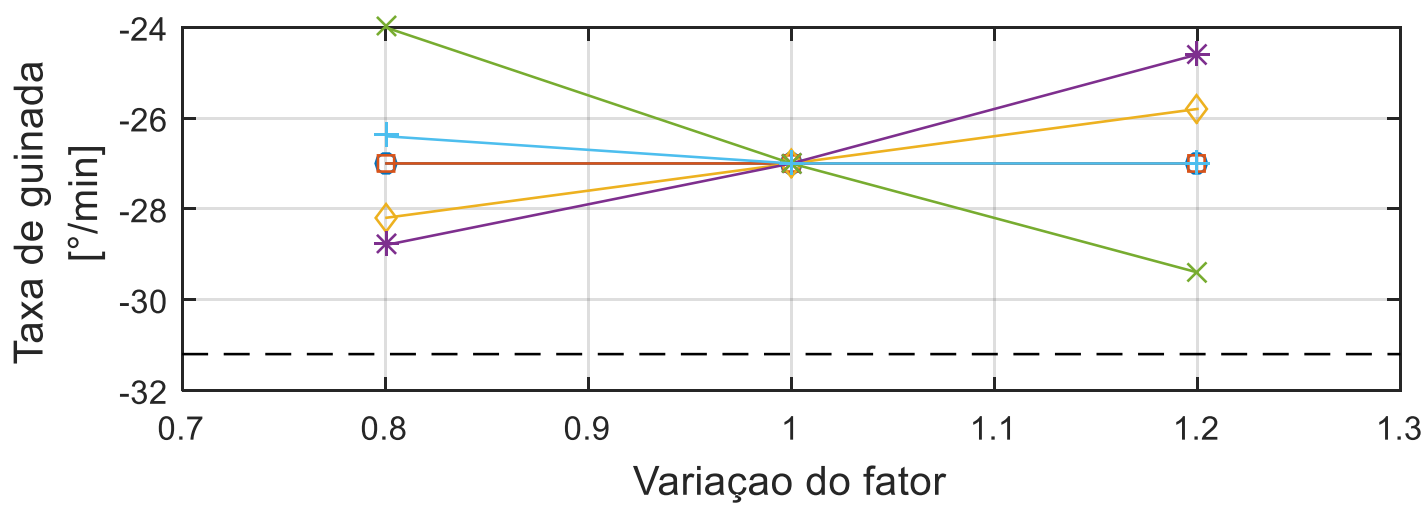

\begin{tabular}{l}
\hline - Massa adicional \\
$\square-$ Amortecimento linear \\
- Amortecimento quadrático \\
$+\quad$ Coeficientes de correnteza transversais \\
$+\quad$ Coeficientes de correnteza momento de yaw \\
$+\quad$ Área do leme \\
-- Experimental
\end{tabular}

Fonte: Autor. 
Figura 149 - Efeito dos fatores no Ângulo de deriva

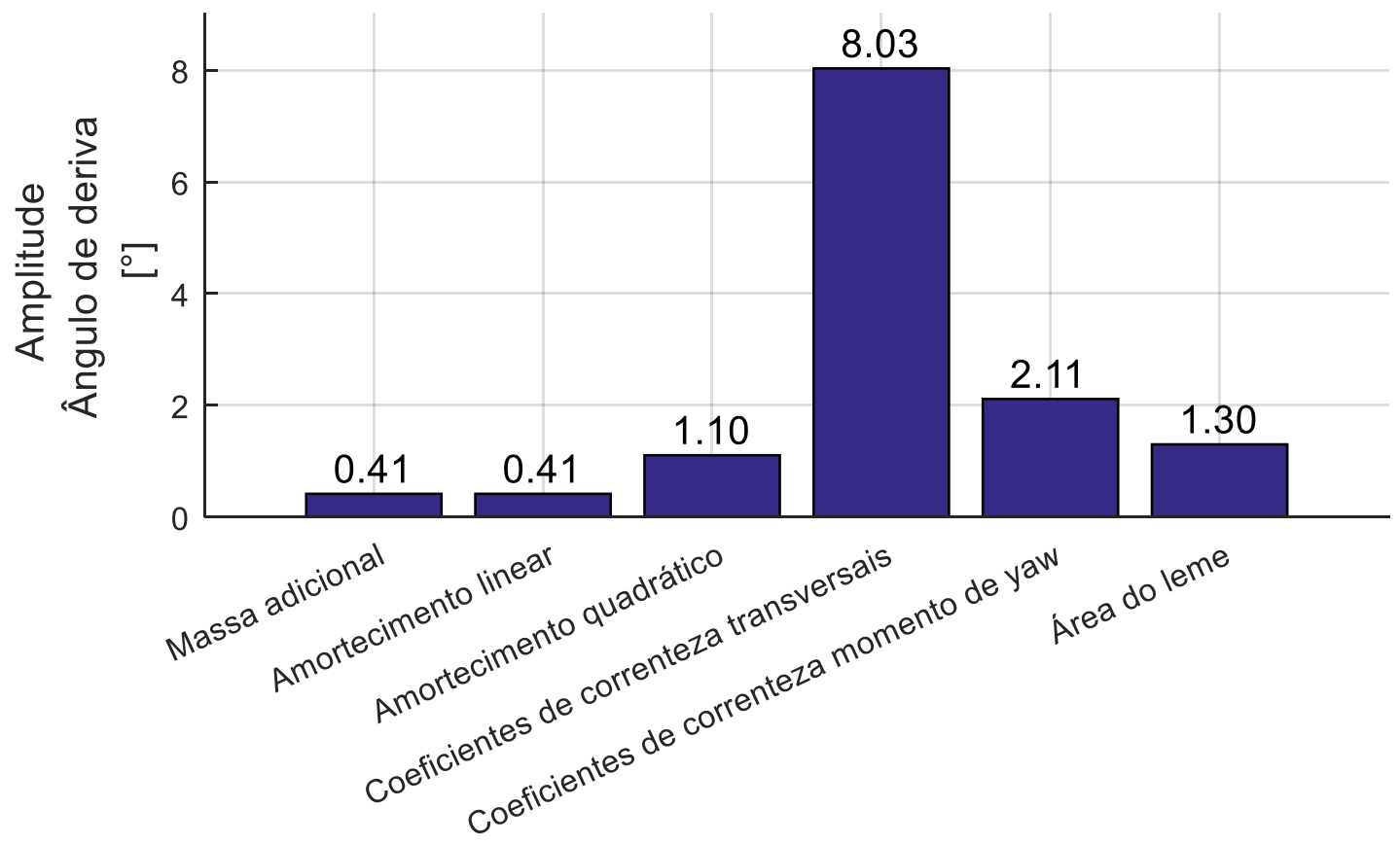

Fatores

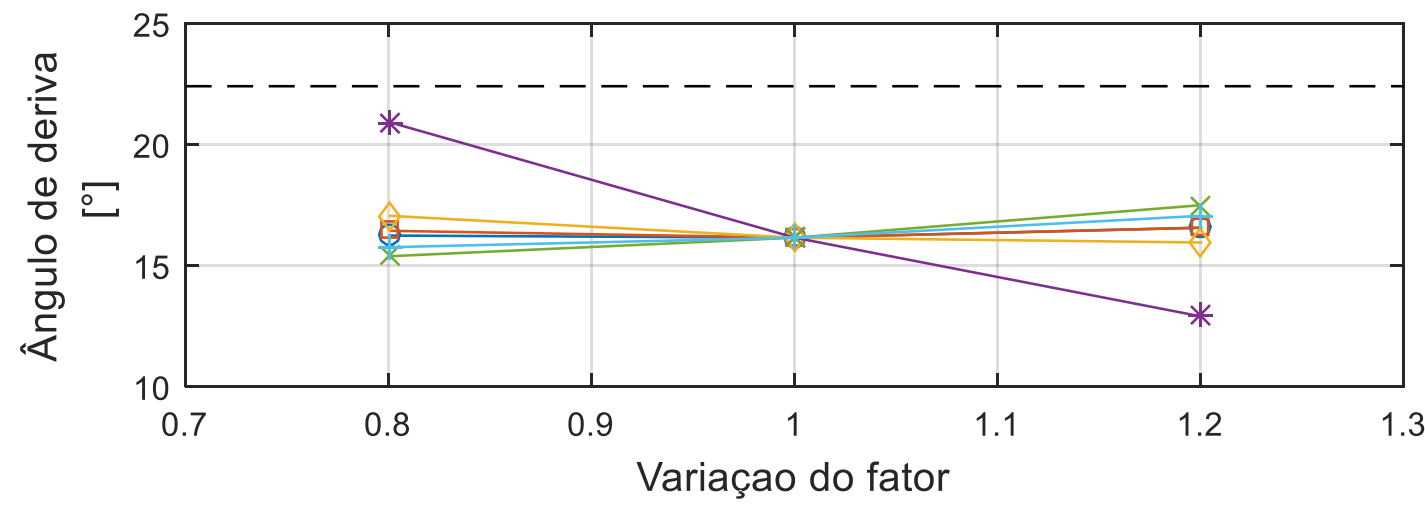

\begin{tabular}{|c|}
\hline $\begin{array}{l}\text { - Massa adicional } \\
\square-\text { Amortecimento linear } \\
- \text { Amortecimento quadrático } \\
*-\text { Coeficientes de correnteza transversais } \\
\times- \text { Coeficientes de correnteza momento de yaw } \\
-\quad \text { Área do leme } \\
--- \text { Experimental }\end{array}$ \\
\hline
\end{tabular}

Fonte: Autor.

\subsection{Manobra 17 Stopping inertia test}

Esta manobra apresentou um comportamento similar ao observado na manobra de crash stop, ilustrado pela Figura 150, indicando qualitativamente os mesmos fatores com maior efeito. 
Figura 150 - Efeito dos fatores na aceleração longitudinal

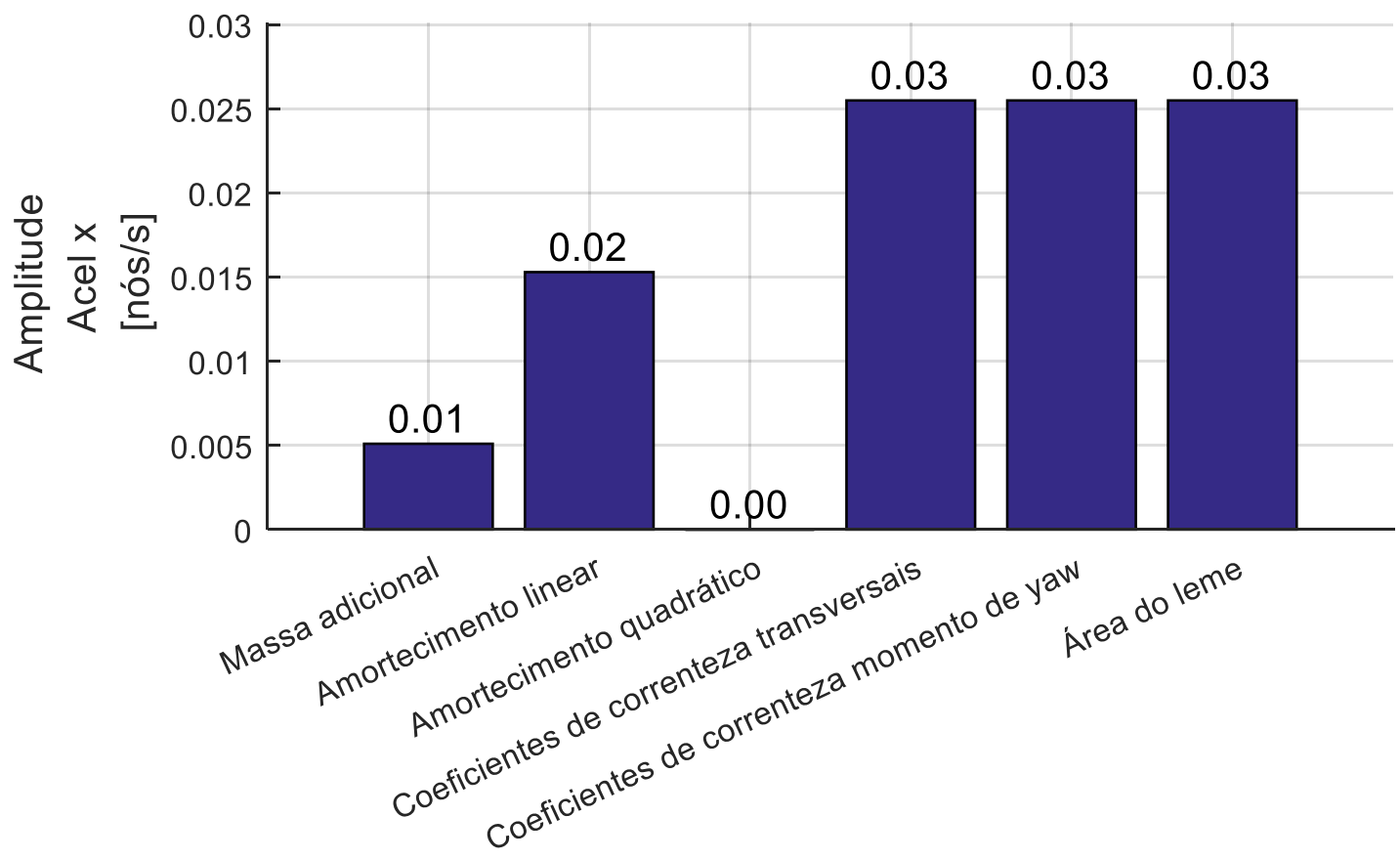

Fatores

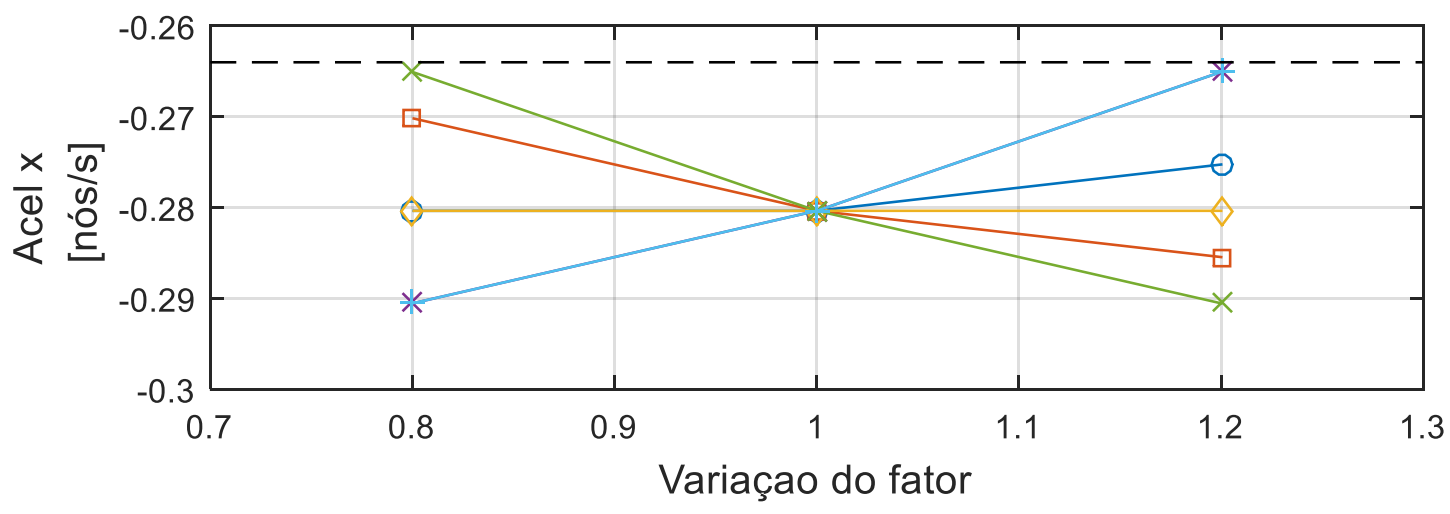

\begin{tabular}{|l|}
\hline$\bigcirc-$ Massa adicional \\
$\square-$ Amortecimento linear \\
- Amortecimento quadrático \\
- Coeficientes de correnteza transversais \\
$\times \quad$ Coeficientes de correnteza momento de yaw \\
$-\quad$ Área do leme \\
-- Experimental
\end{tabular}

Fonte: Autor.

\subsection{Manobra 18 Stopping inertia test - IMO}

Os efeitos dos fatores na aceleração longitudinal para esta manobra sofreram os mesmos efeitos observados para a manobra de stopping inertia test, mostrados da figura 149 a 151.

Para os efeitos no avanço e transferência os fatores já relacionados à estabilidade direcional do navio se mostraram importantes. O efeito da variação da 
área do leme se mostrou igualmente importante aos coeficientes de correnteza para o avanço da embarcação, corroborando com a observação de que a área do leme se torna mais importante para velocidades mais baixas e sem propulsão, comentário feito para as manobras de coasting turn e accelerating turn.

Figura 151 - Efeito dos fatores na aceleração longitudinal

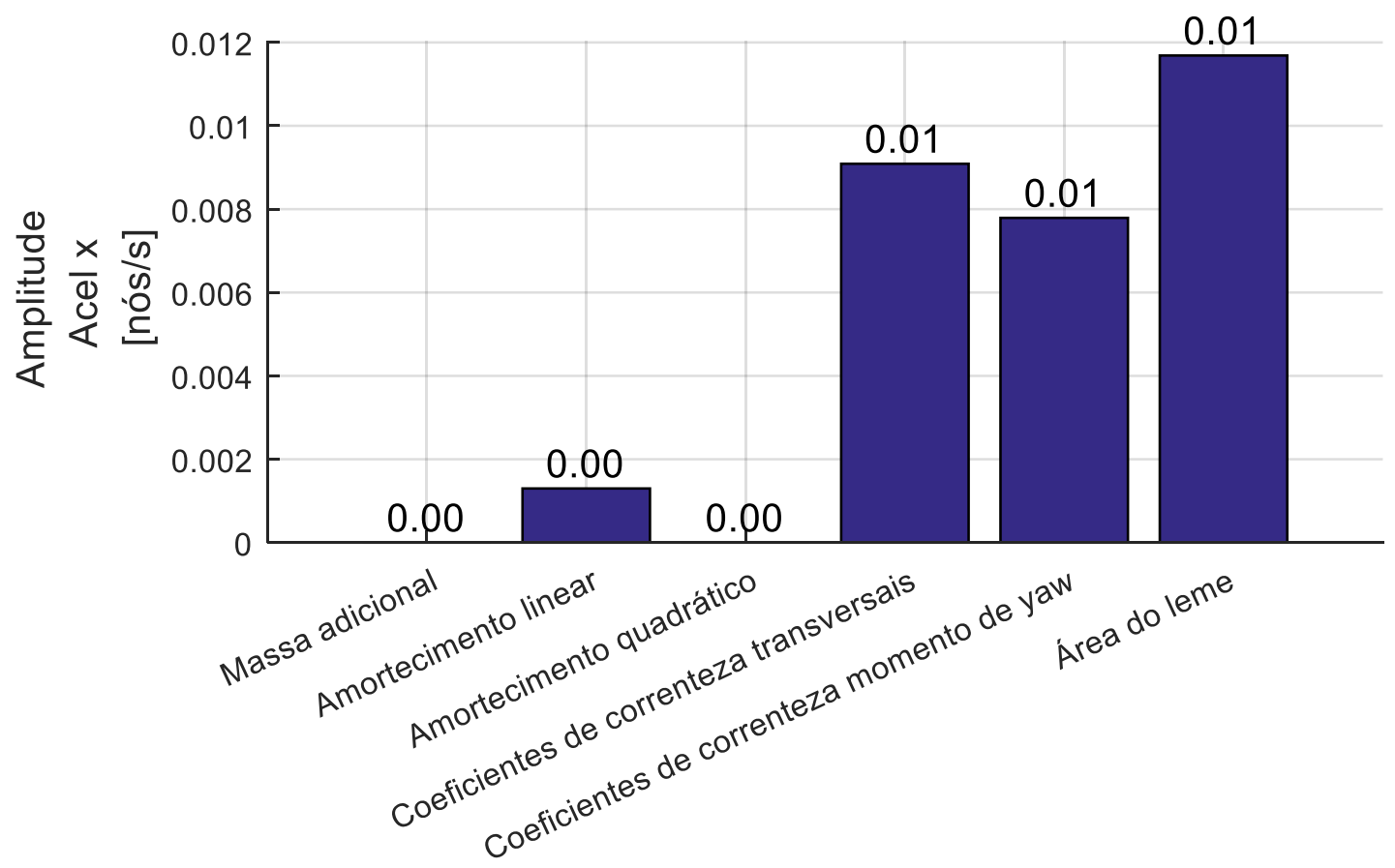

Fatores

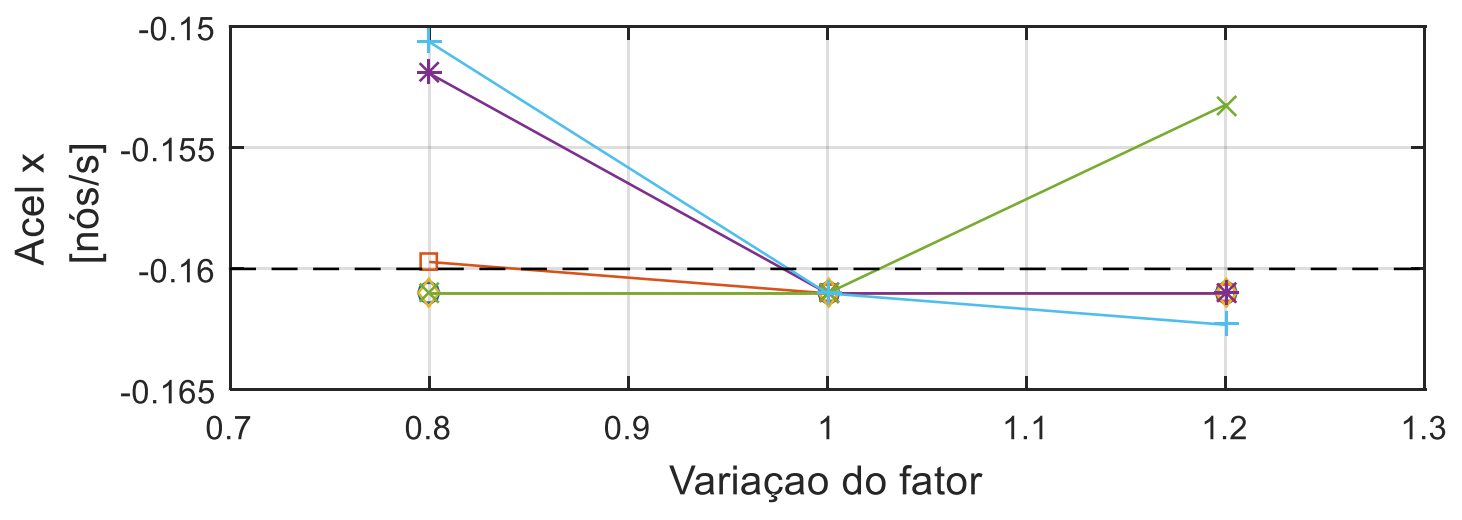

- Massa adicional
$\square-$ Amortecimento linear
- Amortecimento quadrático
$* \quad$ Coeficientes de correnteza transversais
$\times \quad$ Coeficientes de correnteza momento de yaw
$+\quad$ Área do leme
-- Experimental

Fonte: Autor. 
Figura 152 - Efeito dos fatores no Avanço

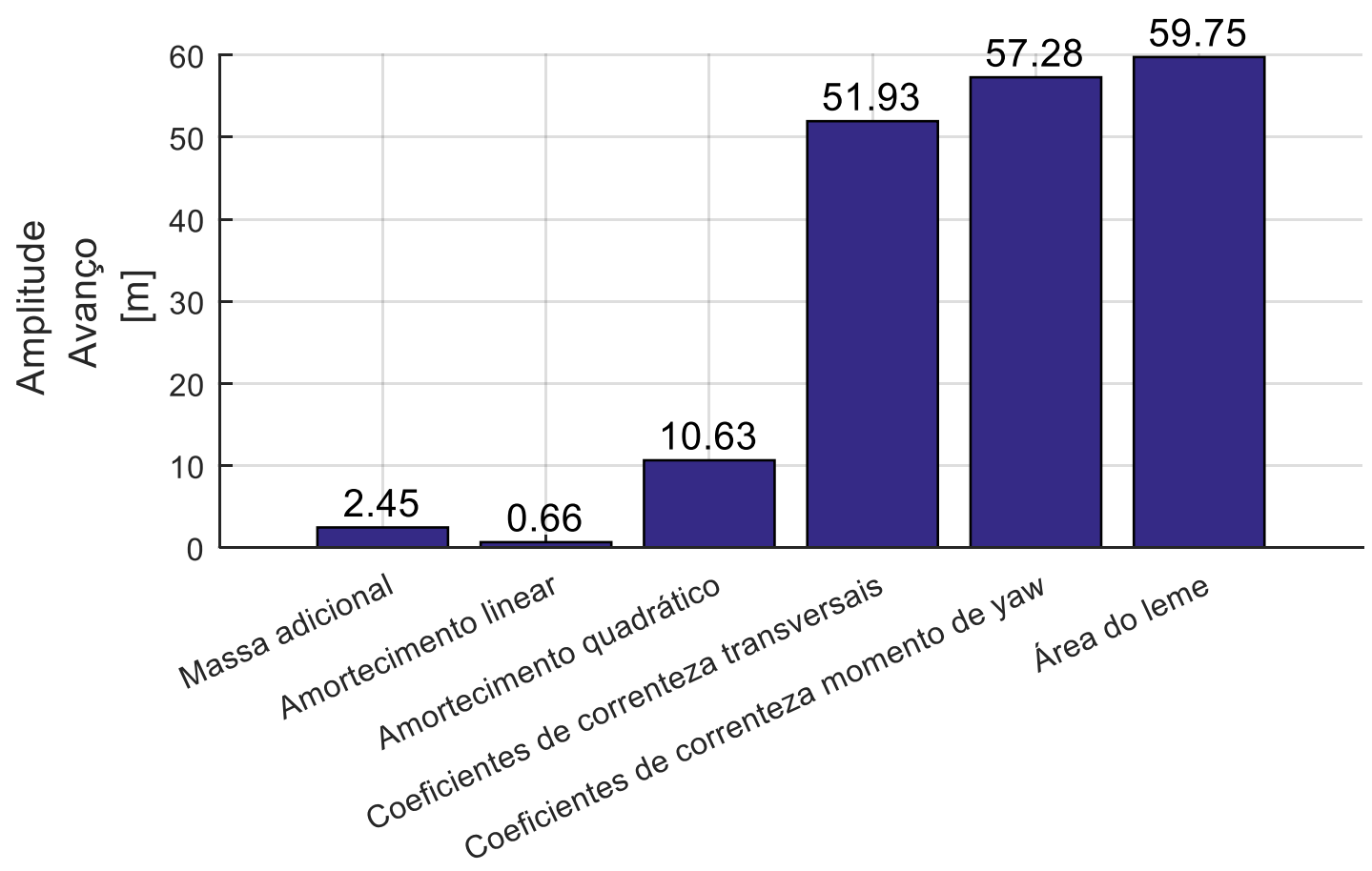

Fatores

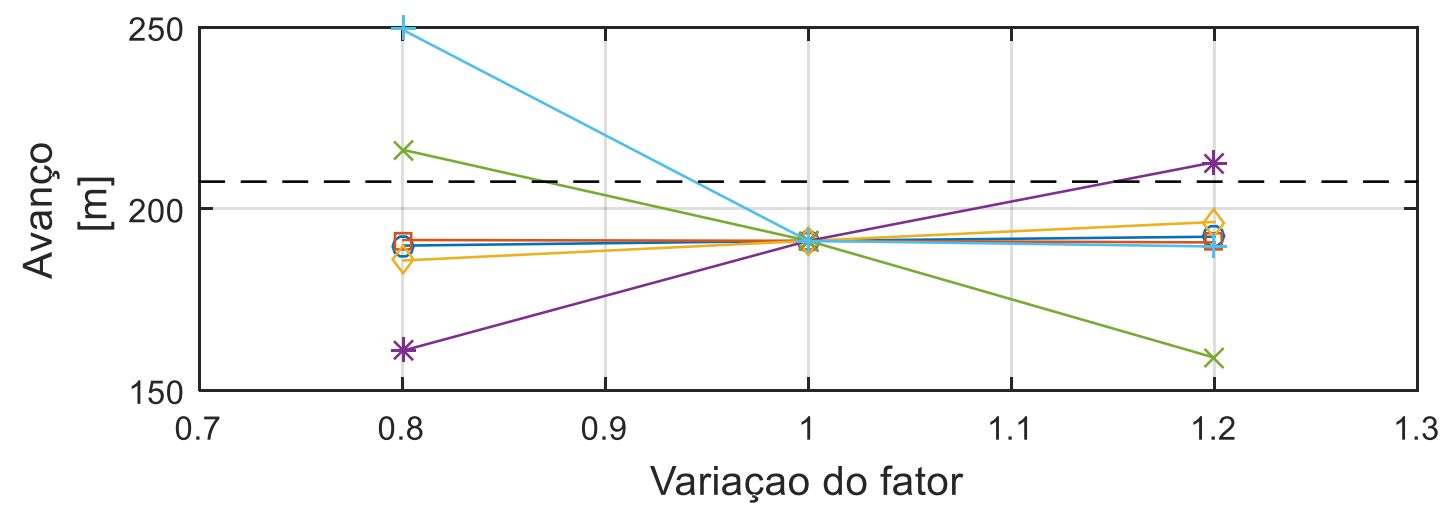

- Massa adicional
$\square$ Amortecimento linear
- Amortecimento quadrático
$+\quad$ Coeficientes de correnteza transversais
$\times \quad$ Coeficientes de correnteza momento de yaw
$+\quad$ Área do leme
-- Experimental

Fonte: Autor. 
Figura 153 - Efeito dos fatores na Transferência

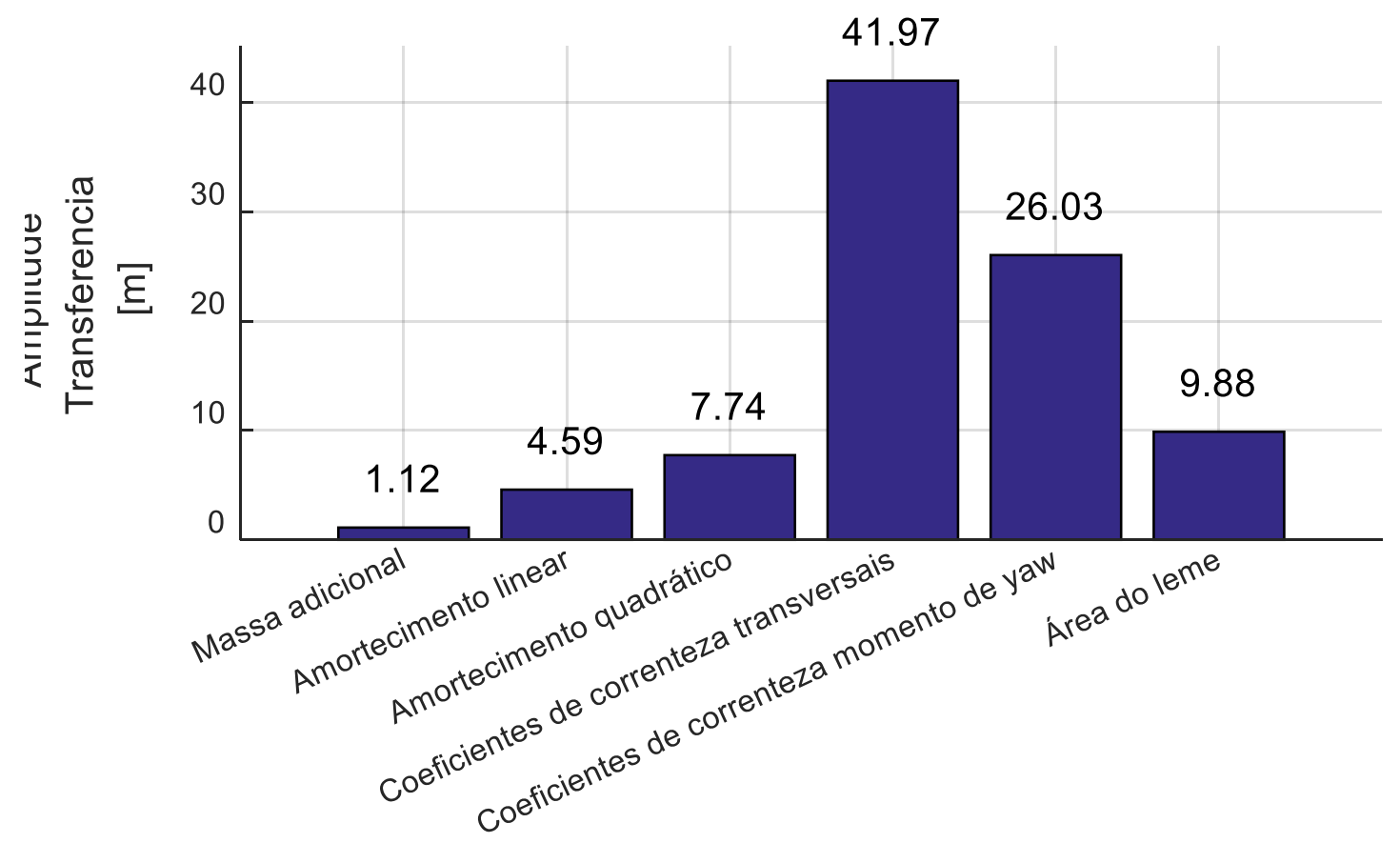

Fatores

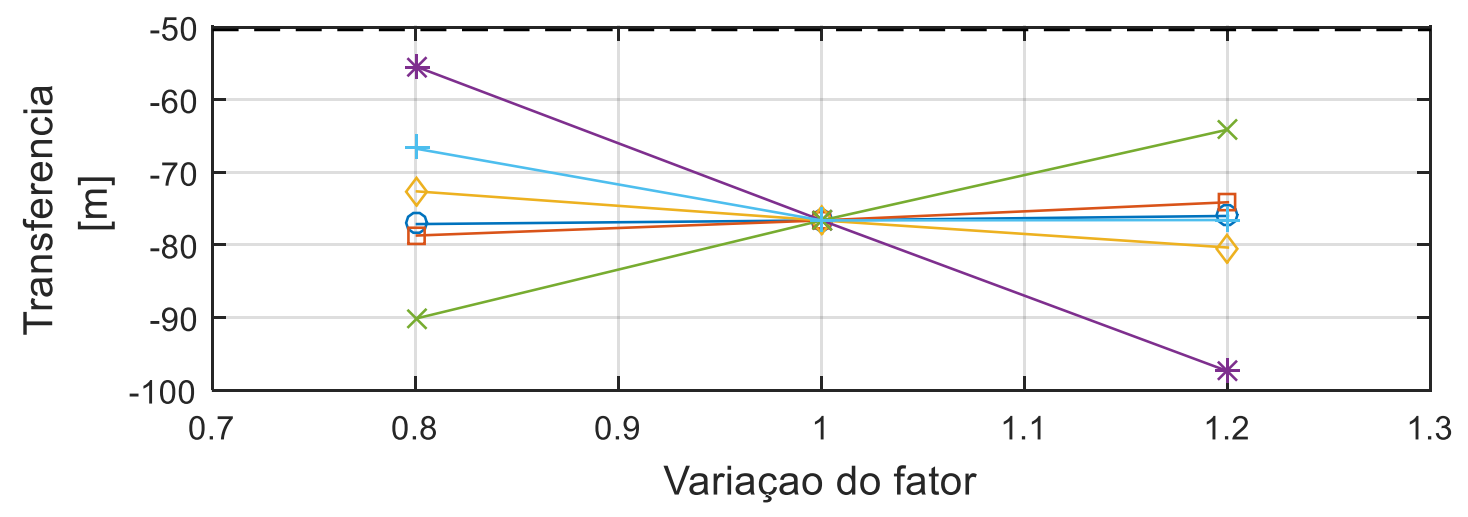

\begin{tabular}{l}
\hline Massa adicional \\
$\square$ Amortecimento linear \\
$\checkmark$ Amortecimento quadrático \\
$-\quad$ Coeficientes de correnteza transversais \\
$-\quad$ Coeficientes de correnteza momento de yaw \\
$-\quad$ Área do leme \\
-- Experimental
\end{tabular}

Fonte: Autor.

\subsection{Manobra 19 Lateral thruster capability}

Para esta manobra os fatores de maior efeito foram respectivamente o coeficiente de correnteza para guinada e amortecimento quadrático de guinada, conforme apresentado na Figura 154, ambos proporcionais à velocidade angular. Os coeficientes $\mathrm{C}_{\mathrm{y}}$ se mostraram inversamente proporcionais à velocidade angular, 
porém com menor efeito do que os fatores de amortecimento quadrático de guinada e coeficientes $\mathrm{C}_{\mathrm{nz}}$. Os demais fatores não apresentaram efeito.

Figura 154 - Efeito dos fatores na Velocidade angular
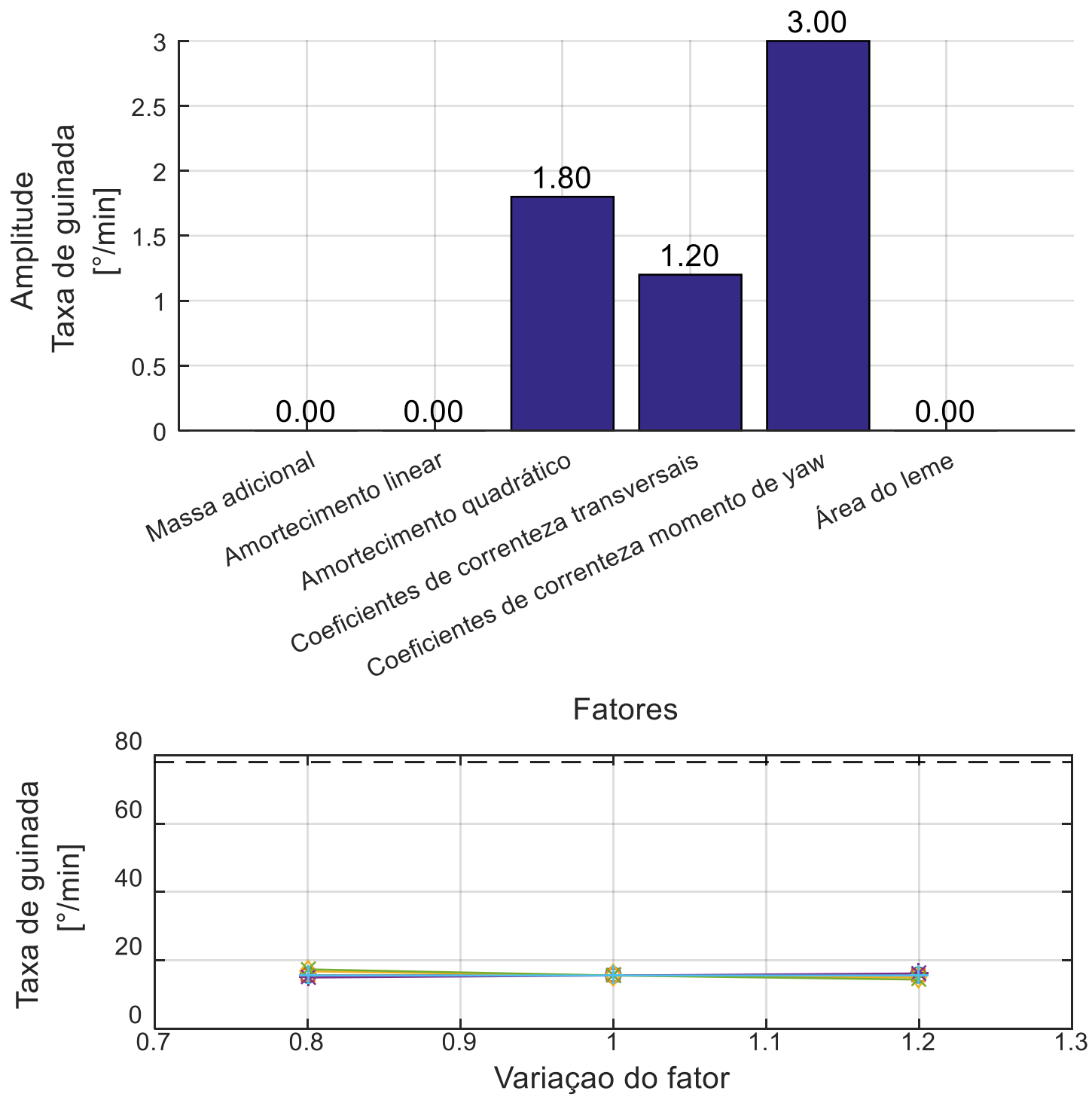

\begin{tabular}{|ll|}
\hline & Massa adicional \\
$\square$ & Amortecimento linear \\
$\square$ & Amortecimento quadrático \\
$-\quad$ Coeficientes de correnteza transversais \\
$+\quad$ Coeficientes de correnteza momento de yaw \\
$+\quad$ Área do leme \\
$+-\quad$ Experimental
\end{tabular}

Fonte: Autor. 


\subsection{Manobra 21 Pull out test}

Esta manobra mostrou que a estabilidade direcional da embarcação está predominantemente relacionada com a área do leme e os $\mathrm{C}_{\mathrm{nz}}$, sendo a área do leme mais importante para manter a embarcação estável no deslocamento em linha reta, como ilustrado pela Figura 155.

O amortecimento linear longitudinal e os coeficientes $C_{y}$ apresentaram efeito sobre a velocidade angular menor do que o apresentado pela variação da área do leme. 
Figura 155 - Efeito dos fatores na Velocidade angular final

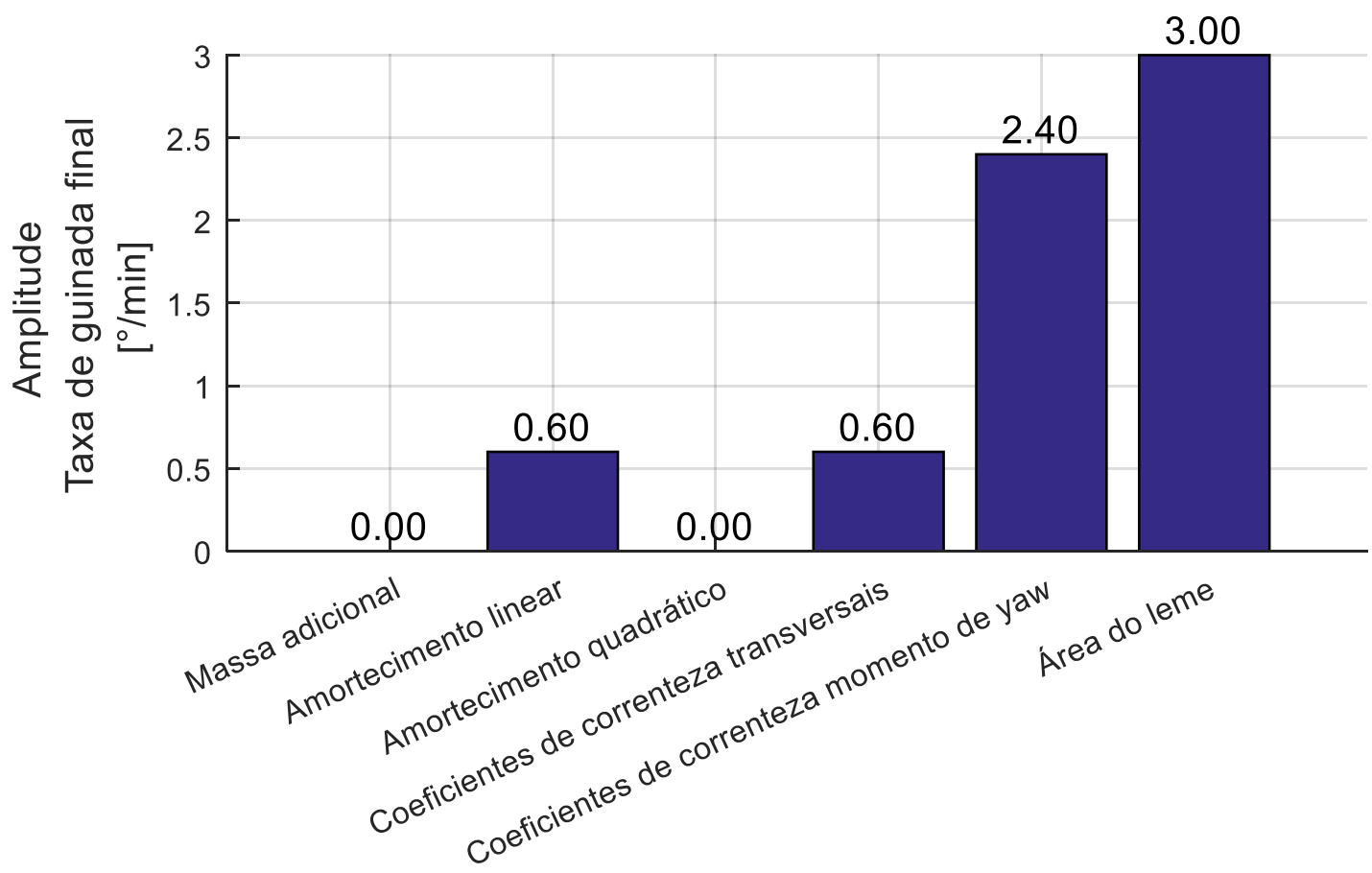

Fatores

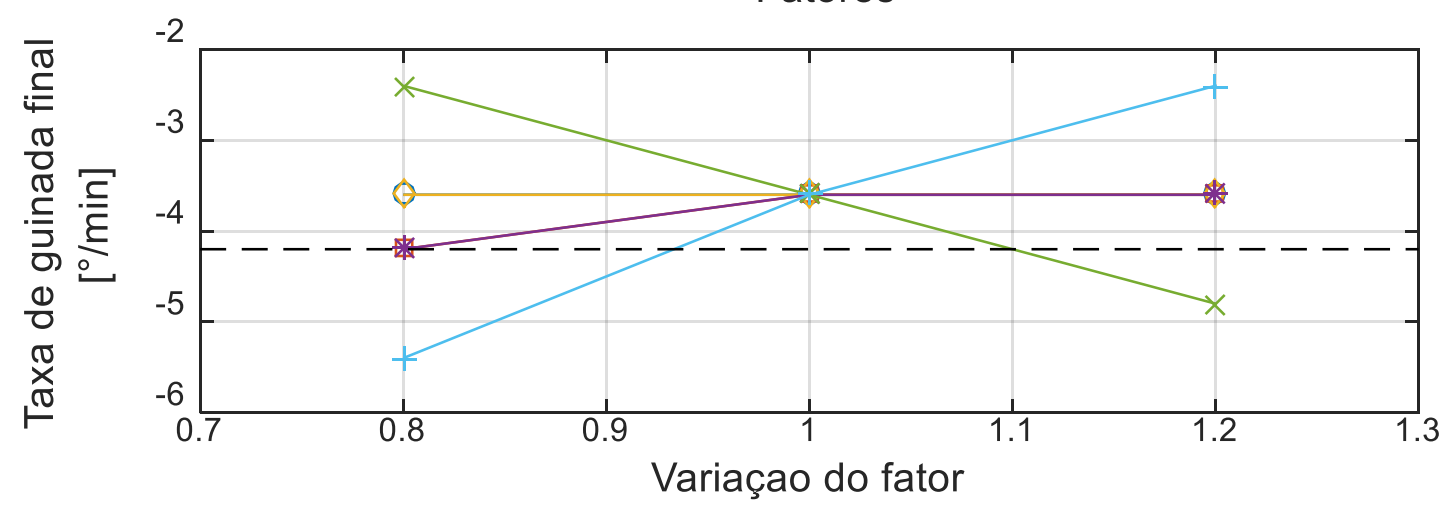

\begin{tabular}{ll}
\hline & Massa adicional \\
& Amortecimento linear \\
& Amortecimento quadrático \\
+ & Coeficientes de correnteza transversais \\
$\times \quad$ Coeficientes de correnteza momento de yaw & Área do leme \\
$+\quad$ Experimental &
\end{tabular}

Fonte: Autor.

\subsection{Consolidação da análise de sensibilidade}

Por fim é apresentada a Tabela 51 que apresenta de forma consolidada a importância de cada fator para os tipos de manobra analisados. Para permitir uma melhor comparação dos efeitos causados por cada fator entre os diferentes tipos de 
manobras e diferentes tipos de medidas realizadas a tabela mostra a relação da amplitude obtida para cada efeito com o valor obtido para o respectivo efeito em sua manobra de calibração, como mostrado na equação (18).

$$
\text { Variação } o_{\text {avanço }}=\frac{\mid \text { maior }\left(\text { Avanço }_{\text {sensibilidade }}\right)-\text { menor }\left(\text { Avanço }_{\text {sensibilidade }}\right) \mid}{\text { Avanço } o_{\text {calibraçao }}}
$$

A Tabela 51 mostra que para as manobras escolhidas os fatores de maior importância foram os coeficientes de correnteza $C_{y}$, seguidos pelos coeficientes $C_{n z} e$ área do leme.

Através da análise dos fatores individualmente pode ser notado que a massa adicional $m_{22}$ da embarcação possui maior influência as distâncias percorridas pela embarcação, tendo menor influência nas velocidades.

O amortecimento linear no sentido longitudinal da embarcação por sua vez apresenta pouco efeito sobre as grandezas medidas nas manobras realizadas, com exceção da manobra de pull out test, que mede a estabilidade direcional da embarcação. Ressalta-se que as manobras realizadas, em sua maioria, avaliam a capacidade de manobra da embarcação quando há movimentos laterais, por este motivo os resultados estão coerentes com a expectativa de que este fator tenha pouca influência para movimentos laterais e maior influência para movimentos longitudinais.

O amortecimento quadrático de guinada por sua vez apresentou maior efeito quando variado nas medidas de transferência, diâmetro tático e diâmetro final, ou seja, sua influência está restrita aos movimentos no sentido transversal da manobra, com exceção da manobra de lateral thruster capability que teve a velocidade angular influenciada por este fator.

Os coeficientes de correnteza para as forças no sentido transversal da embarcação apresentaram grande efeito em quase todas as grandezas medidas, porém sua análise mostra que sua maior influência ocorre para os movimentos de deriva, dessa forma sua variação tem maior efeito no ângulo de deriva apresentado pela embarcação.

Os coeficientes de correnteza para o momento de guinada apresentaram um comportamento homogêneo através das diferentes manobras, porém apresentou um 
efeito de destaque na manobra de pull out test, indicando sua importância para a estabilidade direcional da embarcação.

Tabela 51 - Variação dos efeitos obtida pela alteração dos fatores

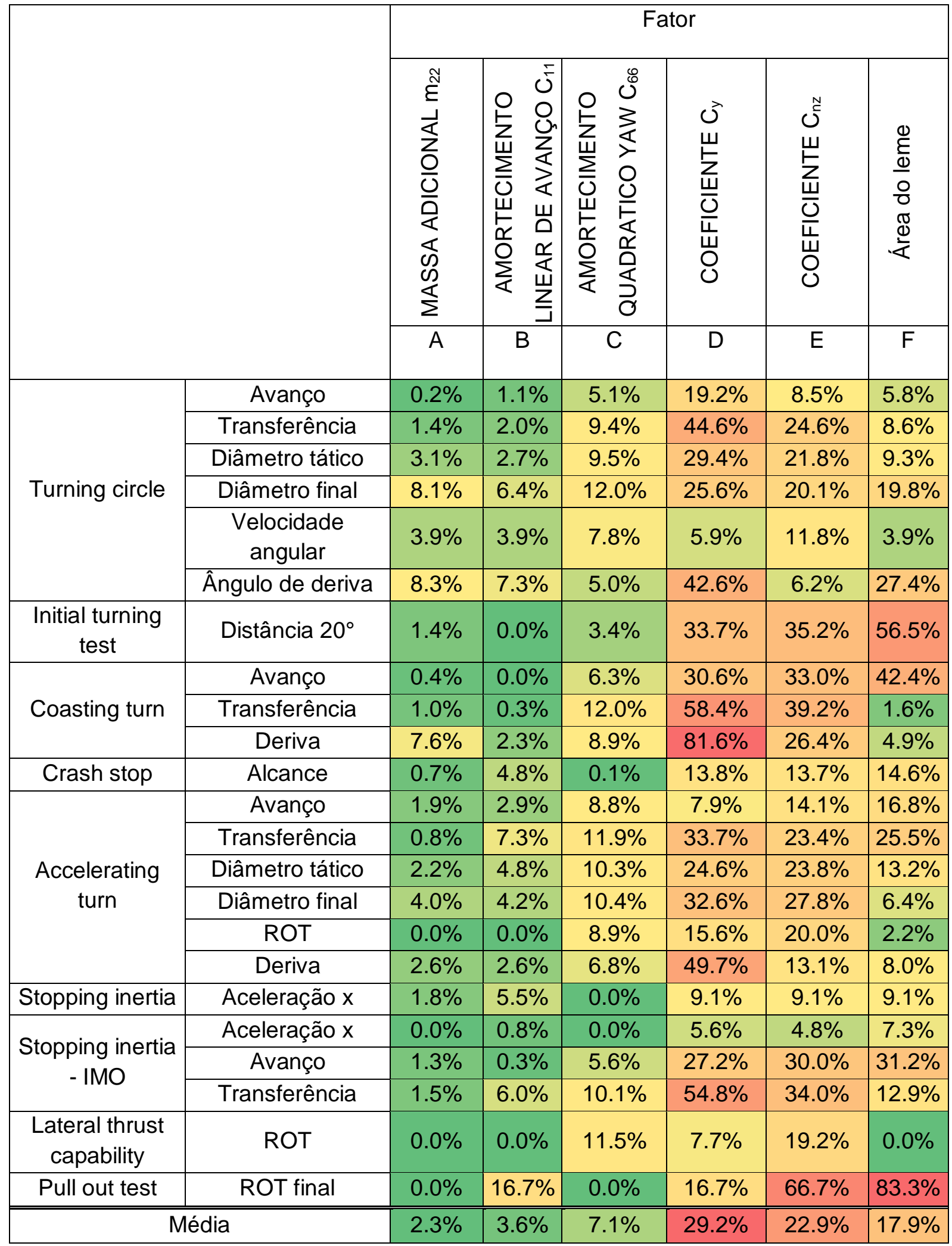

Fonte: Autor. 
A área do leme apresentou desempenho similar aos coeficientes $C_{n z}$, se destacando na manobra de pull out test, porém pode ser visto que também houve um aumento da influência deste fator nas manobras que ocorrem em regime transiente de velocidades.

Por fim a Tabela 52 mostra a média das variações obtidas por todos os fatores para cada tipo de manobra. Pode ser observado que a variação de $\pm 20 \%$ dos 6 fatores escolhidos para a análise de sensibilidade apresentou pouco efeito nas manobras de crash stop, stopping inertia test e lateral thruster capability. Este fato indica que estas manobras são influenciadas por outros fatores do modelo matemático.

Tabela 52 - Média da variação dos efeitos por tipo de manobra

\begin{tabular}{|c|c|}
\hline Manobra & $\begin{array}{c}\text { Variação dos } \\
\text { efeitos }\end{array}$ \\
\hline Turning circle & $12.0 \%$ \\
\hline Initial turning test & $21.7 \%$ \\
\hline Coasting turn & $19.8 \%$ \\
\hline Crash stop & $8.0 \%$ \\
\hline Accelerating turn & $12.5 \%$ \\
\hline Stopping inertia & $5.8 \%$ \\
\hline Stopping inertia - IMO & $13.0 \%$ \\
\hline Lateral thrust capability & $6.4 \%$ \\
\hline Pull out test & $30.6 \%$ \\
\hline
\end{tabular}

Fonte: Autor. 


\section{CONCLUSÕES}

Essa dissertação assumiu como objetivo apresentar a validação do modelo numérico de manobras para navios utilizado pelo simulador $\mathrm{SMH}$ - Simulador Marítimo Hidroviário, e indicar o efeito dos principais parâmetros utilizados para a calibração do modelo, conforme a metodologia para calibração utilizada no laboratório Tanque de Provas Numérico.

Inicialmente apresentou-se uma revisão da literatura que discorreu sobre os tipos de modelo de manobra mais utilizados, baseados em derivadas hidrodinâmicas (que descrevem as forças que agem sobre o navio através de séries de Taylor) e modelos heurísticos (que associam as forças atuantes diretamente aos fenômenos físicos que as causam).

Foram então apresentados o modelo em escala reduzida e o modelo matemático implementado no simulador, sendo a validação do modelo numérico realizada através da comparação dos resultados simulados com os resultados experimentais.

Sobre a caracterização da manobrabilidade de navios, foram apresentadas as principais recomendações e considerações sobre manobrabilidade feitas por organizações que objetivam garantir características mínimas de segurança e operabilidade de navios, e definiram-se as características a serem obtidas para a determinação da manobrabilidade de embarcações, e que foram usadas para avaliação do modelo matemático.

O trabalho seguiu com a comparação dos resultados experimentais de manobras com os obtidos numericamente. Os ensaios permitiram a caracterização da manobrabilidade da embarcação e criaram um conjunto de dados para validação do modelo numérico de manobra.

Por fim foi apresentado uma análise de sensibilidade do modelo onde 6 parâmetros foram selecionados e seus valores alterados em $\pm 20 \%$ em relação ao valor original. Os resultados obtidos mostraram, para as manobras realizadas, uma sensibilidade maior para os coeficientes de correnteza e área do leme em relação à massa adicional e amortecimentos. 
Com os resultados obtidos pelo modelo numérico avaliado nesse trabalho, concluiu-se que este modelo é válido para a representação da manobrabilidade de navios. Os resultados do modelo numérico apresentaram características de manobrabilidade coerentes com as observadas nos ensaios, apresentando erros em relação aos ensaios experimentais inferiores à dispersão apresentada pelos modelos implementados por outras instituições de pesquisa encontrados na literatura. A análise de sensibilidade permite ainda que parâmetros do modelo sejam ajustados para melhoria das características de manobra da embarcação com maior conhecimento sobre os efeitos dos ajustes.

Este trabalho apresenta algumas limitações, de forma que somente um tipo de navio foi modelado, devido à disponibilidade somente do modelo em escala reduzida da embarcação Alpha Crucis. Embora esta limitação não impacte diretamente sobre os objetivos, ela impede uma validação mais abrangente do modelo matemático que poderia ser confrontado com navios de diferentes comportamentos. Observou-se também o impacto da limitação do tamanho do tanque e da área útil do sistema de medição que impediu a realização completa de manobras em escala reduzida como no caso da manobra de Stopping inertia test que demanda um longo comprimento do tanque.

É sugerido para trabalhos futuros que a análise de sensibilidade seja ampliada para mais fatores do modelo matemático. Dessa forma pode haver mais liberdade para a escolha dos fatores a serem ajustados de acordo com o comportamento desejado, e poderá ser feita com mais facilidade a correlação entre os parâmetros do modelo e suas características de manobra. 


\section{REFERÊNCIAS}

ABKOWITZ, M.A.. Lectures on ship hydrodynamics - steering and maneuverability. Lyngby, Dinamarca: Hydrodynamics department, 1964. Vols. Hy-5.

AMERICAN BUREAU OF SHIPPING. Guide for vessel maneuverability. ABS. Houston, Estados Unidos da América: s.n., 2006.

ANKUNDINOV, V.; KAPLAN, P.; JACOBSEN, B.K.. Assessment and Principal Structure of the Modular Mathematical Model for Ship Maneuverability Prediction and Real-Time Maneuvering Simulations. In: International Conference on Marine Simulation and Ship Manoeuvrability MARSIM. 1993.

BERG, T.E.; RINGEN, E. Validation of shiphandling simulation models. In: Proceedings of the 30 International Conference on Ocean, Offshore and Arctic Engineering OMAE. Rotterdam, Países Baixos: Junho, 2011.

CLARKE, D.; HORN, J.R. Estimation of hydrodynamic derivatives. Southampton, Inglaterra: S.n., 1997. pp. 275 - 289. Vol. Volume 2.

FALTINSEN, O.M.; KJAERLAND, O.; LIAPIS, N.; WALDERHAUG, H. Hydrodynamic analysis of tankers at single-point-mooring systems. In: Proceedings of the 2nd International Conference on Behaviour of Off-Shore Structures, BOSS 79. Londres, Inglaterra: Agosto 1979.

FOSSEN, T.I.. Handbook of marine craft hydrodynamics and motion control. Trondheim, Noruega: Jhon Wiley \& Sons, Ltd., 2011.

GAVRILIN, S.; STEEN, S. Uncertainty of full-scale manoeuvring trial results estimated using a simulation model. In: Applied Ocean Research. Trondheim : Elsevier, 2017.

GAVRILIN, S.; STEEN, S. Global sensitivity analysis and repested identification of a modular maneuvering model of a passenger ferry. Trondheim : Elsevier, 2018.

HOOFT, J.P.; NIENHUIS, U.. The Prediction of the Ship's Maneuverability in the Design Stage. Wageningen, Países Baixos: 1994. pp. 419 - 445. Vol. 102.

INTERNATIONAL MARITIME ORGANIZATION. IMO. 2002. MSC.137(76): Standards for Ship Maneuverability.

ITTC International Towing Tank Conference. Full Scale Measurements Manoeuvrability Full Scale Manoeuvring Trials Procedure. 2002.

KOSE, K.. On a new mathematical model of maneuvering motions of a ship and its applications. Japan Towing Tank Committee. 1982.

MASETTI, F.R.; TANNURI, E.A.; ROSETTI, G.; MELLO, P.C.. Deep and Shallow Water Low-Speed Maneuvering Tests - Comparison between Experimental and Simulation Results. In: Proceedings of the 35 International Conference on Ocean, Offshore and Arctic Engineering OMAE. Busan, Coréia do Sul: Junho 2016.

MASETTI, F.R.; TANNURI, E.A.; MELLO, P.C.. Validation of a Modular Mathematical Model for Low-Speed Maneuvering using Small Scale Tests with 
an Oceanographic Research Vessel. In: International Conference on Ocean, Offshore and Arctic Engineering. St. John's, Canada: Junho 2015.

OBOKATA, J.. On the basic design of single point mooring systems (1 report). In: Journal of the society of naval architects of Japan, vol161. Junho 1987.

OLTMANN, P.; SHARMA, S.D.. Simulation of combined engine and rudder maneuvers using an improved model of hull-propeller-rudder interactions. 1984.

Petrobras, Dynasim. Versão 4.5.3.9. Dynasim Manual Teórico. 2014.

QUALISYS AB. Oqus | Qualisys. Oqus Product Sheet. [Online] 2016. Disponível em: $<$ http://content.qualisys.com/2015/10/PI Oqus.pdf >. Acesso em: 13 de Fevereiro de 2017.

QUEIROZ FILHO, A.N., ZIMBRES, M.; TANNURI, E.A.. Development and Validation of a Customizable DP System for a Full Bridge Real Time Simulator. In: The 33rd International Conference on Offshore Mechanics and Arctic Engineering, OMAE. São Francisco, Estados Unidos da América: Junho 2014.

ROSETTI, G.; LOPES, M.. Cálculo das Cargas de Vento e Correnteza no Navio Oceanográfico Alpha Crucis. Argonáutica Engineering \& Research. São Paulo, Brasil: s.n., 2014. p. 31.

SIMOS, A.N.. Modelo hidrodinâmico heurístico para análise de navios petroleiros amarrados sujeitos à ação de correnteza. 2001. Tese - Escola Politécnica da Universidade de São Paulo. São Paulo, Brasil: s.n., 2001.

TAKASHINA, J.; HIRANO, M.. Ship Manoeuvering Motion by Tugs in Deep and Shallow Water. 1990.

TAKASHINA, J.. Ship manoeuvering motion due to tug boats and its mathematical model. 1986. Vol. vol. 160.

TANNURI, E.A.; FUCATU, C.H.; MASETTI, I.Q.; RATEIRO, F.; FERREIRA, M.D.; Nishimoto, K.. Modular Mathematical Model for a Low-Speed Maneuvering Simulator. In: Proceedings of the 33 International Conference on Ocean, Offshore and Arctic Engineering OMAE. São Francisco, Estados Unidos da América: Junho 2014.

UNIVERSITY OF HAWAll. Lines Plan - Moana Wave. University of Hawaii. 1974.

WISHERS, J.E.W.. A Simulation Model For A Single Point Moored Tanker. Publicação No. 797, Maritime Research Institute. 1988.

ZIMBRES, M.. Offshore Simulator Mathematical and Physical Modeling. Tanque de Provas Numérico TPN - USP. São Paulo, Brasil: , 2015. p. 24. 